



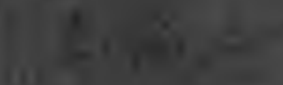

$=$

$x^{2}+x^{2}+y^{2}=y^{2}$

$\cos 2 y=3$

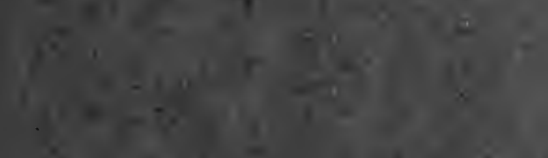

-

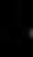

$$
\text { *y }
$$

316

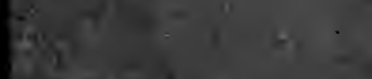 \\ ation $n^{\prime}+4+2$

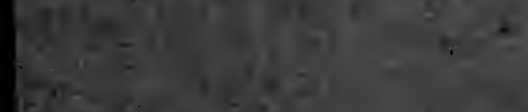

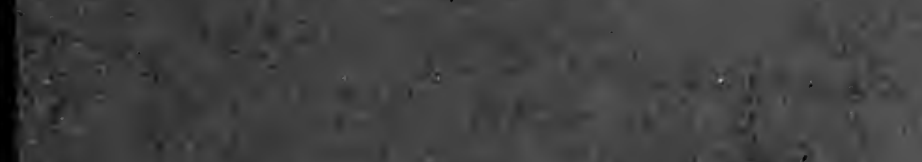

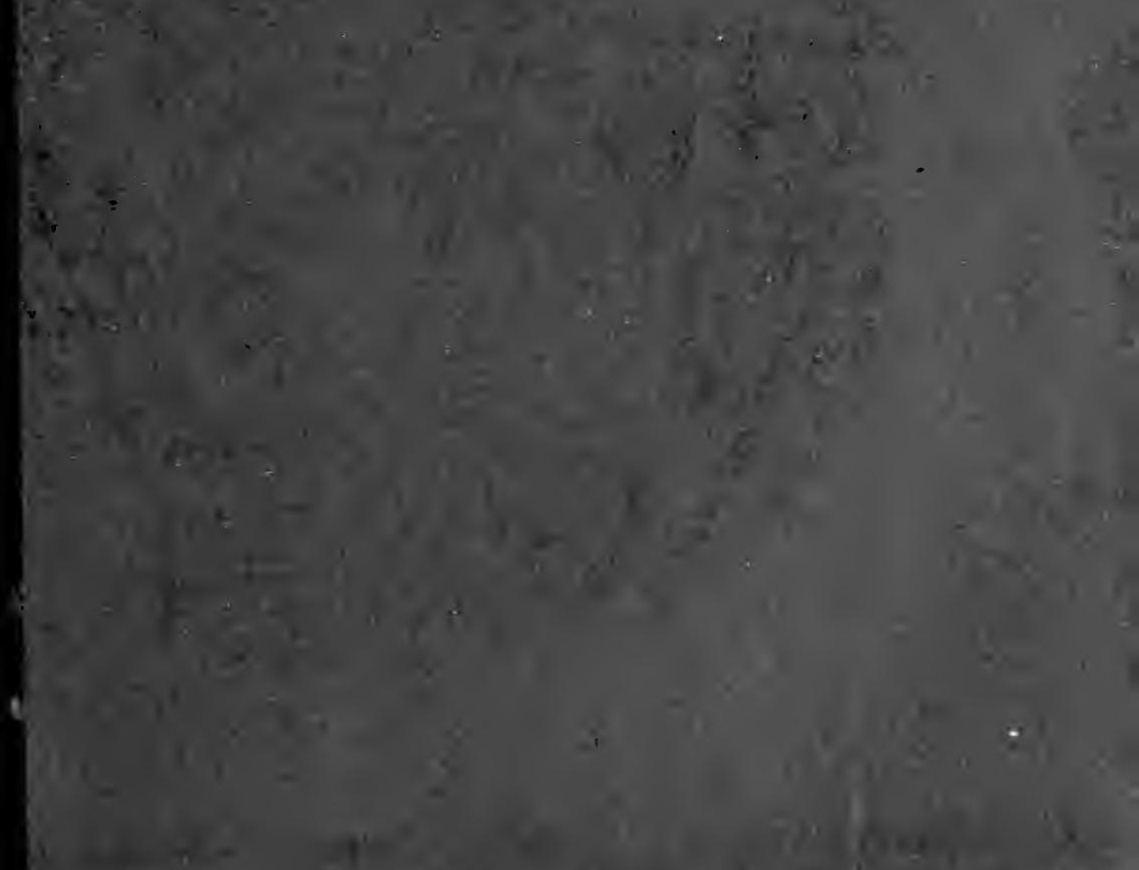



Digitized by the Internet Archive in 2007 with funding from Microsoft Corporation 



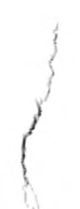





\section{PHILOSOPHY OF KNOWLEDGE}




\section{PROFESSOR LADD'S WORKS.}

PHILOSOPHY OF KNOWLEDGE. An Inquiry into the Nature, Limits, and Validity of Human Cognitive Faculty. 8 vo. $\$ 4.00$.

PHILOSOPHY OF MIND. An Essay in the Metaphysics. of Psychology. 8vo. \$3.0o.

INTRODUCTION TO PHILOSOPHY. An Inquiry after a Rational System of Scientific Principles in their Relation to Ultimate Reality. 8vo. \$3 oo.

PRIMER OF PSYOHOLOGY. 12mo. \$1.00 net.

PSYCHOLOGY; DESCRIPTIVE AND EXPLANATORY. A Treatise of the Phenomena, Laws, and Development of Human Mental Life. Svo. \$4.5o.

OUTLINES OF PHYSIOLOGICAL PSYCHOLOGY. A Text-book on Mental Science for Academies and Colleges. Illustrated. 8vo. \$2.00.

ELEMENTS OF PHYSIOLOGICAL PSYCHOLOGY. A Treatise of the Activities and Nature of the Mind, from the Physical and Experimental Point of View. With numerous illustrations. 8vo. $\$ 4.50$.

THE DOCTRINE OF SACRED SCRIPTURE. A Critical, Historical, and Dogmatic Inquiry into the Origin and Nature of the Old and New Testaments. 2 vols. 8 vo. $\$ 7.00$.

WHAT IS THE BIBLE? An Inquiry into the Origin and Nature of the Old and New Testaments in the Light of Modern Biblical Studv. 12mo. \$2.0o.

THE PRINCIPLES OF CHURCH POLITY. Crown 8 vo. $\$ 2.50$. 


\title{
Philosophy of Knowledge
}

\author{
AN INQUIRY
}

INTO

THE NATURE, LIMITS, AND VALIDITY

OF

HUMAN COGNITIVE FACULTY

BY

GEORGE TRUMBULL LADD

PROFESSOR OF PHILOSOPHY IN YALE UNIVERSITY

NE W YORK

CHARLES SCRIBNER'S SONS 
Copyright, 1897, by

Charles Scrimner's Sons.

CAnibersity 犸ress :

John Wilson and Son, Cambridge, U.S.A. 
THOSE WHO

BY SERIOUS AND PROLONGED

INQUIRY, HOWEVER SCEPTICAL, ASPIRE

TO APPROACH THE TRUTH,

THIS BOOK IS RESPECTFULLY

AND AFFECTIONATELY

DEDICATED 
"Shall we not look into the laws Of life and death, and things that seem, And things that be, and analyze Our double nature?" 


\section{PREFA CE}

THIS book is an Essay in the interests of some of the 1 most profound and difficult of the problems which can
engage the reflective thinking of man. It would scarcely be an exaggeration to say that the nature, limits, and guaranty of knowledge afford subjects of inquiry which exceed all others in the demand they make for deep and earnest reflection. If one were at liberty to construct a Theory of Reality which should be simply a logically consistent and symmetrical affair, satisfactory to the ideals of the architect but without regard to foundations of fact or questions of the right to occupy the ground in this way, the task would seem comparatively light. But in this day, and in the face of history, such a liberty cannot be intelligently claimed; much less can it be successfully exercised. Facts must be considered, and questions of right cannot be thrust aside or overlooked. For the former part of one's philosophical basis, the particular sciences are now responsible; for the latter part - the search after guide and guaranty - a particular form of philosophical discipline, sometimes called epistemology, is inroked. It is this form of philosophy which this book undertakes. Its author asks that the intrinsic character of its problems, and all the perplexities it entails, should be constantly remembered by the reader.

I should probably have found my self-imposed task somewhat less troublesome if I had more predecessors among 
modern writers on philosophy in English. But, so far as I am aware, there are none from whom any help is to be derived. ${ }^{1}$ In Germany a considerable number of books, with the title Erkenntnisslehre, or some similar title, have recently appeared; and German works on Logic and systematic Philosophy have generally the merit of dealing in a more thorough way with the epistemological problem, wherever they tonch its sensitive points, than is customary in England or this country. Now and then a French writer, too, has afforded a hint, or suggestion, of which I have availed myself. So far as these helps have been consciously received, they have been acknowledged in the few references of the text. But I think it fair to ask that this book should be regarded as, much more exclusively than often occurs, the outcome of its author's own reflections over the difficult questions it essays to answer. It asks and should receive the treatment due to a pioneer work.

At the same time it is also true that no other questions, practical or philosophical, are being more anxiously considered or are more influential over life and conduct than those which merge themselves in the epistemological problem. While this problem is reflected upon, largely in an unguided and illogical way, by multitudes of minds, the authorities, who onght also to be guides in reflective thinking, have been of late accustomed to reiterate the cry of "Back to Kant!" As a student for years of the critical philosophy, I have not been unmindful of the demand to place myself in the line of its derelopment of the epistemological inquiry. I have had the method and the conclusions of the great master in criticism before me, from the beginning to the end of my work. Yet

1 An exception cannot be made in the case of Mr. Hobhouse's elaborate work, "The Theory of Knowledge," since it is confessedly a treatise in Logic rather than Epistemology, as I conceive of epistemological problems and method. 
the positions to which my independent investigations have forced me are chiefly critical of, and antagonistic to, the positions of the Critique of Pure Reason.

If I may claim any peculiar merit for the method followed in discussing the problem of knowledge, it is perhaps chiefly this: I have striven constantly to make epistemology vital, a thing of moment, because indissolubly and most intimately connected with the ethical and religious life of the age. I have no wish to conceal, therefore, the quite unusual interest which I take in the success of this book; I sincerely hope that it may be a guide and help to not a few of those minds to whom I have dedicated it.

GEORGE TRUMBULL LADD.

YALE Uxiversity, May, 1897. 



\section{TABLE OF CONTENTS}

\section{CHAPTER I}

The Problem

The Anthropological View - Standpoint of Psychology - Appeal to Reason - Kant's Position in History - Relation to Metaphysics - Freedom from Assumption-The Primary Datum-The Dilemma stated Sources of an Answer - The Implicates necessary - The Method to be pursued - Practical Benefits expected . . . . . . . . .

\section{CHAPTER II}

\section{History of Opinion}

Purpose of the Sketch - The View of Plato - The Doctrine of Aristotle Post-Aristotelian Schools - Origen's Doctrine of Faith and Knowledge Augustine's Merits in Epistemology - The Middle Ages . . . . . 30

\section{CHAPTER III}

\section{History of Opinion (continued)}

The Position of Descartes - Pioneer Work of Locke - Views of Berkeley - Scepticism of Hume - Position of Leibnitz - Kant's Critical Work; His Problem and Conclusions - Kant's Ethical Interests - Hegel and Schopenhauer . . . . . . . . . . . . . . . .

\section{CHAPTER IV}

\section{The Psychological View}

Psychology and Epistemology - Origin of Knowledge - Psychic Factors of Cognition - Corollaries following - Possibilities of the Case - Cognition as Conscionsness - as A wareness of an Object - Misstatements criticised - Problem restated . . . . . . . . . . . . . . 9 


\section{CHAPTER V}

\section{Tuinking and Knowing}

Relations of 'Thouglit to Coguition - Views of Others - Thinking as Activity - and Positing of Relations - Nature of the Cognitive Judgment -

Implicates of all Judgment - Conceptual Knowledge and Reasoning . . 130

\section{CHAP'TER VI}

\section{Knowledge as Feeling and Willing}

The Psychology of Feeling - Emotional Factors in Cognition - Influence on intellectual Development-Impulsive Emotions - Ethical and Essthetical Feeling - Feelings regulative of Logical Processes - So-called "integrating" Emotions - Place of Will in Cognition . . . . . . . 160

\section{CHAPTER VII}

\section{Knowledge of Things and of Self}

Distinction of Subject and Object-Position of Formal Logic - Office of Self-Consciousness - Implicates of Reality - Identity of Self as implied - Distinction of Things and Self - Diremptive Work of Intellect - The Function of Analogy - Epistemology of Perception - and of Science . . 193

\section{CHAPTER VIII}

\section{Degrees, Limits, and Kinds of Knowledge}

Meaning of Terms - Standards of Measurement of Cognition - Relation of Knowledge to Life - Nature of Opinion - Possibility of Knowledge in Dreams - Distinctions Relative - Essentials of Cognition - Limits not Presuppositions - Kinds of Limits - Limits of Perception - and of Science - Kinds of Knowledge - Case of Mathematics - Immediate and Mediate Knowledge . . . . . . . . . . . . . . . . . 228

\section{CHAPTER IX}

\section{IDENTity AND Difference}

Experience and Cognition - Fundamental Principles of all Knowledge Views of Logic - Meaning of Identity - The Principle as applied to Reality . . . . . . . . . . . . . . . . . 268 


\section{CHAP'TER $\mathrm{X}$}

\section{Sufficient Reason}

Nature of Reasoning - Development of Reasoning - Application to Reality - Kant's inadequate View - Causation and External Nature-Origin of the Principle - Use of Cognitive Judgments - Difficulties of Syllogism - Concerned in Self-Knowledge - Assumptions involved - Goal of Endeavor - The Grounds of Natural Science - Fiual Purpose implied . . 283

\section{CHAPTER XI}

\section{Experience and the Transcendent}

Meaning of Experience - The misleading Figures of Speech - Experience necessarily Transcendent - Conditions of Experience - and its Laws . 322

\section{CHAPTER XII}

\section{The Implicates of KNowledge}

The Question stated - Modes of Implication possible - Necessity of Completeness of View - Being of Self implied - and of Not-Self - Influence of ethical and æsthetical Considerations - System of Ontology involved The principal Categories guaranteed . . . . . . . . . . . 337

\section{CHAPTER XIII}

\section{Scepticism, Agnosticism, and Criticism}

Attitudes of Mind toward Truth - Unity of Experience - Sources and Value of Scepticism - Limits of Scepticism - Doubts in Perception and in Science-Necessity for Agnosticism - Limits of Agnosticism Knowledge positive . . . . . . . . . . . . . . . 367

\section{CHAPTER XIV}

\section{Alleged "Antixomies"}

Effect of the Antinomy - Meaning of the Term - Denial of the Doctrine of Antinomies - Claims of Kant examined - Mr. Bradley's Views criticised -Application of the Categories to Reality . . . . . . . . . . . 396 


\section{CHAPTER XV}

\section{Truth and Error}

Nature of the Distinction - Error as non-Truth - Error and Wrong-doing -

Truth dependent on Judgment - and on the Meaning of Judginent -

Natnre of Mathematical Truth - The Truth of Perception - Truth and

Error in Science-Foundations of Scientific Knowledge-Sources of Error-True Cognition of Self-Criterion of Truth-Belief and Reality . . . . . . . . . . . . . . . . 424

\section{CHAPTER XVI}

\section{The Teleology of Knowledge}

Cognition and Action - The Teleology of Perception - aid of Conception - Fina Turpose among the Sciences - Knowledge as End in ItselfKnowledge as Part of Life - Final Purpase in Reality . . . . . . . 472

\section{CHAPTER XVII}

\section{Etilical and Estuetical “Momfetta" of Knowledge}

Character and Cognition - Influence of Feeling on Judgment - Attribution of Ideals to Nature - Benevolence of Law - Limits of the Ethical "Momenta" - Characteristics of Esthetical Conscionsness - Beauty in Reality - The Epistemological Postulate . . . . . . . . . . . 500

\section{CHAPTER XVIII}

\section{KNOWLEDGE AND REALity}

Cognition as Species of "Commerce" - Failures of the Identity-hypothesis - Distinction in Reality necessary to Knowledge - Truth in all Kinds of Cognition - Variety of the real World - Causation as Connection in Reality . . . . . . . . . . . . . . . . . . . 530

\section{CHAPTER XIX}

\section{IDEALISM AND REALISM}

Danger of exclusive Views - Tenable Positions of Idealism - Negation of its Extremes - The Truth of Realism-Criticism of its Denials - The true Picture of Reality . . . . . . . . . . . . . . 559 


\section{CHAPTER XX}

\section{Dualism and Monism}

Conceptions of Number applied to Reality - Unity and Duality of Body and Mind - Unity of the Self - Defects of extreme Dualism - The Truth and the Limitatious of Mlonism . . . . . . . . . . . . . 574

\section{CHAPTER XXI}

KNowlfge ANd the Absolute

Final Position of Agnosticism - Explication of Terms - Danger from abstract Conceptions - Unchanging Laws of Cognition - Presence of the Absolute in Consciousuess - The comprehensive View of Epistemology . 591 



\title{
PHILOSOPHY OF KNOWLEDGE
}

\section{CHAPTER I}

\author{
THE PROBLEM
}

HE struggles of the mind of man to come to a satis-
factory understanding with itself are among the most interesting exhibitions of his greatness. This is true from whichever of several points of view we regard the phenomena. For suppose that - disregarding for the moment the more distinctively metaphysical considerations - we approach the subject in the light of the biological and anthropological sciences. The surpassingly strange spectacle of an animal which is not content with the occupations prompted by a restless and almost unceasing practical curiosity, nor satisfied simply to learn how it may possess and use the instruments of its own temporary well-being, is certainly most attractive to a reflective mind. During certain periods at least of its existence the human animal exhibits a solicitude respecting the truth of its own being; it becomes caretaking as to the validity of its knowledge of the being and transactions of things. But why should not man be satisfied to realize, in mere living, a fairly uninterrupted succession of pleasant states of feeling, and to let the painful experiences that trouble the flow of the stream of consciousness fade away in the dreamlike illusoriness of an animal's memory?

Like the other higher animals, man is consciously earnest and absorbed in the pursuit of various forms of eudæmonistic 
good. But unlike all the other animals, so far as we are able to get behind the barriers interposed between us and their psychical states, man comes to regard this very conception of "truth" as something in itself good. Then he turus upon his own reason with a complaint which is frequently bitter, or with a self-accusation of impotence which may become savage, in the demand that it should furnish him with a more complete authentication for the good which bears this peculiar form. Moreover, the truth, as he conceives of it, is in his thought correlated with what he calls "reality." Indeed, what he means by that kind of truth, which he needs to possess in order fully to satisfy the demands of reason, is not definable without an implicate of reality. But why, again, as merely the highest form of animal life, should man alone among all the species not be satisfied with appearances, if only they be of a pleasant character? Why should he insist on dissecting his puppets to determine whether they have the anatomy of actual living things, or not; why be so eager to disturb the interest in the show of appearance by exposing too cruelly the actual mechanism of the strings? We can discover no wholly adequate answer - no very convincing partial answer - which modern biology has afforded to inquiries such as these. And yet phenomena of this kind are undoubted facts in the complex life of humanity.

Or suppose the same phenomena to be approached from the anthropological and historical points of view. Here it cannot easily be denied that the unsatisfied need for validating as "truth," in conscious attitudes, the various presentations of sense, the trains of associated ideas, and the abstract concepts, as well as the varied and ceaseless efforts which men make to satisfy this need, have always been most important factors to aid in the evolution of the race. All merely anthropological theories of evolution, howerer, appear unable to account for the existence of this need; and we 
beliere that they not only are now, but will always remain, quite outside of such a task. The right claimed by the majority of the students of modern science, distiuctly to aim at keeping clear of all metaphysics and so-called "theories of knowledge," may be conceded. And indeed, if there could be knowledge that is not something much more than this majority will admit it to be, science itself would consist of a succession of presentations of sense, associated ideas, and thoughts, about the truth of which no one would ever even raise a question. From the merely logical and formal point of riew, the peculiar kind of syllogism which belongs to science, as such, may fitly be called the hypothetical syllogism. Its form is as follows: If $A$ is $B$, then $C^{\gamma}$ is $D$; but whether or not $A$ really $i s$, and whether, admitting that both it and $B$ really are, they are actually related as belonging to the same species, or as reciprocal influences in determining the same result, - with this, science need not concern itself. Only now, such science could scarcely be called knowledge; much less, truth. For, as we undertake to show in detail later on, the words " knowledge" and "truth", are significant of mental processes and mental positions which can neither be attained nor stated by the use of the hypothetical syllogism merely. But the moment we consider the crolution of science itself as a growth in actual cognition, whether on the part of the individual or of the race, we introduce the epistemological problem; and this problem cannot eren be considered from the merely anthropological point of view.

It would furnish a most curious bit of research to determine what the development of physical science would have been, if only its students had really held the above-mentioned conception of it. Would it now continue to advance, if investigators and the people generally attached to its conclusions only the significance and validity which belong to dreams? However we might incline to answer this question, 
one thing is sure. "Science," thus conceived of, would suffer a mighty and pathetic fall from its place of dignity in the present estimate of mankind. Theories of evolution as applied to the human race, stand in respect to this instinctive metaphysical faith, less in the relation of satisfactory explanatory causes than of partial effects. They are themselves mental phenomena, for the understanding of which we must resort to a study of the constitution of reason itself.

The conclusion which has just been drawn from a brief survey of the merely biological and anthropological aspects of our problem may be summarized as follows. What mankind calls its knowledge, or science, of Self and of Things, is assumed to be something more than mere self-referring, psychical occurrences, - mere presentations of sense, associated ideas, and subjectively connected thoughts. It is assumed to be the truth, either already attained or capable of being reached and verified. And by "truth" men generally understand a form of mental representation which has its correlate in reality, in the actual being and matter-of-fact performances of things. Yet doubt is constantly arising as to the meaning and as to the validity of this universal assumption. The doubt is productive of restless endeavor, as well as of sadness, increased doubt, and even of indifference and disgust, when the assumption itself is made the subject of inquiry. It is somehow thus that the problem of knowledge has progressively defined and emphasized itself as an influential factor in the development of the reflective thinking of man. The problem is by no means new, as the history of this thinking conclusively shows.

It is to the inereasingly keen and searching analysis of mental processes, to the science of psychology, and to the critical examination of reason - first undertaken in a thorough and methodical way by Kant - that we must resort for the more definite, technically exact statement of our problem. Now psychology, as its very nature and legiti- 
mate mission compel it, considers all cognitions, whether of the ordinary or of the so-called scientific variety, as merely mental (or subjective) phenomena. For it, all beings are resolvable into states of consciousness. Its definition is, "The science of states of consciousness, as such." And as its means for analyzing the content of consciousness become improved and are more faithfully and skilfully applied, and as the laws of the combination and succession of the different states of consciousness are brought to light, the entire domain of knowledge is made the subject of its investigations. All cognitions, all sciences, undoubtedly are states of consciousness; from the psychological point of view, they are simply this. The one psychological assumption, from which no escape is possible, the assumption which is presuppositionless and absolutely undeniable, is this: My cognition is a process in my consciousness. But this assumption is as true for you, and for him (for "the other," whoever he may be), as it is for me. It is as true, when the object of cognition is a thing, a stone or a star or a microbe, as when the object of cognition is definitively recognized as my own state, whether in the form of a toothache or a thought about God. The ultimate psychic fact is simply: "I kNow."

Further, all the researches of modern psycliology tend to show that in those mysterious beginuings of psychic life, which are forever hidden from direct observation and from recognitive memory, idcation and object existed as in a common root of consciousness. One may speak of these beginnings as the "original unity of our perceptive life," as the original "unity of apperception," or as one please. Nothing more impresses students of Kant than his elaborate architectonic in exhibition of the complicated nature of that mental edifice, ascribed in part to imagination and in part to intellect, which the unity of apperception constructs. But those who dissent from the Kantian method and its conelusions, and will hear nothing of "psychic synthesis," even 
as a conscious and self-active energy, are compelled either to resort to the hypothesis of sensations that somehow get together or put themselves together; or else they have altogether to abandon the problem of psychic unity of any kind.

What all are aware of, however, whether psychologists or not, and independently of learned or thoughtless talk about "synthesis" and "apperception," is a most startling experience of an opposite kind. It has already been said that the one indisputable fact upon which epistemological doctrine must build is the "I know" of every man's consciousness. This fact, when repeated and gencralized, becomes the foundation of the most presuppositionless of all psychological truths, - "all cognition is a process in consciousness." But on the very first experience of this fact, and in connection with all experiences of this truth, knowledge appears no longer as a one-sided affair. It appears rather as an affair of Subject and Object; and, in the greater number of its most impressive instances, it becomes an affair implying a fundamental and unalterable distinction between Self and Things.

The generál fact of cognition requires restatement, then, in the following way. It is still, undoubtedly, a state of consciousness; or rather, it is a conscious process. It is also a state of my consciousness, a conscious process which including, as it must, its object-thing - I attribute to myself as subject, and call my own. But this object, which is my object-consciousness, my state objectively described, is cognized as not-me, as "out of" me. Objectivity, in the sense of trans-subjectivity, the really existent out of my conscious state, is, then, as will be shown in detail elsewhere, the implicate of every truly cognitive act of mine. The inquiries, how this can be, and what is implied as to a reality that is trans-subjective, constitute the problem of the philosophy of knowledge. The descriptive science of psychology, in its study of the plain man's consciousness, shows 
beyond all doubt that knowledge, even as admitted fact and state of consciousness, cannot be faithfully described, on the basis of a full and satisfactory analysis, without recognition of this implicate of what is not a present fact and state of consciousness. Thus much, at the very least, must be insisted upon. For the time being let those think, who so think can, that knowledge is explicable without recognition of the reality both of the object and of the subject, as a self-active and self-conscious synthesis, a unifying life-force.

It appears, then, that the subjective and the formal lies, in the process of cognition, actually inseparable as an experience from the trans-subjective and the real. The two exist, as it were, side by side and in a living unity; and yet the two are not incapable of being distinguished both by immediate introspection and by reflective thinking. For cognition is a modification of consciousness that is dependent, in part, for its existence and for its particular form, upon reality outside of consciousness (upon not-my-consciousness). On the one hand, it cannot be, or even be conceived of, other than as a modification of consciousness. It must be explained as dependent, both for its existence and for its form, upon the fact and the laws of the cognizing subject. On the other hand, its existence implies, and its form requires for explanation, some other being than that which is present in the modified consciousness. As to the further analysis and explanation, the import, and the validating of the import, of all this, the philosophical theory of knowledge inquires.

The problem of knowledge is not, however, grasped in its entirety and handled in a manner to promise a solution which is either theoretically satisfying or practically helpful, until it is seen that both problem and solution lie embedded, so to speak, in the very heart of reason itself. It was the distinctive merit of Kant, as has already been 
implied, to make this truth clear as it had never been made clear before. Since his day, the theory of knowledge (Epistemology or Noëtics, sometimes so called) has been one of the most active and fruitful branches of philosophical discipline. Indeed, some have gone so fal as to make the formation of a theory of knowledge coincident with the entire function of philosophy. That which calls itself knowledge of the universe "we call self-knowledge," says Kuno Fischer. ${ }^{1}$ We cannot agree to this restriction in the definition of the sphere of philosophy. And how widely the method we shall follow, and the results at which we shall arrive, differ from the method and conclusions of the immortal thinker of Königsberg, should appear at the end rather than at the beginning of our task. But when Kant asserted, "Human reason has this peculiar fate, that, with reference to one species of its eognition, it is always burdened with questions which it cannot cast aside; for they are given to it by the very nature of reason itself, but they eannot be answered because they transcend the powers of reason," 2 he indicated beyond question for all time the sources of the epistemological problem.

The history of reflective thinking, and indeed of the literature which either embodies, or is tinged by, the results of reflective thinking, has during the last century shown that Kant did not fully realize the suecess which he claimed for his critical philosophy. By following "the secure process of seience," in his "elaboration of the cognitions which belong to the concern of reason," he expected, on the one hand, forever "to deprive speculative reason of its pretensions to transcendent insights," and, on the other hand, "to furnish the needed preliminary preparation in furtherance of

1 "Philosophie ist die Wissenschaft und Kritik der Erkenntniss," says Riehl, Der Philosophische Kriticismus, iii. p. 15.

2 Opening sentence of the Preface to the first edition of the Kritik der reinen Vernunft. 
a fundamental metaphysics in scientific form." 1 But, strange to say, Kant's destructive effort was followed in history by the erection of systems of metaphysics which made, above all others since man began to think, the most enormous "pretensions to transcendent insights;" while his positive intent has left behind few traces of accepted metaphysical science. It is the sceptical and agnostic conclusions as to the cognitions of reason which so-called neo-Kantians accept. The determination and defence of the subjective origin and the objective reference of the "categories," and the rationalized faith of Kant in the postulates of the practical reason are accepted, when accepted at all, by quite other schools of thinkers than those commonly called by his name.

It is not the chief interest at present, howerer, to define epistemological truth with reference to the author of the modern critical doctrine of knowledge. It is rather the purpose to point out that the origin, nature, and importance of that problem which knowledge, with its essential objective implicates, offers to the knowing subject, have in some sort been settled once for all by the critical work of Kant. The human mind, by virtue of its necessary and constitutional way of functioning in all its cognitive acts, contains at once the proposal and the answer, if answer there be, to the problem. Neither the biological and anthropological, nor even the distinctively psychological study of the nature and growth of man's mind will avail fully to explicate or to answer the epistemological inquiry. The rather is this, fundamentally considered, a philosophical problem. And it is inextricably intermingled with the problem of the Nature of Reality, as this conception of reality is applied both to the mind of man and to the object of his knowledge.

It will appear as an opinion for which we shall constantly

1 Preface to the second edition of the Kritik der reinen Vernunft. 
contend that the problem of knowledge cannot be properly stated, much less satisfactorily discussed, without unceasing reference to the conclusions of a scientific psychology. The reference must even be a deference. The point of starting must be psychological. Epistemological discussion must begin by understanding analytically the actual, concrete content of consciousness. But the consciousness which enfolds the problem, and which must be analyzed, and so far as possible understood in order to the best mastery of the problem, is a developed human consciousness. It is the consciousness of a being who has already become apperceptive and self-conscious. It is not, therefore, an animal consciousness; nor is it an inchoate and beginning human consciousness. The study of the psychological origin and growth of knowledge is, indeed, a valuable contribution toward apprehending and solving the philosophical problem which gives rise to a theory of knowledge. But inasmuch as this problem is given in processes of cognition whose essential characteristic is that the knowing subject already distinguishes the forms of his cognition from the forms of existence implicate in cognition, and either naĩvely identifies the two or raises the sceptical question about their identification, psychological study is not in itself a sufficient indication or instrument for its solution. The more distinctively epistemological problem now emerges; the critical inquiry is raised as to whether, and how far, the forms of cognition coincide with the forms of existence.

The fundamental problem of the philosophy of knowledge is, then, an inquiry into the relations between certain states of consciousness and what we conceive of as "the really existent." 1 But at this point a reflective study of human knowledge reveals the fact that its problem is already inextricably interwoven with the ontological problem, - the metaphysical inquiry, in the more restricted meaning of the

1 Compare Hartmann, Das Grundproblem der Erkenntnisstheorie, p. v. 
much-abused word "metaphysics." 1 For suppose that the two spheres be distinguished as follows: Epistemology, or the philosoply of knowledge, deals with the concept of the True; and Metaphysies, or the philosophy of being, deals with the concept of the Real. We find ourselves, however, quite unable to form any concept, or even to hold in consciousness the most shadowy mental picture, of what men affirm, with genuine conviction, to be true, without implicating the for-us-real in this concept, this mental image. On the other hand, no meaning can be given to the word "real" without stating a judgment as to what is considered true. Yet the two words are by no means precisely identical. For the more correct usage speaks of presentations of sense, of images of recognitire memory, and of certified thoughts about things, as true; and they are thus distinguished from images of fancy or from unverifiable thoughts. But men speak of minds and things as real - meaning thus to imply a sort of existence which belongs neither to the true nor to the false mental representations.

We have already (in the Preface) stated that we intend to discuss separately the epistemological and the ontological problems. About the order and the method of these two discussions something will be said later on. The connection of the two - intimate and inextricable as it is - is emphasized at this point in order to show that the impulse to the quest, which it is proposed in subsequent chapters to follow, is indeed set fast in the very heart of human reason. To explicate the problem of knowledge, it is necessary to search to its depths the mind of man. To solve it completely would be to comprehend and expose all the profoundest mysteries of his mind. And not only this: it would be, as Kant held, to prepare the way for a systematic and defensible exposition of the inmost nature of Reality, so far

1 Note the phrase of Riehl, - die metaphysischen Erkenntnissprobleme. See Der Philosophische Kriticismus, Vorwort to Part ii. 
as this knowledge comes within the possible grasp of our reason itself. But, doubtless, this will remain for a long time to come one of the most alluring and important, yet difficult tasks of philosophical discipline. And one thinker can scarcely hope to do more than bear a small portion of the burden of so great a task. There will probably not arise another Copernicus in this stellar science of mind.

Something more should at this point reeeive at lcast a passing notice. It would not be surprising if a critical inquiry into the nature, extent, and validity of knowledge should bring us, at various points along its course, in sight of, if not into closest contact with, certain important coneepts of ethics and of the philosophy of religion. It will be the declared purpose and fixed rule of the present investigation to avoid contested ethical and religious questions as much as is consistent with a thorough treatment of the epistemological problem. And where foresight makes contact inevitable, we shall still try to accomplish our task without undue influenee from ethieal and religious prejudices. But it should be remembered that, in the discussion of all the problems of philosophy, and perhaps in the discussion of the epistemological problem in particular (since over it the forees of dogmatism and agnosticism, of extreme idealism and extreme realism, of crude evolutionism and old-fashioned theology, come to a sort of life-and-death struggle), prejudices are not likely to be all on one side. No author can promise more than we are ready to promise, - namely, to do the best that in him lies. And if it should be discovered that knowledge cannot be divoreed from faith or separated from the life of action (from conduet, which is the sphere of ethics), why! whose fault will it be that this is so? Will not the discovery serve to make the unity of man's total life, and its oneness, in some sort, with the Reality of the Universe, yet more undoubted and more comprehensive? 
The nature and extent of the epistemological problem, the discussion of which is a philosophy of knowledge, can be better comprehended only by emphasizing certain considerations somewhat more in detail. And first of all the following consideration: this problem is the most primary and fundamental, in the sense that it is of all philosophical problems the most free from the influence of necessary preliminary assumptions. To argue it is as near as the human mind can come to presuppositionless reflective thinking. This is, in part, but in part only, what Fichte meant by calling his critical examination of the primary and permanent content of consciousness a Wissenschaftslehre. For the same reason this kind of philosophical study is sometimes said to aim at a "science of science." All the particular sciences necessarily and fitly cherish their own particular assumptions. They cannot be successfully pursued, or even seriously approached, without taking for granted many important principles and not a few fundamental entities. Some of these principles and entities are assumptions of the most ordinary human knowledge; others are presuppositions which have been won for the modern student by the researches of the past along different scientific lines. For example, chemistry adopts the work-a-day assumption of an extra-mentally existent matter, which is capable of actual subdivision into parts that are too minute to affect the senses, and that can therefore never hare their existence verified by immediate testimony from sensuous observation. It also assumes the entity called an "atom," with its marrellous non-sensuous characteristics and its faithful obedience to the law of equivalents. In common with all the physical sciences it assumes the capacity of the human mind to arrice at the truth of things, to bring its forms of mental representation into agreement with the forms of the actually existent. All the particular sciences presuppose, as truths which enable them to be "particular," the extra-mental 
validity of the so-called categories of time, space, relation, causation, etc.

Those branches of philosophical discipline which are called metaphysics of ethics, philosophy of art, of nature, and of religion, as well as of rights and of history, have a complicated net-work of presuppositions, which is the very substance of what holds them within their proper bounds. The actuality of the existence of multitudes of men, in the present and through the past, with a real history of development, and standing in a great variety of actual relations to nature and to one another, is taken for granted in the very attempt to establish a philosophy of conduct; while anything approaching a philosophy of nature receives from the hands of the natural sciences a vast body of alleged, and not a few (we venture to suspect) of only conjectured, principles and entities, which become the necessary presuppositions of its constructive effort.

But with the philosophy of knowledge the case is not the same. It at once and distinctly puts all the above-mentioned assumptions to one side. They may be true, but they cannot be adopted from the beginning by a critical theory of knowledge. The very aim of this theory is to get behind and underneath all these and other similar assumptions. And if there are assumptions back of which the mind cannot go, - because it is compelled to make them by the very constitution of its own most sceptical and critical life, as it were, - then epistemological inquiry will get down to these assumptions also and view them face to face, in calmness and with purified and sharpened vision. For it is not the nature and validity, or the value, of this or that class of cognitions with which the philosophical theory of knowledge aims to deal, - it is the cognitive faculty itself; or, to state the problem in more abstract and objective fashion, it is human cognition itself which is the subject of critical examination in every attempt at an epistemology. This 
inquiry is, therefore, the most nearly presuppositionless of all possible inquiries. It assumes nothing but the one general fact in which all individual cognitions, whether socalled scientific or not, "live and move and have their being," - the one fact, I kNow.

It soon appears, however, as analysis and reflective study of the fact of knowledge moves forward and downward, that this fact is itself no simple affair. By this we mean something more than that "our experience is an extremely complicated web of sensations and intellectual elaboration of sensations, and of the results of their elaboration." Locke would have had little doubt to throw upon a statement like this; and eren less doubt would have proceeded out of the mouth of the great sceptic Hume. The successors of Locke in France, the most extreme of sensationalists in the psychology of to-day, might admit as much. Modern psychological analysis, especially of the experimental type, in its effort to disentangle the "web" of experience, has thus far succeeded in increasing rather than diminishing its apparent complexity. Even the most presuppositionless of all inquiries, then, since it must assume the fact of knowledge, has also to assume a history of the complication of sensations, of the intellectual elaboration of sensations, and of the gathering of the results of their elaboration. That is to say, in the very reception of the datum, "I know," the assumption of an organization of experience has already, of necessity, been made. Nor is it possible to get back of this process of organization, with its complex results, in order, freed from its influences, to examine the fact of knowledge.

So obvious is the truth to which attention has just been called that its statement is often made in half-jocose form. When I most carefully and critically examine this datum, "I know," and when I push my presuppositionless and sceptical inquiry to its extremest limits, what is all this but a going-round in an endless circle? I kNow; and I 
propose, without favorable or unfavorable prejudice, to distinguish the ultimate nature, to get the full import, and to estimate the real value of this fact. But the conduct of the examination is itself, at best, only a series of similar facts: "I know," and again, "I know," or it may be, "I do not know." But this last, "I do not know," is only another way of saying $I$ know, - at least, something, namely, that $I$ do not know. At its best, too, the result of critical examination is itself a cognition, which lies still further from the certitude of envisagement or of the concrete judgments of daily experience. At its worst, the same examination ends in a series of opinions, which are far enough from laying claim to be any kind of knowledge.

Put into more serious philosophical form, the dilemma may be stated in something like the following way. A fundamental critique of the faculty of cognition is now proposed; but if this critique is really to be fundamental, it must be free from all the assumptions which belong to any of the special systems of cognitions, the sciences so-called. Theory of knowledge aims to be presuppositionless, to have no assumptions beyond the one primary datum of my knowledge. In studying the data of actual cognitions, however, so as thus to frame a critique of the faculty of cognition which shall be based upon the facts, I am always using this same faculty. Hegel thus accused Kant of allowing to creep in "the misconception of already knowing before you know, - the error of refusing to enter the water until you have learned to swim." And Lotze compares those who spend their strength upon a theory of knowledge to men constantly whetting the knife, and feeling its edge to see if it will cut; or to an orchestra which is forever tuning its instruments and still wondering if they can play in tune.

To objectors in general, we shall either propose our answer in due time, or else conclude that a much needed work will be better done if they are silently passed by. 
Two things are enough to say at present. Of these the first is this: if the critical theory of knowledge must be satisfied with a completely sceptical or agnostic outcome, then all human science is but consistent dreaming, at its best. For the very guarantee of truth which consistency gives is itself dependent upon trust in the constitution of reason. But, second, the absurdity of an utterly presuppositionless critique of reason must be acknowledged at the very beginning of every epistemological inquiry. All reflective thinking upon this class of problems must be content to move within the incritable circle. The human mind cannot contemplate itself from an outside point of riew, as it were. It must accept at its own hands the terms upon which it will undertake and complete its task of self-understanding.

Here, then, we get the first strong intination of characteristic difficulties besetting the path which must necessarily be followed in the attempt to investigate with critical thoroughness the philosophical problem of knowledge. Nothing, we assure ourselves with encouraging confidence, must be taken for granted, beyond the ultimate and inclisputable datum of all science, - the fact, above or behind or beneath which no one can go. This is the datum and the fact of knowledge itself. But surely this datum must be received as being all that it in fact is; this fact must be held for all that it, as conscious datum, is worth. This is to say that a philosophical theory of knowledge must deal with the whole circumference, as it were, and with the most intimate and inclusive significance, of the psychological process of cognition. Criticism must accept, as its problem, cognition including all its necessary implicates. What is it to know, in respect of all that knowledge is, of all that knowledge guarantees, and of all that it necessarily implicates? It is in the primary fact of cognition, when critically regarded, that we find the sources of the possible forms of conclusion concerning the true philosophical theory of knowledge. The 
permanent sources of philosophical scepticism and agnosticism exist in the incontestable fact that all knowledge is subjective; that, proximately considered, it is a conscious process in time, a mental state which arises and then passes away. Moreover, one of the first discoveries which criticism makes is the truth, also incontestable, that the laws of the knowing faculty, and so the limits of knowledge, are firmly set in the constitution and characteristic development of the cognitive subject. Human cognition, therefore, contains in its own nature a standing warning, and even a vindication of the necessity for doubt of the most fundamental sort. It issues a perpctual call to those self-scarchings which lead into a theoretical reconstruction of our concept of knowledge.

Equally certain is it, however, that the sources from which must come the healing of the wounds which reason receives at her own hands are with reason herself. The primary datum of cognition contains within itself the corrective of agnosticism, the chastening of raw and unbridled scepticism; or else no such corrective and no such chastening are anywhere to be found. The sources of a philosophy of knowledge and of a trustworthy metaphysics also exist, inexhaustible, in the incontestable fact that knowledge is trans-subjective, and, in its very nature, implicates existence beyond the process of knowledge; that cognition itself guarantecs the extra-mental being of that which, by the very nature of this process the cognitive subject is compelled to recognize as not identical with its own present state. Thus the most primary problem of epistemology becomes a concern of reason with the ultimate, the unanalyzable and irreducible momenta and principles of objectire cognition. ${ }^{1}$ The further advance of this concernment may be described as reason becoming more self-conscious in the way of bringing to its own recognition what is implicate in consciousness as objective.

1 Compare Volkelt, Erfahrung und Denken, p. 35. 
Mere recognition of the implicates of cognition is not in itself, however, enough to satisfy all the deinands made by the self-searching and critical activity of man's mind. These implicates must themselves be made the matter of a further concern of reason. Suppose, for example, that I have come to a consciousness of what is involved in saying, "I know" - any simplest truth of fact or of a physical law; such as that the chair is over yonder, or that the force of gravity varies inversely as the square of the distance and directly as the mass of the two bodies taking part in that transaction which reveals the existence of this force. Here, as in every act of knowledge, are two classes of implicates. One of these is the implied control of consciousness by what are called the "laws of the mind." It is an invincible persuasion, belief - use what word you will, if you do not like the term "rational assumption" - of all men that truth is somehow to be attained by the mind. This is the indestructible self-confidence of human reason. Disappoint her as often as you may, deceive her as badly as you can, accuse her of unlimited audacity in enterprises that concern what appears to transcend her powers, and yet you can nerer wholly destroy her self-confidence. So often as she falls, she rises again and makes once more the persistent effort to stand and to walk alone. Or in her more pious moods, if much chastened by rebukes for her many errors, she still "trusts in God and is not confounded."

This trust of reason in herself, which is alwars at least a silent and concealed postulate of all her distrust, itself needs eritical investigation; in order, to drop the figure of speech, that the mental principles of those processes of knowledge which all inrolve the persuasion, or the conriction of knowledge, may themselres be criticised in detail. Certainly we shall not by the critical method escape the necessity of using and of trusting these principles; nor shall we succeed in establishing their claims in a more fundamental way by 
smart and consecutive dialectic and trains of argument. Something better than merely this, however, may be hoped for, which it is by all means necessary to attempt, and which is not without a certain large positive value. We may hope to bring to light the truer meaning of these forms of the constitution of mind, these ways of the functioning of all human reason. Moreover, since there is no little apparent conflict among these principles, as well as vagueness and uncertainty respecting the best ways of stating each of them, we may attempt to effect something in the interests of harmony and clearness. The doctrine of irreconcilable conflict, of fundamental and irremovable "antinomies" of intellect so-called, is favorite with many acute students of the mental life. This doctrine, in itself so distasteful or even abhorrent and frightful to the higher interests of ethics and religion as some conceive it to be, certainly requires perpetual re-examination. To speak technically, the critical and "reconciling" discussion of the "categories" is an important problem for the student of epistemology. And when he is incontinently and even coarsely accused of fostering scepticism and agnosticism, of emasculating a sturdy and effective manhood by calling in question its most fundamental faiths, he may answer: "Nay, not so; for no faith can lay claim to be fundamental, or to contribute to a sturdy and effective manhood, which cannot submit itself to the freest criticism."

To-day and throughout all history, the struggle of a positive and critical philosophy with scepticism and agnosticism over a theory of knowledge is a life-and-death struggle. War to the knife is already declared between the two. He is the emasculator of reason, the effeminate student of the mind's life, who would deprive us of the power to answer ever anew the call: "Let the thinker arouse himself and respond to the demand to give reasons for the faith that is in him, by an effort at improved self-knowledge." But 
surely self-knowledge cannot be improred, or made true knowledge of Self, unless we look below the superficial area of particular cognitions and undertake to validate the principles of all cognition. Surely it is no less true now than it was in mediæral times, when the principle of authority was wellnigh universal in its sway, that the friends of human reason are not those who refuse to have its claims examined. What higher principle of truth can there be than this: That must be true which is so connected with the knowing subject that he must either relinquish all claim to any kind of knowledge or else assume the same to be true? What is actually thus connected with the knowing subject can only appear as the result of a critical investigation into the fundamental laws of the mental life in its acts of cognition. For the theory of knowledge must be a theory of certainty.

But the process of thinking may conform, at least in certain respects, to logical laws without putting the thinker in posscssion of material truth. Whether an agreement of the total activity of knowledge with all the formal laws of intellect would unfailingly guarantee the truth is a question which need not be raised at present. Certainly, neither what is called ordinary knowledge, nor what is called science, consists simply in wearing into a consistent totality a number of universal and necessary laws. A critical analysis will establish the conclusion that thinking alone - the pure dialectical process, mere thinking, if that were possible - cannot produce a certified experience of Reality or a sure conviction as to the essential and unchanging nature of Reality. This truth emphasizes the necessity of extending still further the problem of the epistemological branch of philosophy. Besides the formal laws of intellect, another class of implicates is found in every act of cognition, and furnishes a demand for more detailed examination. These are implicates of beings, of entities, of the really existent. The exercise of "metaphysical instinct," if we may for the 
moment employ such a term, is an indispensable form of functioning in every act of cognition. To know is to make an ontological leap, a spring from the charmed circle of pure subjectivity into the mystery of the real. This instinctive metaphysics maintains its inexorable rule over the human mind, in spite of all sceptical inquiry; and just as inexorably after we have adopted the agnostic view regarding the validity of human knowledge, or the most extremely idealistic theory of the nature of experience, as before. But in its uncritical and instinctive form it is neither theoretically nor practically satisfying. There must be substituted for this uncritical metaphysics some postulate, thoughtfully wrought out, which will show how the contents of developed and carefully guarded human consciousness may be true and valid representations of actual transactions in the world of reality.

The detailed critical discussion of those conceptions which fall under the general concept of Reality constitutes the peculiar field of metaphysics proper. This field, in not a few places, overlays the field of epistemology. The path by which both fields are reached follows the same method, - beginning in psychological science and continuing by reflective thinking upon the problems which this scicnce, as applied to the presuppositions of all the other sciences, brings to our view. Some adjustment of our examination into the problem of knowledge, so as to make it fit in with conclusions that belong to the problem of being, seems not only desirable but even indispensable. Otherwise the criticism of man's cognitive faculty must ineritably fall into one of two extremes. To assume, uncritically, that the forms of our conscious life - our representations of sense, our trains of associated ideas, and even our connected thoughts necessarily correspond with the actual transactions of the real world, whether wo make the assumption according to the plain man's "common-sense" or in the more elaborate 
forms of so-called "scientific realism," is to leave the problem of knowledge unattempted at one of its most important and eren vital points.

On the other hand, agreement in some sort and to some extent between the forms of human consciousness and the real beings and actual transactions of the world outlying the individual's immediate experience, is an assumption from which we can never set free the critique of reason itself. Uncritical faith and dogmatic agnosticism are both unphilosophical. The actual condition of thought and things in every process of knowing, and the indications which the critical study of the process offers respecting the real relations of thought and things, become then a problem for further examination. The apparent contradictions which the epistemological problem contains cannot contentedly be left in the uncriticised and unsettled position in which naire consciousness finds them. To leave them thus would be to confess that knowledge is no knowledge, and that our most essential activities are sclf-stultifying.

But further pursuit of such considerations as the foregoing must be left to the attempted solution of the problems which a philosophy of knowledge propounds. Enough has been said to show how it is that epistemology undertakes, as its important and difficult task, to discover, to expound critically, and to defend both circumstantially and by harmonizing them with each other, the implicates of every act of knowledge. 'This is also its chief theoretical interest.

The method which must be pursued in any partially successful attempt to form a philosophical theory of knowledge has already been indicated. A few words are needed, however, to make this indication clearer. In the study of the epistemological problem, as in the study of all philosophical problems, psychology stands in the relation of a propædeutic. It is this science alone which, when appealed to in faithful and unprejudiced fashion, can put us into possession of 
those concrete and indisputable facts of experience wherein the philosophical problem has its origin. The inquirer who is defective or slovenly in his analysis of psychological fact, of the concrete and feeling-full life of the human mind, will surely fail even to grasp the significance of the problem of knowledge. He certainly can never have in hand the data for helping to make more satisfactory the attempt at its answer. And the epistemology which despises or neglects the assistance of psychological science will either mistake the real nature of its mission, or else its entire view and attempted solution will be ghostly, - an unsubstantial image suspended in thin mid-air. The successful critic of human cognition must have penetrated and resided long within the theatre where the factors of the conscious and self-conscious life are enacting their varied drama upon the mind's stage. Nor will it suffice for this that he shall have inerely studied the logic of the actor. For, as we shall see in detail subsequently, human knowledge is not merely a logical affair.

His despite of psychology, as well as the forlorn condition of the science in his day, and his over-credulous acceptance of the logical schemata of Aristotle in the attempt to estimate the constitution, the presuppositions, and the limits of human cognition, had an eril influence upon even the "astounding Kant." It was chiefly the rigid maintenance of the purely conceptual points of view, the treatment of the categories, or forms of the functioning of judgment, as merely formal, which led irresistibly to the sceptical and agnostic outcome of the "Critique of Pure Reason." But Kant's abandonment of the merely formal points of view, in the other two Critiques, came too late to secure our respect and adherence for the class of objects with which these works attempt to deal. A more comprehensive and truer psychology would have shown the author that it is not a question of pure knowledge here and of pure faith over yon- 
der; of objective cognition free from doubtful postulates in the case of sensuous objects, and of practical trust without intuitive data in the case of so-called transcendent objects. It would possibly have guarded this great philosopherabove all others acute as a reflective analyzer of the formal presuppositions of reason - from claiming, in the interests of a harmonious apriorism, to have "knowledge" in so many places where no knowledge is; as well as from denying knowledge in certain other places where its claim to existence may well enough be maintained. For surcly the Kantian "ideas of pure reason" have as good title to objective validity as have many of the "concepts of pure understanding." The real unity of the soul is, at worst, as much known as is the objective verity of the principle of causation in physics, or - to take another instance - of the principle of reciprocity. Certain judgments to which Kant gives a priori and objective authority, as "making a pure science of physics" possible, are no. more entitled to this distinction than are many of the theological judgments which he relegates to the limbo of dead metaphysical speculations.

We have dwelt upon the example of Kant in order to show that metaphysical acumen and power in reflective analysis, however surpassing, will not serve one to the best advantage in the study of the problem of knowledge, unless these qualities be employed upon a sound and broad basis of psychological fact. But, on the other hand, the mere student of psychology (especially of the purely experimental type) cannot grasp, much less satisfactorily solve, the difficulties inherent in a philosophical theory of knowledge. For the method of stating and of handling the epistemological problem must be something more than descriptive and experimental. The peculiar discursive analysis which philosophy habitually employs must unfold the presuppositions that lie implicate in the facts of cognition. It must 
also be persistently and systematically used in order to attain a consistent and liarmonious theory.

Upon one point affecting the method of epistemology a further word needs to be said. We have seen that the problem of knowledge is in its very nature such as to involve metaphysical discussion in the narrower meaning of the word "metaphysies:" that is to say, it is impossible to discuss this problem without introducing the influence of one's positions respecting the ultimate questions in ontology. Accordingly a dispute has for some time been rife over the inquiry, "Which of the two logically precedes the other in a philosophical system?" The answer of Kant to this inquiry was not equirocal. He held that to attempt a system of metaphysies, or even to discuss any of the great metaphysical problems, previous to a critique of reason itself, was mischievous and absurd. On the other hand, not a few would agree with Paulsen ${ }^{1}$ in recommending, or insisting upon, the opposite order. We have expressed our opinion as to the merits of the question of method elsewhere. ${ }^{2}$ The historical order coincides with that which is advocated by those who oppose Kant upon this point. The logical order, on the contrary, is the one advocated so earnestly by Kant himself. The two classes of problems, and the two branches of philosophical discipline which cultivate them, cannot be kept apart. When historically considered they will be, and when logically considered they cannot help being, cultivated in their relations of mutual dependence. But it does not follow, because the historical order favors the view of Paulsen, that the more logical order may not be entitled at some time in the development of reflective thinking to displace the historical. We can see no scrious objection to allowing any author to follow his own inclinations or convenience in arranging this point in the method of

1 Introduction to Philosophy, pp. $340 \mathrm{f}$.

2 See the author's Introduction to Philosophy, pp. $178 \mathrm{f}$. 
treatment given to the connected epistemological and ontological problems.

As concerns the purpose and the method of this treatise, therefore, all that it is now necessary to say may be summarized as follows. We propose a philosophical criticism of knowledge, with a view to point out its origin and nature as implicating reality; to validate it by reducing to their simplest terms and arranging in a harmonious whole its necessary forms, its assumptions, and its postulates; and to mark out its limits by further criticism and especially by distinguishing the sources and kinds of error and of half-truth. This is the task belonging to epistemology, or the theory of knowledge. We shall go for our facts to psychology, to the descriptive and explanatory science of those mental processes which are called "knowledge," and of that mental derelopment which is called "growth of knowledge." Wo shall subject these facts to a thorough reflective analysis; and we shall use what speculative skill we can command to sct our results into relation with sound conclusions on the other great problems of philosophy.

To any who question the importance or doubt the benefit of such a study as that here proposed, a few words will suffice. There can be no doubt about the existence in cultivated and thoughtful circles of a vast amount of scepticism which has led many minds either to a self-confident dogmatic agnosticism or to a pathetic despair of knowledge. These mental attitudes are, of course, especially obvious toward the transcendent objects which hare always commanded the assent of the great majority of thinkers upon ethics and religion. But the agnostic or despairing attitude toward the problem of knowledge itself lies, both logically and in fact, at the base of all other agnosticism and of manifold forms of despair. The history of mental derelopment shows that, in order to set free the forces of thinking for positive and fruitful activity, there is nothing against which we need 
to guard ourselves more carefully than the haste with which the most important and fundamental conceptions of the intellect are permitted to lose their absolute significance for the cognition of the being and the connections of the real world. Witness the cheap and easy-going fashion with which the sceptical and agnostic outcome of the Kantian eritical system gets itself accepted on erery side. And this oftenest comes about without serious effort to understand Kant aright; and with even less sympathy with the effort which led him to undertake the eritique of reason, - the effort, namely, to save the ethical and religious postulates from the attacks of the speculative reason.

For souls who take themselves seriously and who enter in earnest upon the exploration of reason, if they become tired, discouraged, or misled, there is no permanent cure but that which it lies in the hands of reason, with a profounder and richer understanding of her own self and her own resources, to accomplish. And they do not catch the true voice of the Zeitgeist who cannot hear and interpret it as a call. It is a call for a stronger and sweeter word of healing, spoken in the name of reason to soothe the sufferings and remove the scars which have been inflicted in her own name.

Nor is this mental attitude and its aecompanying tone of the emotional and practical life confined by any means to those who have reflected upon the criticism of the categories. There are thousands of plain men and women who do not so much as know whether there be any critical philosophy, and who have scarcely even heard the name of Kant, but who are profoundly influenced by the streams of thinking of which that masterful mind is the principal modern philosophical source. They, too, are ready to join the complaint:-

"There was the Door to which I found no key;

There was the Veil through which I could not see:

Some little talk awhile of ME-and-THEE

There was - and then no more of THEe and ME." 
And the chances, as the history of humanity abundantly shows, are not altogether against their coming soon to add to complaint this teaching of experience:-

"Then to the lip of this poor earthen Urn

I lean'd the Secret of my Life to learn:

And lip to lip it murmur'd - 'While you live,

Drink! - for, once dead, you never shall returu." "'

Now we cannot believe that it is matter of small importance whether or not any helpful word is spoken to those who are asking of reason a contribution to her own better self-understanding. And if, as has always happened, this word, when first spoken to more serious students, should filter downward and outward through the currents of popular opinion and popular impression, it might strengthen and sweeten the daily life of some of these "plain men and women." At any rate, here is a task worth trying. For the critical study of cognition is essentially an effort to make the total of our human life more dignified and better worth the living. It is an effort to heighten our rational estimate of the calling and the destiny of man. Scant respect is due that doctor in psychology who, when his patient comes to him heart-sick and brain-confused, either makes light of his ills or sends him to the nearest apothecary's shop, with orders to put himself to sleep by taking as much crude opium as some unskilled hand may choose to measure out for him. And, surely, that teacher of philosophy has either mistaken his mission, or else has no real mission to fulfil, who is not ready to welcome any honest and fairly competent attempt at so important a task. 


\section{CHAPTER II}

\section{HISTORY OF OPINION}

0 write a detailed history of the opinions of reflectire
thinkers respecting the nature, origin, limits, and relations to reality, of human knowledge, would be to traverse the whole field of the more important philosophical literature. But a far narrower and less arduous work is proposed for the sketch made in the two following chapters. The character of this sketch is to be understood and its value estimated only by keeping steadily in mind both the considerations which have chiefly influenced it. First, only those authors have been selected for brief review whose opinions have been found most suggestive and helpful in the historical study of the epistemological problem. Second, among the opinions of these anthors only such points of suggestion and helpfulness hare been noted as, on the one hand, seem most distinctive of their particular authors, and, on the other hand, fit in best with our own method of study and with the conclusions to which it has led us. Selections and omissions alike must be regarded in the light of these considerations.

"Antiquity," says Windelband,1 " did not attain a theory of investigation." This statement is true only if by "a theory of investigation" we mean to indicate such a conception and treatment of the grounds of knowledge and of the method of attaining truth as prevail in their modern more

1 A History of Philosophy (English Translation by Professor Tufts), p. 198. 
precise and systematic form. But in Plato, and in many writers from Plato onward through antiquity, not a few nuggets of most precious truth on the "elaboration of those cognitions which belong to the concern of reason" are found scattered. Kant was by no means the first to criticise acutely the "pretensions of reason to transcendent insights" ; neither was he the first who undertook to "make room for faith" by "removing knowledge." Eren much more is true, for there are in ancient and mediæval authors frequent suggestions of a correct theory, variously shaped and propounded, which the modern student of the psychology and philosophy of cognition cannot wisely afford to orerlook. Nor need one hesitate to affirm that in some cardinal particulars the Church Fathers Origen and Augustine were nearer the final statement of facts, and showed more of verifiable speculative insight into the significance of the facts than Kant himself. Yet so distinctive was the conception which the latter held of the epistemological problem, so relatively firm his grasp upon it in all its large roundness, and so unique the answer which he elaborated, that the entire history of human reflection upon this problem fitly divides itself at the Kantian epoch.

It is indispensable for the recognition and use of the suggestions which antiquity and even the Middle Ages afford, that the loose and figurative forms of expression employed by the writers of these periods should be pardoned and set aside. Modern thinking must gladly accept the truths they suggest, although the expression given to these truths may be much too fanciful to accord well with modern philosophical taste. Furthermore, the practical, the ethical, and the religious bearings of the problem and of the solution which happens to be suggested for it are seldom or never lost out of sight by these writers. A purely speculative interest in epistemology, or a rigidly technical presentation of its various possible answers must not be expected from them. 
But in this respect, too, it is far from being certain that the modern philosophy of knowledge has not something vaiuable to learn from its earlier and vaguer forms.

It is the Platonic Socrates and Plato - for we do not care to distinguish the two - who first has something interesting to say to us respecting the origin, the nature, and the ralidating of knowledge. In Socrates' rude midwifery and in the polished dialectic of Plato attempts are not wanting to criticise man's cognitive faculty and its product of so-called knowledge. Nor is the conception of a theory of knowledge, a science of science, unknown to Plato. There are hints at this conception in the distinction between the "what" of knowledge and the "that" of knowledge (between $\hat{a}$ oi $\delta \epsilon \nu$ and ötı oi $\delta \varepsilon \nu)$. The question as to the possibility of such a science is raised in the "Charmides"; and again in the "Thertetus," under form of the inquiry, "What is knowledge?" And although the notion of an absolutely selfdetermined knowledge is disputed by Socrates, it is concluded that, if a science of science can be found, it will also be "the science of the absence of science." 1 The critique of cognitive faculty, that is to say, will give us the absolute criteria of truth and of error in general. This science of science is not identical with self-knowledge; for the former determines that, "of two things, one is, and the other is not, science or knowledge." Neither is it identical with wisdom; for such a science is not the cure of folly, although it is the cure of the scepticism and agnosticism which are the breeders of folly. ${ }^{2}$

The problem of the origin of knowledge was a puzzling one to Plato, as it has always been to all who have made it the subject of reflection. For to give the descriptive history of how the different concrete and actual cognitions arise in consciousness did not seem to him a sufficient explanation of their arising at all, or of the universal forms under which

1 Charmides, 166.

2 Ibid. 172. 
they arose. Such history might explain what I know, why I know this rather than that; but it could not explain, he thinks, that I know rather than have an opinion or a thought, and that this knowledge is an implied seizure of reality. Herein lies the mystery of knowledge. This recognized certainty of present reality appears to Plato as implying some sort of commerce with the invisible world of the ideal. How otherwise can that which is universal, necessary, and eternal be given to every man in the concrete, varied, and fleeting experiences of his earthly life? In the "Meno," for example, the difficulty of defining virtue leads to the conviction of the truth: "Nature is of one kindred; and every soul has a sced or germ which may be developed into all knowledge." Eren Meno's slares recognize some elementary relations of all the geometrical figures. But though the simple sensations which reach the soul through the body are giren by nature, at birth, to men and to animals, reflections on the being and use of the sensations are gained slowly and with difficulty, if they are erer gained at all, by education and by expericnce. But how can education and experience account for all that is in every man's knowledge? It must be that cognition, somehow, is prior to particular cognitions. As to the manner of this pre-existence of the universal and necessary element of cognition, Jowett, misled by Plato's figurative use of words, commits him to the modern evolutionary hypothesis that it "exists, not in the previous state of the individual, but of the race." The rather have we here, though only dimly apprehended, the thought that the origin of knowledge cannot be understood merely empirically, but must be found in the native constitution of the cognitive soul. ${ }^{1}$ How did it get there? Here Plato's characteristic figurative ontology must account for the fallacy in his argument. Socrates is made to say: "But if he did not acquire the knowledge in this life, he

1 Compare Thertetus, 186 ; Meno, 86 ; Phædo, 73. 
must have had and learned it at some other time." And again, Cebes, referring to Socrates, remarks: "Your favorite doctrine that knowledge is recollection." Thus the preexistence and immortality of the cognitive soul is made to stand or fall with the ontological doctrine of the ideal world. For "if the ideas of men are eternal, their souls are eternal; and if not the ideas, then not the souls." 1

The impossibility of giving a wholly empirical account of the origin of cognition, and the necessity of recognizing elements that for their explanation demand an appeal to the reality and eternal existence of the ideal, are tenets in the Platonic doctrine of knowledge. These same tenets are repeatedly affirmed in the treatment given to the essential nature of knowledge; for truth cannot be imparted by the best of the senses, not even by sight and hearing. The disparagement of sensuous cognition is common to Plato with most idealists; and this mistaken view is connected with the failure — which he shares in common with modern solipsism - to recognize that both thought and the mental leap to reality are involved in all perception. And so he distinguishes knowledge from opinion, which is intermediate between ignorance and knowledge, even asserting that the two have to do with different kinds of matter corresponding to different faculties, ${ }^{2}$ and from belief, which may be false, while there can be no false knowledge; and he endeavors to refute the view that perception of things is knowledge at all. ${ }^{3}$ Here the Hindu mysticism, which regarded the soul as addressing itself in every act of perception of a Thing with a "That-too-art-thou," came far nearer the truth than did the Greek idealism. But with Plato it is thought by which existence must be revealed to the soul, if at all. ${ }^{4}$. Dialectic is the true method of rational knowledge. Upon this point Plato comes nearest to the
1 Phædo, 76.
2 Republic, 477.
8 Theætetus, $152 \mathrm{f}$.
4 Phædo, 65. 
truth in the statement that knowledge is true opinion accompanied by a reason, or resting on a ground. ${ }^{1}$ It is this overestimate of dialectic as the deliverer of knowledge within the soul of man, which is the chief error of Plato and of all similar forms of idealism since Plato until the present hour.

On one other phase of the problem of knowledge the Platonic writings are worthy to instruct the student of the epistemological problem to the end of time. Throughout does Plato emphasize the dependence of knowledge on desire, aspiration, virtue, and character. "In the "Phædrus," says Jorett, "love and philosophy join hands." With the exception of some of the writers of the Christian Chureh we have to wait until Fichte to have the inseparable and rital union of cognition with the life of feeling and action so emphatically affirmed. "The true knowledge of things in hearen and earth is based upon enthusiasm, or love of the ideas going before us and ever present to us in this world and in another." Only through the exercise of this lore can that dirine knowledge be attained which is "knowledge absolute in existence absolute." Hence the firm comnection between knowledge and the teleology of the idea of the good $;^{2}$ for, indeed, the idea of the good is the cause of science, and virtue is identical with knowledge. ${ }^{3}$ In a word, it is the distinguishing feature of Plato's doctrine of cognition that he treats knowledge, not as "pure," but as the epistemological and metaphysical presupposition of ethics.

It is the merit of Aristotle to have brought the early attempts at a science of knowledge into much mole definite and systematic shape - especially in his works on Logic and Metaphrsics. On the possibility of such a science we find with him no such expressions of doubt, approaching despair, as are found in Plato; also no such merely tentative and

1 Thextetus, $206 \mathrm{f}$.

2 Compare Republic, 508.

3 To show which, is the aim of the "Protagoras." 
mystical treatment of his problem. Aristotle distinctly recognizes the truth that, since there are certain principles common to all the particular sciences, and since, although these principles depend upon one another, the process of regressive dependence cannot go on forever, therefore there are premises which are themselves undemonstrable, but from which all demonstration begins. ${ }^{1}$ His view of the criteria of cognition seems to have been in part derived from

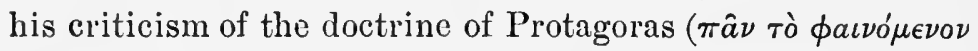
$\dot{a} \lambda \eta \theta \dot{\epsilon} s)$. In spite of Grote's assertion that Aristotle discountenances altogether the doctrine which represents the mind, or intellect, as "a source of first or universal truths peculiar to itself," the doctrine of the Greek thinker amounts to an espousal of a certain form of apriorism in respect of the sources and nature of human cognition. ${ }^{2}$

Knowledge, according to Aristotle, has its origin both in dialectical induction and logical demonstration. The soul, in its thinking nature, possesses the possibility of all knowledge (all knowledge dynamically); but it actually attains to its knowledge only by degrees. ${ }^{3}$ His doctrine of the syllogism leads him to conclude that there are two kinds of ultimate presuppositions: these are (1) the actual fact as known to us in perception without proof, and (2) general principles whose source is in reason ( $\nu$ ovs), - the power of direct, intuitive, and therefore unerring knowledge of such principles. Here we have a hint at the different kinds of implicates which have already been discovered as given in the fact "I know." And although in his psychology Aristotle regards the mind as in some sort a tabula rasa, thought takes the main part in writing some definite object upon the

1 See Anal. Post. p. 100, b. 3.

2 This we should argue, not simply on the basis of an appeal to passages in which Aristotle appears as the champion of "common-sense" (such as Eth. Nikom. I., vii., 14, and Eth. Eud. V., vi.f.), but chiefly as having his general doctrine of the natnre and growth of knowledge in mind.

${ }^{8}$ Anal. Post, p. 71, b. 33; Phys. i., p. 184, a. 16. 
tablet." By "thought" is meant, not a merely sensuous perception, although in perception thought is always accompanied by sensuous images (

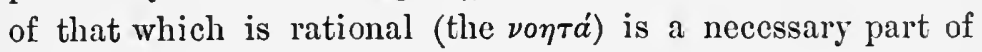

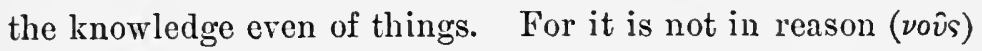

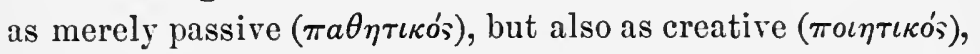
that knowledge has its source. And there is an actirity of the reason as such ("pure"), which consists in the immediate grasping of the highest truths. For knowledge becomes possible only as reason creates, into rational form, the object of knowledige.

Further as to Aristotle's view of the nature of knowledge we learn by following his description of the laws and manner of its growth. The mind rises, he thinks, by successire steps from individual observations to perception, from perception, by means of memory, to experience, and from such experience to the truer knowledge. Aristotle defends the truth of sense-perception. And it is in the interests of this riew — as we should now say, "for the sake of knowledge" as such, and not, like Plato, for the sake of ethics - that he derelops the theory of the syllogism. Complete science is realized only when that which needs to be proved is derired through all the intermediate members from its lighest presuppositions. ${ }^{2}$ In the Metaphysics he discusses the principle of non-contradiction and finds it the most cognizable of all principles; and yet, for this rery reason, quite undemonstrable. ${ }^{3}$ The true object of knowledge he agrees with Plato in holding to be only the necessary and the unchanging. Cognition cannot be explained unless the universal and the particular are "looked at in implication of each other." But with him it is not the universal as extra to the concrete enrisaged reality, but the universal as immanent in the in-

1 Compare De Anima, and for citations see Zeller's "Outlines of the History of Greek Philosophy," p. 207, note.

2 See Anal. Prior. p. 24, b. 18.

3 Met. p. 1005, b. 20. 
dividual thing (universale in re, not universale extra rem). So, then, with Aristotle, as not with Plato, the important truth is emphasized that knowledge is a development resting upon a basis of sense-perception, and requiring rational faculty which proceeds according to laws of its own. In this regard, indeed, the pupil stands far nearer than his teacher to the modern psychology of knowledge. As has been well said, he displaces "the seat of reality" and transfers it from the abstract universal of mere thinking to the concrete particular of sense-perception. ${ }^{1}$

Finally, with Aristotle, far more than with Plato, knowledge has its end in itself rather than in being a means, or requisite. of virtue. Philosophy is itself a greater good than any of the virtues. ${ }^{2}$ Cognition is thus more clearly distinguished from moral activity. Connected with this divergence of theory is another: for, in the view of the later thinker, the attainment of knowledge is much less dependent on emotional and voluntary attitudes; and empirical data are made more important for establishing our eognitions. Desire, aspiration, love, and intuition, retreat into the background. The doctrine of the practical syllogism remains, however: "No creature moves or acts except with some end in view." 3 And the mission of philosophy also remains, as with Plato, "the knowledge of unchangeable Being and of the ultimate bases of things, of the universal and necessary." 4

Little that throws new light on the problem of knowledge is to be learned from the post-Aristotelian schools of philosophy. The Stoics, however, elaborated in a somewhat instructive way the view of Aristotle regarding the criteria of cognition; while. it was a fundamental tenet with this whole group of thinkers to emphasize the importance, for right living, of seientific inquiry. Though the ontology of

1 Compare Grote, ii. pp. 257 f.

2 See A. Grant, the Ethics of Aristotle (3d ed.), i. pp. 226 f.

${ }^{3}$ De Mot. An., vi. f. Zeller, Outlines, etc., p. 180. 
the Stoics undoubtedly has a quasi-materialistic outcome, the content of human consciousness is so sharply contrasted with real being as to give a painful emphasis to the epistemological problem: "How are we to construe the relations by which this content refers to real being and agrees with it?" As to the sources of knowledge, Zeno holds that it must all proceed from perception, as though the soul were a tabula rasa; but Chrysippus defines knowledge as a change produced on the soul by an object. From the impression ( $\tau \dot{v} \pi \omega \sigma \iota$ )

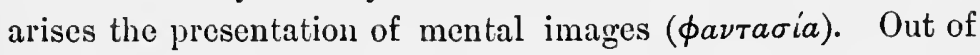
perceptions come recollections, and from these experience; and by conclusions from what is immediately giren in percep-

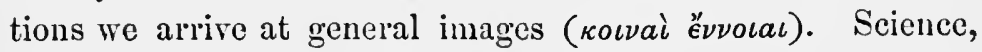
however, depends on the regulated formation and demonstration of concepts. When pressed to the last resort, the possibility of knowledge is made by the Stoics to rest upon the assertion that otherwise no action carrying with it a rational conviction is possible. And so perception and science are both made, in an manalyzed and inexplicable mixture, the sources of cognition.

As to the nature of knowledge, Zeno's illustration (sensation is like the extended fingers; conception like the fist; and knowledge, or science, like one fist clasped by another) seems to resolve the differences in the different stages of cognition into those of degree only. But knowledge is defined by the Stoics as "a fixed and immorable conception, or system of such conceptions." In other words, cognition is a system of perceptions and of notions derived by applying logical processes to perceptions.

Here, at once the psychological doctrine of the nature of cognition is merged in the epistemological doctrine of the criteria of cognition. How is truth to be attained, and how distinguished from the error with which, in experience, it is so closely intermingled? Now part of our conceptions are of such a rature that they compel consent; we are con- 
scious that they can only arise from soncthing real, for they have direct evidence ('́vé $\rho \gamma \epsilon \iota$ ). 'This kind of conceiving

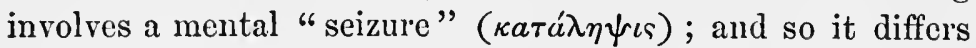
from the passive having of mere notions, even when the conscious contents are the same, by having also the active consciousness of agreement with its object. Cognition, in the form of a "conceptual presentation" compelling conviction, becomes then the Criterion of Truth. ${ }^{1}$ In all the Stoical doctrine the important psychological conclusions are recognized that (1) judgment, produced by the faculty of thought, is necessary to knowledge; ${ }^{2}$ and (2) knowledge which allows of certainty of conviction requires that perception and thought should be somehow brought into harmonious relations. A true perception is one which represents the object as it really is; but how shall we know when we have such a perception? To answer this problem the appeal is sometimes made to the strength of the impression and of the conviction which the impression carries; sometimes to that distinction in the form of notions which laid the basis of the third part added to Logic by the Stoics, - namely, the Doctrine of the Standard of Truth or the Theory of Knowledge; but, in the last resort, as has already been said, to the practical postulate that "unless the cognition of truth were possible, it would be impossible to act on fixed principles and rational convictions." 3 Here we return to the point on the circumference of the circle from which we set out: The search after a firm support for the life of conduct compels us to investigate the criteria of truth; but the investigation of the criteria of truth brings us to the conclusion that these criteria are chiefly to be found in the necessity felt by the soul for a firm support for the life of conduct. Let us not forget

1 This view must not be confounded with that of the innate ideas which was propagated on into the Middle Ages under the Stoie name.

2 Compare Sext. Adv. Math., viii. 70 f.; Diog., vii. 63.

8 This is the position of Plutarch and Stobxus; on the entire subjeet see Heinze, "Zur Erkenntnisslehre der Stoiker," Leipzig, 1880. 
this gyratory motion of the Stoics in their quest for a defensible theory of cognition. It is somewhat of a return to Plato from Aristotle, who regarded knowledge rather more as an end in itself. It may suggest to the modern student of epistemology the truths that, in cognition, the soul is one, a unitary being incapable of divorcing feeling and willing from its thinking; and, also, that the action of so-called necessity and the action of reason is not two principles, but only one.

Little additional to the lessons taught by the Stoics is to be gained by a study of the ancient Epicureans and Sceptics. The former held that, in theory, perception furnishes the criterion of truth and that what is most obvious (by its évép $\gamma \epsilon \iota$ ) is always true; nor can such truth be doubted without destroying the foundations both of knowledge and of action. But, in practice, pleasure and pain furnish the criterion. Yet these teachers were, of course, pressed to the important admission that the knowledge requisite simply for wise conduct needs, besides, cognition of that which is not immediately perceptible; it needs the cognition of the grounds of phenomena and also of the expectations for the future which may be inferred from these grounds. Thus both Epicureans and Stoics, as a sort of fundamental postulate upon which alone the wise man can ground his maxims for the practical life, came to the recognition of the truth that there is agreement of the individual reason with the unirersal, with the World-Reason, - an implied mental seizure upon the heart of Reality.

To something like the same opinion eren certain of the Sceptics were finally driven. They did, indeed, theoretically hold that the essential nature of things is inaccessible to human knowlcdge; nothing is immediately certain; nothing, therefore, can be made mediately certain by processes of argument. This scepticism they defended by calling attention to the conflict of opinions, to the endless regressus in proving, to 
the relativity of all perception, to the impossibility of other than hypothetical premises, and to the circle in the syllogism. It is most interesting, however, to notice how some of them - Arcesilaus, for example - brought forward the view that, in the practical life, the wise man must content himself with a certain kind of trust ( $\pi i \sigma \tau \iota s$ ), according to which some ideas are the more probable, reasonable, and adaptable to the purposes of life.

This impressive exhibition which Greek antiquity furnishes of the relations, both in fact and in theory, between our doctrine of cognition and our life of conduct, as well as its accompanying recognition of "confidence," "conviction," "trust," as an inseparable element of cognition itself, fitly prepare the way for a consideration of the views of two great thinkers among the Father's of the Christian Churcl. In respect of their insiglit into the true state of the case, and as estimated by the important points which they make through their discursive treatment of the subject, Origen and Augustine are entirely worthy to stand beside Plato and Aristotle. To understand their points of riew we must remember that the very nature of the regnant philosophy, and the urgent needs of the age, turned the currents of thought from purely speculative into practical and religious channels. The great doctrine of a "Christian Gnosis" was now the form in which a theory of knowledge was found interesting and was actually discussed. Two important truths derived from non-Christian Gnosticism became, from this time onward, very influential. These were the exceedingly influential conception

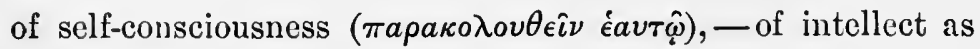

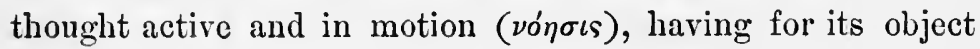

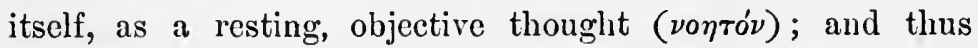
the identification of intellect as knowledge with intellect as being. ${ }^{1}$

1 See Windelband, A History of Philosophy, p. 234; and Plotinus, Eun. i. $4,10$. 
In Origen's thought, as in the thought of Clement and of the Alexandrine School generally, Christianity - its tenets being rationally understood and explained - is Knowledge. But to attain this knowledge, we must advance to it, from faith through philosophy; and, indeed, he who would attain the true Gnosis without philosophy is to be compared to the man who would gather grapes without cultivating his vines. ${ }^{1}$ The sources of such true and highest knowledge are both subjective and objective. Among the former are faith, hope, imagination, love; these are the avenues through which cognition comes to the human soul. Love and mental grasp go hand in hand. Here, then, we meet again with the beautiful and stirring conception of Plato, that the craving for truth is divinely planted, as an honorable passion which may not honorably be denied. Gaining knowledge implies a progressive assimilation of the soul to God. The objective sources of knowledge, in the view of this Church Father, are Scripture and the Church, which are assumed to be in harmony. But the source of all true knowledge is undivided; it is one, and only one; it is divine revelation. God himself, "an incomparable intellectual nature" ("in all parts Movás and, so to speak, 'Evás") is the Mind, and the Source, from which all intellectual nature or mind takes its beginning. ${ }^{2}$ Origen's fundamental postulate, then, is this: The mind of the illumined and cultured man is akin to God, and has thus become capable of knowing the truth of God, the Absolnte Mind. For how could rational beings exist unless the Word or Reason had previously existed? How could men be wise, unless there were wisdom in the world of the really Existent? Rational beings derice their rational nature from God through the Logos. "Now we are," he affirms," "of opinion that every rational creature, without any distinction, receives a share of Him," - that is, of the

1 Compare Strom. II. vii. and ix.

2 De Princ., I. i. 6.

${ }^{8}$ De Princ. II. vii. 2. 
Holy Spirit, the revealer of Absolute Reason to the reason of man.

Origen's view of the nature of knowledge follows from the foregoing description of the sources of knowledge. This thinker felt that, while much of the non-Christian plilosophizing moved in the region of mere abstraction, the Christian Gnosis gave a living grasp upon realities, both persons and facts, which it was his aim to present in the form of a rational system as objective truth. Not by sense-perception alone can knowledge come. For " it is one thing to see, and another to know: to see and to be seen is a property of material bodies; to know, and to be known, an attribute of intellectual being." 1 Knowledge is of the mind, intellectual. But the proposal to change faitl into knowledge does not imply questioning, much less rejecting the entire content of faith; it implies rather the attempt to give to the accepted content of faith a scientific form, such as shall commend it to philosophical or reflective minds. Nevertheless, it has truly been said: "In all such doctrines the interest of science ultimately predominates over that of faith; they are accommodations of philosophy to the need of religious authority, felt at this time."

The distinctive thing about Origen's answer to the inquiry into the sources and the nature of human cognition is that he makes it a commerce of minds. The secret of this epistemological theory is given in the consideration that knowledge is a transaction between rational beings. As to the source of knowledge, it is found in Absolute Personal Reason revealing its true life within the human personal reason. As to the nature of knowledge, it is a certain complex attitude of human personal reason toward Absolute Personal Reason. In this complex attitude, the more practical and distinetively ethical "momenta" of admiring and aspiring love, of faith as a sort of opening of the soul to the truth, which is both

1 De Princ. I. i. 8. 


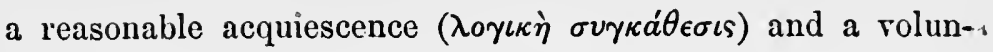

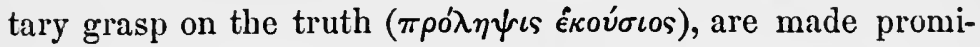
nent by this Church Father. However, since free-will - the capacity for virtue and its opposite, the power to become wise or to refuse to become wise - is the centre of personality, it must co-operate with feeling and intellect, in order to attain the true Gnosis. For low can knowledge be dirorced from free-will, since every judgment, which both accepts and declares the truth, is an act of free-will ?

Origen is neither so happy nor so suggestive in his answer to the question, How shall the false and the true be distinguished? for, whether we emphasize faith, judgment, conriction, opinion as to the content of revelation, or the decision of free-will, each one and all of these may be eroked in the interests of the false as well as of the true. This fact raises the problem of the criteria of knowledge. Origen takes it for granted that the contents of Christian faith, as giren in Holy Scripture and declared by the roice of the Church, are true. The acceptance of what is authentically taught is thus made, by his epistemological theory, the ultimate test of truth. Authority becomes the objectire criterion of knowledge; faith is the right attitude of soul for the attainment of this knowledge. We must not, however, discredit this thinker - the most suggestive of all thinkers within the ancient Church - by understanding his principle of authority in the mediæval or - worse still! in the post-Reformation sense. It is not the ipse-dixit, either of the Biblical writers or of the traditors of churchly tenets, which Origen would elevate into the place of the ultimate test of truth. His epistemological postulate, as bearing upon the criteria of knowledge, is the assumption of an essential identity, in the ground of self-revealing Reason from which both spring, between authority and rational knowledge.

The significance of Origen is so great for an historical study of the opinions of reflective thinkers upon the epistemological 
problem that we gather up his more impressive views into the following statements :-

All knowledge is, by nature, a revelation from Absolute Reason, "a spiritual enlightenment" from the one Holy Spirit of God. Hence the ontological postulate of Origen's theory of knowledge is the reality of the idea of the Good, a truly Platonic postulate. Our knowledge is the human equivalent of the Divine Idea. Thus insight is more emphasized than ratiocination; and the gaining of knowledge becomes, for the soul of man, an epoch, an illumination, a surprise.

Faith and reason co-operate, in the unity of the soul-life, in order to make possible the reception and the attainment of knowledge.

Free-will, issuing in judgment of the truth, is essential to all knowledge; it is, indeed, the very self-activity which becomes knowledge when it is directed rightly toward the absolute and self-revealing Reason. Diversity of will is the cause of the variety in human opinions and in the courses of condnet pursued by different men. Perversity of will is the cause, not only of all evil conduct, but also of all error in judgment. It is the function of the moral will, rooted and grounded in love, to lead on the acquirement of all knowledge and all wisdom to the final goal, which is the vision of all in God. ${ }^{1}$ But this will must be motived, backed up, and spurred

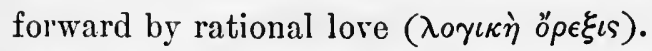

It was Augustine, however, who first grappled with the problem of cognition in a thoroughly psychological and eritical way. Indeed, Augustine may be said to have been the first to place philosophy upon a psychologieal basis. It must be remembered, however, that we have two men expressing themselves in the later writings of this Church Father ; and that these two minds move in opposite directions, and even come to contradictory conclusions. It is not Augustine the

1 Compare De Princ. I. v. 3 ; I. vi. 3 ; II. i. 2 ; II. iv. 3. 
ecclesiastic, alarmed for the foundations of Christian faith and making an exoteric appeal to the authority of the Church as the criterion of knowledge, in behalf of the uninitiated and unenlightened, to whom we may hopefully look for epistemological truth; it is rather to Augustine the master of psychological analysis, and, in some sort, the founder of philosophy upon the indisputable data of consciousness for all places and all times. In Augustine's case the theologian and the philosopher are not, as in the case of Origen, of one and the same mind, equally sincere. The theologian, indeed, is ready at times to run perilously near the final sacrifice of all consistency, if not of all claim to sincerity. But the psychologist and philosopher expounds the principle of the immediate and absolute certainty of self-consciousness in a way to anticipate Descartes and eren to excel him. In his treatment of this epistemological doctrine Augustine is a modern man; or, rather, he is a thinker for all times to venerate.

It is with respect to the criteria of knowledge, the function of philosophical doubt, and the ultimate grounds of certainty, that Augustine rises superior to Aristotle and to all antiquity. Here we are charmed by his skill in psychological analysis and by the thoroughness of his reflective thinking. In these subjects he so far anticipates and even surpasses the so-called "father of modern philosophy" as to warrant what Fénelon said of him, that he would sooner trust Augustine than Descartes upon matters of pure plilosophy ; indeed, the Archbishop of Cambrai even declared that a collection of this Church Father's utterances would be "much superior to the Jeditations" of the French philosopher. And Nourisson ${ }^{1}$ affirms: "It is beyond all question that this great man made use of the method, and put in practice the principles, which Descartes would one day employ in order to reconstruct philosophy."

1 Progrès de la Pensće Humaine, p. 209. 
Augustine sought the way to certainty of truth through scepticism and criticism. He pointed out that all the various kinds of conscious states - memory, judgment, knowledge, and will - are involved in the very act of doubting. He sought also to demonstrate the existence of necessary elements in all cognition in opposition to the Academicians, with whom he at one time agreed as to the practical end of happiness. ${ }^{1}$ In the most primary and incontestable fashion, he thinks, does the certainty of self-consciousness affirm the reality of the conscious subject. ${ }^{2}$ In order even to err, $I$, that err, must exist. Even the possibility of our being deceived implies the fact of our existence, and makes being, life, and thought co-ordinate. Every one who knows himself as a doubter knows the trutl, and from this fact is certain that he knows. Let, then, the man who wishes to have knowledge attain the science of Self. But faith is necessary to knowledge of the existence of other men; and we can only believe (not know) that material bodies exist, though the belief is practically necessary. With profound epistemological reflection Augustine finds the idea of God, as absolute Truth, involved in the certainty of self-consciousness. For how could we so much as question and doubt our senseperceptions, if we had not derived criteria and standards of truth from other sources? The very life of the human soul is such as to show that there is an unchanging norm of truth, - God, who includes all real being. Thus does this great thinker strive to place on a psychological basis the epistemological conclusion that the existence of truth cannot be doubted, and that all Reality is implicate in the being, knowing, and willing of the self-conscious subject. ${ }^{3}$

1 See the De Vita beat, and compare Cont. Acad. III. xi. 26, where he finds the test of truth in disjunctive propositions, and remarks that perceptions are, at least, subjectirely true.

2 De Vita beat., ii. 7 ; Solil. II. i. 1 f.; De Ver. Rel. xxxix. 72 f. ; De Trin. x. 14.

8 Confessions, VI. v. 7 ; De Fide Rerum, i. 2 ; De Ver. Rel. xxxix. 72 f.; De Lib. Arb. II. ii. 6 ; De Civ. Dei, i. 6. 
Augustine's view of the sources and nature of human cognition is, of eourse, dependent upon his positions regarding the criteria of all eognitive faculty. Besides sensation (sensus), he holds that man possesses the higher capacity of reason (intellectus and ratio); we thus have immediate perception of incorporeal truths, - the principles of all judging. Thus, too, all individual consciousness - and no less in its doubting than in every other form of its actual functioning transcends itself as individual; it sees itself attached in its own exercise to something universal and universally valid. ${ }^{1}$ It was, indeed, the influence of theological prejudice against the doctrine of the pre-existence of souls which led Augustine to abandon the Platonic reminiseence (ává $\mu \nu \eta \sigma \iota s)$, and in more nearly the modern way regard reason as the intuitive faculty for the incorporeal world. Yet he eonceives of the existence of the ideas in neo-Platonic fashion. They are principales forma vel rationes rerum stabiles atque incommutabiles, qua in divino intellectu continentur. All rational knowledge is, then, ultimately, knowledge of God; all ideas are in God; $\mathrm{He}$ is the eternal Ground of all form, - the Absolute Unity, the Supreme Beauty. The knowledge which Augustine seeks is, then, summed up as knowledge of Self and of God. ${ }^{2}$ The sciences, which in early life he regarded as avenues to knowledge of God and to salration, he later regarded as of little worth. Nor can there be any doubt that this disregard of scientific knowledge, born of theological prejudice, had, through the influence of Augustine, a decisive and baleful effect upon the subsequent history of Christendom. It is one of the most interesting speculations as to what might have been in the ease of that "long-standing conflict" between science and religion, if the Descartes of Christian antiquity had not been orerlain and submerged by the ecclesiastie anxious to defend the supreme and unquestioned authority of the Chureh.

1 De Trin. XII. ii. 2 ; Cont. Acad. III. xiii. 29 ; De Lib. Arb. II. iii. 7.

2 Deum et animam scire cupio. Nihilne plus? Nihil omnino. (Solil. I. 7.) 
With Augustine, even more than with Origen, the doctrine of free-will is dominant in connection with his entire view of the criteria, sources, nature, and limits of cognition. The primacy of the will is maintained in the entire process of thinking, ideating, and knowing. Only in relation to the higliest truths, the rational cognitions, is the attitude of the mind more passive and receptive. Here revelation, as a divine illumination, has its truest sphere. Hence the doctrine of Truth BY FaIth - a doctrine which Kant revived as the positive outcome of his critical protest against an unwarranted extension of the pretence of knowledge. However, with Augustine, full rational insight remains first in dignity. But such insight is not for the weak nor for the average man; not for the wise even, except impcrfectly. Here again we are made witnesses to the disturbing influence of the ecclesiastic's fears lest the authority of the Church might suffer if knowledge of the transcendent should be too broadly affirmed as lying within the possible domain of the "plain man's" self-conscious life.

On the whole, however, what student of the history of epistemological doctrine can deny the eminent distinction which Nourisson claims for Augustine as a reflective and critical thinker upon the problem of knowledge? To him more than to any one else in antiquity (indeed, he has fow rivals in modern times) we may ascribe the three following important merits: (1) The philosophic use of methodical doubt; (2) the doctrine of self-consciousness as a manifestation, absolutely certain, of the really existent; and (3) the recognition of the evidence for making this particular certainty the criterion of all ulterior certainty.

During the Middle Ages the entire problem of Being and Knowing became absorbed in discussion over the nature and reality of so-called "universals." The significance of this discussion for all mediæval philosophy, on account of its bearing upon the metaphysics of Christian doctrine, is 
at once apparent. The general epistemological assumption of the regnant school was that the more universal substances are, the more real they are. Reality is thus regarded as a matter of degrees, or as measurable by a scale in which things and souls can have more or less of participation. This is the very opposite of the affirmation of Lotze, that the meanest thing which exists is as truly real as is the most important and imposing universal. In the mediæval thinking the identity of Real Being with the thinnest or highest abstractions was thus maintained; real dependence of things and events was also identified with logical dependence. A pyramid of concepts was erected, and to this conceptual structure was given an ontological significance, without further attempt at criticism or proof. From this doctrine a transition was inevitable to the view which saw the universal in every concrete existence (universalia in re). But this doctrine, too, was taken abstractly. One and the same reality was held to be, in its differing status, animate being, man, Greek, Socrates. Formal and logical pantheism - essentially like that of the great Jewish thinker, Spinoza - was the inevitable outcome. The final ontological assertion, built upon the fundamental epistemological assumption, becomes the following: God = Being superlatively real (ens realissimum).

Some wrong would be done to these mediæval thinkers, however, if it were held that they contributed nothing whatever to the statement or solution of the problem of knowledge. In the field of psychology they attained (by speculation, of course, rather than by experiment and induction) a few valuable results. The Platonists and the Mystics, who undertook to exhibit the development of inner life as the history of salvation for the individual soul, were prominent workers in this field. Especially important is their thought that, by virtue of the motive forces of will, faith furnishes conditions to knowledge. Thus Bernard is never weary of denouncing the heathenish nature of the pure 
impulse after knowledge for its own sake. With the great Thomas the psychology of knowledge holds an important place. ${ }^{1}$ The human soul is a substance, incorporeal, imperishable, and capable of apprehending universals. Yet he maintains the unity of the soul, ${ }^{2}$ and informs us that such terms as "the regetative soul," "sensitive soul," "rational soul," etc., are not to be understood as other than designating functions of one and the same soul. By virtue of the same soul, Soerates is both man and animal. The essential form, both generie and specific, comes from the soul, which is the source of all life. With Hugo, cogitation, meditation, contemplation, are the three stages of mental activity which result in knowledge. Man has the eye of flesh to know the corporeal world, the eye of reason to know his own inner nature, and the eye of contemplation to know the spiritual world and God. But Duns Scotus rejects the hypothesis of soul as pure form and energy, possible apart from the body; and between the body and the intelligent soul he introduees an inherent forma corporeitatis.

In accordance with his doctrine of the nature of the soul, Thomas Aquinas plaees it on a sort of middle ground within the hicrarchy of substanees. As to the source of knowledge, it follows that the soul of man does not possess truth per $s e$; it must aequire truth. This it does by experiencing certain elementary notions through the senses as its instrument. The whole problem of the origin and nature of knowledge must, of course, be attacked by the Schoolmen in some form to make intelligible the process by which universal ideas arise in the individual consciousness. Nominalism, in the person of Abelard and John of Salisbury, attempted to show the psychological origin of knowledge. Sensation, as confused idea, gives content to imagination,

1 See his Summa Theol., quæst. 75-90 and 92, Part I.

2 See the section, De Anima, in the Quæstiones; especially, §§ 4-7, 11-13, and 20. 
which grasps and holds together the content; then understanding, by discursive activity, elaborates it into judgments and concepts; and after all these conditions are fulfilled, somehow or other, opinion, faith, and knowledge arise, in which the intellect ultimately knows its object as a single collective perception or intuition. These writers hold to the modern theory that in sensation, perception, and imagination, an act of judgment is performed.

Thomas Aquinas and the Realists generally, howerer, held that all true knowledge - all science - is of the intellect; the psychological inquiry as to the nature, results, and certainty of its functioning is thus made the most important of all epistemological inquiries. The puzzling problem becomes, then, to reconcile the individuality of intelligence with the unirersality of the ideas. ${ }^{1}$ The answer of 'Thomas to this problem is an evasion of it: the power of apprehending the universal is assigned by him to an "intellective soul." This results in a division of the faculties of the soul, which is wholly inconsistent with his maintenance elsewhere of the true view that the soul is one, but gifted with diverse energies. For while some of the faculties, as senses and imagination, are in both body and soul, others, he thinks, like will and intellect, participate in no respect in the body. ${ }^{2}$

With such views of the origin of knowledge as the foregoing, the validating of knowledge becomes a hopeless puzzle. And, indeed, the epistemological and the ontological problems are scarcely conceived of apart. Thomas Aquinas approaches the former of the two problems from

1 See Met. i., proœm., cap. 1 ; Phys. i., cap. 1 ; and comp. Hauréau, Philosophie Scholastique, ii., pp. 110 and 116.

2 Windelband (ibid. p. 325) holds that Thomas Aquinas and Duns Scotus alike followed the old Greek idea that, in the process of cognition, by means of the cooperation of soul and external object, a copy of the latter arises, to be apprehended by the soul. This doctrine Occam rejected and held a view more akin to that of Locke and his followers. With him an idea is indeed, as snch, a state or act of the soul, but it forms in the soul a sign for the external thing. 
the point of view taken by Aristotle in his doctrine of form and matter. The doctrine of universals as entities, and the attempt to explain and to validate knowledge, realistically, by the assumption of these entities, are abandoned by him. Such ideas he regards as mere fictions, wrongly posited in the interests of an attempt to explain the knowledge of things. But God knows all things in themselves, and has no need of the intervention of ideas. In Occam's writings the fundamental separation between the world of sense and the supersensible world bears fruit in the beginnings of a psychological and epistemological Idealism. The world of consciousness becomes another world from the world of things; and sensuous knowledge loses for him its character of being a copy as compared with its real object. Between the psychological, the inner, reality and the ontological, or outer, reality there is a relation, but it is not that of resemblance.

Perháps the most important and distinguishing feature of the doctrine of the Middle Ages is its extension of that schism between faith and knowledge which appeared in the later writings of Augustine. Albertus holds that philosophy (as of knowledge) and theology (as of faith) can no longer be identified. All that is really known in philosophy by the light of nature holds good also in theology; but the soul of man can completely know only that the principles of which it carries within itself. Thomas seems to reverse the relation between faith and knowledge which Origen and Augustine (in his earlier writings) maintained. The relation then becomes one of different degrees of development; but philosophical knowledge is given in man's natural endowment, which is brought to full realization only by the grace active in revelation. Duns Scotus goes further and maintains that theology is a practical discipline, while philosophy is pure theory. Philosophy is thus made a secular science set over against theology as a divine science. Here 
the relation becomes one of separation; and a contradiction is ready to emerge between knowledge and faith. This separation became, as the rights of reason were more vigorously maintained, a charter of liberty for philosophy, but a condemnation of theology to the prison-house of external authority. More especially as to faith and knowledge, Scotus maintains that belief in the Bible and in the infallibility of the Apostles rests upon the authority of the Church.

At one point, however, does this thinker keep alive the warm and vital thought of Plato, of Origen, and of Augustine. As an opponent of determinism, Scotus emphasizes the selfactivity of will - as everywhere else, so also in knowing. He maintains, in opposition to Thomas, that thinking often depends on willing. The beginning of all knowledge can be called an act of receiving, inasmuch as every perception has sensation for its basis et seminarium, which is possible only as the result of an impression or image of the object. Eren this, however, is not mere passivity. In all perception, the external object and the perceiving subject cooperate. ${ }^{1}$ The calling up of the phantasmata and their transformation in memory also implies activity of will; still more does the active intellect, the power of the soul, which is related to the sensible images as light to colors. But especially where the thing is not certain, and the consent of will is compelled, belief (fides), as an act of will, is necessary. ${ }^{2}$ Hence it follows that a great deal of our knowledge is based upon faith; indeed, the greater part of knowledge is but a completion of belief. ${ }^{3}$

These few thoughts concerning the philosophy of knowledge are discovered, only after winnowing them out of much chaff, in the thinking of the Middle Ages. The number of

1 Op. Oxon. I. D. 3 quæst. 4, 7, 8.

2 De Anima, quast. 17; and Report. Par. IV. D. 45, 9.

8 Report. Par., Prol., quæst. 2. 
thoughts which has any essential value would scarcely be at all increased even if this very brief sketch were indefinitely extended. But they show how the continuity of human reflection upon the epistemological problem was maintained, and what are the matters in respect of its statement and solution which it was considered nccessary to keep before the mind for its critical consideration. 


\section{CHAPTER III}

\section{HISTORY OF OPINION (continued)}

$\mathrm{T}^{\mathrm{T}}$ is a statement common among historians of philosophy 1 that the foundations of the modern view regarding the sources, the nature, and the criteria of knowledge were laid by the reflective thinking of Descartes. And there is a certain warrant in the facts themselves for such a statement. For it has been shown how that side of the philosophizing of Augustine over the epistemological problem which, in spirit and with respect to the significance of its conclusions, was opposed to the trustful attitude of Origen toward the illumined reason of the individual, and which upheld the authority of the Church against free critical inquiry, dominated the doctrine of the Middle Ages. Descartes, indeed, took the appeal away from this tribunal of ecclesiastical authority, to that which holds its court of judgment within the inmost recesses of every man's self-consciousness. In doing so, however, he only returned to the other and better side of the philosophizing of Augustine himself. Neither in acuteness of analysis, nor in clearness and beauty of statement, nor especially in his manner of finding the reality of the soul, of the world, and of God, implicate in the primary act of cognition, was the founder of modern philosophy the equal of the Church Father. Indeed, we fear it must be confessed that, with the exception of Kant and Hume, down to very recent years, modern philosophy has not been much superior to ancient philosophy in its handling of the most important points in the problem of knowledge. Logic and 
psychology have greatly flourished; but a satisfying epistemology has been less promoted thereby than it would seem reasonable to expect. The greater freshness and naĩvete of those earlier times, and the more ardent and unconcealed interest in the bearings of sceptical and agnostic conclusions upon the concerns of ethics and religion, make the thought of antiquity all the more profitable for studious consideration. The most distinguished exception to this disparaging view of modern efforts is, of course, Immanuel Kant. He was the first of all the world's thinkers to give to the problem of knowledge a formulated construction; to attempt the following of this problem through many winding ways, down to its lowest depths and out to its farthest limits, in elaborate monographs; and so to set his answer before mankind that thenceforth its immense significance and portentous claim could never fail of recognition. Few - even among the ancient and mediæval teachers of the Christian Church had more upon their heart and conscience the practical outcome of the attempt at a settlement of the problem. Outside of what leads up to, and of what has flowed from, the Kantian critique of knowledge, there is little to add to ancient and mediæval thinking, by way of profit derived from an historical sketch.

Most of the philosophical works of Descartes bear upon his attempt to construct a theory of knowledge. His "Rules for the Direction of the Mind" is perhaps of first importance here; while the "Discourse on Method" is more obviously directed to the same end. Some of the more impressive "Meditations" concern "Things that may be doubted," etc. The posthumous "Recherches de la Vérite" deals, as its title signifies, with similar themes. In the First Part of the "Principles of Philosophy" Descartes discusses the foundations of human knowledge. Both his "Treatise on the Passions" and his "Treatise on Man" occupy themselres with safeguarding the mind against error and assisting it 
in the ascertainment of truth; while even in his "Treatise on the World," his "Happy Life and Summum Bonum," and in many of his "Letters," such topics as truth, error, knowledge, and the validity of our ideas, are continually brought to the front. That there is a philosophical problem which demands inquiry into the inmost nature and the necessary limits of knowledge, Descartes expressly affirms. No subject of investigation, he thinks, can be more important; indeed, in one of his Rules (No. VIII.) he affirms, "There is here a question which a man must examine, at least once in his life, if he love the truth." But his more distinctive merit lay in the proposal to make a methodical search after a science of man's cognitive faculty; and to build upon the truth revealed by this search, when conducted to its utmost possible limits, a superstructure of truths which might withstand all the assaults of scepticism. For so important did Descartes consider method in inquiry that he eren goes to the extreme and absurd length of declaring it better never to discover the truth than not to use method in its discovery.

It is quite unnecessary for our purpose to rehearse the wellknown Cartesian tenets which have a bearing upon epistemological inquiry. The return from trust in the principle of external authority to confidence in the witness whose light shines within the soul of every man, is the important contribution which Descartes made to the theory of knowledge in its more modern form. This inner light is to be disclosed, however, by the use of methodical doubt. In the primary fact of knowledge - the cogito, even if it be in the special form of a dubito - the self-known reality of the subject of cognition, and the implied existence, as not-me, of the object of cognition, are both to be discerned. For the cogito, in barbarous Latin, = cogitans sum : thinking is self-conscious bcing; and there are certain forms of this cogito which, when their nature as mental transactions is fully discerned, cannot be accounted for otherwise than on the assumption that 
somewhat other than the thinking subject has being too. Among those ideas which demand by their very nature an extra-mental correlate, the idea of God stands eminent and supreme. It appears, as of its own evidence, the idea of that which makes irresistible claim to be really existent. It thus becomes the bridge of Reality between the indubitably self-cognizing existence of the soul and the existence of the world of actual things.

The several gaps in that Cartesian argument which sets the limits and establishes the validity of human cognitive faculty have often enough been pointed out. Of it all, only two things remain, forever sure and unchanging so long as the fundamental construction of man's intellect remains sure and unchanged: these are, first, the rights of methodical doubt, or (to use a more modern term) of a eritical self-examination on the part of the knower; and, second, the necessity for acknowledging, theoretically as well as practically, the ultimate limits of this doubt when, by the critical process itself, we stand face to face with the implicates of every act of knowing.

It was a hindrance to the development of epistemology that Descartes' elaborate doctrine of method, with the unwarrantable hopes and perverse trials which it excited, became so influential with his successors. For this he is himself largely to blame. He was always a dry light, with a mind better adapted for mathematics and speculative physics than for critical philosophy. His most admired type of investigation was the mathematical method, as involving "the analysis of the ancients," the "algebra of the moderns," and the application of both to geometry. The scope of this method he considered unlimited; and for it he claimed a decided superiority over all other methods, as being the origin and source of all truths. In fact, however, the entire Cartesian method, as employed by its founder, is, in the last resort, an appeal to the self-conscious subject 
of all the states of knowledge. The final test of all truth is "the self-evidencing conception of a sound, attentive mind." Windelband ${ }^{1}$ is, then, justified in affirming that the disciples of Descartes confounded "the relatively free creative activity" which Descartes himself had in mind (the analytical method as he pursued it) with "the rigidly demonstrative system of exposition which they found in Euclid's text-book of geometry." In "all the change of epistemological investigations until far into the eighteenth century, this conception of mathematics was a firmly established axiom of all parties." It reached its culmination in the pantheism of Spinoza, where, without previous critical examination of the underlying assumptions of the mind, a logical systemization of the most abstract conceptions more mathematico is identified throughout with the essential truths respecting the really Existent. But even in Spinoza's case, the purely speculative interests were not left wholly without suggestion and control on the part of the practical and the religious. And at the last, the glow of that love which is the attitude of the philosophical mind toward the Absolute One warms and illumines the theorems of his barren and frozen theological geometry. In the total system, side by side with the beginning "Definition," "By substance I understand that which is in itself and is conceived through itsclf," stands the closing axiomatic "Proposition": "He who clearly and distinctly understands himself and his affects loves God, and better loves him the better he understands his affects." Thus the way of mathematical demonstration, on the unverified and uncritical assumption that conceptual gymnastics by seizing the rope let down by Euclid can climb alone to the heights of insight into $\mathrm{Ab}$ solute Being, has become the way of salvation. It was in more simple and cffective, if less elaborate fashion, that Jacob Boehme, and the Mystics generally, controverted and

1 A History of Philosophy, p. 395. 
abandoned the Cartesian theory of knowledge. With them, as with Spinoza at the last, the affectional and emotional interests prevailed - through help of the stimulus given to claims of knowing by means of faith, intuition, and the unreasoned leap to the seizure, as truth, of what the soul ardently desires.

It was the Englishman John Locke who first pursued in more elaborate researches the psychological path to the problem of epistemology. But alas! like so many of his avowed or unconscious followers, he was guilty of the fallacy which lies in the supposition - even now so widely current - that a survey of the superficial content of our individual cognitions, and of their more obvious associations and logical relations, is a sufficient answer to the quest for a philosophy of knowledge. Thus having led us face to face with the problem, he leaves both us and it hanging in mid-air. It is indeed difficult to classify Locke with respect to the position which he assumes toward truly epistemological questions. It is, therefore, easy to deny that it is either the position of sensualism or the position of idealistic empiricism, or that of unqualified empiricism. ${ }^{1}$ The epistemology of Locke is, doubtless, an espousal of some sort of empilicism; but then of what sort? To this the most obvious answer seems to be that he never clearly comprehended the inquiry into the nature of knowledge as a speculative problem, which requires an analysis that goes beyond the analysis of descriptive psychology and results in disclosing and testing the ultimate metaphysical assumptions implicate in all exercise of cognitive function. To be sure, there is a recognized problem of knowledge in pursuit of some answer to which his whole course of investigation conducts him. He is induced to recognize this problem by following out his first and purely psychological inquiry, - namely, as to the

1 Thns Grimm denies that any of the current descriptions is satisfactory as applied to Locke. See "Zur Geschichte des Erkenutnissproblems," p. 340. 
rise of the ideas in grounds of inner experience. Even here, a soul, as a real being with an inherent capacity or susceptibility to special forms of excitement, is assumed by Locke from the first. Certainly the founder of English psychology was very far from intending to teach a science of "psychology without a soul."

But from the very first, too, as Locke himself assures us in his own account of what led to his investigations "Concerning Human Understanding," and of what he hoped to accomplish by these inrestigations (namely, first, to "inquire into the original of the ideas;" secondly, "to show what knowledge the understanding hath by those ideas, and the certainty, evidence, and extent of it;" thirdly, "to make some inquiry into the nature and grounds of faith, or opinion "), ${ }^{1}$ there is a goal held up to view which the plain, historical method he pursues can never reach. "Knowledge of our capacity a cure of scepticism" is the heading of one of the earlier articles of his book. But when we are informed that, besides the presentations of sense, there are in consciousness certain other ideas, "originally begotten," which proceed from the operations of the thinking activity itself, and which become apprehended by reflection upon them, the need that criticism should be applied to these ideas is obvious enough. But if either of these classes of ideas, when - to use the Lockean expression - we "become conscious of them," are held to constitute cognition in the special sense, then the problem of epistemology is upon us with its full force. For the "original" of the cognitions is drawn from experience; but the cognitions contain what appears to transcend experience; and thus what Locke defines as "the apprehension of the agreement or non-agreement of our ideas" is, as yet, not cognition at all. To explain its being transmuted into cognition, Locke has only the assumptions of a naire, common-sense realism. His account of "the

1 Book I., chap. i., 3. 
origin, certainty, and extent of human knowledge" comes to an unsatisfactory end within the field of a descriptive psychology. It never becomes a truly epistemological affair; for it never bases itself upon a thorough sceptical inquiry and critical analysis of the processes and postulates of all knowledge. And the same shirking of the real problem of cognition, under cover of a descriptive psychology or a formal logic, has characterized the work of English writers almost down to the present hour.

Perhaps the most important contribution which Locke made to a future theory of knowledge lay in the emphasis he placed upon a distinction between the primary and the secondary qualities of things. Berkeley, while pushing sceptical inquiry into the field of qualities of the primary order, the cognition of which was with Locke a kind of copying-off process, still confined his critical philosophy to the nature and validity of sensc-perception. He raised, however, one forceful question in such a way as henceforth to allow of only one intelligent answer. How shall aught, not in reality mentally represented or mentally representable, be similar to that which is mentally represented? What cannot in any manner or degree be mentally represented, that cannot in any manner or degree be cognized as really existent. It is here that the epistemological problem comes into closest contact with psychology.

In the "Siris" Berkeley takes the position that phenomena - apprehended each for itself, as it were - cannot yield cognition. Their combination through rules or laws is necessary to make the actual world intelligible; and the corresponding combination of our mental representations is necessary to make cognition possible. To be perceived is still held really to be; but now we are informed that God is the ground of all reality, and that to be a mode of his lawabiding spiritual activity is, for things, really to be. Thus those things which formerly seemed to constitute collective 
reality are known to be only fleeting phantoms; God is the one true principle of unity, of identity, and of existence. Knowledge is, then, the work of intellect or reason. Sense and experience make us acquainted with the course and analogies of phenomena (natural events); thinking, reason, intellect, brings us to the cognition of them and of their causes.

It was, however, the acutely critical activity of Hume which began to give to the problem of the philosophy of knowledge its more nearly modern and final shape. This critical activity was, indeed, most effectively directed toward entangling the fundamental concepts of human cognition in seemingly hopeless contradictions. Nor can we agree at all with Riehl ${ }^{1}$ in attributing to the Scottish philosopher the same motif as that which stimulated Kant, namely, to lay the foundations of cognition for practical purposes more securely in rational faith. From the negative and destructive effort of Hume, however, came a most important positive result. It was made clearer that cer. tainty, and true knowledge as always implying certainty, is not attainable through mere thinking, or concepts. From the psychological point of view Hume inquires, much more acutely and fundamentally than did Locke, into the "certainty" as well as the "origin" of human knowledge. It is perhaps not incorrect, then, to speak of Hume as the first to derelop a critical theory of knowledge out of the Lockean psychology of ideas. His supreme effort was to show how, admitting that criticism of the content of consciousness must lead us to scepticism concerning the reality of our knowledge, nevertheless the appearance, the conviction, of real knowledge arises as a matter of fact. Thus he aims at a complete psychological account of the origin of cognition, as comprising those beliefs and ontological postulates which practically defy the assaults of a theoretical criticism.

1 Der Philosophische Kriticismus, I., pp. 66 f.; but compare p. 69. 
In Hume's account of the nature and process of knowledge, however, nearly everything is superficial and merely descriptive; while the shifty and loose use which he makes of the conception of "experience" tends to constant confusion. All cognition, he holds, arises from one of two sources, and so may be divided into two kinds - cognition arising immediately from ideas, and cognition arising from experience. $^{1}$ In working up - so to speak - the material which originates in these sources, Hume emphasizes the imagination. According to three points of view, this faculty is wont to bind together the passively received ideas. These points of view not only form the rules according to which imagination actively combines the ideas; they also give the relations which the mind recognizes as existing between things. They enter, at least partially, into the constitution of that object which rests upon experience, and which can, therefore, never attain an unconditioned certainty. These three points of riew give (1) resemblance, (2) contiguity in space and time, and (3) causality, as the relations under which this combining activity of imagination makes the objects of cognition to appear in the guise of realities. Two of these three classes of relations - identity and the relations of space and time-consist essentially in a passive reception of impressions through the organs of sense. But the relation of cause and effect carries us beyond the immediate perception of the senses, and presupposes a certain further process which perfects itself within the mind. Here the distinctive part of Hume's theory of knowledge comes to the front. This process, which gives objects to experience as real and causally related, is a process of feeling and imagination, and not a process of reason. It is an act of the sensitive part of our nature rather than an act of thinking. Imagination, then, as the lively potency of ideas in combination, is the faculty in which Hume lays

1 Treatise, I., iii., section $1 \mathrm{f}$. 
the foundation of cognition. Memory, sense, intellect, all have their basis in imagination, which imparts lifelikeness to the ideas, and so constitutes the bridge between mere subjectivity and what we consider a real world of things. ${ }^{1}$ This potency itself has its root in a sort of blind emotion on which our intellect can throw some light, but which it is powerless either to beget or to destroy. Feeling, therefore, is shown to be the ultimate foundation of all cognition. ${ }^{2}$

As to limits, it follows that, in the strict meaning of the word, our knowledge cannot reach beyond that of numbers and magnitudes, and a knowledge of facts. The latter, howerer, may be either knowledge of particular facts or knowledge of general facts, - that is, such as hare to do with the properties, causes, and effects of an entire species of objects. In one class we may place the results of our inrestigations into history, chronology, geography, astronomy; in another class, such studies as politics, and the philosophy of nature, consisting of chemistry, physics, etc. Ethics and æsthetics are matters of feeling or taste. ${ }^{3}$

In the attempt to validate our knowledge we see at once, Hume thinks, that one kind - namely, knowledge immediately from ideas - has a perfect certainty; since the relations of the ideas admit of face-to-face inspection, or envisagement, as it were. Its type is the knowledge of algebra, arithmetic, and geometry. But cognition from experience, or a knowledge of general facts by means of the principle of causality, has only a "molal" certainty. In the last analysis, then, as we see again, certainty does not repose at all on rational grounds, but on grounds of imagination and feeling. We are compelled "according to nature" to apprehend, or rather to be impressed with certain ideas, rather than others, in a peculiarly strong and vivid manner. If we surrender our-

1 Treatise, I., iii., section $8 \mathrm{f}$; ; Inquiry, section 5 ; Treatise, I., ir., section $2 \mathrm{f}$.

2 Treatise, I., iv., section 7.

3 Inquiry, section 12. 
sclves to a complete trust in intellect, and try to reason ourselves into knowledge, we have no other device than the choice between false reason, utter scepticism, and a return to unreasoning fạith. It thus becomes a necessity of practical life to cherish certain cognitions.

Few thinkers have had, more than Hume, the fate of influencing the reflections of their successors, by way of suggesting and stimulating new endeavors and new resulting views, while at the same time themselves meeting "with almost universal and even scornful and vituperative rejection. Hume cannot, indeed, be regarded as a serious, though sceptical and eritical, inquirer after a doctrine of cognition, in the fashion of a Descartes or a Kant, or even of his own more immediate predecessor, Locke. At the same time it is doubtful whether any one in modern times, with the single exception of Kant, whom he stimulated and to whom he landed over his central problem, has made more important positive contributions to a theory of knowledge than those which may be gathered from the writings of this philosopher. A modern writer ${ }^{1}$ on the history of this theory has declared that Hume ends by doing away with all important distinctions between luman reason and brute instinct; and, indeed, that thus he does away with knowledge altogether. The critical part of our investigation, however, will make it apparent that knowledge is impossible for man without admitting the validating force of those mental attitudes, or activities, which are closely akin to what we so vaguely call "instinct" in the lower animals. And they who make knowledge purely a matter of intellectualizing, and who disregard what is contributed by imagination, feeling, and will, do away with real knowledge, as men actually have it in the concrete, warm, practical life of work-a-day experience, quite as completely as does the secptical theory of Hume. Moreover, in concentrating attention upon the synthetic force of blind imagination, in emphasizing the value

1 Grimm, Zur Geschichte des Erkenntnissproblems, p. 557. 
and necessity of unreasoning beliefs, in holding that the intellectual use of the causal principle can never of itself serve as a bridge between the subjective world and thingsin-themselves, and in concluding that our choice of certain practical postulates will be necessary in the last resort to validate our cognitions, what did Hume do but anticipate much which Kant subsequently elaborated in detail? And as to manner of saying it, we are obliged not infrequently to ascribe the greater merit to the Scottish rather than to the German thinker. Fortunately, or unfortunately, Hume's more prominent opponents in his own country, the Scottish Realists, had not the insight to see what advantages were offered to them in their advocacy of ethical and religious truths, if, while pointing out the insufficiency of his sceptical analysis of the data of consciousness, they made good use of its sereral positive conclusions. And so, the rather, they abandoned investigation into a really critical theory of knowledge, and made a bid for popular faror in the form of a naive and uncritical return to the position of Realism.

With Leibnitz the epistemological problem is nerer primary; the nature of substance is his primary and all-important problem. It is not until about $168 t$ that we find in his writings any clear recognition of the existence of such a problem. Both before and after this date, what with Descartes was a criterion of truth becomes with Leibnitz an ontological predicate. Leibnitz was at first one of the most consistent supporters of the prevalent view which made mathematics the type of all genuine cognition. He was jesting, indeed, in his "Specimen Demonstrationum ;" but he was seriously of the opinion that philosophical controrersies ought to end in a philosophy which could state its conclusions in as clear and certain a form as that employed by mathematical calculation. ${ }^{1}$ Hence arose his thought of writing out the results of reflective thinking in general formulas,

1 See "De Scientia Universali seu Calculo Philosophico," 1684. 
more geometrico. Hence also his idea of the distinction between eternal truths and truths of fact (vérités éternelles and vérités de fait). The former need no proof, are intuited as true in themselves, as "first truths" or "prime possibilitics."

As to the nature of knowledge, Leibnitz's position is largely determined by the leading motive in all his philosophical thinking, which is the reconciliation of the mechanical and the teleological views of the world, so as to unite the scientific and the religious interests of his age. To this end the important principle was announced and expounded: "Substance is a being capable of action." This principle, although ontological in its character, could not fail to have a most important bearing upon the epistemological problem. By it the Cartesian co-ordination of the two attributes of subtance (extensio and cogitatio) was agail abolished: the world of consciousness becomes the truly actual ; the world of extension is phenomenon. Thus Leibnitz "sets the intelligible world of substances over against the phenomena of the senses, or material world, in a completely Platonic fashion." 1 Substance becomes a unity in plurality, after the pattern of the self-cognizing unitary being of mind; and space and time both belong to mental being. Even the deeper sense and justification of the ambiguity into which his doctrine of the monads, each one "representing" the world of reality, betrays him, as Windelband declares, has its truth "in the fact that we cannot form any clear and distinct idea whatever of the unifying of the manifold, except after the pattern of that kind of connection which we experience within ourselves in the function of consciousness."

It was mainly the criticism of Locke which compelled Leibnitz to develop a theory of knowledge. Concerning the source of knowledge, he attempts a middle way between the positions of sensualism and the high-and-dry a priori theory.

1 Compare Nouveaux Essais, iv., 3, §§ $20 \mathrm{f}$. 
It is here that his conception of unconscious representations, or petites perceptions, arises. ${ }^{1}$ The further important distinction is made between states in which the mind merely has ideas, and those in which it is conscious of having them; that is, between "perception" and "apperception." By the latter he understands " the process by which the unconscious, confused and obscure representations are raised into clear and distinct consciousness, and are thereby recognized by the soul as its own, and thus are appropriated by self-consciousness." The distinguishing activity of the mind as cognitive, the genetic process which conditions the unfolding of the psychical life, is the taking up of perceptions into apperceptions. $^{2}$ The "innate ideas," which with Leibnitz are, like the categories of Kant, forms of the functioning of intellect in its unification of knowledge, are implicit in the petites perceptions, as the involuntary forms of relating activity.

As to the validating of knowledge, Leibnitz would have us distinguish two kinds of intuitive cognitions. Here he follows a distinction as old as Aristotle; but both kinds of intuition must possess the Cartesian marks of clearness and distinctness. Then in the case of one form, intuitive certainty reposes upon the principle of contradiction; in the other form, the possibility guaranteed by perception of the actual fact needs still an explanation in accordance with the principle of sufficient reason. This distinction has reference, howerer, only to the human understanding. For the divine understanding, empirical truths, too, are so grounded that the opposite is impossible, although it remains thinkable for us. More and more, nevertheless, did this antithesis between necessary and contingent truths gain with Leibnitz an ontological significance. God's being is an eternal truth; finite things are contingent and exist only in dependence upon the principle of sufficient reason.

1 Monadology, sections 14 and 21.

2 Principes de la Nature et de la Grâce, 4 ; Nouv. Ess. II., ix. 4. 
In spite of the unsystematic thinking of Leibnitz, and of the fact that an elaborate and self-conscious theory of cognition never was wrought out by him, ${ }^{1}$ he strengthened one or two truths of immense epistemological importance. With him, sensibility and intellect are not separate powers or distinct sources of knowledge; they are at most different stages of one and the same living activity with which the monad soul represents, and comprehends as it represents, the universe within itself. Nor are the world of soul and the world of the really existent conceived of as having a "great gulf fixed" between them, over which some bridge other than the perfect, living activity of the soul itself must be thrown in order to make possible a meeting of these two disparate worlds. The monad knows the world because its own selfknown life mirrors the world; its activity is the law of the world; its mirroring is no passive reflection of dead and inert forms of existence, but an active and roluntary ideating. We are not left where Hume lcft us, to conclude by force of a doubtful use of a principle which itself defies the powers of reason to comprehend or to justify it; in its own life the soul envisages force; and the very principle of all concluding is itself the ontological law of the life of the really existent.

The claim has been made that the "Noureaux Essais" of Leibnitz stimulated Kant to build up its doctrine into a system of epistemology. Whether this claim be historically true or not, there can be no doubt that the lines which had been followed by the problems and answers belonging to the philosophy of knowledge, through both Leibnitz and Hume, united in Kant. To the lonely thinker of Koenigsberg it was given, first among men, to plan and to attempt the critique of human cognition in a manner which left the impress of his thinking upon both problem and its answer to the end of time.

1 He has himself meditated concerning the foundations of knowledge. "None are more important," he says in his "First Reflections on Locke's kssay." 
The space which ean be given in this historical sketch to the Kantian doctrine of the nature, origin, limits, and criteria of knowledge bears no proportion to the importance of this doctrine in its influence upon the reflective thinking of modern times. Certain points will be briefly stated; for the common proof of which only the painstaking and thorough study of Kant can be, in this connection, adduced. For, contrary to the somewhat widely prevalent view, there are few great philosophical writings in whose case single citations, if not taken in connection with prolonged study of the entire circle of the same author's writings, carry so little weight as do citations from the three Critiques of Kant.

First of all, in respect of several most important points Kant cannot be reconciled with himself. How so thoroughly sincere, patient, and penetrating a thinker could involve himself in such patent inconsistencies, we have probably lost the historical clues which might possibly enable us to tell in detail. Although the "Critique of Pure Reason" was so long and thoroughly excogitated and so quickly written, and although all three of the critical masterpieces were written at so late a period in the life of their author as to secure for them his maturer powers, they bear manifold marks that he had not thought himself all the way clearly and thoroughly through. Nor is this deficiency surprising in view of the magnitude of the task undertaken, of its essentially pioneer character (at least in the Kantian form), and of the splendor of the work actually accomplished. Nevertheless, the ambiguities and inconsistencies of Kant are too numerons and too important ever successfully to be denied.

But, second, the deeper purpose of Kant remained from the beginning to the end of his critical era one and the same; and this purpose was, by reconciling the two great schools as to the sources of knowledge, and thus by offering an explanation of the nature of knowledge which should have "sunclear" truth for erery one who once really understood it, to 
set irremovable limits to the pretence of knowledge and to clear the ground from it, in order to make room for the practical postulates of the life of conduct and of religion. The "Critique of Practical Reason," with its discovery of the lost truths of Freedom, God, and Immortality, was no afterthought with Kant. On the contrary, it was from the beginning his chief concern.

Two or three pervasive causes of defect and of inconclusiveness should also be borne in mind in all study of Kant's treatment of the epistemological problem. He, as is well known, constantly depreciates the influence of psychology (or the physiology of mind) upon a satisfactory epistemological doctrine. He wishes to keep his eritique independent of all doubtful opinion regarding the descriptive and explanatory science of cognitions. It must be constructed of a purity, of a universally and necessarily convineing character, which shall correspond to the purity and the necessary character of the elements criticised. But such an attempt to divorce the theory of knowledge from a critical opinion upon mooted questions in the psycliology of knowledge is impossible of execution. The defective psychological basis of Kant is the cause of many important fallacies in his critical system.

Certain naïve assumptions of Kant-for example, as to the satisfactory character of the Aristotelian logic; as to the nature of the so-called a priori concepts in general, and of mathematical concepts in particular; as to a "pure science" of physies; and as to the possibility of setting forth in demonstrative form the results of a critical estimate of cognitive faculty - are themselves in need of being subjected to the severest eriticism. To do this, as has often been remarked, is to follow our leader in the spirit, if not in the letter of his system of thinking. Especially must inquiry be pressed into the sources and validity of those ontological postulates which are so grudgingly admitted in the "Critique of Pure Reason," and so generously but unwarrantably introduced into the 
"Critique of Practical Reason." But about all such dissent from Kant we refrain from anticipating further the course of our own epistemological discussion. Enough has been said to indicate his elaims to precedence beyond all predecessors or successors in this field. They are: (1) the clear and comprehensive way in which he conceives of his problem; (2) the thoroughness with which he employs the critical method as a matter of fundamental principle; (3) the definitively ethical purpose which, although often for a time obscured, is really present and dominant from beginning to end of the critical inquiry.

It has often been pointed out that Kant, by his critique of human cognitive faculty, intended to mediate between the extremes of dogmatism and seepticism. ${ }^{1}$ The position of the dogmatist, who regards transcendental truth as attainable only by some sort of copying-off process, he overthrows with the denial that the universal and necessary quality which such truth possesses could in this way be given to it at all. But he likewise intends to destroy that kind of seepticism which persistently overlooks such universal and necessary quality; and this he will do by showing how it is just this quality which makes any cognition possible. Thus the Kantian theory of knowledge appears before us as a living and inner combination of the two opposed theories held, respectirely, by Wolff and by Hume. Sense and intellect, intuition and eoncept, are both necessary to knowledge. Without intuition concepts are empty, without conception sense is blind. The real thought safeguarded here is illuminating, and widely extends our view of the nature and limits of human knowledge. But, alas, the truth of the postulates which secure the central positions of dogmatic and rational realism is nowhere treated by Kant to a thorough criticism; in

I See, especially, his cxpressed intention " to steer reason safely between these two rocks," - the dogmatism of Locke and the scepticism of Hume. (K. d. R. V. (2d ed.) Analytic, chap. ii., sec. i. § 14.) 
the "Critique of Pure Reason," it is searcely even brought to mind. Then, too, those suggestions with regard to the entire nature and full import of knowledge, with which the scepticism of Hume is so rich, are not made use of, so as to set the author of the three critiques himself free from the limitations of his own dogmatic rationalizing. For Kant's world of reality is cold and formal ; as a world of work-a-day things, it lacks heart and will; and even as a world of conduct in pursuit of ideals, its postulates consist rather of a system of impersonal laws than of a social community, striving and counter-striving with reference to some far-off and dimly descried end of attainable good.

Instructive as it would be, we cannot here follow the scattered indications which show how the critical philosoply of Kant probably took shape in his own mind. The Dissertation of 1770 is still dogmatic with regard to the problem of knowledge; it assumes uncritically a correspondence between the world of concepts and the world of objective real things. It was to account for this correspondence, as growing out of the inmost nature of cognitive faculty, that the critical philosophy was undertaken. As we learn from his letters written to Herz in 1772, the "Transcendental Logic" is the thing on which Kant worked for ten years or more. The answer which comes forth as the product of so much travail of intellect is, in brief, this: The judging faculty, with its twelve forms of functioning (the a priori concepts of understanding, the categories) produces the world of objective real things in the unity of eonsciousness. This doctrine of the absolute dependence of all objects of experience upon the constitutional forms of the functioning of intellect, in the unity of consciousmess, is the Kantian discovery. It was upon the basis of this discovery that he himself claimed to be the Copernicus of epistemological science. But we shall soon be made to see that the way in which its author states his great discovery, together with the unwarrantable infer- 
ence which he draws from it, lands us inextricably in a position of sceptical and agnostic idealism.

In the development of his great epistemological thesis, especially in the "Critique of Pure Reason," Kant states the problem in several different and somewhat confusing ways. Among these, as the most definite proposal for a science of science, he affirms that he is aiming at a critique of all knowledge a priori, - that is, of all those universal and necessary factors of knowledge for which definite and concrete experiences, as such, do not account. "Philosophy requires a science to determine a prior $i$ the possibility, the principles, and the extent of all knowledge." 1 Surely the world needs to see that "there can be a special science serving as a critique of pure reason;" and that there should precede all attempts at metaphysics a "critique of pure reason, its sources, and limits, as a kind of preparation for a complete system of pure reason." But again, the broader question is proposed as the topic for critical investigation: How is experience at all possible? Yet again, the great problem is stated in form more deferential to the students of mathematics and physics: How is pure science possible, - (a) mathematics, and (b) physics? And why do men so persistently follow the attempt at a science of metaphysics, in spite of the undoubted fact that the issue of all such attempt is only the unrerifiable appearance of such a science? Yet once more the problem is proposed in that form, nearer to the logician's heart, in which Kant so early began to reflect upon it: How is it possible that we should frame synthetic judgments which hare universal and necessary validity?

In all the various ways which Kant adopts for stating the epistemological problem, there is something common; and this common part comprises the essential puzzle of a critical epistemology. For whether I know things immediately by sense-perception (or intuition, to use the Kantian term), or

1 New headings in the introdnction to the second edition, No. III. 
know about them by processes of reasoning that rest back upon observation through the senses, I am alike persuaded that my consciousness is somehow put in possession of the truth of things. For knowledge that does not carry conviction of putting us into possession of the truth of things, men decline to call knowledge at all. Experience is attained; science is cultivated and increased; knowledge grows by rising through higher and higher forms of synthesis toward an ideal unity; but all this, from the psychologist's point of view, is subjective, is only a succession of more and yet more complex and contentful states of consciousness. And yet the moment we consider this as knowledge, it is something more; it is the progressively perfect and comprehensire scizure by the human mind of the objective universe, the increasingly exact and detailed correspondence of the flowing stream of man's consciousness with the being and the movement of the world of things. How can this be? Only, Kant answers, because this world of objective reality is the construct of the cognitive intellect itself, functioning in all its different constitutional forms, but always in the unity of the one unfolding conscious life.

We shall not attempt to follow Kant into the details with which he laboriously furnishes us thoughout the first two Parts of the "Critique of Pure Reason." Our positions both of consent and of dissent will be taken in the subsequent chapters, for the most part without reference to him. Two or three main points of agreement and also of divergence may, however, be noted in this historical sketch. In his attempt at reconciling the claims of the exclusively sensational and the exclusively intellectual theories of knowledge, Kant set forth more fully than had any one else the complicated and combined uses of faculty in all our cognition of external things. Such cognition implies, (1) the arousement of the sensitive side of mind in response to stimulation from without (receptivity of sensibility); (2) the combining activity of 
image-making faculty (synthesis of imagination - a much truer statement of the actual facts of consciousness than all talk of mere passive " aggregation" and "agglomeration," or even of "association" of sensations and ideas); and (3) the exercise of judgment in one or more of its various forms of functioning. Without justifying the abstract and separatist fashion in which this schematizing is wrought out, we, too, believe that cognition of things is impossible withont the so-called faculties of sense, imagination, and intellect, all being called forth and developed in their living unity. And it is not so much the complicated nature of the Kantian intellectual "machine-shop" with which we find fault as it is the fact that Kant has left out of his analysis of cognition two thirds of the complete whole.

With Kant's main conclusion, that no analysis of knowledge is complete which does not recognize the universal, the necessary, and the eternal as seated within it, and that no reason for all this can be given which fails to reckon with the unchanging constitution of the mind, we also find ourselves in substantial agreement. Certainly, many of the details of his doctrine of the a priori nature of cognition cannot be maintained. Moreover, his entire conception of this element, at least as he sometimes presents it, may fitly enough be criticised. But, howerer particular and concrete our experience of this or that act of knowing may be made, and howerer contingent and fleeting the mental phenomenon called knowledge (the "relativity" of knowledge) may appear, erery "plain man's" consciousness envelops and cherishes the seeds of that which is absolute and unchanging. That this is so, a thorough analysis of all which is involved in the most primary cognitions indubitably rereals; and how it can be so, can only be explained if, sooner or later in the course of our analysis, we inroke with Kant the hypothesis of constitutional forms of functioning for that living and dereloping existence we call the Self, or 
Mind. As the author of the "Critique of Pure Reason" himself repeatedly states his conclusion, the accredited objective reality of the world of finite physical phenomena can be maintained only in connection with the equally accredited transcendental ideality of the same world. It is the work of mind which makes the world to appear as a system of legally related beings. The subjective gives laws to the objective. The forms of cognizing faculty set terms to our cognition of things.

But from this positive and relatively indisputable conclusion of a critical study of knowledge Kant leaps at once, and often without a show even of laying the stepping-stones of an argument, to a wholly negative and agnostic position. Space and time are, without further eritical examination, declared to be "mere form of our intuition" (blosse Form eurer Anschauung); "they can never tell us the least thing" about that extra-mental reality which, however, - as Kant himself asserts, either naĩvely or perforce, driven by the universal conviction, - lies at the foundation of, and is the ultimate explaining cause of the phenomena. ${ }^{1}$ Now it is plain that unless time has some kind of transcendental reality, change cannot be a characteristic of the real world; and if we are not able to affirm or to postulate the reality of change, knowledge itself - both as respects its subjective content and its trans-subjective reference-becomes impossible. One way of recovery, however, consists in showing that throughont Kant's discussion of both space and time, the question as to the psychological origin and nature of human mental representations corresponding to these words, and the question as to the possibility and the nature of the ontological correlates of these forms of mental representations, are constantly confused. In this confusion the true epistemological problem, as to the nature, extent, and proof

1 See the "General Remarks on the Transcendental Fsthetic" in the second edition. 
of the truth of our mental representations is almost wholly lost out of sight.

So, too, it is declared by Kant concerning all the constitutional forms of the functioning of intellect in the knowledge of things, that they are mere forms of our minding, and can never tell us anything about the transcendental reality of things. The categories, indeed, seem "to be capable of an application beyond the sphere of sensuous objects. But this is not the case. They are nothing but mere forms of thought." M Matter itself is substantia phenomenon. It is nerer known as anything but the intellectualized "phenomena of the external sense." And as to "the transcendental object, which is the ground of this phenomenon that we call matter," it is a "mere somewhat" (ein blosses Etwas, a nescio quid) of which "we should not at all understand what it is, even if some one could tell us." 2 Such nescience, dogmatically asserted and boldly declared forever irremorable, is the negative conclusion of the Kantian critique of knowledge; and that, as to the assumed entities which lie within the comparatively narrow limits of what is admitted to belong to the sphere of knowledge. But when the case comes forward for adjudication upon the merits of the claims put forth to know the Self, and God, or any invisible non-sensuous realities, it goes much harder against the plaintiff. For in all this realm, according to Kant, intellect is lured on by an irresistible dialectic of self-deceit (eine Logik des Scheins). And by this he will not allow us to suppose that there is meant such an estimate of probabilities, or balancing of postulates, as often we must accept in the "room" of surer cognition, and must make use of as man's best substitute for demonstrated truth. But he would have us understand that all our choicest structures of rea-

1 On the "Ground of the Division of all Objects into Phenomena and Noumena."

2 "Of the Amphiboly of the Concepts of Reflection." 
soning on such subjects are full of the dry rot of innumerable paralogisms and antinomies. Therefore they vanish in dust and ashes of this same illusory dialectic, as often as the finger of eritical inquiry touches them.

As to the truth of the charge that human reason is involved in hopeless "paralogisms" and "antinomies," we shall inquire more particularly in a later chapter. And the inquiry will show that most, if not all, of these alleged paralogisms and antinomies exist in rational consciousness only as they are put there by the critic of reason himself. Such of them, however, as cannot be quite so summarily dealt with will be seen to be premises, or starting-points, or incitements, to the outreach after those higher truths in the full apprehension of which the very appearance of paralogism or antinomy passes away. But what we wish now to cry out against involves two quite unwarrantable assumptions in the critical philosophy of Kant. The first of these is his proposal to limit the extent and the claims of experience, with its ripening into full fruitage of assured knowledge, to the domain of sensuous cognition. Epistemological criticism itself shows that neither scepticism nor agnosticism can maintain any right to dig a ditch between the domains of the things of sense and the things of the spirit. Or, at any rate, if scepticism digs such a ditch, and agnosticism consigns to it the alleged entities of the soul and of God, it is quite impossible to keep the choicest curios and even the most substantial furniture of the physical sciences from being flung unceremoniously into the same ditch. The things of science need salvation both by faith and by works quite as much as does the soul of man or the soul of the World-All.

But, second, we object to the off-hand assumption that to employ the Kantian terminology - the transcendental ideality of things is identical with the transecndental nonreality of things. A protest to this crucial estimate of the 
use made of the eritical method by the author of reason's Critique has already been entered. But the protest needs at this point some further explanation and enforcement. Let it be granted that all cognition is, as deseribed by psychology and handed over to the philosophy of knowledge for its profounder analysis, a subjective or ideal affair. Let it also be granted that all cognition, regarded as giving us a world of objects which are set in fixed and legal relations to each other, can only be accounted for by referring it to fixed laws, or constitutional modes of the functioning, of the cognizing subject, - the human Self or Mind. Let it also be granted that no means can ever be discovered, not only of knowing but even of imagining in the most shadowy way, what are the nature and modes of behavior of so-called "things-in-themselves," - meaning by this realities regarded as out of all relation to the cognitive human mind. Still the assumption which Kant impliedly finds fault with Aristotle and with all his own predecessors for making namely, that the fundamental forms of cognition also somehow correspond to the forms of the being of things given in cognition - cannot be curtly dismissed. At any rate the denial that this correspondence is actual, or that it may be actual, cannot be dogmatically made by the critical investigator of cognitive faculty, who remains faithful to his task of analyzing and explaining the entire structure of human knowledge. In fact, we shall show that some such assumption is of the very essence of cognition itself.

To put the same protest in yet more familiar terms, let us suppose that I am told: "All this fair and orderly world of so-called material things is but phenomenon of your consciousness. Sun, moon, and star, as well as the clod beneath the foot and the rose on the bush, and even the child or the wife by your side, is, and ever must be, for you, this only - your idea." What response is possible but this? "Yes, truly, no object of knowledge exists for me, except 
as $I$ know it to exist; and for me, there is nothing known, without my cognitive activity." But suppose I am further assured that the case is worse than this. All the permanent and necessary forms of the things you know - what they appear to you to be and to do - depend upon the character of the tissue, as it were, upon the warp and woof, of your cognitive faculty. This knowing of yours is your knowing; it is your finite, relative, and merely human way of sensing, imagining, and thinking things. Yes, still truly, although, perhaps, not quite so obviously. For I know no way of knowing but that which I suppose I share in common with my fellow-men. I also suppose, if I should ever come into possession of quite other and now wholly inconceivable ways of knowing, that these, too, would still be $m y$ ways of knowing. And if I could not recognize them as "my" ways, then this new form of mentality would not be what I now call "knowing;" nor could I communicate its content to other minds, or even know of the existence of such minds, unless I then, as now, supposed that these other minds were of like constitution with myself.

At this point we come upon the fundamental fallacy of the Kantian critical philosophy in its effort to accomplish the end which it deliberately chose as the highest of its entire endeavor. This end is the placing of the life of conduct upon sure foundations. "I had, therefore," says Kant, " to remove knowledge in order to make room for faith." "All speculative knowledge of reason is limited to objects of experience (the world of things regarded as merely phenomena); but it should be carefully borne in mind that this leaves it perfectly open to us to think the same objects as things by themselves, though we cannot know them." Thus, in the "Critique of Practical Reason," the transcendental realities, and the actuality of our non-sensuous relations to them, are brought back to our possession, but only as postu-

1 Preface to the second edition of the Critique of Pure Reason. 
lates needed for the life of conduct. We may act - nay, we are bound to act - as though a world of ethical personalities constituted like ourselves were in existence, and as though our thoughts about God, freedom, and immortality were true; we must not, however, affirm that such realities are in any way, or degree, given to us as objects of knowledge.

Now the inadequate and false psychology which teaches the doctrine of a "thought" justifiable about things, which neither starts from nor leads to safer foundations of knowledge, and which separates cognition and belief as though they referred to totally different spheres of objects, will be exposed in the proper place. What is here necessary to emphasize with regard to the outcome of the Kantian critical philosophy is this: Human nature cannot be divided into mutilated halves, one of which is valid for the cognition of sensuous things regarded as mere phenomena, and the other of which is ralid for the rational apprehension ("thinking about," "haring faith in," or seizure in any way - call it what jou will) of transcendental realities. Human nature, as cognitive faculty, is one thing throughout; its functioning, in all spheres, is as a living unity; its growth, in all stages and degrees of development, falls under the principle of continuity. The man of science is also the man of good or bad moral character and the man of religion or irreligion. When knowledge has been, whether rudely or ceremoniously, banished by the front door of the temple of reason, it cannot afterward, whether pompously or surreptitiously, be introduced again by the back door concealed beneath corers labelled "faith," or "practical postulate." Religion itself is an attitude of the whole man, - intellect, feeling, will. Knowledge is also an attitude of the whole man, - intellect, feeling, will. Mere thinking, or pure faith, is as impotent in ethics or religion as it is in science. But there is no science that is not of faith, and does not include thinking.

To return to our critical estimate of Kant, one is forced 
by every interest of logical consistency, however strongly adverse other interests may be, either to refuse, almost in toto, the conclusions of the "Critique of Practical Reason" or thoroughly to revise the conclusions of the "Critique of Pure Reason." Accepting the negative and agnostic outcome of the earlier treatise one cannot follow Kant in accepting the positive gift to a rational faith that is offered by the later treatise. Here is the case of a clear-cut and inescapable "cither-or." Believe something and know something, and so perchance be saved for this world and for the world to come; or else doubt and deny consistently, and manfully face your fate in both worlds.

The indubitable law which Kant finds implicate in moral consciousness, in the form of a categorical imperative, he states as follows:" "Act so that the maxim of the will can always at the same time hold good as a principle of universal legislation." There is something painful about the effort which the great critic of all cognitive faculty makes to expound the "purity" of this law, its perfect freedom from all doubtful and empirical data. The argument by which he supports this favoritism shown to the practical reason (as though, indeed, it were a separate faculty or store-house of faculties), and proves its "primacy" "in its union with the speculative reason," fails completely. Unless the life of conduct is known to be regulated in accordance with actual relations of a self-cognizing Self to a system of cognized realities, - selves and things, - it is absurd to speak of it as "practical" or as having any "fundamental law." But if the forms of our cognition are supposed to be merely subjective, and to give objectivity to their own functioning without implicating corresponding forms in the actual relations of the, for us, extra-mentally existent, no meaning can be given to this fundamental law of the practical reason.

"The Kantian theory of knowledge, then, of necessity

1 Critique of Practical Reason, Book I., chap. i., § 7. 
breaks down when it virtually tries to vindicate for the metaphysics of ethics and the practical reason what it had denied as forever impossible in the functioning of the pure speculative reason. We say 'virtually,' for its author obviously foresaw that both scepticism and dogmatism would, from their respective points of view, attack his transcendental ethical system; and he strove hard to defend it against the charge of inconsistency. Kant will not at first call the practical reason 'pure,' because he wishes not to assume a pure practical reason, in order rather to show that it exists. But its existence being shown, he considers that it stands in no need of a critique to hinder it from transcending its limits; for it proves its own reality and the reality of its conceptions by an argument of fact. We may know the fundamental law of the practical reason; it bears the form of a command, - a categorical imperative. Whatever principles are, as necessary convictions, attached to this principle are postulates of the pure practical reason. Hence we find Freedom, Immortality, and God restored from the spaces swept empty by the critique of speculative reason.

"But Kant's categorical imperative is itself only an imperfect and faulty generalization from empirical data of ethical fecling, judgments, and conduct. It is not even an exact summary of the testimony, in reality, of human moral consciousness. Were it a true generalization, however, and therefore worthy to be itself called a knowledge, it could be shown to be dependent for its validity upon many subordinate conceptions and convictions which must also have the validity of known truths. Otherwise, the categorical imperative itself is condemned as the vague and illusory dream of the individual consciousness. Metaphysical postulates, other than the three acknowledged postulates of the pure practical reason, with that inseparably adhering conviction which makes them principles of all knowledge as well as principles of all thought, enter into the very substance of 
this categorical imperative. Beings, with powers called ' wills,' rationally answering to ends that involve other beingsnot-themselves but like constituted, and who may be expected to act as bound with their fellows in a system of moral order - all this, and much more, is involved in the main principle of the practical reason. But what an infinity of knowledge, made knowledge by the suffusion of rational thinking with rational conviction, and in some sort placing the mind of the individual face to face with a world of reality, is here! Some of these are the very things of which we have been told, as the result of the critical process applied to speculative reason, that they may not be spoken of as ' known,' but may only be permitted to thought, without hope of finding content for the empty form, no matter how much we extend the bounds of experience. If these postulated entities and relations are not real, then the categorical imperative and all it implicates is but a dream nay, it is only the dream of a dream. Must we not then, in consistency, either include all - and especially the categorical imperative with its accessory postulates - under the condemnation uttered by consistent scepticism, or else retrace the steps passed over in the criticism of speculative reason, and discover grounds for a larger ' knowledge,' with its eternal accompaniment of rational faith?

"The same fate must await all those theorics of knowledge which end in scepticism as the result of critical processes. Nor is the fate much better of those theories which endeavor to save from scepticism certain portions of human knowledge, while denying in general the possibility of validating knowledge as such. The principle of self-consistency is of the last importance to reason. It is in fact only one form of stating the undying self-confidence of reason. The practical exhortation of experience in noëtical philosophy is, then : Let us by all means maintain a rational consistency." 1

1 Quoted from the author's “Introduction to Philosophy," pp. $186 \mathrm{f}$. 
It would seem as though one lesson in the philosophy of knowledge should be thoroughly learned for all time from the example of Kant. Between the outfit of man for a scientific knowledge of the world of sensuous facts and of their connections, on the one hand, and his outfit for the life of conduct and religious belief on the other hand, no great gulf can be fixed in the name of a consistent epistemology. We cannot "make room for faith" by "removing knowledge"; we cannot posit knowledge in spheres where faith has no province. We cannot virtually discredit the cognitive faculty of man throughout, and then save to knowledge, or to faith, or to practical postulates, some specially favored kind of cognition. Neither can we undermine the foundations of the plain man's consciousness and trust the superstructure of philosophy's more ponderous and towering speculative thought. ${ }^{1}$

In closing this historical sketch we only mention three attempts subsequent to Kant that supply elements to the philosophical account of knowledge which his criticism had either neglected or relatively depressed. Fichte emphasizes feeling-especially moral feeling; Hegel emphasizes the dialectical process, or thinking; Schopenhauer emphasizes the intuitive attitude of will. But neither of these at all approaches Kant, either in the critical spirit or in the patient, detailed investigation which the latter brought to bear upon the problem of knowledge.

Fichte based the validity as well as the constitution of knowledge upon feeling, as yearning and as certitude. The criterion of cognition he makes, not insight, as Reinhold had done, but rather an intellectual feeling of certainty which cannot be explained. This emotional attitude is inseparable from every content of thought, and from all activity

1 In Mansel's "Limits of Religious Thought" we have an example of the futility of trying to secure to faith what has been made impossible or absurd to knowledge. In Bradley's "Appearance and Reality" we have an example of the futility of trying to secure by speculative thinking what has been made both impossible to faith and absurd to knowledge. 
of thinking. It is, however, only immediate and probable, not demonstrable; it is to be assumed as necessarily belonging to every Ego. But the highest form of cognition is that which arises out of the ethical feeling of responsibility, which issues out of a recognized fiat, "Thou shalt." 1

Hegel takes many important exceptions to the conclusions of Kant respecting the possibility, the criteria, and the limits of knowledge. To the latter's agnostic outcome he opposes the claim by logic (now no longer a "logic of illusion") to unfold the very nature of Absolute Leing, reading in the inner movement of reason's dialectic, as Kepler did in the movements of the planets, the very thoughts of God, after Him. "Thoughts, according to Kant," says he, "although universal and necessary categories, are only our thoughts, - separated by an impassable gulf from the thing, as it exists apart from our knowledge. But a truly objective thought, far from being merely our's, must at the same time be what we have to discover in things, and in every object of perception." These two elements, Being and Thought, which Kant had separated, after "denuding them" of what they have in their united existence, Hegel would bring together again. The conceptions which are analyzed out of the process of thinking are the eategories of reality; they must be understood as "moments" in a living derelopment. Our knowledge is not merely of the phenomenon. The rather "is the phenomenon the arising and passingaway of that which itself does not arise and pass away, but $i s$ in itself, and constitutes the reality and the movement of the life of truth."

But this notable and praiseworthy attempt to orercome the agnostic outcome of the Kantian eritique, which Hegel elaborated, itself issues in positions that are theoretically one-sided and practically faulty. Our entire epistemological theory cannot safely be resolved into an assumption that

1 See especially his "Essay on the Grounds of Certainty in Religion." 
when we have discovered the categories, and arranged them systematically so as to construct a circle or globus of such pure concepts, we have justified our faculty of cognition against all the assaults of scepticism and agnosticism, or have even succeeded in understanding it. Moreover, the ontological postulate, or view of reality which eonceives of Spirit as possibly having being-in-itself that is not also being-for-itself, is full of internal contradictions. Nor are the Hegelian antinomies much less dangerous to the validity for reality of our thoughts than are the antinomies of Kant. Indeed, they may be understood so as to prove more dangerous. For Kant's antinomies, if admitted, only affect a limit to human efforts in applying our sensuons imagination to subjects with which it cannot rightly claim the ability to deal. But the antinomies of the Hegelian dialectic, conceived of as an essentially true representation of the nature of all reality, have their seat in more vital parts of the organism of knowledge. And, practically, the history of human experience has since shown that Hegel's philosophy extols theory too much, and makes it a substitute for insight, for instinct and feeling, for morality as conduct, and for religion as life.

There are few passages in any of our modern books on philosophy which, when read in the light of the day of their writing, seem more timely and suggestive than the latter two thirds of the first Book of Schopenhauer's "World as Will and Idea." In these pages the author, with much illconcealed scorn of Fichte and Hegel, and with considerable invective against their views, propounds his own theory of knowledge. His earlier work on the "Four-fold Root of the Principle of Sufficient Reason" presents some of the most technical parts of his theory in a more systematic form. His "Criticism of the Kantian Philosophy" develops his views further, though chiefly in a polemical and negative way. The positive merit of Schopenhauer's utterances con- 
sists in their bringing forward - if we may venture upon such a term - the "biological view" of the origin, nature, and criteria of human cognition. Over against knowledge by concepts - that knowledge which Hegel identified with the very life of reality - Schopenhauer maintains the claims of perceptual knowledge, of the immediate seizure, as a matter of warm feeling and energetic volition, of the really existent relations of things and of events. The Kennen of the artist, or the discoverer, or the true saint, is surer knowledge, he thinks, and less fraught with erroneous fragments of so-called "reason's" manufacture, than is the Wissen of the man of science. For intellect, impelled by the will to live, and guided by the feeling for what is seemingly good to live by and upon, brings us more immediately and surely to the heart of reality. And intellect, in Schopenhaucr's vocabulary, is not a reasoning faculty; it is the unreasoned envisagement of the presence and significance of the principle of sufficient reason as constitutive of the world of things.

We need not delay to criticise the extremes to which Schopenhauer carries his view of the superior value of perceptive as compared with conceptual knowledge. It is enough at present to say that the marked separation which he makes between perception and conception is psychologically false. Knowledge is not, indeed, mere thinking; but, then, there is no knowledge to be had without, at least, the primary activities of thinking faculty. And there is surely no structure of knowledge, no growth and systematization of cognitions which we can take, even on faith, as representative of the world of real beings and real events, without elaborate activity of thought.

We turn now to face for ourselves the different, though not distinct problems which enter into the one great problem of knowledge. This brief survey of the history of opinion, if it does not start us on our way with handfuls of coin which will pass current in the markets of the present world 
of thought, may serve to warn us in what direction our journey lies, through what thickets and swamps we must find a path, and over what mountains we must pass; as well as - surely a no less important lesson - what short cuts we must avoid taking with the vain hope thus more easily to reach the desired end. But when we have reached this end, and look back to find the views we have taken by the way, all confirmed by the more profound insights and permanent impressions of those who have travelled before us, we shall the more confidently believe that the truth of cognition has been found as it is justified in the truth of things. 


\section{CHAPTER IV}

\section{THE PSYCHOLOGICAL VIEW}

THE necessity for steadfastly maintaining the proper psy1 chological point of view in all reflective consideration of the philosophical problem of knowledge has already been sufficiently emphasized. A sketch of the history of opinion has shown how light broke in (for example, through Augustine, Descartes, Hume) upon this problem whenever an improved acquaintance with the nature of concrete mental phenomena was gained. It has also shown how, even in the case of the greatest of all critics of the human faculty of cognition, a certain despite of "mental physiology," or of the natural history of psychical life, and an excessive credulity toward the accepted forms of logic, was productive of important errors. Indeed, throughout the historical development of epistemological philosophy, defective and one-sided views of the psychology of cognition have been the chief sources of the fatal extremes of dogmatism and of agnosticism. We propose, then, to begin our diseussion of the epistemological problem by taking the psychological point of view.

What has psychology, as the descriptive and explanatory science of mental phenomena, to tell about the origin, the nature, and the growth of human cognitive faculty? Whence comes knowledge? What is knowledge? and What is the course of its development? These are the inquiries for which an answer is now sought from experience; and for the kind of answer now sought, there is no proper recourse but to the 
concrete, plain, work-a-day facts of human consciousness. It is not what the master of the subtleties of scholastic logic, or the student of psycho-physics by laboratory methods, or the philosophizer already committed to some metaphysical dogma thinks about knowledge, - which we now wish to know. It is rather just what every one actually experiences who affirms, "I know;" and just what they experience most fully who have made most adrancement in genuine knowledge. But, of course, it turns out here, as everywhere when search is made for the truth of things, that the content of life is much richer, and its complexity of method and of products much greater than human science is easily able to depict or to comprehend. The plain man's work-a-day consciousness perpetually achieres the end of cognition; but it is too deep for the logician, the psychologist, or the philosopher of any school to fathom. And the danger of error from failure to include important elements in one's catalogue of the "facta," or "momenta," implicate in every "I know" is far greater than the risk of putting more into this catalogue than life has itself put there. Indeed, the descriptive and explanatory history of cognition comprises no less than the whole of psychology.

As to the Origin of Knowledge it is possible to speak clearly only after the meaning given to the term has been strictly defined. That psychological fact which induces the search after its own begetting and birthright becomes an actual matter of experience only when the records of the exact history of its sources have been lost beyond the possibility of complete recovery. Men find themselves already well advanced in the growth of cognitive faculty before they begin to ask whence this faculty with its resulting products has arrived. And after a critical inquiry into origins is undertaken, both the inquiry and the summing up of its results in recorded experience must take shape either as knowledge or as the pretence of knowledge. Unless I already know, 
with faculties developed far beyond the point when the first datum fit to be called "knowledge" arose in consciousness, I cannot intelligently raise the question, Whence comes knowledge to me and to other men? If examination is made of the inferior cognitive faculty of the lower animals, or of the earlier forth-puttings, the budding cognitions of the human infant's mind, the examination and its conclusions can assume only those points of view which belong to an adept in the use of cognitive faculty. Now, while this fact does not by any means debar us from forming justifiable impressions as to the manner in which we oursclves, and all other men, begin the life of cognition, it does limit the nature and restrict the proof which is accessible to us by immediate observation of all the actual processes of cognition.

There is one meaning to the word "origin" which is certainly unwarrantable and useless in the effort to throw light upon the epistemological problem. Yet, alas, this meaning has been in the past most frequently, and is now in certain quarters most persistently, employed. The fallacy involved in the figures of speech which are commonly employed by those who undertake the research into the origins of things physical condemns, for their utter inadequacy, all the socalled "sensational" theories of knowledge. These theorics find their explanation of the beginning of knowledge in the assembling somehow of sensations and of the revived images of past sensations, called ideas, under the well-known laws of association. It is assumed by them all that when mental states, or forms of the functioning of mind - even including those elaborations called cognitions - are described " contentwise," they are adequately described. It is also assumed that the particular content called a "sensation," either in its original or transformed character as an "idea," exhausts the entire catalogue of mental contents - the whole life of mind, even when described "content-wise." Now the peculiar fallacy of which all sensational theories are guilty in this con- 
nection is shared by them with the greater part of the modern science of origins, as this science is taught by the current biology. This is the fallacy of so working the prineiple of continuity as to do away with essential differences by substituting for their honest and frank recognition and explanation a connection between them, often conjectural, under the forms of time or of causal influence. A similar fallacy afflicts sorely all the psychological sciences, - the sciences of man both as an individual and in all the various forms of his relations and development as a race. It is the very bone and flesh of the hypothesis customarily applied to these sciences.

In biology one at least knows what real transactions are referred to, if one hears of the "origin" of the individual animal from an impregnated egg, or of the "origin" of the fully developed plant from a germ or seed. In the case of the animal an actually existent cell from the male parent has fused with a cell from the female; and out of the product of this fusion - though in most marvellous and mysterious fashion - has followed a growth which results in the full complement of organs possessed by the adult animal, as united anew in the offspring. In the case of the plant the process is markedly similar. So, too, one knows what is meant when the chemist affirms that water has its origin in the union of oxygen and hydrogen gases; or, conversely, that these gases may have their origin in the chemical analysis of water. But only a most shallow student of biological science considers that a complete account has been given of the origin of the adult by describing the physical and chemical properties of the egg. For, besides such more obvious factors in the scientific account of the genesis and development of animal organisms, there are many others which must come into the complete account. These may be roughly divided into two elasses: such as take the indiridual animal out into what is known of the beings, forces, and 
laws of the "cosmos" at large; and such as end in the unexplained mystery of the "nature" of the individual animal. In the case of the drop of water, too, there is something vastly more in the compound than can be accounted for by rehearsing the marriage service over oxygen and hydrogen gases as a merely numerical formula of 1000 to 2002 .

But the case of the student of psychological origins is notably different from that of the student of biology or of chemistry. For the psychologist there exist no real factors, or actual antecedents, which he may observe in their isolation, or understand previous to their combination or while they are in actual process of combining. Strictly speaking, there are no sensations, simple or complex, and either actually existent or representatively existent in the imagination and thought of the observer. So-called sensations are themselves the product of the analytical activity of self-cognition, - quite impotent, therefore, to establish any claim to be or to act of themselves, as though separable from the cognitive process itself. To speak of the origin of knowledge from a combination of sensations is, then, to deceire one's self with a misapplied figure of speech. Sensations are not entities, even of the psychological order; and if they were entities, they are not the kind of entities to offer, by any combination, in howerer large quantities and high degrees of value, an adequate explanation for the origin of knowledge.

What has just been said of sensational theories of knowledge is also true of all strictly ideational theories. The psychological doctrine of Herbart, especially as it came to its ripest fruitage in the later work of his distinguished pupil, Volkmann von Volkmar, has been of great value to modern psychological science. Its value lias been increased rather than diminished by its frank avowal of the need of metaphysical standpoints and by its tenacious defence of the proposition that mental phenomena are all to be considered as "forthputtings" of the unfolding life of mind. But in its 
doetrine of judgment, and of feeling, and of will, - and so of all these as constituting two thirds or three fourths of cognition, - its weakness is most manifest. Cognition cannot, either for its origin, or for its nature, or for its growth, be considered as completely explained by any theory of ideas. It is true that the later developments of the Herbartian doctrine, especially as set forth by Volkmann, include under the term "idea " various complex forms of mental functioning; true also that they emphasize, in a commendable way, the active rather than the passive aspect of ideation-processes (Vorstellen rather than Vorstellung or Das Vorgestellt). They thus succeed both in getting a richer content into their description of mental phenomena, and in regarding these phenomena "function-wise" as well as "content-wise" much more faithfully than do the adrocates of the sensational school. But we must not be deceived by increased subtlety of analysis and more generous use of terminology. As will be made clear by the detailed and critical examination of the nature of cognition, every mental positing corresponding to the words "I know" implies something far more than can be explained by combination of ideation-processes.

As to the possibility of a purely biological or physiological explanation of the origin of knowledge, the case is so hopeless that it is scarcely worth while to argue it. For those, however, who incline to confuse such an explanatory theory with another contention quite different, we hare presented the subject in another place. ${ }^{1}$

Thus far negatively. In some sort, however, appeal may successfully be made to modern psychology to render an account of the origin of knowledge. Such an appeal may rightfully expect an answer in both of two ways. Psychological analysis can exhibit those manifold factors which may be discerned by the self-cognizing mind as characterizing its activities on the way to, or after it is regarded as already har.

1 See the author's "Philosophy of Mind," pp. 98 f., 115 f., 229 f. 
ing reached, the mental attitude called cognition. Of course, by the term "factors," in all such connection, one must not understand separable entities, or even actual separable elements or momenta of the complex mental state. But the trained self-consciousness of every man enables him to observe with concentrated attention now one and now another of the so-called faculties of mind, or forms of psychical function ing, as they are concerned in the living unity of an act of knowing. This analysis of self-consciousness may be made, by exercise and study of mental phenomena, by growth in depth and in quickness of insights, more rich in its response to the call for a true picture of actuality. The actuality of cognition belongs to every human conseiousness as an incontestable fact; but the analytic discovery and portrayal of this actuality is a matter of combined science and tact, as is every other matter of psychic life. And like all matters of psychological science, this study may be enriched by observation of others and by the experimental method.

Not only the so-called psychic factors, but also the principles according to which these factors combine, may be made the subject of inquiry. In the actual process of cognition the different forms of mental functioning (which are the realities corresponding to the word "factors") rise and fall in extensity and intensity; they come forward and take the lead, so to speak, or retreat into the background of a relative obscurity and insignificance. In knowing anything, for cxample, I am at one instant more obviously sensing it through this, and at another instant through that, avenue of sense. In other words, the particular "Thing" is now to me a thing chiefly of sight; now of touch and the muscular sense; now, perchance, of taste or of hearing. But again, the same thing, in the same complex process of cognition, is rather known by being judged to belong to this or that class of things, or by being thought about as standing in this or that relation to me and to other things. And yet, 
anon, the same thing is more felt and cognized as opposed to my will, - a forceful thing, that will not what $I$ will, and that reveals itself as a resistance to the forthputtings of $\mathrm{my}$ embodied Self. In all this living flux of my conscious life, this stream of consciousness I call my cognizing Ego, with the rise and fall of the varying shades of sense, judgment, fecling, and will, the object there, the " real Thing," becomes known to me.

In the meaning, then, of giving a descriptive history (accompanied by certain meagre and tentative explanatory remarks) of the different factors discorered in what is called a cognition, and of the way these factors behave with reference to each other and to the Self, the origin of knowledge may be said to be explained.

But by the word "knowledge" ("yours" or "mine," or " his," or that of the race) men generally intend to designate something more than a single process of cognition. It is, indeed, only this single process, and usually only a part eren of any single process, which can be made the subject of introspective or experimental study. But in some sort, the mental doing and achieving which ends in the judgment "I know" does take place under the mind's immediate gaze; it may be self-consciously known to be going on. Yet even if this analysis were far more certain and comprehensire than it is, no one would think of claiming that it alone could result in a science of the origin of knowledge. The origin of knowledge may, then, in a certain way be understood by adding to our descriptive history and tentative explanation of the single processes of cognition a somewhat similar history and explanation of the enlargement of the content of knowledge and the growth of the faculty of knowing, in the individual and in the race. Here memory must be summoned to the front; for it is designed tu study our own processes of cognition in their relations to each other, as they hare actually occurred in time. But memory of our own past states will take us only a little 
way here. Hence the value of comparative psychology for a mastery of the descriptive history of cognition. On the general assumption (which is sufficiently well verified) that our own earliest mental states, the forerunners and preparers of the fuller activities of adult cognition, corresponded in kind to such of our present mental states as appear to have least of the more prominent cognitive factors, we may employ introspection still further in studying the origin of knowledge. For example, I may give an attentive study to my own states of reveric and dreaming (when I am more exclusively bound under the laws of the association of ideas), or of absorption in sense or in pleasurable or painful feelings (when I am eating with a good relish, or suffering from toothache, or enjoying music), or of abstraction (when I am more " purely " thinking.)

It appears, then, that the stages through which the growth of cognitive faculty passes in the life of the individual and of the race, may be made the subject of more or less successful investigation; and something may also be confidently asserted as to the laws which control this growth. In some sort all this may properly be called a study of the " origin of knowl. edge." But here again one must not be deceived by the charms of any particular erolutionary hypothesis, whether as applied to the development of the individual or of the race, into supposing that cognition can be wholly accounted for, as respects its sources, by giving the detailed account of that which is not cognition. So often as this is done, the mystery of the actual achievement of cognitive faculty is explained (sic) by being overlooked or buried beneath a heap of rubbishy figures of speech.

The only answer, then, which can be given to the inquiry after the psychological "origin" of knowledge falls most fitly under the titles, the "nature" and the "growth" of knowledge. In other words, when that has been told which can be told in response to the questions: What is cognitive faculty, regarded as activity and as resultant? and, What are 
the successive stages in which it unfolds itself? - nothing more is to be said about the psychological genesis of this faculty. At no step in these inquiries should it be supposed that anything is added to the science of cognition by identifying in thought things which are not actually the same; and a merely genetic and psychological study of the phenomena will nerer suffice for the solution of the epistemological problem upon this point.

Several most important corollaries follow from what has just been said; and these concern both the method of psychological study which is fitted to present the epistemological problem, and also the character and extent of that which our study can hope to accomplish. A certain prejudice, not altogether wrong and unnatural, exists in these days against the refinements and subtleties of analysis. But a theory of knowledge, from its very nature, requires, chiefly and almost exclusirely, refinement and subtlety in analysis. The entire science and philosophy of cognition, the complete mastery of the secrets of cognitire faculty, is necessarily a matter of thorough analysis and of sound discursive reasoning upon a basis of such analysis. Who will tell us all that can be told about the mystery of the conscious processes of every liuman being when he reaches the mental attitude expressed by the words "I know"? Who will furnish the theoretical justification for that trust in the human mind which it belongs to human nature, howerer often and sorely baffled, continually to cherish? Who will set the theoretical limits to scepticism, and administer the convineing theoretical rebuke to agnosticism, for the rational comfort of doubting and despairing souls? Only he who can most fully and convincingly expound the length and breadth, the heighth and depth, of man's power to know, and the extent and strength of the grasp of this power upon reality. But this end can be reached only by analysis. Certain partially successful practical refuges may indeed be offered for extreme scepticism 
and agnosticism. But the only refuge which can serve the persistent inquirer must be found in a better understanding of what it is to know, and of all that every act of knowledge implicates. The path to this refuge is an analytical and discursive exploration of cognitive faculty itself.

From the same statement of the facts in the case we derive a certain set of limitations to our expectations concerning what we may reasonably hope. This consideration of limits is important, both in a theoretical and in a practical way. For depressing scepticism and despairing agnosticism are most often reactions from the breaking-down of unwarrantable expectations or unreasonable hopes. It cannot be too constantly borne in mind, then, that no standpoint outside of reason itself is attainable for the more secure criticism of reason. The self-limiting nature of sceptical inquiry into the validity of knowledge, and the self-destructive nature of the agnostic conclusion to terminate this inquiry, will be shown in due time. But it is well at the outset to remind ourselves that we, as critics of cognitive faculty, cannot claim any point of vantage which towers above the cognitive faculty itself. The philosopher may, perchance, tell the plain man more than he can himself discover of the content and the meaning and the implicates of the plain man's mind; but what the analyst sees, and even what he imagines he sces, is all contained within the known or the imagined horizon of thicir common consciousness. Special gifts at dialectic, claims of intellectual intuition, visions of the Platonic ideas, lofty or profound insights into the mysteries of the transcendental realm, are all of account here only as they can justify themselves and their deliverances at the bar of that reason in which all men have a share. The critique of cognitive faculty neither has, nor can attain, a point of riew outside of the domain ruled over by that faculty. Flights sunward are limited by the sustaining power of that very atmosphere above whose dust and smoke-begrimed regions they rise. 
Again, no eertification of knowledge is possible that is not somehow found actually existent within the process of cognition itself. If scepticism is self-limiting, and the extreme of agnosticism self-destructive, it is equally true that the positive and dogmatic resultant of analysis is self-limiting also. The process of certifying stops somewhere; it cannot, of course, go on forerer. And where this "process" stops as a process, what other kind of certification can be either expected or actually found? Plainly, the answer to this question leaves us with some total attitude of mind, or in face-to-face recognition of certain implicates of all cognitive processes, which do not admit of any certification lying outside of that which they themselres possess. In other words, critical analysis of the nature of cognition, with a view to certify it, ends in the discovery of aspects, or factors, or implicates, of every exercise of cognitive faculty, which are self-certifying. The inquirer after certitude observes or infers his way up to this point, and then finds certitude in reposing there. The detailed exposition of this truth is the most important and difficult part of every philosophical theory of knowledge. But at the outset it promises a saving of time and strength, which will otherwise be wastefully and even foolishly employed, to recognize the absolutely inevitable character of this truth. If by analysis, a fundamental and universal position of certitude belonging to every act of genuine cognition is discorered, we cannot be asked to certify this feeling of certitude by discovering another position of a similar kind. If by analysis we find that judgment in cognition is of its very nature, a positing in reality of the object of cognition, we camnot be required to justify this judgment by a process of reasoning that could itself only repose on judgments of like character. Dispute and argument cannot serve as grounds for that which is assumed in all proposal to dispute and to argue, invariably and with an absolute necessity. They who will not be satisfied until they hare certified, in infinitum, all 
certitude would found the world of human reason as the EastIndian myth founded the world of matter. But the world of human reason is a self-supporting and self-sufficient cosmos, rather than a flat and level expanse, resting on the back of an elephant, supported by a tortoise, - and so on.

Or, to bring somewlat the same truth before us in a statement even more naïrely adapted to make it self-evident, no other kind of knowledge is possible, or cren conccivable for us men but human knowledge, - or just such knowledge as all men know themselves to have. This is a primary and invincible epistemological postulate. The picture of a divine intuition that should have no thought in it, as Kant attempts repeatedly to sketch the pieture, is as purely imaginary as the conceit of a dialectical unfolding of coneepts that never come to a resting-place in any intuitive knowledge. But both are alike due to the unwarrantable hypostasizing of a one-sided recognition of the work actually done by all human cognitive faculty. The effort to exalt cognition by stripping it of some of the fundamental qualifications which belong to it in a living human experience, and then to set it over against its actual self as a something worthy of envy by itself, if only it could be attained, always ends in the very opposite of what is intended. If our human knowledge cannot be shown to include some sure envisagement, so to speak, or trustworthy mental representation of the being and doings of the Really Existent, then no other knowledge more inclusive can ever be the object of our striving or even the subject of our inquiry.

Let us, then, from the beginning, renounce all vague longings and vain efforts after the absurd and the impossible. It is not to dehumanize ourselves by a self-apotheosis that we are called. But, on the other hand, it is not to animalize ourselres by reducing man's birthright to the limitations of a merely sensational and ideating conseiousness. Epistemology does not propose to enter upon the manufacture of knowledge, by putting inferior raw stuffs into an empty receptacle and taking 
out the finished product as the resultant of their combination, before a bewildered crowd of spectators. The mystery of cognition will certainly not be diminished, it will very likely be not a little increased, by what the most aceurate and thorough analysis can accomplish. Nor can the seeker after a eritical theory of knowledge secure or maintain any standpoint superior to that of the multitude of rational souls, from which to view the nature, or to discover the eertification, of cognitive faeulty. What he finds of the supernatural must be immanent in, or implicate within, the nature of all mankind; what of the divine must still be clothed in recognizable human garb. Or, to drop all figures of speech, the thorough analysis and reflective discussion of the cognitive faculty of man - how it behaves, how it grows, what is implied in it by way of feeling, faith, envisagement, postulate, or other form of implicate is all that the psychology and philosophy of knowledge can rightly aim to aecomplish.

The details of the first introspective and experimental analysis, and the resulting descriptive history of human cognition belong to psychology. ${ }^{1}$ As to the Nature of Knowledge, psychologically considered, it will then be necessary here only to call attention to the following series of propositions, which form the basis of further reflectire thinking upon the epistemological problem.

All cognition is consciousness. The reverse proposition, that all consciousness is cognition, by no means follows. What consciousness is in general, or what is any particular form or modification of consciousness, cannot, of course, be known without assuming the activity of self-cognizing faculty. This amounts to saying that without self-consciousness there can be no science of knowledge; and that the systematic study of the nature, growth, and implicates of knowledge demands highly developed activities of the self-conscious order. There

1 For these details see the author's "Psychology, Descriptive and Explanatory," especially chapters xiv., xv., $\mathrm{xvi}$., $\mathrm{xx}$., xxii. 
is abundant indirect evidence, however, that all the very earliest, most of the earlier, and many of the later modifications of the "stream of consciousness," neither of themselves amount to cognition, nor do they terminate in a mental attitude which can properly be called an act, or fact of cognition. But, on the other hand, a continuous stream of cercbrations, a psychic act or factor, or an inference that is not in and of consciousness, certainly cannot have the epithet cognitive attached to itself. The extremest form of a mind-stuff theory, the older or newer forms of the Leibnitzian hypothesis, which assume an unbroken series of consciousnesses, varying from zero to the unity of developed apperceptive self-consciousness whether correlated or not with physical and neural aggregates, have no bearing on the problem of epistemology. The conception of " unconscious knowledge" remains not only untenable, but even impossible to frame. One may be pardoned, perhaps, for saying "I must have felt (or imagined or inferred) it to be so without being fully conscious at the time;" but one cannot say "I knew it, and yet I was unconscious when I knew."

Whatever may be held as to the possibility of certain lower forms of psychic manifestation being correlated with the functioning of the sporadic ganglia and spinal cord of the lower animals, or with the different parts of those worms which allow of subdivision without loss of animation, or with the different micro-organisms, or eren with the life of the plants, cognition appear's to require a highly elaborate nervous organism crowned by a cerebral development. In Schopenhauer's careless language, knowledge of understanding is only the phenomenon of the self-objectification of Will in the brain. It is not necessary to occupy ourselves with the crudities of this, or of any other materialistic hypothesis on this subject. But the biological connection of that most elaborate physical organism, the brain, with the life of eonscious cognition is full of meaning. The white 
blood-corpuscles can do certain wonderful and purposeful things; and so can the cilia on a bit of skin from the throat of the frog. So can microbes, and harmful germs, and helpful germicides, innumerable. How much of such doing, which seems full of a sort of knowing (a Kennen, if not a Wissen), is really dependent on or is, at least, colrelated with " momenta" of consciousness, even if they are not organized into a stream of consciousness, one cannot very confidently affirm. But when we approach an act of cognition, properly so-called, we have long since passed beyond the border-land of the unconscious. To speak of unconscious knowledge would be no less absurd than to speak of "wooden iron." Just as the physical basis of all psychic life reaches its culmination, puts forth its supremely noble blossom in the convoluted hemispheres of the human brain, so does the life of consciousness reach its supreme manifestation, its crowning achierement in those forms of consciousness, called acts of knowledge, which depend upon the employment in their integrity of these hemispheres.

All cognition is a conscious process, a process in consciousness. But not only has each act of cognition a conscious character; it has also a becoming of its own character; it is a coming to a peculiar kind of consciousness. The experimental demonstration of this truth, too, is complete. Reaction-time is prolonged in some sort of proportion to the extent, the certainty, and the clearness of the cognitive process which it measures. If mere sensation is called for, and signalled as arising in consciousness, then the reactiontime is relatively short. If sensation, more accurately discriminated as to quantity or quality by comparison with a memory-image is demanded, then reaction-time is more prolonged. But if the full-orbed and perfected act of cognition, resulting in judgment that posits a relation between self and its object, with the essential accompanying seizure of will and feeling of certitude, is demanded, then still more 
time must be allowed for the achievement of so elaborate a conscious process.

Moreover, each act of cognition, so far as its time-rate, its order of the succession in fusion of different psychic factors, and its richness, clearness, and distinctive characteristics of content are concerned, is an individual affair. No two human beings are alike in these particular features of their cognitive faculty. Habits and "types," in multiform combinations of the different kinds of sensation, and of intellective, affective, and voluntary activity, characterize the individuality of every person. They also impart individuality to eacli exereise of the complex faculty of cognition. To know this or that thing, even by the most immediate and rapid of observations, is a different affair for different minds; a different affair also for the same mind at different moments of its experience. The unceasing and infinite variation of that species of mental states which we call cognitions shows that they are all, properly speaking, not mere states or statical conditions of consciousness, but conscious processes or changing modes of the conscious procedures of psychic life. Special experiment and ordinary experience alike prove that, within limits, the introduction of new elements, whether arising through external stimulus or from internal sources, and with or without conscious volition, changes the character of the cognitive issue; this it does by affecting the "stream of consciousness." After it gets started, so to speak, we can disturb, divert, modify the exercise of cognitive faculty so as to alter more or less profoundly the concluding judgment which marks the attainment of knowledge. Cognition regarded as resultant depends upon the influences which determine the cognition regarded as a process; but it is also a matter of sure proof that cognition is itself a process having a certain termination, appropriate or perhaps peculiar to itself.

This truth regarding the psychological nature of every gen- 
uine act of knowledge can be brought clearly before sclfconsciousness in cases where the conscious process is at the same time slowly evolved, yet vivid and picturesque, and is watched and remembered with interest and accuracy of introspection. For example: I am standing at the strect's corner, waiting for a car and looking straight before me, but absorbed in thought about a lecture to be given later in the day in a neighboring city. Suddenly the stream of reflective consciousness is interrupted. All at once I become conscious of an obscurely perceived (but, by no means, clearly apperceived) human figure which seems struggling toward the focus of attention in the field of consciousness, of a feeling which is a mixture of pleasure in recognition and of perplexity as to the propriety of recognition, and of a distinct motor tendency to bow and to raise my hat. This complex mental "state" (which is not itself, however, a status, a stationary experience) almost immediately fuses with another state in which the perception-content has more clearly defined itself - sensation-wise and memory-wise; now the feeling has become a mixture of disappointed expectation and of lingering though fast failing doubt; and the motor consciousness is chiefly that of a strongly inhibited tendency to move the arm upward and to stare at the approaching form with inquiring eyes. And, finally, the psychic process that started off on the way to an act of cognition which would have been recognition of a friend, with its appropriate affective and motor accompaniments or commingled factors, has become a completed cognition of an object clearly differentiated from the object expected, a self-recognition of the just previous mistaken attitude of the mind toward its object, with the appropriate changes in the affective and motor accompaniments. To use the language of erery-day life: At first I saw the approaching person very dimly, but half-unconsciously fancied it was my friend, felt pleased, and was about to raise my hat and extend my hand. Then I 
saw more clearly, though not with perfect distinctness, doubted my just rising judgment, experienced a reversal of fecling and a eheck to the motor activities which I had begun. Finally, I clearly and indubitably saw that the person was not the one I had at first imagined, then judged without further hesitation, "I do not know you," and deliberately suppressed the rising tide of friendly feeling and the actions which were to give it expression. All this, however, occupied not more than a second and a half. The total experience was not three successive and separate states, or statical conditions, of consciousness; it was one living process, terminating in knowledge. Physiologically described, what probably happened was this. The cerebral hemispheres, in which the physical basis of cognitive conseiousness is laid, were preoccupied with those moiceular changes which are the conjectural correlate of the process of thinking rather than of sense-perception. The lower ganglia and centres of the brain responded promptly and effectively - according to the power which in them lies - to the sensory impulses thrown in upon them along the nerve-tracts of vision. Certain ideation and motor responses habitually connected with similar impulses were awakened in these lower centres; and the impulses were started down the motor-tracts. But as these sensory impulses, in the successive fractions of the second and a half rose, spread over, and mastered the higher centres of the brain, the character of the ideation and motor responses became changed. The new form now given to the latter overtook the earlier motor impulses and inhibited them before they could get the muscles well under way. Psychologically described and explained, however, we have here a cognitive process, going on to its completion in that mental attitude which is called judgment, with its consciously recognized content, its feeling of certitude and other affective moods, its support and ontcome in volition as engaged in attention or otherwise, - 
all under the mind's eye. In one word, we have the birth of cognition, self-consciously known as a conscious process.

All cognition, moreover, is objective consciousness, or awareness of an object. As to the ultimate nature and significance for man's intellectual, moral, and religious life, of the object given to consciousness in cognition, it is the business of the appropriate philosophical disciplines to inquire. But at present it is simply the objective nature of cognition as displayed in indisputable psychological facts, upon which emphasis is laid. Unless the process of consciousness becomes objective, unless the stream of consciousness terminates in a "position" taken and regarded by the conscious subject, as corresponding to the nature and behavior of the known object, we have no right to speak of it as knowledge. Mere sensation, mere belief, mere association of ideas, mere thinking, may perhaps be conceived of, if not actually experienced, as merely subjective; but knowledge cannot eren be so conceived of, or thought about. By its rery nature it is always objective. Conrcrsely, whatever state, condition, activity, or process, in consciousness is capable of being considered as merely subjective, such state, condition, activity or process is nerer to be called "knowledge." Sensation, belief, association of ideas, thinking, may all be considered as constituents of cognition; without them all, no cognition were possible. But merely as such, whether single or in combination, without acquiring by the combination something more than their inherent subjective quality, they cannot be identified with cognition. Indeed, it is this peculiar characteristic of objectirity which, as was seen when we were extricating and defining the epistemological problem (Chap. I. passim), starts the critical philosophy of knowledge upon the basis of the full and accurate psychological description of the nature of knowledge.

Of all the profitless fallacies of psychology, old or ner, that is perhaps supreme which explains the act of cognition 
by explaining away its peculiar matter-of-fact characteristics. In combating these fallacies at their initial position, fortunately or unfortunately nothing can be done which is more effective than to insist upon the actual facts of the case. These facts are given, in spite of any contradictory or disputatious doctrine of so-called psychological science, in every plain man's consciousness. "Fortunately or unfortunately," it has just been said. "Unfortunately" so, if those students of psychological science who wish to accept the concrete and content-full actuality of mental life must be compelled to refute by arguments those who would rule out of their account much more than half of this actuality. "Fortunately" so because, when the very nature of science and of its proofs is understood, it is found that the postulated objectivity of knowledge lies at the base of all scientific research and scientific discovery. Indeed, without it, the very word "science" has no meaning in such connection.

There are several current and yet specious ways of speaking, which may or may not amount to a denial of the real objectivity of all cognition. We are often told, for example, that knowledge can only be "of phenomena." By this it is ordinarily intended to carry some such concealed syllogism as the following: Knowledge is merely subjective; its object is necessarily no thing but what appears to consciousness. Its object is subjective, mere appearance to the subject. Therefore it is illusory; and cognition must not be supposed to afford a correct picture or other mental representation of Reality. All knowledge is only "of phenomena." Now some of this and of all similar talk is undoubtedly true, is merely correct statement of incontestable psychological fact. But most of it is just as undoubtedly false from the start, and contradictory of incontestable fact. It is true, as has just been admitted, that knowledge is always essentially of consciousness, a conscious process; therefore subjective. It is also true that the object given to the grasp 
of consciousness, whenerer an act of cognition is completed, is $m y$ object, is the thing as known to me. It may then borrowing a figure of speech derived from certain acts of vision which is helpful, but, like all other figures of specch, needs careful interpretation - be called "a phenomenon," or appearance to me in my consciousness. But it is the rery reverse of the truth to say that knowledge is merely subjective; for until the stream of consciousness, the state or actirity of the knowing subject, has become also objective, cognition has not taken place. The very problem in epistemology, which excites the greatest interest and calls out the supreme critical effort, is just this: How shall we account for the undoubted and indubitable fact that $\mathrm{my}$ subjective experience can be objectively determined, can become knowledge of an object?

"In vain is the snare spread in the sight of any bird." And this proverb ought to prove true, no matter how foolish the bird or how skilful the fowler. For suppose that one is again reminded: "Yes, undoubtedly the phenomenon you know appears to you as an object, in the fullest meaning of that word, even as a really and extra-mentally existent Thing; but so it only appears, so you think it to be, and so it is as phenomenon merely." The answer of escape is ready as soon as the meshes of this net are made risible. It may be made in this way: Thus stated, the conclusion totally perverts and squarely contradicts the facts of experience. For the very nature of every object of my cognition is such that, as object, it refuses to be identificd with my subjective condition; it will not be described as my sensation, or my thought, merely; or as merc appearance to me, as only a phenomenon. So that the problem remains, deeply and inextricably woven into every portion of $\mathrm{my}$ most fundamental experience: How shall I account for the undoubted fact that when I know, the object of my knowledge is not mere phenomenon? Surely, to tell one that cognition is 
only of phenomena is to ask one to accept an explanation which begins by explaining away the very facts which constitute the problem. "Nor is it true" - to quote from Stumpf 1 - "that natural science deals only with phenomena. There is not a single natural law which admits of being expressed as a law of mere phenomena."

Not more happy and profound, though more convincing to a large number, is the declaration that man can know only his own states of consciousness. Here, too, there is truth of fact mixed up with error in fact and falsehood in inference. That all knowledge is a state of some one's consciousness, or rather, a conscious process belonging to the life-history of some mind, is a fact that cannot be doubted. And how absurd it is to ask for some other knowledge that takes its standpoints outside of or above the laws of human consciousness, or for a cognition that is other than human cognition, has surely been affirmed quite often enough. But to say that I can know only "states," and among conceivable "states," only such as I am obliged to refer to my Self as "my own" states is to contradict twice over the plainest and most universal facts of knowledge. Indeed, it would be truer to the actual, concrete experience of mankind to remark that one can never know any mere "states of consciousness," much less one's own states simply. For knowledge is not more truly to be described as "of states" than it is to be described as "of phenomena." Properly speaking, such extreme solipsistic psychology is a meagre and yet false way of identifying cognition with self-consciousness. To be consistent, it must end with the denial of cognition altogether; and it must couch this denial in terms so absurd as really to be unstatable.

It may be granted, as an assumption implied in a constructire theory of psychology, that having states of consciousness does not necessarily imply cognizing them as one's own. In

1 Psychologie und Erkenntnisstheorie, p. 316. 
other words, being conscious and being self-conscious, even if a trace of the latter be involved in every known case of the former, are not identical processes. But it must be, not simply granted as an assumption, but also recognized as a fact, that to speak of a knowledge "of states only" is to misrepresent all our cognitive experience. That which is given to the cognizing subject as its object in every act of cognition, is something more than "states," whether of his own or of another being. Indeed, the very word, whether used as applied to the self or to things as known by the self, is a relative term; and this word no more fitly represents a real object of cognition than do phrases such as "pure" substance (or substance unqualified) or "pure" quality (qualification, that is, which qualifies nothing, and is - so to speak - auf der Luft). What is meant by "states," and by all terms which can be substituted for this term, is the more or less continuous condition of some being, its mode of existence or of behavior regarded as filling an interval of time. If, then, we mean to limit the cognitive faculty of man by identifying the object of cognition with his own states simply, and thus to deny its power to apprehend or comprehend real beings as in those states, we make the mistake of identifying an abstraction with an actuality. This mistake is the more fatal because it happens at the very beginning of an analysis of the gelluine act of knowledge. Phenomenalism and the extremes of individual idealism are forever, professedly, fighting shy of abstractions. They exhibit an anxiety, usually earnest but oftcn cxcessive, to get at the concrete facts and to tcll a plain, unrarnished tale about them. Hence the customary amount of polemic in the treatises on mental life produced by them, and which is directed against hypostasizing the results of the thinking faculty. But what, taken at its literal worth, is this conclusion which they themselves support? It is an hypostasis of the abstract and purely imaginary statical condition of a being, which is made to 
take the place of the living and acting reality. The abstraction ends in a denial of the possibility of knowledge, because the essential and unique characteristic of the act of knowledge, as determined by its objectivity, is removed from the primary fact of experience. This characteristic assures us that the object of cognition never is, and never can be defined as "states only;" it ever is, and ever must be, "existences in states," - real beings that are suffering or acting in certain ways.

Suppose, however, that the primary psychological datum as regards the object of knowledge is somewhat more generously treated, while stated in terms of essentially the same theory. We are now invited to consider the declaration that the only possible object of cognition is the being I call myself, as known to myself in its various successive states. "I can know only my own states of consciousness" now becomes equivalent to this: The only way of ccrtified knowing is, after all, self-consciousness, and the only kind of immediate knowledge is the knowledge of the Self - my Self (a word which may be identified, according to the psychologist's humor toward the prospect of ethical and theological consequences, either with the so-called "empirical Ego" or with a Ding-an-sich Ego which forever ealls forth but deludes and eludes its own cognitive powers). The false positions and mistakes in philosophy which follow upon setting such a limitation to the objectivity of knowledge, will continually appear more clearly as our epistcmological analysis moves forward. It is sufficient at present to notice that the conclusion at which this theory of knowledge arrives, and usually without any sufficient show of examination or argument, is all involved in its starting with a denial of the plainest facts of the conscious cognitive process. That process is, in its very essence, as experienced by every man, objective with reference to, and with implicates of, a not-self, - this, just as certainly and truly as of a self-conscious Self. 
Perception by the senses, when it reaches full-orbed apperceptive cognition, is just as undoubtedly an act involving the reality of its object, as is the clearest, completest consciousness of one's own states. What philosophy has to say of the more ultimate natures, and of the relations in reality, of these two classes of objects, does not concern the present argument. Be the outcome of further reflective thinking some form of dualism or of monism, of realism or of idealism, the nature of the primary act of cognition remains unchanged. And it is this from which all epistemological theory takes its point of starting. It is this to which it returns for the testing of its validity as conformable to the facts of experience. It is this to which fidelity must be maintained at any cost to the smoothness and consistency of the theory. For if this is lost, all is lost. The denial of the full import of the primary acts of cognition is the denial of the possibility of knowledge of any kind; it is the abandonment of all attempt at a critical epistemology.

Much more than a numerical half of our earlier cognitions, and these the more impressive and important for the safety and derelopment of our entire spiritual life, have for their objects the states and relations of things. About these objects the "plain man's" consciousness affirms, and not without a strong show of reason, a more immediate and certain knowledge than about its own states. Psychological investigation demonstrates, indeed, that the affirmation is not altogether well chosen; for no objects can excel, in the immediacy of their presentation and the strength of accompanying conviction, those that are presented in selfconsciousness. However, our scientifically assured position on this point must not lead us to disparage or orerlook the character of the testimony which erery-day experience gires to the immediacy and certainty of the knowledge of things. So far as obvious and recognizable independence and permanency of existence are concerned, things appear to hare 
the advantage over Self. It is perhaps only when we introduce certain ideas of value, and so consider whether the Self should desire to be independent and permanent precisely in the way in which things are, that the former regains its position of superior advantage. On what ground, then, does epistemological theory deny the affirmation of the universal consciousness that, in a large proportion of those cases where the fullest activity of cognitive function is employed and the fullest certitude of cognition achieved, the object of knowledge is decidedly not my state of consciousness, nor any state of any man's consciousness? The nature of the primary act of cognition by sense-perecption refuses to adjust itself to such a denial.

But at this point, in the effort to escape the full force of the testimony derived from every act of cognition to the truth that all cognition is objective consciousness, resort may be had to a deceptive ambiguity in the meaning of the word "object." Kant's critique of knowledge is full of perplexities due to this ambiguity. Because any adequate account of the possibility of objective knowledge requires that the constitutional forms of the knowing subject should be recognized, it does not follow that this recognition furnishes the entire account of all our objective knowledge. For example, I take my stand in receptive or more active apperceptive attitude before some natural object. I am using my senses to get a knowledge of this bit of mineral I have just picked up in the field. Looking, feeling, smelling, tasting, recalling what I have seen and been told before, filling out the picture with imaginings as to how it would behare should I subject it to certain physical and chemical tests, and reflectively thinking over the whole case, I judge it to be "a piece of feldspar." If the grounds of the final judgment, on reviewing them, seem satisfactory, I say: "I know it is a piece of feldspar." I have, in arriving at knowledge of this sort, reached an elaborate objective con- 
sciousness of this thing. Now suppose, however, that in order to explain such objectivity of consciousness, epistemological criticism points out how, in addition to "receptivity of sensibility" and "synthesis of imagination," there must have been "activity of intellect," functioning according to one or more of the constitutional forms of intellectual function (the so-called "categories"). This it is, I am now informed, in the name of a critique of pure reason, which makes the consciousness objective; all external objects are made to be, and to be what they are, by the intellect itself. In a word, to know things, you must mind them; or - as is so signinicantly said in popular speech — "put your nind into them." If I follow the path of criticism myself, I may be ready to admit all this as necessary to account for any "objective" consciousness whatever. But when I am bidden to accept this as the complete and final account of knowledge, when I am exhorted to believe that this is all I am sure of with regard to the existence and nature of the external object of knowledge, and that this it is which makes it an object, sct over against the subject, as a non-self over against the Self, in the very act of cognition, then I answer, "I will not, because I cannot." Nor did Kant himself consistently maintain this position; because, in fact, he could not. But to prove our statement on this point belongs to the criticism of the Kantian Critique rather than to the criticism of the faculty of knowledge.

The characteristic of objectivity, in a meaning more full than either of the three foregoing forms of limitation admit, must be recognized as belonging to the essential nature of all cognition. To deny this characteristic altogether is to commit the absurdity of beginning a criticism of knowing faculty by overlooking the most essential facts which need criticism. It is virtually to assert the theoretical impossibility of knowledge. To define this objectivity in accordance with the phrases, "Knowledge is only of phenomena;" or, 
"We can never know anything but our own states of consciousness," is to be scarcely less absurd; while we must not be deceived into accepting off-hand the sceptical or agnostic attitude toward the persuasion that in knowledge we somehow come into valid relations with extra-mental reality, by an ambiguous use of the words "object" and "objective." Further details on this characteristic of cognition belong, of course, to the main body of epistemology.

Once more, the psychological nature of cognition is such as to involve all the factors and forms of psychic life and of psychic activity. If we are to speak of "cognitive faculty" - as has already been done repeatedly - then this faculty calls forth and summarizes, by absorption into itself, as it were, all other faculties. Whichever of the current psychological divisions into faculties be adopted, there is no one of them whose employment is not, either as actually discernible or as theoretically necessary, contained in the full account of human cognition. Take away any of these faculties and knowledge would become either much less than it actually is or else actually impossible. But none of them, drawn off from and considered apart from the others, is capable of achieving an act of cognition. Without content of sensation there can be no cognition of external objects. But almost equally obvious is the psychological truth that without this same content, no vital and warm consciousness of Self conld arise; certainly, no development of the knowledge which comes through self-conscionsness is possible without the delimitation and opposition of Self and Things as dependent upon changes in the nature of this sensuous content. Without memory, knowledge of the past would be a meaningless phrase; without knowledge of the past, through memory, present knowledge both of Things and of Self wonld be impossible; and growth of knowledge for the individual or the race could not take place. But only as the form of psychic life called imagination is at work, 
can there be constructed in consciousness that series of mental representations which forms a picture for thought to modify, and for faith to attach itself to, as a true picture of the transcendent Reality. Even in all our more solid and scientific knowledge of natural and physical objects, psychological analysis shows the presence of a sort of substitutionary and analogical activity of phantasy. For all such knowledge requires interpretation based upon the sympathetic projection of the Self into the situation of the other. What is called "knowledge of human nature" is confessedly dependent upon this sort of faculty. But with the most exact of the sciences, with mathematics and mathematical physics, the words and symbols employed cannot serve either as the vehicles or as the excitants of cognitive processes, unless this activity can be supplied by the cognitive subject. "Molecular" and "atomic" motions, "stored" and "kinetic" energies, - these and similar terms have no life, no warmth, no real meaning for the mind of man, unless they are filled with the blood which such an interpretative imagination supplies. ${ }^{1}$

Knowledge, howerer, is not a passire happening, a copyingoff of reality upon an impressionable psychic substance, or a solidarity of ideation-processes empirically produced. Neither is it such a merely reproductive activity that the subject in which the activity is induced goes through a series of processes precisely similar to those gone through with by the reality, regarded as stimulating it to the reproductive activity. Thinking, as an active rational form of functioning, must take in hand the trains of associated ideas, in order that genuine cognition may take place. Thinking becomes cognition, or rather leads the conscious processes up to the completed cognitive act, when judgment

I Die Phantasie ist diejenige Function des Denkens, die in ihrer Bedeutung für die Wissenschaft, für die Weltanffassung und für die Daseingestaltung am meisten verkannt wird. - Duenrivg, Cursus der Philosophie, p. 44. 
on recognized grounds is eonsciously made. All the more purely intelleetual "momenta" become fused in that total attitude of mind toward objective reality, which is most properly ealled knowledge, only when such judgment is attained.

But how necessary to every act of eognition are other than the strictly intellectual "momenta," how truly knowledge is an affair of feeling and will and involves all the affective and voluntary mind, must be made elear with some detail, unless our epistemology is willing quite to mistake the nature of knowledge. The feeling aspects of our psychie life are in themselves just as really varied and variously colored, just as constantly present, as are the intellectual momenta. Were it not for this erer present and vital experience of feeling, our sensations, ideas, and thoughts would all be thinner and paler than the trooping shadows of the vaguest dream, - without interest, without value, without reality of any kind. Nor would our trains of ideas result in judgments apprehending and comprehending the changing qualifications and relations of the really existent; truth would not be seized upon and appropriated with warm conviction as to its certitude and its worth.

Peculiar forms of conscious experience there are which we seem compelled to recognize as the feelings belonging uniquely to cognition. Reference has repeatedly been made to the perfectly invincible conviction that in knowledge we, the subjective, come into some sort of relations with an object that is not-us, that is trans-subjective. Experience by way of cognition implicates the transcendent, - of this, at least a naire and vague confidence seems to be an essential part of every completed cognitive process. But what shall be said of this conviction? The completer answer to this inquiry takes us well into the heart of the epistemological problem. It is, indeed, upon this feeling of conviction that in the last analysis our doetrine of knowledge has largely to 
rely for the defence of its theoretical conclusion: the facts of consciousness are not themselves intelligible without the assumption of an extra-mental Reality on which consciousness is dependent.

That the will of the knower is ever present and taking a part, so to speak, in every act of knowledge, is a psychological truism; it follows from the very conception of knowledge itself as a complex form of mental activity. The psychological doctrine of the influence of attention upon perception, upon self-consciousness, and upon all the growing body of knowledge in which science consists, is an expression of this truth. But below this familiar line of thinking reposes the psycho-physical structure of facts which shows us that cognition itself is never a purely sensory, but always also a sensory-motor affair. In that living commerce with things which requires action, and which consists in doing something to them, with a will and a purpose in it, and in letting them do something to us which restricts or thwarts, or executes our will and purpose, does all human knowledge of things grow. This truth also demands further interpretation.

In this connection the practical value of a comprehensire view has a bearing upon theoretical truth. There are real dangers to the life of conduct and of religion which come from saying: "Intellect is all;" or "Feeling is all;" or "Will is all." The theoretical truth on which the practical rests is this: Knowledge is of neither one alone; knowledge is of intellect, feeling, and will. The final witness, to which we are forced to make appeal for the attainment of truth, and for escape from error, is a sort of complex mental attitude. This attitude involves feeling and will as well as intellect. Emphasizing the aspect of feeling, we may call it a kind of conviction of the truth of the cognitive judgment; in matters of contested evidence, or of practical importance, or of grave intellectual interest, the conriction may become 
of a highly emotional character. Emphasizing the aspect of will, we may refer to it as a mental positing of the reality of the object, which may become a seizure of, and a holding on to, this object in the presence of sceptical temptations; and which may then appear as a quasi-cthical activity. It is just these emotional and voluntary aspects of the total cognitive process that have led men in all ages to regard their cognitions as answers to voices which called to them from out of the depths of Reality, or as intuitions and insights which brought them into the most interior construction and processes of Reality (Einleuchtungen and Anschaunngen as well as Vorstellungen and Begriffe). Recognizing and submitting one's judgment to the voice, to the light, thus gives a moral significance to scientific and philosophical investigation in general. Hence the picture drawn by Augustine of God originally speaking with men as with angels (ipsa incommutabili veritate, illustrans mentes eorum). As said Bonaventura, "Thou hast per se the capacity to behold truth, if concupiscences and phantasms do not hinder thee, and like clouds interpose between thee and truth's ray."

A psychological view of the Development of Knowledge reveals still more clearly the nature of the problem which epistemological philosophy has to examine. In the individual and in the race the growth of cognition does not, indeed, result from the introduction of new powers, or from the sudden appearance of distinctly different faculties, in an epoch-making way. The kingdom of knowledge, like the kingdom of heaven, grows as does a grain of mustard seed. Indeed, if we could only use the word comprehensively enough we might be tempted to declare that it resembles a "biological" development. It is not given to the observer, by a microscopic examination of the mustard seed, to predict the character of the developed plant. Nor can one say that all of the latter is given potentially, or even that its con- 
ditions are present, in the seed. Neither, again, can one discern the separate functional growths, and the corrclation of the organic processes, in the very earliest growth. Yet the forces and principles at work, and with which the investigator must reckon, are the same throughout. In no other realm of inquiry is the principle of continuity more strictly applicable, more obviously potent, than in the growth of human knowledge. The detailed descriptive history of this growth it belongs to psychology to give. The interpretation of some of the more important aspects and portions of this history is, indeed, of supreme interest to epistemology; it will constantly excite our effort in the subsequent chapters of this book. At present a few words in addition to what has already been brought to notice will suffice.

Psychology can describe many of the conditions under which that great "diremptive process" takes place, whose accomplishment is crowned by knowledge as a consciousness of relation between subject and object, and as an objective consciousness of both subject and object existing in this relation. It can show how, as the entire sensory-motor mechanism runs more smoothly in the channels which have become marked out, certain groups of resulting experiences form themselves into a Self, envisaged or conceived of, and certain others into Things, either immediately known or only inferred. And now the whole world of experienced objects has organized itself into two great classes of cognized and cognizable realities; but this world of opposed and yet intercommunicating entities had its growth, psychologically, from a common root! Now, too, the world of science begins to reveal itself as under tuition purchased at the expense of the persistent and rationally ordered experience of the race. A strange world this, of which we are told in terms of highly preferred knowledge! Yet this knowledge claims to be based upon observation by the senses, - of somewhat more than ordinary pretensions to accuracy and painstaking 
care. It results from much looking, hearing, feeling, smelling, tasting, and especially from much muscular intercourse with things; and it is called the "world of sense," in which every sensible man implicitly believes, and to doubt which is to discredit "common-sense" and science alike.

But further acquaintance with this body of knowledge, so precious in the eyes of those who cultivate it, and in the sight of us all, reveals its true character in a different way. It is rather a world of ideas and of thoughts. It makes the most enormous demands upon thinking faculty to carry the mind through tortuous and complicated processes of ratiocination, where symbols and words that surely have no real correlates are the necessary scaffolding for every step. It challenges phantasy far more severely and peremptorily than any poet or artist has ever done. Without doubt, imagination breaks quite down in its effort to conceive of forces that are stored and do not act (or energies of position), of atoms that have no color or shape, of ether that is limitless in tenacity and infinitely tenuous and without weight, etc. The whole structure of this world is underlain and interpenetrated with hypothetical entities, causes, transactions, etc., which are introduced in the interest of observed facts, but which can never themselves become actual objects of observation. Yet if we reject it as merely hypothetical and imaginary, or as the product of purely abstract thinking - a system of mental images and conceptions of most extraordinary and non-sensible kind - we confine human knowledge within undesirably narrow limitations. And, indeed, these activities of imagination and thought, with their underlying postulates, and their inciting and supporting play of the feeling that it is so, and of the will to have it so, are essentially the same as those employed in all the knowledge of our daily life. If science cannot correct common-sense by denying to it the exercise of all its dearest and most important rights, common-sense cannot distrust science without 
surrendering the rationality of all that is of practical interest to itself. For cognition, by the very principles of its growth, tends more and more to the solidarity and yet perpetual flux of a system of living organisms. Nor can science and common-sense safely or correctly draw the line that shall shut philosophy out of this growing body of human knowledge. 


\section{CHAPTER V}

\section{THINKING AND KNOWING}

THAT knowledge cannot be gained without more or less of which no one would be found to disputc. But that there is much knowledge which does not come by mere thinking is a maxim scarcely more to be held in doubt. Thinking is, then, universally recognized as an important and even necessary part of knowing; but it is not the whole of knowing. Or, in other words, one must make use of one's faculties of thought as an indispensable means to cognition; but there are other means which must also be employed, since it is not by thought alone that the human mind attains cognition. This manner of speech is indicative of that trustworthy psychological instinct and its resulting body of opinion which characterizes human nature. And thus, in the elaboration of a philosophical theory of knowledge which shall be true to the facts of life, it is matter of the first importance to compare thought and cognition, and to recognize both their points of resemblance and their points of difference. A sound epistemological doctrine must make clear how much and what of the cognitive process consists in that movement of the intellect which we call thinking; and how it is that truth, with its assured grasp upon the existence and relations of the real - the trans-subjective - world, is thus made the possession of the subject, in the form of states of his own consciousness.

If now the popular opinion, as well as that of the majority of writers on logic, be taken in answer to the question, 
What besides clear, patient, and correct thinking is necessary to a knowledge of truth? there is discoverable an almost complete agreement. It is observation - patient, exact, and intelligent - that lays the basis, so to speak, for the structure of truth which thinking rears. And, moreover, since every thinker is liable to have his thoughts wander, or become too much mixed up with imaginings, and since there is danger from too "pure" or "abstract" thoughts, the results of thinking must be constantly compared with renewed and improved observations of fact. It is thus by using observation to start the trains of thinking, which now - once started - carry us into a wider and more airy domain, where, howerer, our conceptions of things must be tested with ever open eyes and freshened memories of our actual visions, that we gain more and more of assured knowledge. Indeed, under the influence of a natural reaction against former magnificent attempts to handle the truths of the real world as problems for thought only, modern science has often no little contempt to throw upon "abstractions" as compared with that cognition of facts which is gained by observation. Some of its derotees are even tempted to forget that mere observation, if such a thing indecd were possible, would no more create science than mere thinking.

The more carefully analytic studies of modern psychology prove that, in fact, thinking and cognition are, so to speak, per se inscparable. They show that without thinking no cognition whaterer is possible. This is a truth of which no one has ever been more firmly persuaded than was Kant; and it is to be hoped that no one will erer attempt to elaborate it more fully than he did. But what is chiefly needed at the present time is to learn from modern psychology, and to expand and teach in an improved epistemology, the fuller doctrine of the relations between the two. In previous works on logic, and even in not a few of the most important philosophical treatises, the distinction between knowledge by ob- 
- servation and knowledge by thinking has been defectively made or gressly engerated. Not infrequently, the former is called "intuitive" or "immediate" knowledge, and the lattcr-"rational" or "mediate" or "abstract" knowledge. And now the logician thinks it right to hold that when he has given an account of the forms which characterize the mental life of thought, he has discharged his entire duty as a student of mental life. For is not logic a formal affair, -a presentation (usually most dry and lifeless), with dreadful array of strange symbols, of the mere forms of thinking faculty as it conceives, judges, and reasons from grounds to consequences? To the psychologist belongs, in sooth! the explication and the rindication of so-called intuitive or immediate knowledge. How, and on what terms of selfconscious estimate of my own cognitive faculty, and in the exercise of what dark and mysterious rights, do I stand before any natural object - a tree, a stone, a human faccand affirm: "I know you, for sure; that you are, that you really are; and what you are in your actual structure and modes of behavior"? This is a complex and most vexing question which logic is glad enough to turn over to psychology. And yet, it is not a question which can be answered, or even have its import faithfully recognized, without taking into account the application of the laws of thought in all so-called immediate cognition of reality.

There is little reason for wonder, then, when psychology - especially of that "new" type which is prone to abjure metaphysics and epistemology as unworthy members of its own family, and to consort rather with biology and physiology as with persons of its nearer kinship - refuses to take this question off the hands of its ancient partner in intellectual concerns, the stately "scientist" (of the high-anddry a priori order) called logic. For does not psychology aim to become the exact science of mental phenomena, of "states of consciousness, as such"? But at this point other 
questions arise. Is not my cognition of that thing over there - that tree, or stone, or human face - a mental phenomenon, a state of my consciousness? And if it is to be described and explained at all by any form of human science, does not the duty of description and explanation fall upon that science which defines itself as having a right to the sphere of mental phenomena in general, of all conscious states? If, further, cognition is to be described and explained by psychology at all, should it not be scientifically handled in its entirety, without mutilation or suppression of anything which rightly belongs to its mental constitution? Further, is it not clear that objectire reference, warmed with the unchanging conviction of the trans-subjective and the extra-mental, is something inseparable from the very psychic being of cognition? How, then, can psychology shirk the task of an analytic that goes to the very core of cognitive consciousness? But in vain is a piteous pleading for response to these questions set up before the bar of the current scientific psychology. Such questions are by her chief doctors of laws nowadays handed over to epistemology. Meantime they are themselves spending their "labor for that which satisfieth not."

At this point, then, we are again thrown back upon Kant and upon his followers in the same line of critical inquiry. We find this master of analytic constantly insisting upon the truth that knowledge is impossible without thought; mere sensation-content, held up in consciousness as a picture by constructive imagination, does not as yet amount to knowledge. For if "thoughts without contents are empty, intuitions without concepts are blind." But Kant, in the working out of his theory of the relations between "empty thoughts" and "blind intuitions," often so sets intuitions and thoughts in contrast as to seem to make them functions and products of direrse powers of the soul. And - a much more serious deficiency which finally becomes a source of 
disastrous error - he derotes his theory of knowledge wholly to its a priori, formal side. Such a restriction of our eritique might, indeed, be allowed in the interests of narrowing the problem, which is, as Kant attempts to isolate and discuss it, sufficiently comprehensive and profound. But the analysis of form, while it may for a time seem to expose and to account for the peculiar nature of thought, does not for one single moment eren seem to do the same thing for cognition. For when, in the evolution of mental life, we come to knowledge, it is the origin, nature, and validating of the matter-of-fact content which interests and concerns us most. How does sensibility originally come to be impressed at all? and how does it come to be impressed as it actually is impressed, beyond the ability of phantasy and will and thought wholly to control the impression? Whence comes, and what is the value of, that belief in an envisaged reality which is essential to the very existence of every act of intuitive knowledge? In answer to these and other similar inquiries, Kant can only repeat his doctrine of the a priori forms of the two distinct kinds of cognition, $z$ intuitions and concepts; cxcept as he everywhere, at times, by sundry hints and nods and dumb but meaningful gesticulations, indicates the presence in the dark background of a mrsteriots $X$, a Ding-an-sich indeed.

The creation of a fixed gulf between kinds of knowledge, and the relegation, for its sources and its validity, of one kind to an unanalyzable mystery, and of the other to a system of merely formal rules, with the accompanying separation of the faculties involved in all cognitive activity, and a total disregard of the necessary implicates of every cognition, have been the $\pi \rho \hat{\omega} \tau o \nu \psi \psi \hat{\varepsilon} \delta$ os and the chief mischiefmaker in epistemological theories since Kant. Fichte's science of knowledge aimed to attain a systematic cognition of the really existent by a series of states of self-enrisagement. The processes of self-consciousness were here thought 
out into the form of a system of concepts, and then identified off-hand with the sum-total of Reality. With Schelling "the true direction" of cognition is not a movement along the line of sclf-consciousness alone. "We can go," says he, "from nature to ourselves, or from ourselres to nature, but the true direction for him to whom knowledge is of more account than all else, is that which nature herself adopts." I Moving in this direction he would give to the place which thought reaches the characteristics of a standpoint for intuition. "For there dwells in us all a secret, wonderful faculty, by virtue of which we can withdraw from the mutations of time into our ianermost disrobed selves, and there bchold the eternal under the form of immutability; such vision is our innermost and peculiar experience, on which alone depends all that we know and believe of a supra-sensible world." Thus from Schelling's faculty of "intellectual intuition" are both intuition and thought really dropped out; and with them the subject and the object ranish together from the field of the really existent as neccssary "moments" in the operation of cognitive faculty. Knowledge is once more explained by being destroyed.

Hegel showed a saner mind in his appreciation of the relations between thinking and knowing, and between knowing and being. His philosophy has been called "a critical transformation and development of Schelling's System of Identity." His aim, as defined by himself, was (1) "to elerate consciousness to the standpoint of absolute knowledge;" and (2) "to derelop systematically the entire contents of this knowledge by the dialectical method." In accomplishing this aim, an orerestimate is placed upon the systematic arrangement of the mere forms of thinking; absolute knowledge becomes so elerated abore the standpoint of the

1 From the close of an article by Schelling himself in the first volume of the "Zeitschrift für speculative Physik." 
ordinary conscionsness that it cannot be attained or even descried by those who maintain this standpoint; and the critical examination of the import and value of the fundamental assumption, that the forms of thought are the forms of reality, is stopped short almost before it is fairly begun. Hence, in part, it is that men devoted to the enlargement of the field of knowledge as covered by the concrete sciences of nature have, often in extreme ignorance of his real position, treated Hegel so contemptuously. Nor is it very strange that such investigators feel more sympathy with the position of the most contemptuous of Hegel's critics in the common field of philosophy, - namely, Schopenhauer. "Perception," says the latter, "is not only the source of all knowledge, but is itself knowledge $\kappa a \tau^{\prime} \dot{\epsilon} \xi_{0} \chi \eta^{\prime} \nu$, is the only unconditionally true, genuine knowledge worthy of the name. For it alone imparts insight properly so-called, it alone is actually assimilated by man, passes into his nature, and can with full reason be called his; while the conceptions merely cling to him." They "thus afford the real content of all our thought, and whenever they are wanting we have not had conceptions but mere words in our heads." Thought, consisting in comparing conceptions, gives us no really new knowledge. "On the other hand, to perceive, to allow the things themselves to speak to us, to apprehend new relations of them, and then to take up and deposit all this in conceptions, in order to possess it with certainty, - that gives new knowledge."

To all such one-sided views of the nature of knowledge, its growth, and the way, through it, that we come at reality, so to speak, it is the completer understanding of the primary facts of knowledge, especially as they evince the similarities and differences between thinking and knowing, which affords the only satisfactory critical standpoint. Cognition is one living process throughout; and valuable as a distinction of its stages and kinds and points of departure may be, there is one essential body of characteristics to be recognized as 
everywhere present. Intuitive knowledge does not come at first, or grow, without thinking; nor is thinking that is not in some sort intuitive, if such a thing were at all possible, the avenue to more of mediate and indirect knowledge. The first act of cognition achieved by the infant mind is a triumph of thinking faculty. The last and highest achievement of knowledge gained by the highly trained and richly stored reflective mind is also a feeling-full and voluntary envisagement of reality. Cognition purified of thought is deprived of a factor essential to cognition. Pure thinking is never so abstracted from successive steps of intuitive commerce with the real as to be purely thinking; and if it could be thus abstracted, it could not become the beginning, the means, or the end of a cognitive process. The very prevalence, however, of this principle of continuity, as applied to all the growth of knowledge in and through thought, makes it the more necessary that we should understand the resemblances and the differences of these two attitudes of Mind toward Reality.

Let us, then, compare that mental morement or form of psychic life which is called "thought" with our previous description of the nature and growth of knowledge. What is it to think? To answer with Mr. Spencer and others as though thinking were mere generalizing under the principle of comparison is to fail of fully describing what men ordinarily experience when they think, and think concretely, and to some definite purpose. With us all, when we make earnest with our thoughts, the stream of consciousness becomes an active conscious relating of otherwise separate items of cognition. It is subjective and conscious, a process; but a process in consciousness which is better described as distinctively not a passive suffering of something, but a doing of something with our own ideas. Thinking is wiHing; jedes Denken ein Wollen, as Wundt admirably says. ${ }^{1}$

1 System der Philosophie, p. 42. 
Thought is experienced as a transaction produced by ourselves. So that, although it is not to be described as willing per se, and can neither be always identified with the higher forms of self-conscious choice nor - which is yet more certain usually relegated to the lower forms of so-called unimotived volition, it appears as a quasi-voluntary response to a demand.- Often one's thinking is a highly developed and singularly pronounced and self-conscious form of willing. When I am thinking, - always about this or that, - and in proportion as I am not dreaming or letting my ideas run away with me, I am "making up my mind." I, the mind, am making up myself, - although in accordance, as further investigation shows me, with internal necessities called "laws of the mind," and more obviously in attempted accordance with the actual relations and-forms of the behavior of things. Thus men tell each other what $I$ think, about this or that; and they ask each other: "What do you think?" - you, as a self-active, self-directing subject of the conscious process called your thoughts.

Yct again, all cognition, which comes by thinking, involves some seeking, striving after, actual pursuing of the truth; and this necessarily implies willing as a "moment" in the thinking process. Noman is likely to know the truth who does not will to know it, who actively restrains, or passively refrains himself from willing. As we think, we purpose to apprehend and comprehend, to seize hold of and grasp around the object about which we are thinking. And although, of course, language here is pregnant with figures of speech, there are few matters of common experience where figures of speech are more pregnant with truth than are those here employed.

Thinking, too, is a more complex form of psychic movement or activity than is mental representation, - meaning by the latter the morely passive flow of unchecked and relatively purposeless trains of associated ideas. It is upon the basis 
of this lower form of mental representation that thinking, properly so-called, reposes. In saying this, we are probably separating in thought what never occurs wholly separate in the actual life of the mind. In few, indeed, of one's states of reverie and of fancy-play, even in dreams, does one seem to one's self wholly to refrain from taking any part in the character and succession of the ideas which appear in consciousness. Rarely is the Ego a mere passire spectator of the drama enacted by the facnlty of ideation. Even when the ideas get away from me, as it were, and disport themsclves as becomes the ideas of an animal or of a madman, I am still right there, ready to prompt or to repress them, and not wholly theirs instead of their being at least partly mine. Thus, too, in accordance with the active characteristic of all thinking do we distinguish it as a more complex process than mere association of ideas, - endowed, as it were, with a higher style of mentality. Ideation appears as a process given to consciousness; thinking is more fully self-conscious and self-induced, selective and preferential. From this point of riew it has eren been argued ${ }^{1}$ that only free wills can truly think, not to say think truly. For the thinking subject must hare the power to grasp and hold the thought-element (the "moment" which may be used to enter into the judgment) against the destructive influence of the flux of images mechanically determined ; must choose a companion for comparison or contrast with it, and so judge what is true in reality as distinguished from what is passirely determined in the mental train.

In connection with such experiences as illustrate the distinctions already made, we become aware of the peculiar strain and tone of attention which accompanies the thinking process. When one is not thinking somewhat intently, or not definitively and determinately thinking at all, one is

1 Compare Kaulich, "Ueber die Möglichkeit, das Ziel, und die Grenzen des Wissens," pp. $29 \mathrm{f}$. 
like a spectator of a light drama, or it may be of a comedy. One attends with interest, indeed, but with the interest rather of those who will have others do the work or conduct the play, while they amuse themselves by looking on. But let any of the actors (the ideas) challenge and secure another kind of interest; and then the whole strain and tone of attention changes, as one begins to think more reflectively and to conclude about what is going on. For thinking is somewhat of business, is no mere play, for the mind; and business demands attention, directed to the accomplishment of a clearly conceived end. Hence the teleology of thinking as it enters into the final purposes of cognition, and brings the man of thought and the man of action into the unity of one life. With this change in the character of the attention, demanded and given, there goes a change in the feelings, both such as have reference to self and such as have reference to things. For the total affective accompaniment of thinking as a necessary process to the completed act of cognition is of a peculiar, complex kind. I am more selfconscious in thinking, more keenly alive and sensitive to every subjective change as a possible clue to the knowledge I scek, or as a possible temptation or solicitation into some path of error. I care more about myself when I, as subject, make me, as object, the terminal of my train of thought. But if $I$, as subject, make some thing or relation between things, the object of my thinking, the same characteristic wakefulness and feeling-full attention belongs to the conscious processes evoked.

Let all this be considered, as illustrated in men's daily experiences, - remembering that the thinking of which we are discoursing is not that pale and ghostly process of linking together so-called concepts by highly abstract symbols which is scholastically held to represent the formal laws of thought. The rather must the philosophical theory of knowledge primarily deal with the blood-red and sinewy thought of the 
street, the mart, the ordinary waking life of the multitude of men. Actual thinking, as distinguished from the linking of symbols and concepts together in books on logic, seldom for a moment relaxes its firm clutch upon reality, and its invincible conviction that the self-conscious thinker is adjusting his own mental attitudes, with a prompt sequence in adjustment of the appropriate actions, to the real properties and actual relations of selves and of things. But this is the kind of thinking that enters into every primary act of knowledge, of every cognition which, for certitude and socalled immediacy or "intuitive" characteristics, belongs to the first rank.

The most special characterization of thinking as a factor of all cognition is reached, however, only when it is affirmed that all thinking is relating activity. From one standpoint, from which it is always proper to regard consciousness, thought is a recognition of relations determined by the action of objects as they appear to the thinking mind. This is the so-called common-sense, realistic way of stating the facts. What is the metaphysical truth in such expressions? It is a fact of experience which may not be questioned, that one "feels at liberty" to imagine various sorts of relations, between things and their qualities, between things and minds, and between things and things, as one wills and without regard to the actuality of these relations. But if one intends to think, - meaning by this something more than mere play of imagination, - one is under compulsion to follow, either in actual observation or in intent, the courses marked out by reality. In recognition of this passive and objectively determined aspect of the relating function in thought, the pious enthusiast may exclaim: "I think thy thoughts after Thee, O God!" when he has adjusted his own mental representations to the relations of the external world. So also the "scientist" holds himself obligated to think natural objects as they actually are related to each 
other in Nature herself. And the plain man considers his fellow to have lost the most trustworthy possession of his common-sense, if he habitually mistakes imagination for thought as to the qualities and the transactions of things. But the other and opposite point of view must not be lost out of sight. For if to think is active consciousness, and its peculiar characteristic is a sort of "getting-at" relations, then it is right to declare that thinking is relating activity. And, indeed, this goes to the very heart of the question. We cannot, indeed, accept the often repeated dictum of Lotze — "To be is to be related" - as a satisfactory metaphysical prineiple. But that no thing is known, or can be known, as out of relation, or without being in relation, is an undoubted epistemological fact. For the declaration that "to know is to relate" is a valid, if only a partial, description of knowledge. But that activity of the mind which performs the act of relating is precisely what is meant by thinking, in respect of its most fundamental and universal charaeteristic.

The details implied in affirming that all thinking is relating activity, must be referred back to descriptive psychology to tell. From it we learn that relating is not merely comparison, not merely assimilation, or diflerentiation. It serves our purpose - which, it must not be forgotten, is to show how thinking enters into all cognition without being the whole of any complete cognitive act - simply to notice that thinking, as relating aetivity or the conscious and pur-. poseful bringing of our ideas into relations which are believed to be conformable to the actual relations of the extra-mentally existent world, culminates in judgment. Thinking involves diserimination; indeed, the primary phase of the so-called faculty of thought may best be spoken of as "discriminating consciousness." 1 So, too, in its higher forms of manifestation thinking is analyzing activity;

1 See Psychology, Descriptive and Explanatory, chap. xiv. 
and without such analyzing activity, true judgment (at least, in the form in which judgment enters into a finished act of apperceptive consciousness) cannot be formed. For every true judgment implies a consciously recognized duality albeit as existent, combined in the unity of the judgment itself. But it is judgment as synthetic, essentially so, in which all thinking processes culminate, and which becomes an essential factor in every primary act of cognition.

Only, then, as we understand the actual, conerete judgments of men, what they consciously are and what they signify, can we understand the relations of thinking and knowing; and thus, so far forth, frame a theory of knowledge consistent with the facts of experience. Now the actual concrete act of judging is itself a process in consciousness. Strictly speaking, it is not so much a mental seizure and permanent holding of some island in the flowing stream of conscious life as it is a determinate direction in the flow of the stream itself. When, therefore, judgment is spoken of as a "synthesis," it is well not to be deceived by the figure of speecl. In no judgment, not even in affirming the simplest identity of a mathematical or logical sort $(X=Y$; or, All $A$ is $B)$, does the mind stand still while it places the ideas, one upon top of the other, or contemplates them lying side by side. In affirming $X=X, \mathrm{I}$ distinguish the $X$ which is in the place of the subject from the $X$ which is in the place of the predicate; and, then, I posit a certain relation by mentally constituting a synthesis of the two. This I must do, if I recognize the relation existing between the terms of the judgment; that is, if I make a true judgment as the terminal, so to speak, of an act of real cognition. "But here two things of common experience must be borne in mind. I may have some sort of a mental presentment of terms which might possibly be formed into a judgment, or even of these terms as somehow set objectively in the relations appropriate to a possible judgment, without either actually recognizing them as terms of 
a judgment or synthesizing them as an actual judgment of my own. I may see $X=X$, and makc use of this percept as a kind of momentary stepping-stone in an argument, without judging $X$ really to $b e=\mathrm{X}$. It is not in mathematies alone that men conduct complicated trains of ideation, with more or less control by active thinking, and yet only occasionally perform the mental act of judgment, in the more proper meaning of that term. Moreover, in considering the relation of thinking to knowing, it is always esscntial to inquire carefully what it is that is really judged. Is it that $X$ is equal to $X$; or only that $I$ am proceeding along the right path toward the solution of my problem? The life of our daily activities is full of problems for consciousness to solve; but more and more does the practical solution of many of these problems take place ás the result of past acquirements and growths of cognition, with relatively little actual judgment exercised at the precise moment of steh solution. Yet all this psychic life is illuminated by spots of mental awakening to the higher and more complicated activities of a selfconscious and apperceptive sort; and then we find ourselves really judging. Such genuinc judgment is always itself a movement of consciousness toward an end which is a mental synthesis of distinguishably separate terms.

But, second, after saying thus much we must not be considered as adrocates of that atomistic view of psychologists who find insoluble puzzles where none exist, and who even go to the length of declaring impossible what is plain matterof-fact in every man's daily experience. It is not a fair representation of consciousness, or even an adequate suggestion for an outline picture of it, to compare its successive states to a line in which the single sensations, or ideas, are points. The so-called "stream of consciousness" may, not inaptly, be compared to a river that at times widens and at other times greatly narrows its bed; perhaps it sometimes also disappears underground, only to reappear on the other 
side of some considerable extent of the territory measured by objective time. But its unity is never, at any instant, comparable to that of a point; nor is the succession of its states in the one life like the succession of points, or small portions, of a physical line. The fact simply is that, in judging, we are in a kind of conscious active process which terminates in the positing of a unifying relation between two consciousty separable terms.

There is something very significant in the temporal characteristics of judgment as an inseparable factor of cognition; and this is the slowing-up - almost amounting to a pause - in the time-rate of consciousness, when the business of judging takes place. Nor is this characteristic a mere effect in the imagination of the subject. Psycho-physics shows beyond all contradiction, what every unsophisticated observer of men knew beforehand, that it takes time to judge. Unjudged impressions flit rapidly, or troop in confused swarms before the mind. "There they go," - we are accustomed to say; as thougl they were not of our mind and we could not, therefore, detain them. But we "come to" judgment more slowly; we bring the sensations and ideas to some common point of view, and we take a little time to pronounce a synthesis between them. All this is, in some sort, capable of measurement and of expression in so many one-thousandths of a second. How many more $\sigma$ you will need to judge than merely to be the more passive recipient of impressions, can be told you in any psychological laboratory. More than this; we are actually aware of taking a bit of a pause, of insisting on a suspension of judgment, although it seems already to have formed itself, that we may make sure of correct judgment. This time it is our resolve: we will not press the key until we have actually judged that the removal of the screen showed us red instead of green; we will not guess, or jump at the conchusion, but will judge accurately the real state of the case. It is just this judging actirity 
which is the essential thinking part of the cognitive process; the completion of the judgment marks the gaining of knowlcdge as a fact in consciousness. Note how characteristic and peculiar is the feeling of relief and of satisfaction - the pleased release from tension and the joy of recognition, as the judgment is formed! " $\mathrm{I}$ have judged correctly" (according to fact), and "I know" are two different expressions for one and the same attitude of mind.

In the larger doctrine of judgment, as a psyehical affair, the truth is illustrated on a larger seale. The man of deliberate judgment is, other things being equal, the man whose cognitions are sure, because reposing on grounds consciously recognized and estimated. And this is as true of those judgments which enter into so-called immediate cognitions as of those which constitute a body of scientific truth. Knowledge is born of thinking which has arrived at the pausing place of a judgment, - a finished product of synthetic activity. In saying this, however, we must not neglect the value of "insight," or underestimate the part which the quick seizure, the divination under divine guidanee, of the truth has to play in the winning and the increasing of knowledge. For cognition comes through Kennen as well as through Wissen; indeed, no hard and fixed line can be drawn between the two. The poet, the artist, the inventor, on the one hand, and on the other hand the plodder to his conclusions along the thorny path of conflicting facts, upon the wooden clogs of logic, both think and also intuit what appears to them as true. But cognition par excellence, so far as its thinking aspect is concerned, marks its own terminal as a judgment arrived at, in view of grounds which may seem either quite envisaged on aceount of the quickness of our flight from them to the terminal itself, or only dimly remembered because they lie far back upon the path which thought has travelled to this terminal. In any ease, however, the distinctive feature of cognitive consciousness is this: we know only 
when we alight upon the firm ground of a completed judgment.

It is only in books on logic and psychology that judgment consists in a combining of sensations and ideas with other ideas or concepts, - all considered as mere mental products, or psychical states. In real life judgment is the positing of relations between the doings of actual things. This is true at least of all such judgment as brings knowledge with it or, in any way, conduces to knowledge. In other words, when we judge we not merely effect a subjective combination that is different from any combination possible for the ungoverned and flighty ideas, but we appear to ourselves to affirm the truth about a transaction in reality. There are several ways of approaching this claim as to the real nature and significance of the judgments which men actually make. For example, the claim may be approached from the logician's point of view. But this would lead us to emphasize the distinction of "form" and "content," and so, perhaps, would induce the fictitious doctrine, in the interests of the importance and integrity of our particular science, that content has nothing to do with the true nature of judgment. It is the morphology of judgment, the doctrine of the form of all judging, - say most of its students, - which logic inrestigates. But here we must assert, with Schuppe, ${ }^{1}$ that the distinction of form and content, as one of opposition or contrast, or as other than implying a reciprocal inrolrement, cannot possibly be maintained. To borrow an illustration from Schopenhauer, the defect of neglecting the content shows the truth of the Indian proverb:" "No lotus without a stem."

The doctrine of a form of judgment that takes no account of the universal predicate of the content of judgment is a toy logic. It is much more a "logic of illusion" than is that procedure of reason which Kant characterized by this opprobrious term. For this is just what judgment intrinsically $i s,-a$

1 Erkenntnisstheoretische Logik, p. 19. 
positing of the existence of a concrete reality in relation to other realities. In the utterance of the mere form of a judgment we feel that we are not really judging; or, in so far as we are really judging, we are judging something which differs from the mere form. We may be judging indeed that this form is the correct form of judgment; but even this is a judgment, only as it posits the existence of a concrete reality in relation to other realities: "So all men judge" is then our judgment; or, perhaps, "This form of a judgment appears to me correct" (to accord with my own remembered experience and with that which I judge other men to have had). Much more obviously true is it that the distinction between form and content fails to satisfy the demands of epistemological criticism when those so-called secondary judgments, whose nature consists in relating concepts, are had in mind. For, whatever the actual psychological process answering to the term " a concept" may be understood to be, single concepts are never judgments; not eren single concepts of relation. Nor do mere combinations of concepts form judgments; it is the added conriction of positing the truth of what is thought, which converts the conceptual flow of consciousness into a genuine act of judging. When the consciousness of objective validity is wanting, then judgment is wanting; or if judgment seem to be there (as it is usually, if not universally, because no man satisfies himself long by toying with his logical faculty), then it is judgment affirming some other real relation than that which is clearly expressed by the related conceptions.

The fuller description of the knowledge that comes by sense-perception and by self-consciousness, and that is called immediate in distinction from the knowledge which is inferred by virtue of its recognized connection with remoter grounds, must be waited for in order to defend further this view of judgment, as the form of thinking in which cognition is established. "I perceive the snow to be white;" such a sentence throws the burden of the judgment upon the testimony of 
self-consciousness. But when I give this form to the assertion of my act of accomplished cognition, I affir'm a relation which is judged to exist between me and the extra-mentally existent thing. Thus far the judgment is certainly true, a mental positing of an actual relation. I do perceive the object-thing as my judgment asserts that $I$ do. "The snow is white;" such a sentence throws the burden of the judgment, so to speak, upon the extra-mentally existent thing itself. It brings to my consciousness, and to the consciousness of all who hear and understand me, that the whiteness of the snow is a fact to be recognized by every one wlo can and will put limself in like conditions for judgment. In every judgment of perecption, as an integral part of the cognitire act itself, there is discoverable the binding conviction that the object of perception exists and is actually so constituted as we imagine and think it to be. Judgment, in general, is not genuine JUDGMENT, as distinguished from mere sequence of mental states, without a trans-subjective reference, an implication of the actual connection of different " momenta" in a really existent world.

In saying this, however, we have already arrived at the conclusion that judgment involves, as a necessary condition of its own making, something more than mere judgment, if by the words "mere judgment" we limit our meaning to a form of thought. As a form of thought, there is also implied in judgment willing and feeling, - at least in the form of "feeling-sure;" and besides, a postulated correspondence of the trans-subjective with that kind of active, feeling-full thought which all cognition involres. But this amounts to saying that in all actual judging the subject is doing something more than judging, and is suffering in other forms than those of the impression made by the "ideation-stuff" of the judgment itself. Thus much is true in fact; and it is truth which no theory of knowledge can afford to neglect. Postponing for later chapters the further culture of this truth, 
we may most fitly gather a handful of fruitage from the path which has just been traversed.

It is not (as Hegel seems to teach) the doctrine of the concept, but the doctrine of the judgment in which we find: (1) negatively, the denial of the possibility of absolute scepticism, of dogmatic agnosticism, and of solipsistic idealism; and (2) positively, the foundations for a valid epistemology and metaphysics.

On the first point our analysis of the judgment has shown what all subsequent epistemological criticism will confirm, that a consistent and thorough agnosticism or sceptical idealism is impossible as a theory of knowledge. It is impossible as theory, because it is contradictory of the very nature of that primary act of cognition from the criticism of which all attempt at an epistemological theory has its rise, and in the interpretation of which all the conclusions of any particular theory must repose. Cognition involves thinking in the form of judgment; but judgment cannot be considered as a merely formal and subjective activity, because, as a matter of fact, it is not such an activity. It is the positing of reality, as diverse and yet necessarily capable of unification, - in a wáy full of feeling, and full of will, as well as full of thought. That is, he who judges, passes judgment upon the truth; and in doing this affirms both himself and his object to be something more and far other than mere thought-process and mere object of thought.

Furthermore, the reality posited in every act of true judgment is posited as a related reality, - not only that it is, but what it is, so far as here and now judged, in the completed act of cognition. Here appears in the background the shadow of a postulate that may come to be recognized as bearing a noble and truly divine form. For the universal assumption of every judgment of immediate cognition is this: What is subjectively united in my act of judging belongs together in the unity of the really existent world. I unite these elements, which to 
sense seem scattered and diverse, by judging them to belong together; but I so unite them as to reveal my conviction that they are trans-subjectively combined, cxtra-mentally united in the unity of the Real. If this is not what my judgment means to me and to others, it falls short of fixing for me, or of expressing to them, my arrival at one of the firm points of standing called a cognition.

How meagre, however, would the body of human knowledge appear, if it were reduced to the dimensions covered only by so-called "immediate" or "intuitive" acts of cognition! It is, pre-eminently, by thinking that men arrive at conceptual or inferential knowledge. And the form of stating such knowledge may be said to be the "logical judgment." Logical judgment is a synthesis effected between concepts; therefore the kind of knowledge which it cmbodics and conserves may be called "conceptual." It is built up by thinking one's way - at least, so this mental constructive work is deseribed by the current books on logic - through concepts, that serve as "middle-terms," to other concepts; it is a thoughtprocess in which the consciousness of the truth of the final judgment, that marks the new point of cognition gained, is preceded by consciousness of the grounds, or reasons, from which this truth is inferred. Therefore, the kind of knowledge which this judgment embodies and conserves may be called "inferential." Great and even bitter controversy has been held between the partisans of the superior claims of immediate or intuitive and of conceptual or inferential knowledge, - the one accusing the other of narrowness, lack of science, and excessive derotion to fact, and the other retorting with accusations of excessive airiness, abstraction, and disregard for matter of fact. Separate faculties hare eren been derised for the attainment of these two kinds of knowledge; and the controversy has overrun the boundaries of psychology and raged within the fields of epistemology and metaphysies. Kant, Hegel, and Schopenhauer have agreed 
in arraying Verstand against Vernunft, while differing much in their conception of the legitimate use of these terms.

What now are the facts in the case which a critical epistemology must decide? What, as interpreted by a psychology which is true to actual mental life, is the nature and the growth of cognition as dependent upon acquired facility in thinking? In brief, the principle of continuity reigns throughout; and there is no break between the two kinds of knowledge, as there is no generic or specific difference in the employment of thinking faculty in gaining the two kinds. Judgment without both human understanding and human reason (whatever may be the distinctions set up between the two) is not human judgment. Understanding, that is not rational, is not human understanding. And reason, that is devoid of understanding or totally separated from its intelligent base, is a barren fiction; if it exists anywhere, it is not the reason of man. Science, as a form of cognition, rests upon no different foundations from those upon which ordinary knowledge rests; and it involves no different forms of mental activity from those which every man employs in his work-a-day life. Moreover, the whole mental life and activity is essentially the same, when we know the tree, the stone, the human face, over there opposite to us, as when we, by processes of subtle dialectic, or by the leap of faith, arrive at the atomic theory, or the cognition (or postulate) of the Personal Absolute called God.

Further, negatively, it must be asserted that no entities, not even of the psychical sort, no mental products, no states of consciousness, corresponding to the customary description of the "concept," or the "syllogism," are anywhere to be found. 1

Positive testimony of consciousness is not wanting, however, to the important modifications in that mental attitude

1 As to the true psychological nature of the concept, see "Psychology, Descriptive and Explanatory," chapters xiv., xix., xx. 
toward reality which the activity of thinking assumes in order to make possible a growth of knowledge. The "leap" to the judgment which expresses the finality of the thinking process, the journey to the terminal of cognition, may vary greatly in its degree of speed. The number of conscious "momenta" that can be remembered, or recognized as fusing in the judgment, so to speak, may also vary. Immediate judgment is judgment with little or no clear consciousness of the grounds; but judgment, as the recognized result of a reasoning process, is judgment with more or less of clear consciousness of its own grounds. It is the former kind of judgment which is prominent in both sense-perception and self-consciousness; it is the latter which the construction of scientific knowledge demands. The sensation-content involved in the thinking process, and upon the basis of which thinking proceeds, varies greatly in quantity. It also differs qualitatively; so that sometimes judgment is absorbed in the determination of the size or quality of a thing, sometimes in the nature and meaning of an affection of Self. Especially does the form taken by the postulate of, the feeling of belief in, and the more or less voluntary seizure upon, reality differ with the different kinds of judgment involved in the cognitive act. Sometimes the real object appears as an undoubted envisagement; sometimes as an inference so doubtful that we hesitate to call the resulting judgment a cognition rather than a mere opinion or belief. These forms of variation in the thinking process, and in its result, occasion marked differences between our necessitated belief in the reality of the known object of sense or of self-consciousness, and our quest after certified truth as to the general relations and laws of minds and of things. In the former case we feel that the reality is a fact, - given to us, not as the form of our thoughts, but with the irresistible conviction that the reality is there and that we are in commerce with it. In the latter case, we feel that the form of our thoughts is 
a true picture of the forms, in reality, of minds or of tliings.

In all conceptual knowledge, as in so called immediate knowledge, it is the judgment which eonstitutes the final form of the thinking that enters into the cognition. Indeed, psychologically considered, conception is itself a modification of the content and suecession of our conseious states in which judgments are the only possible representatives of reality. The very process of eonception eonsists in having a number of highly schematized ideas, that are judged to be related in certain definite rather than other ways. The moment, however, we eome to inquire after the truth of this process of so-called eonception, we find that the inquiry ends in a demand for the truth of our own relating acts, - that is, of the judgments themselves. But to inquire into the "truth" of judgments, it must be assumed that they are capable of being patterned, so to speak, after the actual relations of things. Here again; then, we see that it is the true doctrine of judgment which must be relied upon for the validating of human thought about things. Every so-called concept implies both mental representations as its content, and also judging activity as giving form to its content. The determinate flow of the successive judgments toward that one judgment which posits the truth which the mind is seeking, and the consciousness of this flow as being determined in its connections by the facts of experience, are the necessary elements of every act of reasoning. Here, again, the result can be called knowledge only upon the supposition that the judgments which enter into the process of reasoning have something far other than mere correctness of form.

What follows, then, in order to vindicate the claim made by all the more highly abstract and conceptual forms of thought, to be a means or vehicle of cognition? These forms certainly make this elaim, sinee they present themselves as a series of judgments leading up to a final judgment in which, 
as in a court of highest jurisdiction, truth appears enthroned. And if the claim does not carry its own vindication, or somehow admit of being vindicated from without, all science is convicted of giving the lie to its very name. For it is in its concepts, and in its judgments relating these concepts, that the truth of science consists. But here, again, the very nature of judgment, as it enters into all acts both of conception and of reasoning, becomes the invincible fortress against the extremes of agnosticism and of sceptical idealism.

Consider, however, in brief, what seems postulated as to the nature of the cognitive process, and as to its claims to truth, in the very doctrine of the concept. This doctrine shows that the mental process of conception is indeed a change, but a change subject to laws. The character of this process is changeable; were it not so, growth of knowledge would be impossible. But it has also the permanent in it; and were this not so, truth would be impossible of attainment in the form of conceptual knowledge. What further is implicate as to the really existent, thus known in the form of the conceptual judgment? It, too, this object itself, the Reality known, must actually change; but not all at once, so to speak, or at random, and in a wild unregulated way. It, too, must change in time, and according to fixed and immanent ideas. The fixedness of the object, as given to conceptual knowledge, in contrast with the changing activity of the conceiving and knowing subject, is itself only a more definite measure both of change and of permanence: shall we say - of the permanence of the Idea as immanent in the changing states of the object? But I, too, the subject, cannot change in an unlimited way, either as respects the time or the direction of change. If, however, my series of judgments is to be thought of as true (and if they are not to be thus thought of, then conceptual knowledge is impossible for mc), the changes in me must, in some sort and to some degree, follow the laws of the changes in the object. To 
know any Thing, I must conceive of it as it really is, as maintaining a certain fidelity to its own nature, while constantly clianging its particular manifestations toward me, toward other minds, and toward other things. Let us try to represent this by a formula: And let $S$ stand for me, the subject; but $O$ stand for the object which I conceive of as always acting according to its nature when truly conceived. Then, in some sort, it must be possible that $S^{1}, S^{2}, S^{3}, S^{\mathrm{n}},=O^{\alpha}, O^{\beta}, O^{\gamma}$, $O^{\nu}$. That is, I can representatively judge what $O$ is, considered as passing through a series of states ranging from 1 toward $\infty$. But as to the meaning of the sign of equality (the $=$ which stands between the series $S$ and the series $O$ ), we have as yet only a clue.

Now, undoubtedly, there is no little metaphysics as well as epistemology concealed in the foregoing paragraph; and one is not compelled to take all of either until both have been further criticised and discussed. Meantime the postulate may perhaps as well be left in a form given to it by Lotze: "The real world does not fall asunder, atomistisch, into merely singular constituents, each of which is incomparable with the others; but between its contents, similarities, kinship, and relations exist." The "petrifaction," and then the objectifying and converting into realities, of concepts, has much to answer for in the history of philosophy. It was one of Hegel's merits of intention that he aimed to do away with this. But, alas! for the relapse of some of his disciples, who seem to have petrified and then hypostasized the very conception of "process" itself. On the ground of psychology, a certain merit - though largely of a negative order - is due to writers like Bacon, Hobbes, Locke, Berkeley, and Hume. But if the view they controverted seemed to contradict the descriptive history of mental phenomena, the view they advocated left all the foundations of science either in the clouds of emotion or in the underground of blind and unverifiable instinct. The doctrine of judgment carries with 
it, in the concrete facts of experience and in the implicates which an analysis of experience reveals, the correctives for both of these erroneous extremes.

Further illustration and confirmation of similar postulates follows from a consideration of the way in which men reason and argue about what shall be accepted and esteemed as "truth." Thought is, indeed, subject to its own laws, to the principles which define logical necessity. Actuality is what it is, as fact; and that is the last word about it. Yes, but most of what $I$ know, and of what the race knows, has come by those processes of thinking which are properly described as reasoning from accepted grounds to new conclusions that, when the grounds are valid and the form of reasoning correct, assume the claims of knowledge. So that here, again, it is not the mere necessity of a logical determination, but the comprehension of actuality by human cognitive faculty, which is the law and the goal of liuman science. It is this assumption of an actual relation, common to thought and to things, through some middle third, which gives us the right to speak of real specific resemblances, real specific differences, real universal relations called laws, etc. What, indeed, is the ultimate ground on which is assumed the applicability of any process of syllogistic reasoning to real things? And how shall epistemological theory account for the larger fact of race experience, that the attempt to apply syllogistic reasoning to real things is successful in enlarging the knowledge of the race? Only on this ground and in this way : a real conformity to law exists and is cognizable according to the principle of sufficient reason.

But so-called syllogistic acts of reasoning are, in reality, successions of judgments in which the mind climbs from stepping-stone to stepping-stone along the path of cognition, clad with the full armor of feeling and of will, and of all that belongs to the mind's life, as it takes each step. Nerer does the mind appear to itself so lightly weighted and so 
thin a ghost as to seem merely to be doing a bit of logical thinking. In fact, in the succession and character of its judgments, as it pursues the truth, it rarely follows the form of the syllogism at all. For reasoning, too, is not capable of being understood merely content-wise. The rather does judgment, only when already affirmed as familiar and expressive of truth, suggest and stimulate other judgment which may perchance, but not necessarily, contain unfamiliar and even new truth.

Suppose, for example, I judge, on the basis of successive observations, that Uranus is not behaving as she should in view of what I know of her relations to her companion planets. I judge next that there may be, or there must be, another companion planet of which no knowledge has been had as yet. I then look to the place where this new planet should be in order to give grounds for the irregular behavior of Uranus; and now Neptune is "intuitively" known to be there. Or suppose I am told of a man who did not die; and I exclaim: "No, for men universally die." Indeed, it belongs to the very nature of man to die. But evidence is offered that such a case of an immortal man did in fact occur; and reasons are presented why I may alter my former judgment without disturbing too fundamentally the entire structure of my experience. And now I may hesitate to repeat my judgment; or I may form a new judgment admitting cases of exception to the "universal" law; or I may adhere to my judgment in its earlier form. Such is the flux in the narrow field of the individual man's cognition; such, too, is the flux in the larger field of the scientific acquirements of the race. If the assumption of an objective connection is merely feigned and subjective, as the sceptic would have us suppose, then knowledge by processes of reasoning is impossible. But if the objective connection is itself a universally fixed substrate, a kind of unehanging being of things, as certain dogmatists would present it to imagination, then the 
life we think we cognize is gone out of the real world. An actual happening, indeed, but a happening under the regulating principle of ideas would seem to be the only postulate as to the nature of Reality which will validate the attainment of knowledge by processes of reasoning.

Further with reference to the problems raised by the analysis of this chapter, there is no need to inquire at the present time. Already it is at least apparent what some of these problems are; and certain of them are obviously metaphysical in character. Among the more definitely epistemological questions involved are such as follow: What are, more precisely, those laws of thought - of judgment, coneeption, and reasoning - whose objective validity is implied in all that knowledge which comes by thought? On what more ultimate grounds than any thus far uncovered must our confidence in the validity of these laws be placed? What may be discovered regarding the relations in which we, as cognizing subjects, stand to the Reality made valid for us in our processes of cognition? How may we test truth, and discover error, and so think as to have our judgments ratify their elaim to real knowledge? How shall the total faculty of human cognition be defended against the attacks which would destroy, or most severely shake, its very foundations? And, finally, what view of the World-All seems best to comport with the essential dignity and worth of human eognition?

But these are profound and difficult questions; and perhaps some of them are unanswerable. At all events, they must be approached through a truer and more comprehensive conception of the psychological nature and growth of knowledge. 


\section{CHAPTER VI}

\section{KNOWLEDGE AS FEELING AND WILLING}

THE psychology of feeling is still in a most unsatisfactory profound or diffieult to discover; although when discovered and reflected upon, they turn out to be such as to encourage only a partial hope of their amelioration or ultimate removal. These reasons are partly historical; but, chiefly, they spring out of the very nature of the subject of all psychological inquiry. Until comparatively recent times the entire movement of the science of mental life and all the interests of its students were direeted toward a better understanding of so-called sensations, ideas, and thoughts or other logical processes. To think $=$ to be a soul, was an indisputable formula of the Cartesian psychology. And when this rational psychology was most vigorously contested, the formula substituted ran somewhat as follows: To be a tabula rasa for sensations, and a play-room for the disporting of revived and associated images of sensations $=$ all there is of soul. We have already seen, too, how the eritical theory of knowledge, in the hands of its great modern author, confined itself to the formal laws of thinking faculty.

This relative disregard of the psychology of feeling and volition, as they enter so abundantly into that conduct which has been called three fourths, or even seren eighths of life, accounts in part for the meagreness of recognition given by epistemological doctrine to these aspects of mind. But, of late, psychology has been eultirated in a more biological and interesting way. Psychological analysis, with the in- 
definitely greater subtlety and more varied and searching appliances that characterize its modern types, shows what an exceedingly complex affair human mental life really is. Into all this life enter an indescribably great number of "moments" or influential factors. Investigation is rapidly adrancing in the recognition, at least, of these complex factors; and thus, as a purely descriptive science, psychology has recently made large and commendable advances. Something has also been done toward explaining anew the primary truths of mental life, - this, by way of discovering the laws of the interaction of the factors, or, more frequently, of giring to psychological facts, already well known, the appearance of a scientific character by stating them in terms of exact formulas prored by psycho-physical measurements. But there are certain fields of the psychic life which are naturally difficult of penetration, or even of entrance with the surreying instruments - the theodolite, the chain, the stakes, and the poles - of the modern psychologist. Here effectirely work the obscure hereditary instincts, the blind umreasoning beliefs that ereep about the very roots of the earliest cognitions. Here occur vague assumptions of values, impulsive and often spasmodic and inexplicable leaps, orer the barriers of fact and of calmly reasoned conclusions, through atmosphere charged with the electricity of emotion, into the very heart of Reality itself. Here is done the artistic building, under the influence of æsthetical and ethical feelings, whose products cannot safely, and indeed cannot at all, be kept out of our most ordinary experiences; for they, too, belong to the general structure of human knowledge.

It is not to be wondered at, then, that introspective and experimental psychology finds the greatest difficulty in coming to an agreement concerning the nature and laws of that part of our mental life whose very nature seems to free it from all obedience to discoverable law. For there is no greater "psychologist's fallacy" than to identify thoughts 
about the feelings with the actuality of the feelings themselves. But the inevitable difficulties of the subject are not, just now, the principal obstacle in the way of its gradual conquest by scientific observers. There is an opinion concerning the nature of all feeling, which is held, perhaps, by the majority of writers on psychology, although intelligently and vigorously combated by a few of the first rank, but which is so incredible that its naked statement might well seem equivalent to its disproof. This opinion identifies all human feeling with the pleasure-pain series, and all variations of feeling, as such, with quantitative changes in this series. Some advocates of this opinion class all the feelings with the sensations; since all pleasure-pain (which = all feeling) belongs to the sensational content of consciousness. And thus from high to low, as estimated even qualitatively and by a standard of æsthetical or ethical values, the account of the rich and varied affective phenomena of man's life becomes like a sum in algebra that has only one indeterminate quantity. The psychology of feeling is then only a question of how large is the value in any case of this $x$; and whether it is a case of $+x$ or of $-x$. Sancta simplicitas! but not of the feeling soul of man; the rather of the analytic mind of such psychologists.

The confutation of so inadequate a view of human feeling, by facing it with the facts of consciousness when investigated in thoroughly analytic fashion, belongs to descriptive psychology. ${ }^{1}$ In the two just previous chapters it has been shown how the psychology of knowledge in general, and, in a more particular way, of judgment as the constitutive thinking element of knowledge, recognizes the function of feeling. But in order to lay a sound and comprehensive basis for the most important epistemological conclusions, it is necessary that the part which feeling plays in all cognition should be further investigated.

1 See Psychology, Descriptive and Explanatory, chapters ix., x., xxiii., xxiv. 
It is often assumed, even by those who do not accept the identification of the entire life of feeling with the changing quanta of the pleasure-pain series, that cognition is especially devoid of feeling, if not actually antagonistic to feeling. But an act of cognition is the fullest expression of the fact of mental life. When I know, then I am - full of life, full-orbed in my being, "all in it," as it were, and as at no other time. But if the "I," that am now come to the fullest realization of my Self in the act of cognition, am essentially a being of feeling, as well as a thinking and willing subject of states, then how can this act of cognition itself be constituted otherwise than as a feeling-full affair? And how can a large variety and profound depth of feeling be separable from any act of cognition, not to say the contrary, or contradictory of any such act?

It is, indeed, a fact of universal experience, and a truth of general recognition in psychology, that a certain kind and amount of emotional excitement is unfarorable to knowledge. Intense anger is blind; and so are all the other forms of feeling when raised to the emotional stage of intensity. The psychology of the emotions shows that their indispensable characteristic is a strong feeling of the bodily and mental disturbances already brought about in the organism and in the train of associated ideas or the succession of combined thoughts. But excessire disturbance of the ideas and thoughts prevents our arriving at a state of assured cognition. How, then, can much feeling, of whatever kind, he otherwise than unfarorable to knowledge? This question has been answered by the proposal of a law of consciousness which would make feeling and knowledge vary inversely.

There is, however, another side to the influence of the affective factors upon our states of cognition; or, rather, there are sereral different sides to be considered in interpreting correctly our experience of feeling. First, all conscious states fall under the general principle of limi- 
tation or finiteness; and more multifoldness of content, or quantity of psychic energy, than a given limit cannot be attained in any psychosis whatever. There is, therefore, a certain truth in the figure of speech which represents the Ego as being unable to have more than so much life in any one field of consciousness; and if this limit is nearly reached, by way of absorption in some appetite or passion, there is, of course, little left of psychic energy with which to do any thinking. And thinking, culminating in judgment, has been shown to be necessary to cognition. Our experience, however, might seem to warrant us in saying, not so much that rage, or grief, or jealousy, or even any highly emotional form of ethical and religious and æsthetical feeling, makes knowledge impossible, as that the more or less voluntary refusal to think makes these forms of emotion possible. Rage, etc., makes a man blind intellectually; but, conversely, the intellectually blind man falls into a rage, etc. Nor is this conclusion the result of mere juggling with terms. The man of narrow mind has less room in his mind for any combination of the three aspects, or fundamental forms, of all mental life; he can live less completely and largely at any moment of time.

An animal indulgence of the intense emotions must also be recognized, in the case of which the intellectual elements sink to the corresponding grade of an animal consciousness. The emotional frenzy of the human animal is a state of consciousness not greatly unlike that of the enraged bull or tiger, the jealous dog, the panic-stricken deer. Then the man runs amuck at the objects of his hate, or runs pell-mell away from the objects of his dread. The division of the army "loses its head" and flees amain; the political or" ecclesiastical party, or the majority of the community "go it blind," as men say.

Here, lowever, we may interpose the somewhat startling but by no means impertinent question: Is God, then, to be 
conceived of as a clear-cut, cold "logic-engine," without any emotions of anger, sympathy, or sorrow, by which to link him, heart to heart, with the blundering, sorrowing, and striving children of men? And are they made in his image only in so far as they can "think his thoughts after him" without any chance to win the ability to pattern their emotions, too, after those belonging to the divine life? Without attempting at present to suggest an answer to this inquiry, we return to examine more closely our affectire experiences as men. And here we recognize the indispensable cognitive value of certain strong emotions. Some truths - it is matter of common observation - can be reached most easily and readily (if, indeed, they can be reached at all otherwise) through the medium of feeling. To love, to late, to long for, and to gricve for, - these are exercises of the soul without experience of which certain sides of reality, and certain profound truths touching the nature of reality, can never be apprehended at all. In the experience of a "grand passion" the mind not infrequently wins its way, in bricf instants of time, to a judgment which it would take long to reach if one had to plod along the paths of inductive or demonstrative reasoning. For that is also true to which Browning celebrates the way in his exhortation:-

"So you ignore,

So you make perfect the present, - condense, In a rapture of rage, for perfection's endowment, Thought and feeling and soul and sense."

The intimate "connection" of feeling with knowledge is, indeed, a matter of fact which no student of the human mind would think of denying. But a matter-of-fact connection between the two so-called faculties of emotion and of intellect is a superficial affair in comparison with the truth which we are desirous of enforcing. This truth is, the rather, that no cognition at all is possible without the 
presence of affective and emotional factors in the very act of cognition, or without the influence of such factors over the nature of the cognitive process itself. To know is to fecl as well as to think; and feeling is as truly an indispensable "moment" in, or aspect of, knowledge as are those factors which our analysis assigns to intellectual faculty. Nor can the slightest conception be formed of what knowledge would seem like, or actually be, if it were not rich also in content of feeling. The illustration of this psychological tenet, which will subsequently be found of fundamental importance for epistemology, needs now to be preceded by reminding ourselres of two truths respecting the nature of all feeling. First, then, and strictly speaking, the actual nature of the various affective phenomena of human consciousness, quoad affective, cannot be construed or conveyed in the form of conceptions. The nature of feeling is in being felt. To know what any particular form of feeling is, there is no other way than the self-conscious envisagement of that form of feeling in one's own psychic life. To know what any feeling is in another consciousness can bo accomplished only when in some way - perhaps, indeed, by the language of feeling, which is of the analogical type - one's own consciousness is definitively determined into a corresponding form of feeling.

But, second, the same discriminating consciousness which is neccssary to every sclf-conscious state, since without thinking we cannot know our own states, must separate and identify, and thus recognize, the affective factors, or the emotional aspect, of the cognitive processes. Thus we become able, in some sort, to describe and faithfully discourse about that in our experience which cannot be put, strictly speaking, into conceptual terms. Thus much of truth there is in Schopenhauer's loose way of interpreting consciousness when he exhorts us about as follows: "Would'st know what feelings of thine are, and what those 
of other men are like? Then look within thyself, and, whatever thou findest wholly incapable of being made an object of conceptual knowledge, call that feeling; regard it carefully, and when thou seest thy fellows giring the signs thou wilt learn by experience to recognize, then believe that they, too, are feeling similarly."

Human feelings, so far as they both constitute and modify the cognitive processes, may be somewhat roughly but conveniently divided into three classes, according to the character of the relations which they sustain, as feelings, to those processes. These three classes we will call the impulsive, the regulative, and the integrating - leaving the moaning of the last term to be explained later on. These are, perhans, not so much different elasses of feeling as different uses of the feelings in the complete cognitive function.

Without that varied impulse from feeling, - which does not come simply as an external push that ceases before the morement of the cognitive process begins, but also continues within the process as its living spring, - this cognitive process itself cannot be understood. In all cognition, it is feeling that starts and keeps in motion the process of thinking. Here is where the function of the instinctive impulses, the natural desires, and the various forms of the sense of need, make themselves felt as an ever present spur to the beginning and to the growth of knowledge. It is as a hungry and thirsty and therefore venturesome little animal that the babe starts to find out how things taste and smell and feel; what, in brief, they are good for, to serve the interests of his own feeling-full and strong appetites and sensations. The fundamental uses of the senses, and the important practical qualities of things as answering to these uses, are learned only in this way. Nor let it be thought that this impulse to the growing process of the primitive cognitions, as it arises in the various forms of restless 
desire and painful need, is something to be reckoned with in a way extraneous to the growth of the cognitions themselves. The rather is it true that the first deseription of any "Thing," that which the thing is to the child, can be told only as a history of the rise and fall, the swelling and contracting, of confused complexes of feelings of craving and of their progressive satisfaction, together with more objective sensations which are getting bound together into a percept, or mental image. Take the feelings out of this complex process, -- actually abstract them, after the fashion in which the psychologist theoretically abstracts them, and the whole experience becomes a pale, thin affair out of which no cognition of a Self as related to a world of separate Things could erer be evolved.

Nor are the feelings which belong to the soul of the infant, and have reference chiefly to other selves, rather than to things, less influential in arousing and giving vital impulse and coloring to the whole life of cognition. The earliest "proofs" of the existence of other sentient beings are laid chiefly in the impulses of altruistic feeling, and in the power these impulses have over the mind to start and to regulate the act of cognition. Moreorer, the first recognized content of any other self than myself is far less a conception than it is a mixture of warm and interesting feelings, produced largely under the psychological principles of imitation and suggestion, and connected in experience with certain projected sensations. For even the adult, the persistence and obtrusive presence in his own consciousness of these developed altruistic emotions is the impregnable fortress within him to which, under the assaults of sceptical idealism, retreats his belief in the extra-mental existence of his fellowmen. And if the retroactive shudder before a logical solipsism is strongest when one thinks of the consequences of denying to onc's self a knowledge of the reality of the members of one's own family or friendly circle, one 
is only carrying out in adult fashion the influenees of those infantile and instinctive feelings which first revealed the existence of the same beings to the ehild. ${ }^{1}$

Who that knows anything of the psychology of childhood can doubt that the impulse to attain a knowledge of other persons is chiefly given in the cravings for sympathy and in the instinctive exercise of sympathy? Both things and persons are first known as objects of interested curiosity, which may become instruments of pleasurable or painful feeling to the child; but persons are first known as that sort of things which ean feel with the child, and can induce it to feel with them. The need of an object for our feelings of sympathy is as truly a human necd, is as surely determined to create something for its own satisfaction, as is the need of an object which shall explain any other form of our experience. Penetration of the spear's point into the oaken board or between the joints of the armor in its search for the victim's heart, would no more take place without a strong thrust behind the shaft, than would "penetration" of the existence and nature in reality of our fellow-men without the push of this passionate interest in them. Modern psychology is working vigorously with the principles of suggestion and imitation to help on an understanding of the origins and earliest development of our life of ideation, thought, and knowledge. And in spite of needed cautions against overworking these principles, it is aecomplishing many valuable results through the explanations they afford. But without the impulsive and regulating presenee of the altruistic feelings which always accompany these principles in the real life of the mind, neither the origins nor the development of intellectual life can be explained.

Moreover, special forms of those feelings which "connect" us with our fellows are indispensable to the explanation of

1 See the criticism of M. Flournoy's position in the author's "Philosophy of Mind," pp. 28 f. 
the special forms of cognition which arise with reference to them. For example, the knowledge of men as actually linked together into a socicty, with common interests and inter-communicating destinies, requires the fecling of dependence. Here may be noted the use of this feeling which has been made by some writers on the philosophy of religion as leading to the faith in, and the vision of, God. The babe against its mother's breast is acquiring an unforgettable lesson, chiefly communicatcd through feeling, in its actual dependence on other existence than its own, for well-being and for being at all. How, indeed, should he erer be led to know that other being is, if he were left in the feeling of his own self-sufficiency? Of course, to question this truth becomes absurd as soon as we understand the history of the origin and development of the conception of Self. For this history is impossible of actual accomplishment, as it is impossible of description, without taking both self-feclings and feelings referent to other sclves constantly into the account. Especially does that knowledge on which depends the entile life of the race, its propagation and continuance in history, and the whole structure of the family and the State, require for its achicrement and explanation the impulsive and regulative action of special forms of fecling. . Indeed, in some of these relations, the emotional factors so largely predominate over those of ideation and judgment that the language of feeling rather than of intellect best expresses them. Nor is it without a profound philosophical import that the specialized form of intercourse between the sexes is, in the Hebrew and other languages, described in terms of cognition.

But it is even more important to notice that in the consciousness of the child almost exclusively, and in the consciousness of the adult very largely, other beings than Self are known only representatively, by an act of imagination which projects into them our experiences of feeling with 
ourselves. What is "the other" - which is not its self but is another self - to the consciousness of the child? Could language accurately define the actual experience of the child when it knows the animal, or the mate, with which it plays, the parent or the nurse that tends and controls it, how would such definition run? Surely not in terms of pure thinking chiefly. Almost as surely not, for the most part, in terms of ideation. It is rather a certain determinate flow of his own emotional consciousness which defines another sentient being to the consciousness of the child. For it the very being of the object - as fact, and marked off qualitatirely from other beings - is largely a compound of its own centrifugally determined feelings. The dog is understood to be a something which differs from that other thing, a stone, not merely in color, shape, size, and mobility, but also and chiefly in this: it feels as the boy fecls, - hungry, thirsty, hurt, mad, spiteful, or pleased, glad, friendly. Indeed, a description of the process of cognition can no more be made complete while neglecting the course of suggested, imitative, and sympathetic feelings than while overlooking the succession of ideas and judgments with which these feelings are fused. Any child is much more capable of understanding its parent as a being that, in all the simpler forms of feeling with which it has itself had experience, feels as it knows itself to feel, than as a being that reasons and judges in terms familiar to itself. And in how much of all this are all men only children! Were it not so, indeed, human beings could not know each other with any approach to completeness, or with any prospect of realizing some good practical purpose.

In this connection should be noticed the essential effect upon the process of cognition which is produced by the pleasurable or painful tone inseparable from most of our feclings. The reality of the world, both of things and of selves, and the actuality of the erents happening in this 
world, are "ground" into us through the changes in our pleasure-pain series which these things and selves produce. When the dog makes itself known to the teasing boy as a something that feels hurt and mad, it sends home to the boy's brain and heart one sure item of knowledge with forceful "tooth and claw." Thus the boy learns his truth about the animal, and ceases from further critical and sceptical experimentation in the same direction. In the future, doubts do not arise, - that the dog really is, and that the boy knows what the dog is. Scverely idealistic philosophers have always jeered at the common-sensc but antiquated doctor who refuted idealism with blows from his staff. And, indeed, there is no logical "argument" in blows. Perhaps such idealism can never be refuted if it chooses to satisfy itself with what are called "mere" arguments. But all arguments go back to the actual facts of our manifold experience; however they may fly abroad in regions of thin air for many a splendid hour, if they wish to get general acceptance they must alight again upon the grounds of experience, and face the facts of daily life. Now the universal fact of daily experience is that mere argument does not result in the cognition which affirms the trans-subjective reality of its object. But the world of things is actually known as hurting us most awfully and much of the time; and for the rest of the time, as giving to us more or less of pleasure. Now I do not like that pain; I hate it; and I will not have it in my consciousness. By a prompt, instinctive, and defensive movement, into which little of thought or of reasoning enters, my motor organism reacts against it; then I get hurt again and even more badly. What now must this experience mean to me as evincing the nature of the object of cognition? The answer which springs from the most hidden and deepest roots of consciousness, as a forthputting of a judgment that is born in the affective rather than the intellective nature, affirms: $M y$ object is not merely my 
idea. That which I so hate, and will not, that which is so often opposing and thwarting my will, and making all $\mathrm{my}$ sensibilities quiver with anguish, is not at one with me. It is my other, and not my self. It is not my nature to have it so; it is the nature of things and of other selves that it is so.

Further confirmation and illustration of the necessary part which this class of feelings take in all human eognition will be offered when we come to consider the terms on which selves and things get differentiated in the development of the intellectual life.

There is no need to dwell in this connection upon the well-known influence which comes to the development of knowledge in the individual and in the race from the intellectual fecling of curiosity. This feeling is, indeed, to be recognized as belonging to human nature in general, and as affording the motif for the ordinary, as well as for the most splendid aequisitions of knowledge. Under its infuence the child searches into the nature and uses of things, and so builds up the experience which is necessary to its own safety and to its very life. Of its intensity in certain cases Augustine bore witness when he declared, "My soul is on fire to know." Plato made a certain divine Eros the only avenue to philosophic cognition; and the Prussian queen affirmed her desire to die because then she should surely know the things as to the truth of which even Leibnitz could not tell her.

There is, however, another important group of feelings concerned in all our cognitive processes, whose function is mainly regulative of these processes themselves. This regulative office is performed by certain logical feelings as well as by the ethical and the rsthetical. In matters of art the fact is almost universally recognized that feeling takes the lead of judgment. The pronouncement primarily made in an affection with a peculiar feeling-tone is the basis for the 
judgment affirming a completed act of cognition. Nor will it avail to object that we are here dealing with matters of mere opinion rather than of genuine cognition. The Kennen of the artist, as well as the Wissen of the man of science, is a form of knowledge; and the truth of the world of real beings and actual relations comes through the conscious attitudes toward it of the former, perhaps quite as much as of the latter. Although, also, there is a broad shadowy region in all æsthetical matters, where opinion or belief rather than knowledge is all that can be claimed, some æsthetical judgments, at least, are affirmative of sure positions taken by the process of cognition. For example, I am listening to a learner on the violin who, in an adjoining room, is running orer scales, sometimes correctly but sometimes striking a tone which I immediately judge incorrect. By what means do I judge this tone to be out of place; or rather, what is the meaning of the judgment, "It is incorrect," as expressive of actual facts of consciousness? Is it not chiefly this, that the feelings of expectation with which I awaited the next tone in the succession have been disappointed by the actual feclings which have taken possession of my consciousness? The feeling, as such, is disagreeable, and this quality belongs to my subjective state of an affective kind; the feeling is not agreeable, it is painful. But $I$ judge the sensation of musical sound to be wrongly placed in the series, - as much out of place as though the child, in learning to count, had offered the series $1,2,3,7$ as an example of correct counting. Besides the disagreeableness of the feeling subjectively considered, there is in my consciousness - what is not the same thing, but has a necessary objective reference - a feeling of dissonance, of the disagreement of this sound with the one which should oceur at its place in the series. The feeling is not the product of the judgment; but the judgment is the expression of the feeling. 
Now in all such cases as the foregoing it may be argued that the judgment itself has no objective reference or objective value. Its total import should, therefore, be stated as follows: "I am disagreeably affected by this tone at this place in the series; and, therefore, I conclude that the series is not a good, correct - that is, a pleasant-series." But such an account of this characteristic consciousness does not recognize all the actual facts in the case. For I am as sure that I am proclaiming a truth to which other properly constituted natures will immediately and unfailingly give assent, when I make this quasi-æsthetical judgment, as when I assert that the violin is being played in the next room. Indeed, I am much surer of the objective validity of my judgment in affirming the discord than of my judgment in localizing the origin of the sound. Let it be reaffirmed that, after all, the judgment must be taken as purely relative to my consciousness, merely relative, and I may at once unhesitatingly deny that this is so. The judgment cannot be so taken, because that is not what the judgment means. It means to affirm an act of cognition, good for myself and for others also. It is not, indeed, good for those who are wholly or partially tone-deaf; it is not eren good, as yet, for the child who is unconsciously making the incorrect tone so disagreeable to me. But the reply is ready: the same thing is true of all our judgments of things as obtained by senseperception. The child would not notice different shades of color easily discernible by the trained adult; it would not be offended by disharmonies of tone-colors quite objectionable to the artist's eye. The simple fact is that this judgment, like every other judgment which undertakes to affirm objective truth, postulates a common nature to which a final appeal may be made. And æsthetical judgment may thus be even more thoroughly objective than one affirming the sensuous agreeableness or disagreeableness of things. One man may not like olives, and another may like them; but 
what of that? It is mere matter of happen-so of taste; and they should not quarrel over it. If, however, you judge that incorrect tone to be correct, I judge you to be wanting in something that belongs to every rightly formed and welldeveloped consciousness. You are for the present quite shut out from one kind of truth; and this is because you cannot feel the difference between the true and the false in respect of this particular standard of judgment.

Now it belongs to the branch of philosophy called æsthetics to investigate the origin and character, and to defend the validity of judgments respecting the beautiful in nature and in art. But whatever views one espouses in this branch of philosophy, they do not affect the truth of the epistemological principle for which we are now contending. This truth is the immediate dependence of the judgment affirming an act of cognition upon the feeling, for its rule. As has already been said, the cognitive judgment is affirmative of objective validity for that which has just been experienced in the succession of feelings. The judgment says not, "I know that I feel;" or, "I feel that you ought to feel with me." The judgment says, "I know that it is so." But if we ask for the cause rather than the grounds of the judgment, we find them to be: I felt it to be so. The feeling was not separated from the act of cognition; it constituted the important and regulating part of the cognition. The "stuff" of the judgment was a certain succession of qualitatively determined and obscurely localized sensations of sound; its spirit and life, its affirmative or negative character as agreeing or disagreeing with a certain ideal standard, consisted in a definite quality and direction of the affective consciousness.

So simple an example has been dwelt upon with what may seem too insistent minuteness, because it may be considered as typical of the primary human æsthetical consciousness in general. And to say "æsthetical consciousness" 
is to cover a much larger and more important part of the actual life of the mind than is ordinarily supposed. How the higher æsthetical and ethical feelings enter into and regulate all our cognitive processes will be made the subject of inquiry in a separate chapter. But there is much of the daily intercourse of men, with its system of practical cognitions and its recognition of what are called "the proprieties" of life, that is really, though half-consciously, regulated by quasi-æsthetical feelings. Indeed, these feelings so blend with, or pass over into the ethical and the logical that it becomes quite impossible to consider the two classes of affective factors apart. The doctrine of "tact" is a neglected but much needed portion of psychology. It is chiefly by what is called tact, as all are agreed, that certain persons know what things are and how to handle them, - all by a lcap, and without any obvious exercise of the faculty of thought and reasoning, as it were. He who can find the explanation of the boy Mozart, playing the grand organ on the first time of his encounter with it, by any theory as to a previous inheritance or development of the merely intellectual faculties, must be easily satisficd with his psychological analyses. To employ such words as "genius" for the human artist, and "instinct" for the animal artist - for the beetle, or the spider, or the bee - is only to cover up ignorance instead of expressing knowledge. Nor can the astute observer sympathize with Hartmann, who, in his theory of the Unconscious, brings together innumerable facts of different orders as though the mere mention of a great number of cases proved his view of the real explanation of any case. But in our own case, as men, we know by sclf-consciousness that many of our most assured and valuable cognitions respecting the nature of things and of other selves are given chiefly in terms of feeling. Not always, indeed, but far too frequently to make it safe for us to despise this means of cognition, the felt truth turns 
out, as tested by subsequent experience, to be the truth indeed.

In smaller degree, and in somewhat but not in essentially different manner, does ethical feeling enter into all human judgments on matters of the morally right and the morally wrong in conduct. Reasons for the important differences between xsthetical and ethical judgments are historical rather than due to the inherent nature of the faculty of cognition; and they are chiefly the two following. In the evolution of morals the more generally accepted principles of judgment have been embodied in the forms of written and unwritten law, of hereditary customs, institutions, and, indeed, of the total environment of the individual man. Matters of æsthetical judgment are much more fluid than are matters of ethical judgment. The total constitution of society forms rules, or dictates, to which cognition must conform to a greater extent in conduct than in art. But this difference is connected with another; and out of the latter difference the former largely has its origin and sources of growth. The consequenees of wrong judgment, or of imperfect knowledge, in respect of our moral action are much more manifest and impressive than in respect of what is merely æsthetically correct or incorrect. Hence it is much easier to bring one's knowledge of the ethically right or wrong into conscious connection with recognized grounds upon which it may be left to repose, to argue about it, and to teach reasons for it to others, than to deal in similar fashion with one's knowledge of the beautiful or the ugly. A high degree of Kennen in conduct is "wisdom;" but in art it is "genius" or "talent." A great deficiency of knowledge in matters of conduct seems monstrous and inhuman; but a correspondingly great deficiency of knowledge in rsthetical matter's makes the rude man or the boor.

These differences, howcver, do not affect the general principle that judgments in matters of conduct rest more 
upon a basis of feeling than upon a basis of thinking; and this in such a way that the judgments themselves affirm the mere fact of feeling rather than the intellectual ground of the feeling. In the conduct of the multitude, of young children, and in much of the conduct of all classes of persons, the whole character and content of the stream of consciousness may as well be expressed by saying, "I feel I ought" (or ought not) as by saying: "I know that it is right" (or wrong). A study of the moral nature and development of man, of the human mental life as fitted for conduct, shows that it is only the feelings of "oughtness" and of "approbation" which are the unique and primal ethical factors. On the basis of these feelings, which spring from the very depths of the soul, as they are called out and connected by the environment with certain modes of motor activity, the current system of ethical judgments is framed. The placing of these judgments by the individual on recognized grounds, whether they are laid in the anticipated conscquences of the conduct, or in some conception of a law or of an ideal personality, is a secondary and later affair. And not infrequently the original forms of feeling linger strong in the community, or die hard only after antagonistic secondary judgments have for some time been formally accepted as the "rational" code. Then occurs that conflict, so interesting to psychology and epistemology, which is due to the fact that moral feeling judges the same thing wrong which reasoning on grounds judges to be right; or vice versa. One man's "bad conscience" may then appear in the form of perverse feeling, and another's in the form of insufficient reasoning. Then, not only do the "men of feeling" and the "men of cool judgment" accuse each other of bad character and bad conduct; but even in the same man's breast, feeling and reason fight it out to get possession of the judgment, which, in this case, howerer, never seems quite to reach a satisfactory determination. For men need to feel satisfied, 
as well as to reason satisfactorily, in order most assuredly to affirm $I$ know - the truth or falsehood of a moral judgment. This curious conflict between feeling and intellect to get control of judgment will be observed in other connections. It is frequent and forceful in cognitions of the ethical class.

Objections may be urged, however, against the use of the word "knowledge" as applicable to matters æsthetical and ethical. Properly and quite strictly speaking, ought one not to say that these are matters of opinion rather than of knowledge? To this inquiry the full and satisfactory answer requires an examination of the grounds of certitude, of the means of knowing truth from error, and of the propriety of speaking of degrees in cognition. Postponing the discussion of these subjects, we turn our attention to another class of feelings against which the same objection cannot be raised. Reference now is made to the so-called "logical" feelings. Thorough psychological analysis shows that there is not a single process of thought which does not hare its affective as well as its intellective aspect. Without the former no thought-process would bring us to the truth. I think, and, finally, I know: examined in one aspect, this simply means that a certain series of ideas and judgments, more or less supported (it is probable) by a frame-work of language, determines itself in my stream of consciousness. While the series is passing, or on reviewing it by repeating it more carefully, I discern other relations of consistency or inconsistency between the ideas and judgments; and at the end of the series, I pass judgment in such final form as to say, "I know." Examined in another aspect, this same experience means that I am doing something, am voluntarily and definitively directing the stream of my own consciousness toward a desired end. But examined in yet another aspect, the same series of conscious states means that I am feeling myself as being modified by the relations toward one another 
of my own ideas and judgments. I am myself affected by that which I actively effect in respect of the connection, and the character of the flow into each other, of my train of conscious states. The feeling of the intellectual processes, whether in sense-perception or in self-consciousness, or in the remoter reasonings about things and selves, is a constant accompaniment of all these processes. It is not merely an accompaniment; it is also a regulative factor in the same processes. It is not a simple, dumb companion in the journey from start to finish; but from start to finish, this "feeling of" the thought-movement is also a guide to the movement of thought.

Consider any of the fundamental exereises of thinking faculty, - for example, such activity of discriminating consciousness as is necessary for the accurate perception of anything. Here thinking, as terminating in cognition, is suffused with, and directed by, affective factors that accompany it all the way through. The feeling of pleased familiarity, which is the affective factor in all recognition, is a part of the intellectual process of assimilation; the feeling of perplexity, in which the mind hangs while "making up" itself, over the particular object's likeness or unlikeness to some class of objects previously cognized, is a part of the intellectual process of criticism; the feeling of shoek and slight repugnance, in all appreciation of the unlike or of the contrary, is the emotional element in the intellectual process of differentiation. In all these and similar cases of intellectual activity the feelings are important and influential guides to the final judgment. Such figurative assertions as follow are, then, true to the facts of conseiousness: The feeling of recognition shows the mind what it shall judge to be similar or the same; the feeling of uncertainty compels the mind to the suspension of judgment; the feeling of difference induces the mind to distinguish and to refuse to judge, under a common term. In the first case feeling is 
satisfied only if we judge, "It is this;" in the sccond case, only if we judge, "I do not know what it is;" but in the third case, only if we judge, "It is not that." It is under the potent influence of these affective regulce that the formation and growth of a system of cognitions takes place. Things are bound together by ties of common feeling, or held apart by feelings of repugnance. But about some things we should not feel right, whether we put them into the class $A$ or into the class non- $A$. In such cases it is vain to assure the wise man that, according to invincible logical principle, everything must belong with either $A$ or non- $A$. He knows of the logical principle; but what he does not know is, to which of these two elasses this particular $X$ belongs. The grounds of his refusal to judge he can also state, at least with a partial satisfaction. But what is the meaning of the other side of every declaration of doubt? Is it not this, that one feels one's self to be "not satisfied" with one's grounds of judgment? If one could only "feel sure" of them, then, etc. What, finally, are satisfaction per se and non-satisfaction per se, but forms of affective consciousness? To suppose that man's intellectual activity could free itself from the feelings which belong to the processes of mental assimilation, differentiation, and criticism, and yet retain its logical effectiveness is almost as foolish as to suppose that the bones and sinews of the bird could fly if there were no stirring or guiding of motive interior to the mechanism.

This doctrine of a regulative influence for the affective elements of cognition applies to sense-perception, to selfconsciousness, and also to extended processes of reasoning. Our perception of anything by sight, by touch, and by any or by all of the senses, is never an affair merely of being passively impressed with the image of an external object; nor is it an activity of mere thinking and of the projection of our thoughts into a thought-produced space. That when 
I see the tree over yonder, the $E g o$ is not merely taking the place of the sensitive plate in a kind of nervous camera, no longer needs statement for the student of scientific psychology. But neither can my perception of the existence or character of the object be described and cxplained on the theory of its being a mere object of my thought. How the reality of my object for me (that it is) depends on a feeling in me, may well be made a separate task for analysis and critical discussion. Here Schopenhauer's sharp criticism of Kant for dismissing the whole affair with the sentence, "Objects are given to us through our sensibility," is not without justification. But, furthermore, precisely what the object of perception is, can never be considered as a question either for mere sensation or for pure thinking to decide. The resultant of the actire discrimination, however promptly rendered, depends also on the regulative function of the logical feelings.

In this connection we note again how the feeling-full and active character of the cognitive processes makes them to be truly cognitive, by preventing them from being regarded as purely subjective processes, whether of sensation, ideation, or thought, and by enforcing and making vital, as it were, their trans-subjective implications. To speak of the object of perception, Kantian fashion, as a "thought-object" is to hypostasize one abstract aspect of consciousness. Purely thinking consciousness is itself an abstraction; there is no such subjective reality anywhere to be found. And to speak of the existence or being of any actual concrete object of perception as merely object of consciousness, or merely thoughtobject, is to be false to fact. "For being is in no wise a constituent of an idea; it is experienced, felt, lived, not ideated or thought." 1

In all such knowledge as is reached through the mediation of trains of associated ideas, or of more carefully selected

1 Riehl, Der Philosophische Kriticismus, II., ii., pp. 142 f. 
judgments arranged in series that correspond to the laws of logical thinking, our feeling of these processes is an important factor in the processes themselves. If those fundamental principles of all reasoning, - the so-called principles of Identity and of Sufficient Reason-without which we cannot even conceive of reasoning at all, and in conscious violation of which no processes of reasoning, however false or inconclusive, can be conducted, are brought to the last test of their value, in what does this test consist? Must not this question be answered by saying: "In the invincible character of the feeling with which all 'men affirm them, and the unconquerable repugnance with which any proposal to abrogate them is universally met"? For argument has here arrived at a stage where reasoning can decide nothing. Reasoning enters into the arena only when the particular application of these principles of all reasoning is the matter of contest. I can perhaps throw some clear, cold light upon the disputed question of the identity of a particular $A$ and a particular $B$. I can illuminate my own mind and the minds of others, perhaps, as to whether the accepted judgment " $A$ is $B$ " warrants the further judgment, " $A$ is also C." But if that principle which books of logic sometimes symbolize by writing, "All $A$ is $A$ " be called in question; or that other principle on the basis of which it is argued that "If all $A$ is $B$ and $C$ is $A$, then $C$ is also $B$," - why, then what can reasoning do about it? For the question now is whether consistency and logic and reason themselves shall be the court of appeal on the part of all would-be reasoners. You and I have nothing but our feelings - both of the potency and beauty of our position of trust, and of the impotency and ugliness of the position of absurd distrust to which we can appeal. Indeed, it is the loss of sensitiveness to these feelings which chiefly characterizes an utter lapse from the level of rational human nature. He who cannot feel these so-called logical principles as true and of 
inestimable value is a lost man. His soul has no reason. It may be a principle of psychic life, of some sort of mock intelligence; but it has no longer the semblance of a rational human being. Its affective core is gone.

The regulative influences and values of the feelings which accompany all processes of ratiocination might be illustrated in almost endless detail. And these illustrations might be drawn from all our work-a-day experiences. But for this very reason little illustration is needed. It will be helpful, however, to notice how the trains of associated ideas along the levels where comparatively little clear-thoughted judgment occurs are guided by their affective accompaniments. Sometimes this guidance brings the mind out upon solid grounds of rerity; sometimes it leads the mind into quagmires and spongy places of doubt and error. Who has not felt, on returning home from market, shop, or study, as though his memory had lapsed or gone wrong on some particular point; but, on thinking it over, has judged this affective consciousness to be misguiding, - only, perhaps, to find subsequently that feeling was the truer indication of the fact? In listening to the discourse of others, upon failure to catch for thought the exact points and clear-cut thread of the argument, how potent are the feelings of satisfaction or dissatisfaction that arise from the most obscure depths of the soul, to determine our mental attitudes toward the various judgments which mark the steps of the argument?

Nor are such experiences to be confined to the sphere of mere opinion or belief, where what is called "prejudice" exercises its most potent influence. How very restricted is the sphere within which absolute certainty can be attained, both as to the "that" and the "what" of the object of cognition, will appear later on. Doubtless all manner of feelings of interest or of indifference influence men to crroneous opinions and to false beliefs; or even to substitute judgments formed under such influences for assured knowledgc. 
But neither of these considerations changes the nature or lowers the value of the truth we are enforcing. The feelings which belong by virtue of the mind's constitution to its logical processes are themselves influential factors in determining the course and the conclusion of those processes. One would otherwise no more know how to hit the mark of truth, or when indeed he had hit this mark, than how to manage his foil in fencing without a guiding influence from the feelings of motion. Herein, also, is contained a wide sphere of individual differentiation. Thus we sometimes hear men arguing whether a certain argument is itself good, with a comparative indifference as to the truth of the conclusions reached by the argument. And one will say, "The reasoning seemed to me excellent, but the conclusion I know to be nonsense;" but another will say, "To me, on the contrary, the conclusions seemed true, but the argument a weak one." On examination it will turn out, probably, that in the former case, the flow of satisfied feeling went smoothly on until the rude shock of the concluding judgment was felt. But the other listener reached a good piece of smooth-feeling road at the end of a journey in a cart without springs over a rough causeway. Now both hearers feel bound, by the sacred obligation which the consciousness of rationality imposes on every man, to pass again in review the experiences of their common journey. The first will rest satisfied only when he has torn up again the road he travelled so as actually to know where and why he should turn off by a path to escape the hateful termination. But the other will strive to build for himself a better piece of highway leading to the same terminal. Only thus will both feel comfortable all the way from the point of starting to their destination; and this is because both are constantly being so profoundly influenced by the regulating force of the feelings which are the affective functions of the logical processes.

There are some forms of affective consciousness in all 
knowledge, however, which are yet more mysterious, and which lie darker and deeper in the depths of the soul. These we have called "integrating" feelings, beeause they seem in some sort constitutive of the very integrity of the cognitive act. But so dark and mysterious are they that it is difficult to deseribe or eren to name them. Let no one suppose, however, that, on this account, they may safely be orerlooked or denied. For they resent such treatment by rising to a fine pitch of emotional excitement. And yet no other feelings are ordinarily so unobtrusive, but without being any the less permanent. Indeed, these integrating feelings color every act of cognition, and really make it to be cognition as distinguished from any form of psychosis which is not completely that.

Here consider for a moment the emotional condition into which, as a matter of fact, the "plain man" is thrown when you bring before him the sceptical question as to his own existence, or as to the existence of the external objects of his cognition, the familiar things of his work-a-day life. Let one lay aside, as far as possible, the psychologist's fallacies and the scholastic philosophical dogmas. Let one try, for the time being, to have the same contempt for psychology and metaphysies which the plain man feels. But let it be a gelluinely "plain man" who is questioned, and not a learned ignoramus who has set up a smattering of borrowed and misunderstood psychology or a pretence of sceptical and agnostic philosophy. How now will such a mind face the questions : "Do you, then, really exist?" and, "Is the stone you are hammering with that hammer something real?" If the attitude of the ordinary consciousness be assumed and held toward the question (not toward the questioner), it will by no means be found describable by affirming simply: I believe that I am; or I imagine that I am; or I have an idea that $I$ am; or $I$ think that $I$ am. One can adequately express the answer only by affirming, I know that I am; and 
by affirming it with emphasis. Knowledge, then, subjectively considered, is something more than mere opinion, mere belief, mere idea, or mere thinking. It will, however, be allowable to express the sum total of this cognitive consciousness by saying, I feel that I am, - if only some qualifying phrase be added: I feel sure, very sure, that I am. But this is to say that strong and unreasoning "conviction" characterizes the act of self-cognition in the case of the naïve and unreflecting consciousness.

It will further be found that the strength of this conviction is by no means wholly dependent upon, or chiefly governed by, the fulness of clear-thoughted conception of Self which the subject of the conviction enjoys. All that self-feeling, which is wrapped up, as it were, in the conception of Self, undoubtedly develops in some manner of relation to those processes of thinking which result in forming the same conception. The self-feeling of the child is, perlaps, less intense and comprehensive before it has become acquainted with itself through activities of thinking. But, however self-feeling may be implicated in this element of conviction as to the reality of the Self, the conviction itself does not result from any argument. Its intensity can neither be increased nor diminished by argument. In so-called "diseases of personality," or alleged cases of double or triple consciousness, and of strata of selves lying one below another, or of Egos bearing numbers one, two, or more, that have been "drawn off" and consolidated in centres of selfhood, it is chiefly disturbances of feeling which initiate the entire aberration of mind. So, too, in the self-assertion of the normal mind, it is this "feeling sure," this affective and convietive function, which chiefly seems to authenticate the reality of the Self. We have just called it "unreasoning." And unreasoning it certainly is, not because it is irrational or unworthy of a living, active reason, but because it does not seem to rely, for its origin or for its authentication, upon ratiocination. For if 
this "plain man" be asked how he knows, or why he feels so sure of, his own real existence, he can only repeat that it is so: he knows - and that, with him, is the end of the whole matter. His knowing is chiefly a feeling-sure.

Put as an argument for the existence in reality of the Self, all this becomes reasoning in a circle; and so short is the circle that we can no sooner start out to "round" its circumference than we find ourselves back at the point of starting. For, in fact, it is not a circulus in arguendo at all; the case is not like the effort to get around, behind, or beyond the act of knowledge in order to know what knowledge is. Here is simply the solid matter-of-fact conviction, - a feeling-sure of my own reality which admits of no examination, because it needs none.

And upon this level of indubitable conviction no one will erer be superior to the witness of the "plain man's" consciousness. Be as subtle in analysis, as curious in psychological criticism, as sceptical in inquiry, as keen in ratiocinative powers as you may, and you have in no respect here any adrantage orer the man who knows and heeds nothing of your psychology or your metaphysics. That same intense, indubitable conviction within you, too, bars the way at this point to any further critical inquiry. "I know I am," or "I feel perfectly sure of my own existence," as guaranty of the here-and-now being of what I call Self, is the last word on the matter. Nothing profounder or more ultimate can ever be discovered along this line of investigation. For along this line of inquiry we have reached, not a "limiting conception" of a negative character, but an actual and ultimate feeling-full positing, which, if we try to dissolve it into its elements, does not lessen its size or soften its quality. And in the whole deep sea of human consciousness we shall nerer find anything other or more, of the same kind, than this. We may drag the surface of that sea with the fine-meshed nets of moder'n psychology, and sink into its bottom the 
anchor of religious faith, and send down to its. lowest depths the skilful divers of metaphysics and epistemology ; but nothing like this, that is not this same thing in other guise, will anywhere be found. But why should one wish forever to anthenticate the surest of convictions with other convictions?

Undoubtedly, the "plain man" will affirm his knowlcdge as a "feeling-sure" with regard also to the object of his cognition through the senses. Undoubtedly, too, the application of the affective function of consciousness in all our knowledge of things must be regarded as furnishing its own guarantee. This is cnough to notice at the present time. It does not follow that the embrace of the conviction of reality must have the same extent in both of its two main directions. That the object-thing really is, and that it is not to be identificd with the being which is its cognizing subject, are certainly held up in every mind as propositions supported by the conviction that makes itself a necessary part of every act of knowledge. The fuller circuits over which reach, respectively, the conviction of the reality of Self and the conviction of the reality of Things, are to be discovered and described only as the result of further critical inquiry.

That the Will is an essential part of mental functioning in every act of knowledge has already been made sufficiently clcar. Of feclings there are diverse kinds, and the ideas and thoughts of the mind are not easily to be numbered. But willing is of essentially one kind, although reaching its highest complex development in the phenomenon of moral choice. In the previous chapters it has been secn that the thinking and judging which are necessary to cognition, and therefore the act of cognition itself, are active - that is, a forthputting of the Self considered as Will. It remains in the present connection only to note how, in that mélange of experiences which comes through the voluntary handling of the bodily organism, the knowledge of Self and of Things gets progressively defined. 
It is not designed to discuss the much debated question as to the origin and nature of the feeling of effort; or the other eren more hotly contested question, whether there exist in consciousness any feelings of activity as actual part of its total content. ${ }^{1}$ The progress of physiological investigation seems rather to show that the nervous currents going out from the motor elements of the brain do modify consciousness. Psychological analysis makes very clear, it seems to us, that consciousness of activity is an unceasing element, or aspect, of all consciousness; in other words, we never cease to will and to know that we are willing.

Now, undoubtedly, it is as having muscular and tactual contact with things - moving them or trying with might and main to move them, and being pushed about and steadily resisted by them-that the knowledge of things is made most vivid and most clear. If I were not a self-conscious will, knowing myself as also a Thing that acts and suffers among other things, there would be no world of other things for me. I could never know that the world of real things is, and what it is, by a motionless, inert life of pure imagination and pure thought. The rather do I enter into a red-blooded strife with things, and by trying to master them and impress my will upon them, learn to know them as that-which-willnot always as $I$ will. It is this relation of wills, with its accompaniment of motor consciousness as an external perception of changes in place, and a more internal sense of the conditions and clianges of the motor apparatus, which chiefly effects the differentiation of the sum total of experience into Knowledge of Self and Knowledge of Things. Unless cognition were always a matter of will, such differentiation could not take place at all. Unless changes of will were accompanied, preceded, and followed by changes in the sensationcontent of consciousness, and also in its affective cliaracter,

1 On these questions, see "Psychology, Descriptive and Explanatory," chapters xi., xxii., xxvi. ; and "Pbilosophy of Mind," chapters iii., iv., vii., viii. 
cognition could not accomplish this differentiation in the manner in which it actually does bring it about. Thus the extension of the doctrine of the nature of knowledge, as thus far set forth, leads to the further study of the division of all the objects of knowledge, into Things and Self. 


\section{CHAPTER VII}

\section{KNOWLEDGE OF THINGS AND KNOWLEDGE OF SELF'}

MONG the various distinctions which it seems necessary
to recognize in order to describe and understand the mental phenomenon called cognition, the most important and fundamental is that between subject and object. Indeed, this distinction seems in some sort to be involved in the very act of cognition. To know, "one must distinguish and make his own some object; for the "I know" which describes the act of cognition is actually a knowledge of something or other, - an activity determined with reference to somewhat that is known. Yet this act is also necessarily regarded as some one's act, or, at least, as some one's experience by way of knowledge, so to speak; since the word "I," which stands as the subject of the sentence declarative of the experience, is as essential to the full meaning of the sentence as is the additional phrase defining the terminal upon which the act alights in the form of a judgment.

Another distinction which is popularly made to apply to different cognitive acts, so as to sort them into two distinct kinds, is connected with the distinction of subject and object. This other distinction is thought of as applying to the objects of knowledge themselres; it divides them into classes which must by no means be confused with one another, if the subject would make good in reality its claim to hare a genuine cognition. On the basis of this latter distinction, then, epis-

1 For a treatment of the same topic from the point of riew of descriptive psychology, see chapter xxii. by the same title, in the author's "Psychology," etc. 
temology has to consider the nature, grounds, certitude, and more ultimate meaning of the Knowledge of Things and the Knowledge of Self. It would appear that account must be taken of the distinction between subject and object, if any theory of knowledge is to be established. But it would also appear that account must be taken of that distinction between objects upon the basis of which a division of cognitive processes into kinds is frequently set up. Indeed the critical examination which all epistemological theory presupposes will show that the former distinction is essential to knowledge as such; but the latter distinction is the basis of that system of cognitions which not only sets the Self into relations with a known world of things, but also sets these things into known relations with each other so as to form a "world" out of them all. The more ultimate bearings of both these distinctions it belongs to metaphysics rather than to epistemology to subject to critical treatment.

Grammar, and for the most part also logic, discusses the distinction of subject and object as a purely formal affair. According to the rules with which the grammarian is busied, any perception or conception can be substituted for the $S$ which indicates the subject, and as well for the $P$ which stands in the place of the predicate and thus objectively determines the subject by virtue of some connection of a copula, if only the rules of correct form be observed. For grammar looks only after violations of the rules for gender, number, and case, or for the positions in which the words of the sentence are arranged according to good usage in the particular language employed, etc. As it becomes more thoroughly psychological, grammar abstracts from considerations peculiar to particular languages, and considers the laws of the expression of human thinking, feeling, willing, in any form of articulate speech. But as to the origin, nature, and validity of the distinction affirmed between $S$ and $P$, as representative of an implied differentiation and unification in 
reality, it is not interested to inquire. Nor is the distinction which it authorizes between the subject and the predicate the exact equivalent of that distinction between subject and object which all acts of cognition imply. For let the sentence under examination be made an affirmation of some act of cognition, and the grammatical theory of the sentence is not changed. "I know assuredly that the snow is white" is not essentially different; for grammatical structure, from "I imagine that, in Utopia, the snow is a delicate grass-green;" or "I remember to hare heard with incredulity that red snow has sometimes fallen." Here, says the grammarian, are three words, _ "know," " imagine," and " remember," - all having the same subject "I," all in the present indicative, and all having for the object of their active mood a dependent sentence or clause. For the theory of knowledge, however, as concerned with the nature and validity of the relations expressed by these different words between the subject and the object, and more especially with the reality of both subject and object as existent in these relations, the difference between such grammatically similar sentences is quite unique.

Nor does so-called formal logic take to heart the distinction between subject and object as it becomes the searcher after a true theory of knowledge to do. This science of logic, indeed, will tell you something more important and more nearly fundamental, from the epistemological points of view, than is attempted by the grammarian. Hence, while the grammarian only occasionally makes an appeal to psychology or philosophy to discover or to justify his opinions, the logician almost constantly and quite ineritably mores along the border-lines between his special inquiry and that of epistemology. Indeed, logical praxis tells us how to make such combinations of $S$ and $P$ as shall lead to expansion of our knowledge of $S$ and $P$, and to the development of truth regarding them. Yet here, even, - somewhat curiously, as it seems to us, - the expansion of knowledge, the develop- 
ment of truth, secured and guaranteed by conformity to the laws of logic, all depends upon the belief that the original distinction, by way of differentiation, relation, and unification, of $S$ and $P$ has been somehow, otherwise than by logic, secured and guaranteed.

When, however, this distinction of subject and object is taken to psychology, as a purely descriptive and explanatory science, it receives a yet more unsatisfactory and tantalizing treatment. For, first of all, in explanation of the distinction itself, as the fact of it appears to be most plainly set into reality by every act of cognition, we are introduced to a series of shallow sophisms and abstractions which end by doing away with the reality of this distinction. It is pointed out that, of course, the only way in which the subject could erer know itself, is to make itself its own object. But in doing this it parts with the privilege of knowing itself as subject; for the self which is known is, by virtue of its being known, an object of its own knowledge. How now shall one find one's self so as to know that one is, and how one is, since in the rery process of cognition, attention must be centrifugally directed, as it were? Yet again, what is the nature of this object-self? When truly answered, the question leads us, we are told, to recognize the fact that somehow a special aggregate of sensations, with a peculiarly vivid and warm colortone of feeling, which may be localized in the throat or elsewhere, gets to be dominant in the field of consciousness. Thus the conclusion of scientific psychology, without prejudice from epistemology or the metaphysical doctrine of a soul, resolres the distinction between subject and object into a distinction between differently colored and aggregated sensation-contents of consciousness, - objectively determined, it might as well at once be added, by influences over which the subject has no control.

But if the subject has disappeared from the actuality of this transaction called knowledge, in which the distinction 
of subject and object is popularly supposed somehow to be involved, what becomes of the distinction itself? It is, of course, resolved into a mere distinction, content-wise (and, perhaps, merely in the matter of sensation-contents) between different kinds of conscious states, - objectively determined. Such psychological analysis no more finds a real soul, an actually existent subject of states standing in relation of cognition to trans-subjectively existent object-things, than the dissection of the anatomist finds such a soul on breaking apart, post-mortem, the elements of the brain. Let it not be forgotten, however, that in consistency the same psychological procedure must be applied to the object of knowledge when that object happens to be some Thing, instead of appearing as my Self. And when this has been done, when our psychology has been beautifully and thoroughly consistent with its analysis of psychoses after the approved modern pattern, then there is left neither party to the now obsolete distinction. Subject is resolved into a passing phase of object, and object, even when object-thing, is a passing phase of subject; the distinction has lost its validity for reality; the act of knowledge is accounted for by denying that it actually is what all men, outside of the ranks of a certain school of psychologists, understand an act of knowledge to be.

It appears, then, that the philosophical doctrine of knowledge requires something more than either the grammatical, or the logical, or the pseudo-psychological account of these distinctions, if it would save itself from the gulf of complete agnosticism. This need begins to be satisfied when we recognize the unsatisfactory character of every psychological account of knowledge which gives us no other and deeper view of self-consciousness and of sense-perception than that which has just been arraigned.

We are told on the authority of Herbart and others that self-consciousness as self-cognition cannot be admitted in 
fact, because the very conception of it involves an attempt at movement in a perpetual circle. It must be admitted that since we are not all at once self-conscious, whether consideration be had of the acquirement of the so-called faculty in the development of the mind or of the individual act of "coming-to" self-consciousness, the origins of this form of cognition are obscure. This is true of origins of all sorts, and generally. Whatever may be allowed for some faint trace of self-feeling, as inhering in every act or state of consciousness, our explanation of self-consciousuess can only be analytical and developmental, as it were. The most fundamental factors appear above the threshold of consciousness as arising out of the obscure, the totally dark background of the nature of the Self. No effort of memory or of imagination can recall or represent them as they originally were. A complete descriptive science of the origins and grounds of self-consciousness is therefore forerer hidden from our ken. On this account, however, we must not fall into the psychological fallacy of substituting abstractions for real and living experiences, and then so manipulating these abstractions, and setting them into antinomic and irreconcilably contradictory relations with each other, as to deny the plain meaning of the experiences themselves. Self-consciousness is not an abstraction. The description of it may be, and often is, a mere abstract relating of abstractions. But, in actuality, self-consciousness is the experience of a being with itself. This experience is at times so rich and content-full, that when fully apprehended and faithfully described, it is seen to involve attending to and thinking about the self, feeling of self, the affection of being, alive as both suffering and doing, and activity that is self-directing as well as self-cognizing. ${ }^{1}$

1 Compare the rather stilted but forceful language of Klein, Die Genesis der Kategorien, pp. 17 f.: "Sein Sichfinden und Sichdenken ist ein Sichwissen, sowohl als Realeinheit (Substanz), wie als Crsache, weil ursachende Sache zugleich (Causalität, causales Princip); mithin ein Sichfinden nicht bloss als Träger des Scheins, sondern als mitwürker, und deshalbs als Träger des Erscheinens." 
Whatever may be thought as to the chronological or psychological priority of the different acts and kinds of knowledge, there can be no doubt that self-consciousness is entitled to priority when viewed from the epistemological points of view. If any form of cognition is destined to be regarded as an envisagement of reality, and to claim the deepest and intensest manifestation of that conviction which we have seen to constitute an integrating factor of all cognitive acts, such form of cognition comes through self-consciousness. An immediateness of knowledge which surpasses that with which I know myself as here and now existent, cannot be gained by any sharpening or spurring of the mental faculties. Nor can any truer and surer envisagement of reality be made eren an object of imagination. Indeed, all that I conceive of as "intuitive," as doing away with all barriers between knowing subject and reality known, is conceived of after the type of my experience with myself. How can angels, or even God, know anything more indubitably and transparently given, object to subject, in the unity of the embrace of cognition, than is my here-and-now existence to my here-and-now existent-Self? If there be a more immediate and indubitable form of envisagement possible, no human being can even get standing for a flight of imagination which shall discern that form. Let not epistemology continue to repeat the mistake of Kant in neglecting this truth.

Introspection and observation of the actual course in development of mental life, helped out by sound reflective thinking, leads to a negative conclusion regarding the distinction of subject and object in the earliest psychic processes. Active imaging and discriminating considered as function, on the one hand, and object considered as point of regard and as content discriminated, on the other hand (Vorstellen and Object), were not originally separate as facts in the one experience of the inchoate mental life. Much less were they extant as separate entities envisaged in the one 
stream of consciousness. To imagine them as, not merely separable, but also as actually separated "moments" or factors in the psyclic flow, is to transpose conceptions resulting from our experience with our own growth of knowledge, back into those conditions when as yet knowledge was not begun. To imagine subject and object pre-existent as entities is to introduce, in another way, the conflict of abstractions, - the abstract antinomies which result in destroving the very being of cognition.

How now did that distinction into subject and object arise, which in its most immediate and supreme form of application belongs to all the knowledge of self-consciousness? This question can be partially answered only by a careful attention to the two main aspects of all conscious states. Every state of consciousness may - indeed, must be regarded as both passive and active. As a state, it is determined by being subjected to influences passively received; but it is also selfdetermining by virtue of the fact that it, as a conscious energizing, takes part in shaping these same influences. It is on the basis of this double nature, which belongs to all our psychic life and which presents every portion of that life as, of necessity, both passive and active, that the distinction of subject and object as applied to the Self reposes. But the realization of this very distinction demands an activity of the mind itself. We do not account for what actually takes place by speaking as though subject and object distinguished themselves, after the fashion of atoms of oxygen and atoms of lyydrogen when a compound of the two is broken up. Each kind of atom then goes to its own place; each aggregates itself, by favor of what we call its "affinity," to the group to which it belongs. But passive atoms of the stream of consciousness do not, of themselves, flow together into an objectself, and active atoms into a subject-self, according to laws of psychic affinity. The rather is it the work of the consciously active mind, by a progressive mastery of its own being, to dis- 
criminate, to assimilate, and to generalize the factors, both active and passive, of its one psychic life. At whatever forgotten and to imagination irrecoverable time, the work of discriminating consciousness became complete enough to introduce this distinction for the momentary diremption of the stream of consciousness, then an act of self-consciousness took place. Then I became aware of myself as doing or suffering in some definitively segregated state. The doing, regarded as conscious discriminating, as thinking activity, as the becoming aware = I myself as knowing. The doing, or suffering, regarded as that of which $I$ become aware=the Self, known. ${ }^{1}$

The foregoing description of an act of self-consciousness is also, in all important features, a description of an act of cognition. It may be more or less of the so-called immediate order, and so comparable to perception of things by the senses, or it may be framed so as to make conceptual and thinking processes more prominent; but in either event it is an act of cognition. We should expect, then, to find that it is pervaded with feeling of a peculiar and appropriate kind; and that it is supported by that conviction as to the reality of its object, and that grasp of will upon reality, which have been seen to characterize all the cognitive processes. What we are entitled to expect, that we actually find. Indeed, this cognition of the reality of Self, as given in self-consciousness, has already (sce pp. $170 \mathrm{f}$.), on account of its feeling-full and firm grasp, been made the typical example of all cognition.

From the epistemological point of view, then, the distinction of subject and object, not as merely formal or phenomenal, but, on the one hand, as entering into the essential nature of knowledge as a subjective process, and on the other

1 The stages in the derelopment of self-knowledge, as determined by the nnmber and character of the bodily or other elements entering into the object-self, or otherwise determined do not concern us here. But see "Psychology, Descriptive and Explanatory," pp. 519 f., and "Philosophy of Mind," pp. 81 f., 245 f. 
hand, as teaching the very nature of the reality of the object of knowledge, is most fundamental in character. Its " intuition" is of the most immediate and supremely self-confident order; it is most unmistakable and inextinguishable. Selfconsciousness is a pre-eminently "intuitive" act of knowledge. But self-consciousness is the experience of a being actively cognizing its own doings and sufferings as they actually are, as they, to speak figuratively, occur under its own eye. The relation of subject and object, as this relation is involved in all cognition, cannot, then, be regarded as a limitation, or a bordering concept that merely marks the immense horizon of the unknown. This very relation, in which the real subject stands to the real object, is an actual, concrete, and indubitable experience; it is not ignorance; it is rather that commerce of being with itself in which the essence of all knowledge exists. In this typical case of self-consciousness, surely, experience is its own guarantee of reality. The realization of this relation, which separates what is really one, in order consciously to judge it to be one, capable of acting and reacting in a living unity of related existence, is not to be spoken of as an impotent deed, a mark of hopeless limitations, a never ceasing and inescapable temptation to scepticism and to agnosticism. The rather is it the method of mind in knowledge, following the transactions that go on in reality. We have no higher type of the divine and absolute cognitive activity than the realization by the conscious human spirit of the actuality of its own inter-related self-activities.

At all events, the maintaining of the validity of the distinction of subject and object, as actualized in every cognitive act, is the sole and sufficient security for all human claims to knowledge of every kind. Once let this distinetion go, with all that is implicated in the distinction as to the being and nature of the really existent, and everything slips from our grasp. For this dual nature of the Real, as actualized in the concrete experience of the Self with itself, is the last for- 
tress, impregnable and centrally situated in the domain of knowledge. If it be taken, nothing remains to mark the difference between knowledge and not-knowledge. This light, thrown from the experience of subject and object, as necessarily distinguished in the very relation which unites them, comes from the sun in the solar system of the mind. With the obscuration or setting of this sun, no celestial light, otherwise derired, can ever break over the scene. Starlight and moonlight are not in these hearens. Landscape and observer are no longer distinguishable; landscape and observer no longer exist. It is not simply as though a more than midnight darkness had temporarily fallen over the whole earth. It is rather that both the earth and the lights set in the heavens to rule over it by day and by night, have forever vanished in the limitless roid. Nothing is; for the principle of creation and the product of creation are alike gone.

It will be well for the successful termination of our further quest after the foundations and limitations of human cognition, and also for our peace of mind in viewing the practical bearings of the theoretical conclusions, not to forget what has just been brought to mind. We repeat, then, - regardless of the risk of being accused of needless prolixity. Whatever may be the true descriptive history which psychology feels obliged to give of the normal development and of the occasional aberrations of self-consciousness, the import of our analysis is unmistakable and undeniable. The reality of the subject and the reality of the object, and the actuality of that relation between subject and object which is essential to cognition, are an indubitable experience in every act of self-consciousness. The existence of the subject and the existence of the object, as herein given, is not a matter of mere thinking, or of mere believing, or of mere mental representation. The relation is not an abstraction or an image of that which may, or may not, be true in reality. In this supreme and most complete act of 
knowledge - the knowledge which I have of the here-and-now being of myself as objectively determined, thus rather than in some other way - the nature of knowledge, with its guaranteed envisagement of reality, most completely and supremely reveals itself. No merely grammatical, or merely logical, or merely psychologieal (if by this latter term we understand the superficial description of the content of consciousness, as a "bundle" or "aggregate" of sensations and feelings) account of self-consciousness suffices to satisfy the facts. For in the experience of self-consciousness, we have given the reality of the subject as an active knower, the reality of the objeet as a being known, and the actuality of a relation which distinguishes subjeet and object and yet binds them in a living unity of cognition. Thus much is given, - just as truly for the insane man as for the sane, or for the vietim of so-called "double consciousuess," as for the proudest possessor of a single self-conscious peerless Self. ${ }^{1}$

1 As to the speculative outcome of this fact, when critically and systematically expounded, see the author's "Philosophy of Mind," passim, and especially chapters iv., v., vi. Various writers emphasize particular aspects of this fundamental truth in more or less forceful and interesting ways. For example, Caspari, Grundprobleme der Erkenntnissthätigkeit, p. 100, says: "Hebt man zu Gunsten von $S$ (Subject) $O$ (Object) auf (Fichte) oder ungekehrt zu Gunsten von $O$ das $\mathrm{S}$ auf (die Sensualisten), oder lassen wir gar $O$ und $S$ coincidiren, und zu einem höherem, beide gemeinschaftlich umfussenden $\boldsymbol{Y}$ zusammenfliessen, so heben wir jedesmal die wahre Natur des Intellects selbst auf."

In remarking upon Laas' question (Einige Bemerkungen zur Transcendentalphilosophie, in the Strassburger Abhandlungen zur Philosophie, Freiburg, 1883). "What guarantees the identity and uniformity of this Self of mine more than the identity and uniformity of Space and of Nature?" Riehl affirms (Der Philosophische Kriticismus, II., ii., p. 78) : “It is obvious that experience is possible only so long and so far as constancy and uniformity actually exist, and are thought of as existing, as well on the side of the object as on that of the subject. Experience would be destroyed, not merely if we think of the persistence and uniformity of objects as annihilated, but also if the subject ceased to be conscious of its own Self in the mental representation of the objects. But it must be confessed that the objective constancy and uniformity is to be recognized only through the identity of the subject whose correlate it pictures."

See also Werner (Grundlinien der Philosophie, p. 6, Regensburg, 1885): "Das Uebersinnliche erscheint im selbstbewusstem Denkleben des menschlichen 
It has been customary to say (chiefly by the old-fashioned dogmatists) that, in the case of the knowledge which comes through self-consciousness, the being of the subject and the being of the object is known as "identical." "I know myself," is its formula. For is it not $I$ that know, and $I$ that am known; and are not the cognizing Self and the cognized Self, of course, one and the same reality? How much of truth there certainly is in all such doctrine, as well as how much of error there may be in some of its applications, the critical examination of the concepts of identity and of reality is needed to determine. Strictly speaking, I cannot affirm either identity or reality of myself - not even as known in Self-consciousness - without going through a process of cognition. And it will be a necessary characteristic of this, as of erery process of cognition, that the distinction of subject and object, as valid in reality, should be actualized in a concrete experience. So that, in some sort, I as subject am not identical with me as object. "I know mysclf to be thus and no otherwise objectively determined;" this implies that the distinction of subject and object as truly as the identification of the two, should be realized in the act of cognition, if the particular cognitive act is to be an act of self-knowledge. But about all this our perplexity and distress pass away when it is understood that the conception of identity which is customarily introduced at this point is itself a most misleading and indeed impossible conception. For' an identity that admits of no form of differentiation, is an identity which on account of the very nature of all cognitive processes, can never be known. It is also a form of identity which can never be realized; for to be identical in this way would amount to not really bcing at all. To be dead and

Geistes gleichsam als ideeles Spiegelbild, dessen Reflex sich erhellend über die erfahrungmässig gegebene Wirklichkeit des irdischen Daseins verbreitet. Das geistige Denkleben in welchem diese Reflexion des Uebersinnlichen vermittelt lässt sich sehr wohl einem Spiegel vergleichen, und seine Thätigkeit in Wahrheit eine Spekulation nennen." 
worse than dead, to be nothing, the mere negation of all being, would be the only actual (sic) equivalent for such a conception of identity. Especially, however, would it be untrue to affirm self-identity of any being which lives and grows, in a way to contradict the validity of the distinction of subject and object as this distinction is actualized in self-consciousness; supremely absurd, too, when it is considered that it is self-cognition which touches the heights of rational life and rational development, by actualizing that which is the only source and guarantee of the concepts both of identity and also of reality.

In the act of self-cognition, a certain unlikeness, an obvious and indisputable distinction of subject and object is implicated. But their complete incomparability is denied; and their actual unification in some form is affirmed. The cognitive act itself is an actual unification of the two. For the synthesis of knowledge must be so conceived of as not to annul the actuality of this distinction. The type of the relation is not identity, - if by this we mean a complete and indistinguishable sameness of characteristics, such as would be equivalent to a denial of all process, cliange, difference in aspects, or forward movement of life. The type of the relation is rather that of a commerce, or intercourse, in which both of the "momenta" or factors retain their reality, but are unified by taking part, as it were, in a common cause. Really, I am not, as subject of my activity in self-consciousness, the same as the me which I both make and find to be the object of this activity. I am partially, but not wholly self-determined by the character of the activity. In comprehending the significance of this statement I gain insight into the nature of knowledge and into the nature of reality as well. For it is in this experience that the foundations both of epistemology and of ontology are laid.

The study of intellectual development assures us, however, that the knowledge of the individual man and of the race 
recognizes another searcely less fundamental and important distinction. This is the distinction already referred to as that made among the objects of cognition. These objects divide themselves into things and minds; and since all knowledge of other minds comes only through one's growth of skill in interpreting the changes in things as signs of changes in other streams of consciousness than one's own, it may as well be said that all knowledge is of two kinds, knowledge of Things and knowledge of Self. Now this division implies a most wonderful process of diremption in conscious states; and the wonder of it may be somewhat vividly brought before us in the following way. That I should know myself - how I think, and feel, and what I plan - is indeed fraught with all the mystery which is inseparable from the nature of all knowledge. This is a mystery, however, which seems less obvious and profound because it is inconceivable that I should be in any particular "states of consciousness," as we are aceustomed to say, without some sort of kinship between me and my own states. I am certainly, in the main, like myself, whether I consider myself as the subject or as the object of the act of knowledge. As psychologists used to say: In the case of self-knowledge the object is a subject-object, whose substantial identity with the subject is affirmed as apparently a necessary part of the very act of knowledge. But in the case of all cognition of things, our experience is, in some important respects, of a quite different order. Here the object is given to me, by the act of cognition, as so unlike me that I call it a "Thing," - a somewhat not-me because belonging, as known by me, to another category of objects. And however much one may become confused as to the accuracy of the objective reference of any particular modification of the sensation-content or the feeling-content of consciousness (as, for example, whether the sound I hear is a cricket on the window-sill or a tinnitus aurium; whether 
the forms I see are insects in the air or musce volitantes), one never thinks of the possibility of confusing one's self with other things. I am; and my world of object-things is, - such is the twofold division of all that is real to me.

In fact, as has already been indicated, the implicate without which all account of cognition becomes absurd, eren when we try to reduce the sum-total of assured cognition to the lowest, most sceptical and agnostic terms, includes the existence of things as different examples of the Not-me. You and I can never communicate, or discuss, our several dogmatic and agnostic positions, without somehow paying each other the compliment to assume for each other an extra-mental existence. But I always remain a thing for you, as I am most immediately known by you; and I am in turn obliged to say - begging pardon - you are only a thing to me. How now can this mystery be brought about in any such manner as to gain credence for itself, that the entire world of known objects with the sole exception of the Self, should be at first hand known as so unlike the Self as to be assigned to an opposite and even contradictory class of objects? For all knowledge has just been seen to hare the essential nature of an intercourse, or commerce, between two, - a relation in which two factors unite without either losing its reality. The whole half, or, for mere bulk, three quarters or seven eighths, of our cognition is, then, a commerce which brings us into a living relation of unity with beings that are by nature relegated to a sphere lying quite out of immediate conscious reference. What wonder, then, that many of the more serious students of the problem of knowledge have so reacted upon this faet as to fall backwards into the gulf of an identity-hypothesis!

It is interesting to notice, however, that our "plain man's" consciousness approves of no such backward leap. For him the surer experience is what, as he supposes, he immediately 
and indubitably knows about the nature of things. He is not puzzled as to whether he will admit terms of familiar acquaintance between himself and an object so wholly foreign in origin and character to himself. His hesitations and dubitations arise, if at all, when he gets a moment's time to consider more reflectively the results of his own self-cognitions. Things I know; and their relations and uses I know, - of course, just precisely as they are; for what else than this does knowledge of them mean? But what I am, and almost whether I am, except at those rare times when I attempt a brief, face-to-face acquaintance with myself, are questions which seem full of mystery. And by the "Things" which he thinks he surely knows as they actually are, he means just what certain psychologists and philosophers choose to call "Things as they seem," mere "appearance" and not "reality."

Noreover, if the "plain man" becomes a careful observer and scientific expert in respect of any particular class of things, while retaining the plainness of his unreflecting consciousness in respect of the nature, ground, and certitude of his knowledge about things, he remains in the same happy condition of uncritical dogmatism and realism. Things are still thought actually to exist as they seem; but now it is rather as they seem when examined by the modern improred instrumentation, - by the microscope and spectroscope, and by the various methods of physical and chemical analysis. And when the more direct methods of determining what things are reach their natural limit, then elaborate methods of ratiocination, with more or less of conjectured entities, hypothetical forces, and assumed laws of action and interaction, are summoned in the interests of increasing our common stock of the cognition of things. All this seems to the man of science, and to his admirers, very true; and if any particular statement lacks the evidence necessary to declare it true (for the man of science is commendably care- 
ful about his evidence), there is never any ultimate doubt raised as to the objects of all such inquiry having a real existence after patterns cognizable by the human mind.

It is important to notice what is the effect upon this body of knowledge as to the nature and behavior of things which is produced by the sceptical and agnostic outcome of the Kantian epistemology. If any one who holds the ordinary views, whether he be a master of some form of physical scienee or not, be told that it is his own intellect which constructs and gives objectivity to Nature, to the systematic sum-total of really-existent known things, he may finally be forced into the admission that the reasoning in proof of this position is unanswerable. He may even himself become an easy prey for that form of idealism which Kant strove to render untenable. Admitting the transcendental ideality of all things, he may, in the strength of his reaction against the naivve assumption of their transcendental reality, fall off into the extremes of phenomenalism. But as man of science, he will always return to the position that scientifie knowledge is of things, as they really are (things - non-egos, notselres). Witness the late Professor Huxley, who, even after affirming himself a Berkeleian idealist in his theory of knowledge, could with difficulty write five pages further without returning to a position of materialistic realism of the most uncritical sort.

The reasons for the strangely inconsistent behavior of men, when their theoretical and their practical attitudes toward the knowledge of things are compared, might easily be given from the psychological point of view. That is to say, on examination it can readily be seen why some of the contents of consciousness should be allotted to so-called Things and some to the Self, why these two should then be set in contrast by the mind as Ego and non-ego; and why a sort of certitude and consistency should seem to belong to the latter which reaches beyond anything that the Ego itself 
can claim. But a profounder inquiry into the import of the psychical facts shows reasons in certain trains of reflective thinking which lead to another conclusion for our theory of knowledge, and for our view of the nature of reality as well. Things are immediately and certainly known as really existent objects of cognition for the Self; they are known as so differing from the Self that they cannot be identified or confused with its activities or its states; and yet they are not so foreign to the deeper and entire nature of the Self as to make that kind of commerce or intercourse called knowledge impossible between the two.

The same conditions as those for the origin of the distinction between subject and object rule orer the further distinction between Self and Things. Out of the same stream of conscious life, which is ever determining its course in accordance with its own nature and also in accordance with the configuration of the territory through which it flows, this latter distinction emerges. Experience is a sort of unity; and yet it divides itself into internal expcrience and external experience, into a growth of cognitions of Self and a growth of cognitions of that which is known as not-self. This distinction does not, indeed, belong to the beginning of experience; but neither does it create itself as an act of pure caprice. It has its origin in the nature of the mind as related to other realities; and yet it can never come to pass except as the mind itself, by its own discriminating, segregating, and unifying activities, brings it to pass. To speak figuratively: a difference in the "stuff" of knowledgc, as furnished out of the store-house of Reality, must be actircly discerned and recognized in the constructive process by the builder of knowledge.

Certain of the sensation-contents of consciousness are early referred to that sentient and bodily Self which is the child's own, and certain others to the things which stand in more immediate relation to this self. This process of 
diremption is chiefly conditioned upon, and guided by, the character of those feelings, with their tone of pleasure or pain, which fuse with and constitute an inseparable part of the sensation-contents. With the irfant, the inchoate and ill-defined Self is a sort of aggregate of strong-toned bodily sensations and feelings of obscure localization, set in contrast with and changing relation to the better defined but much less feeling-full sensations, which are localized and objectified as its limited world of things. But it is in the actualized relations of will to that which resists will, that the process of diremption becomes most acute and most pronounced. In the mélange of feelings which results from the morement of the bodily organs in manifold relations of pressure and contact, or absence of both, amid a world of things external to these organs, certain fixed points of experience and groups of such points are gradually gained. Contemporaneously, and in a constant process of interaction, two strongly marked series of experiences emerge in the one experience. On this basis the one experience becomes, by activity of the intellect, dirempted. It is no longer simply one experience as belonging to the subject of it all, but a twofold experience with Self and with Things; or rather with myself in changing relations to many different things. The chief contents of one aspect of this experience, which is one, yet twofold, are a certain less definitely recognized group of interior sensations, having a strong feeling-tone, and found to be dependent upon that consciousness of selfactivity which is called the will. The chief contents of the other aspect are certain different and more definitely recognized sensations, mainly of sight and touch, with a feeble tone of feeling, and found to be relatively independent of the modifications in that consciousness of self-activity which is called the will. But the very core of the former is this consciousness of self-activity, of will in action; and the very core of the latter is the consciousness of being re- 
sisted, of will as encountering something that "will-not," as it wills.

All this is, howerer, only a description of different phases or aspects of the one mind in its work of setting part of itself over against itself. It only furnishes, therefore, the grounds, as it were, on which the mind proceeds to divide its own experience into two significantly different classes, but without recognizing the significance of its own procedure; and to assign these classes to two opposed subjects. In order now to understand and validate this diremptive process as genuine cognition, as the setting-forth in consciousness of what is true, because the process in consciousness has its correlate in the nature and changes of the trans-subjective Reality, something must be done more than merely to give the description of the process itself. All that can possibly be done, however, is to show that the procedure of the mind legitimately makes the claims which belong to every genuincly cognitire process; in brief, that we are here dealing with a case of knowledge, and not of mere sensation, or mere imaging, or mere thinking, or sheer belief. In order to show this clearly it is only necessary to analyze any genuine act of perception, which reaches the stage of cognition of a "Thing." There is the object, posited as actual and with an indubitable conviction, and assuredly standing in that relation to the cognizing subject which is of the very essence of knowledge. Moreorer, with an equally indubitable conviction is this object posited as not a subject-object, as not a state of the self, but as an objectobject, an actually existent form of the not-me.

If now, from the point of view of the cognizing subject, thorough examination be made of its process or state, including the character of the judgment in which the criticism of the content of consciousness terminates, this process or state will be found to have every characteristic of a finished and assured cognition. In it all the intellectual activities neces- 
sary to cognition are involved; it is feeling-full, and, on being called in question, speedily develops that warmth of conviction, and that grasp of the willing Self upon the actuality of its object, which are the marks of an act of cognition. But especially is it true that, if by repeated acts of volition, amounting finally to the extremest possible assertion of the will of the knower, the attempt be made to determine the non-reality of the exteinal object, the attempt ends in failure. Indeed, so true is this that we can give no more impressive and truthful, albeit figuratire, description of what we know this object to be than to say: "We know it is as Will opposed to, and yet holding commerce with, our Will."

Whatever psychology teaches, by way of fact or by way of theory, concerning errors of sense, illusions and delusions and hallucinations, of various kinds and many degrees, has absolutely no bearing on the validity of the knowledge of things, as thus far expounded. For the question now under consideration does not concern the psycho-physical origin of the sensation-content or the feeling-content of the objects of sense-perception. Neither does it concern the accuracy of the intellectual processes involved in the localization and projection, in a mentally constructed world of space-relations, of the various forms of these contents. Nor, finally, does the present question concern the range and validity of our knowledge of things - as to what they actually are through sense-perception. The undisturbed truth of experience is simply this: Upon a basis of differing elements in our originally united but inchoate experience, an accomplished diremption of the objects of experience into Things and Self must be recognized as having all the characteristics of knowledge; and, moreover, the actuality of things, as not-self, is immediately and indubitably given in our cognitive experience of them.

The shifting way in which we are obliged to use terms for 
the two objects of cognitive experience is largely, but not wholly, responsible for the sceptical and agnostic conclusion regarding the possibility of knowing the real being of things. This shifting use is itself determined largely, but not wholly, by the actual growth of experience. For this growth of experience itself is a growth in our knowledge both of Self and of Things. It involves, therefore, necessarily, a change in the contents of our conceptions answering to the words "Things" and "Self." In the earlier developments of knowledge for all men, in most acts of knowledge for many men, and in some acts of knowledge for all men, the spheres connoted by these two words overlap. For example, all the members of one's body may be regarded eren the most interior and psychologically insensitive and yet supremely important of them, like the cerebral hemispheres - either as things standing in a peculiarly intimate relation to the Self, or as veritable parts of the Self. Thus we may say either, "I have headache," or, "My head pains me." The headache I have is indubitably a state of the Ego, the subject or possessor of which I declare myself to be. Suppose the localization to be inexact, it does not affect the validity of the cognition which affirms the pain, and which ascribes it to the Ego as its pain. But the head which gives me pain is either perceived or conceived of as a thing which is not-Ego, but which stands in a peculiar relation to the $E g o$ on account of its ability to cause a pain, having such characteristics and being so localized. The peculiarity of the relation, and any confusion as to the particular thing which stands in this relation, do not at all affect the fundamental conditions on which it is given to me as a thing. As "a Thing," even if it be my own brain, it is conceived of by me and perceived by others as an actually existent somewhat that refuses to be identified with the Self.

In brief, in clear-cut scientific cognition and in the reriest 
hallucinations, in the sanest aets of the soundest minds and in the ravings of the mad-house or the vagaries of "double" and "multiple" conseiousness, this distinction in the character of the objects of cognition is maintained as a fundamental distinction. Things and Self cannot be identificd; neither can they both be sunk in a third somewhat which is conceived of after a pattern drawn from analogies afforded by neither of the two. ${ }^{1}$ They ean be unified in reality, as they certainly are in some sort unified in every act of completed sense-perception (and this is matter of unquestionable experience), if at all, only if the conception of one of the two - either of Thing or of Self - can be so extended in a valid way as to provide an explanation for the other, and for the relation of knowledge between the two. The solution of this problem, as a problem in ontology, takes us into the realm of general metaphysies and even of the philosophy of religion. As a problem in epistemology, we shall have occasion to refer to it again.

Beyond that narrow but solid ground for standing from which is affirmed the actuality of things as not-self, and the actuality of the Self as given in the relation of the very act of cognition, the cases of the two differ widely. The coneeption of the Self grows in the soil of immediate or intuitive knowledge, and it is worthy to be called an indubitable envisagement of Reality; but the conception of things, of their real nature and their actual relations, is shown to be developed from an assumption which has only the value of an analogy; but which, if this entire sphere of cognition is to be made valid, needs itself to be criticised and defended against sceptical attacks. Anticipating more ultimate conclusions, and speaking strictly, it must be said that the definite and concrete conceptions we find ourselves obliged (or "privileged" ?) to form of Things, amount to a knowledge of their real nature only as a certain assumption is made

1 l'hilosophy of Mind, chapter viii. 
valid. This assumption concerns the right to conceive of things after the analogy of our immediate and indubitable knowledge of the Self.

It may be questioned by the defender of the current naĩve metaphysics of physics - either popular or scientific whether men do actually conceive of Things only after the analogy of the known Self. If this were so, how could men be so sure that things are not-selves? Now the complete answer to the former question requires several chapters in metaphysics, of a critical and scientific order as opposed to that naire thinking in which the question itself arises. But the answer to the latter question comes from a combined study of psychology and of the history of human reflection. This history shows that while men never confuse Self with other things, they do, in their early development as individual men, and also in the early developments of the race, conceive of things quite generally after the very patent analogy of the Self. That is to say, children and uncultivated folk of adult years personify things. In doing this they impart to them, not only those ideas and voluntary activities which seem necessary to account for their purposeful behavior, but also an entire outfit of feelings, passions, and desires, or even of more lofty intellectual and æsthetical sentiments, such as seems necessary to a rich, content-full and valuable existence. Excited and guided in this manner, the religions of men have developed themselves all the way from the lowest form of fetichism to the more refined worship of Nature. The consolations which a feeling of kinship with the system of things administers, and the dread and bondage of that superstition which this way of considering things engenders, have arisen from the same habit of mind. Take away from art the personification of the transsubjective, through the projection of the image of the subjective, and its moving spirit and most valued achievements would disappear together; as the psychology and philosophy of æsthetics abundantly show. 
It is the impression of persons with cultivated scientific proclivities, but without much genuine insight into the processes and significance of science, that our present knowledge of things has attained the power to surrender the necessity, and disprove the applicability, of the aforesaid personification of things. And, indeed, most of the naïvete has departed, with its poetic charm, before the commonsense and the science of modern peoples in their investigations of natural objects. Let it not be supposed, however, that the sphere of immediate and sure intuition into Nature has been enlarged in this way, or that the necessity for rendering all our conceptual information into terms whose real meaning is derived from face-to-face experiences of the soul has been diminished. The thoughtful physicist is still forced to confess that he has attained no valid insight into the interior construction of Things; he can only tell you his generalizations as to how they appear to behave. The scientific character of the information he is ready to impart consists in the ncarer approach to a mathematical exactness for the formulas which mark the characteristic and uniform modes of this behavior. And should he venture upon the hard task of giving to these formulas the most scicntific representation possible, - for example, in a learned treatise upon physics or chemistry, - he is likely to begin by confessing that "what Matter really is," we do not know, and probably never shall know. At this point it belongs to the thinker who sees beyond plysics into metaphysics, to relieve the physicist from the burden of his excessive modesty by pointing out to him that we can tell what any "subjects of states" really are, only by telling what they most uniformly and consistently do; and then to reveal the profound truth that all the choicest, most impersonal terms for even the physical characteristics of matter, if any meaning realizable in experience is to be given to them, must be recognized as abstractions from the immediate experience of the Self with itself. 
Before this view of the significant difference between the knowledge of Things and the knowledge of Self is enforced by instancing a few of the more important particulars, attention is called to the popular way of looking upon the entire problem. This shows clearly that the distinction between selves and things is of a quite different order from the distinction between the Self and that which is immediately known as not-self. In other words, the diremption of the cognitive process which gives to immediate consciousness, in an intuitive way, two unmistakably different classes of objects, Self and Things, is much more fundamental than that which results in classifying all things into other-selves and things which are not-selves. In knowing you, or in knowing the tree, the stone, the star, I immediately and indubitably cognize the object as a somewhat really existent which is not-me, but which is in the peculiar relation of commerce or intercourse with me, that renders it an object of my knowledge. But whether this object is now to be classified among the "not-mes" which are conceived of as other-selves, or among the "not-mes" which are conceived of as things in the sense of being also "not-selves," is a further problem for cognition. And it is a problem of a quite different order. It is a problem which can never be solved except provisionally and with a lowered degree of assurance as to the truthfulness of the answer. Witness how the whole world of observers is divided over the question of the limits in application for the various characteristics of the life of consciousness and self-consciousness. Books on "the psychic life of micro-organisms," or "the soul-life of plants," or the universally present "mind-stuff," by aggregation of which the human mind is sometimes supposed to be satisfactorily explained, startle, at first, the so-called common-sense of men. But, then, they also excite a pleased curiosity; and they often end in convincing their readers that the old-time mythological way of looking at 
things was not so palpably absurd after all. For, perhaps, men nowadays have grown, under the influence of devotion to impersonal entities and bare mathematical formulas, too jealous of the priceless gift of consciousness, and too ready to claim it all for that species of animals to which they themselves belong. That the reasons on which the modern theory of evolution has built up this sort of distinctions are very "shaky" may well be admitted by any one who has experimented with the spinal cord of a headless frog, or who has patiently observed the behavior of the tendrils of climbing plants.

If, however, the proposal is once made to extend the work which is critical of differentiations so as to undermine the very distinction on which knowledge itself is based, we are met by a totally different order of resistance. Such a work of destructive criticism, if accomplished, would bring down the whole house of human science upon our heads. But this has already been made sufficiently clear for the present; and it is time to turn our critical inquiries in another direction.

What it is really to be a Self, we have made the subject of detailed inquiry in other connections. ${ }^{1}$ It may suffice in this connection to say that the description of such a reality can only be given in terms of self-consciousness. It is only what I am for myself to know that can define what I really am as a Self. Of course, then, other selves must be known to me only by interpretation of signs, conceptually, and as constructed after the pattern of my own self-known Self. The existence of such other selves is an implicate of cognition, just so soon as cognition undertakes to be communicative, - even if (and especially if) the communication be argumentative in the interests of a thorough scepticism or a despairing agnosticism. It is an implicate, however, which involves in its origin and application a complicated

1 Philosophy of Mind, especially chapters iii.-vi. 
experience, both of the so-called intuitive and of the conceptual kind. To most of the animals and possibly to the plants and to so-called "mind-stuff," men are accustomed to ascribe some of the lower forms of consciousness, but without ascribing those higher forms of self-consciousness the possession and actualizing of which are deemed necessary to entitle any being to be called "a Self," in the full meaning of that term.

There remains now that class of objects of our cognition which are known as not-selves, in any assignable meaning of the word "Self," but rather as things in the most complete assignable meaning of the word "Thing." Of these beings, too, all human knowledge, beyond that very narrow but solid basis which has already been distinguished as implicate in the way in which they are given as objects of our more immediate apprehension, is, of course, conceptual knowledge. This conceptual knowledge of mere things is of two kinds, negative and positive. As negative, it consists in denying to things certain of the characteristics which selves are conceived of as having, - perhaps, in the extreme case, in denying any faintest semblance of consciousness, eren such as, according to Leibnitz, every monad must possess in order to exist at all. But the positive characteristics which things are conceived of as having are all abstractions from the definite, concrete, and intuitive knowledge of the Self by itself.

Suppose, for example, that one maintains the substantiality of things, or rather of that substrate of all particular things which is called "Matter," and in which, in a moment of great enthusiasm, a celebrated student of physics discerned "the promise and potency" of every form of life. "Matter," as a word, signifies only, as all admit, an abstraction. But what is it, in reality to continue to be, - to exist substantially, while the modes or manifestations of the existence are continually being changed? No answer can 
be given to this question which is not framed after the analogy of the experience of the Self with itself, as the selfrecognized subject of its own changing states. Only as the subject of knowledge, the knower, comes to the recognition of his own claim to have in some sort a real and permanent being, not simply "in spite of," but in and through his own changes, can he attach to things any meaning-full conception of a substantial existence. ${ }^{1}$ Thus the substantiality, or permanent existence in reality, of any particular external object is always hypothetical and depends upon the validity of conceptual thinking. Substantiality, or permanent existence for the Self, so far as it can be claimed to be known, is given in the form of an immediate and indisputable intuition, in every act of self-conscious cognition. And the validity of the hypothesis by which we extend the conception of substantiality to things depends upon the truthfulness of the assumption that, after the analogy of our own experience, things may be considered as in reality permanent subjects of changing states. Otherwise the bond that holds them together is merely subjective; and we must adopt Berkeley's esse est percipi, or a modification of John Stuart Mill's view, and resolve the substantiality of things into our "belicf" in the possibility of having a particular series of sensations repeated.

If, again, inquiry be made into the grounds and the character of the knowledge of things as particular, and as standing in definite relations to each other, the same conclusion follows. All such knowledge also is conceptual; and the form of

1 Kaulich maintains that inasmuch as, in the last instance, all knowledge depends upon the subject's thought of itself, and this thought is a demonstration of the reality of the subject, and receives from this its content, sucl an act of thought (durch sich selbst gewisse) is not to be apprehended as merely a formal act, but that a metaphysical signification belongs to it, besides the certainty of the existence of the subject which is given through it. In self-consciousness, then, we have the bridge which leads over from the domain of merely formal thinking into the domain of the real. See Ueber die Möglichkeit, das Ziel, und die Grenzen des Wissens, pp. $21 \dot{\mathrm{f}}$. 
the concepts bears in each instance the unmistakable tokens of resemblance to their parent, the mind. In recognition of this truth, Wundt, ${ }^{1}$ when treating of the distinction between particular objects and the self-distinction of the subject, remarks: "The circumstance that the thinking subject knows itself as one of these objects, and that it is conscious of its independent existence (Selbstständigkeit) through its own voluntary motion is manifestly here (that is, in the distinction of external objects) of decisive influence upon the elaboration of external perceptions." By following out the same line of thinking we discorer that the "natures" ascribed to different things are only the conceptual modes of their selfactivity in changing relations to other things. That the hidden qualities and forces with which we endow things especially the possession of "force" in general, or of some "mode of energy" - are conceptions abstracted from our experience as self-active in relation to the objects of our cognition, has been pointed out so clearly, and so often, that it would be inexcusable to repeat the argument here. Indeed, we have just seen how in the complex operations of what we call "Will" as connected with sense-perception, there is involved the mental representation of a real being for things, and of a reciprocal action between subject and object. And if the empty term "Energy," or "Force," be displaced by a word which has a meaning representable in some concrete, actual experience, such word is found to signify our immediate knowledge of ourselres as wills. For all has been said regarding the nature of things that can be said from this standpoint merely, when the same self-derived conception is applied to them, and they are called " other-Will."

The epistemological doctrine of perception by the senses as the primary form of the cognition of things emphasizes the same important truths. We may properly follow Zeller ${ }^{2}$ in

1 System der Philosophie, pp. $134 \mathrm{f}$.

2 Vorträge and Abhandlungen, iii., pp. 225 f. 
his analysis and attempt to show the very constitution of our perceptions to be such that, from whatever direction we may approach them, we unavoidably plunge ourselves into hopeless obscurities and contradictions, if we do not refer our montal representations to subjects that are different from ourselves and, so far forth, external to us. We may even go much further and show that it belongs inseparably to the senseperceptions of man to have fused with them, as an organic and integrating factor, the irresistible conviction of a Reality apprehended and belonging to the objects of his perceptive acts. Perception believes, and must believe, in itself as an indubitable experience of the trans-suljective. It is not an arbitrary, it is not even a voluntary or an avoidable affair, that we interpret the collective content of our perceptive acts into a cognition of the trans-subjective. And if a distinction be made between perception and cognition, and between the character and the amounts of the real given in these two mental processes, it must still be admitted that the only fully justifiable means and first source of all knowledge of things is to be found in perception. The instant, however, the implicates of perception are extended beyond the bare mental positing of a really existent somewhat which is given thereand-now as a not-me, the total cognition ean be enlarged only in terms of mind-life. Pereeptive cognition is interpretative of mind-life. What the Thing is becomes known to us only so far as we are prepared to consider it as a manifestation of the presence and power of mind-life.

Moreover, as pereeptive cognition grows, by repeated and intelligent applications to it of the power of reflective thinking, the sphere of the assured knowledge (or science) of things increases. This knowledge becomes more and more conceptual. Things are more and more endowed with attributes and powers which our enlarging perceptive experience of them seems to require for its own most satisfactory interpretation and remoter explanation. The problematical "somewhat" 
which is primarily known as posited, felt to be irresistibly believed in, and grasped upon by an act of will that finds itself resisted, further defines itself as having an abiding reality most manifold and full of content. But in all this growth of knowledge there is a most important difference between the knowledge of Things and the knowledge of Self. In the latter kind of knowledge there is no trauscendental limitation, or merely figurative employment of abstract concepts which experience has no means of filling with the concrete and clearly cognized reality. In the knowledge of Self "no distinction can be made between a thing-in-itself and a phenomenon. . . . I know reality as it is itself, in so far as I am that reality myself." 1 Self-knowledge is always an envisagement of reality, or an interpretation of some experience which is an envisagement of reality. But the case with the knowledge of things is far different. That the really existent is known must indeed be affirmed in both cases; and that the really existent is known as not-me is true of all cognitions of things. It does not follow, thereupon, that the furtlier qualifications in reality, of Things and of Self, are known either to the same extent or in the same way. On the contrary, all the further qualifications of things are known only conceptually and as the projections into things, so to speak, of the immediately known qualifications of the Self.

We sum up the long discussion of this very difficult subject in the following statement of truths which it is intended by repetition to make clear. Knowledge, by its very nature, ralidates in reality the distinction between subject and object. Even in that form of cognition which is called the knowledge of Self, this distinction is not to be orerlooked or explained away. Self-consciousness attains a knowledge of the Self, as acting subject of changing states, and ret as objectirely

1 On this whole matter compare the author's " Philosophy of Mind," chapters iv. and v., and Paulsen, "Introduction to Philosophy," p. 367 , from whom the sentence above is quoted. 
determined otherwise than by its own conscious activity. It is thus a cognition of Self as both active and passive, - as a real being, in an objectively constituted and determined system of beings. But cognition, by its very nature, also validates the distinction in objects between Self and not-self. This distinction, too, must be accepted as valid in reality and independent of our activity, whether in thinking or in any other form of action. The distinction is given as belonging to that diremptive process which is lost in the origins of our conscious life, but which is so fundamental, incisice, and insistent that it cannot be separated from the derelopment of knowledge itself.

On the basis of yet more complicated and doubtful inferences, we distinguish that entire world of objects which are not-the-Self into groups that either claim or are denied the possession of the characteristics we know ourselres to have. Thus, a coarse and doubtful, yet practically useful and, to a large extent scientifically defensible, secondary distinction is made; and all the objects not recognized as our Self are dirided into other selves and other things. But both for other selves, and for other realities that are not selves but are things, no further conceptual qualifications are possible but such as are derived from the same immediate experience with the Self. These two kinds of beings are thus separated, negatively, by denying to one of them certain likenesses to the Self which we affirm the other to possess. But all positire knowledge, all the qualifications which can be interpreted in terms of actual, concrete experience, are in both cases taken from the same source. What other selves are is known only because we inmediately and assuredly know what our own Self is.

But what things that are not-selves really are, we can only tell by a series of purely negative concepts, unless we are satisfied to affirm that, in some respects at least, all things are positively like ourselves. So that the truth of all human 
conceiving of things depends upon the right to maintain some sort of important kinship, as an accompaniment and off-set, as it werc, to a certain number of vaguely conceived and shifting differences between 'Thing's and Self. To affirm a complete identity between the two is, therefore, to contradict the plainest content of all knowledge, whether as given in interpretative perception, or in the scientific conception, of things. But so to separate the two as to make the commerce of knowledge between them impossible, is to set up an unwarrantable dualism on the basis of a difference which the analysis of the cognition of things shows not to exist. For, finally, while the knowledge of Self may attain an intuitive penetration to the heart of Reality, the knowledge of Things remains an analogical interpretation of their apparent behavior into terms of a real nature corresponding, in important characteristics, to our own. The cognition of the world of things by the human mind actually takes place with the passionate and determined assumption of a right to know what things really are. The admission of this right extends and validates our system of concepts relating to things. It is, therefore, an assumption of the highest epistemological value. We shall return to it again. 


\section{CHAPTER VIII}

\section{DEGREES, LIMITS, AND KINDS, OF KNOWLEDGE}

SEVERAL questions which, although they often constitute $S$ the principal matter of heated epistemological discussion, are really of only subordinate importance, may fitly be gathered together under the title placed at the head of this chapter. They all belong, indecd, to the fuller elucidation of the one problem of epistemology; and any light which is thrown upon them will be reflected in such a way as to make yet clearer the intrinsic nature of human cognition and the extent and surety of the fundamental grounds on which the structure of human eognition stands. For this reason a certain scrappy and heterogeneous character may be pardoned in the appearance of the following thoughts.

Even to speak of Degrees of Knowledge will appear in the eyes of many, at least at first sight, to imply a misleading distinction or almost a misdemeanor. For, as is popularly said, if a thing is so, it is so; and if you "know" it to be so, then you do know, and not merely think, or believe, it to be so. It might possibly be added by the reader of the previous chapters, - either with a mixture of fear that the work of ralidating knowledge which has thus far been done is about to be overthrown, or with the agreeable feeling of the confirmed sceptic when he finds a champion of rational faith about to contradict himself: "How ean there be degrees of knowledge, if it is the very nature of knowledge to have the surety which has been ascribed to it?" 
In attempting the question whether "degrees" in human knowledge are to be admitted, it is, of course, first of all necessary to determine in what senses it is proposed to understand the words employed. Not, by any means, that this inquiry is a merely verbal inquiry; but it is an obvious fact that to speak of degrees always implies some standard of measurement. The proposal, therefore, to discuss the degrees of knowledge implies the application of some kind of a common standard to the different classes of cognitive experiences. We are, then, in search of a thermometer which will mark, however roughly, the rise and fall of the feeling of conviction; or of a rod and chain which will determine the magnitude of the convicting considerations; or of a theodolite which will help discern the remoter fixed points by which it is proposed finally to orientate ourselves; or, finally, perhaps, of a graded perimeter of magnificent proportions which will enable the wise critic to measure exactly the are corered by any giren cognitive judgment upon the total sphere of human science.

If now the thoughts of men, as expressed both in their language and in their conduct, be carefully regarded, it appears that there are two widely different meanings which they consider themselves justified in employing, when speaking of degrees of human cognition. One meaning has regard to the strength of the conviction, as reposing on clearly recognized grounds, with which any cognitive judgment is affirmed. Here the standard of measurement is graded by the approach made toward an ideal which is talked about - albeit vaguely and often most ignorantly - as "absolute." But if we inquire more particularly into the interior structure of this ideal of absolute knowledge, we are led into considerations of the most unexpected and portentous character. For the word "absolute" is always a signal which sounds the call to a long chase and a tedious hunt, if indeed any game at all reward us by the close of the day. We shall, howerer, soon 
indicate the direction in which such tracks are sure to allure our quest, and also something as to the value of that which may be gained by its successful termination.

The other meaning in which the ascription of degrees is applied to human cognition signifies a quite different standard of measurement. According to this second standard, different cognitive acts are arranged along a scale of higher and lower gradations; this arrangement, of course, implies some means of vertical rather than horizontal measurement, as it were. Thus what is called "scientific knowledge" may be affirmed to be higher than ordinary knowledge; and, perhaps, philosophical knowledge gets credit for the merit of having several degrees of still greater elevation along this graded standard. On points of this sort, however, one must always expect a wide divergence of opinion. Claims are thrust in upon us from this side and from that, varying in their cogency as they are presented by different claimants and under the differing circumstances of the history of human development. For example, by one person, at all times in his estimate, or by the majority of persons at certain times in the life of the race, religious and artistic knowledge (if the word "knowledge" is allowed at all with reference to religion and art) will be declared "higher" than any other sort of knowledge; but by other persons and at other times, scientific or practical knowledge will be raised to the place of superior altitude along the scale. We are not interested just now to inquire wlether religious and artistic knowledge can, or can not, be rendered scientific; or in what sense, if any, it is to be distinguished from practical knowledge. But certainly, this wide-spread liabit of rating cognitions by bringing them up, or putting them down, along an ideal scale of values is a most impressive phenomenon. Men, in general, either boast themselves orer their fellows because of the claim to possess some more desirable and valuable sort of knowledge; or else they lament their own constitutional 
and educational restrictions which they regard as debarring or hindering them from certain higher forms of knowledge. The late Mr. Romanes, for example, at one time in his brief but interesting life, appeared to himself to have lost both knowledge and faith of the theistic order, out of his assured experiences. Yet he always professed sincerely his regret over an inability to retain, or to win back, something of knowledge that possessed such a high degree of intrinsic value. This inability he ascribed to an indisposition, not wholly devoid of will, to leave the beaten tracks of the scientific intellect for certain cognitions, or beliefs, attractire to his feelings. Apparently, at the last, he thought of himself as having regained a kind of rational hold on religion's great postulate, under the impulse and guidance of feeling, by an act of voluntary seizure, - in such way, howerer, as not to violate his continued confidence in the fundamental principle of all science, the objective validity of the law of causation. Such an experience is popularly called "faith" rather than knowledge. So, too, do we find a certain class of books in our opinion suggestive and practically helpful to many minds, rather than profound and trustworthy for continued and progressive reflection - like Mr. Kidd's "Social Erolution," and Mr. Balfour's "The Foundations of Belief," rirtually recommending the supremacy of intellect in the cognition of certain kinds of truth, and the supremacy of feeling in the faith of certain other kinds of truth. Yet the latter truths as judged by æsthetical and practical standards, are, conceded to be of the higher order. In all such cases the assumption seems common that, so far as the defensible grounds in reality, and the logical processes connecting conclusions with these grounds are concerned, "science," in the narrower meaning of the word, is alone worthy to be called cognition.

How much of truth there is in the abore-mentioned assumption, we shall discuss later on. The thing now to be 
noticed concerns the import of any such discussion. Certainly the discussion itself implies some ideal standard of a quite different kind from that which defines the degrees of knowledge when these degrees are measured as differing in surety based on recognized grounds. This inquiry assumes the value of truth in its relation to life as constituting also a fitting standard of measurement. Is a man's ideal of value the exact correspondence of his mental representations to the carefully formulated connections of objective phenomena? Then scientific truth is the highest kind of truth. To such an extent may this be carried that the microscope, telescope, crucible, and mathematics, may finally seem to such a man the only means of arriving at a high degree of real knowledge. But if one's ideal is rather that afforded by a vivid feeling of the worth of self-conscious life in general, and by the mental and practical grasp upon the principles of conduct, it is evident that another kind of cognition, if attainable at all, will be ranked higher in degree than so-called scientific cognition. But the one truth implied by both standards, and by all contest over the supremacy of any sort of knowledge, is a certain doctrine of the teleology of knowledge. This doctrine too, has its roots in psychology, which shows us that every kind and degree of cognition involves all the so-called faculties of mind in a living unity of action. The epistemological conclusion follows, not as an abstract theory, but as a recognition of the universal import of the language and conduct of men. Cognition cannot be considered apart from life. Whatever kind of value knowledge has, and whatever degree is attainable in any particular kind of value, knowledge is also always means to an end that lies above itself. Whether one says credo ut intelligam or intelligo ut credum, and whether one rates the satisfactions of faith or the satisfactions of intellect most highly, the true state of the case remains the same. All men set up in speech and in conduct some ideal of a life that has worth; and they rate their own 
attainments, and the attainments of others, in the matter of cognition, according to their ideal of the life that has supreme worth. It appears, then, eren at this stage in our inquiry that the import of cognition is necessarily teleological, and that xsthetical and ethical "momenta" cannot possibly be excluded from the theory of knowledge. To these important and fruitful thoughts we shall return again and again. For not only are they portions of every well-considered philosophy of knowledge, but they also serve to connect a theory of knowledge with the philosophy of conduct, the philosophy of art, and the philosophy of religion.

Men commonly distinguish, and often very sharply, between opining, believing, thinking, and mere dreaming, on the one hand, and knowledge, on the other hand. The characteristics which mark this distinction are of two kinds; yet these two kinds are so related in the individual processes of cognition, as well as in the growth of cognition, that they are mutually dependent and mutually serviceable. They are, first, the intensity and tenacity of the conviction which belongs to the judgment terminating the mental process; and, second, the clearness and completeness of the conscious recognition given to the grounds upon which this judgment bases itself. Because both these characteristics can be tested, or realized, in the consciousness of the cognizing subject, all men make, more or less intelligently, a distinction between knowledge and other allied mental states. Yet consider what strange confusion of language and practice prevails in this entire matter! Many men affirm knowledge for themselves on grounds which would avail with difficulty to warrant other men in pronouncing even a doubtful opinion; and the affirmation is "backed up" with a warmth and tenacity of conviction which others reserve for only the most certain and important of universally accepted practical truths. In some minds this way of mental seizure upon the "stuff" of opinion, with a view at once to convert it into the finished product 
of eognition, appears habitual or eren constitutional. But other minds, especially those that possess the so-called scientific bent and method and habit, scarcely venture to affirm knowledge of any kind; and would willingly give to all the accepted categorical judgments in which the matter-of-fact basis of science consists, the pale and sickly cast of mere opinion. Is it time to forget how Dr. Bastian affirmed that, "for a fact," he saw living forms spontaneously generated in thoroughly sterilized fluid; and how $\mathrm{Mr}$. Romanes wrote to Darwin his intention to "believe" in pangenesis, whether he could establish it by proof or not?

It is generally admitted that "opinion" is a word to be used for those of our judgments which cannot be so clearly connected with grounds as to render them entitled to the term "cognitive" ; and also that such judgments do not warrant, and cannot rationally receive, the same degree of conviction as that which attaches itself to genuine cognitive judgments. $\mathrm{By}$ "belief" we oftenest intend to mark those mental attitudes in which judgment is pronouneed under the influence of feeling, but with little or no satisfactory recognition of its justifying grounds, and generally, therefore, with a weaker degree of conviction. When men reason, however, and affirm the judgment in which the process of reasoning terminates as merely their " thought about," rather than their "knowledge of" any subject, they usually mean to emphasize a distinction somewhat different from the foregoing. Thinking, as a mental performance, is per se a placing of the judgment on consciously recognized grounds; no one can, therefore, properly say that he thinks thus and so about any matter of judgment who has not really done some thinking-or tracing out of the grounds of his judgment. The words "I think," rather than the words "I know," may be employed, however, either because the path of judgments, across which the thinking lies, is not itself wholly clear; or because the path, although itself clear, does not lead to any ground 
of the kind which can be called immediate or intuitive cognition.

The distinction between knowledge and dreaming - or any form of that merely reproductive or more constructive association of ideas of which dreaming is the popular type - is of a still different character. Doubtless, if the question as to the amount of cognition possible in dream-life is seriously raised, it receives from experience a somewhat doubtful and contradictory answer. Most intelligent persons are accustomed to regard their dreams as having, at best, little value in promoting a growth of genuine cognition; science, at any rate, does not come by way of dreaming, and few, if any, are the contributions to the assured body of scientific truths which have been made by the most florid dreamers. Other persons, on the contrary, go to the extreme of attaching a superior significance to the impressions, the mental pictures of present or approaching realities, which arise in the mind during its dream-life. It is not our present intention to deny the existence of dreams of anticipation, revelation, or prophecy ; or to dispute the accuracy of the alleged facts on which the efficacy of this means of attaining knowledge is affirmed. Perhaps Tartini did actually dream out his "Devil's Sonata," and Voltaire, one version of his song to Henriadne. Dannecker's colossal "Christus" may lave first appeared to him as a dreamimage; and Jean Paul may be reciting correctly facts of experience when he maintains that in dreams he often saw sights, especially countenances and eyes, incomparable, and which remained of influence with him for a long time. Such experiences, howerer, are scarcely to be called cognition; or if so-called at all, such cognition is certainly of a low degree both of surety and of ralue. Prognostications of a definite sort may also come in dreams; as in the case of the man of whom old Galen tells, who dreamed his leg had turned to stone, and awoke to find it paralyzed. Thus Aristides is said to have dreamed in the temple of Esculapius that a bull 
wounded him in the knee, at the spot where a tumor almost immediatcly appeared. Arnold de Villanova felt himself bitten by a black cat in the foot, where the next day a cancerous ulcer appeared; and Gessner perished of a malignant pustule which appeared in his breast a few days after he had been bitten, in a dream, by a poisonous serpent. As to the psycho-physical explanation of such artistic and premonitory psychoses, the modern science of psychology is not greatly at a loss. They only emphasize the natural and acquired talent at construction and interpretation, of the human image-making faculty, which somctimes hits it right in a manner approaching the surest instincts of the animals, - but then, eren oftener, hits it wrong. What should now be remembered, however, is that these forms of consciousness, for the most part, incontestably lack just those characteristics that distinguish cognition from every other form of mental life. Hence the wise Sirach declares: "Dreams deceive many people, and fail those who build on them."

In this connection it should be noticed that even the most vivid sense-perceptions in dream-life, as a rule, lack the characteristics of genuine cognition by the senses. We are not sure that the words "as a rule" might not be converted into "universally," if only the distinction could always be accurately drawn between the coloring which the act of waking, recognitive memory imparts to the dream and the coloring which it actually had, as a dream, at the time of its occurrence. Generally, if not universally, nothing strictly resembling cognition by the senses - perceptive knowledge of things - takes place in dreams. But then, four fifths of what is called perception in daily waking life lacks the characteristics of a fully established cognition of things. For example, I pass rapidly along the streets, thinking orer some topic which interests me, or intent upon getting somewhere in the pursuit of some plan. The series of mental images, objectly determined, to be sure, yet scarcely noticed and not, 
criticised or judged at all, cannot be said to amount to a fully established cognition of serics of things. If I afterward ask myself, What have I seen by the way? the question is a challenge to that critical and judging attitude which was lacking to the original series of mental images; and the result may be the establishment now, by recognitive memory, of a representative cognition of things. But it is precisely this characteristic of critical judgment which is ordinarily lacking to the sensuous impressions of dream-life; the latter may therefore have a startling vividness and intensity without, for that reason, furnishing the characteristics of objective cognition.

Occasionally, howerer, the critical process which thinking brings to bear upon mental images, in order to test, as it were, their fitness to become terms in a cognitive judgment does take place in dreams. Oftenest this occurs while one is moving along the border line between waking and sleeping. Modern experiments have shown clearly that during the last thrce quarters, or four fifths of the seven or eight hours of healthy sleep, the curve which measures the depth of sleep runs almost parallel with the line of waking. The stream of consciousness then becomes a mixture of two classes of elements and two corresponding sets of considerations. Reality beats its way in fitfully and spasmodically upon the fantastic domain of dreams; it colors the dreams without converting them into waking cognitions, or it gets a momentary standing in the stream of consciousness, from which to push back into oblivion the dream-land itself. We, the conscious subjects of the states (fitfully half self-conscious and half conscious of a reality not-ourselves), are still, for the most part, subjected to the reproductive and low-thoughted creative activity of the image-making faculty. This activity weares before us beautiful and wonderful fabrics, and again patterns of most absurd and monstrous shapes. But it does not tell us what is true. And until we can "come to our self," can so get our 
bearings as to criticise what we see, and to think whether it will fit in to the entire structure of knowledge, we cannot tell whether we are sleeping or waking; whether what we behold as not-me is some real thing or is the pure product of our creative phantasy. Now, lo! we are wide awake, and all is changed. We have entered again into that form of soul-life in which knowledge asserts its own characteristic differentiation from mere opining, mere believing, mere having of sensuous impressions, or thoughts, or associated mental images. We come down hard now upon our cognitive judgments, stand ready to defend them as resting upon grounds which call be given to the recognition of other men, and exercise a sturdy, common-sense confidence in their validity for the beings and relations of the really existent world. Armed thus, we turn with cheerful and courageous spirit to smile at our dreams and to face the actual beings and transactions of the daily life.

But while the distinction between cognition and other allied forms of experience has reference to an absolute standard, the distinction itself is not absolute. The rather is it relative - to the standard. All men have some sort of an ideal of knowledge, which is indisputable as to the strength and tenacity of the conviction accompanying its grasp upon reality, and indubitable in the full aspect of the reasons which justify, by making rational, the attitude of feeling and will toward its truth. To attain such knowledge is to be wholly satisfied in one's own being by the character of the commerce thus obtained with other being than one's own. In the experience of such acts of cognition, one cannot reasonably doubt, and one does not feel willing to donbt. Looked upon from the side of intellection, the evidence for the truth of the cognitive judgment is complete ; looked upon from the side of affective disposition, belief is cordial, harmonizing, satisfactory; looked upon from the side of volition, the affirmation or negation is an act that is devoid of wavering, and 
that appears as a grasping of the real being of the object by the inmost being of the subject. Such an attitude of the whole soul toward Reality is called absolute knowledgeso far as the term "absolute" can be applied to human cognition, regarded even as an ideal.

Now, however, it appears that different degrees of approach to this ideal of an absolute cognition are classed together, or apart, according to a variety of changing conditions. As to evidence, the kind and amount required to warrant knowledge, in distinction from opinion or belief, varies greatly, not only in dependence upon the characteristics of the cognizing subject, but also in respect of the character of the object of knowledge, the kind of knowledge, the amount of eridence obtainable, etc. 'The vague term "sufficient reason" affords no help here. The rather is it one of sereral terms due to Leibnitz and his followers, which has continued to seduce certain minds, peculiarly liable to errors of formalism, into supposing that logical formulas can afford satisfactory tests of real knowledge. But no definition, not to say description, can ever be given as to precisely how much, or as to what kind of evidence is sufficient. Suppose, for instance, that an appeal be taken to the evidence of the senses, with the opinion that upon it alone, when clear and indubitable, the rational confidence of an absolute cognition can be reposed. And now we have to deal, on the one hand, with the man who "thrusts his fists against the posts, and still insists he sees the ghosts," and on the other hand, with the German philosopher who declares that "he will not beliere a miracle eren if he sees one with his own eyes." In such cases as these there can be no doubt as to the relativity of knowledge, in the form of dependence upon the total bent and entire past experience of the cognizing subject, as well as upon the rarying characteristics of the object of cognition.

Account inust also be taken of the reciprocal influence of the different principal factors of an act looking toward cogni- 
tion, in determining whether it shall be accepted as a valid cognition, or only be allowed the rank of an opinion, a belief, a thought, or a product of imagination. Here one's experience is that of trying to bring about an adjustment of all these factors so as to render the mind in harmony with itself, and, so to speak, in agreement with the really existent that lies "beyond" the mind. If we find eridence in perception, or in thought, that the fact is so, the principle true, or that the event will happen, then we feel a corresponding increase of conviction, and firmness of will in laying down the cognitive judgment, "It is so" ; or, "It is true" ; or, "It will happen." But if the right kind of affective and voluntary attitude does not develop in correspondence with a clarifying recognition of the evidence, then the mind fails of knowledge in its own estimate; it feels "in reason bound" to remain in the state of mere opinion or mere belicf. In many cases, however, and, especially, in cases of so-called practical or religious truth, - feeling, with its motive effects in the voluntary attitude or tendency, takes the lead of intellection. We think, we believe, we are of the cherished opinion, that it is so, and yet we refrain from saying, "I know"; this is because we cannot bring into consciousness the grounds on which to justify before our intellects a complete cognitive judgment.

What in doubtful and conflicting cases will the truly rational, the genuinely wise man do? Will he disregard wholly the impulse of feeling and the resulting tendency of will to accept the desirable proposition, the longed-for" "It-is-so"? By no means. Were this resolve firmly made by every human being, it could not be carried into effect. Men will look about for evidence to prore what they desire to know as true; and they will know to be true that which it pleases them to have true, on less evidence than they require in proof of what the affective, the practical, the æsthetical side of human nature reacts against. To say this at all is simply to say that the soul of man is not a mere intellectual mechanism, and that 
it never reaches cognition simply by following the process of ratiocination. It is to affirm again a true theory of knowledge, and to take another step toward putting this theory in defensible relations to the totality of human life. Nor would it accrue to the benefit of the kingdom of knowledge, if its subjects were to serve with less of warm interest and hearty resolve as to the reward of service they are themselres to receire. For in the conquests which this kingdom has made, human feeling and human will, enlisted in the effort to procure room for scttlement upon firm ground of rationality, have, as a rule, taken the part of leader's and guides. They are oftenest the scouts, the sappers and miners, the trumpeters which sound the charge, or the call from sure defeat and final discouragement, of the army which extends this kingdom. This epistemological truth is not confined to matters of conduct and religion alone. It is equally true in matters of science and philosophy. We shall subsequently show that considerations largely of an affective and quasipractical character not only stimulate the discoreries of science, but also enter largely into the very body of scientific knowledge. It is cnough here to notice that the great leaders in the physical and natural sciences hare oftenest felt and willed their way to the first approaches of truth, and hare then, so to speak, backed themselres up by searching out proofs to justify them before others.

It must not for a moment be supposed, howerer, that ignorant and blind feeling, whaterer degree of warmth it may attain, can raise a belief, or an opinion, to the grade of an assured cognition. One would not wisely consult the colored "aunty," who "feels in her bones" that every word of the Pentateuch came by divine dictation, in order to refute the theories of Kuenen and Wellhausen. But eren her feelings may have no small ralue in connection with some sort of belief, that is capable of being raised, by proof, to the rank of a cognitive judgment. For knorledge and faith are not 
really distinguished after the critical fashion which Kant made so disastrous to the integrity of both. Nor is the distinction itself, fundamentally considered and as affecting our epistemological theory, one that has reference to different classes of objects.

It appears, then, that degrees of knowledge must be recognized, not only in explanation of the subjective changes which mark the approach to an ideal standard, but also as belonging to the very nature of all knowledge considered as a growth of experience objectively determined. This undoubtedly requires, in sone sort, a doctrine of the "relativity" of all knowledge. But it certainly would not be justifiable, at this point in our critical examination, to make one grand leap over into the domain of dogmatic scepticism or critical agnosticism. Even if no such prize as absolute knowledge were attainable by man, the other part of the alternative would not, as a matter of course, force the conclusion that no real knowledge is attainable. For plainly the principle of continuity must be used here in the same sensible way in which it is used in other similar subjects of inquiry. For example, an elm-tree is a plant and not an animal; but an elephant is an animal and not a plant. Thus much may be known and affirmed without liesitation. But the elm-tree and the elephant are, in several important respects, alike; and there are some beings possessing the most important of these respects, common to elm-tree and to elephant, about which biology is in doubt as to whether they are plants or animals. Between these beings of a doubtful class and both elm-tree and elephant, a continuous series of living forms can be interposed. In other words, one is not forced to deny the important distinctions between certain attitudes of mind that are plainly cognitions, with all which this implies, and certain other attitudes that plainly fall short of being cognitions, because one can give no universal rule for distinguishing cognitions, or because one finds one's 
actual cognitions capable of being arranged in varying degrees of approach to a standard which measures them all.

'The illustration just given, howerer, is not intended to apply throughiout. For the most important question of all still requires a brief answer. Is there any experience possible for man which actually answers to his own ideal of " absolute knowledge"? To this question one may answer unlesitatingly, Yes. The completed act of self-consciousness, ending in the judgment which affirms my own here-and-now being, for myself, is such an absolute cognition. As involving intellect, feeling, will, all in harmony and, when harmoniously employed, reaching an envisagement of reality that has nothing more profound, or more complete, or more worthy (except the extension of essentially the same cognitive process over wider and wider areas), this immediate knowledge of the Self by itself is, in actuality, the realized ideal of knowledge. In grading other degrees of cognition we employ this ideal as our standard. After this pattern alone can we conceive of the Divine Mind as a fountain of absolute knowledge.

As a matter of experience, the possibility is afforded, and the actuality proved, of a certain form of absolute knowledge by sense-perception also. That my object is there, thus and so determined for me, and by me, and yet as not-me, - this, too, is a cognitive judgment which has all the characteristics belonging to the ideal of absolute knowledge. But how far, at this point and henceforward, the knowledge of Things falls off from and drops behind the knowledge of Self, has been discussed at length in the last chapter.

In respect of the essential characteristics of knowledge, all other forms of cognition have only a relative degree, such as marks their nearness of approach toward an ideal and absolute standard. This is true eren of the knowledge of our own past selves. It is knowledge which, at its best, is guaranteed by the act of recognitive memory, and thought into consistency with all the other experiences that seem to 
have a bearing on the truth of the cognitive judgment. At its poorest, what appears knowledge of the past is mere unjustifiable belief or untrustworthy opinion. Back to these firm points of standing in our so-called immediate or intuitive knowledge of Self and of Things we keep referring all our opinions, beliefs, and thoughts, in order to make between the latter and the former that rational connection which is called "proof." The principles that underlie this process of "making rational connection" await detailed examination. The picture gained as the result of exploring the realm of knowledge, to discover in what respect it admits of degrees, is the picture of a changing and dereloping life of the mind. This is true both for the individual and for the race. Human beliefs are constantly growing stronger or fading away; they are gathering to themselves, or losing from themsclves, the light of intellect needed to convert them into cognitions, to fit them to become part of the body of human knowledge. Thoughts are getting more or less abstract, are flying lower or flying higher -

\section{"In regions mild of calm and serene air,}

Above the smoke and strife of this dim spot,

Which men call Earth."

But the lowest of human thoughts must make connection with the highest, or sink into the mire; and the highest of human thoughts can soar toward hearen only if they return frequently to rest upon the solid grounds of some kind of fact. Imaginations constantly run far ahead of known trutlis; but they vanish in the mist unless they prove the forerunners of truths to be known, bearing beneath them the sustaining limbs of experience and carrying on their backs a good load of the choicest ethical and æsthetical interests of mankind. Is this, however, a pieture to make a brave and thoughtful man sit down in the dust of scepticism, or stick fast in the quagmire of a hopeless agnosticism? We are "of opinion," that it is not. 
The use of the term " degrees of knowledge," witl reference ,to some ideal standard of worth which enables us to rate different cognitions as "higher" or "lower" than one another, needs little further exposition at this point. It is plain that the standard set up is not, in this ease, the excellence of the approach made by aly particular cognition, or set of cognitions, to some ideal which is itself of a cognitive character. The amount and kind of evidence, the strength and tenacity of conviction, the motif and firmness of will in affirming or rejecting, are all integral parts of the cognitive process itself. But the claim of different eognitive judgments - for example, those of the man of ordinary experience, of the scientific man, and of the philosopher, or those of the adrocates of the supreme importance of conduct, or of religion, or of "trutl for its own sake" - to stand above each other in excellence, must be taken to some court of appeal that does not have regard merely to the quality of the cognition as such. We have already declared that the appeal is made in this case to the value of some kind of ideal life. This fact may suffice to indicate the unreasonableness of the alternative proclaimed by many writers ${ }^{1}$ between perfectly clear, indubitable, and certain knowledge and no knowledge at all. Such an alternatire overlooks the rery nature of knowledge and the unavoidable conditions of its growth; to carry it out would oblige us to confine the word to the immediate delirerances of self-consciousness and sense-perception. Science would then not be knowledge. And, indeed, all knowledge would be impossible; for this perfectly clear, indubitable, and certain knowledge is itself a matter of growth, a prize to stimulate achicrement ratler than a ready-made and completed gift from the hand of Reality.

Probably no other branch of epistemology has led to so much misconception as the inquiry into the Limits of Knowl-

1 For example, by Mr. Bradley in his "Appearance and Reality," chapter on "Degrees of Knowledge." 


\section{DEGREES, LIMITS, AND KINDS, OF KNOWLEDGE}

edge. And not a little theoretical confusion, as well as no small store of mischief in the practical life, has resulted from this misconception. Yet almost all that can be said respecting limits to human cognition, so far as the doctrine of limits forms a legitimate part of epistemology, lies near the surface and may be speedily brought to view. Strictly speaking, to describe the limits of human cognition in general would require that one should mark out the entire domain of all the particular sciences, with the accompanying degrees of evidence of various kinds which these scicnces possess and to which they defer. Such "geographizing," however, would add little or nothing to a philosophical theory of knowledge. It would bear about the same relation to our higher theoretical interests which the nautical almanac bears to new discoveries in the science of navigation. It would scarcely have the influence upon the advance of epistemology which may be expected for astronomy from the modern use of photography in mapping out and numbering the stars.

The discussion of the limits of knowledge, in order to be illumining and fruitful even in the slightest degree, must begin and proceed by holding fast to certain distinctions. Of these, the first, both in time and in importance, is the distinction between the limits of knowledge and the presuppositions of knowledge. In some sort, to be sure, the latter may be regarded as setting limits to cognition, because they do mark out the boundaries within which the entire system of human cognitions lies. This amounts to saying that, unless certain conditions are assumed as being fulfilled, no knowledge is possible; but that these same conditions, being actually met in all the origin and growth of cognition, definitively settle the bounds within which the rise and progress of all human knowledge takes place.

But now by a strange leap which is, logically considered, a paralogism, and, practically considered, a mark of natural perversity, these same conditions are spoken of as though 
they cramped and hindered cognition. A man's skin, as marking off the superficial area of the different members of his organism in a smooth, continuous way, is the natural limit of his body. Inasmuch as it has most important physiological, nervous, and rsthetical functions, it is an indispensable condition of the healthy existence, and even of the existence at all, of the entire body. But it can scarcely be spoken of with propriety as a hindrance to his larger and freer development, as a bodily organism; nor is it desirable to attempt the problem of getting "out of one's own skin" in order the better to realize what an unlimited extension of the human body possibly may be.

In the case of that knowledge which comes through the senses, we use the word "limits" with a possible application in both of two directions. Each one of the senses has its natural limitations of capacity, fitted to the peculiar function which it is intended to perform. Indeed, each sense has a number of limits of this kind, that depend upon certain subordinate differentiations of its more general functions. Further, these limits are variable for different human beings, and also for the same human being at different stages of his development, or under different circumstances. And yet these limits are not indefinitely remorable for any individual man or for the whole race, so far as oul knowledge of the characteristics of individuals and of the race at present informs us. The limits of tones, for example, are those corresponding to between 24 and 24,000 vibrations of the stimulus in a second of time; but in individual cases, possibly, between 14 and 40,000 or 50,000. The limits of color's are for most eres between the deep red and the violet rays; but for some, the still lower red and the ultra-violet rays are visible. Possibly, a few eyes can see the halo around the magnet through which an electric current is runuing, although to far the greater number there is no halo to be seen. Yet, again, have not all, of late, been made to see things, before sup- 
posed invisible to all, by the discovery of the Roentgen rays? But, alas! there are some, on the other hand, who are tonedeaf or color-blind; and who, therefore, having ears, hear not, and having eyes, see not - as we who are more farored delight to hear and to see.

Not only is the range of the particular senses limited, although thus indefinitely; but also the number of these senses in all may be spoken of as limited, in somewhat similar way. Until recently the orthodox supposition in psychology held that the special senses of man were in number fire, no more and no less; and we find even that free-lance and credulous philosopher, named Schopenhauer, speaking sneeringly of ally assumption that other senses might possibly be avenues of cognition for human beings, as of a "sixth sense" for bats. But modern investigations liave added to the five senses formerly admitted several others; for example, a " temperature sense," a "joint sense," and perhaps an outfit of "sensations of position" in space through excitation of the semi-circular canals, - not to speak of the debatable "muscular sense," and the centrally originated sensations connected with the cognition of the Self as active and intensely alire. Nor is it quite admissible for the psychologist of fair mind to break off with this enumeration in such manner as to announce his determination to admit no other kinds of "sensation-stuff" (or, to use Kant's shifty expression, "that-which-is-given") as belonging to the domain of knowledge through sense. Believers in telepathy, clairvoyance, necromancy, and all of that ilk, would probably for the present most wisely have their claims to enter the elan of the "scientists" pronounced upon as "not proven." For ourselves, we do not just now even "half-believe," not to say, know that these avenues can bring to the human mind aught regarding the Reality which is not-ourselves. But the phenomena which fall under the various forms of "far sight," and "second sight," and extraordinary "insight," are of a 
character not to allow of an off-hand dogmatic limitation of the borders between the sensible and non-sensuous worlds. They do show plainly, on the other hand, that these two worlds so-called are really one; the two are capable, therefore, of being bound into the unity of experience through that commercio which is the essence of knowledge, in an unknown rariety of ways.

Our experience, considered as some sort of a totality dependent upon racial characteristies and racial development, suggests at this point a somewhat startling conjecture. There is reason to surmise that the lower animals constantly adjust themselves to subtile elanges in their environment, and carry out in that environment what appears to us a system of shrewd plans, through their experience in the form of obseure and confused impressions of a sensuous kind. They are not, howerer, aware of themselves or of their objeets, in all this, in such manner as to entitle the stimulating and guiding acts of their consciousness to be called acts of cognitive perception. Psychology, therefore, speaks of such psychoses as instinet, feeling, tact, etc. But human cognitive development is to be explained, for individuals and for the race, only if recognition is made of a constant relation of reciprocal involution and evolution between such lower forms of psyehoses and genuine states of cognitive perception.

In every series of perceptive acts the grounds of the cognitive judgment in which the acts terminate, as a matter of fact, do not themselves appear in consciousness. In other words, what determines the character of the judgment must largely be spoken of, in every case, as unrecognized causes rather than reasons, or "grounds" in the more appropriate, logical meaning of the word. Yet the judgment is, on the whole, so reached and, when reached, so found possessed of the necessary characteristics, that the entire process is fully entitled to be called an act of cognition. But, on the other hand, 
the grounds of eognitive judgments, as they consist in characteristic detcrminations of the "sensation-stuff," are brought more and more elearly into consciousness, as a necessary element in the growth of cognition by use of the senses. Thus what resembles instinct, blind feeling, and tact is constantly being taken up unconsciously into knowledge; and knowledge itself also consists in consciously recognizing the presence and significance of a great number of factors which, in the ease of the lower animals, appear to remain as instinct, blind feeling, and tact.

Now this process of reciprocal involution and evolution, which is essential to the growth of perceptive cognition, renders it possible that the number of recognized scnses possessed and intelligently exereised by man may be indefinitely increased. And comnected with this prospect is the sure progress of the plysical sciences, helped on by psychology, in devising means of knowing what things are by use of these newly discorered senses. A generation ago, the scientific observer would have been much more disposed to fix rigid limits, both quantitative and qualitative, within which all things, so far as visible, must be known. But both microseope and telescope have extended the limits of secing the minute and the remote far beyond the lines formerly drawn. The spectroseope has made vision an apparent arenue for cognition of the more interior nature of distant bodies. And not only this, as matter of clief surprise; but all of a sudden, and lately, we have had revealed, through use of the eyes, under the action of a force which cannot at present be classified with any known kind of foree, new manifestations of matter in hitherto undiscovered relations to the senses of man. How many of yet more startling disclosures may not await the future of the human race! Even the discovery is not impossible that men have always used a score or two of senses, instead of the five allowed by the traditional psychology; and the future may bring into recognized use, for largely increased 
knowledge of nature, a score or two more that have been hitherto so little used as scarcely to be entitled to the claim to exist.

It should, of course, be said that, after all, our knowledge of things through the senses will always be limited. It is safe enough to predict that the number of human senses will never be indefinitely large; and that the number of distinguishable sensations which rise above the threshold of our human consciousness will nerer reach infinity. Moreover, and quite as much a matter of course, all knowledge of this sort will be limited to such sides, or aspects, or forms of the activity of things as can be known in a sensuous way. In reaction, thercfore, against this limitation, from which no reasonable or even conceirable means of escape suggests itself in our case, it is eustomary to form the picture of beings that cognize things in other and preferable ways. Eren Kant, as a kind of subjective correlate to his Ding-an-sich, admitted the possibility of an intuition which should be non-sensuous; and this intuition, by escaping the limitations of all senseintuition, might furnish an immediate envisagement of the nature of Reality itself.

At once, however, we are mored to inquire: Whence comes this dissatisfaction with the seeming extcrior character and the irremovable limits of the human knowledge of things? To this inquiry our discussions have already provided the prompt and incontestably true answer. The dissatisfaction arises from the innermost cognitive nature of man. But whence comes the fair picture of a possible kind of knowledge which shall, at least in great measure, remove the dissatisfaction, a kind of knowledge that shall not leave things still external to us and leave us feeling shut off from the true nature of things? To this inquiry also, the prompt and incontestably true answer has already been furnished: It comes from the depths of man's rational experience with himself. It is the picture of a being that shall be so constituted as to know things, 
perchance to know all things, as man knows himself. For the Self is known with an intuition which, so far as it goes, both furnishes and guarantees the correspondence of the object of cognition with the reality cognized. But things, as to their nature beyond the negative definition of a beingnot-me, are only analogically known. It is the recognition of this fundamental difference and the conception of a being that shall transcend this difference by having an experience which gives the cognition of things to the Self, after the manner in which the cognition of Self is given to us, that leads men to speak of irremovable limits to human knowledge by the senses.

It is more usual to discourse of the "limits" of scientific knowledge in a meaning quite different from the foregoing. "Science" is supposed to be knowledge par excellence, the only cognition which will bear the tests that are necessary to separate between the genuine, trustworthy metal and the baser admixtures of opinion, belief, and mere abstractions. But those who have most confidence in the validity of all truly scientific knowledge, and most pride in its recent rapid advances, are readiest to admit that its achievements hitherto have compassed no appreciable percentage of what remains yet for science to do. Its field is, therefore, thought of as narrow and limited in comparison with the extent of nature at large, regarded as a possible object for scientific research and scientific discovery. Now, science lays emphasis on that knowledge which has taken the form of the universal, in distinction from the particulars of individual acts of cognition, whether of things or of Self. Science is knowledge of the generic characteristics of large numbers of individuals and of general laws, or of the uniform modes of the behavior of the individuals under certain definitively fixed relations to each other.

It is admitted, however, that in order to have a system of judgments which states the characteristics and laws of things 
and which may be considered as scientific knowledge, the grounds of connection must be made more or less clear and defensible between this system of conceptual judgments and those cognitive judgments which are terminals of the particular processes of perception and of self-consciousness. The bearing of such a connection upon our view of the validity and extent of human knowledge will become evident through subsequent discussions from somewhat altered points of view. From the present point of view it appears simply that the case of that conceptual knowledge at which science aims is not, so far as the application of the word "limits" is concerned, markedly different from the case of perception through the senses. The range of what is already known appears, in fact, exceedingly small in comparison with the conjectured extent of what may possibly yet be known. In fact, also, the amount of that which is known constantly increases. But since firsthand evidence in the form of immediate cognitive judgments must somewhere be furnished, or else our so-called science lacks a sure ground of standing in reality and becomes mere thinking and imagining rather than assured knowledge, the limits of sense-perception set certain limits to the science of things.

Here emerges, however, a very important difference between scientific knowledge and immediate cognition through the senses. Science is not content with knowing enough about things simply to use them cumningly. It aims at explaining things. As has already been said, it claims to state its cognitions in a system of judgments about unirersals, - about kinds of things and about the laws of their behavior in manifold relations. Now the knowledge of facts, even when of the clearest and surest, by no means carries with it the knowledge of the explanation of the same facts. And men are constantly finding out that the most frequent and familiar of facts, as cognitively apprehended, become the most complicated and mjsterious when an explanation of them is demanded. To 
know "that," and a little of "what," is not to know all of what or any of "why." It is no wonder, then, that the limits of scientific knowledge, although actually widening, seem to be growing narrower in comparison with the boundless extent of the scientifically knowable that is as yet unknown. Thus we may, on the one hand, contemplate the fair prospect of more rapid advance for the particular sciences in the future than has been at any time in the past history of the race. We may even expect the fulfilment of those aspirations which, in germinal form, led Paracelsus to declare:-

“Thus I possess

Two sorts of knowledge; one, - vast, shadowy,

IInts of the unbounded aim I once pursued:

The other consists of many secrets, - caught

While bent on nobler prize, - perhaps a few

Prime principles which may conduct to much."

And should this increased knowledge of facts and causes be followed by a corresponding growth of skill and art, then diamonds may be turned out (no longer mere black pin-heads) from crucibles filled a few hours ago with charcoal; and this charcoal itself may be no longer needed for fuel in an age when the atmosphere yields freely its thermo-dynamic resources.

On the other hand, this expected realization of the Tales of the Arabian Nights, under the improved moral restrictions of modern civilization, will itself be a limited affair. There will still remain - so we are accustomed to say in mocking self-pity or in childish complaint - the infinite ocean of undiscovered truth; and the greatest men in science will still be little children gathering a few pebbles upon the shore. How rarely is it remembered that, by this manner of looking at the intellect of man and at the nature of the Reality with which he supposes himself to hold commerce of an intellectual kind, assumptions are being justified that reach even beyond those for which science is wont to rebuke the theologian or the metaphysician of the most dogmatic type! 
As every student of the problem and history of epistemology kuows perfectly well, the question of limits presents itself in a yet more trying and dangerous form to our critical thinking. In Kant's celebrated chapter, "On the Ground of the Distinction of Objects in general into Phenomena and Noumena" he compares the whole domain of "pure understanding" to an island "enclosed by nature itself within limits that can never be clianged." "A wide and stormy ocean," full of fog-banks and of ice, surrounds this island; it is "the home of illusion," but the island is the country of truth. If now we inquire of this critical explorer, who has just surreyed the entire island and laid it out with his analytic spade after the fashion of a French garden in the last century, what constitutes the unchangeable and hopelessly fixed limits, the reply is somewhat remarkable. The "limits" are the constitution of the island itself. But one might reasonably expect to be told the rather: 'The limits are the surrounding "wide and stormy ocean." And, indeed, upon this same ocean Kant, the great explorer, brarely sets sail with the four tables of the categories for his chart, and the interests of a faith which is to take the place of knowledge, when the latter has been "removed," lying heary on his heart. Thus guided and ballasted, as it were, he diseorers in the entire explorable extent of this ocean three will-o'-the-wisp ideas, which, although they are not even to be spoken of as stars, descried from the island through the ocean's mist, and set there by the good God to guide aright poor mariners, must nevertheless be followed and believed in as real; and so, if followed, they will lead to the practical faith which reposes content within a recognized illusion as its "fictive" haren.

But perhaps sufficient fault has already been found with the "Critique of Pure Reason" for its off-hand identification of the presuppositions of all cognition-especially those of a formal sort - with limits or barriers that mark off and exclude cognition from the world of the trans-subjective. The exam- 
ination given hitherto to the nature of knowledge has certainly not justified a premature confidence in warrants for this lcap into agnosticism. To refute it further, and to confirm a mature confidence in more positive and reassuring conclusions, requires no little of remaining critical work. The supposition that human knowledge cannot sufficiently commend and enforce its own ontological implicates must lead to the inquiry as to what thesc implicates are, and as to the terms on which they are given to the intellect for its acceptance or rejection. The denial of the power of experience to transcend its own limits must be met with a profounder examination of the concept of experience, with a view to see whether aught that is so self-limited corresponds to our actual experience. When scepticism and agnosticism challenge our cognition to recognize its limits, it is time to send the challenge back, and to inquire what are the necessary limits of scepticism and of agnosticism. And, finally, the very doctrine of the "relativity of all knowledge" irresistibly brings on the inquiry whether this term, too, does not also imply the absolute nature of some human knowledge.

Only when these and kindred discussions have been conducted to an issue in an unavoidable agnosticism can we consent to consider favorably the merits of a doctrine which speaks of knowledge as though its presuppositions, and even its necessary objective implicates, could properly be turned into fixed barriers of human mental activity. There is quite too much apriorism to suit a genuinely critical student of the epistemological problem in the off-hand assumption that the so-called "catcgories" are hindrances to a cognition of Reality, rather than forms of its truthful mental representation.

Meantime, the preliminary truth which has been derived from previous discussions may be stated in the form of a caution: Transcendent entities and principles, made use of in the interests of explaining experience in general, must be derived from a basis of concrete experiences with acknowledged actual- 
ities. Here the relation of content and form, of substantial existenee and mode of mental proeedure, is such that the two eaunot be considered or critieised apart. The universal mode of mental procedure by which we explicate the transcendent that is implicate in our experience is a morement of eognitive judgments under the principle known as "sufficient reason." Whenever, then, a connection of judgments established in this way leads us beyond the limits of individual experiences, the advance thus gained carries with it the content that is implieate in the form. This is a genuine advance of knowledge, as distinguished from an endless wandering over "the wide and stormy ocean" of illusion, in the vain attempt to convert mere imaginings and abstractions into content of truth, after the fashion deseribed in the Kantian "transcendental dialeetic."

Any discussion of the Kinds of Knowledge, from the epistemological point of view and with the intention to make the diseussion yield fruit for the seience of epistemology, must constantly regard two very simple practical rules: The different species distinguished must all belong to the one genus, - namely, knowledge; and the principles of division aecording to which it is proposed to break up this genus into species must be intelligently chosen and consistently maintained.

In violation of the first rule, Schopenhauer, after berating Kant soundly (and, indeed, not without a show of reasons) for exalting coneeptual above perceptual knowledge, proceeds himself to reverse the positions of the two so as virtually, by some of his expressions, to deprive the former of all claim to be called "knowledge." Indeed, it would seem to be by a kind of non-sensuous intuition, sueh as Kant thought superhuman beings alone could possess, that Schopenhauer arrives at the cognition of the essence of Thing-in-itself as "Will." But how can one speak of kinds and degrees of knowing without admitting that, considered as to its essential characteristies, there is only one kind of knowledge? "Kinds" - 
in this case, as in every other case-are only subordinate species of the one genus or kind. What the essential marks of this genus are, what is the genuine concept of knowledge, has surely been discussed at sufficient length. The discussion has shown that perception and intuition, without thinking, never amount to cognition; but also that mere conceiving, mere judging, and especially abstracting from all content of a quasi-intuitive sort, can neither impart nor advance knowledge. So that when cognition by intuition or envisagement and cognition by abstraction and thought fall into a quarrel over the question which of the two is entitled to stand highest along the scale of surety or of worth, they are obliged in good earnest to admit each other's claims, or they cannot rationally even begin the quarrel. The same thought arises when men of science are heard depreciating men of practical or artistic insight, or the reverse; and when men of firm faith denounce the rationalism of those who do not reason as they do, or men of active intellects decry the credulity of those whose belief differs from their own. For cognition itself is impossible without both insight and argument; and all men must both believe and think in order to know at all.

If, however, the fundamental facts as to the nature of cognition are borne constantly in mind, several different divisions of cognition may be made, according to different points of view and changing principles of division. One of the most important of these attempts at classification distinguishes the pure - often called a priori-kind of knowledge from that which is empirical, - sometimes called a posteriori. Of the former, the science of mathematics is the accepted type; and other kinds of knowledge stand, in the scale of purity, nearer to or more remote from the type, according to the degrees of their approach to mathematics in the character of their reasoning and in the certainty of their conclusions. This entire distinction, however, is usually carried out in a manner to contradict or obscure a true philosophical doctrine of knowl- 
edge. For just so far as mathematics and the so-called mathematical sciences constitute a body of cognitions, and not a mere system of abstractions, they are built up as are all structures of a cognitive kind; that is to say, they consist of a number of connected judgments, which have their source and their verification in a trustworthy commerce of mind with really existent things. The view which regards mathematics and the mathematical sciences as a sort of sensuous transcript or copy of ready-made things, regarded as standing in extra-mental relations to one another, and the view which regards them as purely thought-constructions, having no need of concrete self-consciousness or of perceptions by the senses, are both equally untenable. Like all other cognitions, these also are dereloped by the application of thought to our concrete experiences with ourselves and with things. And the moment mathematical conceptions wander away from the path in which they can make ralid connection with these concrete experiences, they cease to be cognitive in any defensible meaning of that term.

One of the most valuable of the subordinate truths taught by Kant in the "Critique of Pure Reason" is the necessity of finding the source and verification for all our mathematical knowledge in what he considers a priori activity of the constructive and synthetic imagination. If one wants to know what a straight line actually is, then one must draw it, by an act of constructive imagination. But Kant does not emphasize the truth that such drawing of a straight line is quite impossible for a mind that has not preriously traced some line, as seen or felt, actually limiting a thing perceired by the scnses. That is to say, the grounds for the conception of a straight line, on which the foundations of all mathematics of the geometrical order and all the mathematical sciences themsclres are standing, are giren only in the cognitire judgment which terminates a series of sense-perceptions. This process is an envisagement by thinking mind of the nature of the 
really existent as given to it in the object of sense-perception. What is true of those processes that constitute the actual experiences in which we come to the knowledge of the properties of a straight line, is true of all the experience which furnishes all the otler primary conceptions and axioms of geometry. As a science, a system of cognitions, it is not a mere product of imagination or of thought, much less of mere aggregated sensations or of associated ideas. It is rather a product of the entire mind in its actual, living commerce with things.

Whenever Kant discusses the nature and origin of those cognitive judgments which make up the science of arithmetic, the other of the only two divisions of mathematics, he is more than ordinarily unsatisfactory in his account of their epistemological character. Arithmetic is, in fact, from beginning to end, nothing but counting. The activity of the mind in the cognitive processes which enter into counting is, however, exceedingly complex. It involves all the intellectual powers ; it both promotes and implies the development of time-consciousness; it involves recognitive memory and self-consciousness. As applied to Things instead of the successive states of the Self, counting can at first be done only in connection with and in dependence upon successive acts of the concrete cognition of things through the senses. All the science of numbers, as well as the science of space relations, has its sure foundations, as science (as knowledge and not mere imaginings, or thoughts, or beliefs), in that commerce with Reality which all men have through actual, concrete sense-perceptions.

What, however, shall be said of the claims of that mighty and towering superstructure of mathematics, rising higher and still higher with speculations so sublimated that only a handful of initiated priests can even discern the meaning of its mysteries, but which often makes claims to be a temple of knowledge par excellence? In answering this question, one must remain faithful to a critical epistemology, neither hiding 
anything of truth by interposing the agnostic doubt, nor setting down to the credit of mathematics admissions which would annul all true conceptions of the nature of knowledge. The truth lies in the middle path. Mathematics can increase human knowledge, both in the number of its true judgments and in the degree of clearly discernible evidence on which they are consciously made to repose. But mathematical reasoning alone can never furnish us with truth; because it can never, of itself as it were, amount to genuine cognition. So far as the system of judgments which it develops can connect themselres with the known nature and actual relations of real things, this system forms a part of the explanatory science of things. But so far as it cannot make this connection, the clearness and cogency of the arrangements which it produces between its own abstractions give it no claim to be called a form of "knowledge."

Here we may fitly raise again the question touched upon in a preceding chapter (pp. $143 \mathrm{f}$.). What do I really know when I affirm as true some relation of mathematical symbols which I have reached as the result of days of hard work and pages of figuring and plotting of curves? Not necessarily more than this: namely, that, starting from certain assumptions of abstract relations between mere concepts, I have argued, in accordance with accepted mathematical rules, to the conclusion of certain similar relations betwcen eren more abstract concepts. Thus much is true; and I know it to be true. But the instant I propose to apply this process of argument, or its assumptions, or its conclusion, to any actually existent relations between real beings, I am met by the prior question: "How do you know that the nature of real beings admits of their entering into these peculiar mathematical relations?" And eren if the assumptions, in which the argumentatire start began, were known to be applicable to things, it by no means follows that the calculated extensions of those relations admit of such an application. For things may not be 


\section{2}

constructed mathematically all the way tlirough (" according to Euclid," or "to Gunter," as we might say). Indeed, things do not appear to be mathematical throughout. And there is probably no greater or more mischievous fallacy current in scientific circles at the present time than that of supposing that a knowledge of reality, or indeed any real extension of knowledge, can come chiefly in this way. How the failure to observe the difference between mathematical abstractions and the reality of things has led to vain puzzles and to important errors, from the conundrum about Achilles and the tortoise down to the antinomies of Kant, we shall consider elsewhere.

Some light is thrown upon the epistemological problem by considering the effect of distinctions in time as present, past, and future, upon the resulting kinds of knowledge. Undoubtedly memory and inference are necessary to the cognition of what appears, in time, as present matter-of-fact. Indeed it has been seen that memory and thinking necessarily enter into all cognitive processes. But the knowledge of the object here-and-now present, whether that object be the Self or some Thing, differs from the knowledge of the same object by an act of recognitive memory. Experimental investigation of the laws which govern the fading of the memory image, and abundant experience with errors of memory, combine to show that, as respects its surety, cognition by memory is inferior to the immediate cognition of self-consciousness and of sense-perception. It is, however, primarily with regard to the intensity of belief in the reality of the object cognized that the difference is noticeable. Not infrequently the cognitive judgment is more discriminating when it is based upon memory than when based upon the process known as immediate intuition. Sources of error which arise in the affective consciousness generally account for this. On the other hand, the fallibility of memory is as much a commonplace as are the errors of sense or the foibles of self-knowledge. 
It is not in these subjective conditions alone, however, that our superior confidence in present cognition is based. As we project ourselves backward in time by an act of imagination, we do not feel so sure that things themselves were not markedly different in the past from what we now know them to be. Nor does our own cherished and well-remembered Self escape wholly from this doubt. Do I remember how I thought, felt, and planned - what manner of one I was - in childhood or in infancy, so that I can affirm knowledge on the basis of this memory, even when I have apparent memory to bring forward in proof? All men, therefore, think it right to bolster up even the clearest recognitive memories of what was, espccially if the time concerned was remote, by arguing as to what must have been. Thus opinions of memory are lielped up to the rank of cognitions by the arm of rational inference. The individual fact is thus certified to by an appeal to its connection with the universal in experience. Yet, again, the most assured scientific knowledge of things suffers from the weakening effect of long stretches of time. Scientific knowledge is, by nature, universal and so avowedly independent of time. But he would be too bold a teacher of science who should be just as sure of any principle when applied to the physical realities of countless ages ago as when applied to the system of things known to be existent to-day. This certainly looks - does it not? - as though the so-called "system of things" might really be a Life, changing its modes of manifestation or self-realization in accordance with immanent Ideas, rather than a collection of rigid entities, blindly subject in a mechanical way to unchanging laws.

In answer to the inquiry whether knowledge of the future is possible, a negative reply rises most readily to one's lips. But it cannot be admitted that the future is wholly unknowable without virtually destroying the foundations of all knowledge. Indeed, all practical cognition, or all cognition put to use in any way, implies the right and the power to predict. 


\section{DEGREES, LIMITS, AND KINDS, OF KNOWLEDGE}

As a mechanical engineer, after a thorouglı examination, I may affirm, "I know the bridge is safe." The judgment, "the bridge is safe," implies the predietion, "This same bridge will not, the next instant, fall of its own weight." But is it not, after all, possible that the bridge may go down; and do I surely know that it will not? Now if one answers this question by saying that, "abstractly considered," such a catastrophe is possible, the retort follows that the question does not concern abstract considerations, but concerns rather the grounds of the possible cognition of what will actually be. And if it is further said that, perchance, some error has crept into the calculations, and therefore the bridge may fall, then the reply is that such error vitiates the declaration, "The bridge is safe," and converts it into a judgment of opinion, instead of a truly cognitive judgment.

Eren in the case of a judgment declarative of a fact of perception, an implied reference to the future validity of the judgment, if it is truly cognitive, cannot be avoided. "The snow is white; but the clothing of the man standing upon the snow is black." Such a statement, in order to lay claim for recognition as knowledge, must imply something more than a merely subjective connection of forms of mental representation. It is understood to imply an objective connection maintaining itself between the "momenta" and relations of really existent beings. It follows that the judgment must bear examination in order to be true; it must have enough of stability in the world of things to repeat itself in my mind and in the minds of others. If now, when I look again, the snow is no longer white and the clothing of the man standing upon the snow is no longer black, why, then the former judgment was not cognitive - unless, indeed, the color of the snow and of the elothing has somehow been changed. But this very demand for a "reason" why the former judgment should not be withdrawn as erroneous, or else the present change in judgment must be justified by an 
appeal to some new grounds, shows the nature of the relation between cognition in general and the distinctions of time. Knowledge resting on grounds that cannot change is knowledge once for all; it is timeless cognition, and must imply knowledge of the future as well as of the present and of the past. But without some conscious recognition of grounds at least, hurriedly gathered and scanned, although perhaps scarcely to be called "consciously recognized," after all - no cognitive judgment can be laid down. And, as has been already pointed out, the more conceptual and scientific cognition becomes, the more independent it becomes of the gnawing tooth of time. Scientific knowledge is of the unirersal; science boasts its power assuredly to predict and to lay down truths that are independent of time.

And yet this claim of science to an established character, and this boast of the power to extend itself into the indefinite future, can by no means be made wholly good. For we are only relatively sure of the unchanging truth of our most firmly established scientific generalizations. The whole system of things physical may possibly be completely upset to-morrow, - " possibly," with an abstract possibility. But if one cannot say one knows it actually will not be, one cannot claim an absolute certitude for any system of scientific cognitions. Here it is exceedingly important to notice that any doubt or agnosticism which may afflict the mind does not refer to the possibility of the laws of our intellects undergoing an important change. Neither is it due to a recognition of the Kantian claim that human knowledge does not reach to noumena, or to things-in-themselves. The rather is it because men are sure they know Reality well enough to engender reasonable doubt as to how far its self-imposed limits to change may possibly extend. In other words, we know noumena, or things-in-themselves, "too well" to trust them indefinitely to confine themselves according to our rules as to the way they absolutely must change in the future. But it 
is just this very independence of human wills which things display that makes them known to human minds as realities indeed.

Once more, then, by an indirect and circuitous path we reach the discussion of certain questions left over in the very distinction of knowledge from other kinds of conscious states. Now we may the better inquire as to the significance of the contention of Schopenhauer: "The given material of every philosophy" (of all cognition in actuality, and so of all theoretical discussion of the problem of cognition) " is accordingly nothing else than the empirical consciousness, which divides itself into the consciousness of one's own self and the consciousness of other things."1 Conceptual knowledge, however, is the elaboration of this so-called empirical consciousness, in such manner as to interpret and expand its deliverances for the formation of a system of truths that shall have a claim to represent the system of really existent beings, the Unity of the World. But in some sort, the most fundamental eategories of Identity and Difference, of Process and Change, of Relation and Causation, are one thing as applied to Self and another thing when applied to physical beings and physical transactions. Thus it is not the necessity of logical determination, but the understanding of actuality, which gives the law and the goal to our higher cognitions.

Thought is subject to logical necessity: oftener than not, perhaps, actuality is what it is as a fact; and that is the last word on the subject. The actual points of starting for the logical development of concepts of experience lies just where the beginnings of experience itself lie - in the discriminating and integrating activity of mind, having commerce with particular and concrete things. But logical thinking changes these objects of self-consciousness and of sense-perception, according to certain points of view, often arbitrarily chosen, into logically differentiated objects of thought. These logical

1 The World as Will and Idea, ii. pp. $258 \mathrm{f}$. 
entities it places in manifold relations to one another, under terms of "classes," "laws," etc. Especially does it seek for, and imagine that it finds, the formulas to express the causal action of the beings which belong to these different classes and stand under these different laws, one upon another, in most manifold ways. If science becomes especially self-confident and enthusiastic, it converts some of its most abstract generalizations into primary realities and affirms an assured knowledge of their inmost and unchanging character. For example: Energy may be conceived of as an entity that can be stored and transferred, conserved and correlated; the law of its storages and transferences, its conservation and correlation, may be announced as having universal and unbroken sway over things. This is, however, for science only a conrenient abstraction; it belongs to philosophy to tell what that. actually is can answer to this term.

The right to extend knowledge in this way - or, rather, the right to conrert a system of logically related conceptions into a sy'stcm of true cognitions, of judgments affirming laws in reality - may well be questioned further at this point. This question will lead us to consider, on the one hand, the fundamental and irrefragable modes of the functioning of intellect, and, on the other hand, the criticism of those ontological implicates on the basis of which we identify the modes of thought with the modes of the really existent. 


\section{CHAPTER IX}

\section{IDENTITY AND DIFFERENCE}

$\mathrm{HE}$ sphere of experience is larger than the sphere of
knowledge; but the sphere of knowledge is too large to be completely compassed and, having been mapped out, assigned in fee simple as the domain of thinking faculty socalled. We have, therefore, narrowed our problem greatly 'and defined its limits, when for the present we inquire: What are the principles which validate and explain - so far as validating and explanation are possible - the functions of thought in all human cognition? But this inquiry, as it is proposed to the serious student of epistemology, is something very different from the question which logic may propound in nearly the same terms. The logician's point of view is one from which no anxiety need be felt as to the answer obtained, and at which no insight is gained into the deeper, ontological import of the result. For what does formal logic care as to the truthfulness of thought, in the fundamental and incomparably most important meaning of this word? Logic undertakes to show either how men actually do reason, or how they may so reason as to convince those who hold by the common axioms or postulates, - whether they are sceptics, dogmatists, or agnostics, in their theory of knowledge. But epistemology must, by pushing its rights of presuppositionless criticism to their utmost possible limits, ascertain what is the final import of the first principles of all thinking, and how far they seem to carry in themselves, or otherwise to derive, their claim to apply to the trans-subjective. 
In the interests of gratifying that passion for unity which human reason so persistently displays, as well as (one can scarcely fail to suspect) in the effort to be original and to announce some startling new discovery, the principles of all thinking, as these principles enter into and conditionate all knowledge, have often been reduced to a single formula. Such a reduction has, however, never stood the test of an appeal to our actual cognitive experience. At this point let us wait a moment in reflection upon what the epistemological problem really is. It is the problem of the possibility of genuine cognition. But genuine cognition is impossible without thinking; it is dependent, therefore, upon the actual use of the principles of thinking. The constitutional forms of the functioning of human intellect are the necessary presuppositions of all human cognition. Yet again, cognition is not genuine, unless the mental process terminates in an objective judgment, in a form of psychic synthesis which carries with itself the claim of a valid trans-subjective reference. ${ }^{1}$ To say, therefore, that the possibility of actual cognition depends upon the truth of cognition amounts to the claim that the validity of all knowledge implies the right to give to the fundamental principles of human thinking a trans-subjective reference. So far forth, the principles of Reality not-my-Self and the principles of my thinking must be the same. The temptation is accordingly very great to seize upon some logical formula and convert it into the one all-comprehensive, all-illumining, and all-supporting principle of both Self and Things. To this temptation Fichte and Schelling yielded; Hegel also in his great work on Logic, although in far less complete and disastrous form. But the fact and the character of the growth of knowledge, through thinking, itself demonstrates that Reality is no such simple affair. It is not to be thus summarily known as the objectification

1 Nothing conld well go wider of the mark, or wound philosophy in a more sensitive and fatal place, than the random statement of Paulsen ("Introduction to Philosophy," p. 353): "No theory of knowledge causes the slightest change in the stock and value of our knowledge." 
of the logical principle of Identity, or of the syllogistic Process by which the human mind climbs, through stages of partial error and half-truth, to the heights of the Idea. On the other hand, we repeat: No explanation or validating of cognition is possible, except upon the presupposition that the fundamental principles of my thinking are applicable to the trans-subjective Reality.

Many centuries of reflective thinking upon the formal principles of thought have reduced these principles to two; they are, the "Principle of Identity and Non-contradiction," and the "Principle of Sufficient Reason." This result may well enough be accepted as its own warrant. There is, therefore, no one principle of thought which can be claimed as the only source and guaranty of cognition. But there are two principles, both of which are fundamental (although, it may well be, in different ways), neither of which is deducible from the other, and both of which must co-operate, in order that objective cognition may result. Both of these principles must also somelow obtain a guaranty for application to the world of the really existent, both of selves and of things, or else all human knowledge goes without explanation, import, or warrant of any kind.

It has been shown that thinking, so far as it enters into cognition as a necessary constitutive factor, takes the form of judging; and that this cognitive judgment must itself be a conscious, selective, feeling-full, and believing activity of mind. It has also been shown how, although the greater part of experience lies below the threshold of consciousness, and no little logical or formally correct elaboration of experience is possible without the consciousness of the reasons which justify it, yet so far as growth of knowledge is itself to be spoken of, such growth consists in the conscious, selective, feelingfull, and believing connection of judgments with one another as "consequents" and "grounds." "I know this," or "This is so and so," - such is the intellectual form given to a com- 
pleted act of cognition. It is, therefore, a judgment. "I know this, because I know that," or, "This is so, because that is so," - such is the intellectual form of the conscious progress from cognition to cognition. The knowledge of the connection is itself a new and most valuable cognition. It is called reasoning, or a conscious connecting of judgments with other judgments, as finding in the latter the supporting "reasons" or so-called logical "grounds" of the former. Now the "Principle of Identity and Non-contradiction" is the necessary form of every cognitive judgment. And the so-called "Principle of Sufficient Reason" is the necessary form of every cognitive connection of judgments, or process of the logical growth of knowledge. The rather must we say that the former is nothing else than the Self's full recognition of its own utterly presuppositionless and inexplicable, but unquestionable form of procedure in judging; and the latter principle sustains the same relation to the Self's procedure in all reasoning. It will quickly appear, however, that the discussion of this principle from the point of view of a critical philosophy of knowledge leads out into the vision of that broader and grander ontological discussion which metaphysies and the philosophy of religion require. How significant the perpetual recurrence of this fact in every topic assigned to the student of epistemology!

It is customary for treatises in Logic to throw the Principle of Identity into some such form as the following: $A$ is $A$; and $A$ is not, and cannot possibly be, non- $A$. This is true whatever be meant by $A$; and, indeed, whether any reality be meant by it or not. Now it is at once plain that this principle, as thus stated, cannot properly be made a subject of argument; nor can it, strictly speaking, be formally stated without implying it several times over in the very simplest form of statement. For if I do not hold fast to the judgment, or belief, - call it what one will, - that the $A$ of the subject is $A$, I cannot affirm that it is identical with the $A$ of 
the predicate; neither can I negate its identity with the non- $A$ which forms the predicate when the principle of noncontradiction is stated. The same thing is true of the $A$ of the predicate. And since in all actual and earnest work of judging, some definite relation between subject and predicate is affirmed or denied by the copula, the principle of identity must be assumed as applicable in some sort also to the copula. But, further, if I attempt to state my confidence in the identity with itself of either the subject- $A$ or the predicate- $A$, $I$ can only state this confidence in the form of a judgment. Thus subject- $A$ is subject- $A$; and predicate- $A$ is predicate- $A$. And now I am ready to go the whole thing over again from the very beginning. The principle of identity in formal logic appears, then, to be nothing but an abstract statement for the presuppositionless form of intellectual functioning in every act of judgment.

But consider, further, that if this logical formula is pressed to give a full account of its own meaning and of its claims to indisputable authority, it is speedily plunged into the most distressing condition of doubt. And then critical epistemology appears as mocking, with an issue that leads to a kind of demoniacal laughter, her twin sister, formal and uncritical logic. This is the fate which the dogmatic assertion of infallibility, even of the most abstract, formal, and worthless sort, customarily receives at the hands of the sceptic. Nor are we merely jesting, or displaying an insane fondness for picking flaws in the foundations of truth, when we call attention to the following puzzle: $A$ is not $A$, and no $A$ can ever be known as throughout $=A$. For the $A$ which is the subject is not wholly identical with the $A$ that is the predicate; it differs from it, at least, in being subject, whereas the latter is known as being predicate. And if I try to affirm the complete identity of the subject- $A$ with itself, I find myself hopelessly baffled. For in some respects, as first posited, it differs from itself as posited the second time; and then, as has already 
been seen, the positing of the first-posited subject- $A$ as identical with itself, can never be made otherwise than in the form of a judgment. And so we have to go over the whole process in confirmation of the principle, from the rery beginning; but only to end in the same hard necessity at last. Surely, this is a worse and more hopeless task than that given to Sisyphus.

This crude mixture of sport and critical work with the principle of identity may as well be made at once to teach certain truths of no little importance. Criticism cannot expound, without implicating in the very process, the presuppositionless principles of thinking itself. And it appears that howerer we may see fit to express this particular principle, it bclongs to the class of presuppositionless principles. It appear's also that the principle of identity is not merely the logical and formal, but the actual and vital, principle of the judgment, as such; for when I attempt to see how it is that I do actually, and unavoidably, and, in the fundamentally most necessary way, perform any act of judgment, I only exemplify this principle. But when I attempt either to expound or to criticise the principle, I come around to the statement of it in the form of a judgment again. It is itself, as stated, nothing. but the pure and - as the old-fashioned language of philosophy would warrant us in saying $-a$ priori form of all judgment. But as we prefer to express the truth: The Principle of Identity is only the Self"s recognition of its own presuppositionless form of mental life, when in the act of judging.

On the contrary, however, it appears that the term "principle of identity" is not well chosen, if one must understand by identity a complete and wholly indistinguishable sameness. Such identity as this interpretation of the term implies contradiets the very nature of judgment itself. For differentiation - actually performed, as the holding apart in consciousness of two ideas, or thoughts, or other momenta of the judgment - is as necessary to the actuality of any judgment as is the 
synthesis in which the judging act consists. Indeed, the boasted conception of Identity, as it has been made so much use of, both in the interests of logical truthfulness and in the behalf of certain unintelligible and mischievous ontological philosophemes, is a merely negative conception. It may be said to be the most barren and negative of all conceptions. Even to attempt to frame it, one has to refuse to think at all. Moreover, as will soon be shown with somewhat more of detail (although the fuller exposition of this truth belongs to metaphysics), no real being can possibly ever be known as thus, strictly speaking, self-identical. For the $A$ of the subject and the $A$ of the predicate, in the formula of pure logic, no reality can ever be substituted. Fichte was true to the facts in the case when he posited $E g o=E g o$, as the original and the crowning exemplification in experience of the meaning of the principle of identity. But of all examples which could be chosen, the experience of the Sclf in affirming, "I am I, and not-you, and no other," is the best adapted to disprove the vulgar interpretation of the word "identity." Practically, too, the mind has no interest in knowing that either Selves or Things are identical in any such impossible sense. Thus to find the Self identical with itself, if such finding were not made impossible by the very nature of cognition, would be the greatest of all misfortumes. What we want to know, even of things, is that we may trust them (within certain limits which can never be strictly defined until the knowledge of things is itself perfect) to behare, in their different individual behaviors, according to our ideas of them.

If, now, further inquiry be made into the psychological nature and origin of the principle of identity, as it is actually given and as it must be interpreted by the act of thinking itself, it will be seen that this is equiralent to an inquiry into the psychological nature and origin of cognitive judgment. Sensation-complexes, ideas, thoughts, as such and considered abstractly, are not objects of knowledge. In order to convert 
them, so to speak, into objects of knowledge, they must get recognized as belonging together in reality. Sensation-complexes, ideas, thoughts, as such and considered abstractly, appear either similar or dissimilar; and it is by a primal and original activity of discriminating consciousness that we recognize them as such and thus judge them to belong together or apart. But the similar is not the same, and the dissimilar is not the contradictory, - in reality. In order to call two sensation-complexes, or ideas, or thoughts, merely similar, they must be recognized as not the same; the rather as being different in respect of the time of their occurrence, or of the place to which they are assigned in the system of space relations. On the contrary, two objects observed as existing in different times and different relations of space ( $A$ and $A$; or $A$ and $B:-A$ here and $A$ there; or $A$ now and $A$ then; or the $B$ here-and-now that was $A$ then-and-there) may be known as the same. In these cognitive processes the same intellectual actirities have been displayed in apprehending and putting together the similar and in recognizing and holding apart the dissimilar; but the ontological belief which posits the permanent in space and time must be reckoned with in giving account of the origin and nature of the judgment which terminates the intellectual process. Identity or sameness, as distinguished from similarity, is the predicate which cognition assigns to that which is judged really to exist.

If, now, the principle of identity be applied to our thinking in a purely formal way, and as a guaranty solely of the logical correctness of thought, all the pith and marrow is taken out of the principle itself. In merely haring sensations, ideas, thoughts as such, - if, indeed, the subject of conscionsness ever actually exists in states of such mere having, - no application of this principle is possible. As has been clearly shown, it is only in the act of judging that the principle of identity is exemplified; it is to judgments, as a vital relating of sensations, ideas, and thoughts that the principle applies. 
Nor would any conceivable series of mere sensations, mere ideas, mere tloughts, if such series conld be carried on without affirmation or denial of a connection between its different members, violate the principle of identity. I may have, first, the idea of a man and then the idea of quadruped; or, first, the idea of an animal and then the idea of immortal gods; but there is no talk possible of logical correctness or real truth in all this, unless I attempt to judge some relation between the members of these pairs of ideas. If, howerer, I have the mental image of a man and call it quadruped, or of an animal and call it immortal, then I judge. And now it may be said that the principle of identity has been violated, because it has been affirmed that man, a biped, is at the same time a quadruped; or that an animal, a mortal thing, is at the same time immortal. Such an exhortation as this, howerer, is equivalent to saying: "Do not use words in that way ;" or, "Stick to your meaning through your sentence, at least;" or, "Be consistent in your affirmations and negations." In making judgments, one should hold to the same meaning for the subject, the same meaning for the predicate, and the same meaning for the relation affirmed by the copula between subject and predicate. Indeed, one must do so if one wishes the judgment to be true.

"One should," and "one must:" - as to the quasi-ethical character of the obligation expressed by these words, we shall refer in another connection. But who does not at once discover that exhortations like these are insignificant and even absurd, unless an appeal is made to an objective standard of judgment, to an order of connections in the reality known, which is to be followed in human, synthetic mental operations? Why, indeed, should not all men use words as they please, without holding fast to any chosen meanings, - affirming with one breath what is denied the next, or even affirming and denying in the coupled breaths of that conscious existence which is needed for the barest utterance of a single 
judgment? Indeed, other questions may be thrust yet deeper into the centre of the cognizing soul of man and into the rery heart of Reality. Why should words have any meaning at all ; and what gives them the meaning they are understood to have? Why should affirmation or denial, the very essence of the act of judging, be possible at all ; or, if possible, why should affirmation and denial be subject to any limitations except those of subjective, momentary, and ever shifting caprice? The only answer that can be given to these inquiries restores its pith and cogency, as well as its significance and dignity, to the principle of identity. The intellect's standard of judgment is not found in the mere character and sequence of sensations, ideas, and thoughts, as such. Its standard of judgment is objective; it has reference to the known nature and relations of the Self and Things, and of things with one another. The motif and the goal of judgment is, therefore, to connect together in the terms of judgment what has been cognized as being objectively connected together. He who does this, correctly conforming his mental synthesis to the terms of his objective experience, judges true. He who consciously and intentionally affirms that to be connected which he knows to be not really connected, is "a liar; and the truth is not in him." But he who, while intending to conform his mental synthesis to the connections of reality, unconsciously and unintentionally fails of this, is in error; tlie truth, formally considered, may be "in him," but his judgment is, nerertheless, not true. Who, again, does not at once discorer that such common expressions assume a standard of judgment which has reference, not only to connections in reality, but also to a common nature for the judging Self?

If, then, the true interpretation of the principle of identity be accepted and consistently carried out, the differences recognized by logic in the kinds of judgment do not alter the epistemological significance or value of the principle itself. Let, for example, the distinction into judgments predicating 
condition or action, those predicating a property, and those affirming a relation, be adopted. Among relations, let those of identity, of dependent connection, etc., be recognized. In each of these classes, judgmcnts designated as purely subjective may be found described. It is an interesting view of Wundt, ${ }^{1}$ who advocates this division, that the relating of the constituents of a judgment as conditioning each other, is one of the forms of the judgment of relation which has gradually "develnped," in the use of the most abstract and universal forms of thinking, through certain motifs of a scientific sort. We may well doubt the application of any theory of derclopment to legitimate, fundamental distinctions in the kinds of our judgments. But the one epistemological truth which is important here to notice grows out of the psychological fact that no perception of the actions, properties, or relations of things is possible except in and through developed activity of thinking faculty, terminating in cognitive judgment; and that, on the other hand, thought and imagination, whenever they "come to judgment," refer themselves back for corrcction and rerification to the perception of real things and of actual occurrences. Thus a certain validity for reality (a Seinsgültigkeit) ${ }^{2}$ belongs to the very simplest judgments as well as to the most elaborate and abstract. 'They all point to a trans-subjective kingdom of human consciousnesses existing in that commerce with reality which is called truth, the rerifiable knowledge of things, - what they are, how they behave, and low they are related.

What, now, shall be said of this postulated, or cognized, sameness of things, such as seems necessary to make the principle of identity an accepted principle of cognition? What kind of sameness, or identity, is postulated in that recognition of the principle of identity which every cognitive judgment affords? The more obvious answer to this inquiry

1 System der Philosophie, pp. 56 f.

2 Compare Volkelt, Erfahrung und Denken, pp. $146 \mathrm{f}$. 
is a negative answer. All we know about any form of reality - selves or things, either as active or as passire, as possessed of qualities, properties, and attributes, or as standing in manifold relations to each other-shows us that whatever identity realities have, is not the equivalent of an inability to change. Nor, if one wishes to convert an inability into a potency, can the identity of real things be thought of as the equivalent of an ability not to change. The rather are the essential terms, on which all cognition of things is giren to the mind, such as that it is compelled to affirm: "We know that things really do change." On the other hand, however, only as some sort of a limit is set by things to their own changes, and as this limit is observed in the judgments framed by the mind respecting them, can they be known as the same things, in any conceivable meaning of the word "same." The guaranty, therefore, for that application to reality of the principle of identity which every cognitive judgment makes, must be found in the nature of reality, of its ability to change, and yet to set those limits to its own changes which shall enable it to be known as a system of beings that may be called "the same."

The fuller meaning of this postulate as to the nature of Reality, as its nature is involved in the nature of the cognitive judgment, it belongs to metaphysics to unfold. But there is a truth or two, of a metaphysical order, which must be stated in this connection before the fuller meaning of the previous epistemological discussion can be grasped. To get at this truth we must refer directly to the judgments which express any fact of knowledge about the Self. All my states of consciousness - whether present and known by immediate self-consciousness, or past and kuown by recognitive memory, or thought and inferred from grounds of self-consciousness and memory - are known as mine; that is, they are referred to one and the same Self. But I am no rigid, fixed, and ready-made being, maintaining my identity by an inability to 
change, or by an ability not to change. On the contrary, I am the same being because of that limitation to the changes to which I know I am subject; and I know myself as the same because all these known changes are referable and actually referred to the one Self. Indeed, the only conception which I can possibly form of the identity of myself is given just in this life of self-consciousness, of recognitive memory, and of rational inference, which is the sum-total of my cognition of Self. ${ }^{1}$ And every cognitive judgment relating to myself, whatever form of experience it embodies (an action, a suffering, a property or capacity, a relation), is an example under this conception.

But the self-identification which every cognitive judgment lhaving reference to Self implies and enfolds is itself inextricably interwoven, as it were, with a process of discrimination ending in a judgment of self-differentiation. Things which are the objects of my knowledge, even including my bodily organism, piece-meal or throughout, are not to be identified with my Self. And it needs only the expansion of an argument into which we have entered at length elsewhere, to show that the theory of psychological parallelism with the philosophical doctrine of indifference or identity which usually accompanies it, involves the denial of the possibility of all knowledge. Psychologically considered, it is out of the differentiation between Self and Things, as an indubitable and "lived" opposition, that the possibility of self-identification and of the identification of things comes forth. All the foundations of ordinary knowledge and of science are undermined and nullificd by the identification of Self and Things. These two realities, in the commerce which is called knowledge, set limits to each other such as prevent their being brought together under the principle of identity. All experience sets the limits over which judg-

1 For the detailed discussion of the subject, see "Philosophy of Mind," chap. v. 
ment cannot climb so as to unite these two in any other terms than those of irrational imagination, or wild fancy, rather than of cognitive judgment.

Once more, however: What it is for things to be really connected so that our judgments about them may be true, may be judgments of cognition, - this is something which can be known only analogically. How can things change and yet be in any sort the same - with themselves, or with one another as partaking of a so-called common nature? The identity of other selves must be conceived of, and is incontestably known as similar to the identity of our Self. But in what does the identity of things so consist that they may truly be judged to be the same? To this question no reply can be given which does not draw, for its positive and comprehensible meaning, upon our experience with the Self. But this "I know" to which all our theory of cognition constantly refers backward, when having for its object ourself, has been found to be no rigid unchanging, and once for all ready-made affair. The Self is a life conformable to law, and maintaining its identity by this conformity. Not as though, indeed, law were itself some rigid and ready-made entity, that rules over the Self as the inflexible walls of the prison-cell control the prisoner. For knowledge can grow ; or rather, I can grow in knowledge and in all the fulness of that life which belongs to a Self. I seem, then, to be really one and the same, and thus both self-identified and differentiated from other things, because the series of my changes follows the ordering of immanent ideas. Shall we say, then, that judgments affirming the identity and the differentiations of things can be true only if the being of things is like this self-known being of ours?

The principle of identity, subjectirely considered, is but the life of the intellect following its fundamental law; and thus trying to put together in judgment what belongs together in reality, and to separate in judgment what belongs apart in 
reality. But if such an act of intellect can give truth, if the forms of mental combining and separating can be genuinely cognitive and representative of reality, then it wonld seem that the constitution of Reality must be, in important ways, similar to that of the Self. Here, agrain, we come upon a thought which has occupied us already and to which we shall return again. It is the thought crudely expressed in the ancient saying of Chwang-Tsze:-

"The Tao is always One, and yet it requires change." 


\section{CHAPTER $\mathrm{X}$}

\section{SUFFICIENT REASON}

$T_{\text {HOSE simpler connections of the different items of our }}^{\text {experience which are affirmed in the more obviously }}$ true judgments of cognition are a small part of the entire body of knowledge even as developed by the individual mind. But the entire body of knowledge to which the spirit of inquiry in the race has given life and growth is much more a matter of correct and complicated reasonings from so-called "premises" or "grounds." Scientific knowledge is pre-eminently conceptual ; for it is given in that kind of intellectual functioning which sees the universal in the particular; and then, having seized upon the principle, or rule, explains and anticipates the particular by connecting it with the universal. The students of the physical sciences, by the modern methods and in the modern spirit, sometimes boast of their devotion to those facts which the intuitions of the senses can disclose only to the trained observer. This they oceasionally do as though reasoning and perception were opposed as are the grounds of error to the sources of truth. But every student of the psychology and philosophy of knowledge knows that what is called the "science" of external things is nothing but a system of more or less consistent abstractions, devised for purposes of practical or intellectual mastery, in dependence upon favorite points of riew. These points of view are often rather arbitrarily selected and rapidly shifting. Is the Reality such as to be represented in this way? And what postulate is needed in order to save the whole structure of 
modern science from being perpetually imprisoned in the "death-kingdom" of abstract thoughts?

Now it is evident that whoever thinks with a riew to know, and ends by believing that he has thought so as to attain knowledge actually makes the coveted postulate. For in spite of its dislike to consider theories of knowledge or metaphysical assumptions as, of inalienable right, seated in its own realm, physical science is science only as it has already come to unconsciously accepted terms with these theories and assumptions. It aims, of course, to lit reality by its conceptions; and by its judgments respecting causes and laws, when seriously determined and gravely pronounced, to express the reciprocal relations of the really existent. If scientific conceptions and judgments do not aim at this, they are of little real value from any point of view. And if they do not sometimes hit the mark at which they are constantly bound to aim, then all scientific conceptions and judgments are nothing better, from the epistemological point of view, than dreams or other forms of illusion.

The naĩve theory of knowledge, or epistemological postulate, which underlies the claims of science to be something more than dreams, to be indeed a system of cognitions, lowever fragmentary and incomplete, is neither far to seek nor hard to find. So far as concerns our present purpose, it is simply this: By reasoning from known facts of perception one may reach known truths of a more or less general applicability. Knowledge may be gained by ratiocination, if only one will start from knowledge and pursue the course of ratiocination in proper form. But, subjectively considered, the "proper form" of reasoning is that which the very constitution of the intellect sets to itself. So that, in order to reach the truth of things by reasoning, some sort of a metaphysical assumption must be added to the epistemological postulate. The nature of this assumption is so hidden, and its possible sweep in application so far-reaching, that one may well hesi- 
tate before the problem of giving it expression. Its final and fullest expression is very far to seek and very hard to find. Enough of it, howerer, may be brought to the surface at once, to show how it is that, by the subjective processes of his own intellect, man may follow, discover, and prove the changing relations of the really existent world of things.

As to the nature of the reasoning process, an important train of considerations may be introduced in the following way. Students of the derelopment of mental life in children mark a notable change, which comes on either by stages that cannot be readily traced or by more sudden leaps, and which concerns the connections establislied between the different portions of the stream of consciousness. [Discontinuity, lack of established relations of any description, a kind of lawlessness, characterizes the earlier psychoses of the human animal. The first signs of continuity, the earlier relations established so as to bring some sort of order out of this original heterogeneity, are not of a predominatingly intellectual kind. Mind is undoubtedly active from the beginning; for the conception of a purely passire or receptive consciousness is unpsychologieal and eren absurd. Discriminating consciousness is neeessary eren in order to have state distinguished from state, in the flowing stream of conscious life. But, at first, the connections of the factors which fuse into the more complex states, and the connections of the states with one another in the series of states, are, as it were, dictated from without by the character and successions of the stimuli which arouse sensations, rolitions, and their motor accompaniments, and the "cohort of attendant ideas." The next following connections are chiefly such as emphasize the principle of "contiguity in consciousness," in its power orer the primary associations of the ideas; thought is now chiefly actire in the fuller perception of the content of the mental life by virtue of established points for the recognition of resemblances and differences. 
In the progressive organizing of experience, conformity of the subjective connections to law (something other than mere generalized fact of established associations of the idcas) is the notable change to which reference was made above. Established "objective connection" is another term which may helpfully be employed for this change. Because it has already passed one judgment connecting its sensation-complexes, ideas, and thoughts in a certain way, the Self finds itself bound to pass one or more other judgments also connecting its sensation-complexes, ideas, thoughts, in a certain definite way. As yet it may not be that we consciously reason: If $A$ is $B$, then $C$ is $D$; or that we consciously point out to ourselves why the judgment $C$-is- $D$ should follow in consciousness upon the judgment $A$-is- $B$. Let it suffice that the connection between two judgments is simply noticed; when one is made, the other is obserred to follow as a matter of fact. This compulsion the mind comes to regard as a privilege; for in it lies all the mind's power of cxplanation, and all its right to expect, to plan, to act, indeed to live rationally at all.

Further derelopment in the same direction of the conscious life of the intellect consists in the more and more complicated and yet, on the whole, firmer establishment of connections of similar kind; but, especially, perhaps, in increase of insight into the number and character of the terms which mediate between the different judgments already connected in fact. Some of the earlier connections - not a few of them among the most farorably considered and highly prized - become broken up. But many new connections are formed. Someand these among the most valuable for the life of conduct and of artistic endearor - drop almost or quite out of consciousness; but only becausc they have become incorporated into the bodily mechanism and into all the hidden and fundamental structure of the mental life. It may be said of such connections of psychoses that they are the "acquired 
constitution" for the individual mind in its particular environment.

But as a matter of fact, reasoning is not understood to be, and it is not, a blind, compulsory, or unconscious connection of judgment with other judgment, however firm in actual sequence the connection may be. The whole of our consciousness as we find it when we find ourselves already reasoning, or consciously coupling judgments firmly together, is not faithfully formulated by saying simply: "In the stream of consciousness $I$ find $A$ is judged to be $B$; and then (in the temporal meaning of the word) $C$ is judged to be $D . "$ The rather must the formula to express this experience run as follows: "I know that $C$ is $D$, because I know that $A$ is $B$." And the more one's system of cognitive judgments has been made consistent and carried onward toward the ideal of higher cognition, the more ready is one apt to be with an answer to the further question, as to why any one judgment is made dependent upon another. This consciousness of "the Why" is the development of our knowledge through mediate terms. When, then, we come to the consciousness of the entire process which gives to the mind the satisfaction it feels in the judgment $C$ is $D$, as a truly cognitive judgment, and not merely as a product of imagination or of abstract thinking, we find this process depends upon a mediating judgment which may be expressed: $B$ is $C$. And now the completed act of reasoning, as justified in a terminal judgment of cognition, stands before us: If - as I know $-A$ is $B$, thenas I conclude $-C$ is $D$; because - as I know $-B$ is $C$. It is this principle, which enters into all acts of reasoning, if they are to result in the extension of knowledge, that, when the full meaning of these acts is understood, is called "the principle of sufficient reason."

The moment, however, the significance of such a procedure on the part of intellect is brought to the rital test of actual experience, it becomes evident that the procedure itself can- 
not be explained as a merely logical and formal affair. Here is not a simple case of intellect functioning under the laws of its own objective activity, and so making these laws objective, because it cannot function otherwise than according to these same laws. It is not solely by conformity to any intellectual law, whether of its own voluntary assumption or imposed from some unknown outside source, that acts of cognitive ratiocination are either tested or explained. Kant, indeed, endeavored to show that the secret of the cogency which the act of transcendental judgment (the rather, as Schopenhauer correctly affirms, should he have said, the objective reference of the act of reasoning) has, is to be found in the facts of sequence according to a rule. ${ }^{1}$ This was, perhaps, the most pitiful failure in all the "Critique of Pure Reason;" and the failure was the more surprising because, as Kant himself has assured us, it was Hume's sceptical analysis of the idea of causality which aroused him from his "dogmatic slumber" and stimulated him to the task of criticising thoroughly all human cognition.

Something far other than mere conscious conformity to a fixed order of objectire ideas in time must be recognized in our account of the origin, nature, and significance of the principle of sufficient reason. The psychology of the subject, if it had been profoundly considered and faithfully interpreted, would have led Kant to see the unsatisfactory character of his position as taken in the passage of the Critique to which reference has just been made. For the wonderful difference of the results for cognition between the connections of my ideas, when I perceive the successive portions of an object known by the senses, and when I reason my way to a conclusion as to the causal relations of things, depends mainly upon the difference sustained by the two trains of ideation to the activity of my will. This psychological truth is, indeed, linted at and even recognized by Kant. I can

1 Transcendental Analytic, Second Analogy. 
determine by an act of will the order in which I perceire the successive parts of the building orer yonder, whether from upper right-hand to lower left-hand corner, or across and upward, or the reverse, or any other order, to suit my convenience or according to my subjective habits of perception. But I cannot determine by an act of will the order of the successive places in which the sailing-vessel, off there, shall appear in the stream or on the horizon of the sea. The order of the successive portions of the building may be perceived as either $A, B, C, D$, to $N$; or as $N$ through $D, C, B$, to $A$; or, possibly as $D, C, B, A$, and then from $D$ to $N$, or $N$ to $D$. Yet the statical relations of space between $A$ and $B, C$ and $D$, etc., remain, in the resulting perceptive judgment, independent in reality, of my will. And I sum up my different experiences with the changing orders of the portions successively perceived, in the form of a judgment affirming a fixed and unchanging order of these portions in the totality of the perceived object.

The different portions of the same building, so long as they remain related without obvious change, are not ordinarily thought of as doing anything to each other. If, now, I choose to change my point of view, I may at once think of them as sustaining very important reciprocal relations, which call them into unceasing activity, each in dependence upon the other. Indeed, from certain points of riew, I must think of them in this way. From below upward, $A$ is "sustaining" $B$, and $B$ is "sustaining" $C$, and so on; but from abore downward, $D$ is "pressing" down on $C$, and $C$ on $B$, and so on. Or, enumerating sideways, $B$ is " binding" together $A$ and $C$; or this same $B$ must also be thought of as "separating" its contiguous portions on either hand. The words "binding" and "separating" may be used in two senses, bowever, one of which coincides with the sense which is giren to the words "sustaining," or "holding up," and "pressing down." To illustrate this, let us suppose that the order of 
the different portions of the building is being perceived as $A, B, C$, etc., up and down. That $B$ must exist between $A$ and $C$ and bind these two together, whether the order of their existence be read off from $A$ to $C$ upward or from $C$ to $A$ downward, is a necessity which my intellect recognizes as belonging to all material reality, since it is always known to be extended in space and capable of being made the subject of successive perceptive acts in time. In this meaning of the words; " binding" and "separating" are services necessarily to be performed by $B$ for $A$ and $C$, even if all three members of the series stand in the same order as stones across the building rather than as the same stones laid up and down. Now suppose, however, that while getting a knowledge of this building by sense-perception, I miss from its place a certain large stone, $B$, which does not stand in its proper position between $A$ and $C$, but has been dislodged from that position and is lying on the ground. If I confine my reasoning strictly to the conclusions following from the sensuous shock of missing $B$ from the order $A, B, C$, etc., when read off in lateral direction, I find this process results in a terminal judgment of no new or startling kind. If $B$ appears as empty space, or is known to be only air, it will serve as well as would a stone to bind and to separate between $A$ and $C$, as long as the series is thought of as holding in reality, under the conditions merely of Time and of Space.

But the sensuous shock which follows my missing $B$ from its place in the series of successive portions of a building of stone read from $A, B, C, D$, up to $N$, would undoubtedly lead to reasoning that falls under a quite different rubric, and that terminates in a cognitive judgment of a quite different significance and value. To bring this into clearer light for our recognition, let it be supposed that the same real building is being inspected in vertical direction, and that attention is directed to the importance of laving the order complete in this direction. And now we cannot spare $B$ from its place between 
$A$ and $C$; to miss it shocks something more than the smooth flow of the objective series regarded as determined by the intellectual functions of perception, under the formal and purely a priori presuppositions of space and time. Now there are real interests at stake which cannot be conserved by logical formulas or by an elaborate display of the immanent principles of "pure understanding." Other trowels than those which carry the cement of a syllogistic process, regardless of concrete realities, are now needed. Epistemological architectonic which relies upon an analysis of understanding, in a merely formal way, to secure the safety of cognition's structure will scarcely serre the purposes of the present demand for a connection between the successire portions of this experience. For all men believe that, in reality, $B$ has been doing another kind of "binding" and "separating " between $A$ and $C$. Empty space, or thin air, will not suffice for this kind of binding and separating.

Or, to make yet clearer the necessity for something more than the recognition of a sequence of ideas that our will cannot determine, and that is merely the objectification, as it were, of the a priori forms of intellectual functioning, let a yet more violent supposition be made. Let it be supposed that the object of perception is a long steel girder, which appears stretched from one massive wall to the other of a building. The business of the beholder is inspection, - a business concerning most important real interests, and not a dilettante affair of formal logic or theory of knowledge. The agents in the business, or parties to the controversy, are mechanical engineers who are learned respecting the strength of materials, the meclanics of the girder, and other similar physical affairs, rather than experts in the psychology and philosophy of cognition. Under these circumstances it is difficult to exaggerate the intensity of the shock which would be experienced on discorering that so important a support of the building was interrupted at some place, for a distance corresponding to $B$ (we 
will say, for four feet between $A$ and $C$ ). ${ }^{1} \quad$ Lo! a piece of matter, straight and faithful to its important function of supporting an enormous strain without sagging, and yet with one portion entirely gone. To see this, who would trust his eyes, even if after repeated rubbings they continued to bear witness to so great a miracle? This kind of a shock, however, cannot be explained as a purely nervous affair. Nor can the trains of reasoning which it sets in motion and directs for the selection of their major and minor premises be dealt with, so long as we continue to maintain for their explanation the merely formal points of view. Its nervus probandi is neither merely physiological, nor psycho-physical, nor purely an intellectual affair. The rather is it an affair which requires all the elements of the growth of cognition, as a system of interconnected cognitive judgments, to be taken into the account.

In the case just supposed, the inspectors of the building were appointed for the purpose of forming, by use of the senses in perception, a rational judgment that should affirm or deny its proper and safe construction. The successire items of their cognition gained by perception all involve thinking on the basis of previous experience with things as existing under conditions of space and time; and they all terminate in cognitive judgments affirming real connections of the same things in space and time. Inasmuch, however, as this particular structure is being examined with a view to determine something quite different from its conformity to the $a$ priori rules of time and space, all judgments respecting it take a turn appropriate to this end; the processes of reasoning which are started and followed more along lines fixed by a peculiar class of conceptions; and the terminal judgment is of a special order in respect of its origin, its significance, and its value.

1 It was once my privilege to hear a vivid and detailed description of the feelings, thoughts, and actions of an architect who, while inspecting a building, saw the supports of the floor above his head in the cellar visibly yielding to their load. The description was an excellent study for a theory in the psychology and philosophy of knowledge. 
Now we contend without hesitation that all which chiefly interests the mind in the explanation of such a transaction as this is totally unaccounted for by Kant's doctrine of the three "Analogies of Experience." "All phenomena," says he, " so far as their existence is concerned, stand a priori under rules which determine their relation to one another, in one and the same time." I As to Kant's inadequate and lifeless account of the principle of identity (Analogy $A$ ), when applied to objects of experience (his realitatis phoenomena) nothing further need be said. But his account of the nature and grounds of rational judgment, as applied to the cognition of things in relation, is even more inadequate and lifeless. This is because it is our apprehension of causes, and of the reciprocally determining conditions of things which constitutes the adequate and living picture of reality that genuine cognition gives. When, then, one is told that "all changes happen according to the law of the connection of cause and effect," one seems to listen with a kind of approbation which is, after all, only a state of expectation, to familiar but as yet unmeaning words. But when one is further told that the meaning of these words, "being connected as cause and effect," is this: "All that happens (begins to be) presupposes something on which it follows according to a rule," one's disappointment at the shallowness of the analysis breaks all bounds. For here what is secondary takes the place, in explanation, of what is primary ; the regularity of the sequence in connection is made to assume the character of a potency that shall produce the sequence itself. And when Kant, in his following treatment of the Third Analogy, introduces the same problem in yet more expressive terms, and declares that the whole world of cognized objects is bound together by rational judgment under the presupposition that "All substances, so far as they can be simultaneously perceired, are in complete reciprocal interaction (in durchgängiger Wechsel-

1 Heading of the section in the first edition. 
wirkung); and then proceeds to overlook the plainest meaning and most obvious implications of his own terms, in the interests of architectonic formalism and pre-established agnosticism, his most devoted admirer is tempted to accuse him of an unethical juggling with words. ${ }^{1}$

To recur to our illustration of the nature and validity of cognitive reasoning once more: let us consider further that second meaning of the words "binding" and "separating" which, it was said, coincides with the meaning of the words "supporting" and "pressing" down. The mere grammatical significance of the fact that all four words have the same form of ending (-ing) is not without its suggestions of a fundamental truth. This ending is verbal and signifies that the forms of predicating designated by the roots - bind, separate, support,

1 As Adickes says, the Third Analogy discusses the problem of causality, and is, in a special manner, "the focus of the entire Kritik." It does not, however, grapple with this problem in any such way as either to explain our experience psychologically or to satisfy our epistemological inquiries. It is even less successful, because more remote from actual life, than was the explanation of the sceptical critic criticised by Kant, - namely, David Hume. In general, there is scarcely anything, in the line of theoretical discussions, more inconclusive and wearisome than what is current on the subject of causality. Physicists and psychologists both know perfectly well what men really mean when they naïvely, and without prejudice, talk of causes and effects. All men think of things as doing something to each other, and as having something done to them ; and of themselves as doing something to things. Less popularly expressed, everybody believes and must believe, that both things and minds are real; that both things and minds are active; and that both have the forms of their activity conditioned, in a limited way, upon the activity of other minds and other things. The "laws" which science discovers and announces are nothing bnt the known or conjcctured, more or less uniform, modes of the behavior of minds and things in their clanging relations to each other. But let once some precious theory - like that of the conservation and correlation of a fixed quantity of an entity called "Force," or the psychophysical parallelism which, as a revived form of Spinozism, many psychologists have taken quite off its metaphysical base, in the attempt to defend it experimentally - be imperilled, and this belief, at once "common-sense," scientifically defensible and philosophically sonnd, deserts them. They begin, as professed experts, to deal with mere abstractions and empty formulas; as though these could account for anything, least of all for the reasoning processes which deal with them. And yet their very theories, thus falsely or inadequately conceived, sprang from no other source than that very experience the validity of which the theories wonld deny. 
and press - are applied to things because the things themselves are conceived of as in action. The words express the mind's conceptions of the peculiar and appropriate mode of that action of the being, $A$, or $B$, or $C$, to which the words are applied. But the series of judgments employed in such mental acts of reasoning relates to more than one object of cognition; for what is affirmed is not simply that $B$ is "binding" and "separating," or "supporting," or "pressing" down, - in loneliness of being, as a single Thing, isolated from all environment of other beings. But $B$ is binding and separating between $A$ and $C$; or it is supporting $C$ and is itself pressing down on $A$. Nor could we conceive of $B$ as binding and separating between $A$ and $C$, unless both $A$ and $C$ were conceived of as at the same time pulling apart, or pressing together. If, too, $B$ supports $C$, it is itself being pressed upon by $C$; and, in turn, it is pressing down upon $A$; but only with the understanding that it is to be supported by $A$. All this is popularly and naïrely expressed by such phrases as accuse things of acting "upon" each other, or of "influencing" each other.

Note, further, that the particular forms of doing and suffering which the mind conceives of as belonging to things, are varied both by the relations which the same things sustain to one another, under the conditions of space and time, and also in accordance with what is called the "nature" of the things themselres. Nor does this nature hinder things from acting in a considerable number of differing ways, while maintaining the same relations of space and time. The same stone $B$ can, without perceptibly changing its place in the structure, be thought of as both binding and scparating, and as supporting and pressing down - all at the same time. Moreover, the science of physics undertakes to show that each stone is simultaneously, and without movement from its position as a mass, undergoing a considerable number of hidden and mysterious changes (thermic, chemical, electrical, etc.), 
such as are reasoned about by the separate branches of this science.

The thorough student of the mind's development can have little doubt as to the kind of experience in which all naĩve and instinctive reasoning has its origins and its justification $:^{1}$ It is the primal and universal experience of man with the Self, as consciously acting and having its activity resisted, while at the same time observing the simultaneous and succeeding changes which go on in the appearance of Things. This is the very same experience as that in which our cognitions of Self and of Things have their origins and justification. Its indubitable concrete content is given whenerer the self-conscious Self becomes aware of the terms of relation, so to speak, on which the very activity of cognition takes place as a commerce of Self with not-self. And this is just as often as it knows things as standing in relation to itself at all. The original connections along the lines of which the intellect proceeds, and by which it constantly orientates itself in its widest and most daring explorations of the entire domain of possible knowledge, are established in the cognitive judgment. So far as this is a judgment affirming real relations it has its content and its counecting bond in an experience which is more than formal, - something other than mere thought. The causal nexus is an abstraction from the nisus of the Self, as its feeling-full will is found to change content in dependence upon changes in the perceired and remembered forms of the not-self. It is self-conscious activity, self-known force, as evinced in concrete doing and suffering, while the correlated changes in the states of things are observed, that is here most fundamental, rather than any a priori law of intellect dictating changes according to a fixed rule in time. For finite thinking, at least, what Goethe said is true. Deed, power, are here the logical antecedent and basis of thought:-

1 For further detailed discussion and illustration, see "Psychology, Descriptive and Explanatory," chapters xi. and xxi., and "Philosophy of Mind," pp. 212 f. 
"In the beginning was the thought.

But study well this first line's lesson,

Nor let thy pen to error overhasten!

Is it the thought does all from time's first hour?

'In the beginning,' read then, 'was the power.'

Yet even while I write it down my finger

Is checked, a voice forbids me there to linger.

The Spirit helps! At once I dare to read,

And write: 'In the beginning was the deed.'"

Cognitive judgment, however, is not reached without thinking ; on the contrary, it is the terminal of a process of thinking. And further functioning of intellect is necessary to attain those more remote cognitive judgments which mark the termination of prolonged processes of reasoning. The nature of this further functioning is essentially the same as that manifested in the more primary of the cognitive judgments. The processes of reasoning which connect together the judgments involve no new law governing the intellectual operations. Nor can they be explained by simply giving shape to an abstract formula, and then calling it by either the logician's or the physicist's favorite term. If in the name of logic we affirm the meaning of "the principle of sufficient reason" to be as follows, "The intellect demands in explanation of all its conclusions some reason which shall be sufficient as a ground for that, and no other, particular conclusion," no light is thrown on the real procedure of the mind. Indeed, careful examination shows such a formula to be for the most part either unmeaning or tautological. For the important inquiry returns: What is it for one judgment to be "the ground" of another, or to "follow from" that other as its necessary conclusion? And to this inquiry no answer can be given which does not take us back of all mere reasoning activity, as a purely intellectual affair, to an immediate cognitive experience of the Self in its clianging relations to Things.

Nor in the phrase "sufficient reason" can any meaning be given to the word "sufficient" which does not involve the 
entire doctrine of the criteria of truth and error; and this is altogether too elaborate and doubtful an affair to be involved in the very statement of a primal and universal law of the intellect. Moreover, it is not true to experience that the intellect demands an explanation in grounds lying outside of the particular, concrete process of cognition itself, for all its conclusions. The rather does it strive to take all its tentative and hypothetical conclusions back to original cognitive judgments, with the understanding that these, at least, are to be received as having their " grounds," their " reasons" for being held true, in themselves; they are datum of fact. For "that-which-is-given " is in no case an unclothed, naked " that," a mere somewhat unknowable but injected into the process of thought, to give it some "stuff," or matter of content, to work upon. "That-which-is-given" is always this actual and concrete not-me, cognized here and now as being in such and such reciprocally determining relations with my Self. This datum I do not reach, as a pure intellect, by projecting it into a subjectively created a priori frame-work of space and time; or by reasoning my way to it as something alien to my intuition, and needing to submit itself to intellect to see if it can, forsooth! answer the demands thus made upon it. ${ }^{1}$ But I

1 It would be of incomparable value to science, even in its molern boastful devotion to the truth of fact, if its students would, on the one hand, be somewhat more cautious about elaborating trains of reasoning which contradict immediate experience, and if, on the other hand, they would be somewhat more diligent and unprejudiced in the work of reasoning out the conclusions to which experience seems quite clearly to point. I more than suspect that the observance of these rules would quite undermine the "arguments" by which are supported sucl theories as, for example, psycho-physical parallelism as applied to the causal relations of the body and mind in man, or that determinism in ethics which, under a cover of statistical data, or of materialistic psycho-physics, or of the evolutionary hypothesis applied to human history and human society, really brings over from physics its often inept and wholly figurative conception of the causal nexus, and plumps it down npon the life of the Self. Is it not well to remember that the business of intellect is not to explain facts by showing what can be or cannot be, however isolated in appearance and mysterious, but to criticise alleged facts, and to connect its own generalizations as to causes, and laws, etc., with the facts, as finding in them their explanation and ground? 
find it there, present with an ever-increasing fulness of content, as I more attentively and shrewdly observe what it is ; and as I, on the basis of such observation, reason to conelusions as to what further it may be or must be.

From the points of standing afforded by valid cognitive judgments of perception and of self-conseiousness, the intellect proceeds in its work of generalization and abstraction. It is in these latter processes that the form of its functioning as reasoning faculty consists. Our experience with ourselves as acting in ways partly self-determined and partly determined in dependence upon our elanging relations to things, and our experience with things as aeting in different ways when their perceived relations to us and to one another change, beeomes itself the subject of thought, feeling, and volition. These ways of the behavior of things, when remembered and reflected upon, are generalized; they are abstracted from the concrete things to which they are always observed to belong, and are converted into elasses of entities, powers, causes, that may be thought of as related to each other in the form of laws. This is, of course, that very procedure of thought which produces eonceptial and so-called scientific knowledge. Let it be noted, however, that such a procedure is not, in its simplest expression, a fully conscious syllogistic act. When it is affirmed that the judgrnent "Adam Smith is mortal" is a conclusion from the universal principle "All men are mortal," through the mediate coneeption, or middle term, "man" (because Adam Smith, etc.), the real procedure of intellect is neither explained nor properly expressed. Unless the mere name of the individual - in this case "Adam Smith" - means to me some man or other, the problem of the mortality of the being designated by the name is no problem for reasoning at all. And, as has been pointed out with infinite pains by logicians themselves, the real difficulty is to understand the right to postulate the universality of the general principle "All men are mortal," when as yet we 
have not taken this particular man into the account. But in case we admit this right, how can any advance in genuine knowledge come by so-called reasoning?

The formal difficulty vanishes as soon as we leave the logical and assume the less trifling and more profound epistemological point of view from which to regard the act of reasoning and its claims to validity, when applied to the actual relations of really existent things. Here two simple but important considerations must be kept in mind. First, there is evidently some firmly established expectation of a continuity in the existence of things, and a belief in a collsiderable amount of uniformity in the behavior of these same things, under their ordinary relations to us and to one another. But, second, this expectation is only a relative affair; it is not so firmly fixed that it cannot be shaken, and even upset, by new facts of cognition; nor can it be claimed that the belief applies in a perfectly inflexible way either to the particular events of experience or to the entire world of things. To recur to the example brought forward in the last paragraph: we do expect confidently that Adam Smith will die; and we believe that, in fact, he is at present so constituted as to be wortlyy of being called "mortal." This expectation is in some sort an outgrowth of our general confidence in the obedience (to speak figuratively) of things to laws, in their fidelity to tolerably consistent ways of behavior. On the other hand, we are by no means absolutely sure that Adam Smith may not be an exception to the general rule; for, indeed, alleged cases of exception exist which, although lacking in sufficient evidence to allow us at once to pronounce cognitive judgment upon them as a basis, deserre to appear in eridence. Nor can any one deny that the reasons, not only in theory but in observation, for admitting certain exceptions have seemed "sufficient" to many of our fellow-men. still less warranted are we in affirming that any known law of the behavior of things in the whole universe is of abso- 
lutely universal application; even still less in holding that the system of laws which constitutes the body of modern physical science has always been in the past, or will always be in the future, an inflexible control orer the beings to which expanding experience may introduce us.

The sceptical criticism of Hume, in his treatment of the principle of causation, is quite invincible in one particular. No account of the terms on which this principle is applied to the transactions that take place between things can be given without admitting to this account the determining influence of belief and expectation, as bred of psychical habit, and as constantly confirmed by additional experiences. This influence is positive matter of fact. As all critical thinkers now admit, we never discover, either to sense or to thought, any extramentally existent causal nexus between individual things. Nor do we find in mere conceiving, or thinking, the warrant for affirming that such a relation in reality exists between them. Kant's formal analysis of intellect, taken on his own terms, does not supply this needed warrant. On the other hand, it is a fundamental law of our psychical existence that repeated connections in its "momenta," actually established, excite the expectation of further repetitions of the same connections. Connections frequently and vividly impressed become regarded as legal, as naturally and rationally to be expected; and if they are not met with, then both feeling and intellect seem offended and violated. The offence and the violation are primarily of an emotional and practical origin; but they are confirmed by those activities of thought which have actually terminated in judgments respecting the customary modes of the behavior both of Self and of Things.

One may safely go much further, and yet conserve all the interests of the philosophy of knowledge, in one's concessions to the claims of a sceptical empiricism upon this point. Indeed, in fidelity to truths of fact one must go somewhat further. Knowledge neither reposes upon, nor itself guaran- 
tees the perfectly unswerving uniformity of natural laws, or of the causal relations of things to each other, as a principle of all valid reasoning about things. "The uniformity of nature," so-called, cannot be strictly affirmed as an intellectual intuition taking us straight into the heart of reality; nor is it known a priori as the reflection of the uniform mode of all reasoning, the fundamental law of the intellect, projected into a frame-work of space and time. It is itself, the rather, a growing impression or conviction, built up on a basis of conflicting experiences which can establish it, at last and at best, only in the form of a general working postulate. We say, "on a basis of conflicting experiences ;" for, in fact, the very data which furnish the form for the belief in such a connection of the different items of experience as makes it possible to reason from one to another, largely argue against any rigid construction for the conception of uniformity. This is easily explicable as soon as it is remembered how much of the most interesting and fruitful human experience concerns the impulsive volitions, the blind, unbidden desires, and irrational strivings, of the Self. Thus does every man, at the beginning largely, and to no small degree all the way through, act and react upon things in his changing relations, in an irregular and spasmodic way, rather than so as to emphasize a sequence of events objectively determined according to some "fixed rule."

What is true of the basis for reasoning, so far as it lies chiefly in the consciousness of Self, is also true in a smaller degree of the same basis so far as it lies in the perceived relations of interacting things. To the untrained mind they appear little more obedient to law, or unswervingly faithful to the principle of uniformity, and so little better fitted to serve as points of departure for assured processes of reasoning, than does the Self when directing its observant and expectant eye upon itself. Things, too, at the beginnings of mental development, seem full of caprice, driven by desire, and moved by 
conscious strivings, to reach certain particular ends. They act, often enough, as though they had no respect for law. But, none the less, in many most important and impressive relations, all men are quickly compelled to learn that things can be depended upon to behave in uniform ways; and thus the mind can construct formulas for the accustomed and wellknown modes of their behavior as premises, or fixcd points for starting, in its ratiocinative processes. "All fire burns;" and, therefore, I expect this molten mass of metal to burn me unless I keep my skin well cleared of contact with it. But if it be true that a certain royal personage once plunged his finger into such a molten mass, with full confidence in the word of a scientific friend that, if he would do this quickly, no harm would come, he, by deed done in faith, contradicted triumphantly the legitimate conclusion reached by sound syllogistic argument upon premises established by his own most familiar experience.

The growing accumulation of knowledge as to the customary behavior of things, under given relations to us and to one another, forms the basis for those acts of rcasoning which enter most largely into life, and to which reference was made above. They are general judgments which summarize the experience given to us in those indiridual judgments that terminate the process of thinking in recognition of the envisaged relation of Self and Things, as active and passive, and thus bound together by the feeling-full and voluntary act of cognition itself. In some sort, the leap to the individual judgment, "This man is mortal;" or "This molten metal will burn me," may properly be called a conclusion. It is a "drawing-out" of the meaning of what is included in the general judgment, "All men are mortal ;" or, "All fiery things will burn." But neither the reason nor the sufficiency of the process is to be found in the merely formal connection of the conclusion with the premises. The ground of both is in the cognitive judgments which declare the original 
experiences; and here the nervus probandi is sensitive to stimulations from actuality in the form of fact. The law of the intellect is to generalize the facts. In this work of generalization, the intellect carries over to its concepts all the potencies of feeling and will with which the Self knows itself to be endowed, and which it analogically feels obliged to recognize in Things.

The activity of the human intellect in enlarging the bounds of knowledge by processes of reasoning does not, by any means, stop with such relatively simple processes as have already been described. Suppose, to employ illustrations which have served our purpose before, I inquire: Why are all men judged mortal in such way as that I can, with reason, affirm any particular man to be also mortal? or, Why do I regard the stones in any building, in spite of their placid and unchanging appearance, as continually supporting and causing strains, etc.? In answer to the first question one must consider in a more fundamental way what a "man" is understood to be. $\mathrm{He}$ is an animal, a complex organism, a complicated piece of molecular mechanism, generated by a pair in the species, growing in subjection to physico-chemical laws by metamorphosis of physical materials; and so coming under the most general formulas for determining the probable destination of those materials. This now is, largely if not chiefly, what I wish to express by calling him a man, - namely, an animal of the human species. And now I can affirm the mortality of each particular man, because he is a man, with a quite new meaning to my words. I now know in a complicated way a great variety of reasons for the conclusion that "Adam Smith" is mortal. These reasons are, in part, general conclusions already established along several different lines of concurrent experiences. The number of major premises from which I may now start my processes of reasoning to the conclusion is greatly increased. Such premises include not only my individual cognitions about $A, B$, and $C$, whom I have 
known as men, and known to die, but the accumulated cognitions of centuries of experience respecting the nature of matter, the origin and duration of life, the cosmic laws and cosmic changes, - in brief " the science," of the animal called " man." Here certainly we have reasoning of a higher kind; both because it is based on a much enlarged system of cognitive judgments, and also because it is more conscious of the nature, number, and value of its middle terms.

The same aspect of the reasoning process is laid bare by a further analysis of the other example which was chosen for illustration. Experts in mechanical engineering, when summoned to form a judgment affirming or denying the safety of a building, bring with them, in their memories or in their pockets, a number of general judgments already formed, which may serre as major premises. The conclusion at which they plan to arrive admits of statement either in categorical or hypothetical form; and either as a statement of present matter of fact or as a prediction. Thus they may conclude, "This building is (or is not) safe;" or "If this building is not strengthened, it will fall" (or the opposite judgment, "Eren if it is not strengthened, it will not fall"). The major premises for the argument leading to the conclusion are numerous; they concern the strength of materials of various kinds; the laws of strains, loads, and resistances, and the practical principles for distributing them properly; the effects of weather, weights, and different chemical changes upon the strength of materials; - in a word, the mechanics, physics, and chemistry of the day, so far as bearing on the problem. These premises are themselves conclusions reached by a rast amount of reasoning which has been more or less successfully accomplished during scores of generations of men. But the original points of starting from which it was concluded to these premises, to this collectire "science" of safe and proper building, were certain cognitive judgments representing known facts of relation. In all these cognitive 
judgments $A$ was conceived of as doing something to $B$ (as binding and separating, supporting and pressing down, pulling or resisting, etc.), in a more or less uniform way.

If, however, any such act of reasoning is to proceed to its desired accomplishment, and conclusive judgment is to be passed, minor premises also must be supplied. These must be got, chiefly, by observation of the actual facts of the particular case. $A$ - namely, that girder there - is strong enough; but $B$ - to wit, that row of pillars yonder - is too weak or is not properly placed; and $C$-the mortar employed - is dirt, not gritty sand, and has not enough of good cement, and, "therefore," not enough of binding force. Scanty reflection upon this work of collecting minor premises shows at once that, what is expressly true of the last of the above-mentioned three premises is true of all of those mentioned and of all such premises as can possibly be supplied. They imply the confidence of the reasoners that the building is itself an extra-mentally existent being, composed of a vast collection of beings which are all reciprocally active and passive, doing something and having something done to them, according to their customary ways. This confidence is to be derived and explained only in accordance with the primary nature of the operations of complex cognitive faculty, as that nature has been critically examined in the previous chapters, especially in the chapter upon "Knowledge of Things and Knowledge of Self."

What enormous assumptions! What boundless presumption! What reckless and unjustifiable credulity - unless, indeed, it be an activity of the most rational, feeling-full and voluntary faith - is involved in all this! But whatever the implicates are, upon them, as upon its only justifiable basis, does the entire structure of physical science repose. Assumption, presumption, credulity, - or rational, feeling-full, and voluntary faith? this, at any rate, is not of itself a question to be decided by ratiocination; for all reasoning 
and especially all highly coneeptual processes of reasoning require just sueh premises as these. In such premises all reasoning finds its justification or its grounds. But the assumptions are themselves grounded, yet lower down and further back, in the primary acts of knowledge; they are immanent in the cognitive judgments of our indubitable experiences with Self and with Things. All major premises, in themselves considered, are, then, judgments of relation between hypothetical entities, such as can never be made matters of self-consciousness or of sense-pereeption, and between abstractions of properties and powers, such as never find a pure or unmixed realization in the actual intercourse of things; and these entities, properties, and powers, are affirmed to be connected under terms of formulas which are known to be only approximately exact. The minor premises, on the other hand, have just been seen to be shot through and through with those construets of thought and imagination which are derived by the analogical projection into things of the self-consciously recognized reasons for the Self's activity and passivity, in conformity with its observed changes of relations toward things. From the major premises, through terms supplied by the minor premises, the mind "draws," or " infers," or "coneludes," the terminal judgment: "The building is (or is not) safe ;" or, "The building will (or will not) fall." But if, as is apt enough to be the ease, the major premises are eomplieated and somewhat eonflicting, or are not obviously applieable, and the needed minor premises ean be only partially supplied; or even if the theoretical or practical interests of the reasoners are at variance as respects the most " desirable" or " fitting" conelusion, then the judgment terminating the ratiocinative process may be questioned, divided, or totally in doubt. Some will then say, the building is surely safe; but others will say, it is by no means safe. One expert will prediet with confidence that it will fall; but two other experts will offer to guarantee by a large 
sum of money that it will not fall. Meanwhile there the building stands, just as it is and no other, in a sort of silent scorn of all human attempts to penetrate assuredly its entire and most hidden nature. In despite of scientific predictions, in reality it will fall or it will not fall - as it and its natural environment "will," and not as the scientific experts wish, or think, or conclude, respecting its appointed end.

It appears, then, that the goal of that cognition after which the mind strives in its processes of reasoning is the establishment of causal relations that have truth in reality. With this we believe ourselves to be concerned, while conducting those elaborate intellectual operations by which the real world becomes known as a complicated system of interrelated selves and things. In order, therefore, to understand the meaning of the reasoning process, and of the confidence it implies, as well as the limits of its possible achievements in the way of adding to our knowledge, we must investigate the conception of causation itself. This investigation leads us back to the nature of those primary expericnces of knowledge out of which comes all systematic knowledge of the world in which we live. Here we are reminded that in knowing any thing, by the most fundamental and primary cognitions of senseintuition, the Self becomes aware of itself as active, and also as resisted in relation to that which is not-self, which is indeed other than Self. Will and other-being, my will and other will, - these, observed, remembered, compared, subjected to all the activities of a growing consciousness of discrimination, such as is called the development of intellect, or in a word, thought, in the relation of commerce called cognition, furnish the account of the causal conception. It is this same experience which leads thought still further to frame the conceptions of " conformity to law," of "a sequence of events objectively determined according to a fixed rule," of the "uniformity of nature;" and to the pet generalization of modern physical science: "Every erent happens only as an effect ab- 
solutely predetermined by other preceding events which constitute its cause." The experience itself is the presupposition of the conception of law, or invariable rule, etc., - however we may choose to plirase so abstract a summary. The formula is only the more or less highly developed exhibition of repeated and indubitable cognitive experiences of Self and Things as known in various relations. The fact is indubitable, it is, indeed, matter-of-fact of every completed cognition. But the establishment of uniformities, laws, and forms of general relation of an abstract kind, is always a relative affair, never complete, but subject always to the possibility of doubt. Our cognition of the particular reasons which must serve as middle terms for the reasoning process is very often uncertain, rague, meagre, and ambiguous, - no fitting representation of the actual, indefinitely manifold, and yet precise causal relations of nature. And, finally, this picture of known causal relations, as the only actual and possible relations, the picture, namely, of a vast and self-contained mechanism, erery part of which is bound solidly together from beginning to end, and from centre to circumference by unyielding laws, is itself no a priori structure of the human intellect. It is not a wholly defensible work of the artistic imagination; it is not even a creditable dream of what may possibly sometime be reasoned out into a conception resting on grounds of incontestable cognitive judgments. Much less is it God's final truth about the whole matter.

The truth of our critical estimate of the use of reason in the knowledge of nature might be elaborately argued and satisfactorily established by an appeal to the particular sciences themselres. This task, indeed, belongs, with all its details, to the philosophy of nature; and no other task cries out more loudly for some masterful hand to undertake it. The physical and natural sciences, in spite of their recent wonderful adrances (perhaps rather in consequence of these advances), were never before so full of abstract conceptions 
that need a critical treatment by philosophy. Our present purpose, however, requires only a glance at certain fields covered with a mixture of flowers, grains, and weeds, that await the efforts of the expert analyzer.

And first, it may be questioned whether there are any plysical laws so universal as not to be forced to recognize wholly inexplicable exceptions in the very heart of the domain over which they hold sway. For example, the law of gravitation affirms that, without exception, all physical bodies attract each other, directly as their mass, and inversely as the square of thcir distance. But this law, or abstract formula, explains only the movement of bodies near the earth, of the planets around the sun, of the satellites around their planets, and of a select few couples of the stars. It explains these morements of bodies only if other considerations may be neglected, such as never are in reality neglected by the bodies themselves. All these bodies which most obviously fall under this law are, however, moving together onward in space with an apparent complete disregard of all other bodies outside of their own system. The directions and velocitics of the several movements of the stars fall under no common principle that astronomy can discover. And, to take an extreme example, one of them (" 1830 Groombridge") is flying through space at a rate many times as great as it could attain if it had fallen through infinite space, from all eternity, toward the entire physical universe. What caprice of Will gave it the initial fling that has enabled it so to flout at the principle of sufficient reason in the form of the so-called "universal law of gravitation"? Again, it is a well-nigh universal law of plysics that both solids and fluids contract when cooled and expand when heated; but there is the startling wellknown exception of water at the degree of freezing. It is a law of chemistry which affords one of the main props for the atomic theory, that fluids hold in solution more of the solids soluble in them, at a higher degree of temperature. 
But calcium sulphate (or gypsum) dissolves to a limited extent in cold water, but, on a rise of temperature to about $135^{\circ}$ Cent. it deposits; and calcium hydroxid (common slaked lime) is more soluble in hot than cold water. If the case of the gypsum is "explained" by its passing from a hydrated to an anhydrous form, such an explanation for the lime can at present only be suspected. And then there is the case of common salt, which, for reasons only known to itself, has practically the same solubility in both cold and hot water. But, however these and similar "exceptions" to laws of the widest applicability may be explained, the fact of there being exceptions is itself what carries the import of greatest use to our present discussion. This import administers a crushing rebuke to those who hold the "reign of law" (whatever this may mean) in such manner as to contradict the concrete internal and external facts by which the raried Life of Reality is actually made manifest.

Another ficld from which to gather illustrations for our present contention is afforded by entire bodies of scientific truth, whole "sciences," so-called. We are not unmindful of the fact that it is customary to speak of this " reign of law," and of the resulting uniformity of human nature, by students of psychology and of the psychological sciences, of economics, sociology, history, and even ethics and religion. But here the distinction must be insisted upon between knowledge and hypothesis, and between an hypothesis that conforms to known facts for their better theoretical handling, and one which is itself framed in the interests of yet more doubtful hypotheses. One might even descend from psychology into some of the physical and natural sciences to illustrate the truth that alleged "uniformities," a "reign of law," and the conception of "sequences objectively determined according to a fixed rule," are themselves too frequently abstractions unsupported by the facts, or eren figments of imagination most plainly contradicted by facts. It seems to us that the 
time is fully come to recognize not only the truth of the fragmentary character of all science, but a far profounder and more wide-reaching truth. How do we know that it is the Nature of Things to be under "universal laws," if by this term be meant fixed rules imposed from without, or lying mysteriously immanent in things? How do we know that uniformity, in the sense of unceasing repetition of the old relations according to unchanging formulas, is the fundamental principle followed by the Really Existent? If now an appeal is made to the past successes of this assumption, the case is not at all so conclusive as it is customarily represented to be.

In all of the physical and natural sciences, improved methods of observation have recently extended the number of inexplicable single facts, and of whole classes of such facts, much faster than the reasoning faculty has been able to provide laws for them. The seventeenth and eighteenth centuries were characterized by a few splendid generalizations, which seemed to their discoverers and to the age destined to reduce the entire universe to a mechanical system whose terms should be strictly calculable. In these generalizations was to be found the unfailing source of the "reasons" why things bchaved as they always did behave; and also the "grounds" of the confident predictions that they would continue unswervingly to behave in the same way. In the present century, when the Darwinian hypothesis, in spite of the pitifully narrow range of observed facts and of incontestable judgments of experience on which it was "grounded," was placed by $\mathrm{Mr}$. Huxley and its other ardent admirers on a level, for certitude, with the principle of gravitation, it seemed, indeed, as though all life, even up to the life of the artistic, religious, and cognitive spirit of man, was about to be formulated by similar treatment. Nor are claimants for the name of "science" yet wanting who neglect a truly scientific reserve, and are ready to accept or reject, to interpret fairly or to sophisticate, the 
facts according as they bear upon foregone general conclusions confirming their particular theory of evolution.

On the whole, however, the nineteenth century - and especially the last quarter of it - has been growing into a distrust of glittering generalizations, with their high-sounding claims to reign over the whole realm of the concrete, contentfull, and seemingly capricious and ever mysterious Being of the World. Even astronomy, the most mathematical and deductive of the applied sciences, has of late been multiplying facts faster than it has been able to reduce them to the uniformity of laws, by reflecting upon their connections through either known or hypothetical middle terms. And to pass at once to the other extreme - he who has seen an amœba and a fresh-water hydra, after due preparation and preliminary skirmishes, fight it out to a finish in truly heroic and artistic fashion, is much more likely henceforth to conceire of them as beings with appetites, passions, conscious cunning, and no mean resources of will and intellect, than as molecular mechanisms that may soon be served up as examples of problems solved in thermo-dynamics and the lawful action of merely physico-chemical forces. So, too, when one hears what is given out as a "science" of sociology in terms of biological and mechanical evolution, with much talk of "social forces," "social organism," and of inexorable "laws" to which this organism is subject; and when one turns to face the concrete and life-like picture of the multitudes of men in the present world and in the course of history ; then, too, one inclines to believe that these souls are themselves the forces, and that their ever varying and self-chosen relations to the wolld of things and to each other are the laws which constitute the figuratively so-called social organism. Forces are not existent, so far as the science of sociology goes, until the souls are existent; they are no more uniform than are the souls from which the forces spring. And as to laws of a "social organism," there are none, except those 
which are made by the action and interaction of the souls themselves. But these are not ready-made laws, as it were; they are only the actual, but ceaselessly varying and, as we hope, improving modes of the behavior of the individual members of the so-called organism.

In brief, men reason about things for practical purposes, and thus know them increasingly so far as getting along well with them is concerned. Fortunately, those things that most nearly determine human daily interests, the common weal or woe, are found to be tolerably consistent in their beharior. The solid ground on which men walk, the sourees of their support, the implements they handle, and in mueh inferior degree, the animals of their eustomary intercourse are fairly trustworthy. But sometimes out of a clear sky the lightning strikes; or out of a sweet air the Russian influenza falls; the weather and the dependent erops are uncertain; all learn to be eautious in matters involving the behavior of the lower animals and of their fellow-men; and those who reside in Japan know that, at any moment, the ground beneatl them may be lifted aloft or sunk into the depths. Nerertheless, further and more careful observation, helped on so far as possible by experiment, gives grounds for reasoning to a new and higher confidenee in things. In a measurable degree we discover middle terms, in the form of minute entities (the molecules and atoms), or of hidden masses (the internal fires and eaverns underground), or of unsuspected properties and relations (thermic, chemical, biological) which serve to connect the seemingly contradictory experiences into a more rational whole. Many of these connections, at first hypothetical, lead to somewhat broad generalizations whieh, when they are themselves employed as major or minor premises, land the mind on the firm ground of verifiable cognitive judgments again. Expeetations are modified; some are strengthened and others abandoned. The courses of the reasoning processes and of the concluding judgments are 
changed. The convietions which give them their special cogency prove alterable, in respect of degree and of points of application. Even the general conviction that by reasoning man can find out the ultimate Being of the World, or extend his cognitions of its actual nature and uniform modes of behavior (if, indeed, It has such modes), is sometimes shaken. But, on the whole, the coneeption of the World of Things as some sort of a Unity is enriched and deepened.

Once more at this point, however, we must return to make further examination of our knowledge of Self and of Things as a basis for the general confidence in our reasoning processes. It will be found that all "reasons," or "grounds," from which conclusions are drawn may be divided into two quite different classes. Both these elasses of reasons are employed in every completed process of reasoning. Both of them, moreover, when examined, quickly lead our thought to the limits of what is immediately known; and from there they point it beyond to what must always be a matter of rational postulating, or abstract theorizing, or fanciful conjecture. These two classes of reasons are embodied in current conceptions of the "nature" of things as both active and passive, and of the further conditions determining the modes of activity or passivity, as found in the "relations" of things. Thus the complete reasons for the behavior of things are thought to reside both in their own nature and in their relations to other things.

When, for example, I let a certain quantity of a gas $O$ mingle with a certain quantity of a gas $H$, under determinate relations of temperature, pressure, ete., $=X, \mathrm{I}$ find that a compound of a totally new nature, $W$, is the result. I therefore express my knowledge of the chemical constitution of water by the formula $\mathrm{H}_{2} \mathrm{O}$; and my knowledge of the law of the combination of hydrogen and oxygen gases, when brought under the relations of $X$, to be a proportion of 2002 to 1000 . This is reasoned and conceptual, or scientific, knowledge. But 
now if I press still further my inquiry after reasons, and demand to know why this thing, $O$, behaves in this particular and no other way, when it is brought under these precise, and no other quite dissimilar relations to this other thing, $H$; and if $I$ also demand to know as much with regard to the latter, the $H$, I can hardly fall back on reasons at all. I can only blindly say: It is the "nature" of $O$ and $H$ so to behave, under these and no other dissimilar "relations." But then, the chemist can describe many other modes of the behavior of both $O$ and $H$, under a great variety of relations besides $X$ to an almost endless number of other things, with natures of their own. But why is it the nature of $O$ and of $H$ precisely so to behave; and why do these particular relations, $X$, have anything decisive to do with the changing modes of the behavior of these things? To such a question no answer can be found; in fact the things do so behave, and in fact relations of things do always have to do with how things behave. The limit of all cognition by reasoning has been reached in the unreasoning recognition of cognized facts.

"We have no answer to make," and "We have reached the limit of all cognition," - but only if we are unable to get the facts into our consciousness in another way, and thus to regard them from a new and higher point of view. For if the cognized facts are deeds done by a Self, with a consciously recognized end in view, then it is possible to explain to its very centre the "reason" for the facts. If I simply find myself to be acting and suffering in certain more ol less uniform ways, with relation to observed changes in the active and passive condition of things, but without any conscions discrimination or choice of aught to be gained as a good, or avoided as an evil, I have no further reason to give, or to seek, for such facts. They are so, and that is the end of the matter. To ask, further, why they are so is to ask an absurd and unanswerable question. But in experience this is not the case with all deeds of cognition. Certain items, and 
those not a few, in my experience do, indeed, end in this way. Thus I act and thus I suffer, without any consciousness of a "why," of a reason for acting and suffering thus rather than in some totally different way. That is to say, out of the dark and incomprehensible "ground" of my own nature in its unintelligible relations to the dark and incomprehensible nature of things, these states of my being seem to proceed. Such procedure in reality makes necessary the ending of my own reasoning processes in that which is not a subject for reasoning. On the other hand, certain other items of my experience - and these not few in number, but of the greatest practical and rsthetical as well as cognitive import - involve the consciousness of activity and of passivity as determined by chosen forms of intercourse with things, in the pursuit of conscious ends. This part of my experience, when made the subject of further reflection, throws a new light upon the meaning and the limits of reasoning. It leads to a consideration of the teleology of all knowledge, and of the corresponding immanence of final purpose in the really existent objects of knowledge.

Nor can the consciousness of an end be separated from the explanation of the nature, and the defence of the validity of any act of reasoning. This consciousness is operative in the determination of the primary cognitive judgments from which all reasoning takes its start. This consciousness itself forms a part of the original experience with the causal conception; and it gives characteristic coloring to the "connection," to the "bond," which is assumed to exist between Self and Things, as well as among things themselves. We are not unaware of the present wide-spread denial of this fact; and alas! of the sometimes monstrous and mischierous conclusions derived from this denial. It is enough at present to stand by those facts which are indisputable and inseparable " momenta" and presuppositions of all knowledge. The "grounds" on which all acts of reasoning repose, so far as they can possibly 
be explored by an analysis of knowledge itself, are laid bare when we behold the nature of the Self revealing itself in the pursuit of some conscious good. This is the final answer to the question "Why?" And the answer cannot be divorced from the conception of that causal relation which all reasoning assumes as binding together, in reality, the things of the physical world. For it is in the same experience that the answer to the question "By what cause determined?" las its origin and its import.

A sleeping postulate, therefore, underlies all our account of the principle of sufficient reason. The explication of this postulate belongs to metaphysics as ontology. But we must recognize it as implicate in a satisfactory theory of knowledge. Two somewhat opposed directions, however, seem indicated for this theory, if it would conform itself to the facts of cognition considered as falling under the principles of identity and sufficient reason. One direction follows the lines of thinking rather in opposition to those of the actual being of things; the other seeks to demonstrate that the forms of thought are the forms of the being of things. One teaches us to consider how much of an antecedently unthinkable sort seems necessary in order to give full recognition to the nature and the limits of our reasoning processes. The particular, the unique, even the perverse and contradictory, interpenetrates the content of knowledge. ${ }^{1}$ Every act of cognition is a problem, and the problem cannot be solved by reasoning alone. The very Being and the Becoming of the World, as given to the human mind, seems full of contradictions. IT is the great riddle itself; and there is none greater to be suspected behind it. The extreme apriorism which maintains the absolute universality and objective necessity of those imner modes of apprehension that are employed upon the world of things may fitly be criticised by showing to how

1 Compare Uphues, Kritik des Erkennens, p. 106. Lasson, Der Satz vom Widerspruche, Philosophische Vorträge, 1885, pp. $208 \mathrm{f}$. 
low and pitiful a condition this alleged universality and necessity may fall. Even the lugical and mathematical prinples upon which the adrocate of this extreme apriorism bases his claims may in certain cases show unmistakable signs of being "shaky" or of entirely giving way.

And further, if the attempt be made to exalt either of the most primary principles of all human thinking to the place of an autocrat or irresponsible creator of cognitive judgments, and to hypostasize either of them as a formula representative of the complete being of the world, the reward for the attempt is not a knowledge of Reality, but a delusive mistaking of formal abstractions for the real content of things. In the name of the "Principle of Identity" the innermost essence of Reality has often enough been proclaimed as Absolute, changeless Being, whose conception cannot be constructed further without sclf-destruction. $A=A$ is, indeed, a proposition which appears to have a demonstrated simplicity and clearness; or rather, an indisputable a priori character which puts it beyond all need of demonstration. But $A=A$ is nothing but an empty, meaningless symbol, to which no known reality corresponds or ever can be conceived of as corresponding. In our self-consciousness, where all cognition hegins, and to which it ever returns for fresh sources of a vitally renewing kind, the abolition of the fundamental opposition between subject and object is a return to nescience so complete as to be quite unable to state itself even in negative form. And when the doctors of philosophy have put to sleep, or quite anuulled, the living process of a self-realizing Cosmos, they can never restore what is gone by uttering over the corpse incantations in the name of a mystical Principle of Identity. Moreover, every concrete application of this principle must be made only on grounds of actual cognitive judgments; and critical examination must test each application. For the processes of thinking and the actual connections of Reality cannot be, off-hand and without a seeptical and critical process, identified. 
The same cautions must be observed with regard to the Principle of Sufficient Reason, objectively applied as a socalled universal law of causality. The abstract conception of causality is itself no ground of explanation; there is no sufficient warrant for its being raised to the place of supreme adoration and hypostasized as embodying the whole essence of the really existent World. Especially inept is that process of reasoning which, after having based itself upon this very conception of causality, proceeds to divide the world of reality into two unrelated halves, two disconnected processes, that run on eterually as it were, side by side. ${ }^{1}$ But without employing again the causal principle to connect together thoughts and things, we are never able to get one glimpse of a reason why the processes should be two rather than more, or even infinite in number; or why thoughts and things should run parallel rather than at right angles; or how out of this diversity of actually disconnected processes the unity of experience and the Unity of the World can come. Is it not an astonishing outcome of the tenderness shown this principle of sufficient reason, as employed for the interpretation of Reality, that it should be so hardened as to become unable to depart from one of these two lines of process and thus bind together into one the physical and the psychical World? But no less surprising and self contradictory is the outcome of every attempt to vindicate an absolute logico-mathematical necessity for the really Existent, in the name of the principle of sufficient reason or of its objective correlate, the principle of causality. The suppositions of eternally unchanging uniformity of mass, or of force, and of complete similarity of conditions, with rigid bonds of law binding together the entire mechanism, are abstractions which are neither derived from the sum-total of experience, nor do they accord with this sum-total.

But the result of a critical examination of the principles of

1 As, for example, Paulsen does; Introduction to Philosophy, pp. $87 \mathrm{f}$. 
identity and sufficient reason is not such as to let the entire structure of human knowledge dissolve, at this point, in the canstic of hopeless contradictions, or disappear in the soft mists of an equally hopeless agnosticism. The mind of man retains its undying confidence in the possibility, by reasoning processes, of gaining an increasingly large and true cognition of Reality. It will bear chastening, but it will not lie down in despair. And it need not do this in order to vindicate its confidence in the rationality and validity of its own procedure. For Causality is itself no invincible bond that, in a quasi-external way, seizes hold of things and forces them into a Unity. Neither is it necessary to go out of experience to realize that causal nexus, in the confidence of which our reasoning about things continually proceeds. This nexus is, after all, when profoundly inspected and analyzed by critical reflection, not so much like the external connections of a machine, which lay themselves bare before the eye of sense, as it is like the interiorly recognized and felt connections of a conscious and reasoning Self.

This, then, is the conception which is suggested as the postulated truth of the nature of the Being of the World. It is, after the analogy of the Life of a Self, striving forward to a more and more complete self-realization under the consciously accepted motif of immanent Ideas. This conception, we say, is suggested. It appears as the sleeping postulate whose presence and potency must be recognized if we would understand and validate the employment of ratiocination for the increase of our knowledge of the World. The postulate implies, (1) some sort of unitary Being for this really Existent; (2) that this Being is Will ; (3) that the differentiation of the activity of this Will, and the connection of the differentiated " momenta," - the separate beings of the world, - is teleological and rational, like that of our own Self. But it is the task of metaphysics to criticise and derelop such statements as these. 


\section{CHAPTER XI}

\section{EXPERIENCE AND THE TRANSCENDENT}

$T_{\text {circumstances, transeend his own experience is custom- }}^{\text {HAT man ean, in no manner and under no conceivable }}$ arily thought to be a proposition so self-evident as to stand in need of neither argument nor explanation. But the history of the controversies which have raged for centuries between extreme empiricists and their opponents shows clearly enough that explanation, at least, is imperatively demanded for the proposition itself. Indeed, the shifting meanings which are given by the contestants to such terms as "experience," " eognition," "the transcendent," etc., and to the concepts of relation embodied in the rarious judgments that affirm or deny the possibility of effecting a union between these terms, are the most significant thing in the greater part of the controversy. It is important, then, for every attempt at an epistemology to raise such questions as the following: What is to be understood by the term, "experience"? What is the relation of knowledge to experience? and, What would it be to transcend experience by cognition, or in some other way, if only such a thing could be conceived of as possible?

The history of epistemological diseussion diseloses a surprising characteristic group or set of fallacies. They are of such an order as to awaken one's shame and distrust respecting the power of the human intellect to treat fairly its own most familiar modes of activity. For the most part, they seem to be connected with the misapplication of a single, easily apprehensible figure of speech. Empiricists generally, 
and their opponents quite too frequently, argue about " Experience" as though it were actually some material thing, laving a fixed or a changeable and expansive area, as spread out in space. Certainly, if experience is like a circle which includes only what is within its own area and by virtue of its very nature excludes all else, then, by defining experience inclusively enough, the necessity of its being absolutely exclusive of what transcends its own limits may easily be shown. Or, to bring up again the figure of speech which Kant so effectively employed : - and now experience is an island, surrounded by a boundless ocean of impenetrable mists and fogs. Moreover, since this island has its circuit eternally fixed by the unchanging laws of pure understanding, it can never make advances into the surrounding ocean. And since the critical philosophy has made a finality of the exploration of this island, all its inhabitants should cease to delude themselves with the hope of some day passing beyond its rocky coast-lines. Only, since they are possessed of reason as well as of understanding, they will doubtless keep on turning the spy-glass of an "illusory logic" toward the paradise over-seas, where God, Freedom, and Immortality are imagined to be, and whence comes the attractive, siren-like song of the transcendent ideas. Eren Kant will allow - nay! he will by and by demonstrate the necessity of a faith which shall overreach the limits so inexorably fixed by experience to human scientific and speculative cognition.

Now, by all the most primary concepts of geometry, it is forbidden that circles, laid ont on flat surfaces, shall include and exclude at one and the same time. For is not the very definition of a circle,-so much of space only as is included within a curred line that is drawn through points equidistant from a central point, until it returns upon itself? And circles constructed according to the modern "higher geometry," with their inconceivable qualities contradictory of the plainest requirements of the mind that imagines a la Euclid, may fitly 
be denied all likeness to "experience." For is not experience supposed to have something to do with actual existences? And actual circles are never known to behave in any such contradictory fashion. Islands, too, although exceedingly changeable as to boundaries in certain cases, and sometimes even disappearing in the depths of their surrounding ocean or rising into mid-air on the wings of submarine volcanic forces, do not include and exclude the same territory at one and the same time. Thus far, at least, they submit to the fundamental principle of identity; and if they ever change the limits of their territory, they do this in accordance with the principle of sufficient reason.

But, after all, is the total experience of man precisely like a geometrically correct circle, or like an island with fixed boundaries? Is it even enough like either to allow us to proclaim, as a self-evident proposition, that it cannot include and exclude at one and the same time? May it not, at least, include in one sense what it excludes in another sense of these two words?

Doubtless, the origin and nature of all language is such that, even when we are employing terms current annong thinkers acquainted with the very highest critical philosophy, the spatial and "thing-like" meaning of words is exceedingly influential. It would be awkward, indeed, and we fear practically useless, to attempt so to express ourselves on this subject as to escape all influence from this meaning; indeed, the meaning itself reveals a considerable number of important truths connected with the philosophy of knowledge. For the present, then, we shall continue to employ words which carry with them the influenees inseparable from the figure of speech they embody. In succeeding chapters, where the attempt will be made to analyze more critically and in detail the conclusions somewhat crudely and plumply affirmed in this chapter, other terms may be substituted that are better adapted, perhaps, to reveal the real trutl of the case. But here our 
main purpose is simply to expose the problem, and the characteristic fallacies which have so frequently embarrassed its solution. Preserving the same language, with its figurative meanings, we affirm, then: However extensive in its meaning we make this word, "Experience," critical examination shows that experience is always and necessarily transcended by cognition. The answer to the question whether man can trauscend his own experience is this: If man did not transcend his own experience, he could, as a man, have no cognitive experience. This is what makes some of our expericnce rational,namely, that it does, in a peculiar manner and to a most marrellous extent, always transcend itself. Indeed, the immanent and the transcendent, the inclusive and the exclusire, the merely subjective and the trans-subjective, the mental and the extra-mental, are not contradictory of each other, or opposed to each other in the facts of human knowledge. The rather must it be recognized that what corresponds to both these classes of terms equally belongs to, and is equally necessary to, the explanation of the very concept of experience.

For let this concept of experience be examined with a view to see what it necessarily implies. In beginning the examination, the term may be considered in its widest possible signification. When employing the word "Experience" in its most inclusive meaning, we are wont to think under it everything in any way concerned with human conscionsness, - whether as fact, condition, law, or implicate. But in forming the rery conception of itself, experience has already transcended itself. The fact of consciousness - or rather, consciousness considered as fact, as being just what it here-and-now is for me, and no other - is, from one point of riew, all that there erer is of my present actual experience. Let this fact be exalted to the highest pitch of excellence, extended so as to embrace the widest possible content, and suffused with the intensest and most potent objective conviction, still it is a fact of consciousness - here, and now, and nine - and no more. The next 
fact of consciousness will, in its turn, be the sum-total of my actual experience regarded as an empirically indisputable fact; and so will the next, and the next, as long as the stream of consciousness I call myself continues to flow. $\Lambda$ nd as to the "experience of the race," so long as the same point of view is maintaincd, it is but a fact of my imagination - another fact absorbing the entire experience of an individual consciousness, somewhere and at some definite time. Now, from the point of view of the advocate of empiricism, strictly limited and consistently retained, this is all that can ever be made out of the concept of experience. But this is not at all the concept of experience as formed and contended for by the empiricist; and he is as quick as any one to see, when it comes his turn of advantage, that such a concept is self-contradictory and obviously and scandalously absurd. For such a concept of experience can not so frame and hold itself together as to maintain its integrity for a moment in the ficld of philosophical contention. Even the concept of ghosts has morc of fleshand-blood reality, and is better wortl fighting for than is such a concept as this. For, in truth, to say " concept" - just that and nothing more - implies the continuity of the conceiving subject, some sort of continuity and conditionated existence for things, and some standard of judgment and authority in other conceiving subjects. But herc is a mighty host of transcendent beings already intrenched in the empiricist's camp. ${ }^{1}$

No class of men, among psychologists or philosophers, insists more upon carefully observing and studying the conditions of experience than do the empiricists themselves. Ordinarily, too, the particular kind of conditions which they think it best worth while to study are of the most recondite and unapproachable kind. With the eritical epistemology of Kant and the neo-Kantians, they will have nothing to do;

I For a concrete instance of the desperate condition to which such empiricism reduces one, see the examination of M. Flournoy's case, in Philosophy of Mind, pp. $28 \mathrm{f}$. 
indeed, they cherish for it secretly, if not openly, no little contempt. As to the uneritical apriorism of Hegel and the neo-Hegelians, they are quite unable to speak contemptuously enough. As empiricists, they propose to confine themselves, and all of us, to a study of experience, as actual matter of observable fact and as reposing upon matter-of-fact conditions. ${ }^{1}$ These conditions, howerer, are only such as physiological and physical science can handle and verify; they consist in antecedent and concomitant brain-states, or in other physical ehanges which, flowing in upon man's stream of consciousness, if not wholly accountable for its existence as a conscious stream, determine what the factors and the direction of it all shall be. Who does not see, however, that the rery assumption of any sort of conditions for our experience, which are not present in the concrete and actual ex. periences as conscious facts, shows the mind to itself as already transcending experience? Let no one fail at this erucial point to comprehend the question at issue and the significance for its answer, of the procedure of every mind, whether it be committed to the baldest empiricism or to the most high-and-dry apriorism. This question does not refer to the admissibility or adequacy of any particular order or kind of the conditions of experience. The question refers rather to the significance and validity of the assumption that the present experience has any conditions at all. That some of the conditions of human experience are physiological and physical, or eren that all of them are such, may be admitted by the opponent of a consistent empiricism as cheerfully and safely as by its most determined adrocate. No psychoses without antecedent or concomitant brain-states; or all psychoses are only epiphenomena, mere successive steam-clouds "thrown off" from and floating above the brain, - if you now will. For this is

1 Among other significant failures due to the effort to get the necessary assumptions while refusing to reckon with their origin or significance, see Professor Fullerton's Address, Psychological Review, January, 1897. 
not the question at issue; namely, What are the most important and effective conditions of human experience? The question is rather: Why does the concept of experience, for all men, itself include conditions that transcend the individual experience? Why is the concept of an unconditioned experience, of an experience containing all its grounds within itself, an absurd and eren impossible affair for the human mind to attempt to contemplate?

Of course, it may at once be claimed, and correctly, that these assumed conditions of every present experience, as facts of consciousness, hare in some form themselves previously been matters of present cognitive experience. Last of all men would the most thorough empiricists be, to place the conditions of experience where they could themselves, in no sol't, be verified by experience. In the particular case under consideration, some of our past experiences have themselves consisted of conscious facts appertaining to the brain and to its states, and to the other physiological and physical conditions of human experience. Fortunately, moreover, not a few of these conditions admit of being repeatedly observed under such circumstances as to provide checks for mistaken speculative inferences; some of them admit of frequent or occasional experimental determination. So that the inference of other conditions, which are not obviously implicated in the present experience, is very far from being an effort or a claim to transcend all experience. On the contrary, it is sticking fast by the lines, and dealing with the facts, of experience only: it is mental consistency within the fixed lines of our empirical destiny.

Now, such a view is, we suspect, not really all that, or precisely what, the empiricist originally meant when he proclaimed his confidence in brain-states as affording the conditions of this and of all human conscious experience. It is likely that no one would more quickly resent the charge of proclaiming a theory of materialism, or of psycho-physical parallelism, or 
indeed any other theory merely in the interests of his own mental consistency. The truth is, that the epistemological view of his own meaning and intention comes to such a thinker only when he finds himself driven into a corner by the pressure of questions for an explanation of experience itself in a thorough-going empirical way. Really he means that an actual system of things, a brain, etc., most of which never has got, and never will get, into his own or any other man's experience, must be assumed in order to explain every fact of his experience in particular, and in general, all human experience. But this is just the meaning upon which we are insisting at the present time. And the same searching question recurs: Why is a conditionless experience absurd? Why does experience, in order to explain itself, need to transcend itself as mere fact? And if the very nature of experience is such as to render it incapable of realization as a mere fact, tormented with the actual limits set for it and unable to conceire of itself without transcending itself, why should we compare it to a closed circle or to an island in an impenetrable ocean? If one must employ spatial and "thing-like" figures of speech, would not one speak truer to the facts if one said: The rery nature of experience is perpetually to transcend itself, both for its own explanation and for its fuller realization? In cognition always, as soon as we inquire critically into its grounds and its significance, we see the mind leaping beyond its present limits into the real world that is unseen and unrecognized by any present act of consciousness.

Suppose, now, that the effort be made to construct a scientifically defensible conception of the conditions of all human experience, both that of the entire race of men now in existence and also that of the race of men (and, if it please you, of their ape-like ancestors) sinee its first origins upon the face of the earth. Can this effort be made in any wise successful without freely bringing what is properly transcendent within the circle; or without orerleaping the circle, 
and so, by some act of belief, inference, or postulate, reaching the embrace of the transcendent? By no manner of means. And the more bold in the use of its resources, and rich in content, the scientific treatment of man's nature and history becomes, the more does the concept of human experience, taken as a totality, include factors, faiths, inferences, postulates, which transcend all present experience. The cry of physics to beware of metaphysics, and the wailing of anthropology to free itself from ontology, have their answer in the facts of science as dependent upon the nature of all knowledge. There is no science of physies without metaphysics; there is no anthropology without ontology. A purely " $\mathrm{cm}$ pirical" science is not a ne-plus-ultra but a nonentity and an absurdity. For science itself consists in the discovery somelow of the "conditions" upon which the present facts of experience may reasonably be supposed to have come to be facts at all; nor is the most scientific concept of experience itself different as respects its origin, character, or obligations, to the transcendent. Tracing this concept steadily backward and outward, we are obliged, in the interests of that very science which boasts itself to be founded only upon experience, to pursue the path of the following assumption: $\mathrm{My}$ present experience, as a fact, has its conditions lying outside of itself. These conditions are partly in my bodily organism, and, especially in that part of it of which I have had no experience, - in my brain and central nerrous system. They are also, partly, in my past mental operations as productive of tendencies and habits; and these conditions, too, very largely lie outside of any experience which I have ever had or can ever hope to have. What is true of my present experience is emphatically true of the totality of my experience. Its conditions are physical, and belong to the great world of nature which lies outside my experience; they are also biological and sociological, and so dependent not only upon the collective experience of the race but also upon many 
conditions of which this collective experience has afforded no mental representation to any member of the race. This collective expericnce of the race, together with all its concomitant conditions, whether physical or psychical, and with its so-called laws of heredity and variation and of modifying relations to environment, etc., is still further scientifically conceived of only as having conditions which transcend itself. And no one is more forward and confident in the matter of transcending present facts (this charmed circle of human experience) than is the ardent defender of the mental propriety of sticking fast by the facts. But he evinces on that account the more forcibly the truth of our position: The concept of experience itself cannot be framed without including within itself, "momenta" which transcend its bounds. In other words, what sets out to be a purely empirical theory, with reference to the nature of experience, cannot explain itself without passing out of, and so confuting, itself.

Shall we, then, admit this self-contradictory nature of all experience in proof of the fact that we cannot critically examine and so know what we are really about in having cognitive experience without discovering how much actually enters into it, of blind inference, of unexplained faith, of postulating of unexperienced entities, etc.? Precisely so, for this is, in part, what we desired to make clear. But only in part. The real trouble with the advocate of an empiricism which tries to conceive of human experience as a closed circle, from which the transcendent is forever excluded, is this : he does not understand himself. He would have a science, if he had his own way epistemologically, which involved no real thinking and no completed perception or self-consciousness, - not science at all, but scarcely a logically consistent dream, or a vision of an insane mind." But if " science"

1 As Volkelt truly says (Erfahrung und Denken, p. 75, note) in criticism of Göring, "one of the most radical of the defenders of pure experience" (see his articles in the Vierteljahrsschrift für wissenschafliche Philosophie; 1877, iv., 
means knowledge, then it is necessarily not of the merely subjective, but of the trans-subjective, too. And the logically established system of existing beings, actual forces, and real relations, conceived of as occurring in time and space, and so forming necessary conditions of all human experience, is the transcendent. Modern empirical science is certainly far enough from reducing all this to the "trans-subjective minimum," as a sort of postulated plus lying outside of experience. On the contrary, it goes on heaping up its tremendous demands upon faith to the verge of a most irrational credulity, and postulating its own grounds in a speculatire scheme of entities whose very nature is fast reaching the ntmost stretch of imagination this side the grotesque and the absurd. Who would not undertake to remain within the limits of experience and believe in angels rather than in ether; in God rather than in atoms; and in the history of his Kingdom as a divine self-revelation rather than in the physicist's or biologist's purely mechanical process of erolution? But why should students of science express themselves as though Kant had never written, or critical philosophy exposed the nakedness of their own most cherished metaphysics? Why should they not rather see that, if thinking enters into experience to convert it into a system of cognitions, experience must somehow involve the transcendent? For thinking, as a function, when it demands assent to itself as ralid for reality, is eo ipso a postulating of what is not concrete matter-of-fact experience.

The concept of experience which was presented by the great critic and destroyer of empiricism is itself, however, inconsistent and inadequate. The "island" of Kant is as mythical as is the circle of the modern empiricist. For let it be supposed that unirersal objective validity is imparted to experience only because all experience comes under the con-

352 f., and 1878, i., 108, 114), in this meaning of the word, "I may twist and turn experience as I will, and yet I can never get anything else out of it alone, except that it shows to me processes in my own consciousness." 
structive or regulative influence of the a priori, or constitutional forms of the functioning of understanding; and that from this critical discovery the conclusion is drawn of man's inability to reach the transcendent. Experience is now, indeed, rendered objective; and sure tests are supplied by which to discriminate between dreams and cognitions. Now the limits of knowledge, although no longer set by sense, but by the unchanging and necessary laws of human intellectual faculty, are all the more close-fitting and irremorable. Empiricism is forever rendered hors $d u$ combat; and to the object of our thought is given, so that it can nerer be taken away, a "phenomenal reality." But a real reality - if one may be pardoned for finding one's self forced to a coinage of such uncouth inscription - lies still beyond all limits of experience; nor are these limits the less, but rather the more inflexible, because they now have their source in the intellect itself rather than in any of the physical or biological conditions of sensuous intuition. How now, indeed, shall this caged bird, "knowledge," escape from its cage "experience" ? - since the material of the cage is the more impassable and entangling because invisible to the prisoner.

We maintain that the concept of experience which emphasizes its internal laws rather than its exterior conditions, is equally inadeqnate, quite as self-contradictory and absurd as the concept of the empiricist. For how am I-or if I am too poor a thinker, how is the stalwart critic Kant to know, or even to conceive of "laws" as a priori forms of experience, without transcending experience? The impossibility is so patent as scarcely to need detailed exposure. Only by reflection can the mind form any conception of itself as subject to laws set fast in its own constitution. Laws are only the more or less frequently repeated and uniform modes of the belavior of things. In this case the particular thing, upon whose customary modes of behavior reflection is required, is the Sclf as consciously known to itself. But how 
large an amount of the transcendent (the "trans-subjective minimum") is involved in the origin and growth of the cognition of Self has already been made the principal subject of our epistemological inquiry. A critical science of mind, competent to speak of "laws," etc., cannot escape the necessity of including at least this trans-subjective minimum in its conception of human experience.

But, indeed, the Kantian conception of cxperience included much more. For it was not his experience, not the experience of the local celebrity of the little town of Königsberg, which Kant thought of as giving laws to itself. This profound and patient thinker attempted to discern the immutable laws of all human experience, the very God-given or otherwise originally fixed constitution under which all human selves have done, are doing, and will continue to do, their work of thinking and cognizing one another and all external things. But how can such a conception be framed unless experience is of itself inclusive, ratler than exclusive, of the transcendent?

Here, again, it is vain and quite misses the true significance of the question to reply that, after all, Kant was only cxplaining his own experience in terms derived from itself. For in this case, too, the original inquiry recurs, and with redoubled force: Whence comes the impulse and the felt necessity thus to explain my experience by appeal to a standard of universal authority? And how does it happen that this standard, not only is found, but in order to explain my experience must be found, in the existence of a system of interrelated beings whose minds eternally and necessarily function as I discover my own mind to function? The only possible answer to these questions involves an inference, a postulate, a faith, that transcends all experience in order to explain, to control, and to validate it all. For knowledge, as such and essentially considered, implies the existence of universal rational consciousness, as an objective standard of truth. The "laws" of intellect can no more be accounted for than 
can its conditions, without the ontological assumption of other intellect which can nerer come into my experience except as my experience transcends what are, strictly speaking, its own bounds.

It is time, however, to drop from our argument the figure of speech that has hitherto been employed in order to correct the very fallacies to which it so persistently gives rise. Certainly enough, I cannot know without knowing. I cannot know aught that is not somehow implicate - either as fact, condition, law, or entity - in my experience. But these truths do not at all warrant the critic in regarding experience as constructed after the pattern of a closed circle, or of an island with rocky barriers raised toward an ocean of impenetrable fog and mist. For the real relations of experience to the transcendent are not of this order. The rather, if we preserve the figure of speech, must the truth be expressed by representing the mind, in all its cognitive activity, as perpetually leaping beyoud itself, and somehow transcending its own circuits by discorering within them the potent presence of other-being than its self-closed Self. Or, if we prefer the Kantian figure of speech, we must regard each inhabitant of the before-mentioned island as finding that the surrounding fog and mist lift upward and sweep backward, and as discorering in the ocean only another and larger home for his own cognitive soul. For the true meaning of both figures of speech is this: without actually reaching and grasping, by all those potencies of the soul which cognition involves, the real conditions, universal laws, and related entities of the Self and of Things, we cannot even form the concept of human experience. What these conditions are, psychology and epistemology unite to discover, describe, and criticise. What these laws are - how they arise and get validity of application, and what we mean by them - the two chapters preceding this have already partially discussed. Further discussion will bring beforc us the nature of Truth and Error, the alleged 
Antinomies of Reason, and the Limits and Justification of Scepticism, of Agnosticism, and of Criticism in Epistemology. The ontological Inplicates are now about to be examined.

We pause a moment to snatch a practical suggestion from this study for an epistemological theory. It scems that he who would be so cautious about knowledge as not to trust himself beyond the strictest limits of his own little mental domain, may end by becoming the most credulous and childish of men. To think that "cock-sure" confidence in empirical science alone should end in complete despair of all science! To find that, when we hedge in so carefully our laboratory, and light it with the latest electrical apparatus of the highest candlepower, it should still, to the spiritually enlightened eyes, seem full of fanciful sprites, thick with the ghosts of a metaphysics which nineteenth-century positirism and agnosticism have pledged themselves to expel! Shall we then steal, silent and despairing, into the dark forests of a total agnosticism, or run shrieking to the mad-house where untamed imagination and irrational feeling hold their riotous sway; or shall we set our teeth and button up well our orercoats against the cold and go about our business, resolutely believing what we know to be untrue? Perhaps we may find a yet "more excellent way." For it may be that faith and intellect, feeling and thinking and willing, can all be combined into a right attitude of our cognitive souls toward truth, life, and all Reality. 


\section{CHAPTER XII}

\section{THE IMPLICATES OF KNOWLEDGE}

H ITHERTO we have been occupied with a critical exam11 ination of human cognition, - its nature, laws, and grounds, - with a view to test the validity of its claim to be a system of mental representation framed and connected after the pattern of a really existent World. In other words, we have sought guaranties for Knowledge in gencral; and the search has been conducted in the most presuppositionless way possible. It is now time to reverse the terms of inquiry and to ask ourselves: What does human knowledge gnarantee? What sort of Reality is validated for all men, in the unchanging nature, necessary laws, and fundamental grounds of their own cognitive activity? Any detailed answer to these questions would furnish an elaborate system of ontology, a metaphysical structure in the narrower meaning of the word "metaphysics." But epistemological discussion aims at ruling out ontology so far as the process of exclusion is possible, or, at most, conrenient. The truth of the admission made early in our discussion has been growing constantly more apparent; the philosophy of Knowledge and the philosoplyy of Reality, epistemology and ontology, offer problems that cannot be kept wholly apart; for these problems are only different aspects or stages of one and the same problem.

No one need fear, howerer, that the standpoint of free criticism is now wholly to be abandoned, or that a system of ontological metaphysics is about to be introduced under pre- 
tence of having already sufficiently guaranteed the power of our cognitive faculties to construct such a system. This task we wish, as far as possible, to reserve for another time. For the proposed change, in our point of view, is here introduced in the interests of the thoroughness of our criticism. This will appear clearly as soon as the bearing of the conclusions already reached upon the further pursuit of epistemological problems is considered. It has been shown by a searching criticism of the very act of cognition - of that fundamental datum, "I know," in which the problem of epistemology originates - that no guaranty of a character external to the act itself can possibly be produced. All the validity that knowledge can attain, theoretically, consists in its being what it actually is, namely, knowledge, and not a mere having of states of consciousness, of whatever sort or howsoever arranged and combined. But, then, it has also been shown that knowledge, ultimately considered, validates itself; and that it does this in such a way as to leave nothing further to be desired or even to be conceived of as possible. It does this so as to guarantee, for the cognizing Self, its own real existence and nature as a Self; and so as also to guarantee that other beings, actually known as not-selves, exist, and what they are; but this latter, only if we may accept as ralid the assumption that things share in the qualifications which the Self knows itself to possess. Now, plainly, it is a legitimate and indispensable extension of the epistemological doctrine already established, when we enter a little way into the further critical examination of these qualifications themselves. This, then, is the problem now before us. What sort of a being is guaranteed for the really existent World by our exercise of cognitive faculty in its own constitutional and supremely self-confident way? What, in brief but more precisely than they have hitherto been distinguished, are the Implicates of all Knowledge?

In answering this question, it is our aim to remain as cau- 
tious and even austere toward all claimants to a title to a-priority as we have all the while been. We are, indeed, the adrocates of a certain "faith-philosophy," and determined opponents of the unwarrantable Kantian separation of faith and knowledge ; but we are not ummindful of Schopenhauer's sarcasm as directed against Jacobi, "Who only has the trifling weakness that he takes all he learned and approved before his fifteenth year for inborn ideas of the liuman mind." Nor can Kant himself be cleared of the charge of multiplying unnecessarily the formal factors and laws necessary to gire an account of the origin and nature of cognition. Let us aim, howerer, at moderation. It is not the farthest possible extension of ontological implicates of human knowledge which seems alluring just now; it is rather the critical estimate of what has been called the "trans-subjective minimum." Such implicates as appear of this order will certainly be amply able to bear those final attacks of scepticism and agnosticism to which they will then be subjected.

That the trans-subjective - some being other than the hereand-now being of the state of consciousness, objectively determined - is implicated in every concrete act of cognition, has been found to be both postulated and proved, or erinced by all actual examples. On the one hand, phenomenalism belongs to the very nature of knowledge; for " "we can cognize any object only as it manifests itself in our consciousness, or as it appears to us to be." On the other hand, the ontological nature of knowledge is equally apparent: it is eren much more apparent; for it is the peculiarity of cognition, that what is not consciousness, what transcends the mental act of representation, appears in consciousness as inseparable from this act. The critical doctrine of the ontological implicates of knouledge is, therefore, a necessary part of the theory of knowledge. This doctrine may be established in the form of an attempted answer to a problem; and to borrow from mathematics a figure of speech, the nature of this problem may be sugges- 
tively expressed in the following way: What is the value of the $X$ (the real Being) which is actually found implicate in every act of knowledge?

Students of Kant are well aware that he vacillated and gave different and doubtful answers to the ontological problem. In a general way he attempted its answer in terms of a conception answering to the words "Ding-an-sich," or "Gegenstände überhaupt" ("Thing-in-itsclf," or "Objects in general" and not specifically determined as concrete objects of actual cognition). But the Kantian conception of "Thing-in-itself" admits of no satisfactory description; neither can it be made to agrec with the terms of the fundamental and unassailable formula, "I know" as this formula asserts and vindicates itself in every actual performance of the faculty of cognition. No negative and merely limiting conception can be substituted for the $X$ of the problem, in such a way as to solve the difficulties which the $X$ of actual experience offers. The being of the $X$ of experience is not an abstraction; nor is it a bare so-called "act-of-positing," or a mere law of intellect functioning under the categories of substantiality and causality. The refutation which every cognitive experience brings against this interpretation of the Kantian formula has already been sufficiently provided. In our cognitive experience, the reality, $X$, does not stand as the hypostasis of a limitation, actually experienced by the intellect in every attempt to transcend its constitutional limits.

What Kant (especially in the first edition of the "Critique of Pure Reason") attempted to show as true of the transcendent reality imagined to be in consciousness was true only of Kant's own imagining and of its abstract and unreal product. For there is an unmistakable fallacy involved in converting the proposition "All objective cognition has its source in our mental representations" into the proposition "All oljective cognition consists of our mental representations" as worked up into abstract forms by the intellect functioning according 
to its twelve constitutional forms, the so-called categories. ${ }^{1}$ This actual, concrete presence of the Being $X$, which cannot be resolved into a mere mental image, or into an abstraction, or into a dialectical process striking against a limit, like the nose of the blind fish in a small pool running itself into the mud, creates a demand, which epistemology must meet, for its own further explication. The trans-subjective is implicate in cognition; it is implicate, of necessity, as positively there in all cognition. It is the transcendent Real, present in experience, whenever the life of consciousness becomes a completed act of knowledge.

Much has already been discovered, in the course of the foregoing critical discussion of knowledge, which is rightly alleged in answer to the question, What is the Being of $X$ ? But what has already been discorered only appears to make more desirable the task of gathering together the scattered remarks and wearing them, if possible, into some consistent whole. No other task is more important for the student of epistemology than that of examining further the character and determining the final value of this $X$; it is this task which builds for him the bridge upon which he may safely cross into the otherwise forbidden domain of ontology. To drop the figure of speech, the implicates of all knowledge must be discovered, critically expounded, and defended both circumstantially and by harmonizing them with one another' for only in this way can the theoretical interests of a philosophy of knowledge and the practical ends of conduct be attained and conserved.

A preliminary inquiry, which is largely of a psychological character, but which has never received the attention it deserves in psychological investigation and literature, fitly precedes the criticism of the ontological implicates of human knowledge. This inquiry concerns the meaning of the word " implicate," in so far as it can properly be used in this con-

1 Compare Wundt, System der Philosophie, pp. $184 \mathrm{f}$. 
nection and authenticated by our actual experience. How is it, in fact, that Reality is caught and enfolded, so to speak, within the ever flowing stream of man's conscious life? Here we are forced to raise again the sceptical question. No fact is surer than that this "stream of consciousness" is in a condition of perpetual flux. It is itself a scries of conscious facts, each of which is particular, circumscribed, and always ascribable to some individual Ego, which is itself known as existing at all only while this same stream flows ever onward. In the largest conceivable significance of the words, " $m y$ experience" must comprehend, within some particular portion of this flowing stream, all the Being that there is for me,whether envisaged or ideated, or believed in, or postulated, or willed, or thought. Now the scepticism which follows from the reflective consideration of this truth is no new doctrine; it is found in every age of the world and in every race that has reflected in any age. It appears as the doctrine of Mâya in the ancient East, and as Spencerian agnosticism in the modern West. The facts will continue to breed such scepticism until the end of the last of all the ages.

Just as certain is it, however, that certain facts exist, indubitable and etermally potent and effective, within the stream of consciousness, which check, limit, correct, and finally reverse the tendencies to scepticism and to its termination in agnosticism or other doctrine of illusion. Such are all the facts of knowledge. These must, indeed, be received as facts in the flowing stream of consciousness, - as a part of the series which is a perpetual flux. But as facts, they must be received in their entirety and with their full, actual significance; and when this is done, it becomes once for all obvious that, if facts of consciousness, as such, are always empirical, some facts of consciousness, as facts of knowledge, are always also "superempirical." Or, to state the truth in terms made more expressive by the discussion of the last chapter: It is quitc impossible even to frame the conception of experience of the 
human sort, without introducing that which is for us extramentally real and which is actually related to us, and to itself, in a variety of effective relations.

Somehow, therefore, Reality is indubitably known to be implicated in knowledge. But may we know " how," more particularly, this implication takes effect? Or, to change the form of the question: On what precise terms of conscious recognition, or appropriation, so to speak, is that which exists beyond consciousness discorered to be "part and parcel" of man's conscious and cognitive life? Is it as "envisagement" or as "inference," as a leap upon the staff of the principle of sufficient reason, or as a climb by more considerate processes of ratiocination of a speculative order, as an act of faith in God, or a rational postulate, as a blind instinctive grasp, or a deed of free self-assertion, that I, the conscious subject, reach my object, the actually existent, which is beyond my subjective state and which is not to be identified with my self-conscious Self? The true answer to this inquiry has already been giren in detail. But in recalling that answer, it will be helpful to consider briefly how the same question has been answered by others who have discussed it in more or less unprejudiced fashion, whether as a matter chiefly of psychological research or as a concernment of their philosophical systems. And here the significant fact of history is that the answer lias been given in all the aborementioned different forms; and in each of them, orer and orer again. Upon this question the great critic of cognitive faculty is, as has already been said, racillating and quite generally unsatisfactory. When expressing himself nairely, and ret under the influence of his extreme doctrine of the separability of form and content as respects the dependence of knowledge on reality, Kant has only to say, "It is given." Elsewhere he would seem to wish that we should believe; nothing is given but this - that "It" really is. That is to say, the bare Being of $X$ is receired as an act of blind instinc- 
tive belief by the soul of man. Curiously enough, agnostic modern science is accustomed to declaring, first of all, "We know nothing as to what Matter really is ;" and then to proceeding with volumes of instruction about this Unknown, and to speaking deferentially of it as a "that-which." Yet, again, Kant teaches that Reality is implicate in cognition as a negative terminal of a process of abstraction, or as an "Idea" which is speculatively pursued by the employment of an illusory logic, in the mind's effort to unify the totality of its experience.

On this one point Schopenhauer is undoubtedly much superior to Kant, because nearer the indubitable and common facts of experience. According to the former, the intellect proceeds upon the a priori principle of sufficient reason to a kind of envisagement, or seizure, of the concrete reality in the act of perception; but of this act of the intelleet no other account or vindication is possible. Reasoning, he thinks, never gives the knowledge of reality. Confusion and even self-contradiction, however, afflict the different statements of Schopenhaner in answer to this question: In what form of conscious experience is reality giren to man? Especially is this true of his doctrine of the will, as immediately apprehended somehow without intellect's aid, and yet as the true essence and real being of the individual Self. In Hegel's system, reality is assumed to be known - both that it is and what it is - in a dialectieal process which is, happily, the very opposite in character from the illusory dialectic of the Kantian epistemology; this process is, when it understands itself, seen to be the complete and only truly Existent, as rercaled in the consciousness of the individual man.

Sully, James, and some other modern psychologists, have agreed rather with the thought of Augustine and the Early Church Fathers, and of the eeclesiastical writers of the Middle Ages. It is in the form of "belief" - not blind and irrational but, as of the very nature of reason and, perchance, 
leading the mind out toward the higher realities, whose fuller revelation awaits the attitude of trust - that reality finds entrance within the stream of human consciousness. Yet others (as, for example, Riehl) lay down the ductrine that, somelow, knowledge $=$ thinking + reality ; but no clear information is afforded by them as to how the second member of the right-hand term of the equation gets any place in the equation at all. And, alas! if we may regret the absence of opinions which would probably only add to the confusion, the multitude of minor writers on psychology pass the problem by in silence; or perhaps they even think, by skilfully manipulating sensations and "fainter images" of sensations, and by combining them under psycho-physical formulas, to succeed in hiding the fact that there is a problem after all. $X$ is there, lowever; and, "How did it get there?" is a question which can neither be summarily dismissed nor overlooked by a generation scientifically disposed.

The instructive thing to notice about all these views is that so long as they are positive, and yet confessedly partial, they are unanswerable. They meet with effective opposition only when they claim to be complete and so undertake to deny or to explain the facts upon which are founded rival riews. The truth is that Reality is implicated in our cognition in all these different ways. First, it is manifest that the operations of the intellect imply and actually involve a trans-subjective world of real things and real minds, standing in actual relations. The cognitive judgment affirms it; this is, indeed, precisely what it concretely and actually does in order to terminate in knowledge any process of thinking. All exercise of intellect implicates reality, in every effort to give an account to itself of its own origin and laws as an activity. Why should I judge the elm-tree to be orer there; and the star to be up yonder above my head? No answer can be given, or suggested, for any question like this, except the answer:- Because $i t$ is, and is, in some true 
meaning of the words, not in my consciousness, but actually "over there" or "up yonder." The idealism which denies the truthfulness of such judgments, by so reducing their terms that they involve no reality other than the states of the judging subject, convicts the intellect of a fundamental absurdity. The intellect cannot, and will not, endure the insult of that. So, too, as has been abundantly shown, all conceptual knowledge gets validating only as it finds the relations of reality involved in the processes of conception and of reasoning. The last "grounds" of all intellectual endearor are reached in the intellect's self-justification of this answer to its own everlasting, Why? - Because it is so, and this is an end of the controversy. Moreover, this is all the truth there is in the Kantian or other agnostic doctrine that the $X$, the Real of cognition, is a negative and limiting concept. It is negative in that it positively denies the right and the expediency of further sceptical questioning; it is limiting because it forbids the vain effort to discorer a merely abstract Ding-an-sich behind the reality which is actually inrolved in its own life.

But, second, they are also clearly in the right who find all the most fundamental feelings of the soul committed to the tenure of reality as known by it. Nor are these feelings exhausted by speaking of them as "faith," or "belief," of a metaphysical or ontological kind. Feeling does, indeed, attach itself to the $X$ in such fashion that it cannot be removed or shaken off. I believe in my little real world, with all my might. It is indeed little as compared with that great world whose rague conception floats alluring before my mind, - beings physical and psychical, rank above rank, in manifold now inconceivable relations, and the great God in, and through, and over All. Now whether there be any such Great World or not, I may doubt. But my world is very real to me; and I believe in it with an invincible and passionate faith. For, as a real world, it lias in it those 
with whom my most quick, vital, and supreme interests are concerned, - the things $I$ own and hope to gain, and above all, the persons whom I fear, or hate, or trust, or love. And I do not wish it reduced to a dream; even if it be a very logically consistent and scientifically constructed dream, after the pattern of an "If-this-is-so - then-that-is-so," but without anybody's knowing what is really so. The plain truth is that men generally, howerer sceptical in regard to a theory of knowledge or to an ontological system they may be, have all their feelings in view of what they regard as reality. That is to say, - Reality is somehow implicate in the feelings of man, as a cognitive soul. And if we recognize a peculiar form of ever-present and effective feeling, and call it a general "bclief" in r'eality, a sort of ontological faith, convincing in every concrete act of cognition, we do not eren then seein to be misstating the case.

Nor can one fail to notice that it is almost impossible to express the belief of the cognitive soul in the reality of its own cognitive products without using words which turn the attention away from the merely affective aspects of experience. We will have it so; and this is, paltly, because we know that it would be quite useless to will otherwise; for there is that "other-will" always to be reckoned with. To know the really existent World - the trans-subjective beings in their actual matter-of-fact relations - I must will, indeed; but I caunot know this world purely as I will. How I know it, then, depends always upon felt and known relations between my will and that real $X$ which is not-my-will, but which may be the will of some other Self or non-self Thing.

Thus the question as to how Reality is implicate in consciousness, when consciousness takes on the form and assumes the rights of completed cognition, leads to the same truth which is reached by an analysis of the nature of cognition. It is not as an intellectual leap or well considered conclusion simply, nor as any kind of feeling merely, nor as a deed of 
will, more or less intelligent, alone; but it is as all of these combined, that the real existence of this Self and of Things is implicate in cognition. Or, to invert the statement, the entire complex condition of the Subject, in the act of cognition, involves and guarantees the Being of the trans-subjective existent. As envisaged, judged, postulated, believed in, felt, made object of active will and respondent in the form of reacting will, the Being of $X$ is "given" to me, when I hare that commerce with this $X$ which is called knowledge.

What, in particular, are the implicates found guaranteed by knowledge, - not as critically and speculatirely treated so as to form a developed ontology, but as enumerated in the constitution of that "trans-subjective minimum" without which knowledge, as a universal experience, is unintelligible? This question might be put into the language of critical philosophy, after the Kantian fashion, as follows: To what categories, in accordance with the very nature of all cognition, must transcendent application be assigned? IIere the true position reverses the conclusions of Kant. Since all human knowledge has a certain necessary form, therefore a body of metaphysics, as ontology, is guaranteed as involred in this knowledge. For, without admitting certain ontological implicates, the most primary and universal of our cognitions are rendered absurd. Something as to the content of the really existent is interwoven inextricably with the conscious life of the cognitive subject.

In explicating what of an ontological character is thus implicate in all the subjective processes of cognition, we come first upon the Being of the Self. No language can possibly state the absurdity of the agnosticism which, starting from the conscious facts of knowledge, attempts to deny reality to the self-conscious subject of knowledge. A hidden core of changeless existence, a "thing-like" substrate, at which self-consciousness can never get, and which must be supposed to lie dormant and incapable of ever making itself 
known beneath the so-called phenomenal Ego, may well enough be denied. 'There are, indeed, no facts of self-knowledge to guarantee a Kantian Ding-an-sichheit for the conseious subject of those processes in which the facts consist. But that I am, that I was, and that I have been, - a conscious, living Self, - are ontologieal propositions which are involred in all $\mathrm{my}$ present eognitive experience. Some sort of merely sensuous or ideational existence, some dreamlike being with a ecrtain show of slurewd intelligence, might be had without establishing a right to posit its own reality. Were this the sum-total of man's accredited experiences, his metaphysical postulates and beliefs would, no doubt, be exeeedingly meagre, - if, indeed, any postulates and beliefs arose, for critical examination, above the horizon of his conscious life. Beings that have only a sensuous and imagemaking experience hare, probably, no "threshold" of an ontological consciousness. The metaphysical credo of the most intelligent of the brutes is, at longest, very brief. But the Self is a being that lnows - itsclf, and various truths about other selves and, as well, about so-called material things. Moreover, the cognitive life of the Self is an historieal development. The knowledge of the individual man is a growtlı; and each new eognition is dependently connected, by the principles of identity and of sufficient reason, and by acts of recognitive memory and of rational inference, with antecedent cognitions. Thus this Life implicates and guarantees its own real existence, as that of a Self developing according to the modes of its own constitution and in accordance with immanent ideas pcculiar to it, in a continuous life-history.

If, moreover, the question arise, What is this Being of the Self, thus implicate and guaranteed in the unfolding life of eognition? no answer can be giren except that which points out the characteristic modes of doing and suffering known as belonging to the Self. They involre the "trans- 
subjective minimum" of every man's consciousness, so far as this consciousness has reference to his own reality. Further speculative inferences, or rational faiths and hopes and fears referring to the future being of the soul, may find ground for their standing in this primary and unirersal ontology of the Self. But all such inferences and faiths must validate their rights by doing battle with contesting theories, and with that spirit of doubt and of nescience which attacks our metaphysics of the phenomena of soul-life. Whoever confines his metaphysical views to the reflective and harmonious treatment of the universal and unchanging implicates of the life of cognition, may feel obliged, indeed, to move in a somewhat narrow circlc. But within that circle he is impregnable. So far as self-cognition extcnds, the reality of Self - that it is and what it is - is guaranteed beyond the possibility of sceptical invasion. The metaphysics of mind is to this limited extent involved in all the mental experiences of a cognitive order. ${ }^{1}$ So much and such Being I have, as I know myself to have had. What lies below or back of this may be matter of legitimate inference or of merely doubtful conjecture. What lies above, or in the future, must be got at through knowledge of the present and of the past, by reaching out, perchance, along the lines of persistent faiths and hopes. But what lies within this circle is known to be true; and "truth" means here, what truth always means to serious minds, - the mental representation that accords with the really existent.

My real existence is an undeniable implicate of my selfknowledge; and, indeed, of all my knowledge. This is a proposition from which all metaphysics takes its rise; and to which it returns, as to an impregnable stronghold, as often as it is assailed, or to an all-illuminating centre, as often as it

1 It is this ontological doctrine which, with only a few extensions beyond the sphere of the known, the author has tried to present in systematic form in his "Philosophy of Mind." 
finds itself astray. To deny the ontological significance of the primal fact, "I know," is to deny the possibility of all knowledge. For it is always $I$ that know; and if this " $I$ " lose itself, or become subjected to complete aberration of self-knowledge, then it becomes incapable of being longer the subject of any kind of knowledge. What is true for the individual is true for the race. Let the entire multitude of men be conceived of as losing this Being of the Self, - whether by complete aberration of self-consciousness in "double consciousness," or by attaining to an identification with "the Other" in "intellectual intuition," or by the enjoyment of Nirvâna, or otherwise, - and, then, the knowledge of the race (practical, scientific, etc.) is gone. Some one must "come to himself" - significant phrase! - before cognition can return to man. And if "that Other" lose his Being-for-Self, or be supposed never to have attained it, and thus share at the same time the sad fate of a race of men that have lost themselves ; then all cognition is gone. And what would remain? Nothing of which one could even say :-

\section{"Ich habe keinen Namen}

Dafiir. Gefühl ist Alles."

We could then neither posit the existence of phenomena nor of noumena. The agnostic $\theta \epsilon o ̀$ áp’óntos would then as surely vanish as would the idols of the South Seas. For feeling, imagination, thought, cannot of themselves guarantee the bare existence of the otherwise Unknown; cognition must accomplish this, by union of all the powers of the self-conscious mind.

All attempt at a theory of knowledge - no matter how sceptical or agnostic - starts from, and returns to, the firm centre of the Being of the self-known Self. Just as, however, this "I know" is not a rigid, fixed, and ready-made formula, but the characterization of a living and clianging relation of subject and object, so is the Being of the Self, which is implicate in the formula, not a rigid, fixed, and ready-made existence. 
The substantiality and the causality of this Being are ever repeatedly affirmed afresh in every cognitive judgment. Throw this affirmation into the form of an "existential judgment" and it reads: "I experience that I am; I live and know I live" - an indubitable positing of the here-and-now being of the subject of the state. But the same affirmation involves also a transcendental judgment, which reflective thinking is obliged to read thus: "Out of this present conscious state, I was and I have been" - independent of my own present being as the subject, too, of those other states.

Interwoven with the very texture of all cognitive processes, and with an almost equal intricacy of relations and firmness of manifold connection, is an implicate of the real existence of other minds like my own. We are not concerned just now with the psychological theory of the processes by which this interweaving takes place. The detailed descriptive history of these processes would not alter the epistemological and ontological significance of the facts. Other beings exist, in whose streams of consciousness somehow occur cognitive facts which, in their conditions, laws, and postulates, resemble my own: I am not the only one who ean say, "I know;" there are others, and many of them, who have their own experiences of a cognitive order. This, however one pleases to state it, is an assumption inseparable from the rery experience we hare with ourselres as cognitive; and it is so implicated in this experience that, strictly speaking, no sceptical or critical examination of the facts of human knowledge can eren be entered upon without it.

It may doubtless be pointed out that Descartes, and all who have wished to push to its extremest limits a sceptical inquiry into the foundations of knowledge, hare assumed as the only perfeetly unassailable proposition: " $I$ know." Whether any one else knows, or not, and indeed whether there be any one else, to know or to be known, is thus held in suspense as a matter of legitimate doubt. Moreover, all knowledge of other minds- 
both that they are and that they know, and also what they are actually engaged in knowing - comes by the interpretation of physical signs. But since the reality of the very beings whose changing relations to us are given in the form of physical signs of conscious states may itself be doubted, there would seem to be two great gulfs of nescience dug between each selfcognizing Self and the other selves that are to be known as self-cognizing, too. The psychological history of the way in which the individual mind comes to know that other minds really exist, must, indeed, be accepted: We know other selves only as we learn to interpret into terms of our own experience, more or less skilfully but always with much chance for error, the physical signs which have become connected with the different kinds of that experience. No other being, besides myself, do I know so fully and confidently as I know my dearest most familiar human friend. Other visions may be shattered, and the world seem not so much actually changed; for still, "I am I" . . . and "thou art thou."

But this very psychological history introduces into epistemology one of its most interesting and fruitful paradoxes, not to say practical self-contradictions. For what men know in this doubly complex and doubtful fashion is, after all, seen to be most firmly, simply, and indubitably implicated in all their knowledge. Let not the point of the present contention be missed. The being of other cognizing minds, like the being of one's own mind, seems to lack the stability and permanency, in the order of the real world, which unconscious things appear to have; and in the mental construction of the historical conditions of all human knowledge, modern science is wont to posit an elaborate system of "thing-like" beings existing through countless ages before the first process of knowledge actually took place. This may all be warranted, or it may not be; it is of no interest to us to dispute just now about the warrant for so-called anthropological and biological evolution. But from the point of view of the critical 
philosophy of knowledge - and this is our chosen point of view - how different does such so-called science appear! For let one attempt now to call in question, to doubt, or even to criticise this postulate. One ean only do this by assuming it to be quite valid and even indisputably true. Or, since one naturally prefers to be on the side of one's convictions and where one is sure of winning, let one defend the implicate of another's real being against that other, who assails the general postulate of which this particular implicate is an example. It is now proposed to argue the matter; and to get arguments adjudged as true or false, probable or improbable; and to see if the contestants cannot get together upon some common grounds.

Plainly, now, all proposal, argument, or effort to reach a conclusion, and all the clothing given by the symbols chosen for these otherwise incommunicable mental states, themselves imply the real being of many minds. One cannot even propose one's sceptical idealism, or solipsistie agnosticism, as a view to be considered by one's self, in the deepest solitudes of one's most retired chamber, without being guilty of the extreme of absurdity. In vain does one soothe the consciousness of such guilt by the claim that the search is, after all, in the interests of a self-consistency; for what is that which it is proposed to render self-consistent? Ideas, opinions, thoughts, conceived of as mere psychoses or portions of the ever-flowing stream of consciousness, are not entities that need to be harmonized with each other, lest they actually quarrel and fight it out with one another, to the death. Shall it be claimed, however, that it is consistency with one's self which the inquiring defender of solipsism seeks? But this is to be had only by being of the same opinion all the way through - unless, indeed, it is something more than mere self-eonsistency which is sought. Is the proposal, then, to test the truth of the doubt, or denial, of the reality of other selves than one's Self? But what is truth? The question is now more puzzling than it 
was in the mouth of Pilate, unless it be admitted that some standard for the judgment of one mind exists in the structure of other minds.

It is customary with those who take their solipsism most seriously to whip themselves around the post, and reach, as the conclusion of this painful self-discipline, the periodic affirmation that, after all, they are sure of nothing except the circular character of their own motion. For what, they continue to ask, are these other beings to me, but just my own percepts, mental images, and abstract conceptions, - mere moments in the flux of that stream of consciousness I call myself? Such a conclusion, however, seems to neglect the very pertinent fact that, somehow, the post is still there; and that the satisfactory completion as a fact, and even the valid description of the circular character of the motion has a meaning only as it assumes the extra-mental existence of the post. The criticism of percepts, mental images, and abstract conceptions, with a view to see how much of truth is in them, even as a bare proposal to one's self, implies some standard to determine the justice of the issue. This standard is not found in the mere fact "I think," as a purely subjective phenomenon; but it is found in those implicates of "I know," which refer my thinking to the universal terms of cognition really existent in the laws and operations of other minds.

But if the bare proposal to reject this ontological implicate of all our cognitive processes ends in absurdity, much more obviously is the actual discussion of the question as to the validity of the implicate a supreme height of absurdity. Higher, indeed, up the rocky and dangerous ways of agnosticism, by attempting the path of self-contradiction, it is possible for no mind to climb. This feat is itself a demonstration of the wondrously ambitious athletic quality of unchastened human reason. And one can scarcely aroid suspecting the triumphant adrocate of the solipsistic hypothesis of learing his vanquished opponent with the secret feeling that, in the 
eyes of their common mistress, The Truth, he has made himself a being of little account. For plainly, if the dogmatic or sceptical denial of the reality of other minds is capable of being held consistently by any individual Self, it is quite incapable of being made a matter of communication to other selves. If one knew it to be so, one could not tell another this truth, without assuming and affirming that it is not really so, is not truth. The principles of identity and of sufficient reason, by their combined and most strenuous efforts cannot hold one to a proposition more self-evident than this: Communication of knowledge, or even, and not less surely, of doubt and of nescience, assumes the reality of at least two minds, like constituted, as well as the actuality of certain relations established, in the very act of cognition, between them. Try to tell me that this is not so, and you imply that, rerily and beyond all doubt, it is so. Try to inform me that you doubt my riew on this point and are preparing to contest it (with an elaborate article, we will say, in the "Journal of Sceptical Philosophy"), and you only avow its incontestable truth many times over. For, however the implicate of other cognizing subjects, like the cognitive Self, gets into the structure of erery cognition, the implicate is there; and it is there in such fashion that not only all philosophical discussion, but also every thought and deed looking toward the communication of any form of knowledge, is solemnly pledged to its continued existence and support.

Nor would it be difficult to show that the existence and use of language, or of any other symbols for the communication of knowledge between men, also involves the same ontological truths. The proof of this truth does not depend upon doubtful inferences as to the origin and value of human language, or as to the nature of those means of intercommunication that are employed by the lower animals. In man's case, at any rate, we know that knowledge is, as we figuratively say, "conreyed" by language. This does not mean, of course, 
that knowledge is some sort of vendible or otherwise disposable goods, which can be carried orer from one warchouse in the mind of $A$ and deposited, little changed or injured in transit, within another place of safe-keeping, the mind of $B$. But the existence and actual use of any means by which, within a sccond stream of consciousness, cognitive processes may be set going, that resemble the cognitive process in a first stream of consciousness, implicates the real being of a number of "like-minded" minds. When it is considered that nearly every cognition for the individual, and all the growth of learning, science, and philosoplyy for the race, depends upon the communicability of knowledge, the solid depth and widereaching extent of this implicate are apparent. For me, and for all men in all ages of the world's history, knowledge is a growth. The roots of each individual cognition penetrate and ramify through the entire existence of the human race. The individual's knowledge draws its vital sap and receives its form of manifestation from the common life. The substance and the morphology of cognition, the form and the content of every cognitire act, are generic and social affairs. Remove all this, whether it appear as the uncritical and instinctive or as the critical and developed metaplysics of the human mind, and little or nothing is left to make my knowledge distinguishable as mine.

These considerations bring us face to face with the fact that the entire solid mass of human feelings and convictions is found at this place to resist all attacks from scepticism and agnosticism. The influence of ethical and rsthetical considerations upon the very structure and suretyship of human knowledge affords a theme to which detailed reference will be made later on. If there were only this to rely upon in resistance to such attacks, there need be no fear for the citadel of truth, or for the region it immediately defends. Men will never credit the statement that indubitable knowledge of the real existence of other minds is impossible. The guar- 
anty of this would be sufficient, if it were to be placed among those truths whose final evidence, according to Lotze, ${ }^{1}$ is not logical at all, but rather æsthetical - not the impossibility of not thinking them, but the unseemly absurdity of their disproof. The feclings of every individual commit him too unalterably to a belief in the reality of his fellow men to allow of much more than spending an idle hour of speculation in the effort to see if he cannot persuade himself that they are but the projection, upon a subjectively constituted background, of his own mental images and experiences of an affective type.

In the fact of cognition, however, and in the defensible theory of knowledge, the implicate of the reality of other minds belongs to the very structure of experience. Every factor of my cognitive life - thought, feeling, and will; and however expressed, whether as inference, blind belief, rational postulate, instinctive or determinative action - pledges me to the reality of other beings, that are known as selves like me, but are not-me. The reality of such beings is an ontological implicate that admits neither of denial nor of disproof. It does not even admit of question or statement in the form of doubt, without revealing at once the intrinsic absurdity of contradicting it.

Once more, the reality of a system of things which have some sort of separate being, and yet are connected together in some kind of unitary way, and to which I find myself related in varying terms of reciprocal activity and passivity, is an ontological implicate of all human cognition. Undoubtedly, this very complicated statement of the truth of experience will be contested by not a few reflective thinkers upon the problem of knowledge. But, here again, even in contesting, they will admit it; for thus much of known reality is inextricably bound up in, and guaranteed by, the fundamental experiences of every mind in cognition, and the most ardent advocate of the extremest form of solipsism is unable to free himself from

1 Logik; the last part of the chapter, Die apriorischen Wahrheiten. 
the charge of absurdity in proposing to argue this implicate. Further critical examination of this epistemological truth reveals the fact that in defending it, we are only affirming the validity, for all known Reality, of the most fundamental of the so-called "categories." And this is the inevitable conclusion from all the analysis of knowledge which has been accomplished up to this point in the discussion of the epistemological problem. The simple truth is, then, that we must either abandon all claims to knowledge, in any meaning of the word which can get recognition by the facts of human experience, or else we must admit the claims of some such implicate as this.

The detailed discussion of the scparate categories discorerable in this ontological implicate, the complicated affirmation as to the Being of $X$ which is involved in the totality of human cognitive life, is a treatise on metaphysics, - if only the discussion be combined with a criticism of those bonds which are held by all men to connect the differentiated things together into some sort of a Unitary Reality. Such discussion is, of course, reserved for another essay. But a few words upon several points seem necessary to bring the epistemological discussion to a satisfactory conclusion at this point.

All human knowledge both assumes and guarantees the validity of the application of the category of Relation to the really existent world. This category has, not inaptly, been called "the mother of all the others ;" " only it must be remembered that categories are not the breed of one another, after the pattern of biological entities. This concept is derived from the self-observed form of the intellect as operative in every cognitive process of whatever character. Relation applies to phenomena and other phenomena, to phenomena and the realities of which they are phenomena and to which they are phenomena, to thoughts and thoughts, to thoughts and things, and to things and things. No other category is so unirersal; and, there-

1 A phrase of Günther's. See Klein, "Die Genesis der Kategorien," p. 32. 
fore, no other is so impossible of definition or even of description. It cannot be made clearer than it is in itself. It gets its most immediate and indubitable application to reality, in the actual concrete cognitions of self-consciousness. And if we say of things that they have such qualities, and stand in such relations, as matters of our cognition, we ean attach no meaning to the words " have" and "stand," unless we translate them into our experience, as self-conscious selves, with our objects of cognition. What is it really to be related? What relates; and what is related? A critical metaphysics shows that no answers can be given to such questions, unless things are conceived of as self-actire beings, with their various modes of behavior interdependent and yet united under a framework, so to speak, of immanent ideas. Unrelated Being is, indeed, unknowable; but, then, this is not the fault of human knowledge, which forces it to become hopelessly agnostie because it cannot rise above its own inherent faults. It is rather due to the fundamental truth that knowledge is a grasp upon reality, and that unrelated being is unreal; it is no Being, but only the figment of an ill-disciplined imagination which, having got loose from the facts of experience, is trying to "cut capers" in air too thin for its own healthy existence.

The valid application of the connected categories of Change and Causality to the really existent world is also implicate in all human cognition. The real Being of $X$ is given to human knowledge not as an Eleatic One and Unchangeable but as a Principle of Becoming. It has, indeed, its own Unity, or Oneness, the nature of which the human mind may eagerly strive to apprehend. It has, too, its regulative principles, from which it never swerves, and which stand, themselves unchangeable, amid all the changes of finite minds and finite things. But to deny or to doubt the reality of change - of a system of interdependent changes constituting a connected and unitary process of Becoming - is to deny or to doubt 
the possibility of knowledge. And why some huge monstrosity of an ontological sort, a great all-embracing death'shead of a Ding-an-Sich, should have superior attractions for metaphysical philosophy, it is difficult to determine. At any rate, change is here, in the real world as men know it; and it is so bound up with the life of human knowledge that its remoral sacrifices the life itself.

Without further specifications, - lest the task of epistemology be too much burdened and the task of ontology be made correspondingly too light, - we close this chapter with two remarks. And, first, the philosophy of knowledge, when its critical analysis is extended and made more penetrating, comes to regard the categories as, above all, those forms or determinations in which the spirit, in its process of becoming selfconscious, finds itself by its own constitution compelled to apprehend itself and its own life. All the so-called categorics are but the forms which reflectire recognition gircs to the facts of self-consciousness. This they all are, epistemologically considered. Ontologically considered, they become forms of being, as "implicate" in self-consciousness. But that "Self" which, as a concept, is the spirit's own construction, embraces other being, and other life, in its own cognitire and self-conscious development. Therefore, a true and full knowledge of Self is the prime condition of a valid and ever larger knowledge of all Being.

Strangely enough, that great reflectire genius, Kant, failed here, and introduced all the modern fashion, so far as it has followed him, of treating the categories as dead or merely formal modes of the functioning of mind in judgment. When, however, these same categories are seen to be the indubitably trustworthy modes of the soul's life of cognition, in its immediate and yet growing apprehension of its orn Being and its justifiable and necessary but analogical apprehension of the Being of the World without, the face of the critic of cognitive faculty begins to wear another look. The real 
trouble of modern epistemological theory lias been with the Kantian formalism, and not with the facts of experience. The facts, indeed, lead to moderation in theory and to caution in life. For the island of the human mind has not, as yet, been thoroughly explored by any critic; and there are, indeed, unknown and, perhaps, unknowable stretches to its limiting ocean. But if I will begin by knowing myself, not in a merely formal and logical way, but as a concrete, active, and free rationality, having valid commerce with the world of the really existent-however restricted that commerce may be - I need not forever approach with despair either the woods and jungles of the island or the mists and fogs of the surrounding seas. For I am thus empowered to make certain affirmations and certain denials with regard to the Nature of all Reality. Positively, its nature is, so far as known, like that of my own Self. This conclusion does not take the form of a command to declare the complete and unalterable impossibility of a valid cognition of Reality; the rather is it the discovery of Reality, as it actually is, implicate in my cognitive consciousness. Cautiously interpreted and correctly understood, so much is true of that most complicated and obviously anthropomorphic of all the so-called categories, the concept of causality. When it is seen how this category, in all its concretc richness of content, as developed by the mature self-consciousness, is but the assertion of the Self's valid experience in its cognitire commerce with things, the necessity becomes apparent of regarding the principle as something more than merely formal, as ratler a true mental representation of the Being of the extra-mentally Existent. Under this category is obtained a valid cognition of real things, actual transactions, true relations, etc. Just as all our formal thinking reposes, for its formal correctness, upon certain cognitive judgments of perception and of self-consciousness, so does our varied knowledge of the beings, transactions, and relations of the real World, ground 
itself firmly in the immediate knowledge of ourselves as really existent in actual relations of reciprocal dependence to the objects of perception through the senses. ${ }^{1}$

But certain current conceptions as to the nature of Reality, instead of being confirmed, are quite distinctly disproved by this view of the way the categories get application to objective experience. We cannot so apply the principles of identity and non-contradiction, or of sufficient reason, as to affirm that the entire Nature of the World's real Being is given to us in conceptions answering to terms such as these: "The reign of universal Law;" "The unalterable Cosmic Order;" "The dominion of universal Reason," - meaning by "Law," "Order," and "Reason," what is customarily concealed in the words. True, the principle of identity and non-contradiction cannot be gainsaid; and under it there is given to cognition a really existent World that must be known as some sort of a self-consistent whole. But when it is asserted, in the words of another, " The contradictory is a category which can only belong to the combination of our thoughts, but not to any actuality," we must beware of the temptation illegitimately to reduce all things to the terms of a perfect logical and formal consistency. Actuality, as known, is full of the most baffling contradictions, when it is approached with the determination to throw a halter over its neck and tame it completely with reins and whip of the "pure understanding." But, then, the Self, in terms of whose own life we, analogically and by application of the categories, gain a knowledge of that other Life, is not mere law, or order, or pure understanding.

1 Again attention is called to the effects upon the philosophy of knowledge which follow from that most mischievous and absurd of all the current psychological heresies - the theory of psycho-physical parallelism. It should by this time be apparent that this theory is not only scientifically quite indefensible and void of support in facts, bnt inextricably connected with the most complete and hopeless agnosticism of an epistemological sort. Moreorer, it totally destroys the foundations upon which is based the conception of the whole of experience the World - as founded in a real Unity.

2 Dühring, Cursus der Philosophie, p. 30. 
The Being of the World need not be any less real, or less validly and indubitably known, if it is conceived of, in part, in terms of the passionate feeling-full, cthical, and æsthetical nature of man. Such anthropopathic cognition need be not one whit less true to facts than the cold-blooded anthropomorphism of plysical science. Especially does the scientific observer of nature require caution as to the use he makes of the category of causality. In the current scientific use of this term it has, indeed, absolutely no warrant for a complete and inexorable application to the Being of the really Existent. As Riehl has correctly said, ${ }^{1}$ this conception and its accompanying conviction "is obviously wanting even to-day in the majority of men, and appears to have been wanting to the philosophy of antiquity down to the time of Democritus." And when the conception of causality is itself confined to the law of the conservation and correlation of energy, and the whole World is reduced to a problem in mathematical mechanics, the state of our knowledge, and the hope of it, become meagre and pitiful indeed. It is, then, in point to call attention to the fact that, really, there is no such thing as mathematical Space or mathematical Time; no such reality as a sum-total of Physical Energy ; and that we have no such assured knowledge of its entities or actual relations as is needed to validate the preposterous claim that the world of Things and of Minds corresponds to the conception of a machine.

But, second, we may venture, even in the name of the philosophy of knowledge and by a permissible extension of the speculative privileges which belong to its serious student, to suggest another and much more admirable picture of the real Being of the World. This $X$, which is the Being of the World (the "World-Ground" or the "Absolute," as metaphysics is accustomed to call It when developing the doctrine of it speculatively), must be further conceived of so as to be a true explanatory principle for all our varied cognitions of Things.

1 Der Philosophische Kriticismus, II., ii., p. 80. 
It must exhibit the meaning of the world, as known to man, by throwing its radiance apon all particular beings, particular erents, and special relations. That $X$ cannot be made to do this work as a task performed in deduction under strictly logical formulas, follows from the way in which the principlc itself is found implicate in all concrete, individual cognitions. It may do a similar work, however, as a kind of epistemological postulate so constructed by reflective thinking as to be itself guaranteed by these concrete cognitions, while, at the same time, shedding the light of its radiance upon them all. But it can perform this task only if it is conceired of both as a principle of manifoldness or differentiation, and as a principle of unity. It must be a principle of cxplanation for the actual manifoldness of the one real World. Now the reality of a system of inter-connected changes has been found implicate in all the life of the cognitive subject. It would seem, then, that the fundamental principle must serve as the Ground, the Law, and the Final Purpose of this system of changes. Moreorer, this system is known as a sort of unity that has centres of self-activity which are not complete in themselves, but which are bound together into a formal whole, because they are existent in Space and Time, whose characteristics they all share, and are also bound together in more vital ways by the actual operation of what we call a causal connection. It would seem, then, that some kind of an Absolute Being must be postulated for that final summary which shall express the full force and meaning of the ontological implicates of all human knowledge. For, as has been said, $X$ must serve as a principle both of differentiation and of unity.

This generalization from the ontological implicates of knowledge, under one term, must be further criticised and explicated by metaphysics. For here, if anywhere, is discorered the sacred bridge orer which ontological philosophy mas pass to conquer as much of the region on the hither side as its forces can, by combined and prolonged effort. Just now it 
does not appear as though a long campaign were necessary to establish, at least, several impreguable strongholds in this region. For our cognition of what is real has been shown to be all, either of the Self, or of the not-self, - the latter known assuredly, but only after the analogy of the Self. Human experience indicates, then, that the one postulate of its system of cognitions must be stated somewhat as follows: The Being of the World is a Unity, self-differentiating in accordance with immanent Ideas. Translated into terms which are nearer to daily experience and have a more positive content: The system of interrelated beings, which are objects of man's knowledge, is known only as it is a manifestation of Intellect, Feeling, and Will. The Being of the really Existent must include all these qualifications, for they are all implicates of that life of cognition which the Self knows itself to have. 


\section{CHAPTER XIII}

\section{SCEPTICISM, AGNOSTICISM, AND CRITICISM}

$T$

HE attitudes of men's minds toward the different forms or scts of cognitive judgments, as well as toward the nature and validity of all cognition, admit of a considerable and most instructive variability. Practical considerations do, indeed, always draw a tight rein over the neck of "pure understanding" and of "rational faith," in their efforts to afford to a merely speculatire or emotional regard for truth and reality its fullest satisfaction. One may adopt and adhere as consistently as possible to the most extreme form of a sceptical idealism, but one must behare as though other minds and other things were existent in a reality of which their appearances to us are in some sort a correct and trustworthy cops. He who attempts to act, with a strict logical consistency, according to the hypothesis that the world of objects known to him is merely his "idea," runs no small risk of pursuing his dream-like life in the confines of the madhouse. It is, indeed, confessedly difficult - perhaps impossible - to lay down rules for the infallible distinction of a great variety of illusions and hallucinations from the plainest facts of normal perceptive experience. Erery observer knows, moreorer, that the most completely logical systems of a scientific or philosophical order are most apt to encounter invincible opposition from the concrete facts of nature and of human life. But the alternative, if one wishes to "get along" at all satisfactorily in the world, is certainly not to be found either in the confusion of all limits between the normal and the 
hallucinatory in sense-pereeption, or in the refusal to take pains to think with theoretic clearness, or in the rejection of all guidance from reason in so-ealled practical affairs. Especially true and noteworthy is the fact that in matters of conduct, sceptieism and agnosticism meet with exceedingly firm and comprehensive resistance. He who even expresses a complete nescience, or an unlimited doubt, as to the surrounding body of judgments about the right forms of behavior, although his mental attitudes may not lead him to the practice of his scepticism or agnostieism, is isolated from the community of his fellows by their distrust and scorn; and he, too, may end his days in some cell of a prison or mad-house.

So-ealled practical considerations influence cogently the tendencies toward a sceptical or agnostic attitude of mind in respect of certain oljects also, which are more fitly regarded as belonging to the realm of faith than of "pure understanding." No one can doubt that, in fact, it is the needs, desires, hopes, and fears of men which so largely stir and guide them in the mental relations they assume toward God, freedom, and the immortal life. As Tolstoi makes one of his characters affirm, it is in life rather than by processes of reasoning that men find God. Most men - and, perhaps, in the last analysis, the most argumentative of them - refuse to be satisfied with the statistics and meehanical formulas of the determinist; beeause these do not accord with their ideas of value rather than purely beeause they do not harmonize with the details of the world of fact. And "ideas of value" are allurements and helps to conduct first; only afterward, and then somewhat raguely, do they yield themselves to scientific and philosophical treatment. The forlorn and lonely soul who has just seen lowered away - " earth to earth, ashes to ashes, and dust to dust" - what was but yesterday so really present and so tenderly dear to him, finds little enough of logical stuff for a demonstration of immortality in the earth beneath, the sky above, or the sad mortals around him; but 
perhaps he cannot bear, and will not bear, to have it so as that this is the end of all.

Yet scepticism and agnosticism remain legitimate and valuable (even indispensable) attitudes of the human mind toward all the objects both of knowledge and of so-called faith. Their legitimacy is proved by the obvious experience of the individual and of the race. This experience plainly shows that the phenomena represented by the words are not incidental, abnormal, or superficial in the mental and moral development of man. On the contrary, they belong to the rery deepest things in the life and growth of reason. To doubt and inquire, to refuse to affirm, and to deny, whether applied in the interests of conduct, of science, or of speculative thinking, are as essential to the processes of cognition as are faith and affirmation of the most positive and undisturbed kind. Moreover, the attaining and holding of our most assured products of cognition are dependent upon those mental attitudes which fall under the terms "scepticism" and "agnosticism"; and the history of science and philosophy - yes, also, and not less abundantly, the history of ethical and religious opinions and faiths - shows the indispensable value of these dubitating and negative states of mind. It is not simply that in this way only can error be constantly discerned and separated from truth; but it is also and chiefly that the very life of the mind, in its most eager and successful pursuit of truth, necessarily follows the same path. The dignity and worth of the Self, as known to itself, and so the dignity and worth of all that really existent World which can be known only analogically, as implicate in and correlated with the knowledge of Self, depend upon the ability to pause, to withbold judgment, to check the tendency to a rash dogmatism, and even to remain in intelligent and arowed nescience where knowledge is denied. Although there remains the indestructible confidence of the soul that the world of fact and the world of values is somehow one and harmonious, and although we can never divorce knowledge from its own teleological con- 
struction and import, it is better for the present to doubt and suffer, or to acknowledge a discontented and hopeless ignorance, than to believe a lie or to prostitute reason for the satisfaction of a lust after pleasure, or a longing to escape from pain.

At the same time, experience is one; and the effort of thought is to explain in its totality what must be taken in its totality. A human soul, divided against itself, cannot stand. And woe to the generation which, while affirming a scientific or philosophic knowledge of one thing, keeps up its courage by exhorting faith and conduct "as though" anotler and opposite thing were true. For that generation is doomed either to reject the exhortation or to become a generation of weaklings and hypocrites. Neither can we believe that natural science and philosophy on the one hand, and conduct and faith on the other hand, are so different in either their sources, their nature, or their ultimate principles, insights, and imports, that they admit of thus being divorced. What retribution is visited upon those who continue to preach as right in conduct what they make no attempt to practise, and who hold fast to dogmatic tenets and credos in religion which they are sure science has transcended or removed, there is history enough to show. But here is one of those rules which are poor indeed if they do not work both ways. And dogmatic tenets and credos in science or philosophy do not, in the long run, and when judged by the ultimate standards, fare much better, if they claim for themselres an immunity from scepticism and agnosticism which they will not grant to so-called ethical and religious faiths. Human nature will not forever bear to be arrayed against itself. If Kant failed of success in removing knowledge in order to make room for faith, the original effort of Mr. Spencer, in his "First Principles," to reconcile science and religion upon a basis of complete agnosticism, has been a ten-fold more conspicuous failure. Nor will the wise student of the history of man's 
derelopment place much confidence in any of the current proposals for a "reconciliation" which is to be effected by assigning one set of faculties, as it were, to science, and another to conduct and religion; or by proposing that one attitude of mind shall be turned toward the world of things as natural science sees it, for six days each week, and another contradictory attitnde toward God and immortality, for, at most, an hour and a half of the remaining day. For the simple truth is that, sooner or later, men will walk all the way through their experience; they will try to survey it on all sides; and as they walk and look, they will be human natures still, thinking, feeling, planning, full of interest, not only in the world visible and present, but in the world unseen, and in the world that is erer about to come.

It is not our intention, however, in this chapter to attempt a historical or a critical estimate of the sources, nature, and value of the sceptical and agnostic attitudes of mind. Nor does the present purpose require that any particular form of truth should be defended against assaults made by those who persistently assume either of these attitudes. The latter and more restricted of these two inquiries would, if thoroughly pursued, lead to a detailed examination of the nature and limits of the evidence and proof which may be demanded by each of those special groups of eognitions and opinions toward which it is possible for the individual mind to be either dogmatic, sceptical, or agnostic. And here Aristotle's view seems as wise and fitly applicable as ever. We must not expect the same kind of proof or evidence for all kinds of subjects. For although our experience is one and cannot be discerned except as illumined from the full-orbed and central light of the selfconscious Self, yet the different objects of that one experience get themselres accepted as real, or are denied place in the world of reality, in widely differing wass and upon terms that are by no means precisely the same.

For example, those concepts of all physics with which the 
most mathematical branches of astronomy deal are as truly mental products, that cannot be understood without a correct doctrine of the feeling-full and voluntary nature of the cognitive judgment, and of the presence and influence of ethical and æsthetical "momenta," as are the concepts of ethics and theology. At the same time, no one would think of affirming that truths about the movements and physical constitution of the solar system are discovered and expounded or defended with precisely the same methodology and emotional and volitional accompaniments as are truths of duty and religion. From such irremovable differences it follows that the province and values of the sceptical and agnostic attitudes of mind are very different in physical science and in matters of conduct, faith, and worship. Indeed, it is largely upon this difference that we have elsewhere ${ }^{1}$ divided the whole subject-matter of science and philosophy into that which concerns what $i s$, the Real, and that which concerns what ought to be, or the Ideal. The critical estimate of the scope and validity of sceptical inquiry and of an agnostic outcome, as concerned with these two great kinds of material for reflective thinking, and also as concerned with all the particular subdivisions of these kinds, is a theme for a more special inquiry than that of the present treatise. $^{2}$ On the other hand, a history of scepticism and agnosticism is not a part of epistemology, however valuable a propædeutic it may be.

1 Introduction to Philosophy, chapter viii. : "The Divisions of Philosophy."

2 There are few more alluring and promising fields for a critical use of the reflective powers in which philosophy arises thau those afforded just now by the physical and natural sciences. I have several times already expressed my conviction that these sciences are more than ever before full to the hrim, and ready to burst, with ontological conceptions and assumptions of most portentous dimensions and uncertain validity. Surely scepticism and agnosticism, now nearly sated with feeding upon the ancient body of alleged truths in ethics and religion, will soon turn their devouring maw upon the structure generated and nourished by the modern scientific spirit as dominant in chemico-physical and biological researches. And if the strength of their appetite and the vigor of their digestion remain unimpaired, must we not fear that even the bones of this structure will disappear from our view? Consider, for example, what would be left of the hy- 
Some critical estimate of the sources, nature, and value of the sceptical and agnostic attitudes of mind toward cognition, as such, has already been implied in all the previous discussions. For it is possible to doubt and to deny, or to profess ignorance, respecting the trans-subjective validity of cognitive faculty itself. This is, indeed, a part of the supreme activity of the self-reflective and critical human mind. It is not simply as to the truthfulness of particular judgments and the rerisimilitude of particular concepts, but as to the possibility of attaining truth at all - as to the trustworthiness of all mental representation of the being and transactions of the really Existent - that the extremity of scepticism and agnosticism raises our doubts. In raising and pursuing these doubts the mind makes its own cognitive processes its object of cognition. It is this very thing which critical epistemology proposes to do; and for this reason it has been called "science of science," "theory of knowledge," or Wissenschaftslehre. It is the employment of a certain amount of scepticism which is commended by the declaration that epistemology is the "most presuppositionless" of all branches of philosophy, the one exercise of the human mind in reflective thinking which insists upon starting with a "metaphysical minimum." That is to say, nothing is to be assumed as true respecting the process or the object involved in the primitive act of cognition, except what, as we immediately discover, is inseparable mattel-of-fact belonging also to the rery proposal to undertake such sceptical examination. It is this very plan which we have been following; and the result has been to show that all scepticism and all agnosticism are, even in their most actire and extreme forms, self-limiting and self-destructive.

pothesis of biological evolution, if a thorongh critical and sceptical treatment were given to its metaphysical basis, its postulated ontological conceptions and assumptions. Surely, the way in which many students of these sciences vacillate between the most comprehensive professions of knowledge as to what the world is, and how it came to be, and the most abject confessions of ignorance, is little better than scandalous. 
The sceptical and agnostic attitudes of mind must not be conceived of as once for all fixed and unchanging. If to these attitudes we add the dogmatic and critical, we have the picture of a ceaseless shifting of what may perhaps be called the "temper" of affective consciousness toward the propositions in which men express their cognitive judgments. The dogmatic attitude of mind accepts these propositions without previous sceptical or critical inquiry into the grounds on which they rest; it, nevertheless, holds them with the warmth and tenacity of conviction that are made thoroughly rational only as a result of such inquiry. The sceptical attitude begins by doubting the propositions, and by proposing to examine the grounds of their alleged truthfulness, while maintaining meantime a temper of non-assent toward them. The attitude which avows nescience, or no-knowledge ( $a$ knowledge), toward these propositions may be called agnostic. By the critical attitude little else can be meant than that fine and intelligent balance in the action of cognitive faculty which is sceptical before the grounds of judgment are examined, and agnostic when the alleged grounds turn out mistaken or insufficient; but which is equally ready positively to affirm, or positively to deny, when the process of inquiry has justified the required cognitive judgment.

Now it is obvious that there is no kind of knowledge, and no particular alleged cognitive judgment, toward which it is inconceivable that all of these attitudes of mind should be assumed at different times. As a matter of fact, different minds do manage to differentiate themselves on occasions where the feelings and practical interests as well as the amount of evidence "in sight" seem to warrant such differentiation, in accordance with all these types, although respecting the same propositions. It is scarcely possible to throw any cognitive judgment into the form of such a proposition that all men will either accept or deny it; or, perhaps, will consent to regard its truthfulness as doubtful. And the very 
growth of knowledge, in the individual and in the race, depends upon the possibility of every individual, and of each generation, changing somewhat freely its "temper" of consciousness toward propositions current in the past. We are especially fond of boasting that the present age is predominatingly critical. It is, indeed, sufficiently sceptical and agnostic toward many ancient and important truths (or alleged truths), - especially those of ethics and religion. But it is also commendably anxious to weigh fairly the evidence; and if this evidence seems sufficient, it is willing not to persist unreasonably in the merely sceptical or agnostic position. How often do we hear the Zeitgeist sincerely and pathetically lamenting its inability, on rational grounds, to affirm knowledge, or to act in the full faith of truths that, nerertheless, appear to it to hare a high idcal ralue! Or else it attempts that divorce of faith and knowledge which we have alrcady declared to be as mischievous as it is, in the final issue, impossible. Thus it comes about that, as never before, the multitude of men are sensitive to all the rapid changes of objective temperature; they either feel themselves cooling off toward some truth to which they have formerly been most warmly attached, or else unable to resist the heating effect of the atmosphere of opinion which, for the moment, has made certain other propositions glow and shine like the sun in the centre of the solar system. What use, for example, nowadays in expressing one's thoughts upon any matter without frequent phrases, largely meaningless, taken from the theory of biological crolution? How many "scientific" minds can be found who are daunted as quickly by the mysterious and contradictory attributes of the "ether," as by the difficulties attaching themselres to the current theological conceptions of a Supreme Being?

What is true of the attitudes of scepticism, agnosticism, and criticism, with reference to particular forms of the cognitive judgment, is true of the same attitudes toward knowledge in 
gencral. Yet the course of our discussion has most clearly shown how, when assumed toward the activity and the product of the mind in all knowledge, these attitudes are selflimiting and self-destructive. 'That is to say, it has been demonstrated by a critical examination that complete and consistent scepticism and agnosticism, with reference to man's power mentally to represent the being and the transactions of the really Existent, are impossible. The whole inquiry, then, becomes one respecting the limits of scepticism and agnosticism, - with respect to the propositions laid down in the course of a critical epistemology.

It is evident that in dealing with epistemological problems, scepticism quickly reaches a position in which it is strictly limited, on the one hand, by a perfectly clear and indubitable cognition, and on the other hand, by a quite irremovable and impenetrable agnosticism. Agnosticism, in its turn, now appears as an attitude of mind toward cpistemological inquiries which can arrive at no conclusion; and which cannot even posit its own existence without assuming both the validity of knowledge and the rights of an untrammelled but by no means nescient function of scepticism. Moreover, all this is just as fundamentally true and important where the sceptical and agnostic attitudes are the positions of a mind that proposes to transcend, by following the critical path mapped out by Kant, the dogmatism commonly concealed under both these attitudes. For the more candid and thorough our use of criticism becomes, the more clearly does it appear that epistemological scepticism and agnosticism have their fixed and impassable barriers in the very nature of cognitive faculty.

To illustrate the statements just made, let us suppose that the so-called "immediate" cognition of things by the senses is being made the special subject of a thoroughly sceptical and agnostic treatment. We have "on hand," so to speak, the common-sense riew of the nature, significance, and valid- 
ity of the perceptive act. This riew assumes that things really (that is, extra-mentally) are what they seem to all men to be. Or in other words, things perceived and apperceived, things as known by me when I exercise my normal powers of cognition through the senses, under fairly favorable circumstances (as respects degree of stimulus, concentration of attention, freedom from temporary impairments or permanent unfitness of the organs, etc.), are given to me within consciousness "about as" they really exist and actually behave in the world that is out of my consciousness. [We have designedly been thus indefinite, because the most dogmatic adrocate of common-sense realism will admit a certain indefinite range of inaccuracies and non-correspondences between things and their mental copies.] Now scepticism makes short work of this easy-going common-sense view as it is held only by the unreflective mind, and yet as it constitutes the practical hypothesis of the most sceptical of epistemological inquirers. In the name of botl psychology and physics, it first attacks the so-called "secondary qualities" of things. Their color, feel, sound, smell, and taste, are all resolved into subjectire affections which, as described by psychology, bear not the faintest resemblance to those causes of the affections that, as physics demonstrates to its satisfaction, reside in the massive or molecular structure and functions of the physical world. If, at about this point, psycho-physics and physiological psychology take "commonsensc" in hand, and subject its clearest deliverances to their critical testing, nothing is left of the common-sense view of perception. For science shows that perception is not a sort of fairly accurate " copying-off," brought about in consciousness through the action of ready-made external things. And when a more critical psychology, helped out by the metaphysics of physics and (though often without much clear recognition of what it is about) grown sensitive to considerations derived from a sceptical epistemology, has discussed the 
origin and nature of the "primary qualities" of things, not a restige of standing-room seems left for the most obvious declarations of the "plain man's" consciousness as to his sensuous knowledge of things.

It is to be noticed, however, that psychology, psychophysics, and physics, while they have united in a sceptical attack upon the ordinary view of the cognition of things, as a valid representation of trans-subjective qualities and relations, have all the while been indulging themselves in a dogmatism of their own. It is altogether likely that they have done this with some unseemly vociferation against the presence in these "sciences" of the least taint of metaphysics or of epistemology. Yet no writers have, on the whole, been more crudely dogmatic in respect of their noëtic and ontological conceptions and assumptions than have those whose avowed aim las been to treat psychical phenomena from the standpoint of a science that is sceptical as to all the ultimate problems. Let, now, the sceptical inquiry be pushed forward into that mass of alleged cognitions as to the constitution and behavior of things which modern science has substituted for those sense-percepts that men, in general, find given to their mind. The imagination of the most myth-making of the ancients, or the untrained fancy of the most superstitious of the savages, has never resulted in so marvellous and surprising a picture of the "unsensed" reality of things. It is confessedly impossible to recognize in these things, as they are, the prototypes of things as we know them in our work-aday life. Yet this world of seientific discovery is the proposed substitute for the world of commonl-sense. That very sceptical process, which has resulted in the destruction of our confidence in so-called common-sense, has been accompanied by a more or less dogmatic construction of an extra-mentally real world, which is now relied upon to explain the world of common-sense, and at the same time to serve as a barrier against the march of scepticism forward to a completely agnos- 
tic outcome. From a world which all men immediately know and believe in, we have been led by scepticism to a world about which we indirectly know and believe in anything whatever only as we trust the intellectual processes of others, under the principles of identity and of sufficient reason. What now if scepticism, recognizing that it has been cheated of its full rights, attacks the validity of these principles, and so threatens the reality of the world which imagination and thought have constructed by following them?

And now the destructive work of sceptical inquiry begins over again. But its field of inquiry is changed to that realm of lofty imaginings, abstract conceptions, and generalized formulas, for which science holds itself responsible. Its structures, although built by a community of stout hearts and skilful hands and noble purposes, are even frailer on some sides than are those products of sense which have been, often so inadvertently, called "illusory" and " unreal." Once more, however, as has already been shown, a limit is reached beyond which scepticism cannot go. There is in my perceptive consciousness that which, somehow and at some first time, I have come, indubitably and with the clearest cognition, to recognize as not merely the state of my consciousness but as known certainly and immediately to be "not-me." Here scepticism meets the insuperable barrier of a positive Somewhat that is in consciousness but is not the mere product of consciousness, - that is subjective, because it is an object of $m y$ cognition, and yet is trans-subjective, because it is the cognized "opposite" of the Self. That such a limit is actually set to the sceptical treatment of the knowledge of things by the senses, and that it is applicable to all both normal and abnormal processes of perception, has been shown to be true, over and over again.

But it is equally plain that the sceptical inquiry must be accompanied, from its point of starting to its final issue, by confessions of ignorance or nescience that cannot, all of 
them, be considered as temporary or unimportant in respect of the nature and growth of knowledge. For if I stop at any stage of the sceptical inquiry to ask after explanations for all that I seem to know, or for all that I know I doubt, the only answer which can be truthfully given must often be, "I do not know." And at the end of the most candid and thorough criticism of cognitive faculty, it must be replied to a vast number of particular questions, though falling under a few general classes, that such things are not given or permitted to man to know. From this it follows, as a matter both of theoretical economy and of practical wisdom, that the mind should recognize the unreason and the absurdity of even attempting to answer certain inquiries. Both science and scepticism - however paradoxical the statement may seem appear to be constantly limited by nescience. The very nature and the laws of the development of knowledge itself require us to learn to say, "I do not know." And where the experience of the race is sufficiently clear and cumulative, the spirit of philosophical criticism is not violated by saying: "I do not think that any man will ever know, or that the human mind is capable of knowing."

For example, something of this sort seems necessarily to be true in respect of all human knowledge of things, whether immediate through the senses, or indirect and inferential as a body of accumulated information about things in terms of physical science. This is true of the dicta of the most ordinary common-sense. "Sugar is sweet;" but "lemons are sour:" "The grass is green;" but "the heavens are blue, with whitish or blackish clouds scattered here and there." But why is the sugar sweet and the lemon sour, the grass green, and the sky blue, but the cloud white or gray? Common-sense is nescient in answer to these inquiries, and must ever remain so. Or it may substitute teleological reasons for causal action, and thus explain further from another point of riew; but nothing characteristic of the constitution of these 
objects, which shall determine the effects they have upon our consciousness, appears to the observer who maintains the point of view of ordinary perception. Science, however, attempts the answers to such questions. For one of them it proposes an elaborate theory of optics with measurements of wave-lengths in the hypothetical substrate called ether (a most marvellous being); this theory it joins on to a more doubtful theory of the chemico-physical value of pigments in the retina of the eye; and it then finds its way further by the path of an eren more doubtful theory of nervecommotions in certain cerebral centres, where, alas! everything disappears from the view of the scientific observer in a bottomless pit of metaphysics concerning the "relations" of matter and mind. And as to the scientific explanation of the ordinary sensations of taste, nothing is known worth seriously taking into account.

Suppose, however, that we had all such mysteries cleared up, and a straiglit and traceable path laid from the centre of the solar system, or from the piece of matter put into the mouth, to the psychoses of visual or gustatory sort. This would indeed be a splendid and highly desirable extension of scientific knowledge; but it would also extend correspondingly the sphere over which the darkness of an impenetrable nescience would reign. Why should a particular wave-length of luminiferous ether, after getting itself translated in the form of definite determinations of chemico-physical processes and specific kinds of nerve-commotions, be finally correlated with sensations of blue, green, white, black, etc.; while other disturbances of the molecules of ordinary matter, after exciting similar chemico-physical and neural changes, appear in conscionsness with representative psychoses of the quite different olfactory or gustatory order? To questions of this kind the growing science of sense-perception offers no answer; and there is little or no prospect of any successful attempt, in the remotest future, at any answer. Or, at least, 
if these or any other more precise terms in which the problems are proposed for explanation should receive light from the discovery of new facts, the expanding domain of certified knowledge would still be given to us as covering a bottomless abyss of unexplained and inexplicable facts. All answers to the question Why? as applied to the correlation of particular facts, leave us in the agnostic attitude as to the ultimate reasons for the correlation itself. We know that so it is; but $w h y$ it is so, we neither know nor discern any prospect of knowing. Indeed, as there has already been occasion to remark before, the progress of modern science is extending the realm of accepted but unexplained facts far faster than the corrclation of those facts under either old or new principles of explanation. And thus the very nature of knowledge is such that the limit of all sceptical inquiry is set in the confession of mystery and of nescience, as well as in the profession of formulas under which the facts may be regarded as sequences from some common ground.

When, too, attention is turned from the particular facts to those generalized modes of the behavior of things which are called "natural laws," the most sceptical inquiry appears limited, on the one hand, by assured and trustworthy cognitions, and, on the other hand, by a complete and seemingly permanent condition of nescience. This appears the more strange from the point of view held by science as to the nature and signification of the causal principle. Why violets should emit one characteristic odor, and the reddish-brown substance obtained from a bag behind the navel of the male of a certain species of deer should emit a quite different but equally characteristic odor, is not a question that science can at present satisfaetorily answer. Scientific curiosity would be gratified, however, if these facts could be brought into connection with others, and if some so-called law of the chemical constitution of odors could be brought to light.

When we ask why the arrow shot from the bow, or the 
stone loosened from the coping, or the meteor caught within the magic influences of this terrestrial sphere, all agree in falling, although by very different lines, to the ground, the law of gravitation is the answer to the inquiry for all three. And not only so, but also does this law embrace in its compelling folds the planets and their satellites, and even some of the remoter stars. But why should masses of matter attract each other at all ; and why directly as the mass and inversely as the square of their distance apart, rather than in accordance with any one of an indefinite number of other different formulas? In spite of the many and persistent efforts made to answer this question, there is still only one answer possible: "We do not know; and we have not the least glimmer of a reason why." Just such a confession of neseience must always limit that knowledge with which science puts us into possession in the shape of its so-called laws. Concerning the causal explanation of the most assured and triumphant gemeralizations of science, our agnosticism is as complete and invincible as it is concerning the most startling and unique exceptions to those laws. The law of graritation is as mysterious as is the exceptional behavior of " 1830 Groombridge" in apparent contrarention of that law. The expanding of water at just the degree of $32 \mathrm{Fahr}$. is actually no more an incomprehensible puzzle in etiology than is its contraction all the way from $212^{\circ}$ Falır. down to that degree.

Common-sense - it was said some time ago - "may substitute teleological reasons for causal action, and thus explain further from another point of view." Science is accustomed to proclaim that it canuot take this other point of view. It must confine itself to asking why, in a way to indicate the need of complicating further the mechanism, unless the new fact can be brought into terms of harmony with the formulas generalized from other facts. Common-sense is often satisfied with the naive suggestion that, perhaps, some good end may 
be reached by departing from the strict and unswerving application of the general formula. It may be, for example, that the ideal purpose of the universe will be better served if all the members of the solar system do, for a very long series of ages, obey the law of gravitation, and if 1830 Groombridge does not. Or if water follows the law of contracting down to about $32^{\circ}$ Fahr., and then - "He knows why " - all of a sudden departs from that law, the earth will be more fit for the habitation of man, etc. And here a flood of light upon the physical constitution of things, as it is actually known to exist, seems to burst in upon the sensitive mind. Such anthropomorphism the strictly scientific construction of the nature of Reality refuses to accept. Science has its own limits to its own anthropomorphism; and these compel it to arow an agnostic attitude of mind toward the ultimate reason and significance of all natural laws. But, here again, it has been clearly shown that the conceptions employed in the statement of these laws, as well as the relations affirmed in the several combinations of the conceptions, are all patterned after the analogy of the most fundamental experiences of the selfconscious Self. The only way, then, to ralidate these laws for a really existent World of things is to accept the postulate that its being and transactions are somehow truly represented in human experience.

In this way, then, does the weary dove, sent through that window of the senses which opens toward the endless expanse of unexplored waters, return to its own ark within the soul of man. The so-called illusions of the world of sense are known as illusions only if our sceptical examination of the sensuous deliverances is constantly accompanied and justified by a faith in human cognitive powers. And after this faith itself, and the grounds on which it reposes, and the springs from which it proceeds to enlarge the spliere of science, have been subjected to sceptical inquiry, the barriers that are a combination of indubitable cognition and irremovable nesci- 
ence, are only pushed a little way further back. Thus the final state of the case is reached, and the last word which a critical philosophy of knowledge can utter is spoken. The soul knows itself with an increasing clearness and fulness of content; and it knows that somewhat not itself is giren to it to know, with all its own powers sharing duly in the actirities of sense-perception. Such are the limits of its scepticism both by positive cognition and by nescience. The limits of its positive knowledge are extended only upon these terms, - that it accept these objects of its knowledge as somehow forming a unitary system for the communication of this other and larger Self with its own Self.

After what has been said in the preceding chapters ${ }^{1}$ it is scarcely necessary to discuss in detail the self-limiting nature of scepticism and agnosticism as applied to the epistemological problem of self-knowledge. Here the sceptical attitude very speedily receires a clieck to its progress in any direction. Do I raise and maintain a doubt as to the here-and-now being of my Self? Whaterer iny general epistemological position may be, and whaterer interpretation I may give to the conceptions current in every form of metaphysical discussion, - eren the most agnostic and scornful, - there are fixed limits for this region within which doubt cannot eren lift up its head. Whatever you mean by "knowledge," in that meaning, at the worst, I know that I here and now am. Whaterer your conception of "bcing," you cannot deny the validity of the proposition, I here and now am. The same thing is true concerning the remembered existence of Self. Meaning for the word "knowledge," or material for the most meagre conception of any sort of "existence," cannot be had without admitting so much of indubitable self-cognition as this. But this is itself, at one and the same time, the indubitable affirmation of a positive knowledge, and the setting of a limit of nescience to the process of sceptical inquiry.

1 See also "Philosophy of Mind," chapters iii.-vi., and xi. 
The limits of both indubitable conviction and of nescience must, so far as we hare any present information, or prospect of information in time to come, be recognized as absolutely irremovable. They belong, indeed, to the very nature and growth of cognitive faculty. The cognitive judgments in which are expressed the answers to the questions, "Do I here and now exist?" "Did I exist in that yesterday, when, as I remember, I thought, felt, or acted in such a manncr?" "Have I, in any sort, been one and the same Self from the remembered 'then' to the self-conscious 'now' ?" - are so clear and positive that no higher stand point, or profounder and more comprehensive view of truth and reality, can possibly be gained from which to gainsay or dispute these judgments. They fix the irremovable barriers to scepticism in its attack upon the truth of self-knowledge. But as we contemplate these questions and their indubitable answers critically, we find both questions and answers freighted with a great load of mysteries, which psychology, epistemology, and metaphysics are by their combined efforts quite impotent to lessen or to remove. Nothing remains for us but the answers "I do not know," and "Knowledge here seems denied to all men," when these questions are proposed.

How is memory at all possible, - that present phase of consciousness which carries with it the unique guarantee of an existence of Self and of Things in the past, and so itself makes possible a continuity both of cognitive development and also of the being of the objects of cognition? Psychology is destined to remain agnostic in answer to this question. The wisest students of mental phenomena are the readiest, not to place its ultimate solution in "brain-memory" or in experimental determination of the "laws of association," but to confess nescience when problems of this order are proposed for scientific treatment. How, indeed, in the last analysis, is knowlcdge possible; and who will vouch for the extra-mental validity of that primitive and fundamental conviction which is 
furnished by the mental process of knowledge itself? From the point of view of genetic psychology we may expound and glorify the descriptive history of cognitive faculty. From the point of view of epistemology we may analyze and discuss critically the maturing functions and the necessary implicates of this faculty. But the results of all this must be expressed in a series of propositions: "I know," or "I do not know ;" "I think or opine this;" or "I do not think, and guess not, that." Such is the nature of the science of psychology, and such is the nature of the philosophy of knowledge. Nor does psychology differ in this respect from other sciences, or epistemology froin other branches of philosophy. Yet the more intense and thorough scientific inquiry becomes, the quicker does it pass over the road that leads at last to the reil through which man cannot see. The only answer now left to the causal "Why?" is a confession of nescience. "I do not know" is all that science or philosophy can say to inquiries after further explanations under this principle. But if we will admit to the confidences of our speculative thinking the question of the teleological "Why?" we may perhaps frame a rational hypothesis as to what lies beyond that veil.

Epistemological agnosticism, like sceptical inquiry, is by nature self-limiting; it is also encompassed by the limits on the one hand of assured cognitions, and on the other hand of reasonable and helpful faiths and practical postulates. Indeed, in pursuing the course of sceptical and presuppositionless inquiry through all the chapters of this book, we hare been setting positive and invincible limitations to epistemological agnosticism. More than once has it appeared that the alternative reached by a course of reasoning which is consequential, and which goes to the heart of the ultimate problems, forces this alternative: Either an agnosticism which amounts to complete philosophical nihilism, and which ends in absurdity so absolute as to be unstatable, or else the admission that human knowledge guarantees the transcendental 
use and validity of the categories and of the ontological implicates which analysis shows to be necessary "momenta" of all knowledge. As the ultimate outcome of epistemological criticism it has appeared that the extremest form of the agnostic proposition itsclf assumes a whole World of Reality, — Self and not-selves interrelated in quasi-systematic fashion, which may be truthfully represented by the human mind.

For let us now briefly reconsider the different meanings which it is possible to give to the " cognitive judgment" of the agnostic. Certainly his judgment bears a distinctly cognitive form ; since its proposition is, not merely "I doubt," but in its minimum of trans-subjective reference, "I do not know." But this "I-do-not-know" is itself an experience which is pregnant with meaning only as it carries within itself all the life from which springs a world of transcendent reality. For the "I" which avows itself to be in this state of nescience is as truly a self-known Self as is the confident $E$ go of the most credulous dogmatist. The state of nescience, or non-knowledge, in which it knows itself to be is meaningless except as contrasted with the memory-image of previous states of knowledge. Indeed, so far as epistemology, in distinction from psychology and logic, is concerned, the judgment "I-do-notknow" is not to be distinguished, with respect to its grounds or its implicates, from the judgment "I-know." Now, it has been explained in great detail that all cognitive judgment necessarily implies the existence of a number of beings other than the Self, to some of whom - namely, the other selves it always appeals, as furnishing in their nature common characteristics with our own, and thus as acknowledging with us some objective standard of truth ; so that the "I-do-not-know" is an affirmation of an experience which is as truly transcendent, in a legitimate sense of that word, as any cognitive experience can possibly be.

"I do not know" may be a sincerely modest and truthful affirmation of the experience of the individual cognitive soul; 
and it may be accompanied by the proper feelings, and made in a commendable spirit, when applied to problems of epistemology. It may signify a state of nescience, out of which the soul may reasonably expect to emerge, if only it will follow good guidance along the path of self-criticism. Even if any individual agnostic prefers to plunge sideways out of this path of careful inquiry, in the faith that he may somehow "feel" his way to slelter from the gathering storm, his case is not hopeless. For, as will soon be shown clearly, all cognition has its teleological aspect and its ethical and rsthetical factors; and, although self-knowledge is the only sure path to the truth about all knowledge, many men are, by constitution or by habit, not of robust frame and steady head enough to climb the heights of assurance by this path. So, then, the experience of all alike, when the narrative of that experience is finally made up and fully disclosed, teaches the same truth with regard to the limits of agnosticism.

Suppose, howerer, - and this is for the most part the case of the arowed agnostic regarding epistemological problems, that the judgment affirming nescience means somewhat more than appears upon its surface. Now, this "I-do-not-know" may mean also "You do not know," and even "Nobody knows, or ever will know, or ever can know." This is nescience venturing into the field of epistemological philosophy, and laying down a universal proposition. But it requires no critical insight, or work of analysis, in order to show that such nescience is the most self-confident and comprehensive kind of knowledge, if only it be regarded from certain perfectly unprejudiced points of view. Such an agnostic may always be asked, with the most complacent of countenances, "What is it that you and I and all men are constitutionally doomed to remain ignorant about?" The reply, if it is to be stated in terms that can be defended, cannot possibly include any of those laws, factors, implicates, or faiths and postulates, which our previous critical discussion lias shown to belong of invin- 
cible right to all human knowledge. Indeed such an agnostic assumes to know even more than our presuppositionless theory of knowledge undertakes to guarantee: Other minds exist, and are subject to like limitations with the mind of the agnostic; the laws of these minds, and the cognitive relations they bear to that Reality which even the Unknown, the $X$, is assumed to have, are going to remain forever unchanged; the nature of these minds and of their cognitive processes, together with the appropriate feclings of doubt and despair, have already been explored so deeply and tested so thoroughly that no more of latent vital capacity for cognition is even to be suspected. Moreover, there is assumed a positive and conclusive knowledge that the common mental representation of the reality of the world of things is not indeed what it claims to be, - namely, cognition; it is mere sensation, mere ideation, mere abstract thinking, and cannot be the truth in the sense which men usually attach to that word. But who does not see that so much nescience as this involves a vast amount of the most positive and comprelsensive propositions, which, instead of confessing a sceptical attitude of mind toward Truth and Reality, the rather manifest an attitude of extreme dogmatism concealed under agnostic guise?

If, however, the more absolute and universal agnostic formulas are understood as limited in relation to the positive content and proper implicates of all knowledge, they take on a totally different character. That not a few questions may be asked about knowledge and reality to which the reply must always be an unequirocal declaration of nescience, few students of epistemology and metaphysics would think of denying. Epistemology and metaphysics concur in showing that this is necessarily so. But here again these very sceptical inquiries and their agnostic answers are based upon a foundation of assured, positive knowledge. Some things I know indubitably in answer to the sceptical inquiry as to the Being of the really Existent; some things also as to what 
Knowledge is, and as to what of Reality my knowledge implicates and guarantees. Without recognition of these fixed points, as it were, in the flux of the cognitive processes, the agnostic answers to other questions could neither be reached nor eren stated.

To return now to the illustration of which Kant makes, for his theory of nescience, such telling use: It appears that the case as between our cognitive minds and the transcendental being of the world is not at all as this great thinker made it to be. The island of our cognition is not a well-defined amount of ready-made "stuff," already completely explored by epistemology and mapped out in unobjectionable and unalterable outlines, within which no increment of extra-mental existence can, as it were, enter. Nor does Reality stand related to this island of cognition as a boundless and wholly impenetrable ocean, forever covered with a veil of mist and fog. What Kant means by "the island" is an ever-expanding life of the Self ; and this life may - it is, at least, conccivable - extend its self-knowledge indefinitely; but it always knows itself as real and as standing in actually experienced relations to a system of other beings, that are known as not-itself. Instead, then, of the island being impenetrable to Reality, its very life and growth consists in processes of the absorption and assimilation, so to speak, of the real with the expanding Self. And the surrounding ocean is thereby more and more cleared up for vision from that island, if only one will take the loftier and more cloudless points of view. For the ocean and the island are, indeed, not throughout to be identified; neither do they run parallel to each other, like the two tracks of a railroad bed. But they are parts of one World; and they are known in one experience as belonging to the unitary Being of that one world. And what the nature of the ocean is, beyond the many inlets and bays with which it interpenetrates the island, and beyond the line where the fog and mist retreat on the sunniest of our days, may be conjectured, brarely 
and rationally, from these better points of view. For the faith which takes us through the fog and the mist is not of the nature of an irrational plunge into a tide where no swimmer can hope to survive; it is only, after all, of a nature common to the postulate of an analogy between the Self and its World,-by confidence in which all the particular sciences progressively make conquests of this one world.

It appears, then, that the sceptical and agnostic attitudes of mind toward truth in general, as well as toward those particular truths in the establislıment and critical reconstruction of which the very growth of the body of science consists, belong to the life of the cognitive soul; but they are not attitudes in which the soul may rest and be satisfied with conclusions that follow upon the view of experience from these attitudes alone. Scepticism, or that inquiry which originates in the spirit of doubt before the propositions of an uncritical dogmatism, is the fit incitement, the rational privilege, and the seal of dignity, for human knowledge. It is limited both by that fuller and more certain cognition, and also by that enlightened agnosticism to which it points out the way.

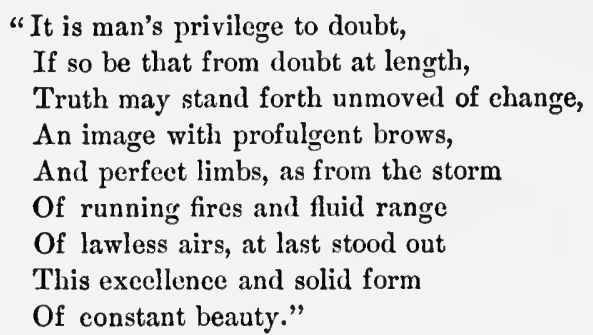

Agnosticism, as distinguished from scepticism, is either a truthful confession of a temporary and curable condition of the individual mind, or else it is a positive and universal proposition which itself aspires to the position of a wellgrounded and comprehensive cognitive judgment. In the latter case, however, it cannot possibly deny for itself the 
ontological significance which every universal denial, and, indeed, erery negative cognitive judgment, necessarily possesses. Here the principles of non-contradiction and of sufficient reason, of the transcendental use of the categories in all universal propositions, and of the ontological implicates that inhere in those processes which terminate in the cognitive judgment, have their most rigid and complete application. All such principles set invincible limits to agnosticism, which are of positive and supreme epistemological value. But, on the other hand, all human knowledge is, not so much rigidly encompassed and limited by the unknown as interconnected with and based upon presuppositions, postulates, and unanalyzable data of fact, concerning the origin and causal explanation of which no answer whatever can be given. As all science explains only by reference to the unexplained and the inexplicable, so a theory of knowledge is philosophically grounded only as it admits that much of its critical effort ends in nescience. In view of this it is customary and appropriate to say that the process of explaining by giving reasons, and by connecting one "moment" of experience with another, cannot go on forever. But what we have been trying to show is something more fundamental than this. The human mind does not refuse the effort to explain because it gets tired at some point or other in moving along the line of that effort; nor is the task of epistemology like that of milking a he-goat into a sieve. The rather is our conclusion this: The positive character and indubitable ontological validity of human knowledge, but also its limited character and inevitable failure to frame the full and perfectly clear picture of the extra-mentally existent World, must both be recognized and combined in an epistemological doctrine which shall claim the warrant of all our experience. A "trans-subjective minimum" is always found, left over, as it were, from the most corroding tests of a sceptical and agnostic criticism. This remnant, "which shall be saved" from the fires of doubt and the frosts of nescience, has always 
enough of life in it to generate anew a system of confident cognitions touching the nature and meaning of Reality as given to men to know. And when the higher life of conduet, of art, and of religion, is breathed into this remnant, it soon takes on a diviner and more clearly recognizable shape. But the revelations which it then makes of its own nature are only for eyes that have been touched with another Spirit than that which fitly rules over the course of a critical epistemology; although such a critical epistemology, if it reaches a point near the goal of the fullest and worthiest self-coguition, prepares the way for such revelations. Nor is there any so very marked break in the course, when we pass from knowledge of Self and of Things to so-called faith in the Supreme and Ultimate Reality.

At this point, it is not only interesting, but suggestive of a truth whieh merits and will receive further examination, to notice again that scepticism and agllosticism receive most of their needful correction in the life of feeling and of action. The rights of philosophieal criticism must never be discredited or denied; and after having taken so much pains to think our way through the clouds of doubt and nescience, we are not going to fall back again upon the refuge of mere feeling, or of a doing that is irrational and does not strive, as far as possible, at self-understanding. But knowledge itself has been seen to be something more than mere thinking. The rather is it an attitude of the entire cognitive soul toward the reality with which the soul has commerce in the act of cognition. If those who "dabble in the fount of fictive tears" and thus "divoree the feeling from her mate the deed," fail of the highest truth, so also do those who forget the question and answer of Goethe, "How can a man learn to know himself? By reflection never, only by action." It is by laving actual transactions with, by handling, as it were, ourselves and other things, that we know that we and they are, and what we and they are. ${ }^{1}$ From

1 Compare Psychology, Descriptive and Explanatory, pp. 512 f. 
this point of riew it is not mere juggling with words, when it is claimed that the practical confidence of men in their cognitions of themselves, of other men, and of the world of things, gires the lie to all professions of a sceptical idealism or of a complete and consistent agnosticism.

"There is no Unbelief!

Whoever says to-morrow, the unknown, The future, trusts that power alone

Nor dares disown."

Nor is such faith to be spoken of as though it were a foreigner that can find "room" in the mind only after knowledge has been "remored." It is the handmaid of knowledge. And the deed which it motires, and the reward which follows only upon the deed, are the fitting expression and appointed adjunct to the growing life of cognition. 


\section{CHAPTER XIV}

\section{ALLEGED “ANTINOMIES"}

7 HERE is only one conceivable way in which the most knowledge could end in complete agnosticism as to any trans-subjective value for the functioning and the products of our cognitive faculties. To follow that way one must demonstrate beyond doubt the existence of genuine "antinomies" in the very heart of reason itself. Perhaps, however, the theoretical outcome of the employment of reason as compelled to be self-critical, but doomed to reach so unhappy a conclusion, would better be described as a peculiar kind of scepticism. Dogmatic universal agnosticism it could not well be; for, as has been shown in the preceding chapter, such agnosticism affirms a vast amount of assured cognitions, although in a quasi-unconscious and self-contradictory way.

But suppose that the ultimate result of our critical inquiries - incited, urged on, and guided by a restless and determined spirit of doubt - is the discovery of fundamental and irresolvable contradictions, both of an epistemological and of an ontological reference. Suppose, on the one hand, that we find the very laws of our own cognitive life compelling us to think or believe truc what they themselves, when considered from other and equally tenable points of view, show cannot possibly be known to be true, or what must even be held to be false. Suppose, on the other hand, that the Reality which appears to be given to us, with clearness and self-consistency, by certain forms of cognition, shows to the more searching analysis of 
philosophy certain inherent and irremovable contradictions. For example, It must be known as both "One" and "Many," - in meanings of these two words which are carefully adapted to make them positively inapplicable to the same subject. Or, It must be known as never changing or in any way subjected to the differentiations which the phenomenal reality of things displays; and yet also known as ceaselessly changing and as itself the subject and ground of all change. Or, again, It must be known as Absolute in the sense of being wholly unrelated to aught else and quite incapable of any self-differentiation which shall bring it into a system of self-relations; and yet also known as the subject and ground of all relations. Or, once more, It must not be known or thought of as personal, because personality is essentially limitation; and yet every applicable conception which we can possibly form in our most happy moments of insight and aspiration, as a matter of fact is, and as sound doctrine of epistemology must be, taken from our experience with our own self-known Selves.

Now, it is tolerably plain that any issue to the process of sceptical inquiry similar to the several conclusions given above might possibly force this alternative upon the mind experiencing it: either resolutely to maintain the sceptical as distinguished from the dogmatically agnostic attitude, or else to get orcr into the attitude of affirmation in some other than the critical way. It is a fact of no little epistemological significance in the history of philosophy that most reflective thinkers have preferred to esponse the latter nember of this alternative. Reasons for this fact, which lie deep in the nature of man, are not wanting. It is not a pleasant or satisfactory condition for the human mind to be consciously turning over and over the problem of knowledge,-like a squirrel pawing a revolving cage, and looking through the bars upon tempting fields outlying, but with the conviction that cage, and outlying fields, and the being who is ceaselessly turning and looking are all alike parts of one phantasmagoria. Both 
the heart and the mind of man revolt at this. But nothing else is strictly logical for one who discovers " antinomies" in his own cognitive faculty - in the most appropriate meaning of that much abused and ambiguous word. Just here, therefore, the influence of practical considerations is apt to become very strong. The way out of the cage seems, in some sort, to open for "faith;" or else the necessity, if not the rationality, is discorered of acting as though the truth were on one side or the other of the still unyielding antinomy. This practical solution of the alleged antinomies of reason is apt to be accomplished either with considerable show of violence and some scornful reference to the futility of metaphysies as an ontological affair; or else it puts forth the sweet assumption of superiority to all considerations of a merely reflcetive kind, and poses as an attainment of great ethical and religious value.

It scarcely need be pointed out to any one who lias thoughtfully followed the course of our critical investigations up to this point that we cannot accept such an alternative without abandoning all the best results attained by these investigations. To speak truth, we have scant respect for the alternative. We do not find ourselves forced to take it, or to adopt any other form of a similar alternative. For we believe that all such "antinomies" - that is, all alleged contradietions in the fundamental laws of cognition, or as between those "categories" whose ontological application is necessary to the construction of a conception of the really existent World - are fictions of the critic's imagination. In other words, they are only spurious antinomies. This negative conclusion, with its justifiable scorn, in answer to the agnostic scorn for metaphysies, or to the weakly sidling out of the diffienlt path of criticism into the refuge of a merely emotional and practical faith, is defensible on grounds of history. As to the "family of faith," we, too, claim an inalienable right to be counted among its members. As to "confidence in reason," 
it is a reasonable and prudent confidence of this sort which has been confirmed and expounded by following the course of a presuppositionless criticism. As to a proposal to "divorce" the two, we will hear nothing of it. No irreconcilable quarrel has yet been discorered between faith and reason, but rather, their indissoluble union in the very nature of the cognitive process itself. And the history of human reflective thinking shows that the mind of man, both in the actual development of knowledge and in its maturer judgment respecting the theoretical outcome of a criticism of knowledge, does not rest in this alternative.

The full historical disproof of the existence of real antinomies in the cognitive functions of the human mind, or in its reasoned conception of the really Existent, cannot, of course, be undertaken in this treatise. We shall, however, make a somewhat careful testing of several alleged examples as proposed by two writers on this subject. Of all critics who have discorered antinomies in human reason as the result of a critical examination of its nature, Kant is undoubtedly at once the most thorough, subtle, and seductive, if not convincing. It would be difficult to put the doctrine of antinomies into a more defensible form, whether as regarded from the theoretical or from the practical point of view, than that giren to it in the "Transcendental Dialectic" (the "logic of illusion," Die Logik des Scheins). The recent work of Mr. Bradley on "Appearance and Reality" propounds a similar doctrine in even a more unmistakable, but cruder and less elaborate form. One or two of the special examples brought forward by these two adrocates of irreconcilable contradictions in the faculty of cognition as applied to extra-mental Reality will suffice for illustration and enforcement of our negative position toward all antinomies.

The examples both of Kant and of Mr. Bradley are not antinomies at all ; they are, rather, spurious contradictions which can always be got up when abstract conceptions of more or less 
doubtful empirical origin and of perverted or mutilated construction are hypostasized and brought into relations that are themsclves either fictitious or abstracted inconsiderately from the relations of real individual things. Of other examples that might be culled from history, - for they grow thick enough along either side of the path of epistemological criticism, there would seem to be no need. Conclusions like those found in the unhappy and largely absurd attempt of Dean Mansel to recommend faith in God by involving the conception of Him as Absolute in hopeless contradictions may well enough be left to feel the force of the treatment accorded to this particular example by John Stuart Mill ; for, although this quondam positivist left a posthumous declaration of his personal faith in God, he freely and indignantly consigned himself to eternal perdition rather than believe in such a Divine Being as the juggling of ecclesiastical agnosticism had commended to him.

But before illustrating our unequivocal denial of all alleged antinomies, it is necessary to review briefly the affirmatire position to which the critical process has led us. It has been made clear that while, from the psychological point of view, every cognition is a process in consciousness, and subjective both as to content and function-wise, no cognition is merely subjective; on the contrary, the very nature of cognition, epistemologically considered, is trans-subjective and ontological in its reference and its implicates. Speaking with a broader and more inclusive view before us, experience is indeed always capable of being represented as, for every individual mind, its very own and no other. And yet, in every cognitive experience, it - that is, the experience considered as a single " moment" in the flux of consciousness - is itself transcended. No cognition is of itself as a mere momentary state; it is of some existence which must be regarded as not dependent for its being upon that state. The possibility of transcending experience by knowledge can be denied only if we refuse to enlarge the meaning of experience itself so as to include both 
the implicates which criticism of the processes of knowledge discovers, and as well the legitimate conclusions, as to the nature of the Self and of Things, which result from the thinking that enters into all cognitive experience. So that when scepticism seems about to bring us to the position of complete agnosticism, or of the positivism which denies the possibility of transcending experience, it always destroys itself in the depths of absurdity to which it has sunk.

In connection with this critical result, the transcendental use of the so-called "categories" is vindicated. Among these categories Relation and Change are, in some sort, supreme. We know that relations really are, and that changes actually take place. Indeed, this proposition is not itself debatable and matter of argument; but to dispute it is to enter upon an absurd attempt, by an affirmation of nescience, to overcome, in making the affirmation, the constitutional forms of cognition itself. What it is "really to be related," and what it is "actually to change," is given in the indubitable experience with the Self, as really changing its own states in dependence upon immediately cognized or reasonably inferred relations to things. But if to dispute the trans-subjective reference and validity of these categories is absurd, to explain them in terms that are simpler and more intelligible is impossible. All explanation, in other words, assumes and makes use of the same categories; and all explanation makes use of them with the assumption that they are valid in reality. Now, this concrete reality, really related and actually changing, is the reality which we immediately and indubitably know. Reality - in general, and spelled with a capital $\mathrm{R}$ - may be a mere abstraction; and to oppose it to the known reality, after the latter has been degraded by calling it "Appearunce," may be equivalent to an act of highway robbery. Such an act is no less indefensible because the proceeds are subsequently handed orer to some ethical or religious Reformatory. But if the question be pressed, What further is this Reality, thus known 
as really related and actually changing? we can only answer: "It is the Self and that which the Self knows, both negatively as not-self and positively in so far as it appears analogous to the Self, - in an indefinite variety of relations and an endless series of changes."

The detailed reconciliation of this transcendental use of the categories of relation and change with the conception of something permanent and unchanging, belongs to a critical metaphysics. But the detailed examination already given to the principles of identity and of sufficient reason, not only in their logical and subjective aspects but also in their ontological and trans-subjective references, forlids that conceptions of Substance, Law, Identity, Unity, Causal Nexus, etc., should be so constructed as to create antinomies between them and the concrete facts of the life of cognition; that is, valid conceptions of substance, law, identity, unity, causal nexus, etc., must be framed upon the same basis of cognition as that in which are employed, so to speak, the categories of relation and of change. Speaking in a more general way, contradictions cannot be theoretically introduced that do not actually find themselves resolved in our cognitive experience with ourselves and witl things. This known world is known; it is known really to be. Antinomies between it and the world of abstract thinking - whether conceived of as oppositions and contradictions between "phenomenal reality" and "noumena" (Ding-ansich), or between "Appearance" and "Reality" — are not genuine antinomies. And if agnosticism is to return upon us in the shape of rational antinomies, then, as was said of the unfortunate into whom an increase of demons entered, "the last state of that man is worse than the first."

This brief résumé, however, is quite sufficient to remind us how the appearance of irreconcilable contradictions may emerge to a criticism that is one-sided, and that fails to grasp the essence and the significance of knowledge in its totality. For here, it may be said, is the very hearth and source 
of antinomies: Knowledge is subjective and yet trans-subjective; it is intra-mental phenomenon, and yet it implicates extra-mental reality. The categories, or modes of the functioning of mind in all knowledge, are capable of being regarded as purely formal; they afford themes for psychology and logic to discuss, just as though no question of a real world were anyhow implied in the discussion. Yet some at least of these so-called categorics are the very essential and inescapable forms of all the reality about which aught can be known or even conceived.

We may not indeed affirm off-liand that the Reality is just as we find ourselves compelled by the laws of our understanding to think it; but what that is unthinkable and inconceivable can lay any claim, at the door of either our understandings or our hearts, to a place in our world of real beings and of actual transactions? Now, if the terms for such oppositions as these are correctly understood, they suggest different modes of regarding our one cognitive experience, instead of irreconcilable oppositions in the very nature of that experience. The antinomies which they suggest are solved practically, up to the limit which marks off the agnostic attitude toward the foundations of all experience, by every special act of cognitive experience. To know anything is to solve these antinomics. For every act of knowledge may - nay, must - be regarded as both subjective and trans-subjective, intra-mentål phenomenon, and extra-mentally referent. Each cognition is an individual, concrete experience which transcends itself, regarded as individual and concrete. It gives to consciousness some portion of the world as its idea; and also as other and more than its idea, - as Reality in action over against the ideating Self.

Now, if certain abstract statements or laws seem to follow from the facts of cognitive experience, which appear to be contradictory or "antinomic" in the deeper meaning of that latter word, we shall do well to remember: "Actuality has 
ways and means to make that possible which looks to us as though it were afflicted with irreconcilable contradictions." This practical solution of seeming contradictories is actually accomplished by the human mind for itself every time it posits, in a feeling-full and voluntary way, a cognitive judgment. Body and soul, the Self (as it were, intellect, fceling, and will), takes possession of the extra-mentally real, and makes it its own. Hence the agnosticism of the idealist or positivist who denies the actuality of this reconciling experience must be satisfied to place its own alleged antinomies upon a basis of logical abstractions which, in their turn, have no other ground than these very acts of cognition that afford the practical solution of all such antinomies.

Ordinarily, however, the antinomies proposed by the sceptical critic are not the products of so deeply seated a disease. They are not even to be considered as "antinomies" at all in the sense in which their discoverer would have us believe he uses this word. This observation fitly leads to a brief discussion of the several possible kinds of contradiction which may be found lurking in the alleged cognitions of men. That facts of cognitive experience, quoad facts, can contradict each other, no one would think of claiming seriously. Statements of alleged facts may well enough be found in irreconcilable opposition to each other. But this is the opposition of truth of fact to error in matter-of-fact, or of one error in matter-offact to another, rather than an antinomy properly so-called. Science encounters innumerable such contradictions, as does also our ordinary practical knowledge ; and the smooth progress of knowledge is much embarrassed, while its solid and matured growth is fostered, by them. Conceptions, too, when framed by different minds upon the basis of fundamentally similar and yet, after all, exceedingly various facts of experience, may contain opposed or contradictory elements. So that not only may men, without conscious lying or error, affirm, the one, "It was so," or, "So he did," and the other, 
"It was not so," or, "So he did not," but they may also express their most deliberate judgments as to the constitution and behavior of familiar things in quite squarely contradictory terms. Nor does the recent rapid progress of the physical and psychological sciences seem to diminish, but rather to multiply and to intensify these opposed conceptions. The highest and most comprehensive conceptions, the most general and demonstratively assured laws, of these sciences are all capable of being filled with apparent contradictions, if only the limits of their accuracy in application and the tentative and fluid nature of their constitution be disregarded. Indeed, if one choose to look at the matter thus, - and this is a permissible and even fruitful manner of regarding it, - all growth of knowledge depends upon the principle of contradiction being active in a very comprehensive and lively way. I do not conceive of anything now in such manner as to escape all contradiction of my conceptions of twenty or thirty years ago. "When I was a child, I spake as a child, I understood as a child, I thought as a child; but when I became a man, I put away childish things." Of every individual and of the race it must now and always, we doubt not, be said: "For we know in part, and we prophesy in part." Not once for all, but always and continuously, is the hope of the individual and of the race: "When that which is perfect is come, then that which is in part shall be " - contradicted partially, and largely transcended, and so - "done away."

In some sort, all specific orderly arrangements of the results of the observation of facts are liable, and even certain, to be contradicted by similar arrangements of other facts, or even of the same facts looked upon from other points of view. No law (or nomos) gets realization in the world of experience without limitation, opposition, and contradiction from other laws (or nomoi). Laws, when set into actual operation by the behavior of real beings, ineritably reveal 
their inherent oppositions (are anti-nomoi). For real beings do not actually divide their qualities according to the terms in which we describe them; nor are their transactions actually separable according to the forces and laws which we speak of as " seated in" or "ruling over" them. Why, for cxample, does not the projecting part of the coping stone fall, in obedience to the law of gravitation, from the top of yonder building? Because, as physics declares, the forces of cohesion, acting under quite different laws, thwart and oppose, for the time being, the law of gravitation. In the reality itself, the law of gravitation and the laws of cohesion exist as antinomies (nomoi that are anti-nomoi). But now, after a frosty night, the coping stone actually breaks off and tumbles to the ground; for that unique law which makes water expand forcibly at $32^{\circ} \mathrm{Fahr}$. has contradicted the laws of cohesion and has restored to the law of gravitation its temporarily suspended rights over this mass of matter.

As science rises in its observations and generalizations from the relatively simple and more massive forms of the being and behavior of real things to the more complex and molecular or atomic, it is obliged to posit a great variety of new forces which act against the unrestricted reign of those laws that suffice to express what belongs to the simpler and more massive forms. The picture which the chemico-physical view of the world presents to us is an indefinite exemplification of the antinomic action of various forces so-called. Indeed, the specific qualifications of those elementary physical beings, the atoms out of which chemical science gets the orderly construction of actuality, consist - to the extent of fully one half their entire content-in just this: they can, in accordance with laws of their own, contradict each other in their common strife after fitting partners with which to make a temporary combination. But molecules and atoms are all constantly united in contradicting the more primary laws of physics. Chemical laws and physical laws, in actuality, are antinomies. 
The pitiful failure of the modern effort to make out of biology a purely chemico-physical science affords numberless other illustrations of the same truth. And the effort to establish a theory of mental life in terms of the combination and differentiation of sensations and ideas is, eren now, giving tokens of a yet more pitiful failure. Whenever I do anything with a conscious motive in view, I put myself in opposition to the uninterrupted action of the merely chemico-physical and the psycho-physical mechanism.

$\mathrm{He}$, however, who denies the possibility of knowledge, or the possibility of the existence of a unitary system of things, because human knowledge of things is an unceasing recognition of the immanence of many conflicting forces acting under laws of opposition and resistance (laws, that is, which when brought face to face seem to be antinomies), reasons falsely and goes quite wide of the true state of the case. For it is just in the recognition of the facts of opposition and of the modes of the actual behavior of things under conflicting laws that quite one half of all our knowledge consists. Moreorer, it is only while maintaining their own specific being, and refusing to be identified throughout with one another, that these many Things make up the Unity of the World.

If now any one is offended because this fair and orderly cosmos has just been accused of being full of antinomies, he may perhaps be appeased by thinking out more clearly what is meant by "laws," and in what sense laws can be "opposed" to one another ; in what sense, that is, "antinomies " can exist for critical discovery and recognition. At present it is sufficient merely to note that the word "law" simply means a more or less uniform mode of the behavior of things, as looked at from one chosen point of view. But, in reality, no thing is so mean or so restricted in its equipment of capacity for doing and for suffering that it can ever be satisfactorily considered from one point of view simply. Every Thing - according to the very terms of the hypothesis - is one thing; and what 
it is now doing is one specific transaction under definite terms of relation to many different things. But the real being of each thing is infinitely complex; and its actual doing may be considercd under an indefinite number of relations, from an indefinite number of points of view. What falls into contradiction is our abstractions; and this they always do if we inconsiderately plump them down as though they were the sole measures of the real, even as it is known to us. The fact that antinomies thus emerge does not discredit human knowledge; the rather is it proof of the richness and variety of human knowledge. Nor does it show that there can be no reality answering in any way to our system of cognitions; the rather does it show the infinite richness and variety of content belonging to Reality, as not simply answering to, but far surpassing the terms under which it is known by man. The further exposition of this subject, too, must be left to the details of a critical metaphysies.

When, however, the question is raised whether antinomies exist in all knowledge, and so in all reality as known to us, the answer must assume a different form. Yet the form appropriate to this answer has already been suggested. Whenever antinomies of this sort and extent in their applicability are propounded as a result of the criticism of cognitive faculty, the exercise of this faculty by the critic himself must be subjected to a careful revisionary criticism. For it may turn ont that the alarming noise is merely the result of the petrified abstractions of the critic which are meeting in midair and exploding each other; and this surely may take place without great actual damage either to human knowledge or to the world of the extra-mentally existent which is given in this knowledgc. One may then return more calmly to the belief that truth is to be had by right exercise of human cognitive faculty. One may even get increase of conriction that no truth has anything to fear from other truths; while illusion and error - no less in the higher regions of philosophical 
criticism than in the denser air of ordinary sense-perceptions - have every truth to fear. Then, too, Truth may come to mean again what it always has meant to minds undisturbed by epistemological scepticism or agnosticism, - namely, mental representation which affords a valid cognition of the being and transactions of Reality. Such revisionary criticism of the antinomic conclusions of a previons sceptical criticism we shall now briefly attempt - as was promised above - in the two following cases.

The claim made by Kant that the purpose of his critical examination of man's cognitive faculty was the remoral of knowledge (rather the illusory pretence of knowledge) in order to "make room" for faith (in God, Freedom, and Immortality) has not, of late, been sufficiently credited. The sincerity of this claim is, however, beyond reasonable question. It is proved by his own declaration, by the many indications in the "Critique of Pure Reason" which look forward to the "Critique of Practical Reason," and in the latter work, which look backward upon the earlier work, and also by the very bulk and chosen method of the "Transcendental Dialectic." The "Transcendental Logic" is, indeed, that part of the "Critique of Pure Reason" which has excited interest and promoted hermeneutical discussion, far out of proportion to its size. But the relatively condensed form in which Kant left it, and the changes which he made in the second edition for the avowed purpose of increased clearness and of defending its doctrine against the charge of sceptical idealism, indicate that Kant himself regarded this part of his "Transcendental Logic" as only subsidiary to his main critical intent. This intent was chiefly, then, to establish beyond controversy the doctrine "of a logic of illusion" (eine Logik des Scheins). It is in this doctrine that the resolve of its author to "make room" for faith comes to a culmination with the sceptical conclusion: All cognition of noumena is, by the very constitution of the mind, forever rendered impossible. Here the 
critical examination of those processes by which the mind thinks to gain a knowledge of Reality shows that these processes are, in their essential nature, deceptive. The "dialectic of pure reason" is declared to be "natural and inevitable ;" its illusion is "inherent in, and inseparable from, human reason;" and "even after the illusion has been exposed," it will " never cease to fascinate our reason." But such dialectic is an illusion, utterly and forever incapable of telling us any truth about the real Self, or the actual World of things. The reality we know is but an appearance of reality (phenomenal reality); the actual reality - if so uncouth a phrase may be pardoned - is unknown and unknowable, whether our minds strive toward a satisfactory knowledge of Self or of Things.

It is not our purpose here to discuss thoroughly the general positions of the "Transcendental Dialectic." Indeed, the most important of them have already been considered, either with or without direct reference to Kant. But whatever view may be held as to the other significant aspects of the epistemological problem, the success of the critical effort to establish antinomies, in the Kantian sense, would have the effect which their original proposer intended that it should have; it would destroy forever the possibility of knowledge in the sense which we have found ourselves compelled to give to that term. According to Kant the reason of all men is afflicted with a constitutional and incurable tendency to start from something which is known, and by false syllogistic processes conclude " to something else of which no conception ever can be had, but to which, under constraint from an inevitable illusion, there is, nevertheless, attributed objective validity." Thus do all cheat themselves who suppose that they know the truth about the real nature of their own souls, of the world of things, and of "a Being of all beings," whom faith calls God. All these phrases stand not for concepts based, in a valid way, upon a real cognitive experience; "they are 
sophistications, not of (individual) men, but of pure reason itself, from which even the wisest of men cannot escape." Kant's main object is to show that they are indeed sophistications; and that the syllogisms by which these conceptions are reached, form a species of juggling rather than a trustworthy activity of reason (eher vernünftelnde als Vernunftschlüsse zu nennen). Both reasoning and conceptions, as established by the reasoning, are involved in hopeless internal contradictions.

For our present purpose it is not necessary to distinguish between the epistemological and logical standing of the "paralogisms" and that of the "antinomies" of pure reason. Both are given as instances under the agnostic conclusion of Kant's sceptical examination of human cognitive faculty. The knowledge which the soul has of its own real being, or rather fancies itself to have, is reduced to an "inevitable illusion" of reason "which drires us to a formally false conclusion;" because we are continually substituting a conception of the soul derived from the mere form of thinking, under which it appears to itself, for its nature as really existent. Thus the application to the soul of the categories of substantiality, unity, and relation to things, is a work of illusion. But the contradictions which Kant finds inherent in these so-called paralogisms are all put there by him; they are the products of his own tendency to substitute formal and seductive abstractions for concrete and content-full realities. Such substantiality, unity, and relationship to possible objects in space, as he declares that reason attributes inevitably to the soul, may well enough for the most part be denied. But the real illusion, on the part of both Kant and of the theologians whom he controverts, consisted in attributing their arguments to a necessity of reason. It is not, therefore, a criticism of all reason which is needed, with a view to detect its indestructible, illusory dialectic; it is only a criticism of certain awkward and self-contradictory conceptions, as applied 
to the soul, which shall result in substituting for these conceptions others that are formed upon the basis of our actual cognitive experience.

The alleged contradictions of reason to which Kant himself gave the name of "antinomies" have been so often subjected to criticism and their fallacies pointed out, that it would be threshing straw already many times under the flail to criticise them in detail over again. Let it not be forgotten, however, what precisely is the conclusion which Kant wished to prove from them. Not only must both Thesis and Antithesis of each antinomy appear plausible and even true, but both must spring up ever afresh and alike inevitable and convincing, so often as the attempt is made to square our cognitions with the reality of Things. For what the proof pledges itself to accomplish is precisely this: Thesis is irresistibly concluded by a constitutionally fixed ratiocinative process embedded in the very faculty of cognition; antithesis is concluded in the same way; thesis and antithesis are evenlymatched contradictories; therefore - reason is honeycombed with antinomies, and knowledge of Reality is impossible. Now, in no one of the four Kantian antinomies can either one of these pledges be made good. In two cases both thesis and antithesis are only probable at best, but with varying degrees of probability; in two cases the thesis and the antithesis are not fairly opposed; in no case can both be said to be proved as inevitable illusory conclusions of reason; in no case, therefore, is the doctrine of antinomies established in a form to justify the accusation of a transcendental illusion inherent in all human knowledge of the world of real things. Indeed, the admissions of Kant limself with regard to the third and fourth examples virtually abolish their character as contradictions of a rational kind.

In the case of the first antinomy, if by "World" (Die Welt) be meant the stellar universe as at present known to us, the thesis is much more probable than the antithesis; but for 
neither is there any a priori proof. Properly speaking, pure reason tells us nothing upon this problem sufficient to demonstrate (Beweis) either thesis or antithesis. But our growing knowledge of the system of things seems more and more clearly to indicate that " the World," as known, is now in such condition as to imply that its extent is limited, and that it began to be, although an indefinitely long time ago. Against this conclusion, our ignorance of how the world began to be is no "proof"; neither is our inability to conceive of past time in which the World was not (eine leere Zeit) a ground of legitimate inference. Indeed, this very inability is something that Kant himself seems to call in question, when, in the "Transcendental Asthetic," he declares that "we can well take away phenomena out of time." Our inability to represent things as existent out of space and time, instead of being the source of an illusion, is the result of the fact that our positive cognitions of things are in space and time. What it is really to be in space and time, and how a world of things can be conceived of as beginning to be in space and time, are questions of speculative metaphysics, the answer to which must be made to depend upon concrete and valid cognitions of things, if answer is to be given at all. Nor, if it should be found that agnosticism is the only attitude toward these questions, does it follow that reason is full of antinomies, and that the knowledge of things, in any respect as they really are, is impossible.

The second example of the "antinomy of pure reason" is so far-fetched and inconclusive that it seems as though Kant must have invented it purely in the interests of a spurious architectonic symmetry. Its obvious fallacies are its author's own; they cannot be fathered upon the productire energy of " reason in general." The conflict is one which results from confusing our perceptions and corresponding mental representations of concrete experiences about things with abstract and purely mathematical concepts of the formal conditions of 
space relations - abstractions treated as though they were realities. "The entire antinomy," we agree with Adickes in saying, " has originated solely out of a confusion of concepts." Space, abstractly considered, may be theoretically treated as though it were indefinitely divisible; indeed, it must be so treated. When space is treated in this way, our sums in the pure mathematics of space "prove" themselves in accordance with the principles of such proof. But that things are not infinitely divisible is the present conclusion of those chemico-physical sciences which are based upon observation of the actual modes of the behavior of things.

The thesis and the antithesis of the third example of an " antinomy of pure reason" are so full of faulty conceptions and inconsequent argument as to require a detailed treatment of the doctrine of causation in order properly to criticise them. It is well known to students of Kant that his own conception of causation was ambiguous and changeable. As a mode of the functioning of pure understanding the conception gets (as has already been pointed out) a wholly unsatisfactory treatment in the table of the categories. But "other" causation than that which is here denominated "according to the laws of nature" is assumed as the source of "that which is given" in Kant's own account of the origin and nature of sensuous experience; while his theory of the nature and grounds of the life of conduct, and of the teleological interpretation of the world, finds itself obliged freely to postulate such other causation.

There is little doubt, however, that discussions of the socalled "self-determining power" of the Self (eine Kausalität durch Freiheit) are particularly fruitful of apparent antinomies. Here theology discovers its irreconcilable contradiction between the divine foreknowledge and predestination, on the one hand, and the imputability and spontaneity of human personality, on the other hand. No small part of the most persistent difficulties which philosophy finds in its en- 
deavor so to construct its conception of the "Absolute," the "Ultimate Reality" (or whatever other term it may choose for its final attempt at synthesis) as not to impair the legitimate grounds of ethics, first appears in connection with its analysis of the causal principle. Indeed, the experience of every individual man, as well as the experience of the race, involves both sides of this so-called antinomy. The tragedy of life, its conflicts, defeats, and victories, is fraught with the same experience. The outcry of humanity is this: "I find then a law, that when I would do good, evil is present with me;" and - "I see another law in my members, warring against the law of my mind." This is the great antinomy, or conflict of laws (the nomoi that run anti), under which the moral derelopment of the individual and of the race takes place. And according as the Self, aroused and enlightened, throws the weight of its choice, and of the influence resulting from choice, upon the side of one law or the other, the issue of the antinomy is actually decided. On the one side is a law, or a system of laws, that binds the Self within the confines of what we call Nature, - working blindly and in fixed mechanical fashion along a seemingly endless chain of causes. On the other side is another law which, with an equal absoluteness of imperatire, sets before the Self a course of conduct, to follow which demands breaking over the limitations of the former law, in the effort to realize its own destiny through conscious fidelity to an ideal. Between the two laws, as it were, and under perpetual limitations from them both, stands the Self and exercises its choice. Thus it becomes, from the ethical point of view, either more and more enslaved by the one law, or more and more free by habitually choosing to follow the other law. This is, indeed, a picture of actual experience; perhaps no one else has more forcefully presented it than has Kant himself. It is undoubtedly, by its very nature, a description of a conflict-and, eren, in some sort, of a contradiction - of ruling principles which forces us 
to the agnostic position in respect of its satisfactory understanding, but which is practically solved by all men in the courses of conduct which they pursue.

But this is not, as Kant claims, an Antinomy of Pure Reason, an irreconcilable contradiction of thesis and antithesis, which spring alike out of the very nature of cognitive faculty, and yet are both equally invincible in their appeal to "proof." The appearance of this sort of an antinomy is remored, when the origin, nature, and legitimate applications of the conception of causation are correctly understood. It is thus shown that our conceptions of "causality, according to the laws of nature," and of " another causality, that of freedom," both originate in one and the same experience of the reflective Self. 1 Both are true, in so far as they are formed in recognition of the fundamental facts of that cognitive experience in which they originate. They become apparent contradictions, inherent in the very life of reason itself, only when one (or both) of the two conceptions has been framed in disregard of our total experience, has been hypostasized, and then illegitimately extended for the explanation of what requires them both to be kept in mind. Here, too, as everywhere else, explanation is limited by the inexplicable; the analysis of cognition leads to inquiries before which the agnostic attitude is alone reasonable.

In the fourth example of "the antinomy of pure reason" both thesis and antithesis are products of such complicated and doubtful speculative efforts that, in the form in which Kant here states and "proves" them, they can no more be charged to the account of human cognitive faculty in general than can the $a$ priori system of physics which, in the Transcendental Logic, he also takes for granted as rationally necessary truth. How much confidence in the Absolute it is necessary to attribute to reason, and to make use of in the very structure of

1 See Psychology, Descriptive and Explanatory, chapters xxi. and xxvi., and Philosophy of Mind, chapters vii. and viii. 
knowledge itself, will be briefly considered later on. Indeed, from this point on the entire "Critique of Pure Reason" becomes, more than before, a series of doubtful speculative propositions of a negative and sceptical kind, set over against other spcculative propositions, rather than a genuine criticism of human cognitive faculty.

The recent work of Mr. Bradley follows the method of Kant in one important respect. It is an acute and determined attempt to set forth the inherent contradictions that afflict our mental processes in their claim to form true, as distinguished from merely logical, judgments. Unlike Kant, however, Mr. Bradley does not avowedly aim to "remore knowledge" in order "to make room" for faith - in God, Freedom, and Immortality. The rather does he strive to destroy confidence in all human cognition of things as they "appear" to us, in order to make room for a theoretical and speculative construction of Reality, of a highly scholastic sort. Under the title of "Appearance," the whole world of minds and things, as actually known to man, is discorered to be a collection of irreconcilable contradictories. The solution of these contradictions is to be found in a certain conception of Reality. This conception is supposed to be framed, not on a basis of confidence in the truth of experience, whether cognitive or practical, whether of knowledge or of faith and conduct, - but in the speculator's power to absorb the contradictions into the structure of an abstraction. " $A p$ pearance" is made a term to cover all the realities of which, or about which, we have knowledge; but appearance is denied reality because it is, eo ipso, self-contradictory. "Reality" is then speculatirely constructed, with the utmost disregard of all our actual cognitions, either of or about any known realitics. It seems then that, while Mr. Bradley in his destructive effort agrees with Kant, in his constructive result he only sets up one of those very products of speculation as to "Reality," which Kant deemed mere negative and problemat- 
ical concepts and intended to render forever "hors $d u$ combat" for all truly critical minds.

Again, a protest is entered against this entire way of conducting mixed epistemological and metaphysical discussions. If the work of criticism ends by dismissing man's cognitive faculty from the front door, by reason of a complete loss of confidence that it can give us the truth of Reality, no valid idea corresponding to this term can be surreptitiously introduced by the back door, either in the name of faith or of philosophic speculation. If knowledge is not for all men something other than an "appearance," then all academic abstractions are forever prejudged; they present an absolutely worthless claim when they mark themselves with the label of "Reality." If the common categories, in that fundamental use of them which every cognitive judgment illustrates and enforces, are in no wise valid for the really existent world, then all the criticisms of scholastic epistemology and the speculations of scholastic metaphysics are no better, "truthwise," than a madman's dream.

But, as has already been declared, we do not admit the existence of antinomies, or contradictions eitlier of fact or of law, so inherent in the very life of cognitive faculty as to destroy its power to present us with a trustworthy picture of Reality. So far as alleged antinomies are actual, they belong to the very nature of human knowledge as positive and worthy of confidence; they enlarge the true picture of the nature of the actual World. But, for the most part, thoy are only alleged and spurious; they are due to the faulty abstractions of the critic; and this seems to us to be eminently true of Mr. Bradley's doctrine of antinomies.

The most convenient example, perhaps, to select for testing Mr. Bradley's agnosticism with refercnce to the ontological applicability of the categories is that afforded by his chapter ${ }^{1}$ on "Relation and Quality." The antinomy which he here

1 Appearance and Reality, chapter iii. 
wishes to establish is stated by him as follows: "Relation presupposes quality, and quality relation. Each ean be something neither together with, nor apart from, the other." While, then, they are the necessary forms of all our knowledge of "appearance," - a term which covers, in the author's use of it, the entire field of all concrete realities, both Self and Things, as we seem to know them in their actual relations, - "the ricious circle in which they turn is not the truth about reality." If we may throw this inherent contradiction into somewhat more definitely antinomic form than Mr. Bradley himself has given it, we may put the sad case of our cognitive faculty thus:- Thesis : qualities are unintelligible, are nothing, without relations ; antithesis : qualities, taken together with relations, are equally unintelligible and incapable of giving the truth of reality. Therefore, our cognitive faculty, which, confessedly, must know the Self and all things as having qualities and standing in relations, is shown to be afflicted with such inherent and irremovable contradictions that it can give no "truth about reality." Thus is accomplished the object of this chapter, as of every other chapter in the first Part of the entire work (Book I. Appearance),-namely, "to show that the very essence of these ideas is infected and contradicts itself."

Now we unhesitatingly contend that the thesis of this antinomy, when its language is rendered intelligible by being adapted to express the facts of our actual cognitions, is neither metaphysically unintelligible nor infected and self-contradictory in respect of the essence of its ideas. But the antithesis is unintelligible, either becausc its terms must be left as barren abstractions that have no ground of standing in our actual experiences, or else because they are made to be infected and self-contradictory by having a meaning put into them which they need not bcar. Both thesis and antithesis are faultily expressed. For while the naïre and commonsense meaning of their terms has been transcended, the meaning which those same terms come to hare to a con- 
sistently critical epistemology and metaplysics has been either obscured altogether or expressed unhappily. "To find qualities without relations is surely impossible," says Mr. Bradley; and to the truth of this proposition one may assent, while demurring at the abstract form, with its implication that qualities and relations might be conceived of either as themselves realities, or as some sort of appendages or superficial qualifications of reality as it appears to us.

By the term "Quality," as applied to things, men always mean to designate certain facts of cognitive experience which require, and admit of, further analysis. The qualities of things are those immediately known or inferred modes of their behavior, both active and passive, by which we classify them (sort them out according to the ways in which they answer the question, Qualis?), recognize them when we meet them again, and so adapt our conduct with respect to them. This conception of qualities - not as themselves existing, either " together with" or "apart from" relations, but as the modes of the being and doing of realities - is a complex conception. It summarizes, in fact, a number of the so-ealled categories. To argue about it as though it were some simplex, stuck to the thing or inherent permanently in it as in a core of abstract reality devoid of qualifications, is true neither to popular impressions nor to eritical metaphysics. When we hare analyzed the conception of quality, we do find that it, like all those conceptions which enfold the conerete facts and ultimate laws of knowledge, involves much that is mysterious, - much before which, unless we can rise to the higher and more ideal points of view, we have to maintain the agnostic attitude. But this is a very different thing from accusing this idea of being, in its "very essence," infected and selfcontradictory.

The complex conception of concrete things as variously qualified involves the category of "Relation." But this category does not admit of further analysis. The idea of 
"relation in general" is but an abstraction derived from a cognitive experience which always gives us reality as actually related in some concrete and definite way. On the epistemological side, then, we only recognize the very nature of the thought-process, as it enters into all knowledge, by saying that "to know is to relate." On the ontological side, we only describe the most fundamental and positive characterization of all known beings, when we affirm that they are all, in as far as known or conceivable, actually related. To deny either of these truths is theoretically to render that commerce between the cognitive subject and the cognized object, in which knowledge itself consists, quite impossible. The fullest and most ultimate experience in which our consciousness of these truths originates has already been sufficiently described. If by calling the description, or any of the ideas involved in it, " unintelligible" Mr. Bradley means that nothing more simple and ultimate than that which is stated in terms of these ideas can be said about knowledge and reality, this is true. But this is quite a different charge to bring against the activities, forms, and content of human cognition, from that of being, in their very essence, "infected" and "selfcontradictory."

That "qualities are notling without relations" is, then, true as tested by the nature of our actual concrete cognitions of things. But when Mr. Bradley undertakes the proof of the antithesis, that "qualities taken together with relations are equally unintelligible," he begins to labor heavily. In fact, his entire so-called argument seems here to go quite wide of its aim. That "nothings cannot be related, and that to turn qualities in relation into mere relations is impossible," no one need hesitate to admit. But what the critic himself makes a show of doing, is to turn the mere abstract idea of relation in general into an entity, in order to set up some kind of a deadly quarrel between it and the equally abstract and more unjustifiable lypostasis of the conception of quality. Indeed, 
is not this the "vice in procedure" which clings to all the so-called antinomies? The actual forms of the most indubitable cognition of all realities are treated as though they were themsolves realities; and they are then set into a position of contradiction which arises from the attempt to find in some one or more of them, separately, a complete account of all the forms in which the eoncrete realities reveal themselves to the mind. Surely this procedure ought not to be so easily possible after Kant's treatment of " the Amphiboly of Reflective Concepts" and of the unsatisfactoriness of all merely conceptual views of the World. ${ }^{1}$

The outcome of the discussion of this ehapter has a certain quasi-ethical significance, to which fuller consideration will be given in other connections. For human reason, even in and especially in - its work of self-criticism, must recognize its own inherent responsibilities and its undiminished regard for teleological considerations. To the critical use of reason, in some sort, applies the rule which it is so ready to eall to mind, in the case of less important individual differences: Falsus in uno, falsus in omnibus. This must not, however, be held in such way as to deny that error may mingle with truth; much less to affirm that truth is not to be attained at all if any risk or taint of error seem to threaten all human inquiries after truth. But if the entire cognitive faculty of man is, by

1 With Mr. Bradley's aims, and with many of his most important positive conclusions, we find ourselves not only in full sympatlyy but in large measure of agreement. But no ontological conclusions whatever, whether largely agreeing with, or wholly dissenting from, those at which the author arrives in his second Book (on "Reality"), can possibly be trusted, after the sceptical and agnostic outcome of his first Book (on "Appearance") has been accepted. When once the constitutional forms of human coguition have been shown to be ideas that have mere seeming, and that are in "their very essence" "infected" and "self-contradictory," there remains nothing further to be done in the way of establishing a rational ontology. Any ontology thus constructed is prejudged; it is already twice plucked up by the roots, dead and withered, before it can put in the "appearance" even of a truly rational life. And if the critic does such things in the case of the green tree of his own metaphysies, what will not the next critic do in the case of that same tree when it has already become dry? 
its constitution, compelled to think and to accept the truth of squarely contradictory principles, or to frame ideas which implicate correlated forms of the being and behavior of the really existent World, so that they shall "in their very essence " be " infected" and "self-contradictory," it is something worse than intellectual vanity to elaborate systems of metaphysics. Nor do we believe that faith will ever come to occupy the room made vacant by the removal of knowledge in this way. For experience is some sort of a unity; and unless what appears to man as reality can somehow be known as "true reality" (Mr. Bradley's strange phrase) we, as critics of the cognitive faculty, are "of all men most miserable." 


\section{CHAPTER XV}

\section{TRUTH AND ERROR}

T $T$ may seem to some readers that the trustworthiness of 1 our cognitive judgments, the value for the transcendent of our experience, and the validity in general of human knowledge, have been over-emphasized. The preliminary survey of the nature of knowledge showed that its problem is proposed to philosophy in the form of a question: How can cognition, which is, psychologically considered, a subjective affair, a mere process in consciousness, be also transsubjective or ontologically referent, so as to put the mind in possession of truth respecting Reality? From a sceptical beginning, and following carefully the critical method, positive and comprehensive conclusions have been reached. In all cognition, the reality of the Self - that it is, and what it is - is immediately and indubitably given; and the reality of Things is also given, - that they are, immediately and indubitably, and what they are, if we accept in good faith the postulate of their being and behaving after the analogy of the self-known Self. To doubt thus much is theoretically to deny the possibility of knowledge. When subjected to critical analysis the very denial is found to be inherently contradictory and absurd. All knowledge is, indeed, on the one hand, limited by barriers of accepted and experienced fact, and, on the other hand, by the necessity of responding with an agnostic answer to many questionings after reasons and causes. He, however, who, because he must often say, "I do not know," refuses to accept and 
live by the positive truths implicated in the affirmation, "I do know," will never attain to intellectual peace. He may even commit the unpardonable sin against the spirit of truth.

Moreover, the nature and growth of human knowledge is such that truth, as contrasted with error, must always be the fundamentally positive and more inclusive thing in human experience. Critics of our common faculty of cognition are quite too much accustomed to pessimistic conclusions. To take Schopenhauer's estimate of the negative results of Kant's criticism for an example: "Kant discovered the subjectively conditioned and therefore entirely immanent nature of knowledge, that is, its unsuitableness for transcendental use, from the constitution of knowledge itself; and therefore he very appropriately called his doctrine the "Critique of Reason." ' Now, to translate this statement into the terms which our analysis has shown to be descriptive of the exact facts of the case, it amounts to saying: The only trustworthy outcome to a thorough examination of human cognitive faculty is the discovery that, although its trans-subjective reference and "transcendental use" is immanent in its very constitution, we are somehow forced to call this aspect of it an illusion or a lie. But the very terms "subjectively conditioned," "immanent nature," "transcendental use," "constitution of nature," etc., are either pregnant with conclusions that contradict the sceptical outcome of the Kantian Critique, or else they are themsclves utterly empty and meaningless. Ultimately, even the words "illusion" and "lie" are found to derive all their meaning from conceptions of truth and reality which remain unimpaired by the sceptical process. And the fundamental illusion of the critic himself may be said to consist in the impression that he can thus gire the lie to the common consciousness, with its undying, warm conviction, of the truth

1 The World as Will and Idea, iii., p. 27. 
of Self and of Things, and yet save the results of his own criticism. This is indeed the $\pi \rho \hat{\omega} \tau o \nu \psi \psi \psi \epsilon \hat{v} \delta o s$ of epistemological agnosticism.

The amount of Truth in the present possession of the human mind may always be looked upon as small indeed compared with the conceivable extent of truth. What this means so far as concerns the truth that is in present possession, has already been made sufficiently clear in treating of the nature, kinds, degrees, and limits of human knowledge. A becoming modesty will always characterize the genuine spirit of science and philosophy, in view of the smallness of the field of present attainment, as compared with the incommensurable magnitude of the still unknown. And since the growth of scientific and philosophical knowledge has always so largely consisted in the correction of mistakes of fact and errors of conception, there is more than sufficient reason to suspect that large admixtures of the untrue still remain with what now appears to be true. The compatibility of this experience with a positive confidence in present possessions of truth, and in the validity of the distinction between truth and error by reference of both to Reality, is a subject for epistemological inquiry. But we are now interested in inquiring whether the valid claims of scepticism and agnosticism have not, of late, been greatly overestimated. A generation ago Mr. Herbert Spencer ${ }^{1}$ set out to establish an elaborate doctrine of nescience; but he began with the announcement of his conviction that there is "a soul of truth in things erroneous." Since then, this original conviction appears to have been quite too much overlaid with the great mass of dogmatic agnosticism accumulated by both the master and his more or less confiding disciples. Even Mr. Spencer's more positive conclusions as to the possibility of knowing the Ultimate Reality have suffered unwarrantably in the same way. $W e$, too, believe that there is

1 First Principles, chapter i. 
a "soul of truth in things erroneous." Indeed, we believe that all errors "live and move and have their being," only in and by the possession of this warm and active prineiple of truth. And as the soul of truth that was originally in things erroneous is recognized and developed into its due characteristic form and proportions, the husk of errors falls off and perishes.

To state the same experience in another way: We actually find much more truth than error in all those judgments of men which seem to them to embody their most assured cognitions. He who would accept them all for true, rather than false, and would diligently seek so as finally to discorer the "soul of truth" in them, would thereby gain. a much more satisfactory and valid picture of Reality, than would he who should content himself with the negative and agnostic results of epistemological criticism. To win truth, it is better to present a genial than a repulsive side toward the common opinions and beliefs of men. For truth is a mistress who does not like a sour and distrustful countenance, however resolute and masterful. Her chosen favorite is courteous as well as persistent; trustful toward his mistress, while not being, on due occasion, without jealousy for her honor. In every field of truth - practical, scientific, philosophical, religious - trust is more productive than distrust; and certain positive conclusions are usually more justifiable and better worth the making than are any negative and agnostic conclusions. The great brain and the big heart of the multitude of men are the seats of true thoughts and of fitting emotions; they give birth to the important truths with reference to the being of man and to the allembracing Reality, however frequently they go astray in some of their functions. Human science, no matter how doubtful about its facts, and faulty in its generalizations, is much more to be credited than discredited as regards the truth of its total message when that message is rightly understood. 
Nor was there ever propounded a system of metaphysies so recondite, illogical, or fantastic, that it did not embrace more of fundamental truth than of falsehood. And that portion of human cognitive experience in which arise and grow, as in a fruitful soil, the mental and emotional attitudes of men toward God, Freedom, and Immortality cannot be torn out by violence or excised by the keen knife of sceptical criticism, without leaving in unrecognizable fragments the whole body of such experience.

It is, then, in some respects a harder task for epistemological doctrine to determine how error arises, to show its reality in experience, and to furnish the means for testing and detecting it, than to perform the same offices for truth. This task cannot, however, be shirked or set one side on account of its inherent difficulties; nor, because truth is the more abiding and inclusive thing in human experience, can we assign to error only a negative meaning and a wholly subordinate significance. Not a few students of the episte. mological problem have chosen to regard all error as either partial truth, or else as the merely negative limit of truth on its way from lower to higher stages of expression and degrees of development. There are certain important considerations implied in giving this turn to our phrasing of an answer to the epistemological problem. Error is essentially not-truth; but one can searcely reverse this proposition and declare that truth is essentially not-error. Moreover, as has already been implied, no erroneous proposition can be posited, and no false judgment can be framed, except with reference to some positive correct proposition as expressing a true judgment. So that there is a certain justification for the paradoxical statement: he who blunders most miserably is nearer the absolutely correct than the absolutely incorrect announcement of a real eognitive experience; and he who lies most outrageously tells more of what is true than of what is false, in the very terms of his lying propo- 
sition. Only Satan can be "a liar from the beginning;" and of the manner of his accomplishing this remarkable feat of escaping all truth, one can scarcely form a defensible conception.

Still further, many - perhaps we should not go too far in declaring, that all - of the most important truths dawn upon the consciousness of the individual and of the race in the form of half-truths. In the history of scientific progress few things are more instructive than to notice how the most wonderful classes of new facts, and the strangest discoveries regarding the classification and formulation of these facts under laws which express the relations they sustain to the present system of scientific cognitions, have their anticipatory stages and fitful periods of obscure apprehension. Seldom, indeed, is the earlier recognition given to the truth at which science aims, other than very fragmentary and partial. Similarities and differences are not definitirely marked out; and eren the most fixed terms of relation to the fundamental existences of nature are expressed in a faltering and changeable way. An interesting example of this progress in knowledge may be found in the history of bacteriology.

Nor does the more "finished" form of science feel that it is capable of expressing the full and final significance of a single fact in human cognitive experience; much less that any of its laws are the complete and unchangeable expression of the being and transactions of that part of our experience which we call "Nature" (whether regarded as naturans or naturata - to borrow a distinction of long standing). Now, from this fractional character belonging to all the truth we know, or think we know, it seems to follow that the other fraction necessary to complete the totality of the apparent sphere of human knowledge, is entitled to be called error rather than unknown truth. This would appear to justify the epistemological conclusion that all our truth 
is half-error (more or less). Such a conclusion might, in turn, be converted into the proposition that all error is partial truth; "because it is solely due to negative limitations inherent in the very nature of truth itself. For, finally, how shall ignorance and error be distinguished, since men are perpetually bound to assume that they know what they are only entitled to believe or to opine, and since all the truth actually known is, after all, not more than fractionally true?

We have little taste for the dispute over "poles of opposition," over "negatives" and "positives;" or for the debated question whether all truth can be reduced to a kind of illusion or error, and all error to a partial or limited truth. As in the more purely ethical realm, sin and wrong-doing are not mere negations or limitations of righteousness, so in the more purely intellectual realm does the case stand with error and truth. Error is not merely the negative of truth; mistaken judgment is not always to be defined as simple failure to express correctly the whole of one's cognitive experience. Every cognitive judgment, from the epistemological point of view, is just as positive when it negates as when it affirms; and there may be, of course, quite as much error in denying what is true as in affirming what is false. Moreover, to affirm of "all" what is true only of "some" is an erroncous proposition, - a judgment not only logically faulty but also metaphysically false. But to fall short of affirming of "all," because, although the universal truth of the proposition may bo clear to other minds, the judgment has not yet become cognitive for our mind in this universal form, is to be "true" in the noblest sense of the word applicable to the functioning of a human intellect.

On the one hand, the ethically wrong has respect to matters of conduct more purely. Judging, and propounding the results of judging, are indeed matters in which will takes part. Our analysis of the nature of cognition has 
shown this to be true. Much human error, too, is mixed up with more or less of wrong-doing; and the relations between "conduct," in the ethical meaning of the word, and false and erroneous judgment are far from being loose or remote. Nor can these relations easily be confined to any particular kind of truth, so as to exclude from the obserrations and experiments of physical science the moral defects of self-conceit, insincerity, and selfishness, while admitting that so-called religious faith or metaphysical speculation may easily be corrupted in this way so as to destroy the fractional "soul of truth in things crroneous." On the other hand, the so-called laws under which the two kinds of action take place are not, by any means, precisely the same. Wrong-doing, as distinguished from going wrong in judgment, stands in quite a different relation to righteousness from that in which error, as distinguished from wilfully sophisticated or slovenly judgment, stands to truth. The intellectual conditions which determine that form of action we call the cognitive judgment are more strict and inflexible than are those forms of conception under which moral conduct in general takes place. Here we discover the sphere in which differences in the kinds of truth become most important.

The main principle of differentiation now to be recognized is the relation which the alleged truth sustains to the emotional and practical life of man. Erery court of justice brings out the fact that errors of senso-perception are frequent in all matters of observation by the senses. The same thing every psychological laboratory also can easily demonstrate. What the court of justice shows more clearly than does the psychological laboratory is this: such errors are most frequent in the direction of interests of an cmotional and practical sort. But every director of a physical or chemical laboratory knows how many mistaken inductions have in the past been built into the body of so-called 
"science," and how difficult it is to exclude such inductions from the constant edification of that body. When "experts" meet to testify on different sides in the same court of justice we learn, in larger measure, one set of reasons why so-called scientific conclusions do not agree. Moreorer, the attitude of cognition toward Reality is necessarily such that the cognitive judgment feels the fuller force of the inescapable and seemingly rigid character of concrete entities. Con. duct, although under such control from the really existent World of things that it cannot be determined in disregard of its being and behavior, is itself a much more flexible and fluid thing in its relation to that world. My pleasing and willing undoubtedly have much to do with my knowing at all; and also with what I know, if I know at all. Yet men do not say that it pleases them, or that they will, to frame their cognitive judgments thus and so rather than otherwise; but they affirm that they conduct themselves, within much wider boundaries, as they please or as they will.

The fuller explanation and significance of such considerations as the foregoing best become manifest, so far as epistemology requires, in connection with the theory of knowledge thus far adopted. Detailed discussion of the means for establishing truths and detecting errors, theory of method in general, and the technique of investigation and proof belonging to the particular sciences, offer many interesting problems into which we cannot enter. Our present aim is simply to show what meanings are properly attached to the terms by which men distinguish truth and error; how the distinction originates in accordance with principles determining the growth of knowledge; and what are some of the more general criteria that may fitly be employed for making and defending the distinction. In a word, the epistemological problem under discussion is: How is the fact of knowledge consistent with the existence of both error 
and truth? Here, too, as in the discussion of every epistemological problem, reference must be constantly had to Reality; and thus the problem is not merely epistemological but is also ontological. For who shall arbitrate in the friendly game or bitter fight between so-called truth and so-called error? It is only in the somewhat contemptible arena of the ancient sophist, or in the mildly inane "debating society" of modern times that men appeal to rhetoric or to logic alone to adjudge the case disputed between them. In what is significantly called "real life" the issues at bottom, however their presence may be overlooked or concealed, have regard to something other than the judicious ordering of persuasive arguments or an apparently strict conformity to the rules of the syllogism. These issues submit only when Reality itself decides the appeal made to it. For the question at issue reads best as follows: What is true, and what is false? - not, Who has stated his case most judiciously and convincingly? Now, in fact, this very appeal embodies the entire theory of knowledge as it has already been stated and defended. Mere arguments submit to the arbitrament of the logician or the rhetorician. They ask for judgment framed by the mind that moves methodically and smoothly from accepted premises to derived conclusion. But alleged cognitions make an appeal to the being and transactions of the really existent world; and they are often obliged to carry this appeal through lengthy and tortuous processes of ratiocination (as, for example, in the case of an inquiry like that concerning the "localization of cerebral function," or "the origin of the synoptic Gospels"). But "rough and ready," if only it will enable the mind to envisage and interpret what is actual, is a most acceptable motto for him who aspires to know the truth.

It is obviously the correct doctrine of the cognitive judgment to which one must turn in order to discover the profounder meaning of the words "truth" and "error." It is 
admitted by all, even by those who take the merely logical or psychological points of view, that truth and error can be affirmed or denied of judgments alone. He who simply has sensations, ideas, feelings, conative impulses, as such, whatever the characteristics of these psychical phenomena in themselves may be, - cannot be either commended for truthfulness or condemned for falsehood. To a second being who affirms or denies the existence of these psychoses in the consciousness of the first being, the term "true" or "false" may be applied. For epistemology, however, it is important to go beyond this point: only alleged cognitive judgments can properly be called either true or false. Truth and error belong to the attempts of men at knowledge. We think correctly or incorrectly, if we may conceive of ourselves as merely thinking; we act aptly or ineptly, whenever we can isolate action from the cognitive judgments which it so frequently expresses or applies; and we feel appropriately or inappropriately, if we regard merely the affective aspect of consciousness in its relation to other subjective factors. But it is when we think, feel, and will, in such manner as to set the total Self into those relations toward Reality which the cognitive judgment embodies and expresses, that we become capable of apprehending truth or of committing error. He who affirms "I know, etc.," must either have truth on his side, or error against him; and the testing of the affirmation is always made in the form of an appeal to that which men call "actual" or "matter-of-fact."

By Truth, then, all men understand such a judgment, affirming cognition, as corresponds to the being and the transactions of the really Existent. By error they understand such a judgment as lacks this correspondence. And sinee any alleged cognitive judgment may partially correspond and partially fail to correspond, they recognize that "fractional validity" of many cognitive judgments to which attention has already been called. Now, at this point there 
is, of course, a very tempting opportunity for the confirmed epistcmological sceptic and agnostic to enter his old-time objections and protests. For is not erery alleged cognitive judgment itself as thoroughly subjective as are mere sensations, ideas, and the most primary impulses? And what can be meant by "the being and transactions of the really Existent," that is not a complex and abstract product of the subjective processes of imagination and thinking? How can an appeal be taken to Reality, as though reality could get into the mind in some other way than as "appcarance" in the form of alleged cognitions? What there is of substance in those rery objections and protests has already been examined at great length. After we have finally parted from him who doubts or denies the very possibility of knowledge, we cannot consent to tread again with him the same worn and wcary path through the darkness of nescience and doubt toward the light of assured and intelligent cognition.

What, however, shall be said in answer to those who, like Mr. Bradley, ${ }^{1}$ deny that any truth is given in the judgment, so far as it is cognitive and categorical, and on the contrary affirm: "Any categorical judgment must (the italics are our's) be false." "The subject and the predicate in the end cannot either be the other." "Quality either adds nothing or adds what is false," etc. Strictly understood and accepted, such a view of the cognitive judgment would secm to place us in the position of the man who, having all his life long implicitly beliered in the truth of dreams, at last dreamed that he was infallibly assured of the falsity of all dreams. Thus was he doomed to the perpetual circle in arguendo: "If all dreams are true, then this dream is true, and all dreams are false. But if all dreams are false, then this dream is false and some dreams may be truc." What a prospect is this, of forever grinding at the mill, while

I Appearance and Reality, pp. 361 and 362 (note). 
starving for lack of some small grist of truth! Understood, however, as its author seems to intend, these statements give a self-destructive form to the attempt to unite the outcome of a sceptical epistemology with a rational system of ontology. But men do not mean to identify the "being" of subject and predicate, whenever they pronounce categorical judgments; neither do they understand that the truth of their thinking is dependent upon the metaphysical identification of this thinking and what is real. Nor do they, any more than does Mr. Bradley himself, regard Reality as a rigid Entity, totally independent of all change, movement, and Life, which must be known completely and as it eternally is, if it is to be known at all.

The further qualification that judgments are to be considered either true or false only in so far as they assume to be cognitive, enables us much more clearly to distinguish the nature and to define the limits of both truth and error. Here another consideration respecting the nature of all actual judgment becomes important. For every judgment exists, as a realized product of the Self, only after it has been both framed and pronounced. So far as psychological analysis can throw its light, whether derived from introspection or from experiment, into the very centre of this subject, judgment is dependent for its very realization upon some form of motor activity. Men universally incline to asseverate with one kind of motor symbolism and to deny with another. They posit, plant, ground their propositions: or they withhold, uproot, and withdraw them. They detect themselves as setting into some form of action, often in talking over with themselves, the series of judgments which leads up to the terminal judgment; and this they love to "establish" and make clear and impregnable to themselves by repeating it over and over again. Whether such motor expressions of the judgment must be accounted essential for the individual in order that he may recognize and adopt its 
truth as his very own, or not, it is obvious that one man's cognitions can be made the subjects of another man's judgments only as they are set into reality by some motor expression. The acceptable human form of expression for the cognitive judgment is language. That is to say, truth and error are customarily predicated of alleged cognitive judgments as expressed in verbal propositions.

And now in considering the nature of truth and error, and in endeavoring to determine defensible limits between them, the task becomes twofold. The question as to the truth or falsity of any judgment is thus always connected with, and generally much complicated by, this question: What does the judgment, as propounded, actually mean, both to the one judging and to others who are asked to pass judgment upon it? For what a judgment really is canuot be known apart from what the judgment, as expressed, means to the inquirer after its truth or falsehood. So that theoretically the experience becomes necessary which we find to be actual in our every-day intercourse with men: We cannot, from the primary point of view of epistemology, pronounce any judgment either true or false until we know what such judgment intends to affirm or deny as understood by the mind that makes the judgment. It has been seen, however, that cognitive judgments are not perfectly rigid and unchanging connections, established once for all between concepts which are themselves conceived of as unchanging entities. Nor do the words in which men's judgments are announced have a fixed and unchanging meaning. Far from it; each one of them embodies the attempt to catch and formulate an indefinite number of doings of the really existent world of Self and of Things. Reality is much too varied and agile in its lifeexpressions, as well as lofty and profound in its principles of behavior, to be caught, firmly held, and fully encompassed, by as many words as the arerage man can master the meanings of. Moreover, each one of these words changes 
its meaning - on the one hand, gaining a richer content, and, on the other, being more precisely delimited - as the growtl of knowledge goes on in the individual and in the race. Still further, all words, in those meanings which afford the most direct and inviolable expressions of the reality known, are apt to be employed figuratively. Every student of language knows how children and childish peoples express the truth as it is revealed to them, and indeed often most fitly and beautifully, in figures of speech. 'The highest abstractions of science and philosophy can find words in which to embody themselves only as they consent to be more or less artistic and indefinite in the meanings assigned to those words. Has it not been proved, indeed, that the truth of our most assured cognitive judgments concerning what the world of things really is can be vindicated only by regarding it as being and behaving like the Self ? Its qualifications are known as they really are, only on the supposition that the analogies cmbodied in our language are justifiable figures of speech. We are far, indeed, from holding that no distinction is to be made between so-called "real trutll" and error, or that all contentions for the truth are best resolved by the acknowledgment that, after all, the dispute is only a logomachy. On the contrary, there are not a few subjects where contest for the truth against crror is a war to the knife; and the ongoing revelation of Reality to the human mind will practically annihilate one party to the strife. Yet, in general, a most fruitful way of helping ourselves and others into the truth, and of eliminating error, is to bring about an understanding as to what each alleged cognitive judgment actually means to the one propounding it. Socratic midiwifery alone will never rid the woods of all manner of dxmons of falsehood, sprites of untamed fancy, and unsubstantial ghosts of doubt; but it will much improve and multiply the regions held by the family that derives its lineage from essential truth, the faithful mother of a chosen race. 
Truth and error, then, are most fitly attributed to judgment, but only in so far as it is cognitive, and is understood according to the meaning given to its expression by the judging mind. He whose only failure consists in the misemployment of terms for announcing his cognitive judgment commits, indeed, a serious fault. His judgment, if adopted by others as their own, in accordance with the meaning they are forced or deceired into giving his terms, may be wholly or largely false. But if, with the meaning he gives the terms, the judgment announces a fact or a remoter relation in reality as known to him, it is more properly called incorrect in expression than false or erroneous as tested by a standard of truth. This limitation of the epistemological significance of the terms "truth" and "error" enables us to understand two classes of subjects that stand farthest apart, as ordinarily considered. We are accustomed to being told that the most certain and unassailable of all truths are the truths of mathematics; but that the senses of men move in the peculiar realm of illusion and error. Yet are not both truth and error always defined with reference to realities? And what student of the purest and highest mathematics is so ardent as to claim that his formulas represent the real being and actual transactions of things? On the other hand, where do men come face to face with the reality of things, in such way that all human knowledge of them depends ultimately upon the validity of this intercourse, except in the ficld of sense-perception? Must it, then, be admitted that the most assured truth gives no knowledge of reality; and, on the contrary, that all seeming knowledge of the reality of things is mere "appearance" or sheer "illusion"?

What is the nature of the truth which mathematics imparts; and what is the relation in which this truth stands to actuality, whether of Self or of Things? The correct answers to these questions confirm instead of contradicting 
the theory of knowledge which we are advocating. For the premises, reasonings, and conclusions, of the "purest" mathematics are properly called true only so far as they are known to correspond to the real being and actual behavior of our world of cognition. And yet, of all kinds of knowledge mathematics and formal logic are remotest from reality, - most "pure" in proportion as they are most unreal, imaginary, and abstract. Nor is this an oceult truth which needs the assistance of epistemology to disabuse the mind of the mathematician or logician of his erroneous pretence of knowledge. For example, let us suppose that the conclusion of some course of algebraic reasoning might be correctly expressed by the formula $x=\sqrt{y^{3}-1}$; in what sense can the judgment of such a formula be said to be known to be true? Only as reference is made to the being and transactions of something really existent. If it is proposed to test the truth or falsity of the conclusion, appeal may be had to a serics of mathematical terms united by signs of equality and inequality, of addition and subtraction, etc., upon a sheet of paper, to see if repeated inspection by the senses will reveal any "error" in them; or some other series of other terms, based upon the same premises, may be employed in order to test, or prove, the correctness of the suspected series. But the truth obtained in this way is not expressed when it is satisfactorily shown that two little black marks crossed $(x)$, and two short lines parallel ( $=$ ), and a $v$ with a long arm extended on its right side $(\sqrt{ })$, etc., are placed precisely in such an order, rather than some other, upon this particular real sheet of paper herc displayed. Surely, this is not the meaning for reality which such a series of algebraic judgments possesses. But neither is it meant that any really existent thing has its being, or its behavior, correctly represented to imagination or to thought, either by the statical relations of these symbols, or by the movement of the argument through which the state- 
ment of the relations is reached. The "purer" and "higher" our mathematics becomes, the less conceivable does it become that any thing or number of things should "realize" the truth of such processes in its own real being and actual behavior. Eren if the supposed case be one of applied mathematics, the truth of any conclusion such as $x=\sqrt{y^{3}-1}$ does not depend upon some real thing being discorered, to be called $x$, and some other real thing to be called $y$; and then upon these two going through exceedingly complicated but mutually dependent processes in order actually to arrive at a sort of statical agreement with each other - after the pattern of the successire strifes and partial reconciliations in the thought of the mathematician which end in peace being declared on terms of $x=\sqrt{y^{3}-1}$. The truth of mathematics, indeed, gets an approximately exact realization whenever things, being taken quantitatively and measured and counted, as all things may be, undergo changes in size or in spatial relations, corresponding to those symbolized by algebraic and geometrical formulas and demonstrations. But it must not be overlooked that the truth in reality of the formulas and demonstrations, as thus regarded, is always only approximate and conditional. That is, so-called mathematical judgments are held to be true for things only in case certain presupposed conditions continue to be fulfilled by the things; and even then only in so far as the things are quantitative and quantitatively related. But what the actual conditions are under which things exist, and act, and change, can only be known by our experience with them; and this experience bases itself upon cognition of the actuality only so far as cognition takes place through the senses.

What now, however, shall be said as to the truthfulness of the axioms and demonstrations of "pure" mathematics, both arithmetical or algebraic, and geometrical ? The answer to this question depends upon understanding how the fundamental conceptions of mathematics originate, and why it is 
possible to arrange them in satisfactory form. This answer may be given in the form of a paradox. The pure mathematics are so undoubtedly true, because they are so independent of, and one might even say so false to, the real being and actual transactions of things. For things always are much more and other than merely quantitative; and the behavior of things is determined by many other considerations than those of the mathematical order. Water $i s$, for example, approximately described in terms of quantitative analysis, by the formula $\mathrm{H}_{2} \mathrm{O}$. But both oxygen and hydrogen gases, and the compound resulting from their combination in terms of this formula, are, and are able to accomplish, infinitely more than this formula describes. When, then, mathematics becomes perfectly pure, the truth it tells concerns nothing more than the way in which a certain kind of our thinking enables, or compels, us to relate its own abstractions. For, so far as pure geometry knows, its space is a pure abstraction; and so far as pure algebra knows, its numbers and symbols stand for pure abstractions. The truth here is the truth known as determined by a certain thinking and ideating activity of the Self. I not only know that I can regard things as capable of being counted and as actually extended in space, but I also know that I can abstract from all the concrete qualities, definite dimensions and space relations, which things as known by the senses have; and I can then treat the concepts of number, and of space qualities and relations, as though these concepts were themselves real objects of knowledge. The truth thus immediately known belongs to the actual behavior and real life of the Self; it ean be carried over into the world of things only upon the bridge of that analogy to which reference has so frequently been made.

We see, then, that the truth of mathematics is twofold in its aspects; but in both of its aspects it looks toward Reality for its sole testing and justification. In so far as 
experience shors us that things actually obey the laws of number and of quantity, our mathematical judgments may be cognitive of things. Truth and error are not abstractions here. Every building that falls, every bridge that goes down, because of miscalculation as to amount of strains or strength of materials, is a terribly real proof of this. But when sophists deny motion or change in reality, because the mind can so juggle with mere abstractions as to show, with logical satisfaction, that the arrow cannot really fly or Achilles actually overtake the tortoise, they are more ingenious in needless self-deception than either knowing or wise. For human cognition affirms that the arrow does fly; Achilles and all the spectators know that he soon overtakes the tortoise. The puzzle which arises when it is asked, How can this really be? does not require any alteration of judgment as to the nature either of knowledge or of reality. For the puzzle consists in the sceptic's foolish effort to make that true for the actual world of things which is only conceivably possible even when abstractions, recognized as such on one side, are, on the other side, identified with realities in a false and illogical way.

How far Reality follows human mathematical conceptions and imaginings as to what It might be and do, if things were only a system of merely quantitative beings, we have no offhand means of saying. The appeal must be made to cognitions of sense. We learn a little more about this as our knowledge of things grows. But the complete failure of mathematics to describe and to explain the actual World is increasingly apparent. The theoretical ass of Buridanus could not more toward either bundle of hay, so subject was his "being" to the dominion of mere quantity. But then there really is no such ass anywhere, - not even among the most primordial and undifferentiated of the forms of protoplasm, or the atomic subjects of the law of chemical equivalence. We ourselves are governed by rarious other 
considerations, and have many other ends to realize, than those of pure mathematics. How far this is true of the Other Self, man can scarcely be said to know; but there are certain reasons in human experience which lead to the apprehension that It cannot be bound strictly by the axioms and formulas of the most speculative mathematicians.

From time immemorial the illusory and hallucinatory nature of that knowledge of things which comes through the senses has been celebrated, not only by reflective students of the phenomena of perception from psychological and philosophical points of view, but also by poets, essayists, and religious enthusiasts. This epistemological conclusion has generally been more or less closely connected with ethical and practical interests. Thus the "sensuous" side of things has been held to be the seducer of the mind into paths of error, and of the spirit into ways immoral and prejudicial to the interests of the higher good. Modern physical science has naturally felt no little repugnance toward such a view of the nature, the limits, and the tendencies of the cognition of material things. It has aimed to establish the superior claims to exactness and certitude of this kind of cognition; and even to extend its method by using mathematical formulas for the expression of quantitative qualifications and relations, over all the fields of human knowledge. It has pointed with justifiable pride to the recent extension of the dominion "ruled over" by known laws; and it has expressed high hopes that the barriers to its further almost inconceivable advances would even be overcome. All this, it has held, is happening so as greatly to benefit rather than to injure the practical and ethical interests of man. Of late there has been a growing disposition to admit that "scientific" knowledge would somehow be found to be not wholly incompatible with religious faith and emotion, even if the ancient basis of accepted truths of religion were quite removed.

A certain curious inconsistency of opinion has seemed, 
however, to characterize the modern defenders of physical science as respects the truthfulness of the plain man's cognitive judgments touching the reality of things. On the one hand, the scientific attitude toward sense-perception is that of confessed confidence and even of deference amounting to homage. No one more excites the scorn of the "scientist" of to-day than does the speculator who, like certain quondam disciples of Schelling or Hegel, evolves a Natur-philosophie, or elaborate system of metaphysics of physics, from his own higher consciousness in accordance with a preconceived theory of "Ultimate Reality." "Back to nature," and in all cases of disputed conclusions - again "back to nature," is the inspiring and promising call of the scientific Zeitgeist. But, of course, there is no other way to get back to nature than that of regarding the facts, as they appear to the trained and careful observer through his bodily senses; and while modern instrumental equipment furnishes an enormously increased range of perceptions within which thought may inquire as to what is true and what is false, it contributes no wholly new order of facts from which to derive a new standpoint for testing the truth and falsehood of our preconceptions touching the nature of Reality. The highest powers of telescope and microscope, the most delicately sensitized photographic plates or cunningly derised apparatus for spectroscopic analysis, the startling new exhibitions of "Roentgen rays" afford, after all, no less an "appearance" to sight, a mere visual phenomenon, than does the naked eye of the unscientific man, as he moves about among things visible for the transaction of his daily business. Indeed, new doubts and wranglings over what is actually observed constantly accompany the exploration of these new fields. And the most cautious and thoughtful of explorers are coming to confess that the same frailties and bias from intellectual and emotional prejudices must be guarded against, with even increased diligence, if truth 
and error are to be separated in the scientifie observation of things. ${ }^{1}$

On the other hand, it is constantly more apparent that the underlying strata of hypothetical metaphysics are quite as extensive in the domain of modern physical science as are the cultirated fields of fact, open to the inspection of all observers. These facts afford the witness of a general confession that truth or error about things is not wholly a matter to be determined by sense-perception; and when joined to other facts and inferences, they may lead the student of epistemology to inquire whether, after all, a defensible theory of knowledge and of metaphysics are not equally necessary to save both the scientific and the ordinary cognitions of things from being convicted of complete invalidity.

Meantime, certain advances in the psychological science of perception have brought the epistemological problem before the age in a somewhat new and more emphatic form. The "new psychology" has devoted itself with commendable zeal and industry to the scientific investigation of illusions and hallucinations, as mental phenomena. No doubt, it has sometimes conducted these investigations with a blameworthy forgetfulness that certain epistemological truths must be assumed in any investigation. Whenever, for example, any theory of possible errors of self-consciousness ("double," "triple," or otherwise hallucinatory) threatens the fundamental cognitions of Self, - as real, unitary, and existing in relation to other realities, both selves and not-selves, it is approaching the limits where all its own claims to scientifie character must be let slip into the bottomless pit of a self-contradictory nescienee. Whenever, too, the psychological theory of illusions and hallucinations in senseperception assumes to involve in doubt all knowledge by the

1 See, for example, the instance referred to; "Psychology, Descriptive and Explanatory," p. 511, note. 
senses, it becomes itself involved in those same primary fallacies which afflict every species of sceptical idealism.

Our previous critical examination of the nature and certitude of human knowledge authorizes and compels the view that the terms "truth" and "error," with their full epistemological significance are properly applied to sense-perception. Eren to speak of illusions and hallucinations of sense implies, in such manner that the implicate cannot, so to speak, be separated from experience or from the terms chosen to express it, that in sense-perception men reach cognitive judgments which are truly representative of the nature and the relations of things. Indeed, from almost cqually justifiable and serviceable points of view, one may proclaim the apparent paradox: Cognitive judgments, as based upon immediate perception through the senses, are in general both true and also more or less illusory and hallucinatory. This paradox follows from the nature of perception as a form of knowledge, and from the nature of the reality known by perception. For, on the one hand, perception is a complex cognitive process that is dependent subjectively upon an indefinite number of factors, which are different for every individual perceiring mind, and which change in the very erent of erery individual perception. But, on the other hand, the reality known in sense-perception is no rigid and unchangeable somewhat; it is not a thing, or a system of things, that is precisely one and the same for all perceiving minds, or for erery individual perceiving mind in all of its perceptions. Perception, on our part, is an actual process of change, a living and moving achievement of mind, resulting in cognitire judgment. Nor is the cognitive judgment to which the very terms of truth and error must be applied a rigid entity, with its two parts, or poles, bound in an adamantine way to one another under the logical principle of identity. Eren far more abundantly able is the reality of things to lead that infinitely varied Life which displays itself diversely (and all 
the more wonderfully and beautifully thereby) to the perceptive consciousness of every man. He commits the fundamental error, from which he must retreat with shame and confession before he can know the highest Truth, who denies that the world of the really Existent is actually rich enough in content to correspond to the varied cognitive judgments of all perceiving minds.

This correct view of truth and error in sense-perception is not an esoteric mysters, but is something habitually confessed by the language and action of men; nor does it render unessential and inoperative the distinction between truth and error in this realm of cognition. On the contrary, it validates the distinction and also gives it value in the place where the teleology of all cognition is most apparent, namely, in our use of things. To illustrate this, let us take an example. You rise in the morning, and glancing hastily from the window declare that it has been snowing in the night; or, having put on hat and coat, you go out into the open air and soon affirm, "It is colder than it was yesterday, and the temperature must have fallen in the night." But in the one case an error of inference may be corrected by pointing out that the judgment "The ground is covered with snow" was due to the glister of the parement under the reflected light; in the other, consulting the thermometer may convince you that the truth would be expressed by simply affirming, "I feel colder than I remember to have felt yesterday, probably because of a poor night's sleep." Such mixtures of what men call truth and error are, as every one admits, frequently found in the cognitive judgments of men. In cases similar to the former of these two, an error of fact, due to hasty observation, has led, by otherwise legitimate inference, to an erroneous conclusion; in the latter, an indisputable truth of fact has been assigned, by illegitimate inference, to a wrong cause. In neither of these cases, nor in any similar cases, is there any element of the experience 
which contradicts true epistemological doctrine touching human knowledge of Self and of Things, as it has already been defended against a sceptical idealism or agnosticism. Nor, as a matter of universal experience, does the admixture of illusion with truth impair the confidence of mankind in the possibility of some assured cognition through the senses.

Suppose, however, that two observers, equally confident in the trustworthiness of their own senses and equally mindful of the necessity of care in the use of the senses, pronounce opposed judgments as to any real thing or actual event. The final issue of their self-criticism, as well as of their argument with each other, is the conclusion, on the part of $X$, that $A$ is $B$; and on the part of $Y$, that $A$ is not $B$. Now any one of several suppositions - which, if needed, are satisfactory to men in general and actually often employed - will save the situation from the agnostic conclusion that no assured truth whatever is obtainable by the senses. Granting that both $X$ and $Y$ are communicating to each other the exact state of their case, - that is, are expressing their respective judgments of an alleged cognitive order so as to represent their actual experiences, - the following suppositions are possible: either one or both of these subjects may be abnormally defective in respect of the particular sense chiefly involved; or the intellectual and æsthetical culture of $X$ may make it possible for him to perceive in $A$ certain qualifications $(B)$ which are denied to $Y$, and therefore denied by him as belonging to his $A$; or, again, it may be that $A$ actually is both what $X$ and $Y$ understand by $B$ and also by not- $B$. Our examination of the nature of cognitive judgment, as falling under the supreme controlling principle of identity, has shown us that it is only the particular judgment, as made at this time and by this particular cognizing mind, to which the principle of non-contradiction in its absolute form is properly applied. The principle of identity, 
in other words, does not limit the rapidity of change, or the multitude of the phases, of which any real things are actually capable. But upon either of the foregoing assumptions, the truth of both the cognitive judgments that seemed contradictory would much outweigh the error that could be fastened upon either. In other words, true knowledge of real things by the senses is understood by every one to be knowledge of them as they appear through the senses. And when it is admitted that the same real things appear differently to different minds, and even to the same mind at different times, this is only affirming the correct epistemological view; for this view makes the perception of things dependent upon, and relative to, the perceiving mind. This view is also entirely compatible with the true metaphysical doctrine, which finds the ground of the different appearances, not solely in the differing mental processes, but also in things themselves. For cognition, however gained, is of the nature of a commerce between conscious mind and the really existent; but in this commerce both the mind as cognitive and the really existent are, so to speak, all alive. And my truth is not the less truth, because it is mine; nor is truth any less correctly described as a correspondence between the cognitive judgment and the being and transactions of the really existent, because the details of the form of this correspondence are so indefinitely varied. My perception of things may be as true as yours, although it contains factors which yours lacks or lacks factors which yours contains. Nor does it follow that both of us are partially in error, or even that one of us is wholly in error, because we squarely and honestly judge scemingly contradictory attributes to belong to the things perceived. For you and I are still two judging minds, although perceiving the same thing. And no Thing is so mean and poor in content that it cannot reveal itself to various minds in an unknown variety of ways; while the limitations of all knowledge by the senses may 
very easily cause that to appear as contradictory to you which is a matter-of-fact qualification of my cognition.

When, then, I correct a so-called error of sense-perception, whether in myself or in some one else, I effect a partial readjustment of the cognitive attitude of some mind toward reality which brings it nearer to the standard of the common judgment as tested by the most approved means of determining that standard; but I neither make a confession of the untrustworthiness of sense to afford any knowledge of reality, nor do I afford any new kind of truth regarding the relation in which the reality stands to the sensuous experience of men. The fundamental positions of epistemological theory are left unchanged. The conclusions warranted in the interests of psychological science may be stated, on both sides, in the following language. "Looking first at the side which disparages our knowledge of things as they really are, the following considerations present themselves: All mental activities are involved in common acts of perception. . . . In this complex process (perception of the quality of weight) the data of sense are profoundly modified by central states and activities. . . What we call normal perception involves many illusory influences - not only those of physical and physiological origin, but even more so those due to the functions of ideation, memory, and imagination. Indeed, suggestion and imagination control all our perception by the senses. . . But on the positive side, confirming us that somehow we perceive things as they are, sereral important facts may be observed. Illusions work according to laws which may generally be determined. As these become known we may gradually learn how to rule out the illusion. The known physical and physiological illusions do not necessarily delude us, because we may make allowance for them. Similarly, we may now make an approximate allowance for the illusions of weight and for all other illusions, due to intellectualized feelings, as they become 
recognized. The view that illusions and hallucinations do not act according to law is as wrong as the view that mind in its normal capacity is lawless. The more thoroughly we become acquainted with the laws of illusions the more accurately will our sense-perceptions fall in consensus." 1

Once more, the way in which the emotions, interests, and plans of men, as well as the limited and imperfect nature of their mental activity, lead them to blend remoter inferences with the content of apperception as immediately given, affords much of the needed explanation for the illusory and hallucinatory character of many sense-perceptions. Here again, however, a partial relief is found, and an added justification against the conclusions of unlimited scepticism, in the doctrine of the asthetical character and the teleological import of all human knowledge. Indeed, what we properly call illusory and hallucinatory from the psychological standpoint, may itself become a guide and a helper to an enlarged and nobler growth of knowledge. This is, in part, the real truth involved in Kant's doctrine of an illusory logic, natural and unavoidable for all human reason. But, "in part," only; for truth given in emotional and figurative form is still truth. And the being and behavior of the Self and of Things, when mentally represented by art and by religion, may be quite as faithful to the Reality as when cognized only from other and lower points of view.

The existence and significance of truth and error in all forms of science is to be explained in accordance with the same principles. But the peculiar nature of so-called scientific cognition involves special combinations of these principles. All science may, from the epistemological point of view, be considered either as chiefly descriptive or as largely also explanatory. As merely descriptive, if the term "science" is to be applied to such forms of knowledge, the

1 From an article by C. E. Seashore, Ph. D., in "Studies from the Yale Psychological Laboratory," iii., pp. $66 \mathrm{f}$. 
truth or error belongs to the cognitive judgment when understood to be affirmatory of the facts of self-consciousness and of sense-perception; as a form of knowledge, then, the epistemological theory of descriptive science has already been sufficiently considered. In general, however, no cognitive judgments offer themselves for critical discernment of the truth or error which is in them that do not admit of some sort of express or implied reference to grounds. Both the psychological and the epistemological doctrine of judgment agree in affirming that thinking and inferring enter into those propositions about the truth or falsehood of which men inquire and debate. But science is pre-eminently conceptual knowledge; and thus to it, as explanatory, the considerations which have been taken into account, in reference to the valid application to Reality of the principle of sufficient reason, especially apply. The effort of scientific research, as well as the reward of scientific discovery and of reflective thinking, consists largely in the improved and purified conceptions gained, and in the more accurate and well certified bringing of these conceptions together as terms in cognitive judgments of general validity.

In order better to understand what kind, and how much, of truth science affords, and what is the nature of its errors, one may consider the subject in the following way. The general form of the purely scientific judgment is, as has already been pointed out, the hypothetical: If $A$ is $B$ then $C$ is $D$. As employed in the extension of that knowledge which scientific classification embodies and advances, this form of judgment means: If any newly perceived being or event is like another already conceptually known being or event in certain particulars (if the perceived $A$ has the attributes $B$ ), then one may, with a good degree of safety, expect that it will be like in certain other particulars; and one may put all such beings or erents into a common class bearing the same name (then one may affirm that, as being 
$C$, it has not only the attributes $B$, but also the attributes $D$ ). But as employed in the extension of explanatory knowledge, this hypothetical judgment is affirmative of influential connections or causal relations. It may then be interpreted, somewhat crudely, as follows: If anything or group of things is behaving in a certain recognized way (if $A$ is acting according to the well-known formula $B$ ), then, looking backward, one may infer, that something else has furnished the reason for this, by itself previously behaving in a certain way; or else, looking forward, one may expect that the behavior of something else in its own way will find its reason in the observed event (if the perceived event is a case of $A$-is- $B$, then either the ground, or the result, or both, may be inferred as a case of $C$-is- $D$ ). But the hypothetical judgment, considered as in any sense explanatory, may itself be thrown into the categorical form: " $A-i s-B$ " and " $C$-is- $D$ " then become judgments dependently conneeted; but, after being united in the hypothetical judgment, "If $A$ is $B$ then $C$ is $D$," they remain cognitive judgments only in case a connection in reality is somehow established for cognition between them. The truth of the hypothetical judgment, then, like the truth of every other form of judgment (like all "truth") must be referred to the test of reality. And this reality, like all that reality in correspondence to which every alleged cognitive judgment is tested, is neither a merely formal correspondence of the judgment to the bare rules of our understanding, nor a super-cognitive entity (a hypothetical and abstract Ding-an-sich); but it is the reality given in experience. How such reality is given in experience has already been explained in detail, both with reference to Self and to Things.

So-called scientific truth has, then, only the same foundations to stand upon as those upon which all truth reposes. It is truth verified by experience in the properly guarded and well-trained use of cognitive faculty, - especially, of 
course, on account of the nature of its objects, if it be the science of things which is under consideration, in the use of the senses in observation, and of thought in elaborating the facts gained by observation. Errors arise in science, as ccrtainly (however less frequently, if even that can be maintained) as in perceptions of the ordinary, unscientific kind. To certain forms of error, which depend upon the remoteness from that testing of the concrete and more immediate cognitions of sense to which thinking must carry its processes, science is peculiarly liable. But this very liability is the price science has to pay for its superiority in the height and breadth of its conceptual knowledge. And its final aim is to eliminate progressirely those sources of error which arise in the unguarded and untrained or ill-trained use of cognitive faculty; while at the same time, by a sort of organic growth, in which many vital elements under the influence of common vital forces take part, and by preserving the sound portions of the building of other generations and adding to them from age to age, it proposes to outgrow many of its old mistakes and to improve the quality and certainty, as well as increase the number, of its valid cognitive judgments.

What theory of knowledge and what conception of the nature of Reality are needed in order to validate the cognitions of science? How shall our minds escape the doubt whether it be not all - this goodly temple of modern knowledge with its foundations upon the bed-rock of fact and its stones inspected by skilled and critical eyes as they are painstakingly built into the structure - no more truly valid transsubjectively than is a fair and stately dream? That I am not the whole of this world, that things other than myself exist, I can by no possibility doubt. But what is there that my science gives me which is true as corresponding to this Other Being and to its actual Transactions? We see no way to answer, and no prospect of the discovery of any way, that 
neglects the faithful use of the fundamental postulate to which reference has so frequently been made. The "scientist" who does not accept the validity, and the value, for Reality, of the conception of things as a system self-organizing after the analogy of the self-known Self, can only comfort his doubts with the beauty and formal consistency of his own dream. Knowledge would seem, somchow, to be denied to him except on terms of repentance and of faith.

The more fruitful discussion of the Sources of Error must be in the main psychological and logical. But the philosophical theory of knowledge enables us to see how errors naturally and necessarily arise in the employment of cognitive faculty under the conditions of human life and human mental development. For knowledge is not an affair of presuppositionless and "pure" thinking; or of immediate insight with a clarified and full-orbed vision into the inmost mysteries of Absolute Being; or of disinterested and dispassionate ratiocination from indubitable premises, along clear and unobstructed dialectical lines, to an absolutely sure and universal conclusion. Only the immature Paracelsus dare say:-

"I saw no cause why man

Shonld not stand all-sufficient even now,

Or why his annals should be forced to tell

That once the tide of light, about to break

Upon the world, was sealed within its spring."

Grown wiser and more expericneed in both truth and error, the critic of human faculty from the highest attainable point of view discerns how the case really stands with man, - a case to be pleaded, in the interests neither of an unreasonable transcendentalism nor of an equally unreasonable agnosticism.

\footnotetext{
"Power - neither pnt forth blindly, nor controlled

Calmly by perfect knowledge ; to be used

At risk, inspired or checked by hope and fear:

Knowledge - not intuition, but the slow

Uncertain fruit of an enhancing toil,

Strengthened by love."
} 
As arising out of the nature of cognitive faculty the sources of error may fitly be considered under two heads: first, such as spring from the inevitable, natural limitations of cognitive faculty; and, second, such as come from a partially remediable but universal lack of energy and of balance in the use of cognitive faculty. The doctrine of the limits of knowledge, as it is connected with the doctrine of degrees of knowledge, has already been sufficiently discussed. But the inherent weaknesses of man's mind in its efforts to attain and to enlarge its system of assured cognitive judgments, not only necessarily result in setting limits to his knowledge, but they also inevitably conduce to an admixture of error in these judgments. In saying this, we must not be understood as retracting our former contention that partial truth is not to be identified with error; nor do we revoke the more recent claim that the variety of the cognitive judg. ments which different men pronounce respecting their most immediate experiences with the Self and with Things is, to a large extent, an enlargement of the total sphere of truth rather than of error. But these same limitations do also, in some sort, commit the most carefully guarded and finely trained minds to no small amount of positive error. So that the complaint of being not only bound to know little truth, but also destined to accept as knowledge mueh nottruth, is by no means without foundation in the very nature of the cognitive subject. Here again, however, there are reliefs to be gained from taking the higher and more comprehensive points of view; from these are discerned the teleology of all knowledge, and the more fixed and important relations between knowledge and what men call "Reality."

The natural limitations of the human mind, in respect of each one of those various forms of functioning which combine in cognition, and in regard to each kind of the objects and fields of cognition, are undoubted. In the use of all of the senses for the attainment of that knowledge of things 
which comes in this way, the more precise qualification, the intensity, the time-rate, and the field or content possible for one "grasp of conseiousness," are limited. And since sense-perception essentially consists in interpretation of sensuous data into terms of ideation and thought, misinterpretation may result from any one of the several kinds of limitation. When the intensity of the sense-consciousness is stronger or weaker than a certain indefinite and variable limit, the cognitive judgment is, as we say, "more or less sure" to be erroneous. The same thing is true of the timerate of sense-consciousness; errors increase in the cognitive judgment as this rate rises above or falls below a certain limit of best results. Be as honest and faithful in the use of the senses as one possibly can, one is thus doomed to many so-called mistakes. For attention itself, the indispensable condition of the accuracy of our discriminations and of the truth of our recognitions cannot possibly be kept at a constant strain. But all men, to some commendable degree, succeed in correcting, or at least, in making rough but practically fruitful allowances for most such errors. Indeed, it is in acquiring just this sort of skill that the training of the senses, and of mental faculty through the senses, so largely consists. More particularly, the modern experimental study of psychology is trying - and with some success - to investigate these errors of sense, to point out their causes, and to discover their laws. What has already been ascertained shows that errors of sense are not nearly, even in the average and untrained mind, so numerous as they might be, if the adaptation of the senses to the truth of cognitive judgment were less firm and obvious. For example, there are few more uncertain mental processes of the sensuous order than those concerned in the localization of sound; yet the average person, when as attentive and discriminating as he can be, makes a relatively small percentage of serious errors; and some of the more serious possible errors he never 
makes at all. So that, if one were at liberty to say that man's cognitive faculty, as employed in the localization of sounds by the ear, is given to him in order that he may, by a fair amount of care and cultivation, get along well with things acoustic, one would have no reason greatly to blame the author of this faculty.

The more definitively and elaborately intellectual processes, by reason of these natural and unavoidable limitations, lead the mind into not a few errors. Because one cannot think more than so quickly, or so intensely and clearly, or about more than so many things, what thinking one can do when at one's best, not infrequently goes wrong. Memory, too, in its most definite and trustworthy manifestations, cannot be implicitly relied upon to give accurately the details of our own past experiences with ourselves; and when it is summoned into the court of self-consciousness to bear witness to the truth as to past experiences with things, the errors of the original observations may become more important. In all such matters, no clearly marked and fixed line can be drawn between ordinary and scientific knowledge. More or less careful observation, and more or less careful thinking, enter into both. And into both may enter the errors resulting from the unavoidable limitations that hedge round all observation and all inference. But the presence of many errors, now more or less heartily confessed and more or less completely abandoned, in that body of scientific knowledge which has been growing through past generations, is undoubtedly the more impressive fact in proof of the unavoidableness of human error.

Indeed, the more complex forms of conceptual knowledge are peculiarly liable to certain kinds of error. To those who justly value such knowledge highly, the temptation is almost irresistible to make the clear and the logical the measure of the true. If the advance line of science did not yield to this temptation, and so constantly maintain that 
what the minds of explorers, unrestrained by the control of other and seemingly contradictory facts, think ought to be true is true (the general postulate that Reality is throughout rational), then science itself would not advance so rapidly as it does by the aid of hypothesis and of experimental testing. On the other hand, in this way the body of accepted scientific truth is itself always so constructed as to retain within itself a certain amount of material in the form of erroneous conceptions. But in time, the facts plainly refuse to validate many of the most rational conceptions; and the saner minds, first, and, finally, the multitude of the students of the particular science either greatly modify or wholly abandon them. Here, indeed, the error may be said to be - abstractly considered - avoidable. For it is conceivable that all men should hold the valid application of as yet unproved hypotheses as to the reality of things, in a hypothetical way. A most interesting example of this may be seen in the history of the table by which Mendeléeff undertook the orderly and regular grouping of the chemical elements. This conjectural arrangement resulted in two correct predictions which elements have since appeared to observation to verify; but it also resulted in even a larger number of mistakes.

It is often exceedingly instructive to see how, when pressed hard with questions from the seeker after only well-verified knowledge, the most ardent advocates of favored scientific hypotheses admit the necessary distinction. For example, some years ago, in his pleased recognition of the significance of certain Western "finds," Professor Huxley is reported to have publicly proclaimed the still doubtful hypothesis of biological evolution to be on a par, for its undoubted truthfulness, with the law of gravitation. But did this man of science actually know, not to say sincerely believe, just that? Even the law of gravitation is, so far as the greater number of the physical masses in the universe is concerned, itself still an unproved hypothesis. In this 
connection it may be well to refer to those indubitable facts of our cognition of things in which all confidence in even the limited action of human intellects as applied to things, has its foundations: These are sufficiently summarized by Wundt ${ }^{1}$ as (1) the independent variation of the material and the formal constituents of perception; and (2) the constancy of the general properties of the formal constituents. But there is ample reason to suppose that the natural limitations of cognitive faculty prevent us from representing, without large admixture of error, both the variable constituents and the formal constants of things, precisely as they really are and actually behave.

At this point there enters into the doctrine of error another important consideration which is unavoidably due to the natural limitations of cognitive faculty. We have seen that all positice and detailed knowledge of other objects than the self-known Self is analogical. This would seem to render our alleged cognitive judgments more sure and defensible within certain middle grounds. What is here meant may be illustrated as follows: In the cognition of one's Self there is a certain region where all seems clear and undoubted. Here I, with a perfect assurance, know myself as I really am. When discussing the degrees and limits of knowledge (pp. $243 \mathrm{f}$.) it became perfectly evident what is this region of most clear and indubitable cognition. But surrounding this region, and separated from it by no fixed and indelible lines, are regions below, above, and on either side. There blends with this well-known life of mine a being that I know only much more indefinitely and doubtfully or not at all; it is characterized by obscure instincts, by animal impulses, by rague, inchoate, and unmeaning ideas, by unanalyzable and fitful emotions and sentiments. I may speak of this as the "lower self," if I choose. That of which it is apparently the analogue may be observed in the lower animals, or in

1 System der Philosophie, pp. $116 \mathrm{f}$. 
childish and savage human minds, or in the subjects of hypnotic trance, the insane, etc. Moreorer, when I try to understand the earlier developments of the Self I call my own, I find my observations most often baffled, and always somewhat sorely in doubt whether my own mental representations correspond to the reality there. In this lower region of obscurity and confusion, my cognitive faculty is likely to be, on account of its natural limitations of adaptation to what appears as a higher sphere of being, largely at fault.

Again, above the region of greatest clearness and certitude there seems to be another region of possible cognition, into which I enter with more or less of confidence as borne thither on the wings of analogy, but where I am not alike sure of being free from erroneous conclusions, - do the best I can do. In my own Self I find certain insights, anticipations, aspirations, confidences, and sublimer hopes and fear's, to which I give signification in proclaiming the cognitive judgment: "I am something more and higher than my present weak and erring human sclf." I, too, have a divine Being; the higher life of the Supreme Reality is actually present and operative in my life. This is, indeed, what I cannot understand or make intelligible to others as I can the judgments which affirm the facts and laws of the middle region of my experience with the Self. Possibly - nay, probably, and even assuredly - there is more of not only incompleteness but of positive error in the precise forms of those judgments by which concepts formed on the basis of such experience are united in a totality of mental representation.

And now I look wonderingly toward the heavens and. listen to the marvellous tales of the modern astronomer; or I peer through the microscope at the indefinitely small, and hear the biologist discourse concerning the mysteries of bacteriology or of the physiology of plants. To the huge masses overhead I ascribe force, obedience to law, and all the equipment necessary to playing their part appropriately 
in the drama of the universe. To the micro-organisms, too, I give an important place in the later acts of the same great drama, and speak boldly of their being and their performances in terms that are meaningless unless they imply some controlling principle from a sort of all-embracing Life. But it is chiefly when I contemplate the phenomena of human development, the ethical, political, social, and religious evolution of mankind, that I feel the impulse and the need to construct my conception of Reality, as a whole, in terms to satisfy this higher Self of my own. Let it be noticed, however, that, on the one hand, I am always bound in the interests of clear thinking to make this construction with a consciousness of an increasing danger of error as I get further away - using the same principle of analogy from the clear, middle regions of my own experience as a Self. But, on the other hand, I am at no time really forsaking the guidance of thought or making a blind rush into the by-paths of an irrational faith. I am simply extending the one principle of all cognition into regions which, while they are never to be separated by a fixed and unalterable barrier from those of our most assured cognitions, are, nevertheless, regions where the principle must be more doubtfully applied.

This, however, is itself a conclusion derived chiefly from the more purely intellectual considerations that bear upon it. There is need that it should be supplemented and possibly modified by considerations derived from the doctrine that all knowledge, judged from the point of view of its worth, is teleological; and that ethical and rsthetical "momenta" enter into all the higher forms of knowledge.

The metaphysical factors, or ontological functionings of mind in cognition, are natural sources of error. This is, of course, true only when these factors are themselves required or allowed to take part in that cognitive judgment whose truth or falsity is under consideration. All truth - 
such is the nature of cognition - flows from a sort of transsubjective compulsion; but we do not satisfactorily account for this compulsion when we follow Kant in ascribing it solely to the constitutional forms of the functioning of our own intellect. The rather is it also a necessity which has its source in the nature of extra-mental Reality. When, however, the attempt is made more carefully to define the character and the extent of this necessity, and to describe the laws or universal forms of its operation, we enter the realm where error is almost certain to mingle with truth. Some of such error, too, is due to the natural and unavoidable limitations of human cognitive faculty. For it is not possible by thinking alone, to know completely the grounds of one's own bcing, or to put into incontrovertible form, for knowledge, the laws which we actually follow in our cognitive commerce with the real being and actual transactions of things. We are here - in the embrace of Reality! But how we got here, no man may be able to tell; and in the attempt to tell, one is quite sure to commit not a few errors. Indeed, not a bad case might be made out for the apparently paradoxical statement that in those subjects which seem simplest and clearest to all men, most error is likely to be committed in every attempt to give to vague impressions the form of assured cognitive judgments. What other books have ever been written that contained so much which would not stand the test of the truth of Reality, as books on formal logic or demonstrative systems of general metaphysics? In the course of this treatise, we have had occasion to show how erroneous, in reality, are current conceptions regarding the principle of identity, the principle of sufficient reason, the essential nature of things, the principle of causation, etc., etc. ${ }^{1}$

1 According to Caspari (Grundprobleme der Erkenntnissthätigkeit, i., pp. 156 f.) three pseudo-concepts result from "overdriven" indiridualizing: (1) the $X$ of the Democritean concept of absolutely empty Space; $(2)$ the $X$ of the Leibnitzean "Pre-established Harmony;" and (3) the $X$ of the Herbartian "quiescent Cau- 
In the development and use of cognitive faculty, the judgments made may approach ever nearer to, and may finally become, a species of conduct. Thus some judgments are held to be, like every species of conduct, not simply correct or erroneous, but also commendable or blameworthy. For in the thought and practice of men, the possession of the power to know carries with it an obligation, under the recognized natural limitations from which no man can escape, to make our judgments true and not false. From this point of view also, actual errors are graded, in a rough way, from those into which the wisest man might be almost completely excused for falling, down to the most inexcusable and blameworthy of falsehoods and lies. Here ethics joins hands with psychology and logic for the execution of a work in which all have a common interest, - namely, the purification of judgment. But epistemological theory explains all such errors sufficiently for its purposes by simply pointing out that they may be ascribed in general to the unbalanced action of those different forms of functioning which are combined in the formation of every judgment. This view scarcely needs more than a single illustration or two. Thus in the use of the senses, under the control of will, undue haste may lead to the formation of judgment on insufficient data; but undue sloth and tardiness of morement in the Blickpunkt of attention may cause a similar erroneous result. Lack of emotional interest may at one time be a source of errors similar to those for which excess of emotional interest, at other time, accounts. In the expressly guarded and more refined observations of the physical and

sality." As pseudo-concepts arising from excessive generalizing, he instances the "mathematical Indeterminate," the "Absolute" - whether as Ding-an-Sich, Absolute Idea (Megel), Will to Live (Schopenhaner), or " the Unconscious" (Hartmann.) The source of about all metaphysical error is the attempt to explain light out of darkness. Thus we have Stoff-an-sich in one place and Form-an-sich in another. (This, we remark, is the really delnsive dualism, and not that of our concrete experience, as it actually exists between mind and body.) 
natural sciences, judgment takes up into itself the characteristics of the affective tendencies and forms of bias belonging to the investigator. The investigations of the psychological laboratory confirm what the most obvious experiences lead us to suspect; hour by hour, and respecting the simplest and plainest of matters, men judge wrong under a great variety of not wholly unavoidable influences. Thus the shrewd observer is always on his guard against being deceived by his own changing emotional tendencies, as well as by his more settled habits of conviction, and by the lower but always pervasive physiological and physical conditions. But this very shrewdness, when itself excessive and full of natural suspiciousness, has prevented many a man from knowing in a satisfactory way much of which he would most gladly have been assured. Indeed, the higher wisdom often leads one not to be too nice about details, lest one commit the graver error of misjudging or neglecting the important matters. And just as we are congratulating ourselves that we have thus escaped mistakes and have gained a firmer and more comprehensice grasp upon the truth of reality, we find some seemingly trivial oversight has revenged itself by convicting of error our entire carcfully prepared case. Neglected trifles have succeeded in throwing many a scientific brief out of the highest court of appeal.

It is with such experiences in mind that men often most eagerly and hopefully inquire after some universal Criterion of Truth. Surely, they think, the Spirit of all veracity should have provided them with a conclusive standard, a general infallible judgment regarding the necessary and universal characteristics of all valid cognition. If this can only be discovered and carefully applied, it will preserve them from every error. But a more seductive will-o'-thewisp than this was never proposed. There is no single, infallible means of testing truth - known, conceivable, or 
possible. If $a$ criterion of truth were discovered, we should indeed have all honest souls paying any price of industry and self-renunciation to possess so great a treasure. But the rery nature of truth as dependent upon the characteristics of the cognitive judgment is such as to render absurd the conception of a single and universally applicable criterion. The nearest approach one can make to the bare conception of such a criterion of truth is that evidence which is found in our clearest, most feeling-full and contentfull, voluntary self-consciousness. But the attempt to apply such a criterion to all human cognitive judgments would defeat itself in a most annoying, or amusing, or disastrous way. The very attempt would render all growth in knowledge impossible; it would bring upon one the charge of a ridiculous and monstrous egoism, and would prove quite impotent to tell one anything worth knowing about the real being and actual transactions of things. Moreover, the mind that demands such a criterion needs to be brought, in no gentle fashion, up against the chastening reminders that life consists in something more and other than sitting down to test judgments by a cunningly devised scale of absolute values. Better be happy and effective in action that is full of intellectual blunders, than be miserable and inactive through the effort to conform the intellect to so machinelike measurements.

Criteria for testing, in a more or less satisfactory way, the various kinds of judgments which their makers esteem cognitive, are not wanting, however. They are as abundant as are the different main forms of corrective discipline which human life affords for all who share in it. The whole course of infantile development consists in getting the - understanding and application of these criteria better in hand. The practical test of the child's early judgment that the lighted candle or burning coal is a species of good, to be made further acquainted with by taste and touch, is the 
experience which follows the effort to set that judgment into realization. Of all the so-called criteria of the falseness or truth of judgments, such practical tests, if obtainable, are most valuable. So that there is really no demand made which is out of the natural order when alleged truths of politics, ethics, or religion are recommended to a similar criterion. The well-known tests of scientific hypothesis and induction are not, in principle, markedly different. All criteria are included in the persistent effort of the individual and of the race to arrive at an harmonious and satisfactory experience. Such an experience necessarily includes all that can be gained, by growth of knowledge, toward an harmonious and satisfactory explanation of experience. But, as we have already seen, experience is much larger than cognition. And the sphere of cognition is larger than the sphere of judgment, even when the judgments are established by proof most satisfactory to the intellect. Knowledge itself is a vital body, a vital growth.

When, then, any particular alleged cognitive judgment is pronounced, it appears in consciousness, by virtue of its rery claim to be cognitive, as the solution of some problem respecting the real being and actual transactions of things. It carries within itself, for the mind pronouncing it, a demand for the acceptance ("Belief") either of some object of sense-intuition so-called, as a really existent other "notme," or of some truth about objects, regarded by the mind as resting on such or such grounds. It is this "reference for proof (in the wider and looser meaning of the word) to a somewhat separate from us, and not possessed by us, which gives their peculiar significance to the expressions of certainty and logical compulsion." 1 Thus the criteria of the first order for the testing of the truth of every cognitive . judgment are properly thought of as an integral part of the judgment itself.

1 See Volkelt, Erfahrung und Denken, p. 283. 
Any cognitive judgment may, however, have its truth challenged and the further demand made that it shall submit itself to a process of critical examination or testing. This demand may arise from within the judging mind, and thus constitute a proposal to apply the criteria furnished by other outlying factors of the individual's experience; or it may arise from without and because the alleged cognitive judgment is not found harmonious and satisfactory to other judging minds. In either case the pronouncing of the judgment is held suspended, as it were, until this particular alleged cognitive factor in the sum of experience can be submitted to a process of testing. Here not only will other judgments, more or less firmly established and built into the very texture of the mind, exercise their influence under the general demand for a conscious intellectual harmony, but also will the emotional prepossessions and voluntary tendencies of the individual mind contribute their share to the process. Nothing is more instructive on this subject than to notice how men, as an obvious matter-of-fact, apply tests to those new forms of judging truth which disturb the harmony of their mental life. In the last resort, no criterion lies further back or lower down than this same sense of harmony. But alas! there are few minds, indeed, which succeed in bringing into such an harmonious and satisfactory condition the various items of truth which their total experience seems to present.

In the larger life of the race the testing of truth, for the elimination of error and the confirmation of the truth itself, goes on through the ages in essentially the same way. Only here there is no wider and more inclusive experience to which the individual minds of any age may make their final and most convincing appeal. For, even if one admit the fullest reasonable claims that can be made in the behalf of revelations of truth that break in upon the race from the Source of all Truth, these revelations themselves can ulti- 
mately get accepted only as they are able to submit to essentially the same criteria; and being accepted, completely or partially, they become integral parts of that experience of the race which is itself the ultimate test. But to admit this statement is a very different thing from accepting the tenets of either the current empiricism or the old-fashioned rationalism. The depth and height and breadth of this difference can be appreciated only by recalling all that has already been said concerning the transcendent in human experience, and concerning the wealth of assured content which belongs to human knowledge, beyond anything that mere ratiocination can supply.

It appears, then, that there is no cause for overwcening confidence in man's cognitive powers to afford insight into the complete interior nature of Reality, as it were; but even less cause for despairing of all knowledge and for resorting to either a sceptical or a dogmatic doctrine of universal nescience. The plain man's consciousness, in his simple work-a-day transactions with things and observations of himself, cannot set itself up as the measure of all the truths of science and philosophy. It affords no so very penetrating insight into the real nature of things, and no systematic and well-reasoned cognition of Self. But it has in it the everlasting truth of the Ego's self-active Life; and it enables its possessor to make his own the ancient mystic saying of India, "That too art thou." The feeling of the unity in difference of the Self, and also of its oneness with the World, are present as the abiding truth of all such knowledge. "Cock-sure" science and arrogant philosophy, claiming either a perfect immediate insight or an irresistible apodictic, cannot vindicate themselves in the presence of a correct doctrine of human cognitive faculty; they contradict the experience of the race with both truth and error. But he who brings against science and philosophy the railing accusation which Milton more fitly brought 
against the makers of civil law, that they are perpetually "hatching lies with the heat of jurisdiction," cannot speak the few words of his accusation without implying an excessive confidence in his own science and philosophy. 


\section{CHAPTER XVI}

\section{THE TELEOLOGY OF KNOWLEDGE}

$\mathrm{O}^{\mathrm{c}}$ UR eritical examination of the epistemological problem has constantly brought us nearer to the place where it seems to merge itself with, and be lost in, the larger problems of all human life in its relations to Reality. And, indeed, what is more obvious than that knowledge cannot be considered as a phenomenon separable from the entire complex existence and development of the race? It cannot be explained as a kind of mechanical combination resulting from the fusion, under predetermined forms, of merely sensational and ideational factors in the individual consciousness. Other theories of cognition, too, which, like that of Kant, include an enormous amount of the purely formal a priori, but fail to admit the affective and voluntary aspects of the mind's life to a share in the cognitive attitude toward reality, are surely destined to show this original deficiency, either by theoretical inconsistencies and contradictions or by failing to afford a practical and ethical satisfaction. Men must live, and strive, and die, in the use of their minds. And to put the case in a superficial and popular but expressive way: If our mental faculties are not "made to live and die by," to guide us in our striving after every manner of truth, then either socalled knowledge, or the larger conceptions which we designate by Life and Reality, are vain and illusory. For the cognitions which men have, or think they have, and ever strive to get, they insist shall serve some purpose in relation to the higher and more comprehensive good. 
In brief, all ineritably regard their own cognitive faculties from the teleological point of view. In the higher realms of ethics, art, and religion, men are generally prompt enough to ask, "What is the use of trying to know?" How, then, can the student of pure science or of philosophy regard the teleological question when applied to his own favorite studies as unmeaning or impertinent?

And, indeed, the question of use, the attempt to bring knowledge itself under the conception of worth, is never unmeaning or impertinent. For every individual cognition, as well as the entire body of human knowledge, not only may but must be regarded from the teleological point of view. The very structure of cognitive faculty is subject to the idea of final purpose; and if knowledge is to be validated as a mental representation of the real being and actual transactions of things, then the idea of final purpose must somehow find its place in Reality, so far as known or knowable to man. Now, as to the illustration of the teleological idea in the very nature and development of all human cognition, there can be no doubt; for the facts and data for analysis exist where they can be approached and studied. But as to any corresponding application of the same idea to extra-mental Reality, our way of approach is over the bridge of that same analogical postulate, which has been found necessary to give validity to all knowledge "as to what" things really are. The necessity of escape from that extreme of sceptical idealism or agnosticism which has been found intrinsically absurd is, however, just as great in this case as in the case of any other form of the inquiry after the validity of human knowledge.

The nature of human knowledge, as revealed especially by a study of its origins and earlier developments, shows the indispensable part which action takes in the first apprehension of things. Only as the child does somewhat to things, and has somewhat done to him by things, can he come to 
know that they are, or what they are. Genetic psychology places this beyond doubt. It is matter of universal observation that the inactive child is backward in his apprehension of concrete physical objects; and-that the "dreamy" man is most apt to doubt the real existence of such objects, as well as least aware of how they are to be handled in order to "get the good of them." It is action that, moving along organic lines in the pursuit of ends, secures growth of positive cognition and banishes doubt. For, as has just been indicated, action, as soon as it becomes conscious volition guided by ideas, is teleological in its attitude toward the objects of sense. In the attempt to use anything, the child gains new knowledge of that thing; and the success or failure of his attempt, starting from the advanced cognitive point of view already gained, is a stimulus to the strife after yet more knowledge about the same thing. Thus does knowledge grow by use, in order to the end of improved and larger use.

From the point of view of psychological analysis, every mental event of a developed order appears as an illustration of the idea of final purpose. This is the scientific truth which leads to the epistemological position: No cognition can be considered as the mere equivalent of its psychic factors or psycho-physical causes. As Wundt ${ }^{1}$ has said, even quantitatively considered, every spiritual event surpasses its causes. Perceptions, regarded as mental constructs out of composite psychical factors, can never be explained by, or deduced from, their sensational and ideational elements. But, on the contrary, when we begin by considering what they are as concerned with the appropriation of things to our uses, and with the adjustment of all our changing relations to reality so as to live, and to live more abundantly, both as individuals and

1 So enthält ein räumliches Bild ausser den Empfindungsqualitäten, die in dasselbe eingehen, die specifische Qualität des Räumlichen, und diese Qualität führt extensive Massbeziehungen mit sich, welche zu den intensiven Grössen der Empfindungen hinzukommen. - System der Philosophie, p. 345. 
as a race, the completed perceptions, in the light of final purpose, impart a new meaning to their own sensational and ideational elements. If, from the more mechanical point of view, psychology is warranted in describing the perceptions as what they are, because of the sensations and images of sensations which enter into them, and even in maintaining that pereeptions exist at all only as the sensational and ideational basis is laid in the psycho-physical mechanism, still from the teleological point of view, epistemology also is warranted in holding that the active mind, in order to secure its own good, has selected and combined these particular elements into the totality of the perceptive construct.

Only as the full force of the teleological principle is admitted, can the fact be satisfactorily explained that percepts of the same things by different minds are so different. On this point it would better accord with a true doctrine of knowledge to say that only the telcological view of all perception by the senses shows us why things are so different as they are known by different cognitive subjects. For every man is forced to know things according to his capacity for receiring impressions and retaining and reviving ideas; but every man also consciously strives to know things according to the relations in which they seem to him to stand to his own purposes for attaining a good. Things impress one according to one's sensuous and ideating faculty; but one also knows them for what they seem worth to one in the carrying out of one's ends. To the man who cares to know nothing further, a Stradivarius is "no thing" but a fiddle. To the modern riolinmaker it appears a model replete with lessons as to the selection and disposition of various materials, the shaping and combining of parts, the soundness and texture of belly, back, and bridge, the curvature of sides, etc. But to its artist owner it is an instrument of his musical ideas and feclings, - an instrument, and something much more; it is a tried and sympathetic servant, a belored and comforting compan- 
ion. To the mind's eye of the physicist, however, it appears as a collection of molecules and atoms whose acoustic properties come under the laws of his science; or whose wonderful performances may furnish new problems to that science. But which of these - and if none of these, what - is the real violin? The very question, in connection with the experience out of which it arises, shows that all perceptive cognition of things is teleological; for perceptions themselves are mental constructs depending upon the selective action of will as guided by ideas in the conscious pursuit of some end.

The same truth may be maintained with reference to the construction and development of those abstract mental pictures which, speaking from the psychological point of view, constitute our means for the classification and recognition of things. The schemata, or general images of sensuous objects, are mental constructs whose very nature embodies and illustrates the principle of final purpose. Men's perceptions of things differ, according to the selective action of will in pursuit of ends; but their ideas of things differ in the same way more abundantly. One's mental image of a thing cannot contain sensational elements of which no sensuous experience has ever been given; but one's mental image of any class of things is even more dependent upon what one wants of those things; that is, upon one's perceptions. What is called a concept must be regarded as a mental construct ruled over by the principle of final purpose. It is described by logicians as a complex of marks that have been abstracted from a number of objects and combined into a totality which is valid for application to any one of those objects in as far as it belongs to the class. The concept of a "man" will tell you what $X$ is, as a man, simply; but it will tell you nothing as to "what sort of a man" he is; in order to know that, you must know $X$.

But I am no more set free from the rule of the teleological idea when I fall back upon the general conception of man, 
and agree with myself not to take the trouble to know $X$ in particular, than I ain when, equipped with this concept, as it were, I deliberately enter upon a "plan-full" course of procedure having for its conscious purpose the detailed acquaintance with this individual. For I may be forced at once to raise and answer the question: With what end in view have you formed your conception of a man? And to which one of the many possible sorts does this conception of yours answer? Is it the mere exterior semblance of an erect biped man; or the man scientifically defined from the point of view of biology and anthropology; or the business man's man, with whom one may barter, and whom one may estimate, for purposes of trust, by referring to the lists of some Commercial Agency? Is it the man as lie constitutes a possible constituent of some domestic or social combination; or man with an immortal soul to save or lose, according to the theologian's point of view? In any and every case it will appear that the concept must be regarded as a construct which has been framed from elements more or less consciously selected with particular ends in view. Its so-called "general" character is, indeed, supposed to be framed after the pattern of certain extra-mentally existent characteristies of a similar kind possessed by a number of individuals. And from this metaphysical point of view, the concept appears causally determined, irrespective of any use to which it may be put by a conceiving mind. But from the intra-mental, or rather the psychologico-social point of view, the truth appears, that all men want certain ends to be serred for them by their fellows; therefore, they agree in forming a so-called general concept of "Man," which may be regarded as established and made compulsory in its acceptance, quite irrespective of individual ends. Even this restriction to the limits of the control exercised by the teleological principle in its application to the conceptions of the race is only apparent. Indeed, the restriction itself illustrates the truth of teleology. For one finds one's self compelled to clas- 
sify men as both knowers and known, according as they have it in mind to be scientific, or commercial, or social, or religious, etc. And if one thinker feels bound to know no man after the spirit, but only after the flesh, others may side with the Apostle and declare: "Wherefore henceforth know we no man after the flesh." In which case it does not seem to be determinable a priori that one point of view will be any more arbitrary or unproductive of genuine knowledge than the other. The question may still be raised: Which is the real man to whom the true concept rightly applies?

In fact, however, both psychological and philosophical study of the nature of cognitive judgment has shown that neither perceptions nor conceptions can be understood as mental entities which exist in some sort of separateness from reality. For it is this judgment which creates them both; it is cognitive judgment which makes any of our psychoses capable of being brought to a standard and pronounced either false or true. It is continuity in the growth of the faculty of forming such judgments - more clearly, with richer content, with firmer and more unassailable reasons and corresponding convictions, under the control of developed will and in the service of higher and purer emotions - that binds together into a spiritual unity the entire life of the soul. Such judgments, however, always affirm some sort of relations as existent in reality. These relations, as the judgments affirming them become connected together into so-called chains of reasoning, are thought of as connections which actually exist between the different real beings and actual transactions of the world. Thus the connections themselves become a problem for the thought of man to solve; and in solving this problem it is necessary to consider them not merely as falling under the principle of sufficient reason, but also as subject to the idea of final purpose. This teleological necessity arises from the very nature of thought as leading up to the terminal judgment of cognition. Indeed, both the principles of sufficient reason 
and of final purpose originate in the same root of experience, - namely, in the consciousness of a Self which mentally determines its ends, in the view of certain fixed relations already known to be sustained toward other beings, and which directs its actions toward these chosen ends, while itself existing within a system of beings on which the results of its action are dependent.

In the work-a-day life of the multitude of men - that which is so significantly called "real life" as-distinct from the pursuits of the mere student or scientific inquirer - they think only in order the better to carry out their purposes. Thought, in its effort to put the thinker into correct relations with Reality, is definitively and consciously practical; that is, teleological. There is certainly something sublime about the way in which the meanest of human beings regards all other selres and other things. "What is it good for, to serve me?" - this is the chief object of human inquiry and research. The multitude are made indignant or aggrieved by the immense and fundamental forces of nature when these forces so elude their insight or calculation as to thwart, or even fail to further, their final purposes. Why should winds blow, except to swell the sails of their ships? Why should science discover new means of mining and reducing ores, of smelting and hardening metals, of driving and controlling carriages, except for the increased comfort of themselves and their families? Eren the cold, calm stars, so far beyond the influence of human passions and so remote from the more obvious connections with human interests, must needs be thought of as set to light and to guide their way by land or sea. All these things, and all other things, they will think or inquire about, only to know how better to realize some final purpose in the obtaining of good for themselves.

When considering the nature of all reasoning faculty as coming under the general principle supposed to control erery process of reasoning, we discovered that the end of erery such 
process is set by some terminal judgment. The particular judgment sought is knowledge valid for the relations of really existent beings. To quote (p. 308): "It appears, then, that the goal of that cognition after which the mind strives in its processes of reasoning is the establishment of causal relations." That is to say, Reality in its different interrelated manifestations is a problem to be solved, if at all and however partially, by consistent and persistent thinking. To reverse this statement, - and it certainly admits of being reversed without impairing its truthfulness, - all our more deliberate thinking is essentially teleological ; it is thinking toward the end of an improved solution of some proposition placed before the min'd in the form of a problem. Is the case really thus or otherwise? What do you judge about it? But if one's judgment is not already formed, or prepared to leap into consciousness with that firmness and warmth of conviction which indicates a readiness also to allege satisfactory grounds for itself, one must still think about the matter; and one will think soundly and successfully, indeed, one will think about this matter at all (instead of merely letting thought run wild), only if one's thinking be suffused with conscious final purpose.

It is true that many of the "best thoughts," both of the individual and of the race, "occur to," or "spring up in," or "flash upon," the mind when it is not consciously directed toward the solution of any definite problem; or, at any rate, they do not seem to be born of thought directed upon particular problems. In his strong despite of the work of intellect, that baser tool of Will which is indeed only a function of the brain, Schopenhauer exalts the function of intuition and the province of insight. Place yourself before the concrete image of the thing in Nature or in Art, and, without thinking, but the rather carefully abstaining from all that making of distinctions which is so fatal to the apprehension of the Idea, let the higher truth arise within you : such is his exhortation. We, too, admit the value of the contemplative 
as distinguished from the scientific attitude of mind toward Reality. We are prepared to maintain the validity of the judgments often largely arrived at by this method of cognition. The artistic and religious views of the world, or of any single meanest thing in the world, are not to be despised, either in the behalf of common-sense or in the name of science. But this way of using an alleged cognitive faculty only affords another kind of illustration for the correct epistemological theory of all cognitive faculty. Artists and seers, men of insight of every description, seek to interpret the meaning of the real things and actual transactions of the world; and all interpretation of meaning is peculiarly a teleological affair. So that art and religion - like philosophy in this respect, which, however, transcends both by comprehending them in harmony with the standpoints of science and of the ordinary work-a-day consciousness - habitually tell us the truth they have to tell, in its adaptation to promote the interests of the total life of man. The fact remains, however, that there is no such way open to truth as that which Schopenhauer, in his superabundant and ill-regulated use of figures of speech, describes and commends. Artists or religious seers, and men of so-called insight generally, must do a bit of clear thinking now and then; or others must do it in their behalf, if artistic and religious representations of truth are to enter into the organism of human knowledge. Every judgment which seers pronounce must still appear before the luman mind as a problem demanding thought for its better solution. Indeed, every announcement of a new truth or of a largely modified form of an old truth, is pretty sure to illustrate the teleology of all cognition, twice over, as it were. For it is likely to be set up, in the first instance, as entitled to reception because it gives new meaning and serviceableness to the organism of accepted truths; and then, by a process of testing, it finally becomes clear that this particular truth is entitled, on grounds of the valid connections it can establish 
with that organism, to be considered one of its useful members. The test of adaptation to the ends of truth never fails, in the long run, to be pretty rigidly applied.

The right to insist upon the inherently teleological nature of tlought itself might be indefinitely illustrated and confirmed by appeal to the procedure of all the particular sciences. All the sciences are full of unsolved problems, and these problems are being perpetually "investigated" by deyotees and experts in these sciences. He who does not know what the problems are, and how in general goes the approred method of attacking them, is little likely to increase the body of cognitions which constitutes his particular science. But investigation means a "following in the tracks of," a hunt after, some cognitive judgment or set of judgments in which the problematical attitude of mind may come to a settled and peaceful termination. And, however much of experiment and mechanism may be used as a means of the investigation, all this is merely a matter of conrenience, which is wholly external to the epistemological doctrine concerned. For the experimental method and the mechanical helps only furnish the guides, the checks, the fixed points of attainment, for the thinking process. Investigation is not a matter of the smootl running of machinery; nor are discorery and verification always most abundant where appliances are most numerous and costly. The thoughtful mind must be supplied, in order to follow the tracks of fact and of accepted law, in the hunt after valid and appropriate cognitive judgments. Thus does thought itself show most obviously in collcrete form its immanent teleolngical cliaracter.

Few things about the development of human knowledge, as illustrated from the history of the particular sciences, are . more impressire than is the multiplication of problems brought about by every solution of a problem. The more men know about the world of things, the more do questions present themselves about which they must inrestigate further in 
order to know. In these further investigations the answers already obtained to the older problems may be used as known quantities; but this very use either reveals a large number of quantities still unknown, or it throws the previous solutions into doubt, so that the old problems recur in modified form. Never before did the picture which human knowledge enables us to draw, of the real beings and actual transactions of things, itself present so many features that require for their clearer delineation yet further and more complicated investigations. So often as we feel at liberty to substitute $a$ and $b$ for some $x$ and $y$ in a problem, because what was an unknown quantity has now been reduced to terms that we can comprehend, new and hitherto unsuspected unknown quantities appear ( $z$, etc., adrancing in number toward $n$ ). Not infrequently some coefficient must be added to our $a$ and $b$ which converts them into terms much more difficult to handle than the original $x$ and $y$ appeared to be (perhaps even into a $\left.\sqrt{-x^{2}}\right)$. Thus is all growth in scientific knowledge compelled to regard itself as dependent upon the use of past thoughts in order progressively to enlarge and purify the body of such knowledge. Each single cognition appears not to have its end in itself ; the rather is it of use to suggest new problems to thought and to aid in the solution of those problems. But as these, in their turn, being at least partially solved, become incorporate with the body of cognition, they also must be made to serve a new day and a more exacting generation of explorers.

This teleological connection of the truths which constitute the body of scientific knowledge, regarded as mere knowledge, might be further illustrated by considering how the different particular sciences admit of arrangement under the idea of final purpose and as respects their reciprocal relations. The very nature of the cognitive judgments with which they respectively busy themselves, is such that the sciences serre each other's ends, as those placed higher in a roughly graded 
ascending scale of values come nearer to the most complex and important interests of human life. Note, here, how eager the students of each particular science are wont to be in the defence of the claims of their own science to a high place in this scale; how jealous of its honor in answering the demands to display these claims before men; and frequently how grasping and mean in the spirit shown toward the students of some other and rival form of science! Thus is one compelled to listen to the arrogant demand that all assured forms of human cognition shall be reduced to physical or chemical phenomena; and we who are students of psychology as the science of mental phenomena are summoned to acknowledge unquestioning allegiance to "authorities" - too often self-erected and the more disposed to be domineering - in biology or anthropology.

But even the weaknesses and vices erinced in such contentions are instructive. More and more obvious and indisputable is it becoming that no one of these great departments of human knowledge is going readily to absorb the others. The strength of every piece of wood or metal, the behavior of a twisted wire or of a bit of magnetized iron, the construction and use of any simple machine, require much more than mathematical physics can furnish, in order that they may become objects of scientific cognition. But the principles of mathematical physics may be regarded as the indispensable means for the attainment of this cognition, and for reaching one of the ends for which these principles are fitted in the service rendered to such cognition. The chemical constitution of the simplest compound substances, and the laws of the behavior of the elements which enter into this constitution, afford problems which physics is entirely unable to solve. But physics affords a species of knowledge which is essential in order to solve the problems of chemistry; its study is subsidiary and auxiliary to the end which a knowledge of the atomic structure and atomic qualifications of things real- 
izes. Many heroic attempts hare been made to conrert biology into a purely physico-chemical science; but they hare all been baffled hitherto, and the progress of the more complex study of living beings is constantly outstripping the increase in the outfit of means which such physico-chemical science supplies. Not an amœba, however obviously undifferentiated even as respects endosarc and ectosarc, and not a germ of any lowest order of plants, that does not offer problems before which the combined efforts of physics and chemistry are forced to acknowledge their impotency. Yet the scientific biologist must study physics and chemistry in order eren intelligently to approach the study of biology. If, now, we go on from this point of view to arrange the remaining branches of the scientific tree in accordance with any of the current schemes, we only illustrate and enforce the same truth: All the particular sciences may be looked upon as necessary and serviceable to the completer and more satisfactory knowledge of the history of human derelopment.

If, however, a scheme for the arrangement of the sciences should be constructed from some other point of view than that for which the understanding of the unfolding life of the race is the final purpose to be served, this altered scheme could not be free from obligation to illustrate the teleological idea. Such are the connections, in fact, amongst the various cognitive judgments that, in order to test and improve or enlarge any particular group of such judgments, we have to make use of means derived from other groups. If the body of human knowledge be not considered as built after the likeness of the human body, where, from one point of view, all the other members may be regarded as serviceable to the supreme and controlling portion of the nervous system, still it must be regarded after the analogy of some sort of an organism. A system of cognitions that sustain no relations of reciprocal dependence and ministration to the whole body of cognitions can scarcely be conceived of as existing within the horizon 
of human thought. If the vertebrate be not a favorable type for our fittest figure of speech, let it be the radiate or the molluscan. These, too, are plans of structure, and thus evince the immanent teleology of human thinking. Lower forms of knowledge in order to higher forms ; or one branch of knowledge running in one direction away from a common centre in whieh other branches, radiating differently, take their rise ; or a hard shell of external fact, which seems lifeless but surrounds the mysterious and vital "pulp" of truth, — use what analogy one will, the thought of the different sciences is so related that no student in any one of them can free himself from the necessity of serving them all.

Thus far the teleology of knowledge has been considered as immanent, so to speak, in the very nature of knowledge itself. Each partial activity or stage of eognition has been regarded as serviceable to some other cognitive attainment or advanced stage of cognition, - a certain knowledge to the end of more knowledge. The particular bodily activities in eommerce with things, the aets of attentive perception, recognitive memory, and ratiocination have been explained as looking to something lying beyond themselves ; and the systems of cognitive judgments grouped together into the so-called sciences have been regarded as serving to advance each other's interests. Thus does knowledge exist, and grow, for knowledge's sake; but we eannot, howerer, regard this as a satisfactory statement of the final purpose most obviously served by human cognition.

Is knowledge ever - whether one has in mind some particular eognition or the entire development of cognition for the race - an end in itself ? This is a question to which neither an offhand affirmative nor an unqualified negative affords a satisfactory answer. The sehoolboy, whining over his tasks and rebelling against the limitations thus enforeed upon the joyful exercise of his powers, angrily inquires as to the use of what he is about. How much of all "the stuff" he is set to learning will repay him any form of good in his future life? 
Observe that the request, however disrespectfully made, is reasonable: he will have his knowledge serve his Self. But if his present point of view seems to be selected too much in the interests of selfishness, let him be inquired of, whether he does not think that his knowledge should also serve other selves than his own. It is not unlikely that a fair answer may be obtained to this suggestion, and that the boy's investigations into the teleology of knowledge may be so modified as to shape the question thus: Of what use to my Self, or to any one else, will it be, that I should acquire this particular knowledge? Now before the profoundest student of epistemology undertakes the discussion of this question, even as it is asked from the point of view of the most ignorant tyro, he must take his choice of one of two possible epistemological positions. Either he must affirm, or he must deny, that knowledge is rightfully to be held responsible in the demand to show its usefulness for any end lying outside of itself. Confusion upon this point is by no means confined to those whose nearer relations to the petulant schoolboy force them into unthinking answers to his inquiry. For example, the biologist may defend the tenet that the very existence of cognitive mind in man is satisfactorily explained by showing the usefulness of the more primary stages and subsequent developments of mind in the struggle for existence. Mind is of use to the end of life, - mere life, and more and more of life. But now let the biologist be asked this question: Of what use is your own theory respecting the evolution of life (Lamarckian, Weissmannian, or other) in promoting the fuller and higher life of man? Can he then consistently fall back upon the alleged truthfulness of his own theory to justify it in its seeming attacks upon those faiths and hopes which are good for men to live and die by?

When the question of the teleology of knowledge takes such shape as the foregoing, we begin to realize the awkwardness of our mental situation. On the one hand, we cannot satisfy our total consciousness with the unqualified claim that knowl- 
edge is an end in itself; and that it may therefore rightfully be sought and, when found, promulgated to others without the slightest regard to its ministrations in the service of a higher and more comprehensive good. On the other hand, we feel it unworthy of our rational manhood to regard the use of the cognitive faculties of man as having merely an instrumental value; and we shrink from the estimate of the efforts and attainments of science and philosophy solely according to the services they render to the material advantages of humanity, or even to the increase of their pleasures and the alleviation of their miseries, as though it were a narrowing and degrading estimate. This is an apparent antinomy of a practical rather than of a purely theoretical sort. It admits of solution only if the limits of purely epistemological discussion be somewhat transcended, and the philosophy of ethics be taken into account as furnishing a possible standard for the required estimate. In other words, the question has now become so comprehensive in its bearings that it requires light to be shed upon it from one's view as to the total nature and supreme ideals of the Self. But surely there is nothing introduced which is intrinsically foreign to the answers already given to the epistemological problem, now that the question has been definitively raised as to the meaning and final purpose of our total personal Life. For these answers themselves showed that this same Self is all concerned - intellect, feeling, and will - in every concrete cognition. Nor can the development of the individual Self, in its total being, be divorced in theory or in practice from the growth of knowledge; and the same thing is true concerning the evolution of that complex organization of selves which is thought of as the human race. But, further, the world of things - NATURE, "writ large," and made imposing by the use of capital letters - is known only as revealed upon conditions furnished by the development of the Self, and as actually possessed of qualifications analogous to those which we know ourselves to possess. How, then, can it 
fail to be true that the question as to the meaning and the final purpose of all human knowledge becomes merged in the question as to the total nature and ideal ends of Sclflood? The epistemological problem is answered by reference to the aims of the Being that realizes the highest and best conception of Life. Cognition is part of the very life of the Self; but it is not the whole of that life; it serves that life in its striving after the realization of its ideals.

The complaining schoolboy is told that he must acquire knowledge in order to be happy, respectable, influential, successful in life. For it would be disgraceful for him to remain in ignorance; uneducated, he could never succeed with his fellow-men ; and "knowledge is power." So far as all this is true and has a bearing in the direction of a defensible answer to his complaints, it means that knowledge is an indispensable instrument to a better and more content-full life. Those sciences, like chemistry, botany, zoölogy, physiology, bacteriology, psychology, and the so-called science of sociology, which stand in closer relations to the practical interests of men, are fond of slowing how much they have done, can now do, and hope to accomplish, for making the existence of men more tolerable and happy. Meteorology has helped to make the farmer surer of his crop and the sailor of his craft; and do we not all thereby know, at least a trifle better, when it is safest to go without umbrellas or orercoats? The world of manufactures has been built up, and the world of finance convulsed, by the rapid increase of knowledge in metallurgy. Even the student of the higher mathematics and the wakeful watcher of the stars put forth a less boisterous claim that somehow - very indirectly oftentimes, to be sure - the happiness and prosperity of the race has been increased by their discoveries.

And, indeed, the history of the physical sciences shows that those truths which at first seem most remote from the lives of men not infrequently become closely connected with their 
very ordinary but important interests. In bacteriology and physiology, for example, it is not unlikely that to the theoretical interest in the problem of life, rather than to the benevolent desire to benefit mankind, must the recent helpful applications of these sciences be ascribed. But this only illustrates how man, in the conscious and deliberate pursuit of knowledge, most often actually serves the end of improving the condition of mankind. The discoverers in physical science are thus justly to be reckoned among the great benefactors of humanity. Psychology, too, having withdrawn its long-standing offer to theology of an "apodictic" proof for the immateriality and immortality of the human soul, has recently promised to render invaluable services to pedagogy and to the therapeutics of the insane and of the criminal. While an indefinite number of groups of empirical data, some of which have hitherto received only a very vague speculative treatment, are now, under the name of "sociology," striving to attain a high grade of approbation from the public, by offering the services of the science into which they have been agglomerated, for the improvement of actually existing social conditions. What if, for the present, the will must be taken for the deed? All these branches of knowledge virtually confess that they have not their end in themselves, as knowledge merely, but that they exist and grow in order to enlarge and ameliorate the total existence of man.

Science, however, is not satisfied with so much of such service as it has already furnished or can hope to offer in the future. It spends months with the microscope over diatomaceous deposits or volcanic ash, examines, describes, and classifies the wonderful minute forms which it discovers, publishes the results, to the credit of the investigator and perhaps in the name of learned societies; and then all minds interested in science agree that such work is admirable and worthy to be done. Who would not be justly indignant at the suggestion that the benefit of all this expensive work is to be measured 
by the possible discovery that deposits of the one kind may be cmployed as polishing powder or as a non-conducting packing for steam-pipes; and that deposits of the other kind have their most important use in the manufacture of soap? But, after all, why should science go into such matters; and of what real use is much of the knowledge of this kind?

At the other end of the line from this infinitely detailed description of natural matters-of-fact stand those forms of knowledge, or those attempts at knowledge, which are most purely abstract and speculative. We have already referred to the case of pure mathematics in another connection. It was there shown that the truth it discovers is not the truth of things, but the truth of possible connections between abstractions derived from the quantitative aspects of things. More deeply considered, it appears as truth concerning certain forms of the perceiving and thinking - the actual transactions - of a reality called mind. In other words, in no other speculations is thought dealing so purely with its own abstractions as in mathematical speculations. But now let the question as to the final purpose of such cognitions be raised; and to repeat the answer which is usually given to the schoolboy groaning over his first sums in arithmetic, or to the academician struggling with the new geometry or with calculus, - namely, that the acquiring of this kind of knowledge is in the interests of "mental discipline," - is to subscribe, in almost too easy-going fashion, to the supremacy of a narrow teleological idea. No one likes discipline or seeks it for its own sake. All, howerer, like activity, enjoy being alive in some way; and all discipline is to the end of a fuller, richer, and higher life. If, now, we declare that the enlarged capacity of human life, - not only, and perhaps not chiefly, intellectual, but æsthetical and quasiethical, which these studies in mathematics and the natural sciences bring - is the end to which the discipline of acquiring such cognitions tends, we surely shall not be so very far astray. It is not vapid sentimentality, but the application of 
truths forced upon us by our entire epistemological inquiry, when it is said: Such knowledge is worth while if it makes human souls stronger, more beautiful, and more happy. Like all other knowledge, it exists and grows in the interests of the Self, and for the better progressive realization of the consciously aceepted ideals of the Self. But in saying this the essence and the meaning of knowledge have been absorbed in the spliere of conduet.

There are certain cognitions, or attempts at cognition, which belong more definitely to the moral and religious sphere. With regard to the realities corresponding to these classes of judgments when they assume a cognitive form, the actual attitudes of men are exceedingly various. The average man, who has neither great store of seientific knowledge nor gift of reflection and speculative thinking, seems to hold a position toward the alleged truths of ethies and religion that belongs to a sort of middle ground. These truths are not so sure for him, nor are they given in the same way to his cognitive faculty, as are the ordinary aceepted truths about material things. He has a different conviction, and a larger assured content of knowledge, when he is talking or thinking about his material surroundings, having just left off talking and thinking about facts and principles in morals or about the existence and attributes of God. But he may be readier to assent with heart and head, to take the attitude which he identifies with that of knowledge, toward the fundamental truths of morals and religion, than toward the speculative mysteries of atoms, or of ether, or of fourth-dimensioned space, etc. Moreover, he is disposed to be liberal in his demands upon things for a perfectly constant and intelligible behavior; if only his newer and more surprising cognitions will minister to a longing for the unfathomable, and to an interest in the world as a possible home for human Selfhood in its infinite capacity for life and for development.

We are not just now writing a treatise on Ethies or the 
Philosophy of Religion. We are not eren discussing what, in special, are the foundations and the criteria of truth concerning these subjects. We believe, however, that such truth originates in and is rendered objectively valid by, the attempt to harmonize our total experience substantially as all truths originate and are rendered objectively valid. What is now to be noted is that the more plain teleological import of the truths of ethics and of religion is, in itself considered, greatly to their advantage. To think on Freedom, God, and Immortality, and to attain such items of knowledge - such facts, conceptions, and judgments although involving large possibility of mistake and even no little error - as may be had by a diligent, judicious, and prolonged endeavor, is best worth the while. For in their relations to that final purpose which all knowledge serves, and which has been somewhat vaguely defined as the enlargement and elevation of the total life of the Self, these subjects are of pre-eminent final purpose. Knowledge of diatoms, and of the bones of extinct animals, of the probable order of the strata as affecting the possible arrangement of the biological series in accordance with the Darwinian hypothesis, is a good to be obtained, if possible. But one ounce of knowledge as to how the soul of man shall attain the better realization of its own ideal is worth tons of information as to fact, or of speculative theory, as put forth by the researches of the foregoing forms of natural science.

The statement just made is true, however, only in case one is tempted to serer the rital ties which are meant to bind all human knowledge into the greatest possible organic unity. If the eager advocate of the value of scientific knowledge for its own sake is also disposed to depreciate the alleged truths of morals and religion because of their nneertainty and uselessness from his own standpoint, he may be reminded of the following two epistemological principles: All human cognition implies a willing; believing, and sympathetic Self; and all cognition has its end in the cnlargement and eleration of the Self. But 
it is time to consider another important aspect of the teleology of all knowledge. To state this aspect as it now appears in its most obvious and extreme form: The particular cognitive judgments, and the sum-total of cognitions present at any particular time in the history of the individual, or of the race, must be considered in the light of the principle of final purpose; but knowledge itself has been seen to be a certain attitude of the mind which implies a correspondence between mental representations and the being and transactions of the really Existent; it follows, then, that the principle of final purpose must be immanent in all Reality, so far as known or knowable to man.

The conclusion just announeed may be arrived at and stated in a somewrhat different was. Human experience, when it becomes cognitive, becomes essentially trans-subjective. This is, indeed, the essential thing about cognition; it is this qualification which gives epistemology its central problem. But at its birth, and at every stage of its growth, the system of cognitive judgments not only follows the principle of suffieient reason, but it also goes in the direction indicated by the end desired to be gained. Only in this way does cognitive faculty fulfil its appointed mission. I want to know; I inquire and reason to know; I actually attain to know, because I want to reach some form of good, or to avoid some form of evil. And even that experience which I have with real things, so far as they do not scem to be connected with my more immediate practical interests, appears significant as a complex in which cognition is directed by, and subordinated to, the end of a larger and higher life. Now this trans-subjective quality of all knowledge, which carries with it the validating in reality of the principle of sufficient reason, does the same thing with the principle of final purpose. The objects of cognition are known not only as connected into a system of interacting beings, but also as related to each other under the principle of final purpose. They are known as actually thus 
related; and this as truly and obviously as they are known to be, in reality, causally connected. Here, again, however, just as one is obliged to turn to one's most primary experience of the Self in order to find out what it is to be, in reality, causally connected, so does one have to turn to another aspect of the most primary experience of the Self to discover what it is for the idea of final purpose to be immanent in Reality. And just as all human knowledge of what Things are, in respect to their interdependent forms of activity, is framed after the analogy of this experience with the Self, even so is all human knowledge of the ends which things realize dependent upon the postulate of an analogy that arises in the same Solf as its source.

The critical doctrine of the immanency of final purpose in Nature belongs to Metaphysics and to the Philosophy of Religion rather than to Epistemology. The same doctrine belongs also among the discussions of the philosophy of conduct and of the beantiful. The unirersal presence of the teleological idea in all branches of philosophy, silently awaiting either the scornful rejection, the uncritical reception, or the patient examination of every profoundly reflective thinker, is itself an instructive epistemological phenomenon. It proves that some kind of a teleology must form a fundamental part of erery system of philosophy. How, indeed, could the fact be otherwise, since all knowledge involves the entire life of the Self; and since each cognitive judgment about things known as not-selres ascribes to them some quality, or action, or relation which is derived, in accordance with a postulated analogy, from the depths of the Self?

But do the objects of human knowledge, in reality, exist and behave for the actualization of final purposes, as they undoubtedly seem to us to exist and to behave? The fuller answer to this inquiry is not a problem for epistemology to undertake. Yet the critical doctrine of knowledge has already put before us certain trutlis that offer a partial answer, and 
that suggest lines of thinking along which one may follow in the hope of attaining much toward the fuller answer. When the object of cognition is the Self as known by itself, there can be no doubt as to what the answer must be. I know that I am, in my real being, a living embodiment of the teleological principle; and that it is actually the explanation of much which I do. This is only to say: I know that I am so constituted as to set ends before me for realization; and that much of my action, including my use of cognitive faculty, is, in fact, controlled by the principle of final purpose.

But while proceeding along this line of inquiry for ends, as along that line which the principle of sufficient reason marks out, the mind comes upon not a few errors; and I quickly reach the place where limits of nescience meet the eternal effort to get an answer to the question, "What for?" as well as to the question, "Why?" The outfit of human faculties, body and mind, roughly considered, may be brought under the teleological idea; but to the finer and more complicated questionings after the supreme ends of human actirity and human life, only answers that are either highly conjectural or obviously liable to large admixtures of error can, in general, be given. Even so, however, this case is scarcely more hazardous than is the case of those answers which plysiological and psychological science gives to the inquiry after a causal explanation for the structure and functioning of the same faculties. Indeed, the causal explanation of all states of consciousness cannot be satisfactorily put forward without large recognition of the immanence of the idea of final purpose in the actual life of the Self. I know myself as actually adapted for, and striving after, certain ends; no class of judgments can be clearer or surer than such as affirm the knowledge of these ends.

What is true of self-knowledge in this regard is also true of the knowledge of other selves. We know our fellow-men as objects in which the idea of final purpose is immanent, - 
necessary to explain to us their nature and their behavior. What is matter of envisagement on every man's part for himself is matter of incontestable inference for the real being and actual transactions of other men. Indeed, without the growth of experience along the line of the teleological idea, all knowledge of human nature is impossible. All the sciences treat of man as a being capable of consciously adopting ends and of making them determinative of his actions in the pursuit of these ends. What is called "practical acquaintance" with humanity, and the happy knack both of understanding others and of influencing them in conduct, consists largely in this rery kind of cognition. Even to speak of having a science of man, in his complex relations to nature and to his fellows, that should be built up in complete disregard of the principle of final purpose, would be to utter a mockery.

The higher species of the animals below man are also known as actually possessed by the principle of final purpose, and as acting and developing in certain ways rather than others, because they pursue ends that are set by some conscious form of good. Only very recently has modern biology shown signs of a return to a larger sanity of mind in its attitude toward teleology. It may be - indeed, it seems to be the truth - that man alone is capable of setting before himself the attainment of knowledge as something valuable for its own sake; and a fortiori man alone can hold up in consciousness, and pursue in conduct, the ends set by the ethical, the æsthetical, or the religious ideals. Neither do the lower animals appear to have the mental equipment necessary for selecting eudæmonistic ends that are rery complex and elevated, or that are realizable only in the distant future, and by the patient combination of complicated instrumentalities. Less evidence is there that any of these animals ever holds up in consciousness, as an end of effort, the realization of his selfhood in accordance with a consciously accepted ideal. Now this is precisely what erery human being does who be- 
comes developed into full ethical consciousness. All the animals of the higher species, however, - and, indeed, it is becoming increasingly difficult to say how low down this same observation may not extend, - are known obviously to acknowledge the presence of the idea of final purpose. Their real being and their actual transactions cannot be expressed without vindicating the applicability to them of the teleological principle. Indeed, some of the advanced seers of biology and of comparative zoölogy even dare to predict that whereas not long ago it was proposed to make psychology a brancl of biology, and biology a branch of physico-chemical science, the next era will see biology itself treated largely as a species of psychology.

He who can watch the embryonic development of any animal without once thinking of change and growth in accordance with immanent ideas, must have strange powers of thinking indeed. A critical metaphysics can show that no conception of any real thing, however mean in nature or strictly "material" in structure and behavior, can be framed without availing itself of the "immanent idea." But now let it simply be noted that the advancing knowledge of all beings which really live and actually grow, falls, of necessity, in large measure under the influence of the principle of final purpose. Every answer to the question, Why do the embryonic changes occur in this rather than some other way?-a proliferation of cells here, an aggregation of cells there, a wonderful differentiation of what hitherto appeared homogeneous in one place, and in another a multiplication and massing of similar elements - must always appeal for help to teleology. The scanty knowledge gained by observation as to the efficient canses which control the development of a complex organism from an impregnated ovum does not reliere the mind from the necessity of considering the final causes of the same history of development. The truth is rather that increased complexity of the known efficient causes only 
emphasizes the need of an opportunity to regard them all in the light of the ends they appear to serve.

One service to epistemology, as well, as to the current theology, was done when the special and restricted application of the teleological principle to the more complcx of the animal organisms was so vigorously contested. The necessity was emphasized of either applying the same principle to the entire world of objects, or of withdrawing it from this special and restricted sphere. On the one hand, this necessity saragely shook the confidence in our complete ability to define within any sphere all the ends which the mind is warranted in conceiving as immanent in the real being and actual transactions of things. It also compelled a confession that the bridge of the analogy on which we cross from our own limited and self-contained, most obvious final purposes to the teleology of all Reality, brings the inquiring mind into a region where something more than eyes trained to behold the niceties of mechanical adjustments are needed for vision of the whole truth. The roices that speak, not only of moral goodness and of beauty, but, as well, of the awfully dark and tragic side of Life, must now be heard. Looking and listening may only carry our cognition up to the outer fringes of the all-comprehending truth. For this truth has to do with the all-inclusive and ultimate Reality. But, on the other hand, the same attack has led to a more cautious but vastly more comprehensive extension of the current teleology, and, under it, to at least half-truths, to ralid intimations, and to reasoncd faiths that strive to harmonize all the objects of our knomledge with the demands of the total Self. These objects thus become, not merely interconnected beings and transactions obedient to law in fact, but "moments" in the Life of a Being that is actually realizing its own immanent ideas. 


\section{CHAPTER XVII}

\section{ETHICAL AND ESTHETICAL “MOMENTA" OF KNOWLEDGE}

$T_{\text {their apprehension and the more subtle and profound truths require for }}^{\text {HAT }}$ ration, is a statement which has often been rendered of practical effect. This statement is commonly thought to be especially applicable to truths of ethics, religion, and art; but it has been by no means confined to such truths. Current views as to the nature of this preparation of soul for a certain kind of commerce with Reality - if we may in a figurative way state a truth already discussed - have differed greatly. But in general the doctrine has been supported that the character of the preparation must bear some relation to the character of the truth which it is designed to gain. Thus, for example, in case the truth sought for belongs to the sphore of ethics, the preparation itself should be ethical. An ethicoreligious attitnde of mind and turn of development are then considered necessary for the apprehension, discourse, and application of the truths of religion. Again, philosophical problems can be comprehended as problems, and their approximately satisfactory solution found, only by one who approaches them with a certain training and in an appropriate frame of mind. Did not Plato make Eros the sole guide to intercourse with the Ideas? and did not the very word "philosophy" originate in the thought that its truths reveal themselves to those who seek them with a suitable affection? Eren in those pursuits of the physical and natural sciences 
in which spiritual attitudes and conditions might properly be considered of least account, one hears much of the "scientific spirit," and of the "methods of research" which this spirit encourages and actually pursues. In some quarters it seems to be held that a certain peculiar mental fitness is essential for the observation of details of fact, as well as for the deepest insights, highest flights, and broadest surveys, of the larger work of science. Indeed, so much of late has this so-called "scientific spirit" been eulogized, and so diligently cultivated or zealously assumed, that the very demand for it has frequently bred a display of narrowness, bitterness, and contempt toward certain most precious, if unscientific truths.

In this same connection might be noticed the many positive errors and the failures to reach more than half-truth that are currently ascribed to a lack of fitness for some particular kind of cognitions. Indeed, some men are thought to hare become so biased toward truth generally that, as the popular saying is, "They cannot see it if they want to ;" or, "They do not know it when they see it." On the other hand, all thoughtful critics praise a certain geniality of spirit, or hospitality of mind that keeps open house, and gives cordial welcome to any kind of truth. When such authorities express themselves with severe caution about matters to which they have giren attention, their opinions are more highly esteemed than are the most verbose demonstrations of their contemporaries; and when they say, "I know," even other experts of contradictory but well-considered opinions are brought to a respectful pause. Frequently, in the growth of the knowledge of the race, have a few veracious spirits reversed the judgment of the multitude.

It is customary to account for such facts as the foregoing by simply pointing out the influence which human interests and emotions exert over the opinions of all men; and, perhaps, also by recognizing the limitations which belong to the cognitive opportmities and attainments of the individual and 
of the raee. When considering the sources of error, we took occasion to look upon the matter in this light. But there seem to be some mueh deeper trutlis here for the philosophy of knowledge to investigate. Epistemology we have considered as a doctrine of truth implicating reality, rather than as a physiology and therapeutics of error and illusion; and this doctrine does not permit that the verities of ethies, art, and religion should be looked upon merely as subjeetive beliefs or sentiments, after a criticism of cognitive faculty has resulted in confining all knowledge to phenomena of the senses. Neither does it permit the distinetion between "Appearance and Reality;" as though what men esteem to be knowledge were all illusory and, in essenee, "infected" and "self-contradictory;" while reality is apprehensible only by the favored few, after it has been sublimated and idealized to the vanishing point, in a way of which no account ean be given that is intelligible to either faith or understanding. On the eontrary, we have been steadily winning our way to the position from which all cognition may possibly be regarded as a species of conduct; and from which all eognitive judgment implies a correspondenee of the being and activity of the Self with the being and transactions of Reality. We cannot stop or draw back from certain other suggestions and conclusions, just at this point. A few steps further on, and all the epistemological problems which have been raised may be handed. over to metaphysics, to ethies, to æsthetics, and to the philosophy of religion.

In the formation and criticism of every alleged cognitive judgment, the entire mind of the subject, whose is the judgment, takes part. The knower is all in the knowledge; and the cognitive judgment is, for the time being, an expression of his total selfhood. But this subject of knowledge, this knower to whom all the judgments belong, is a human being, developing to maturity in the possession and use of all the faculties of man. He is not merely a knower of truth, as logically deter- 
mined and presented, but also an ethical, æsthetical, and religious being. As is said, in the use of a familiar abstraction, man has a moral, an artistic, and a religious, as well as an intellectual nature. But human nature is one; and man could not be the subject of conduct, the creator and critic of the beautiful, the maker of, and believer in, that Absolute whom "faith calls God" (or even, the "gods many and lords many"), were he not also an intellectual idealist and a metaphysician. An idealist and a metaphysician, in all his cognitions, man certainly is. How, then, can the reversal of this proposition, in some form, be escaped? How can man know aught, without potent influences from his ethical, æsthetical, and religious nature? Must it not be that all human knowledge will be suffused with influences from this complex ideal nature of man's? In a brief consideration of the affirmative answer to these questions, the epistemological problem comes into connection with the general philosophy of the ideal.

But we shall not catch the true import of the foregoing inquiries, if the word "influence" be understood in too external a way. The different aspects or sides of human nature do not stand apart, as it were, from the ordinary working of cognitive faculty; although, undoubtedly, the effort is sometimes unfortunately made to treat them as though this were the case. The rather must they all be considered as factors, or "momenta," essentially present and effective in the integrating process that gives the object as a totality to the mind, and that shapes the actual synthesis in which the cognitive judgment consists. In a word, whaterer be the object of cognition, - stone, tree, star, or fellow-man, - and whatever be the particular character of the truth concerned, sensuous, scientific, practical, or so-called truth of morals, art, and religion, - all the cognitive" influences" may be expected to be at their work. Indeed, the very effort to disregard or to dispel any of them can only end by introducing them in some other form. It is not, as Kant held, by an illusory logic which 
leads out from the known, along an endless chain of conditions, in search of the unconditioned, that ethical and æsthetical feelings and ideals influence the structure of the cognitive judgments of man; but it is rather as motifs, suggestions, insights, and beliefs, without which men do not, in fact, come to cognition at all.

The presence and efficiency of ethical and æsthetical (we shall no longer speak of the religious as distinct) " momenta " in man's knowledge of things may best be illustrated by appeal to certain indefinite and broad areas of fact. The vague and shifty nature of this influence is necessarily connected with the truth that the concrete facts and judgments which express our ethical and æsthetical ideals are so little fixed or clear. The philosophy of conduct and of the beautiful is a reflective treatment of these facts and judgments to determine the origin, nature, and validity in reality, of their respective ideals. Ethics deals with the ideal of conduct, with that which "ought to be" in human character and behavior; æsthetics deals with the ideal of the beautiful, with that which "would be," in case æsthetical feeling were completely to be satisfied. But conduct is a fact, and is always based upon an indefinite number of considerations that concern matters of fact; and the beautiful object, whether in nature or in art, is itself a concrete matter-of-fact. Ethical and æsthetical judgments are also always psychic facts; as judgments they involve and employ the same cognitive faculties which all judgments involve and employ. So, then, the real things and actual events to which ethical and æsthetical ideals are applied are the same things and the same events as those known by common perception, scientific reasoning, or philosophical reflection.

Now, however, a most significant class of experiences may be recalled for criticism from this point of view. In his cognitions man is not satisfied to consider things as mere existences in fact, or their transactions as mere occurrences in 
fact. He construes things as though they were in some sort capable, like himself, of conduct; and he pronounces judgment about their transactions as though these were a species of conduct. Or, to say a similar thing in another way, we all naturally tend to perceive in things and in their behavior those qualities which would be there if things really were themselves subjects regardful of ethical and æsthetical ideals. What are the "real" things? Are they the things of every man's familiar daily environment and customary possession and use ; or the things of his more elaborate scientific knowledge; or the same things as they appear from the highest reflective points of view? From whichever of these standpoints one chooses to regard them, one prefers to know them as something more than matter-of-fact existences; and as responding more or less perfectly to the standards of ethical and æsthetical ideals. Man cannot readily cognize things otherwise than as somehow responsible to his own ideals.

This virtual persontfication of things, which goes so far as to attribute to them not only life and intelligence, but also quasimorally good or bad beharior, and beauty or ugliness in themselres, has frequently been explained on purely psychological grounds. To it, as thus explained, the origin of some, or perhaps of all the forms of religion has been ascribed; and with a certain degree of historical correctness, if only the terms employed are properly selected and correctly understood. But, as a rule, it is now held that all such anthropomorphism is the peculiarity of childish, or sarage, undeveloped minds, and is destined to retreat and disappear before the more scientific and verifiable knowledge of what things really are. It is not our present interest to determine precisely what are the limits which truth and reality put upon this psychological tendency to personify things. The fact to be noted which has a profound epistemological significance is this: the banishing of superstition and the growth of physical science have not essentially changed the fundamental tendencies or the actual 
operations of human cognitive faculty. Things continue to be known only under a potent determination to make them conform to certain ideals. The ethical and the rsthetical " momenta," however diminished in naïveté and obtrusiveness, are not less truly present in almost all classes of the so-called cognitive judgments of mankind.

The necessity for regarding the being and action of things from certain quasi, if not completely, ethical and æsthetical standpoints, and for affirming ethical and æsthetical qualifications of them, follows as a corollary, in some sort, from the argument of the last chapter. In this chapter it was shown that the application of the teleological idea is almost, if not quite, coextensive with cognition itself. But the essence of ethics and of æsthetics is teleological. The former is indeed the study of conduct as related to a consciously accepted ideal. And doubtless it is the recognition of this limit - " consciously accepted" - which, in large measure, accounts for the common readiness of even the most cultivated minds to consider the things and events of the physical world as really coming under the category of the æsthetically beautiful rather than under the category of the morally good. On the other hand, there can be little doubt that the very conception of final purpose, even when it is rendered as negative as possible by abstraction of all thought from a consciousness which accepts the end and renders effective the adaptation of the means to its actual realization, leads the mind to ways of perception and of thought that are scarcely separable from the distinctively ethical and æesthetical. We prefer, however, to illustrate the propositions of this chapter, in as great independence as is possible of the cognate truth that all knowledge is teleological.

The character of the feeling with which men instinctively regard those events of nature which affect their interests most immediately is instructive on this point. It is not the superstitious savage, or the pious civilized farmer alone who when these events, for example, result in the destruction of his dwell- 
ing, his herds, or his erops, summons them to the bar of reason to stand judgment pronounced on ethical grounds. The sentiment of a grievance that is something more than grief, of a wrong received that needs to be righted in some other than a blind and mechanical fashion, is not only native but also wellnigh ineradicable with man under such circumstances. He is scarcely free to choose between an outbreaking and a deeper, suppressed resentment that is equally unintelligible; he must rather choose between some feeling of resentment and the conquest of that feeling by the sentiment of resignation. But neither resentment nor resignation would appear to be a proper attitude of mind toward any mere matter-of-fact. It is so; that is the only judgment appropriate to be pronounced with a complete freedom from ethical feeling. Pain and sorrow are the feelings which recognize such mere mattersof-fact for all that they are worth. As to meaning, or worth beyond, how can one think or speak? In vain, howerer, does Epicurus scoff at the thought that the gods concern themselres in things like these. In vain does the fatalistic poet bid us lift not our hands to Heaven, -

\section{"for IT}

As impotently rolls as you or I."

And it is not the atheist, if such there really be, who is least likely to shake an imprecatory fist toward the stars, when the fateful lightning or flood has singled him from among his fellows for its work of destruction. On the other hand, is he the wiser man who succeeds in suppressing all movements of a genial and grateful spirit toward the "good dame Nature" when her hand has just been extraordinarily bountiful to him? Or is it altogether evident that the judgment which virtually affirms the event to be an act of goodness on her part is squarely contradictory of the most recent physico-chemical explanations of the same erent?

To consider an example: What used to be called " natural theology" has no harder task at present than the reconcilia- 
tion of the facts of modern bacteriology with its traditional doctrine of the goodness of God. Or, to change the point of view to the more scientific and philosophical, What shall one say in answer to the problem afforded by the attempt to give a meaning to such facts as observation reveals? Innumerable species of animal and plant life - microscopic, inconceivably prolific, exceedingly obscure as to their habitat and their modes of propagation and of procedure, inescapable - fill the air, the water, the soil, and support their life upon the elements of every organic structure belonging to the physical life of man. Of what worth are they; and how can their existence be justified in the great scheme of natural forces and laws? But such a question as this shows the inevitable influences upon man's way of viewing natural things and events that have their origin in the ethical and æsthetical points of view. For if bacteria are to be looked upon as mere matters-of-fact, we cannot ask to have a question of value concerning them solved so as to seem to justify their existence. As to " rights" of existence, there is, in fact, no possible question to be raised. These things exist; and they deal disease and death to man; and there ends his cognitive judgments regarding them.

But now we are compelled to recognize another fact of experience, and this is the pleasure with which the announcement is made and heard, that harmless bacteria are much more abundant than are the deadly kinds. Nay, more and better news is brought to us from the researches of field and of laboratory. These minute beings are the makers of valuable ferments, and the causes of agreeable and wholesome flavors. We are even assured that without the silent, unobserved services, through untold centuries and in absolutely inconceivable numbers, of such lowly forms of life, the higher forms, whose crown is found in man, could never have come into existence. The mind has now something more than a mere increase of information on matters-of-fact. It experiences a significant satisfac- 
tion of its demand that Nature shall reveal herself to it as not all bad, or "half bad," but as capable of a deeper wisdom and a more profound beneficence, it is likely, than that which is apparent upon the surface of things. Be the argument valid or not, this does not signify much when one contemplates it from the present point of view. For we are trying to understand the nature of knowledge itself; and such facts of human experience lead us in a new way to see how deepset in the activity of the mind is its tendency to regard things as somehow responsible beings, and their doings as though they were a species of conduct that might properly be regarded from ethical and æsthetical points of view.

Undoubtedly, the influence of ethical feeling and ideas upon the cognitive judgments of men, as applied to the being and transactions of things, is much more obvious when they are dealing with Nature "in the large," as it were. Her general forces, and the important events they produce within the sphere of human living, seem more properly to be held responsible for some kind of conformity or subservience to ethical ideals. Thus it is not in poetry alone, or by sentimentalists merely, that "She" is virtually pronounced remorseless and cruel, or bountiful and beneficent, according to the varying relations which physical objects and forces sustain to human interests and to human endeavors. Perhaps it would not much exaggerate the case to say that modern science, with its large extension of the principle of mechanism, has nevertheless been scarcely less anxious to justify the ways of Nature before quasi-ethical consciousness than was formerly the theologian to obtain for Divine Providence a similar fair reputation. But so far as the theory of knowledge is concerned, what difference does it make whether it is a theodicy or a "physiodicy" (if such a word may be coined) that is secretly had in mind, when natural events are brought to judgment? If we cannot aroid detecting a tendency to judge the system of natural objects and events as 
though it were arranged so as to make its messengers out of the wind, and its ministers out of flames of fire, in order to control the weal or the woe of man, the selection of a word to spell with a capital, as the Power effecting such arrangement, does not signify an essential difference for our epistemological doctrine. For the present, let IT be called Nature, the Absolute, or God.

The reasons why men generally feel more hesitancy about attributing ethical qualifications to single natural objects or to events that seem trifling, are not difficult to discover. It is only that action which appears to have a meaning when contemplated in the light of certain primitive and unique forms of feeling, to which ethical judgment applies. Conduct, and not mere action, is felt and declared to be right or wrong, worthy of approbation and meritorious, or the opposite. Things, therefore, when regarded merely as having qualities or forms of being, and not as doing anything to man, are not entitled to judgment under any of the ethical categories. Moreover, when men beeome acquainted with things in action, and even as doing that which most seriously affects human well-being, the things appear for the most part as the helpless instruments of forces that lie outside of themselves and which they cannot oppose, but must perforce obey. Eren the most ignorant savage does not charge to the account of the poisoned arrow from the bow of his enemy his own approaching death, in a quasi-ethical way; but the destruction wronght by the bolt that falls from hearen impresses him as a quite different species of action. Even the most enlightened modern believer in Providence thinks of the cyclone itself as standing in a different relation to God from that sustained by the particular brick or beam which has been "driven by" the eyclone upon the head of some member of his family.

It would be a mistake, however, to suppose that what have been referred to as "ethical momenta" in the cognitive pro- 
cesses of man's mind, have no modifying influence upon the cognitive judgments that apply to particular and even minute things. The presence of this same influence, for example, is powerfully felt whenever the question arises as to the matter-of-fact origin, nature, and functions of some member of any complex organism. The difficulty which the mind finds in accepting the singgestion, or even the seemingly wellfounded conclusion, that any member of such an organism has no function, or that its function is not beneficent with reference to the total organism, does not seem to be wholly a deduction from our scientific knowledge as to the nature and conditions of life in general ; it is rather a quasi-ethical and rsthetical postulate. The feelings of satisfaction with which observers contemplate the services of the cilia in keeping clear the respiratory passages, or of the saliva and the gastric juices in rendering poisonous substances innocuous, or of the phagocytes in actually surrounding and counteracting foreign and deadly germs in the circulation, are not wholly born of the logical faculties. He who refrains from adding to the cognitive judgments which affirm, "That is what they are," and "That is how they behare," the other judgments, "That is what they are for," and "Bravo!" or " Well done!" suppresses a tendency of his own nature which is as deeply seated and as sure to demand its satisfactions as is the desire for knowledge of fact and of law. It belongs, however, to the metaphysics of ethies and to the philosophy of religion to consider the more comprehensive and profound problems as to the nature of Reality which are suggested by the influence of man's moral feeling and ethical ideas orer his cognitive judgments. Our analysis thus far has shown that this influence is rather a tendeney than a compulsion. It has also partially evinced the truth that in order to render this tendency satisfactory to the cognitire faculties as a whole, the conception of that Reality whose being and transactions these faculties aim truthfully to represent must itself be sub- 
ject to expansion, to purification, and to progressive elevation in the direction of the supreme Ideals of man.

Esthetical consciousness differs from ethical consciousness in some important particulars. The influence which the former exerts upon our cognitive judgments, and the class of cognitions in which this influence terminates, are correspondingly different. It is conduct that moral feeling approbates or blames; but æsthetical feeling leads the mind to judge beautiful (or the opposite) both the quiescent being, or "still life," and also the behavior and interaction of things. Whether that which does not at least suggest some form of Life in action can awaken rsthetical feeling, and be pronounced beautiful, need not be discussed in this connection. But we may certainly say of some things, considered as removed from causal connection with other things, and as not affecting our personal interests, "They are (or are not) beautiful." Schopenhauer,' in a highly exaggerated and largely erroneous but effective way, has described at length the nature of the æsthctical judgment. It may be pronounced as the conclusion of a process of perception; and it has the objectivity and universality of a cognitive judgment. I know the object as beautiful, with as much appearance of immediateness and indubitableness as I know it to have certain spatial or other qualifications. Undoubtedly even æsthetical judgment is, quoad judgment, subjective; but so is every form of a cognitive judgment. It is suffused with a peculiar form of feeling; and when the effort is made to trace its origin, this effort would seem to end in merely recognizing the justification which the feeling itsclf supplies. That is, the ultimate grounds on which rsthetical judgments appear to repose for their validity are to be found in the rsthetical feelings awakened in us by certain classes of objects. But, on the other hand, the feelings themselves have just this peculiarity, that they seem to us to warrant, and even to compel, a judgment that is not subjective. The æsthetical

1 World as Will and Idea (English translation), i., pp. 219 f., and iii., pp. 173 f. 
judgment does not simply declare, "I feel ccrtain pcculiar affective changes in my consciousness;" but "The Thing over there is (or is not) a beautiful thing." Esthetics is the branch of philosophy which critically examines the origin and nature of this class of judgments, and the peculiar feelings which the judgments manifest; its metaphysical problem concerns the nature of Reality as known in this way. Epistemology, however, cannot avoid noting the significant existence of the entire class of such judgments. That men's contemplative perception of things results in ascribing æsthetical qualifications to things, in the form of the most confident cognitive judgments, is an important fact for epistemology and its correlative view of Reality; and that men do make such judgments - confident, objective, and liable to be employed both as points of starting and as goals to be reached by endeavor - does not admit of doubt.

It is commonly supposed that the body of cognitions which science and philosophy support is uninfluenced by æsthetical considerations; that its so-called truths are solely matters of observed fact and of conclusions arrived at by following strictly logical processes. We do not believe, however, that the case is so. The body of scientific truth is a constitution in which considerations of order, harmony, symmetry, and adaptability are supremely significant; and philosophy finds its very life and its ultimate justification in the reflective treatment of ideals. Now, the conceptions of order, harmony, symmetry, and adaptability, and the nature of any ideal, are themselves such as to awaken strong æsthetical feelings; and these feelings can by no possibility be wholly kept apart from those observations and from that work of generalizing in which the so-called laws of science and the speculative solution of the problems of philosophy have their rise. The student of physical science, as a rule, does not understand himself, however expert he may become in the understanding of nature. As an æsthetical being, he loves and admires order, harmony, 
symmetry, anà adaptability; as an æsthetical being, and not as a purely logical being, he also finds in nature what he lores and admires. The whole history of the physical and natural sciences would on examination be found replete with examples to illustrate this truth: the scientifically ideal and the oesthetical qualifications of nature always have the presumption on their side. Order rather than disorder, some sort of harmony and symmetry - which may be all the more beautiful and significant if the less obvious, superficial, and easy to be found - rather than the opposites of these, are the assumed ends and idcals of the system of physical beings and events which physical science proclaims. It confidently relies on finding these ends and ideals realized in nature; but the warrant for this confidence does not exist solely in the state of the case as bare matter-of-fact.

For an illustration we may turn to modern astronomy: $\mathrm{By}$ far the greater majority of the stellar universe, so far as this science has any information from observed facts, are behaving in the most disorderly, unharmonious, and meaningless fashion. Millions of masses of matter, void of any life that could follow a pattern known to us, are rushing through space in all directions and with an indefinite number of velocities, paying no attention to each other, and seeking no end, - doing notling in fact that has conceivable significance or use. Yet the steadfast faith of the astronomer proclaims the order and harmony of the stars; and his soul kindles with a fecling of the sublimity and beauty of the celestial scenery as he applies his trained eye to telescope or heliometer. Is the proclamation based merely on inference from the facts? Do the feelings arise at the call simply of a cogent logic? We do not believe that either of these questions can be answered affirmatively. Or again: There is current just now a highly elaborate and largely metaphysical doctrine of evolution as applied to the known facts of biology. This doctrine is exceedingly optimistic in its riew of the significance, the tendencies, and the issue 
to be expected from the facts. That which is better is, on the whole, winning the day; the way is long and weary indeed, and it is well strewn with slime and blood. But the end is to justify the way. And the same Nature which appears relentless, cruel, and hideous in certain aspects of the descriptice history of animal life, is, after all, believed to be striving toward a goal that has an ideal value sufficient to pay all the costs and more of the passage. Now, on what basis is this so optimistic theory of erolution actually placed? Is this basis simply what is known of observed facts, and what may be concluded by fair but strict logical inference from observed facts? Or is not every form of the evolution theory, so far as it is pronouncedly optimistic, largely derived from æsthetical demands which arise in the nature of biologists themselves? What kind of theoretic handling these same facts and laws admit of, if treated in their relations to our human conceptions of a good to be realized, becomes apparent when the decidedly pessimistic temperament takes them in hand. The optimist is ready to ascribe the pessimist's conclusions in such a case to the temperament of the investigator. Doubtless the charge is largely just. But the very point at issue is whether the prevailing optimistic conclusions are not themselves largely a matter of "temperament," or rather whether they do not need for their full explanation the admission that æsthetical influcnces enter into the cognitive judgments of the natural sciences in a very prevalent and pervasive way.

If science seems always impelled to give more or less of an ideal construction to the facts of the physical world, philosophy is from its very nature definitively and consciously an effort to harmonize all human experience in terms of the ideal. It starts indeed from matters-of-fact, - from what is, and is known to be. But, inasmuch as philosophy begins at once to inquire after the meaning and the larger and more intimate and ultimate relations of what is, it early defines its object of pursuit as belonging to the World of the 
Idea. As every student of its history knows, its most seductive temptation - indeed, the temptation to which all the greatest speculative thinkers have probably in some measure yielded, so much as to sway them from the truth - is to force the facts which experience presents and guarantees as facts, whether of eognition or of existence, into conformity with xsthetical ideals. Philosophy indeed grows quite as mueh ont of the æsthetical as out of the more purely intellectual nature of man. This is to the discredit neither of its truthfulness nor of its value. For truth discovers itself to the æsthetical nature; and man does not live by bread alone.

Perhaps no more impressive illustration of the cxtent to which the influence of æsthetical considerations can be carried in the treatment of a philosophical problem ean be found than that afforded by the "Critique of Pure Reason" itself. This illustration is all the more impressive on account of two eonsiderations : For, first, the problem itself is of a character which does not take the eritic far afield into tangled thickets of obscure and contested facts, or out upon the foggy and limitless ocean of ontological mysteries; it only involves the analysis of processes of eognition with a view to determine their laws and formal, subjective characteristics. All temptation to mysticism would seem to be remored on Kant's part by his restricting the problem to the legal and formal aspect of knowledge; since it is in the trans-subjective and ontological aspect of the same problem, in the origin and nature of "that which is given," that the realm of mystery chiefly seems to lie.

But, second, no critic could easily affect a method and a style more high-and-dry in its elaims to apodictic certainty on grounds of its strictly logical and unemotional procedure than that of the author of the "Critique of Pure Reason" in this particular work. Rarely during its several hundred pages does a sentence glow with the heat of even suppressed ethical and æsthetical emotion. Kant appears determined to use the 
dissecting-knife upon the whole body of human knowledge, to let out its life-blood before our eyes, and to display its skeleton bared of all fair clothing of sensitive flesh; but he will do this grimly, and as a matter of derotion to mere truth, without influence from æsthetical considerations. He will not once let his eye pity, or his arm stretch out to sare. In the text of the body of his eritical work it is only occasionally (for the most part in the second edition) that he reminds us of his ulterior design to "make room" for faith; occasionally indeed he does appear to drop a sentence or two which shows the "state of his heart" toward the problems of God, Freedom, and Immortality. Yet the final outcome of the Kantian critical thinking does not disprove the saying, "Das Pathos ist der Grundton des ganzen Daseins - des Weltalls." Even in its more purely destructive work, and in spite of Kant's own warning against letting desire and imagination run away witl his logic (lest he might himself become a Vernunftkünstler), he could not keep his own skirts clear of blame.

We believe it can be shown that the entire architectonic of the "Critique of Pure Reason," as well as the subordinate divisions and conclusions which are ranged under the main titles, is much influenced by its author's æsthetical ideals. It embodies preconceired views as to what sort of an harmonious and symmetrical structure human reason ought to be, quite as much as the actual finding, in the name of either sound psychology or valid epistemological analysis, of what human reason $i s$. The reader who understands may note everywhere the stupendous products of Kant's fondness for effective parallel and contrast, and of his confidence in his ability to embody his own ideal of a Reason that should be equipped with a perfectly symmetrical and harmonious outfit of original faculties. The picture which he draws of such a system of faculties cannot be recognized as coinciding throughout, or eren in many most important particulars, with the reason actually possessed and used by the race of living men. Thus the im- 
pression made by a careful study of this picture corresponds to that produced by an asthetically great creative composition, rather than to that of a portrait true to life. Very few arc the students of the "Critique of Pure Reason" who finish it with the feeling of conviction, "I have seen my own face as in a glass," rather than with a feeling of admiration and wonder at its author's art in dramatizing human nature in such a lofty and interesting though unreal way. A reason actually constructed after the pattern of Kant's architectonic would surely be a most marvellous piece of mechanism ; and since everything necessary to cognition is strictly determined a priori by this pattern (with the insignificant exception of what is given as content of sensation), we may ask: How could such a reason fall into any erroneous judgments? But, on the other hand, how could it attain to any truth, in the meaning of that word which interests the hearts and binds the consciences of all men? For whatever may be the last word of criticism, the hearts and consciences of men revolt against the conclusions of a sceptical idealism; and finally, the question arises whether, in the critical endeavor to clear away all mystery from the primary fact of knowledge by an analysis of intellectual faculty, the critic is not bound to pay tribute to his own æsthetical and ethical tendencies in another and no less uncritical way.

For the fundamental epistemological truth seems to be that the rational order of cognition proceeds from the concept of Self, with its numerous ethical and cesthetical impressions and ideas, to the more barren and less certainly valid concept of a Nature stripped of such impressions and ideas. But the latter concept, instcad of being valid for Reality, because built upon verifiable facts that can stand apart from the conception of a conscious Self, and so account for the latter by a process of aggregation or development, is itself derived from the latter by a process of abstraction and progressive separation of dif- 
ferent, seemingly separable "momenta." 1 At any rate we saw that this form of procedure takes place in all that application of the principle of sufficient reason to the world of things which the development of the physical sciences requires. Nor is it strange that the spirit of man, in spite of all warnings to the contrary, and notwithstanding a never-ceasing series of misapprehensions and errors brought about in this way, persists in regarding the cosmic mechanism as the mask or hull behind and underneath which spiritual processes are working. Whatever term be employed, - whether it be the term "Nature" as used by the physicist, the "Absolute" of the philosopher, or the "God" of the theologian and the religious devotee,-ethical and æsthetical feelings and ideals will make themselves manifest in the final construction which human thought gives to Reality. And, indeed, the "momenta" of this character which enter into the very essence of our cognitive judgments are such and so many that it is doubtful whether they can be remored, and leave to those judgments the semblance of being the product of human cognitive faculties. Man's own life of final purpose, of conduct directed with reference to a consciously accepted ideal, and of admiring satisfaction in what appears to him under the conceptions of order, harmony, symmetry, etc., suffuses his judgments as to the being and transactions of the really existent World. He knows that he himself is actually influenced by ideals of conduct and of beauty; he is constantly inclined, and eren impelled, to know things as though they too were influenced in an analogous way. In a word, the Universe is known, so far as known at all, rather as an Idea that seems to give true answers, though meagre, obscure, and mysterious in their deepest meanings, to the whole soul of man. And indeed, if the lighest knowledge is a kind of commerce of Spirit with our spirits, how otherwise should the fact rightly seem to be?

1 Compare the remarks of Wundt on "Die Natur als Vorstufe des Geistes," in his "System der Philosophie," p. 559. 
But now the question arises as to the truthfulness of those forms of mental representation that stand under the influence of xsthetical and ethical considerations, and of the cognitive judgments into which æsthetical and ethical " momenta" most abundantly enter. According to the conception of truth which our critical theory of knowledge has compelled us to hold, the answer to this question leads on to the affirmation or denial of an esthetical and ethical being for Reality itself. But how illusory does the search for the truth along such lines of thinking seem to many minds? To be sure, many men, and even - it must be admitted - men generally, seem to themselves to know that real things are beautiful or ugly; and that they do behave in admirable and commendable, or in morally dubious and even detestable, ways. But among all the seeming possessions of the human mind, in its growing mastery of the real being and actual transactions of things, no others are so fickle, evamescent, and easily controverted as are such judgments as these. Is not the sphere of ethics, then, strictly limited to the actions of men, when those actions are directed toward the realization of ends which they themselves hold in consciousness? And, on the contrary, what more obviously imaginative and emotional, instead of strictly cognitive, than the impressions and opinions of men about the beauty of different natural objects; or even about those artistic products which they know to be consciously constructed in the effort to realize some particular person's conception of what is beautiful? Surely anthropomorphic and anthropopathic tendencies derived from excesses of emotion and imagination should be checked by the stern hand of reason when they propose to construct Reality after a pattern suitable to their mind. At this point we have surely come to the limits of affirmation in the light of a critical epistemology.

Now the sincerity and forcefulness of such protests as the foregoing must be cheerfully conceded. Human knowledge of real things and of their actual transactions, as properly 
falling under ethical and æsthetical ideals, - if, indeed, one may speak of "knowledge" here, - is certainly of a somewhat different order, and appears to repose on different grounds from the order and the grounds with which the analysis of the primary cognitive judgment has made us familiar. That this is so, the language and the action of men render obvious enough. For men are usually willing to say, "It seems to me so," or "Such is my opinion," rather than "I know," whenever their first unqualified affirmations of an æsthetical order are called in question. Two observers, standing before a scene in nature, or a work of art, would discuss the question of its æsthetical character in a quite different manner from that which they would inevitably follow, should one of the two deny the existence, in reality, of the object under discussion. And although there is nothing about which contention may become more earnest than about the ethics of the Divine dealings with man, it is only necessary to bring the contention to those tests of truth which are ordinarily offered either by logical praxis or by epistemological theory, in order to make clear certain characteristic weaknesses in the grounds on which such contesting arguments repose. Moreover, the study of the history of opinion shows that what seems to one man proof of the ethically and æsthetically Divine appears to another no better than sure marks of the controlling power of a wholly bad and ugly Devil. Ormuzd and Ahriman both appear to have their eternal and unshakable thrones in the deepest recesses of Reality, if once we begin to admit that Reality is known at all as coming under ethical and æsthetical ideals.

All such considerations, however, and any others which can be adduced, do not orerthrow or modify the integrity of the position to which we have been forced by taking the point of view of a critical epistemology. And some of the considerations usually considered adrerse have no hearing on the problem as raised from the purely epistemological point of . 
view. Whether Reality is a mixture of the ethically and æsthetically good with the ethically and æsthetically bad; or whether it is all good or all as bad as is compatible with the conditions of existence; or, finally, whether it is only a process, in which the good and bad are contesting the place of supremacy, with the end held responsible for the justification of the process, - these are problems for the metaphysics of ethics and of estheties, and for the philosophy of religion, to answer. Perhaps human reason can find no satisfactory answer to these questions. But even if it cannot, the facts which affect the epistemological problem remain the same. The continued influence of ethical and æsthetical considerations upon human knowledge as to the Nature of the really Existent is a matter of fact. Ethical and æsthetical "momenta" are found actually to enter into the very structure of large numbers of what seem to the minds of men generally as true cognitive judgments. We are, therefore, not prepared to deny all value, for cognition, to these influences and to this class of "momenta." If the ethical and æsthetical nature of man urges him on to know the real being and actual transactions of things, in the light of their meaning, and with reference to certain ideas that have for his soul an incomparable worth, epistemologieal theory cannot readily admit that this urgeney leads only to error and illusion. For there is at least the possibility of another view. Things may really have a meaning: the Reality may itself be the actual Ground and real antitype of these very ideals. If so, the one fatal and unpardonable error, the crime against the Spirit of Truth that camnot be forgiven, is the refusal to make one's subjective ideals conform to their antitype in Reality. By a legitimate hypothesis, the large truthfulness of the judgrments which men frame under these influences may be vindicated; and the limitations and errors which belong to these judgments may be satisfactorily explained.

- It has been the almost universal opinion that the great 
artists and the prophetic minds of the race are discoverers and teachers of important truth. This opinion implies that ethical and æsthetical insight, and constructive imagination and thought founded upon such insight, give to the mind something that it may trust regarding the real being and actual transactions of things. We share in this opinion. We, too, refuse to believe that truth is attained or demonstrated as a purely logical affair. In the ethical sphere, inspiration and revelation are not to be regarded as extraneous to universal human experience, or as contradicting its fundamental convictions and ordinary modes of construction and development. The rather is the belief in inspiration and revelation founded upon facts which are integral and permanent factors in human experience. The æsthetical feelings and their resulting judgments, as they hare found expression in works of art, cannot be denied participation in the constitution and growth of that entire body of truth which represents the sum-total of the achievements of human cognitive faculty. Who will for a moment suppose that if we could take from men the conceptions and opinions they either incline toward, or more definitely frame, under influence from ethical and æsthetical considerations, we should thus increase or improve their knowledge of "the truth of things"? Trutlis of conduct and of life - the best attainable answer's to the questions, "What ought I to do?" and "What may I hope?" - are undoubtedly the peculiar sphere within which moral and artistic insight is most effective and trustworthy. But one should nerer try, as did Kant, wholly to separate these questions from that question which he called "purely speculative;" from the question, namely, "What can I know?" Reason, in its practical and artistic employment, does not comprise another and somewhat distinct set of faculties. What I should do, and what I may hope, are dependent upon what I can know. And what I do know, or assume with an irresistible intensity of conviction that I 
know, is, in turn, dependent upon what I believe should be done and may be hoped.

For human reason is not a compound of loosely related faculties, - with an a priori outfit of rules designed for things, of intellectual ideals that compel or allure it into error, and of practical maxims that must be believed in, and acted upon, although they afford no objective truth. Reason is a living unity; it is nothing less than the entire soul of man regarded as both active and receptive in commerce with Reality. In its own ministrations, whether as belonging to the individual or to the race, there is no sacrilege which it visits with a more dreadful vengeance than that committed in the effort to extinguish any of the sacred fires which are burning on its one altar.

Even the most non-intellectual, the least conceptual and ratiocinative of the arts is a ministration of truth to those whose ears have been touched so as to be open and receptive to it. Music, as such, conveys a message to the human soul which cannot be thrown into the forms of cognitive judgment, or of a convincing syllogism that illustrates the invincible character of the principle of sufficient reason. It is the incomparable master, however, of the simpler, more massive and fundamental, the universal and unchanging forms of human emotion. The life which it expresses, cultivates, and expands is the life of those feelings that have, in themselves, something of an undying and an ideal value. But he would have a hard task who should undertake to convince any lover of music who is at the same time intelligently appreciative and reflective as to the meaning of his own experience, that no truer view of the nature of life and of all Reality is gained through its æsthetical ministrations. The rather would such an one be inclined to maintain that an epitome of the history of the human soul, and of the race, etched in broad lines of emotion, may be given in a great musical composition as in no other way. 
It is in poetry, however, that ethical and æsthetical influences may combine with products of accurate perception and careful, well-grounded reflective thinking to create pictures of life and Reality that have a high degree of value for the truth they consey to the mind of man. However one may decide the contention between those who exalt the pleasure-giving function of poetry and those who emphasize its didactic power and disciplinary offices, - and this contention does not concern us here, - there can be no doubt that men generally, and in all time, have looked to the greater poets as to seers of the truth of things. "Imitative art in its highest form - poetry," says Aristotle - " is an expression of the universal element in human life;" and, again, "Poetry is more philosophic and of higher worth than history." This estimate may seem exaggerated, and the accompanying depreciation of history unworthy. But when a modern critic declares that "a great poet must be a man made wise by large experience, much feeling, and deep reflection; above all, he must have a hold of the great central truth of things," he is enforcing the same epistemological truth which we are expounding. And the demand which the art of poetry makes upon the soul of its derotee, if met successfully, enables the product of the art not only to give æsthetical enjoyment for its beauty, but to "improve all opportunity" for conveying to other minds a truer and broader conception of that meaning which lies in the real being and actual transactions of things. The poet's work may exemplify what Aubrey De Vere says of the work of Wordsworth : -

"Wisdom sheathed

In song love-humble; contemplations high,

That built like larks their nests upon the ground;

Insight and vision, sympathies profound

That spanned the total of humanity."

"Poctry," says Matthew Arnold, "interprets in two wass: it interprets by expressing with magical felicity the physiognomy and morement of the outward world, and it inter- 
prets by expressing, with inspired conviction, the ideas and laws of the inward world of man's moral and spiritual nature. In other words, poetry is interpretative, both by having natural magic in it, and by having moral profundity." Whichever of its two great offices poetry worthily fulfils, whether it be the artistic representation of the actual world or the creation of ideals that refine and rest the soul, it may fitly claim to be the teacher of truth to humanity.

It is not, of course, easy - and perhaps it is not possible - to vindicate the objective truthfulness of the judgment which the average man makes when, on contemplating some particular thing in nature, he declares it to be beautiful; or of the judgment which the devout believer in Providence pronounces when he makes a declaration as to the ethical significance of some natural event. For such judgments as these are confessedly do not rest upon major premises which themselves represent the incontestable summaries, as it were, of the experience either of the individual or of the race. One does not say, "The tree is beantiful" with preciscly the same degree or kind of conviction as that with which one says, "The tree is bare of its leares," or, "The tree is beginning to turn green." And the devoutest believer in Providence ean scarcely turn from the man who denies in toto the truth of his opinion respecting the providential character of a natural event with any stronger feelings than those of a subdued sadness at a lack of religious insight or of so-called faith. On the other hand, the reflective student of human nature will constantly recur to such general facts as have already been sufficiently called to mind. They concern the deepset tendency to take an æsthetical and an ethical view of the entire World and of what takes place in it. And if this view does not contravene or impair the cognitions that arise when things are considered from other points of view, the significance of this tendeney, and the theory of Reality it tends to support, cannot be overlooked in fidelity to a 
comprehensire philosophy of knowledge. We may, perhaps, even fcel warranted in adopting the admonitions of the preacher, Frederick Robertson: "But of coursc, if you lead a sensual life, or a mercenary or artificial life, you will not read these truths in nature. A pure heart and a simple, manly life alone can reveal to yon all that which seer and poet saw."

It is not a part of the legitimate task of epistemology, howerer, to assign to the beautiful and to the morally good their places in that system of beings which is known to man as real. Other branches of philosophy must discuss the question, whether Reality itself is not the Ground of all human ethical and xsthetical ideals; is not Itself the allbeautiful and ethically perfect One. But the critical study of the problem of knowledge prepares the way for an approach to these questions. It does even much more than this; it indicates what that answer is likely to be. And to make this clear we have only to recall at this point the different impulses which have been receired from the conclusions reached upon the varions subordinate problems of epistemology. These all appear to combine in enforcing a unitary conception of the Reality that is made known to us in our system of cognitions both as individuals and as members of the race.

The life of the mind of man must be described as beginning and proceeding in the form of an ever richer and more content-full knowledge of the Self, existing and acting in manifold relations to beings that are indubitably distinguished from the Self as not belonging to it, - whether as its states or its doings, - but as the states and the doings of not-selres. What these "not-selres" really are, and what they actually do, can be known only as the mind constitutes them after the analogy of the self-known Self. That they are known. as thus constituted is a fundamental epistemological fact; and the denial of the import of this fact leads to a scep- 
tical solipsism so complete and so absurd that it does not even admit of intelligible statement. That " non-selves" really are thus constituted is the truth which, in the form of an ontological postulate, is needed to validate the results of all human knowledge; and which is, in fact, virtually accepted by all cognitive minds as validating these results. Those fundamental forms of the thought-process, which are called the principles of identity and of sufficient reason, implicate this "self-like" constitution of things. Things are known as having any identity, as really being at all, only on the supposition that they in their changes remain true to immanent ideas. And they are known as united together into the unity of one real World only when they are regarded as being and beharing in a quasi-rational and teleological way. Indeed, it is only when we regard them as "momenta" in the Life of a Being which is actually realizing its own immanent ideas that we can be said to know them as belonging to the system of the one great and orderly World. For the ontological implicates - "envisaged, believed in, or inferred" - of all human knowledge, both as a fact and as a growth, may be gathered into one inclusive implicate: The System of interrelated beings which are the objects of knowledge is known only through its manifestation of the attributes of a Self. Whatever characteristics which we know to belong to ourselves must be excluded from our conception of this System; still only such implicates as the Self knows itself to have can be included in the conception.

It is at once obvious, therefore, that ethical and rsthetical predicates are by no means necessarily shut out from man's knowledge of Reality. It is no more intrinsically absurd, as it were, to attribute predicates of this kind to the system of interrelated beings than to attribute the other predicates given to this system by the physical sciences. But what particular self-known predicates may be assigned to Reality, and with what modified meaning, it belongs to reflective thinking 
to determine. Even among themselres, men differ greatly concerning the conformity of particular beings, or of concrete actions, to their own ethical and æsthetical ideals. This difference shows that the mind is here dealing with subjects which, although not to be wholly disconnected from its most assured cognitions, are not connected with these cognitions in the most assured way. They belong to the realm in which feeling, and what is called "faith," have a more important part to perform. But this conclusion is a very different thing from assigning all apparent cognitions concerning these subjects to the realm of illusion, or of the wholly unknowable. For it has been shown that feeling and faith are factors in all knowledge. And, above all, what we do most assuredly know about Reality is farorable, rather than otherwise, to the confidence that when the voice of humanity gives It an ethical and an æsthetical significance, this roice is not publishing the dreams of its own night already past, but is rather proclaiming a truth about Reality that is adrancing into the clearer light of the more perfect day. 


\section{CHAPTER XVIII}

\section{KNOWLEDGE AND REALITY}

THERE are two questions of very general import and further discussion in the light of the conclusions at which we have arrived from a critical study of human knowledge. Of these the first concerns itself with an attempt more precisely to determine the relations in which the cognitive processes stand to that Reality which they claim mentally to represent; and the second aims at so apprehending the nature of this Reality as best to comport with the assured conclusions of a critical but positive epistemology. In other words, we raise again the inquiries: What has reality to do with knowledge, and knowledge with reality? and, What kind of a theoretical construction of the system of real beings and actual transactions is most compatible with the results of epistemology? It will be seen at once that both these questions are metaphysical. 'The former borrows from metaphysics a certain ontological conception, that it may the better clear up our conceptions of the nature and validity of knowledge; the latter criticises and purifies the ontological conception of (and so lends something to) metaphysics by adjusting it to already accepted conceptions of the nature and validity of knowledge. Both of these questions have occupied us frequently: the detailed discussion of the former is drawing to its close; and the latter must soon definitively be merged in a systematic and critical doctrine of Reality. But the task of a critical philosophy of knowledge will be more 
satisfactorily accomplished if its general positions on these subjects are separated from the details of subordinate discussions, and briefly presented in broader and stronger outlines.

The relations, in general, which exist between Knowledge and Reality have thus far been expressed in a variety of ways. For example, it has been held that cognition can take place only as a living relation between subject and object; and that in every act of cognition the object is some form or manifestation of reality. Knowledge itself then appears as an actual commerce between the knower and some really existent either Self or Thing. For who can escape the force of such an argument as this: No possible knowing without a real knower and a real being known; and no actual knowing without a relation, in reality, being established between them? But when psychological analysis was employed to show how the entire mind is concerned in knowledge, different words were used to express the peculiar relations in which the different so-called faculties, or forms of mental functioning, stand toward the object, in the unity of the cognitive process. Moleover the different kinds of knowledge such as immediate and mediate - seem to require a still further differentiation of these relations. In knowledge by sense-perception or self-consciousness, for example, words like "intuition" or "envisagement" appear appropriate to express the relation actually existing between the cognitice subject and the object of cognition. While in both immediate and mediate knowledge, the part which the will takes for all cognition is essentially active - is expressed in highly figurative terms, as a sort of "seizure" of reality. Feeling, too, appears to present its claims to some part in this series, or system, of complicated relations; and its claims are best satisfied by assigning to the affective powers of the soul the function of believing in, or entertaining a conviction respecting, reality. 
And now if one enters into the details of the relations in which reality stands to knowledge in the processes of senseperception, when considered under terms of a psycho-physical and psychological theory, one will be compelled to emphasize strongly the admissions that slip or are wrung from the founder of modern epistemological criticism. For Kant's doctrine, strictly interpreted, forbids him to assert, and even to postulate or conjecture, any definite forms of relation between the mind and things-in-themselves ; since there can be no other than a merely negative and limiting concept of extra-mental reality. But Kant himself constantly assumes and speaks as though the content of sense, in distinction from its form, were "caused" by a reality that is something more than our phenomenon; and every attempt at a science of psychology is obliged to deal with the experiences of cognition through the senses in the same way. The precise terms employed by the psychologist to express this relation of dependence may vary greatly; but in some form a certain relation or set of relations must always be assumed. That which actually happens in what really exists, but exists as a not-me, either "causes," or " excites," or "stimulates," or " runs parallel with" my sensory-motor consciousness considered as a cognition of changing things. So, too, when we come to consider the nature of thinking and the part it plays in cognition, we seem compelled to express the essence of the relations between knowledge and reality as some sort of a "correspondence." The "categories," so-called, are not, indeed, to be conceived of as copies of transcendent realities. But neither can they be regarded as pure rules of our understanding, that are wholly independent of extra-mental realities, and govern in a world apart, as it were.

Cognition itself appears to itself to be essentially this : the mental representation of the real being and actual transactions of things. And no other better word can be found for summing up the manifold relations of Knowledge and Reality, essentially considered, than this word, a "commerce" between 
mind and its object, the truly existent. Finally, it was shown that a world of reality is so "implicate" in human knowledge that the denial of all meaning to this term - pregnant as it is with an entire brood of relations - lands us in the very depths of absurdity. Whereas, if we will once admit with hopeful intelligence and reasonable cheerfulness what we are bound to admit in some manner and to an indefinitely large extent, namely, the correspondence or systematic relationship of the cognitive Self with that all-inclusive Reality which encompasses it, when conceived of as an Absolute Self, - then all the separate and subordinate forms of relation are taken up into and merged in a relation between the individual and the Universal, both cognized in terms of Self.

It is some such view as this which we desire now somewhat further to expound and to defend; and perhaps the fittest beginning of both exposition and defence will be to remove certain misapprehensions which commonly stand in its way. Here, as so often liappens in every branch of philosophy, the most serious and dangerous misapprehensions arise in the form of those half-truths that represent the results of overhasty and too comprehensire generalizations. Among such generalizations the various forms of an Identity-hypothesis are particularly prominent. But the relations between cognizing subject and object cognized, - the knower and the known, - in which cognition itself consists, cannot be summarized with fidelity to the facts and laws of human experience in any form of a theory of identity. To know is not, in fact, to identify one's Self with the object of one's knowledge; and to know one thing from another, or any one particular thing as related to others, is not simply to pronounce upon the selfidentity of this one thing, or to affirm the identity of all things. That the very nature of knowledge implies some kind of an interrelation in a unity of knower and of all objects of knowledge has been the ontological thesis to which all our eritical examination of the epistemological problem has been tending. 
But that knowledge is essentially based also on the making of distinctions, and that in its very essence it validates a difference in things - a self-differentiation that must be regarded as trans-subjective, as also ontological - has been made equally clear. We cannot even admit the truth of Wundt's declaration ${ }^{1}$ that, in fact, object and active mental representation ( $\mathrm{Ob}$ ject and Vorstellung) are originally identical ; and that, therefore, in this fact is to be found the easy and complete solution of all the difficulties which belong to the problem of the transsubjectivity of the object of cognition; for unless an active mental representation distinguishes the total content of consciousness in such a way as to result in an object that is not and cannot be identified with the representing subject, no cognition of things can take place. Psychologically, the process on which such cognition depends is one of discrimination, which results in setting the Thing over against the Self as a not-self.

And even that process of assimilation and conscious recognition which results in knowing the Self as one with itself, and the Thing as one thing that is, however, a not-self, bears no real resemblance to the cognition of an identity in that meaning of the word which is employed by the theory in question. For the very conception of identity has its warrant in the activity of a discriminating consciousness which recognizes that the successive differences in the appearance of Self and of things follow some order, as though controlled by an immanent idea. At no time in the growth of its knowledge can the self-conscious Subject regard its object-thing as identical with itself. To succeed in doing this would be to destroy the existence of the thing as an object of cognition. Nor could different things be known as identical without destroying both the subjective influence and the objective validity of that very connection between things which makes all our conceptual and inferential knowledge of them possible. The principle of

1 Compare System der Philosophie, p. 142. 
sufficient reason has been shown to be regulative and suggestive in the cognitive experience of man, rather than an adamantine and quasi-physical law of identification. It guides and stimulates the mind in its effort to know things as bound together into an ideal unity, although still of necessity different and individual, because in fact they pay attention to each other. This may be expressed by saying that things, however different, are known as regarding not only their own but each other's immanent ideas. Even as applied to objective phenomena, the principle is not so much dictatorial and compulsory as insinuating, persuading, divining, like the rules that control an object of art. In self-consciousness, too, it was seen that the relation of subject and object is not properly, and is far from being completely, defined as one of identity. Nor does the so-called identity which I know myself to have - the highest conceivable form of identification - appear as the principle which defines the relation of subject and object in knowing. Even here the complete identification of the two would be the complete cessation of the life of self-knowledge. In self-consciousness, therefore, where the ultimate ground for the identity of subject and object is sought, the question must still be dealt with, whether this fundamental opposition, as it were, in all Being, this immanent activity that differentiates subject and object, can be abolished, as the ontological identity-theory maintains.

If every vestige of a claim ta explain the subjective character of knowledge by an identity-hypothesis ranishes before the critical analysis of psychology and epistemology, every trace of comfort disappears when the same hypothesis is tested on the side of its ontological value and validity. The conception which it offers of an absolutely changeless Being, an Entity that is rigid, self-identical and definable, if at all, only by the possession of a fixed set of most highly abstract qualifications, is theoretically untenable. It accounts for nothing as a working hypothesis; and measured by the teleological idea or brought 
to face the standards of ethies and rstheties, it proves of no practical value. And then such a Being is not, and eannot be, an object of any kind or degree of knowledge. Commonsense does not recognize it; nor will it explain or serve the work-a-day life of humanity. Science knows it not, and can get no actual service from it as an assumption or a theory. Philosophy, feeling, like the lioness, that she must bring forth only one offspring at a birth, has often, indeed, tried to heighten the claims of this single product of her conception by increasing the seeming extent of its superficies at the expense of organic variety within. Thus has human thought about the One Being, in which all particular beings have as it were their share, been rendered much too vague and devoid of content to assist in explaining the origin, the characteristics, or the import of the meanest of things. But epistemology reminds ontology of this inevitable obligation: Unless the conception of the really existent World is made to contain within itself the principles necessary, not only for establishing its own Unity, but for explaining the infinite variety of the growing cognitive experience of humanity, valid knowledge is itself rendered impossible.

From whatever point of view, therefore, we approach the subject, it appears that the relations of knowledge and reality cannot be summarized in terms of an identity-hypothesis. There is, however, another and more subtle set of considerations which are often employed unwarrantably to restrict the variety of admissible relations felt to be necessary, as existent between the knowing subject and Reality, in order to validate human knowledge. These considerations grow, in part, out of that temptation to conceit which makes men feel that their way of looking at things alone conveys the truth of things; or, at least, that the particular truths which come to them are, so to speak, preferred truths at the supreme court of absolute reason. Thus do we find men of science despising that knowledge of natural objects and relations which makes 
up the entire product of the "plain man's" cognitive activity. And as for philosophy and its points of view for regarding Reality, how often do both the unscientific and the so-called scientific regard it without effort to conceal their contempt! But, alas! philosophy has, in turn, frequently forgotten that its own business is to appreciate and understand the arerage consciousness of mankind, and that the deep and high things of its own seeking are all therein contained; while, in these modern days, to be ignorant of scientific truths is to be incapable of effective work in philosophizing. Yet again, no more bitter contempt of others, or arrogant conceit of superior knowledge, or confident assumption of being a favorite of the Absolute, is anywhere to be found than exists in the breasts of those who know neither science nor philosophy. Witness the conversation and the conduct, in spite of all that is called "modern education," of the multitude of men in trades, business, politics, and eren the so-called "learned professions"!

Now, so far as such misapprehensions are due to ethical and æsthetical influences, the theory of knowledge cannot deal with them. But there is really an intellectual fallacy here which is in conflict with important epistemological principles. This fallacy consists in the assumption that only one way of mentally representing the real being and actual transactions of things can be true; or, at any rate, that the truth to be preferred, for all purposes, before all other truths, is either the so-called "common-sense," the scientific, or the philosophical. Such a view of the nature of knowledge, of the nature of Reality, and of the nature of the cognitive relation between the knowing subject and the reality known, is - to speak plainly - both false and degrading. Eren the most meagre human cognition results from an inner play of powers that are capable of catching and truthfully reflecting many sides of the real being and actual transactions of things. And Reality is rich enough to supply a true and manifold content to all degrees and kinds of cognizing minds. The truths of 
the plain man's consciousness, of the scientific inquirer, and of the reflective thinker, are not contradictory. They are all valid; because they are all authenticated by the infinitely varied Life of the really Existent. Should one doubt or fear for this Life, that IT will not be able "to live up to" the growing life in cognitive consciousness of the whole race of men?

On the contrary, every single thing and every event actually is all that - and, doubtless, infinitely more than - it truly appears to be, to the various observing and reflecting minds. What is needed to destroy the current fallacy is, not to diminish the content of knowledge, but to increase the conception of the content of Reality; for there is actually that in every thing and every event which is sufficient to correspond to all the different ways of cognizing its reality which are actually realized in all the different minds.

Let this trutl of fact and of epistemological theory be illustrated by the following examples. I am standing upon the shore of a body of water, and I stoop down and gather a handful of the sand which lies at my feet. To me it appears to be what it would appear to be to any one else of similar constitution of sense-perceptive faculty, who had had a similar experience in the most ordinary developments of conceptual knowledge. It is known as mere "sand," having such qualities as the common senses of men discern and such uses as have been ascertained by the growing experience of the race. But now I take from my pocket a magnifying-glass of good lens-power, and, by looking through it, transform the common sand into an innumerable collection of significant forms, either crystals whose molecules have arranged themselves in seeming obedience to mathematical formulas, or shells that show their origin in having been deposited by millions of living beings in the past of long ago. I carry this collection to the chemical and mineralogical or biological laboratory, and the experts there spend much time in determining the genesis, the atomic constitution, the specific qualifications and 
physical or organic connections of the elements of that which to the naked and untrained eye appears but common sand. From them I learn, with increasing wonder and admiration, of the wealth in reality of that which seemed at first so poor and ordinary a thing. And as I reflect upon the mysterious action of the forces that either rapidly marshalled the atoms along what appear to be consciously selected lines of preference, or more slowly built them into a tiny organism according to a more or less obvious plan, I am encouraged to attempts at higher flights of cognitive faculty. The marvellous inner life of what the scientific man calls Nature, and the mindful manifestation of what the devout soul recognizes as the power and wisdom of God, impress me profoundly. Speculative interests are aided by ethical and æsthetical interests, - although, perhaps, of a vaguer and less easily defensible sort. But, yielding to the serious impulse I proclaim as a cognitive judgment: this tiny thing, when considered as what it is in itself, and what, in its origin and connections, it represents, is indeed a "moment" of the Divine Life, a realization in particular of the Universal Spirit, of the Absolute Self.

Now let it be noted that, while all these alleged cognitive judgments as to the being and implied powers of this handful of common sand do not rest upon precisely the same foundations for their genesis or for their ralidity, they do not at all, of necessity, contradict each other. They may all be alike true; they may all be needed to express, even imperfectly, the reality of this particular thing. They seem, indeed, to follow so quietly and beautifully in train for the mind that will not brusquely (and almost brutally) interrupt its own life of cognition that they have good seeming of being true. That sand there $i s$, - white, hard, heary, and good for mortar or to be burned for lime; but it is also, known to chemistry as constituted out of certain hypothetical clements, to biology or to mineralogy as haring such a mechanical struc- 
ture or vital genesis, and to the naturalist as a part of the great system of inorganic and organic evolution. But to the higher philosophical reflection it is, in very truth, a thing of spiritual import, a being that finds its existence and attributes in the same Ground in which all existences, with all their attributes, are found. To the knower, then, this one particular thing stands, under the general relations of knowledge, as being at the same time, and in reality, all that sense-perception, science, and philosophy tell him that it is. And if he would know, as completely as man can know, this thing, this common sand, he must regard it from all these different points of view.

What is epistemologically true of any particular thing is true of every particular thing. Each most common and lowly member of that system of real beings and actual transactions which forms the ever varying and yet ideally faithful object of human knowledge, presents an indefinite number of sides to the mind of the knower. Of the chair beneath me, of the table before me, of the books upon their shelves over yonder, I may truthfully say: they are really all that ordinary perception, all that every branch of scientific analysis and theory, and all that the supreme generalizations of reflective thinking, or the insight of the philosophic spirit, proclaim them to be. Each of these things reveals itself to the senses in terms that are peculiar to each sense, and that are dependent upon the special relations which each sense sustains to the trans-subjective object. But without dividing its unity or annulling its existence as an object of sense-perception, each of them also appeals to the sciences of chemistry, physies, biology, and even to the history of the development of the human race, to tell us what it really is. Volumes issued under the titles of the particular sciences might be filled with truths and half-truths without exhausting the description of the real being of the most commonplace thing. Nor should a false shame keep us from declaring what a true reverence com- 
mends: It, too, is not so mean and obscure a thing as to fail of attaining some of the fundamental qualifications of our own selfhood. And as, under the enthusiasm over that wonderful inner structure which modern physico-chemical science so elaborately describes, we seem to see yet further into each lowly reality consecrated to the commonest of uses, we do no indignity to the Infinite Will that is the core of all Reality if we declare its self-realization to be recognizable even here.

What is true of each particular thing is also true of each event. For every event actually is, at one and the same time, a transaction cognizable from an indefinite variety of points of view. Before the eye of every beholder the stone falls to the ground, the arrow flies toward its mark, or the shooting star sinks exhausted in the distant horizon. This is the socalled "phenomenon," the truth of reality that appears to the senses from their characteristic points of view. But either of these events is capable of being regarded, and if it is to be known in the fulness of its actuality, must be regarded, from other and varied scientific points of view. The formulas that express the laws of gravitation and of the resistance of the atmosphere, and whatever is known of the great cosmic forces concermed in each one of these events, do not contradict the truth that is in the phenomenon. It and they may, indeed, be so stated as to involve themselves in seeming contradiction. This result comes, however, because error or halftruth is possible in such judgments as are pronounced, from whatever points of view. But the reality experiences no difficulty in appearing to the senses in one way, and at the same time and in the same transaction being known to science in a variety of other ways. Nor do the truths of sense-perception and of science conspire together with an agreement to offer common opposition to him who will regard the same erent as an item of Divine Providence, - a truly æsthetical or ethical affair. The stroke of lightning is actually seen as a zigzag 
line of blinding light; and it may be conceired of as the behavior of an electrical current according to its own laws, no more, and yet no less, if we conclude also to regard it as the messenger of the Divine purposes in the execution of a great World-plan. Here, again, attention must be recalled to the difference in the grounds and in the character of the judgments pronounced from these different points of riew. What is claimed is this: They may all alike be true; for Reality has enough of content and of varied forms of action to satisfy all.

What is true of each thing and of every event is emphatically and necessarily true of that sum-total of Reality which is, always very partially and often defectively and erroneously, given to human cognition. In sense-perception men know the truth of things; the real being and the actual transactions of the existing World are the objects of cognition through the senses. In all his work-a-day and ordinary consciousness of what is under his eye and hand, of what sounds in his ears and breathes odors upon him or furnishes the gratification of his tastes, every man stands in the presence of Reality. He knows he did not make it, nor can he destroy it. He regards the statements of an idealism like that of Schopenhauer, for example, as no better than the ravings of a madman. These first points of departure and lowest stages of cognition are, indeed, exceedingly obscure, evanescent, and unrepresentable. Perception is a first witness to the presence of truth, - trustworthy but dumb, uncertain, and difficult to comprehend. Yet heaven and earth will pass away before men will believe that it does not speak words of a meaning to them which has other origin than in the nature of their own sensibility and object-constructing mind. For cognition of the world of things through the senses is essentially trans-subjective; it is not a purely subjective affair, but an actually established relation with that which is other and real.

That knowledge of the world of things which comes through 
scnse-perception is the firm basis to which scientific knowledge returns again and again. Scientific knowledge is largely a system of unseen entities and generalized modes of behavior which the intellect constructs in the effort better to understand and to anticipate the repeated cognition of things by sense-perception. It has already been shown that this entire system of conceptions and judgments is unworthy of the name of knowledge, unless we admit the postulate that Reality actually is quasi-rational, and, at least in part, teleological. Science, in other words, assumes that the categories are applicable to the system of real beings and actual events with which it aims to deal; this assumption is the prerequisite of all its quest after the truth of things. But all its progress, on the other hand, is a perpetually concrete verification of the same assumption. For Reality, on the whole, keeps justifying the assumption, although it disappoints many of the hopes and cludes many of the devices of the scientific inquirer. For the very conception and the reasoning which science employs always carry with them the postulate of the transcendent. The Reality which appears as so related to us in senseperception that we can speak of the relation in terms of an envisagement, appears in our system of scientific cognitions as still real but postulated as transcendent and yet further known by complicated and valid processes of inference. The cognitions of science do not, however, contradict those of scnse-perception; for the really existent World, as known both by sense-perception and by scientific inference, is one and the same World.

Nor does the philosophical view of things come in to orerthrow or contradict either the ordinary or the scientific view of the same things. That insight which deciphers the inner nature of Nature and renders, at least partially, intelligible its import and valuc, does not despise or contravene either the knowledge of sense-perception or the more conceptual and abstract knowledge of the natural sciences. "It results," says 
Schopenhauer," "from this whole objective consideration of the intellect and its origin, that it is designed for the comprehension of those ends upon the attainment of which depends the individual life and its propagation, but by no means for deciphering the inner nature of things and of the world which exists independently of the knower." This despotic dictum of a mind professing a proud scorn both for common-sense so called and for science, contains an important epistemological truth. This truth concerns the teleology of knowledge. For our cognitions of things, as they are won by every man in that living intercourse and work-a-day commerce with reality which actually makes up the existence of most minds, or as they are refined, elaborated, and made apparently to undergo a total change by the use of instrumentation, and by inference of a carefully regulated kind, are designed for the attainment of certain ends. These ends, however, rise to heights far above those described by Schopenhauer as the life of the individual - a mere" will to live" - and the propagation of the species. But something more is emphatically true of the knowledge both of ordinary sense-perception and of scientific generalization; it is also designed for "deciphering the inner nature of things and of the world that exists independently of the knower." This independently existent world is the very world known by the "plain man's" conseiousness as well as by the more systematic and highly abstract cognitions of science. The germs of insight into the "inner nature of things" lie waiting recognition and development in every human mind. Every man is a metaphysician and a philosopher; he who can say homo sum is forced to confess both an interest in this inner nature and an undeveloped potency of insight. Nor is the insight something far away from him,_- "over seas" or " up aloft." It is rather, if he will liear it, a word near him, and ready to be put into his own mouth.

Moreover, men generally - all men, as soon and as far as

1 World as Will and Idea (English translation), iii. p. 21. 
they reach the reflective stage of derelopment - recognize in every natural object a somewhat that goes far beyond what the senses receive as a quasi-passive impression. This instinctive and natural recognition, given by the human Self to the other Self which is immanent in each individual manifestation, is the source both of the worship and of the philosophy of Nature. It was shown in the last chapter that the liuman mind can only with difficulty, if at all, regard the individual thing as not answering in some degree and manner to the teleological principle. A more detailed metaphysical discussion wonld make it quitc clear that the essential being of erery thing consists in just this, that the series of its changes, whether regarded as self-determined or as otherwise determined, comports with certain immanent ideas. As long, then, as human minds and the things which are the objects of their senseperceptions and of their scientific observations and inferences, are constituted thus far alike, insight into " the world which exists independently of the knower" cannot be wlolly denied to those minds. The feeling of awe akin to reverence, and of mystery that is allied to religious faith, with which crude peoples regard many of the most insignificant of natural objects, is a witness to this craving of human nature. The satisfaction to this craving which the more reflectire knowledge of all such objects brings, is a witness to the power of insight in all men. And that student of chemistry or biology who, on account of his comparatively petty attainments in the laboratory, has parted with this craving and its satisfaction, or who has ceased from the feelings of awe and of mystery before the things he daily analyzes, would do well to go to school to the " child of nature." But, in fact, if the manhood of the knower has kept any sort of pace in its derelopment with the growth of his technical knowledge, the scientific observer of things is the better fitted for deciphering the inner nature of a world that exists in independence of his cognition. He who knows things, whether by the senses and as they are 
adapted to the ends of individual life, or by all the methods of modern science and as a system of interconnected realities, but fails completely of this " insight," is fatally defective in his cognition: He does not know things as they really are. Nor does he need to cease from ordinary sense-perception or from scientific generalizations in order to add to his knowledgc the truth that is obvious only from other points of view; for things themselves are rich enough in content, and are actually varied enough in their behavior and in their relations to the knower, to make good in reality all the demands that are made upon them.

In a word, if we may speak of ordinary knowledge, scientific knowledge, and philosophical knowledge, as three distinguishable kinds of cognition, they are not to be understood as in any way contradicting, or even dispensing with, each other. In so far as any cognition is attained, whether by the use of senses and intellect, as in every man's daily life, or by scientific investigation, or by reflection upon the essential constitution and final import of things, it is all valid for the one Reality. If we part with this conviction early in the course of our epistemological inquiry, or indeed at any given point along its path, we can never successfully recover it again. Science can give us no genuine claim to know what is the nature of the really existent World, after the senses of man have been pronounced wholly illusory and incapable of affording any such knowledge. Philosophy cannot introduce its reflections as valid means for deciphering the inner nature of things, after the objective consideration of the intellect as employed in the constructions of science has resulted in a sceptical idealism or in agnosticism. But the knowledge of ordinary life, of science, and of philosophy is all needed in order to fill out to its rounded symmetry the cognitive relation of the knower to the real being and the actual transactions of things; and the contradictions which this diversity of cognitions from different points of view seems to the objector to 
introduce, all vanish as soon as it appears clear what is, as thus indicated and evinced, the nature of Reality. For it then appears that Reality itsclf is, what in all these ways it is known to be, an ever active and infinitely varied Life manifesting itself to the subject of cognition in indefinitely varied ways.

Another list of misapprehensions respecting the relation of Knowledge and Reality may be charged to incorrect or imperfect conceptions of the nature of "cause," and of the application of the causal principle to concrete experiences generally. These misapprehensions are either positive or negative. They consist either in the misapplication of some subordinate form of the causal principle to the relation between the cognitive subject and Reality, or in the denial of the application of this principle in any form to the same relation. The fuller discussion of this topic also belongs to the philosophy of mind and to general metaphysics; but certain observations are a quite indispensable part of epistemological theory.

No other conception has been more loosely held or seductively employed than the conception of cause; and no other principle needs to have its meaning and the metaphysics it carries with it more suspiciously criticised than the so-called principle or "law of causation." Science and philosophy hare striven, within their own domains and against each other, so to fix its meaning as to gire to some peculiar metaphysical theory, or even to the denial of all possibility of metaphysics, the cogency with which this conception and this principle are supposed to rule the human mind. In this and in other writings, ${ }^{1}$ both on psychology and on philosophy, we hare had repeated occasion to rehearse the descriptive history of its origin and to show its raried legitimate or illegitimate uses. In much of the current discussion of causation, it appears as

I See Introdnction to Philosophy, pp. $236 \mathrm{f}$.; Psschology, Descriptive and Explanatory, chapters $x i$. and xxi.; Philosophy of Mind, chapters vii. and viii.; and the present Work, chapter $x$. 
though each adrocate of some highly specialized metaphysics, whether of physics or of mind, supposed himself at liberty to restrict and define the signifieance of the terms employed at his own good pleasure. The supporter of a mechanical theory of the universe argues as though causal problems were mere sums in matlrematics. The biologist or psychologist, of certain tendencies and committed to certain interests, reduces all causation to the law of the conservation and correlation of energy; and this in spite of the fact that he cannot make the slightest valid pretence of accounting in this way for the behavior of a muscle-nerve machine, much less of a leucocyte when, on approaching the walls of a blood-vessel, it throws out a pseudo-pod, and thus penetrating these walls, rallies to the defence of the organism against its enemies, in the company of its comrades, upon the other side of those walls. Conservation and correlation of energy, indeed! By all means let the physicist use his appropriate differentiation of the universal principle which binds all beings, both things and minds, into a living unity, in those relations of material things to one another to which he empirically demonstrates it to be applicable. But if the causal principle, as gathered into the law of gravitation, does not account for the bchavior of molecules or atoms, why should it seem improbable that the physicist's pet form of the same universal principle should fail of legitimate extension to all changes and relations of living and sentient beings?

The variety of uses giren to the conception of cause, and the different forms in application of the causal principle, are all adequately explained in the light of its own origin and development; it is itself nothing more than the expression of the general fact of some sort of connection amongst all the items of our experience. Its origin has been shown to lie in that complex of cognitions which marks the earliest intercourse of the Self with things, as knowing itself to be active in the pursuit of ends, and yet restricted and determined by 
its changing relations to other things. In this complex of cognitions all the numerous subordinate classes or phases of the conception of cause get the fullest expression. Out of this complex of cognitions, as it develops into a more manysided and symmetrical body of cognitions, these classes or phases have their origin. Such of them, and such only, should be applied to the relations of things with one another, as are known to belong to things; and to each peculiar class of relations such and such only as are discovered, in the growth of human knowledge, to be actually adapted to each class. Relations of mere quantity, when these relations change, may possibly be expressed in terms of mere quantity. But in other relations, quality counts and even dominates as respects the form given to the causal conception. Again, ideas and final purposes and deeds of will count; they, too, may be so influential as quite to displace any of those forms of conceiving the causal rclation which are applicable only to masses or to molecules of matter.

What is in general true of all attempts at an application of the causal principle to Reality is emphatically true when the particular class of applications in question concerns the relations, in cognition, between some particular reality and the cognitive mind. Here it is imperative that we should be precise in both our affirmations and our denials. For even to speak of these relations as eausal, in certain meanings of the word "causal," is to go contrary to all that is most certainly known about the nature of all knowledge; but to deny that these relations are causal, in certain other meanings of that same word, is to go a long way in the direction of undermining the validity of all knowledge. This position, as both negatice in its guard against important epistemological and metaphysical errors, and positire in its assertion of important epistemological and metaphysical truths, will now be briefly illustrated.

Nothing can warrant maintaining - either openly under 
the honorable arowal of the materialistic hypothesis, or covertly and less honorably because espousing the view while disclaiming the name - a "causal" relation between the knower and any other reality in a manner to imply that such other reality is the maker, or author, or producer, or real subject, of the cognition itself. I know that the cognitive process, and the judgment of cognition in which it terminates, is mine. I, and no other being, either known to exist or conceivable as existent in unknown relations to me, make this judgment. That reality which I know as my Self is the author, the producer, of the knowledge which, as subjectively considered, it necessarily attributes to itself. That self-consciousness, which is a prerequisite of the development of all knowledge, is the perfectly unimpeachable authority for the assignment of the knowledge to the Self as its subject; to this Self which I call mine, this particular cognition, and every other cognition, belongs as the product of its total being intellect, feeling, and will.

And no other being stands in any causal relation similar to that of the Self, to any act of cognition. The knower knows that he, and he alone, is the maker of the cognitive judgment, and the subject of all the experiences in consciousness which lead up to this judgment. No other being can be conceived of as standing in similar causal relation to this judgment. Knowledge cannot be conceived of as the product of bodily changes, as "made by" or "thrown off from" the brain; or as having any physico-chemical changes in the cerebral substance furnish the subject to which it can be attributed as to an initial cause. Every explanation of a particular cognition which omits this reference to the subject as the real being whose the cognition is, fails of affording a full explanation by missing the most essential and universal factor in all cognition. Even by evoking the most extreme theories of "divine assistance" or of "seeing all things" in God, we do not in the least undermine or diminish this essen- 
tial " moment" of all human knowledge. Every primary fact of knowledge, no matter how simple and primary, must be expressed by the formula, "I know;" and this formula is rendered meaningless by the attempt to substitute for the subject of the sentence (for the " $I$ " that knows) any other being, whether conceived of in terms of so-called matter or of so-called mind. All theories which break down the invincible certainty of this truth of cognition, in the name of science, physiological or psychological, juggle with words that, when brought to the test of experience, really have no meaning; and this is so whether these theories maintain positive or negative positions toward the main problem of epistemology. $I$ do know ; and I cannot conceive of my knowledge as being produced by any other being than the knower who claims it for his own.

But, on the other hand, to deny all causal relation whaterer between the cognitive subject and other reality is equally, although not so obviously, unwarrantable. And here we can as little sympathize with the squeamishmess as with the audacity which so widely prevails. All the ordinary experience of men with things is pledged to maintain the right of employing the causal conception, in some one or more of its sereral significations, to express actual relations between their cognitions and the real being and actual transactions of things. Changes in real things account for, explain, determine, and are in different ways eausally related to, our changing cognitions. The blow upon my skin, or the burning coal applied to it - an actual and extra-mental transaction - causcs the painful cognition of my own body as struck or burned. 'The various phases through which my cognitive consciousness runs, as I watch some connected series of erents or some long-continued process in the external world, are known as dependently connected with that series or process regarded as a trans-subjective affair. Nor do I really in the least alter the state of the case when, by prolonged study of psycho- 
physics, I assume myself to be wiser than most men are, concerning the more immediate and hidden antecedents of my changes of cognitive consciousness. Speaking in the name of "science" (what name more abused than this?), and taking on lofty airs of superior information, does not accomplish a deliverance from those necessities of intellect and imagination which characterize all human knowledge. "Cerebral states" remain nothing but hypothetical changes in an inferred reality, interjected between changes directly observed in external things and correlated changes in our own cognitive consciousness. If they explain these known conscious changes, then they must themselves be conceived of as actual transactions in some really existent thing, that is not known as part of the Self, - in this case, the substance of the cerebral areas. If there are such actual changes in real things, and if these changes actually explain the changes in the conscious states of cognition, then the former trans-subjective changes must, in some sense of the word, be the "causes" of the latter and subjective changes. For this is precisely what we inevitably mean by the very word "cause," in the most common of its several meanings. Indeed, one of the most fundamental and useful of the laws governing the scientific search after causal relations may be stated thus: If the being $A$ (the cognizing agent) regularly passes through the series of changes $A, A^{a}$, $A^{\beta}, A^{\gamma}$, in sequence upon the observed or inferred changes of the other being $B$ (the brain) in the series $B, B^{\mathrm{a}}, B^{\mathrm{b}}, B^{\mathrm{c}}$, then the latter series is, at least, a part of the cause of the former.

In vain does the science of physiological psychology - out of an artificial and uncomely regard for the universal integrity of certain physical principles of a quite limited applicability, or for other similar considerations - strive to escape the obligation which its own discoveries impose upon it. To substitute other terms for the word "cause" when, after all, you really mean cause, is but a subterfuge that advances no genuine scientific interest. The resort to a theory of psycho- 
physical parallelism introduces, in the alleged interests of scientific explanation, a view that, essentially considered, is a violation of every canon of genuine science; logically carried out, it results in undermining the entire foundations of intellect by separating it from all real connection with the transactions that go on in the world of things.

But why hesitate to use the word "causal," with the proper limitations, to express the relations between the cognitive mind and those changes in things which stand in most intimate connection with the mind? Is any ethical interest liable to injury thereby? Is it a crime for Reality to have a decisive influence in determining what I shall know to be true; espeeially when the apparent object of my knowledge is mentally represented as some phase of or transaction in, this Reality itself? If my cognitions were not dependent upon the real being and actual transactions of things, and somehow causally determined by them, how should I ever know the truth of things? If any degradation is suffered by my cognitive faculty in thus being dependent upon the causal efficacy of those physico-chemical processes which I call "my hrainstates," the remedy for this would seem to be in my not being an animal at all, rather than in resorting to a theory which makes a complete breach between my mentality and my animality. In fact, however, most of the modern advocates of the theory of psycho-physical parallelism do not appear to bo chiefly mindful of its ethical outcome or of the unhappy position in which it places the human soul - cut off, as it were, from all valid connection with the world of Nature, and left to manufacture and put on sale a commodity which is labelled "knowledge," but is utterly devoid of the most essential claracteristies of genuine knowledge. The extreme tenderness with which the principle of causation is applied, in any form, to the relations of body and mind, is customarily due simply to reverence for that peculiar conception of the principle which applies to certain branches of physies alone. 
But that conception of cause which has its origin in experience, and which experience justifies, is elastic enough to cover these relations too; and, on the other hand, it refuses to cover these relations in such a way as to invalidate no small part of our most trustworthy cognitions.

In brief, then, we may - nay, we must - conceive of the mind which has the cognition, and of the things which are objects of its cognition, as standing together in one causally connected system. This system we necessarily conceive of as including a great variety of beings that are, considered from one point of view, self-determining or active in ways corresponding to their respective natures; and yet all of them, minds and things, are conceived of only as they are manifestly parts of the one system. Reality is thus known as a vast complex; in which knowledge emerges as a fortlputting of mind in its varied causal relations to other forms of reality. The transeendency, or trans-subjective application of the category of relation is, therefore, an essential presupposition of the very existence of cognition. And all particular relations, inasmuch as they are all realized only as belonging to that complex system of Reality in which the cognitive mind has its life of doing and suffering, may be said to exemplify some form of the causal principle. To exist as a mind is consciously to do and to suffer; and to know, as the human mind is capable of knowledge, is to become aware of the doings and sufferings of the Self, and of Things that are notself, in their reciprocal relations of interdependence. Only here, the sphere of the Reality that is not included in our self-known Self is far larger and firmer in its consistency, as it were, than the sphere of that reality which is known as the Self. All this amounts to saying that the very existence of our cognitive activities, and of the products which mark their development, whether for the individual or for the race, rests upon the general assumption that things and minds do so causally determine each other as to show that they belong to one system of Reality. 
Within certain limits, for example, the speed, intensities, and range of the changes of minds and things admit of being compared in terms of number. Within certain other ranges, they admit of being more concretely represented as qualitative and quantitative rearrangements, adapted to certain ends that are more or less clearly perceived as ends. Within certain other limits they seem to admit of being stated in terms that have for both minds and things an ethical and æsthetical value. Within all these limits and ranges, however, and whatever may be the differences of qualification which we are obliged to recognize, we must never, on the one hand, so conceive of their relation as to sink the reality of either in the reality of the other, nor, on the other hand, so deny all valid relation and connection between the two as to invalidate the actual unity of the system to which both belong. Whether this Unity is complete or not, we may be unable to say. What we do know is that its extension is coterminous with, is indeed the presupposition of, all extension of human knowledge. And what the Nature of this Unity is, the resources of philosophy in its branch of metaphysics must be summoned to discorer as its own profound problem.

It is, therefore, both true to the facts of the case and in accordance with a true theory of knowledge, when the relations of the knower and the things known are represented in various ways, as applicable to different kinds of knowledge and to different forms of functioning in the process of cognition. For example, the relation of the molecular excitement, caused by various forms of physical energy within the sensorium to the changing scries of sensory modifications of consciousness is best represented by speaking of the former as the "stimulus," or occasional cause, of the latter. This particular relation is, on the contrary, not truthfully represented when it is either spoken of as a producing cause or as a mere disconnected concomitance of a phenomenal kind. Again, the relation of the different modifications of consciousness 
to the Ego is truthfully representable only by some such terms as "subject" and "state."

Moreover, the different factors of that total activity or coudition of consciousness which is called "knowledge" stand in various relations both to the subject and to the object of knowledge; and these various relations need for the most fitting mental representation a variety of terms. As a merely feeling Self my relation to Reality is not the same as that which I sustain when considered as a willing or a thinking Self. But, then, in my knowledge of the real being and the actual transactions of things I am never merely a feeling, or a willing, or a thinking Self. So, too, the relations which I sustain to the object of my cognition need several terms, rather than one term only, in order trutlifully to express my experience. When this object is some present state of the Self, regarded as self-consciously known, the term "envisagement," or "intuition," is needed to express the immediacy, the "face-toface" nature of the relation. But when what $I$ know is a proposition in geometry that reposes upon a complicated demonstration, or a generalized fact in physical science, or a historical statement, the relation in which I stand to my object is not properly represented in the same way. To object to the statement that the reality known may be regarded as "inferred," or "believed in," is virtually to deny that actual variety in the life of the mind which it displays in its relations to the various objects of its knowledge.

Nor is there any obscurity or inconsistency in admitting a variety of relations between Reality and Knowledge, but just the contrary. Obscurity begins when the attempt is made to generalize unwarrantably; and then, upon the basis of such a generalization to force one set of abstractions upon the life of the mind so as to make its actual complexity conform to the barren thinking and meagre imagination of some psycliological or metaphysical theory. But who shall determine a priori that the human soul cannot, in and through 
cognition, stand in just this living diversity of relations toward Reality? As though, indeed, Reality itself were too poor in content, and in its outgirings and forthputtings too stingy to offer itself to the mind of man in a rich and generous dirersity of relations!

What question is more pertinent to such a case than this: In what experience do all the different forms of relation, considered as mere mental functioning, themselves arise? In other words, where does the category of relation, with such differentiations and shadings as it really undergoes in the life of men, itself originate? Of course in men's experience as subjects of knowledge. In so far, then, as knowledge, on the one hand, is a relating activity and, on the other hand, implicates Reality, it may be expected that the different forms of relation will find their justification and validating in knowledge. But this is only the presumption which all human experience ratifies and illustrates; for in knowledge the mind finds itself actually assuming all these forms of relation toward Reality.

Finally, we inquire whether there is any way of summarizing an epistemological doctrine of Knowledge and Reality so as briefly to express the truth of the experience in which men appear to themselres to sustain this variety of relations. I, as cognizing subject, am set into manifold forms of dependence and of intercourse with a system of beings, both minds and things. How shall I best represent to myself the essential features of all these manifold forms of relation, as they emerge to my consciousness in the unfolding life of the mind? In the attempt to answer this question, a certain reserre, or eren modesty, of opinion is becoming; and whether the question can be answered or not, the firmly established facts in which the trial for an answer originates must not be overlooked or their full value and significance sacrificed. Error here, howerer, is likeliest to arise in unduly restricting our riews of the life of Knowledge and of the nature of Reality, 
rather than in careful attempts to expand and to elevate these views. A large faith in the higher insights of humanity is better adapted to lead one to the truth than is a shrinking scepticism or a despairing agnosticism. It is, then, our faith in reason which is pledged to the answer of this problem;but only if the answer can be so understood and defended as to admit of all the facts and truths which an epistemological examination has brought to light. We believe there is one figurative and yet valid and true way of representing the essential features of the relation of Knowledge and Reality, one and only one valid and true way. Human cognition is all to be understood as a species of intercourse between minds. In all man's knowledge the real being of the finite Self is in actual commerce with the Absolute Self. This relation of an intercourse between Selves is the one fundamental and permanent conception under which may be truthfully included all the particular forms of relation of which we have experience in the development of the life of cognition. 


\section{CHAPTER XIX}

\section{IDEALISM AND REALISM}

W ${ }^{\mathrm{HAT}}$ theory of Reality best accords with the plainest facts and the more obvious laws of man's life of cognition? This is a question with which epistemology may attempt briefly to deal; for, as has already been shown, although this question is obliged to borrow from metaphysics certain views as to the nature of things, it borrows these views in order the more profoundly to comprehend the nature of Knowledge. And when the completer discussions of ontological problems which is the business of metaphysies, ask a return of the loan, it may be repaid with accumulation of interest.

Such an answer to the question just raised as our previous discussions enable us to give, shows how each of the more prominent ontological theories is checked and corrected, as soon as it develops a tendency to proceed to extremes, by a true and comprehensire philosophy of knowledge. In their eagerness to obtain logical consistency and argumentative clearness for themselves, Idealism and Realism, Dualism and Monism, are accustomed to override the considerations which naturally and fitly suggest moderation, and even a complete change in the point of view, before settling definitely the problem of unirersal Being. Each one of these two pairs, as against the other of the same pair, has valid claims to present. These claims are ralid, for they rest upon foundations of assured knowledge. When pressed into a conflict with opposing or contradictory claims, if their forces are liandled by a com- 
mander skilled in brilliant dialectic, they may appear to emerge from the conflict quite victorious. A complete conquest and systematic subjugation and exploration of the entire realm of Being is then announced; and one of these four titles, spelled with imposing capitals, is forthwith proclaimed Conqueror and Dictator over the whole domain. But this boasted freedom from "inconsistency" and "obscurity" may prove only a poor and temporary reward for the neglect or the slaughter of facts and laws that were, at the beginning, most loyally arrayed on the other side. Nor is this kind of "pacification" likely to be more than superficial and short-lived. Indeed, as will now briefly be shown, every one of these four theoretical constructions of all Reality, when it becomes disregardful of the legitimate claims of the opposed construction, conducts itself in such a way as to suffer arrest and legal execution at the hand of epistemology.

Idealism and Realism, in whatever form presented, are always the ontological correlates of certain assured facts and laws of human knowledge. We know what warrants both these views as to the nature of minds and of things. Indeed, the "I know" in which the epistemological problem originates in its most presuppositionless form contains within itself the perpetual warrant for the truth seized upon and expressed by both these theories. But both Idealism and Realism, whenever they begin to overlook or to pervert the plain significance of the facts that oppose their unrestricted extension, become so inrolved in a sceptical and agnostic view of some knowledge as really to destroy the grounds for a rational confidence in all knowledge.

Let us begin with the position of subjective idealism, unassailable so far as it is affirmatory and positive. I know my own affections, all the thoughts, feelings, and purposes which I call mine. Those objects of my cognition, which are called external things, are certainly given to me only as they are in consciousness and in my consciousness; they are, from 
this point of view, as truly subjective as are the most subjective of my own experiences. For my sensations are nothing external to my mind; nor can they be regarded as copies of, or impressions derived from anything external. They are, positively, nothing but modifications of my sensory consciousness. And even if a certain qualification called "extensits," or undefined "bigness," be allowed to the sensations of certain orders, or eren to sensations of every order, their inherent subjectivity is in no wise altered. Such sensations, howerer qualified extensivcly, are still $m y$ sensations, subjectire modifications of my sensory consciousness. Neither do they lose this subjectivity by being combined into manifold so-called "sensation-complexes;" for no potency can be detected in mere combination which should, like the philosopher's stone, change the baser metal of subjective sensibility into the gold of envisaged extra-mental reality. And now if we are at a loss to understand how mere subjective modifications of sensuous consciousness can come even to appear as things objective, we may introduce either the Kantian theory of knowledge, or some other equally idealistic theory; thus the objectirity which things appear to have is itself ascribed to the laws of the activity of my own mind.

My cognition of objects, no matter how intellectual and comprehending it mas become, is still a passing phase of my consciousness. The realities called "Things" are really phenomena in the ever flowing stream of my mental life; they are to me as they appear to me, - pictures in the mind, or forms of mental representation. And what is true of those objects which at least make the claim to be considered real namcly, that they appear concretely in my life of mental sense-presentation - is a fortiori true of all conceptual objects. The so-called entities and laws of science, so far as they exist for me, whether conceired of as immediately appertaining to $\mathrm{my}$ conscious experience or only as most remotely connected therewith, are alıke only my ideas and thoughts. 
Being more abstract than are the perceptions from which they spring, they have even less tenable claim to be exempted from the universal dictum: Things and their relations and their transactions are ideas, - "momenta" in the ever moring stream of consciousness. Nor, finally, can this Self, and all the higher spiritual existences in which it believes and to communion with which it so ardently and persistently aspires, fail of being brought under the same truth. I am to myself my own idea, my own conception. Other spirits, men, angels, and God, are existent for me, as the flow of consciousness, under the constitutional or acquired norms of understanding determines momentarily that they shall be. "The World is my Idea," - who can resist the logic which proves, or the impressiveness of the metaphysics which proclaims, this celebrated dictum?

So long as subjective idealism states its position in a purely affirmative way, and refrains from denial of the other aspects and truths of cognition, it commands assent; because it is psychologically defensible. But if not (as is customary) in its elementary and positive statements, then in its more ulterior and negative developments its case is far differently decided at the bar of a judicial epistemology. Grown conceited witl its triumphs in psychology, it attempts a philosophy of knowledge and a theory of Reality as follows : Nothing is, or can be, known as aught but my idea. I am shut in, without conceivable means or imagined possibility of escape, by the circle of my mental representations. And if you allege as existing in fact, or propose as tenable in theory, some means of transcending this circle, you allege or propose the impossible. "Envisagement," "inference," "faith," what are these, or any other similar terms, but words for some actual or fictitious form of the idea? Can I, in knowing, transcend the consciousness whose peculiar form the very process of knowing is ? All concrete cognition is nothing but appearance; and that which appears in every cogni- 
tive act is nothing but my idea? How, then, can so-called Things be known to me as other than my own ideas? Or, if it must be admitted - albeit most tardily and in surreptitious and shame-faced fashion - that some extra-mental reality is, some thing other than my ideas, how ean I ever hope to know, or even venture to conjecture, what this something is, - since what it is to me is ever only my idea? The reduction of my ideas to as much as possible 'of apparent consistency among themselves, and the pursuit of practical ends by the problematical means left at my disposal, wonld seem to be the only attainable end of cognition in a case like mine.

We hare scen, however, that this subjective idealism, with its sceptical or agnostic outcome respecting the real being and actual transactions of things, and, indeed, respecting also the reality of the soul, is met and disproved, in its negative positions, by the psychology and the philosophy of knowledge at every point. Its affirmations can, indeed, be pieed to. gether so as to afford to a few minds a seductive picture of the truth. But its denials can never win their way either with the popular, or with the more reflective views upon the nature of cognition, and of the Reality in possession of which the cognitive soul is placed. The brilliant dialectic of Berkeley, and of his exceedingly infrequent later disciples, will always find itself wholly unable to cope with the "common-sense" of mankind. For although this common-sense is no adequate equipment for philosophical pursuits, it cannot be flouted at or neglected by any form of philosophical theory. That detailed analysis of the nature, the criteria, and the "implicates" of all knowledge with which we have attempted to answer the epistemological problem, has shown, not only the serious defects, but also the complete absurdity of subjective idealism. All knowledge is, in its very nature transsubjective. Its fundamental affirmation - an affirmation from which it never for a single moment, or so much as in one 
lonely instance, departs - is of the extra-mentally existent. Knowledge is not merely an appearance in consciousness of ideas; it is a living commerce with the real being and actual transactions of minds and of things.

Moreover, this form of idealism cannot state its positions, cannot even open its mouth to proclaim or to whisper them forth, without confession of its own complete absurdity. Its very profession is such a confession. For its profession is an appeal to some standard of truth that exists, realized somehow and somewhere, outside the flow of the ideas in the stream of the individual consciousness. And if, at first, this standard is conceived of as the simultaneous and concurrent flow of other ideas, in other streams of consciousness than my own, even this is a confession of faith in an extra-mentally existent world that is not merely my idea. But the confession implied in the profession of subjective idealism is always something much more than this. For it is only through my cognition of a system of things, "not-self," that I come even to suspect the existence of a standard of truth. All the earliest derelopment of knowledge, as has been sufficiently emphasized, is an unceasing commerce of Self with Things, known as mutually dependent and interrelated. It is as part of a real world, cognized only on such terms as prevent my considering it to be merely my mental representation, that I have come to know eren my ideas as my own. The very nature of my knowledge, therefore, inevitably compels me to the contradictory of the solipsistic position; it compels the conclusion, "The world is not merely my idea." It is all, always, known to me as something other and more than my idea. In vain does the adrocate of this kind of idealism, when impaled upon the spear-points of an array of epistemological facts, strive to extricate limself and retain enough of life in his dialectic to carry him either forward or backward. Forward he cannot go, for the facts are invincible. Backward he cannot retreat to the idealistic position from which he 
set out; the facts follow and rout him even there. They slow that while the objects of every form and degree of knowledge may all properly be considered as ideas (in the most general sense of this word, as appearances in consciousness), they must all be considered also as not mere ideas, as transsubjective, as really existent minds and things. Nor will the continuance of the distressing ambiguity in the Kantian use of the word "objective" save the metaphysics of subjective idealism from the attacks of the realism which epistemology warrants.

Common-sense Realism, too, in its naïve and homely fashion, affirms certain important truths which are confirmed by the conclusions of a critical theory of knowledge. When, however, it contradicts or overlooks those facts and laws which are emphasized by its rival theory of reality, it is opposed and confuted by epistemology. If this form of realism never becomes quite so palpably absurd as does subjective idealism, its salvation is perhaps due to the fact that what is "commonsense" always fecls certain constraints from which more scholastic and exquisitely refined speculations are apt to fly free. The cruder realism takes its original position in the uncritical affirmation of a knowledge of things; both that they are and what they are, it is assumed, without asking permission of psychology and philosophy, everybody knows. That things do really exist, extra-mentally and in independence of me and of all human cognition, seems to the cognitive judgment of the average unreflecting consciousness an indisputable proposition. How they can exist otherwise, in respect of their characteristics and modes of behavior, than they are known to exist, is something of which no conception can easily be formed by such a consciousness. This voice, with its proclamation that things really are and what they are, seems to come, not from the depths of consciousness as the guaranty of an objectively determined idea, but straight from the things themselves; as rays of sunlight flow from the sun, or rass of heat from the 
fire. And it is to the things themselves - which are never to be thought of as in my consciousness, but as standing readymade over there - that the confident appeal is taken in case any question arises concerning the truth of particular cognitions.

The physical and natural sciences fitly espouse and maintain this positive datum of common-sense realism. But for them the things that most really are, are really not the things that are seen and temporal. The real things are rather the more primary and elemental factors of things, and the unchanging physico-chemical laws which are supposed to control the combinations, dissolutions, and changing relations of these factors. As to the epistemological principles involved in this assumption, however, "scientific realism" maintains the same positive attitude toward external reality as that which characterizes the realism of the "plain man's" consciousness. At this stage in the philosophy of Reality, the particular forms given to the construction of the concrete realities are not the important and determinative considerations. Both common-sense realisin and scientific realism regard things as extra-mentally existent, - ready-made, as it were, and independent, for their existence and their transactions between themselves, of all human knowing. This ontological assumption alone it is which warrants modern physical science in drawing, with such lofty confidence and minuteness of details, the picture of the evolution of Reality, when as yet there was no eye to see, no ear to hear, no hand to handle, and no human mind to perceive, conceive, or comprehend. The same assumption it is which encourages the prediction as to what will be, not only next year or next century, as respects important physical affairs, and without regarding the cognitive attitude of the whole race of men (let them perish, meantime, of plague or war), but when the earth and the sun shall be even as the moon now is, - burned-out coals. Nor would all the ideas and all the deeds of will, of all the race of men, change by a single iota the statement of the 
great physical laws which sun and moon and all the stars unceasingly obey. And we all, even the most pronounced of Berkeleian idealists or arowed solipsistic sceptics, listen with reverence to this descriptive history and its predictions for the remotest future. Even Schopenhauer is compelled to prove his proposition of the illusory character of intellectual conception as to the real nature of things by referring to things as though they really existed and actually behared after the patterns set by the conceptions of modern physical science.

This form of realism, when allowance is made for its crudely figurative way of speaking, and so long as its positions are affirmatice of the positive, cognitive attitude of men toward Reality is incontestably in the right as judged by a critical epistemology. It regards, indeed, the operation of cognition in a way which is, after all, not so much intrinsically erroneous as it is one-sided and inadequate. The apparent instantaneousness, and the predominatingly passive character, of much of our perception of things by the senses leads to an over-emphasis of one side of the cognitive process. Thus cognition comes to be spoken of, and even thought about, as though it were merely a copying-off, or a receiving of impressions from, the readymade things. But the most naive realism is ordinarily ready to admit that this is not precisely what its confidence guarantees ; and whether it makes the admission or not, the admission must be insisted upon in its behalf. Thus the most uninformed man is brought to consider what every scientific man has already for a long time known, that cognizing things through the senses is somehow a relative affair, and involves other characteristic activity than that of the extra-mental things. But what is insisted upon is this: Things exist, not simply while, or as, they are known by us; but all the while, and in independence of the voluntary or involuntary exercise of human cognitive faculty. What is also further insisted upon is that their characteristic modes of being and behavior belong somehow to them, and are not simply the resultant of the forms 
of the functioning of any man's mind. Things have their own qualities, their own laws, their own forms of life; and they have been, and will be, in this possession, obeying these regulations, and enjoying and exercising this life, whether we continue to think, and feel, and will, with reference to them, or not. It is some such ontological affirmations as these which are needed to satisfy the objective consciousness of the realist, rather than a crude and easily disproved theory of knowledge which, whether with respect to the secondary or to the primary qualities of matter, considers the perception of things as a species of photography. But the truth of this realistic assumption has been provided for, and most amply guaranteed, by our critical study of epistemology. Even the practical instinct which makes men value things, only if they may not lightly regard them as the mere creatures of their ideating activities, but as somehow raised above nen and set where the whole human race cannot destroy or greatly defame them, has also been satisfied. Provision has even been made by the later derelopments of epistemological theory for the æsthetical and the religious view of the nature of physical Reality.

When, however, the realism either of common-sense or of physical science denies the existence, the efficacy, or the value, of that which it is pleased to consider unreal, because ideal, it meets with stern rebuke and inflexible opposition from epistemology. If it takes, as is usually the case, a materialistic turn, it not only runs great risk of sinking into the slime, from the ethical point of view, and of dragging down the subject of all ideas with it; but it also most unequivocally makes itself absurd in the eyes of a critical student of cognition. For now ready-made things have become exalted to the place of supremacy; they are the alone indubitably real; by their behavior they account for all knowledge - not only for its sensuous content, considered as of varying intensity, time-rate, and qualitative complexity, but even for the combining activity which shows itself in the unity of the content, for the comparing 
activity which results in the content being teleologically constructed, and for the metaphysical faith, intuition (or whaterer you please to call it) which makes the content known as an existent Thing. Or to put the case negatively; - now the existence, the effective agency, the ideating and relating significance, of the subject of cognition is denied. The idea is made of no account in the world of reality. Things would not only be, but they would have been all that they now are, if no mental reaction of any kind had ever taken place. This mental reaction, the idea, is itself naught but an insignificant and fleeting phenomenon, an "epi-phellomenon." And as its courage grows, such one-sided realism may go on with its negations, and think to advance from the conquest of the microcosmos, in the name of ready-made and all-creative things, to an attack upon the ideal in the macrocosmos. Then its philosophy affirms that no potency or profit from the Idea can be found any where in the great Universe. Things, in the large, are only what physico-chemical science knows them to be; and to speak of ideas being "immanent in things" is worse than merely anthropomorphic imaging; for it is anthropomorphism of a confused and yet pretentious character. The World is a piece of mechanism; the Ideal is but the artistic fancy, the unrealizable dream, of hyper-æsthetic and over-exquisite minds.

But sucl extensions of the negative positions of realistic students of nature, or of common minds that lack ethical and xsthetical impulses as well as philosophic insight, are forbidden by the theory of knowledge. For you can never get to things, whether in the particular or in the large, - to that single Thing, standing so silently over there, and challenging your right to deny its existence, or to a World undergoing the most elaborate system of natural erolution, - except in reliance upon the cogency, the validity, and the significance of the idea. Here all the positive considerations of subjective idealism negative the denials of this form of realism. Particular things are given to me only in and through modifications of my consciousness; 
and if the much abused term "idea" be employed for every modification of consciousness, however complex and saturated with feeling and voluntary activity, then it is incontestable truth that all things are known to me as my ideas. The bridge which leads over to the realm of the extra-mental Reality is itself a mental affair, - some factor, or "moment," or" phase of an idea. Even if the chasm between mind and things be spanned by two kinds of structures, like the "sacred bridge" and the bridge for common people at Nikko, still mystical envisagement and matter-of-fact inference are alike in being phases of the idea.

Nor can the realist guarantee the existence and inherent qualities of his ready-made things, without accepting in good faith the work done by his own cognitive faculty; and this faculty, considered as a complex form of functioning, reaches its supremely self-confident architectonic, as it were, in the construction and validating as reality of the idea of the Self. For what I do know, eren if all other knowledge fail, is that I am actively and consciously striving for the realization of my own ideas. The one being, then, which I most certainly and unequivocally know, is a being whose very essence consists in having, and in acting under the influence of, numerous immanent ideas. Moreover, our critical examination of the epistemological problem has shown that, when the object of cognition is not the Self, but is rather not-selves (eren in the form of those things which seem at first sight most completely unlike the Self), cognition is possible only on the general admission that to the so-called categories is given an objective validity. But, primarily, by "categories" we mean simply those forms of the arising, the self-relating, and the derelopment of our own ideas, which we believe to be shared by all men and hold to belong to the unchanging constitution of the mind. Only, then, as things get ideal construction have they any existence for man. Yet further, it has become more and more apparent as the course of critical examination has led 
to the subtler and more profound truths of the teleology, and of the ethical and rsthetical "momenta" of knowledge, that the validating of these categories for the objects of ordinary and of scientific knowledge always implies that things are, in their connected real being and systematic actual transactions, analogous to the Self.

When, then, any form of realism, starting out with the assumption of the ready-made being of things, and relying upon the validity of human cognitions of things for its justification, denies the cogency, the objective validity and significance of ideas (as this word is used by the rival theory of idealism), it ends by destroying the very foundations on which it undertook to build its theory of Reality. It has taken all sense out of its boasted common-sense; it has destroyed all science in its excessive zeal for the supremacy of an uncritical physical science. "A theory of Reality" it cannot construct; for to theorize about reality implies that reality is more than such a form of realism admits. Theory of Reality implies that Reality is itself in fact ideal.

It appears incontrovertible, then, that any ontological theory which will not consent speedily to undermine its own foundations by assuming a palpably false epistemological thcory, must accept and, if possible, harmonize the positive truths of both Idealism and Realism. It must also reject the errors into which both fall when they deny each other's rights, and set themselves up for complete and satisfactory exponents of the real being and actual transactions of things. Such a harmonious theory of Reality involves, first, the admission of the truth that reality interpenetrates and supports all our life of the ideas, as they succeed each other in the flowing stream of consciousness. The subject of these ideas is real ; and he is a part of, a living element or moment in the great life of Reality. Man's ideas are not mere ideas, - whenever they become a knowledge of objects. This flux of my ideas is nerer to be explained as, for indeed it never really is, a suc- 
cession of mental representations that may be considered apart from the real being and actual transactions of things that are not-my-ideas. Psychology, as treated by certain psychologists, may pretend that the case is so; it may properly enough define its own business as that of dealing with ideas, or "states of consciousness, as such." But cognitive states of consciousness are never presented for examination as mere states of consciousness, as simply the subject's ideas. They are ever presented as though reality were admitted into, were actually there, in human consciousness. In all the development of sense-perception, including that obscure growth of knowledge which compels the mind to difference in a radical way between the Self, as the subject of ideas, and the body considered even as the remotely inferred physicochemical changes of the brain, this admitted reality is satisfied only if the claims of both idealism and realism are admitted. I am real, and things are real. The relation established between us in knowledge is not the denial, but the everlastingly firm and incontestably true affirmation, of both realities. In knowing that I am real, - in realizing the idea that I am, I am in a most firm and undeniable connection with Reality. The Life of the really existent World flows into the life of my ideas. This is the witness of my cognitive faculty. This is the last criterion and the highest significance of cognition itself.

But the reconciliation of the valid claims of both Idealisin and Realism requires, second, the inclusion of the world of extra-mentally existent things within the Idea. Or, rather, - to state the same truth in a less abstract way, that system consisting of the real beings and actual transactions of things, which common-sense and scientific realism regard as self-existent, ready-made, and independent of all ideas, must itself be conceived of in ideal terms. By a subjective idealism, the plainest facts and most obvious principles of cognition are contradicted ; it is made impossible to justify 
or even to frame any consistent and tenable theory of Reality. Such an idealism, when once it has, by its brilliant but shallow dialectic, disposed of all structures which afford any means of passage from the conscious idea to that which exists extramentally and in independence of the idea, attempts in vain for itself an escape to the other side. Poor bird! its wings are self-clipped; and it can only flutter and expire in the sight of those onlookers whose very reality it feels so sensitively, although it has often enough reduced them, too, to its own ideas. But if our minds keep faith with the most valid conclusions of a critical epistemology, we not only may, but we do and we must, cross from the domain of psychology, from the realm of the mere idea, into the great World of the really Existent. But this is done with the knowledge that IT, too, is a realm reigned over by ideas. For just as ideas of things are not mere ideas, and the scientific and philosophic conceptions of Reality are not mere products of thought and imagination, so things are not mere unideal things, and the total Reality is not a bare existence, but a realized Idea.

That some such reconciliation of Realism and Idealism as this is demanded by a true theory of knowledge, there can be no doubt. The elaboration and defence of its details must be handed orer by Epistemology to other appropriate philosophical disciplines. 


\section{CHAPTER XX}

\section{DUALISM AND MONISM}

$\mathrm{T}^{\mathrm{H}}$

HE questions in debate between the various forms of Idealism and of Realism concern those qualifications which shall be assigned to the different classes of the objects of cognition. The problem which they discuss may be stated as follows: How shall we mentally represent the inner and real nature of those beings which to the cognitive faculty appear as vastly differentiated and separable into many kinds? The answer which epistemology suggests to metaphysics, as the only answer compatible with the most assured epistemological facts, is that all beings, both Selves and Things, must be considered as both real and ideal. In some way, then, the theory of reality must be answerable to the theory of knowledge for a reconciliation of the ralid claims of conscious ideas and of real things. But conneeted with this metaphysical problem is another, which may be described as the problem of the ultimate number of classes of objects to which the qualifications of reality shall be distributed, as it were. Are all real beings capable of being classed as One Bcing; or must the ultimate number of really different beings which refuse to be classificd together be considered as two, or even more? This inquiry, too, of course, raises an ontological problem; its elaborate and well reasoned solution belongs to general philosophy, to the philosophy of Nature and of Mind, and perhaps especially to the philosophy of religion. But epistemology offers certain suggestions looking toward its better understanding and more satisfactory treatment. The conclusions which we have taken such pains to reach cannot 
be indifferent upon all the subjects debated between the different forms of Dualism and Monism. Indeed, only such a theory of reality as shall reconcile the valid claims of both sides to this contest comports with a sound theory of knowledge.

There are two sets of terms, however, which are, almost of necessity; so ambiguously used in the customary discussions of Dualism and Monism, that without coming to some sort of preliminary reckoning with these terms, all treatment of this subject is mere logomachy. One of these comprises certain terms of number; the other comprises certain terms of relation. In general, terms of number and terms of relation, abore all other terms, lend themselres to ambiguity when the subjects to which they are applied are complex and capable of a living development. To illustrate from a classic dispute in a field where one form of the conflict between the two rival theories we are about to examine takes place: All are agreed that, in some meaning of the word, the soul of erery man is a unity. "I am one, and you are another," is a declaration so indisputable that it cannot be questioned without admitting it. "I am I," and "thou art thou," - it is upon a common admission of the validity of such declarations that all intercourse, even the fiercest battle over the meaning of so-called "double consciousness," is based. But in what sense am I "one," and you "another," and both of us, considered together, to be called two, or perchance one, as the case may be ? The answer to this question should carry with it a final adjustment of the disputed use of certain terms of number. Kant's well-known refutation of the "transcendental parallogism" was valid against such a unity of the soul as certain theologians, in their desire to demonstrate for it a non posse mori, had attributed to it. But in denying that the soul is self-known as a real unity, Kant himself was as fanciful and far away from the truth of the facts as were the theologians lie confuted. 
Thus, too, even in speaking of the body as one, whether we contrast the body and the soul as making two in number, or fuse both into some form of a unity that includes both but really is neither, our psycho-physical mathematics certainly stands in great need of careful criticism. Two beings are not constituted a real unity, in any use of the numerical idea which is fitly applicable, simply by calling them "one." in some other quite different meaning for the same word. Nor are two beings, which are actually bound together into a unity of living connection - a ceaseless action and interaction - made really to be "two" disconnected beings by pointing out that they are, in another meaning of the same words, two rather than one. In what sense "one," or "two," or "many" ? this is certainly a question which can nerer properly be lost entirely out of sight in discussing the claims of dualism and monism. The same thinker may well enough be both a dualist and a monist in his theoretical views of body and soul, of matter and spirit, of things and Self, of finite and Absolute, according as he allows himself to shift his conceptions under these terms of number. For the body itself is really one; or it is really a considerable number, an infinite host, according to one's point of view. It is one with the mind, or just as clearly another than the mind, so that the two are quite distinct realities, according to one's meaning for the term "unity." All unities and all dualities are alike mysterious and, ultimately considered, inexplicable, if only one chooses to look at them in that way. I am one, or twofold, or manifold in my being, whether considered as a Self or as a soul. My body, too, is one, or manifold, or only a most inconstant flux, a mere temporary and ever shifting channel for a sinall part of the stream of Nature to flow through, if in any one of several different but equally true ways it pleases the observer to regard it.

Certain ambiguities in the use of terms of relation also attach themselves to those conceptions which are customarily 
insisted upon by the dualistic and monistic theories of Reality. These ambiguities are not easily separated from the foregoing; indeed, both classes of misconceptions originate and derelop in the same soil. It is only as they fall also under the category of relation that terms of number can be applied to any being or to any class of existences. In the case of the highest, most well-certified and yet complex of unities, - namely, the Self as the object of self-consciousness and of recognitive memory, - the unity attributed to it depends upon the character of the relations under which it is proposed to bring a variety of phenomena. All the different psyclic actirities and states may be theoretically brought together and attached to the conception of one Self, because they are all known and remembered as related to each other in the stream of consciousness, and are assignable (which implies a form of relation) to a single subject of them all. But two classes of relations, and the words we are compelled to use in order to express them, are especially liable to ambiguity. These are the relations which are conceired of under terms either of dependence in being or of interdependent action. How much, and what kind of dependence of one being upon other beings is consistent with a valid claim to be itself considered as a unity of independent being? On the contrary, what amount of reciprocal determination between tro apparently separate beings warrants us in proclaiming that the apparent twofold nature of their being is to be resolred into a more fundamental oneness of being? There are no a priori means for the solution of such problems; and, indeed, any solution which may be offered for the concrete cases in which such problems present themselres, depends for its validity, and even for its intelligibility, rery much upon the use which the proposed solution makes of the abore-mentioned terms.

If a total independence of all other existences were necessary for any being, in order that it might claim the indiridu- 
ality and the unity which the word " one" implies, then no particular existences could ever satisfy such a claim; then no particular existences could really exist as separate unities, in any sense of the words. Then all Being would be One; the many would not be; and the complete simplicity and complete uselessness of the Eleatic view of Reality would justify itself. Yet how often do we hear of demands virtually made upon the human soul that it shall show its independency of matter in general, of brain-states in particular, or even of its own constitution and laws of development, if it would lay valid elaim to be called " one" and "real" in its being. If, on the other hand, the lack of any particular kind of connection, or method of action between two beings is a sufficient warrant for considering them as wholly disconnected entities, then the question arises: How shall the Unity of one World be brought about by the mere presence in existence of a vast multitude of such disconnected entities? Once more, if the belief or the knowledge of men, that all the separate and independent beings of the Universe, both minds and things, are bound together into an ideal Unity, is to be the warrant for denying the reality of the fundamental differentiations in which human cognitive experience takes its rise, how shall any diversity be left, ont of which to construct this ideal Unity? The detailed answer to these and similar inquiries is an elaborate system of metaphysies. But the answers already won for the related questions in epistemology furnish a light which is both a guide and a warning. They guide the mind in a strictly critical path for the determination of the rights of both dualism and monism, in their use of terms of number and of terms of relation, as applied to real beings; and they warn the mind against being deceived by the sophisms concealed in these terms, especially in the form of assumptions and points of view contradictory of the facts and principles of cognition.

The positive claims from which both the dualistic and the 
monistic theories of Reality take their rise accord with the plainest facts and most obvious principles of cognition. Dualism begins in the recognized differentiation, the cognized opposition of Self and Things. As has already been pointed out, the one indispensable form of duality, so to speak, is an actualized distinction without which even the conception of knowledge is impossible; it is the distinction between subject and object. But this distinction is emphasized and set, with especial firmness and irresistible strength, into experience, when the object of cognition is some thing. There, set orer against me, and by no possible action of my will, or stress of my desire, or aberration of my intellect, is that which is notme. This often repeated experience of that which is other than the being I am, and yet, since it is my object, capable of being reckoned in relation with me, makes an indestructible dualism of the sum-total of experience. I am one, and it is one; I and it are two, and not one. For although it is, as object, in my consciousness, it is there on such terms as prevent its fusing with my Self, through the process of cognition, into a unity. However like myself it may be conceived of as being, and however intimate and constant the connection between us, still $I t$ and $I$ are two separate and independent beings. We are separate and independent, because the very terms of our acquaintanceship, so to speak, are such as to show that we actually can separate, and yet each retain its own existence. I continue to live as a Self, after this particular thing ceases to be my object. It continues to be a thing, after I have withdrawn from it my cognitive activity.

Nor is the case altered, so far as the essentials are concerned, when the particular thing which is perceived, or imagined, or thought, is one's own body, - whether as a totality, or as some particular portion or special series of bodily functions. My body is mine, to be sure; and thus it is a thing in which I am particularly interested, and with which I hare a more intimate acquaintance, in some respects 
at least, than with other things. As to a theoretical or actual dependence upon its structure and functions for the life of cognition, we are not at this moment concerned to inquire. But when I make any external part of this body an object of sense-perception, or when any internal part forces itself as an object upon my most acute attention, it appears to me upon the same terms as those upon which other things appear. It is a separable and independent being; it, too, is seen as colored extension, heard as resounding, felt as hard or smooth, cool or warm, as something other than me; and so, as making with me a sort of pair, or duality; I and $\mathrm{my}$ body are two instead of simply one. Even more obviously true are the facts to which the dualistic view of reality appeals when it acquires that form of science and specialized erudition which modern histology and physiology have imparted to it. $\mathrm{My}$ brain and $\mathrm{I}$, who think and argue about this brain and its relations to consciousness, are during all this process, with its termination in an alleged judgment of cognition, two quite separable and distinct beings. $I$ imagine it; $I$ think about it; $I$ draw conclusions which affirm either a monistic theory, or a theory of psycho-physical parallelism, or some other theory respecting its relations to me,- only as we are considered to be two rather than one.

Moreover, the more refined and well certified the science of the constitution and functions of the body of man becomes, the more definitively is it classified with those not-selves which are things, and which together with the cognizing Self make a dual world, rather than a world that has only beings capable of being identified as belonging to one class. This object of our modern " cerebral science," so-called, must be imagined as (and wherever it is perceived, is actually known to be) somewhat spread out in space, - weight so much, colored so, with separable gross masses arranged in such an order. Put under the microscope, it is further known in precisely the same terms as those which characterize the tissue of a plant, or of some 
one of the animals which is farthest removed from correlation or correspondence with the self-conscious Self. Analyzed in the laboratory, it is so much water, so much of phosphorized fats, etc. And if its behavior could be inspected when it is most intimately and influentially related to human cognitive activity, this behavior, and the being that thus behaves, would doubtless hare to be classified with amœboid bodies in general rather than with the self-conscious Self. Now, science cannot orercome or diminish this dualism. It is there, in the really existent, and unconquerably persistent. The chemico-physical investigation of cerebral substance, or of living bodies generally, widens and deepens instead of narrowing or filling in the gap between the self-conscious knower and any portion of the world of not-self. And psycho-physical investigation, whether it puts us into possession of any new truth or only renders the more definite certain quantitative and qualitative relations already recognized, has no other effect upon this natural dualism. Its very field of investigation can be defined and explored only upon the assumption that the more or less uniform relations of two beings are the subject of inrestigation. The moment that the Ego's conscious life of cognition is identified with the chemico-physical changes in the cerebral substance, the whole field of psycho-physics is withdrawn from the view of the scientific mind.

Still further, what is true in the microcosm, man, is also true in the macrocosm, the Universe at large. For every human Self, this duality is a necessary fact of experience, a permanent and fundamental truth to which the actual state of the case, as it were, must always correspond. The most definite and indisputable thing which I know about the world of the non-self is this: There are other selves existing on terms with themselves and with the total World of real beings and actual transactions, similar to those terms on which I know myself to exist. It is of the very nature of selfhood that this duality should persist. Each one of these other selres, of 
my so-called "fellow men," is inevitably a consistent dualist, in practice and in theory. For each one there is existent, on the one hand, the Self that knows and feels itself and plans for itself, and the world of other beings that are not-self, both minds and things. This must always be so, as long as selfconscious selves form any part of the sum-total of existence. This distinction, as valid in reality, no religious or other mystical experience, and no philosophic or otherwise esoteric doctrine, can at all invalidate. The attempt, even in thought, to annihilate this dualism of being which belongs to the essence of selfhood, can succeed only if all differentiation of selves be itself destroyed. Absorption of the many selves into the One Self, into the Absolute, is conceivable only in a negative way. It is the mere, the otherwise undefinable negation of my being, and of all other beings now known as my fellow selves. It is also the negation of all things, as they are now known to them and to me; since, both for them and for me, knowledge of things is only conceivable as a commerce in which selves take part, as dependent upon their relations to that larger and other Self.

It is, however, when dualism begins its denials that the corrective facts and truths of a monistic view of man and of the world must be invoked against it. As a rule, these denials make use of terms of number and terms of relation in a misleading or defective manner. Thus in guarding against a too hasty or too strict unification of seemingly diverse phenomena, in one meaning of the words, the dualistic hypothesis may deny all possibility of any kind of unification. It may thus destroy the unity, in reality, of man and of the world in which man's place is set. The motif for such an extreme of dualism may arise in any one of several ways. But it is not the task of epistemology to give to the dualistic hypothesis a thorough critical handling. In cortain of its several windings, however, the theory of knowledge easily follows, overtakes, and confutes it. This is especially true of 
that form of dualism which makes of body and mind two unrelated kinds of beings (to use the Kantian phrase, when considered as phenomena realitatis) by first breaking off all actual connection between the two main classes of psychoses. We refer again, of course, to the theory of psycho-physical parallelism, when it has taken the form of a consistent and thoroughgoing ontology. This is the favorite modern form of an exhausted and barren mediæral metaphysics arrayed in meretricious garb so as the better to coquette with science. This theory makes such a duality of body and mind that neither can influence, determine, or causally affect the other. The old-fashioned theological way of putting the case was this : body and mind cannot act on each other, for they are separated by "the whole diameter of being." It had a claim to respectability, for it designed to further the interests of the human soul. Such a claim to respectability is quite lacking to the present doctrine of psycho-physical parallelism; and a critical examination of the nature, origin, and growth of knowledge has shown that such a separation of the nature of man cannot be maintained.

Experience is without doubt one, - some kind of a unity. It is, also, without doubt, such a kind of unity as requires the combined action of Self and of Things. But all other things influence, act upon, or causally affect (one may choose what terms one pleases to express the truth of the actual relation) the Self, so far as experience and empirical science can safely go, only as they influence, act upon, or causally affect the body. That the human body is bound into the world of physical beings and events, and so constitutes, in some valid meaning of the words, a part of this unity of the World, cannot be denied without denying all possibility of knowing what the body is, - and, indeed, all possibility of thinking or talking about it as "body." This particular organism exists only as a part of the sum-total of things, as one among many other organic and inorganic beings, in the Unity 
of the one World. It is, then, only through the body, so far as any science of relations to the complex system of things can be framed or even conceived of, that I, as a conscious and cognitive soul, am united with the world. Mystical and occult forms of connection established between Reality and my Self, there may be; at present we are not concerned to affirm or to deny the possibility of this. But there is no science of the relations which the Ego can sustain, as a cognizing subject, to the real being and actual transactions of things, that does not validate itself, in the last resort, by an appeal to the changes produced by these things within the human physical organism. Telepathy, spiritualism (in the more rulgar meaning of the word), occult religions, and other forms of alleged communication, may be allowed whatever rights they can make good; but both in the work-a-day life and in all the established science of man, it is through his physical organism that his conscious $E g o$ is related to the world of physical beings and physical events.

Now it follows, most incontestably, as it seems to us, that to deny a further and essential unification of body and mind, as a system of interacting beings, is completely to cut the mind off from the world of things. It is to convert the psychic existence and psychic development of man into an unreal and ghostly affair. Here am I, in the unity of my one experience, seemingly aware, with great intensity and perfect clearness of conviction, of my own dual existence. I, indeed, never completely identify my Self with my body or with any part of it; much less do I fail to regard the remainder of the world of things as having another being than myself. But that I am in actual living relations with this body, determining not only its grosser movements but its more refined and subtle changes, in dependence upon my ideas, feelings, and volitions; that I am constantly being determined in these ideas, feelings, and volitions by its grosser movements and more subtle changes; and that I am thus united with it into the oneness 
of complete human being, and through it, am connected with the Unity of the World of things, - of all this neither common-sense nor science seems to leave us in doubt. For the development of cognitive experience itself is bound up with such assumptions; and the truth of the same assumptions is, in turn, illustrated and made valid by the content of cognition in all the development of experience. To deny such a unity of body and mind, and of the mind with the world of things through the body, by invalidating the reality of the connections which experience establishes between the two, is virtually to deny the possibility of all knowledge of the body and of all other things. What strange bed-fellows does this meaningless denial bring together liere! For a theory of psycho-physical parallelism which has been conceived and bred in the interests of a science of physical things, and which is exquisitely sensitive toward physical and biological formulas, has fallen into the embrace of a sceptical and agnostic idealism.

This modern extreme of dualism, however, when applicd to the larger World of Reality, shows plain signs of a tendency to lapse into the positions of the most old-fashioned theological Manichæism. The world of things that are not liuman, the system of animals and plants that are graded by natural science as below man, is, nevertheless, so full of the tokens of mind that the theory of psycho-physical parallelism cannot consistently limit itself to the dual phenomena of human life. Even non-living things are not wanting in similar tokens of the mind that is in them. The theory, when applied beyond the limits of man's dual nature, must, therefore, resort to a universal "mind-stuff" which runs its career as a system (sic) or an incoherent jumble of psychic "momenta," parallel with those suggestive movements in space which all things are wont to undergo. Between these two, the matter and the " mind-stuff," no commerce or actual connection can be allowed. Neither is it allowable - at least as some of the adrocates of 
this form of dualism are ready to maintain - that we should unite all the psychic "momenta" by theoretically connecting them with some one subject, a so-called Infinite Mind. It is thus assumed that the human imagination can compass, in a way to guarantee its possible reality, the conception of an everywhere present but disparate "Mind-stuff," or a diffuse and impersonal Spirit; but it cannot be trusted to construct the consistent idea of an Absolute Personal Sclf. But it is chiefly the business of the philosophy of religion, or of a system of general metaphysies, to inquire into the mythology of the "mind-stuff" theory of the world, - a shamefaced way of providing for gods many and lords many, without courage to invoke the Spirit of One Living God. We are satisfied now with maintaining that such a form of dualism gets its rebuke from a critical doctrine of the nature, origin, and validity of knowledge. To admit an infinite number of psychic centres, each of which is really cut off from connection with the being and the transactions of the system of things, is to destroy the unity of the real World, both as it is known to us and as it is existent in independence of our knowledge. In opposition to such a dualism, almost any monistic theory which makes a fair show of comprehending all the phenomena as an interconnected system will always have a decided advantage. And this advantage does not grow simply out of the tendency of reason to unify and ground all experience in as few principles as possible; it grows also out of the fact that the form of dualism which it opposes has so little standing with the phenomena of cognition.

It is not necessary for our present purpose to follow the course of the monistic theory of mind and things through the details of its positive or negative conclusions. What could be said both in defence and in criticism has, perhaps, already been sufficiently indicated. In its attempt to maintain the incomparable unity in reality of the self-conscious human Soul, it has on its side all those practical and theoretical considera- 
tions which are most potent to assist such an attempt. The very nature of knowledge is an impregnable fortress for a monistic doctrine of the human Self. But this Self is further known as bound into a more complex and looser sort of unity with the body, by a system of complicated interactions; and through this system it is bound into the larger unity of the total World of things and of other selves. But on the other hand, as soon as the monistic view leads to the denial of those certified facts, and those valid inferences from the facts, which the return to the dualistic point of view always brings to mind, it makes this denial at the expense of its own support from a tenable theory of knowledge. The solipsism which identifies all reality with the Fgo's states, effects this denial in one way; the materialism which will hear only of one reality, and that the reality of things, takes another course. But the cognition of man persistently affirms the reality both of the Self and of Things. And finally, every monistic theory of Reality which so identifies all different beings as to destroy the actuality of the differentiations which cognition validates, is thereby self-confuted. The many existences of the world of our experience are not so one as to lose all individuality, or as to annul the reality and the worth of that system of relations in which human cognition finds them, and which it is the business of human cognitive faculty to discover, to recognize, and to proclaim.

Here again, then, the Philosophy of Knowledge demands that it shall itself be supplemented by some Theory of Reality which will admit and harmonize the valid claims of both Dualism and Monism. We do not believe that to meet this demand is a hopeless, or even an overwhelmingly difficult task. On the contrary, the indices that point the directions in which the search should go have been appearing from time to time, during the course of our epistemological in restigation. No good reason can be given why so-called " common-sense," and science as conducted from both the physical and the psy- 
chical points of view, and the last word of philosophy as involving an attempt at that final synthesis of the reflective powers which interprets the inner meaning of things, should not all be in substantial accord upon this great subject. The cosmic mathematics of the unreflecting, of the scientific, and of the philosophical mind, although somewhat figurative in its expressions, need not be full of internal contradictions. Terms of number - one, two, or more - even when applied to abstract principles, to complex ideas, or to systems of belief and of impressions that are subject to ethical and æsthetical prejudices, ought not to be absolutely unintelligible or afflicted with inherent contradictions.

Suppose, then, that we take our start on fair terms of understanding with the plain man's consciousness. He has no doubt that he, as a conscious subject of states, is "one" in a sense of that word which cannot be made to gather and bind up with these states any others, into a unity of the same being. In this sense of the word, he cannot be made to believe that any thing, not even that physical organization with which his consciousness is most intimately comnected, is a part of the same unity. But he has scarcely less doubt that this duality, which exists between himself as conscious subject of states and his own body, is not inconsistent with, but is rather explicable only in terms of another kind of unity. This new unity, which embraces the duality of mind and body, is that which makes him to be "one man." Its essential characteristic, the deprivation of which would reduce this unity from a highly significant reality to a fictitious and delusive dream, is the actuality of the causal relation between body and mind. Accepting this relation as valid in reality he finds himself, as one man, howerer separate in this unity of his manhood, still bound into a social and a comprehensive psycho-physical unity with the world of his environment. It is this, to him, more indefinite and yet all inclusive unity in which he has life, and motion, and being; for he is, at the 
same time, always a child of nature and a child of human society. By all his practical activities, as he accepts the dominion of nature and ret reacts in order to subjugate to his uses her materials and her forces, he makes acknowledgment of the reality of this all-comprehensive Unity. In the higher exercises of the ideal life, in ethics and in art, and in religion, he expresses a similar confidence. He is always thinking of himself as one Self, with a body making one man, set orer against the rest of the world of selves and of things in this unchanging duality; and yet he knows he is a part of that which must be regarded as a supreme and ultimate Reality.

This way of accepting and nairvely blending the dualistic and the monistic views has, undoubtedly, much in it which needs critical investigation and readjustment, if it is to be fitted to meet the more profound insights and needs of the scientific and reflective mind. But there is, we believe, not a single essential feature of the portrait it draws which is not true to the real facts in the case. And, on the other hand, there is not a single fact or law known to the sciences of human nature, whether chemico-physical or psycho-physical and psychical, which can be brought to bear against the truthfulness of this common-sense view. Reality, as these sciences know it, would seem to be actually constituted on this same plan. IT is a system of beings, in which there are selves that know themselres to have a unique unity and incomparable separatencss from all other beings; but it is also a system in which these beings and all beings are bound together into the higher and the ultimate unity of the World-All.

But philosophy inquires as to how this Ultimate Unity shall be so constructed by reflective thinking as best to satisfy all the conditions involved. To this question epistemology has already pointed out the approximate and prorisional answer. Reality, in order to be known as this ultimate and all-inclusire Unity, must be conceived of as having all the characteristics 
of our highest ideal of a Self. For it is only a SeLf that provides for the actualization of ideas, and for a Reality that is the correlate and satisfaction of all ideas. Only a Self can be such an Ideal-Real as this cognized system of real beings and actual transactions is known to be. Besides this, it is only in such a Self that the principles both of differentiation and of unification can be satisfied. If Reality actually is constructed, so to speak, after the pattern which we are obliged to follow in our fragmentary and wavering cognition of its manifold manifestations, then the last demand of a critical epistemology is satisfied. We have carried the epistemological problem to the place where its answer merges into the theory of Reality. 


\section{CHAPTER XXI}

\section{KNOWLEDGE AND THE ABSOLUTE}

$T \begin{gathered}\text { HERE is an unsettled strife between the extreme of } \\ \text { agnosticism and an uncritical metaphysics over an- }\end{gathered}$ other problem about which epistemological investigation has important suggestions to offer. This problem may be somewhat indefinitely stated as the following question: Can man know the Absolute? Every system of metaphysics, and indeed every fragmentary proposition of an ontological character, seems compelled to make some sort of an affirmative answer to this question. But agnosticism does not correspond to its title unless it proposes some form of a negative answer to the same question. Here, then, there seems to arise a contradiction which admits little hope of being adjusted by inducing each of the contending parties to accept the more important claims of the other. It was partly this experience of the race, and especially of the generation just preceding his own, which led Kant to the conclusion that, on the one hand, reason will continue to cheat even the wisest of men into believing that they can, by the dialectic of illusion, reach a cognition of the unconditioned, and yet, on the other hand, that all metaphysics, as a credible ontological system, is intrinsically impossible.

A critical examination, however, of these contradictory extremcs - with their "Yes" on one side and "No" on the other side, so plumply asserted - shows that neither is able to state its positions clearly without admitting into them considerations of a modifying order taken from the positions of the other. The unprejudiced historical critic of this long- 
time continued and unsettled strife might safely challenge us to produce a single notable combatant on the side of agnosticism who has not made ample confession of his own confidence in certain truths proclaimed by the philosophy of the Absolute; and there are few among the most daring ontological system-makers who do not at times show signs of the consciousness that they are themselves soaring in air too thin to enable even the wings of fancy to support them in safety. If we needed illustrations, where could one more patent and forcible be found than the illustration offered by the great apostle of agnosticism among philosophical writers in English ? A more stupendous system of alleged cognitions that hare an absolute value, and that concern ultimate and permanent entities and unalterable truths, has never been put forth by any reflective mind than the system issued under cover of this agnosticism. Hegel and Schopenhauer were not more confident and dogmatic in their ontology, were not on higher terms of professed intimacy with the Ultimate Reality of the Universe, than is Mr. Herbert Spencer. Here we hare "Being," as it was and is and ever will be, and the fundamental law of all "Becoming," as the law has been, is now, and will continue to be, calmly and confidently set forth in many volumes by a finite creature of the nineteenth-century order of so-called scientific development. To what height above this can Absolutism ever renture to climb? Not only the "Transfigured Realism" and the formulas which, replete with ontological assumptions, define the Ultimate Reality, but also the detailed elaboration of the agnostic doctrine, from its opening proposal for a reconciliation of science and religion in a common creed of nescience to its final words on society, is one huge body of ontological metaplysics.

It is not our intention, however, to reproach Mr. Spencer for having elaborated a doctrine which gives the complete anatomy and physiology of the Absolute, with so commendable patience, industry, insight, and learning. There are 
many others whose efforts might be cited in illustration of the same truth. All philosophy or attempt at philosophy, eren the most agnostic, necessarily assumes some sort of conscious mental relation of man to the Absolute; but on the other hand, all philosophy or attempt at philosophy, howerer dogmatic, is forced to acknowledge some sort of a limit beyond which any such relation as can properly be called " knowledge" cannot be claimed to extend. It will not do on this account to resolve the conflict between the extremes of agnosticism and an uncritical metaphysics into a mere logomachy. This shallow and indolent way of treating important standing disputes of a rational kind is the more reprehensible when applied to the profound and difficult problems of philosophy. The path which reflective thinking follows in its effort to give content to the conception of the Absolute can fitly be trodden only by the most serious and carefully trained minds. It leads to many difficult and profound problems; the rather is it strewn with such problems. These problems, like all those which have been raised in the last several chapters, must find their fuller solution, if at all, in other forms of philosophical discipline. But the question "Can man know the Absolute.?" concerns, not only the constitution of the conception answering to a term which is capable of such varying meanings (the "Absolute"), but also the nature of knowledge, and the character of the relation to his object in which the knower is placed. It is for these and other kindred reasons that epistemology has certain suggestions to offer in answer to this problem.

The previous detailed consideration of the philosophy of knowledge has led us far enough to see that there are certain fixed and unalterable "momenta" which belong to human knowledge, whether it be considered subjectively and as an affair of human mental life, or trans-subjectively as implicating the real beings and actual transactions of the world of things. It is possible, then, that in some sense of the word 
"absolute" a good and fair correspondent for it may be somehow provided - at least suggestively - by the theory of knowledge. It is not simply possible, but it is perfectly obvious, that there are current meanings of the term "The Absolute," which cannot be accepted; for they are incompatible with the very nature of cognition and with the entire relation to the trans-subjective which cognition implies. Claims to a knowledge of the Absolute, as set forth in such terms, will liave to be dismissed as soon as their character is disclosed; knowledge itself is known to bear a fixed and unalterable character which will not tolerate them. For example, if by "the Absolute" it is meant to designate that which is totally unrelated, - absolute, because absolved from all conceivable relations and, as it were, spoiled or dishonored by being brought under the category of relation, - then there is little need to discuss the question, whether man can know such an absolute. The relation of subject and object has been found so fundamental that cognition cannot exist, even in the barest outline of its conception, without this relation being set into reality. Further, every concrete cognition is an actually established relation between the mind and its object; and it is a relation in which the dependence of the mind on reality for entering into this relation is emphasized, although the dependence of the reality of the object on the mind's willing, feeling, and thinking is never wholly abrogated or annulled. And if we take the trans-subjective point of view, and have regard to the nature of real things as known to the mind, the catcgory of relation is that characteristic which, above all others, they wear most manifestly as their very own. To speak, then, of a knowledge of the totally unrelated, or of that which must be conceived of as incapable of relations, whether shrinking from them, or shirking them, or being too pure and high, or too remote and unsubstantial to undertake them, involves a contradiction in terms which needs no refutation; it is too glaring to be put into intelligible language. 
Nor is knowledge of the Absolute possible if this word must be identified with the unchanging, - with that which is absolved from all alterations of its own states or of the relations in which these states stand to human eognitive consciousness. Reality, eonceived of as One and permanently the same, as respects both its own internal being and also its interactions with the cognitive subject, cannot be an object of human knowledge. For the very nature of cognition is such that it must represent in ehanging and yet orderly sequent states of the eognitive subject the real being and actual transaetions of things. Knowledge is an ever varying life of a Self; and beings, in reality, must "live up to it," in order that they may become the objects of knowledge. To suppose that Reality is dead and inactive, or is a monotonous beingrelated of a Ding-an-sich, that is loath to ehange in any manner which may serve as the actual ground and correlate of the changes of the human life of cognition, is to render the truthfulness of all eognition invalid. The proeess of knowing is not, indeed, a mere copy of what is, and is going on, in the trans-subjective object of knowledge. But it eould not be that eonfident and warm eommerce with the world of real beings and of their actual transactions which it purports to be, unless varied action and fulness of life could be conceired of as characteristic of its object. They, the things that are not-me, the other selves and the things they perceive, are all alive. They eonstitute for me, and for every cognitive subject, an all-embraeing Life of varied changes in which the Ego, by cognition and by the aetion which cognition induces and guides, takes its subordinate part. This view which regards the nature of things as centres, systematically ordered, of unceasing changes which the eognitive subject partially but, with an increasing degree of truthfulness and in dependenee upon the growth of eognition, mentally represents, is the scientific and the philosophie view. The Reality, thus revealed in its most permanent and unchanging eharacteris- 
tics, is not devoid of life in time or of ceaseless change; the rather is it the ground and essential inner principle of all changes, and the Life of all liring and non-living things. Only as Itself actualizing all the true formulas for the changing relations of things, and thus affording the ultimate explanation of the varied cognitions of these changing relations which different minds represent as their subjective experiences, can this Reality be known at all. Its very claim to be thought of as Absolute depends upon its being able to satisfy in reality the demands for a trans-subjective ground of all subjective changes.

Once more, the rery nature of cognitive faculty forbids making the Absolute an object of knowledge after this object has been, by a process of abstraction, stripped of all definite and representable content. If by the terms employed it is meant to designate that which is absolved from all particular relations, so that the human mind is obliged to hold and to say nothing positive about it - an Absolute $=$ an $X$, whose value can never be determined, even with the remotest degree of approximation - then, too, it is idle to discuss the possibility of finding such an object of knowledge. That which has no positive characteristics that are presentable or representable in consciousness, cannot be known. Purely negative and limiting concepts, if such concepts there be in themselves considered, must not be confused with cognitions. On this point, the Kantian caution remains forever commendable.

To speak in homely fashion the plain truth about this word, it would seem that it should not be employed except as an adjective to qualify some noun whose meaning must have been previously stated in terms of positive knowledge. "The Absolute " is nought; by itself, it is mere refusal to think, to give any positive content or discernible direction to the stream of consciousness. What is it about which the qualification of absoluteness, in some definite meaning of this qualification, is affirmed or denied? - this is the question which must always 
follow immediately upon the proposal to discuss the problem of knowledge and the Absolute. To such a question one must always answer in terms of Some Being, about which there is thinking to be done; it is affirmed or denied that this Being can be really existent, if it is thought of as freed, or absolved, from certain particular sets of relations. But the "absolu. tion" from certain relations thus granted or denied can never destroy all the positive content of thought that belongs to the Being which is the claimant for absolution. The moment the predicate of absoluteness ceases to be relative, that is, to apply to certain relations only, that moment the objectivity for possible cognition also ceases. In other words, whaterer I know is some thing known to be existent thus rather than otherwise. Whatever I conceive of must hare content for its conception. Whatever I think about, however raguely, and whatever I conjecture, however unwarrantably, must be thought about and conjectured with reference to some positive experience of Reality - either of my Self or Things - somehow delimited or defined. You cannot know Nought. You cannot know, or know about, the Absolute, if by this term you mean to designate the negation of all positive and particular characteristics.

It is a suggestion which is found to be as hopeful and comforting from the point of view of man's practical necessities as it is promising in epistemology and metaphysics, that the enrichment in content of the conception of the Absolute is better than its imporerishment. Reality is not best conceived of, in its sum-total and complete significance, as a barren and characterless affair. It is not dignified or gratified most by being placed remote from the work-a-day life and varied cognitions of humanity; it receives no added crown on bcing banished to the deatl-kingdom of abstract thought. There is more that the man of science knows how to explain, more than philosophy can give complete insight into, that meets the worshipper when he makes his fetish of the 
commonest materials. The Platonic ideas do not fear contamination from the dust and the mire of daily life. To every man the inessage of Reality comes: this "word is nigh thee, eren in thy mouth, and in thy heart." The absolution from illegitimate bounds is much greater when we begin to try to tell ourselves all which Reality may be affirmed to be, than when we seek to guard it carefully from being qualified too richly and too manifoldly, by rehearsing what it is not. But whether one affirm or deny, both affirmation and denial have significance for human consciousness only as they are clothed with some positive content. Then, and only then, can affirmation or denial enter into a contention that at least has a meaning and a possible outcome, whether terms can ever be discovered for a complete reconcilement or not.

Having thus safeguarded our word from a complete lack of significance we may receive from epistemology three kinds of suggestions which have a bearing upon the problem of knowledge and the Absolute. One of these suggestions comes from an analysis of the subjective nature of knowledge; another takes note chiefly of the relation which knowledge establishes between subject and its object, considered as really existent; and the third arises from the somewhat vague and yet important doctrine of Reality to which the theory of knowledge points the way. The very behavior of the mind in its cognitive activity, even when regarded as a subjective affair, suggests the presence in consciousness of that which is entitled to be called "absolute." The different particular factors of the substance of knowledge may all be regarded as relative and capable of indefinite variations according to no permanent and unchanging standard. There are so many of each kind of sensations - a quite indefinite and seemingly unregulated number - for every individual; there are so many myriads of color-sensations for $A$ and an unlike number for $B$, as the accidents of birth and of the exeitations of environment happen to fall. Nor is the case different with other sensations, except as, for 
some unknown reason, the numbers are increased or diminished. Color-sensations are representable by a triangle with a curved apex, from which the bottom has dropped off; but sensations of sound are represented better by a straight line which has neither beginning nor end; and smells may not be easily plotted according to any kind of curve. Nor does the particular order which the serial states assume in the stream of consciousness seem to be subject to absolute and predetermined rules. Looking at any mental life merely content-wise, as such and so much of sensation, ideation, conscious motor activity, etc., everything seems relative to ererything else. Change is mere change. No ruler over all appears. But with the total life of cognition, viewed as it appears to epistemological analysis, the case is not so. For such analysis discloses certain limiting and guiding principles that define the life of cognition as a rational striving toward some form of that which has value in itself. This conscious. ness of the Absolute that every cognitive subject carries within his breast, is nairvely expressed by the plain man in the satisfaction he feels respecting the unconditioned truthfulness and the worth, for all rational minds, of certain of his own thoughts and ideas. The more ignorant he is, perchance, the surer he is that the very truth of God, and the truth of all the ages, resides within himself. In his narrow and shallow stream of consciousness he feels flowing the waters that come from the celestial hills, and that are passing on to the ocean of Infinity. He knows that he is, and Nature is ; and that behind and beneath both, there is Another - with a strength and tenacity of conriction which will not be gainsaid. He attains to such a sufficiency of knowledge that he freely calls the Universe to account for itself at the bar of his judgment. Splendid audacity, but as amazing as it is splendid! For have not positivist, and agnostic, and the disciples of the critical philosophy exposed the fallacy of all this, with untiring patience and tiresome prolixity? But the plain man goes 
steadily on, handing in his practical adherence to another form of epistemological doctrine. $\mathrm{He}$ is a born absolutist with respect to the rights of his own cognitive faculty.

And when we extend our psychological analysis of knowledge in such thorough way as to merge it in epistemologieal criticism, we discover the warrant for this universal confidence in the absoluteness of certain states of human consciousness. To the theory of knowledge the stream of consciousness is no longer an inconstant flux of psyclioses. It is the life of a rational being who gropes after trutl, and stretches out his hands toward the Infinite and the Unconditioned, and betimes lays a satisfying grasp upon a portion of that for which he feels destined to strive. In this life, considered as a subjective affair but also considered in respect of the profounder depths of its subjectivity, change is not mere change; nor is each factor purely relative to something else which is alike fleeting and conditionated. But all states appear - in addition to the relations they sustain to each other - as relative to the one subject of them all. Erery state must indeed be related to antecedent states; and so it is capable of partial explanation as sequent to and consequent upon these antecedent states. But every state must also be regarded as relative to a Self whose it is, as all these other states have been, and as all succeeding states will be. And now we discover that this subject of the states, this Self, is not a characterless affair. What it is, cannot be made wholly dependent upon its states and relative to them - a mere summing-up of the events which they are. It has a nature that is fixed, unchanging, of its own. In our ignorance of the depth, the breadth, and the significance of this fact, we regard this so-called "nature" as theoretically divisible into two portions or sets of characteristics. Of these one is the nature of the individual Self and the other is the nature which the individual has, and shares, in common with the race.

Of every man it must be said that he lias the cognitive con- 
stitution of humanity, and also that he has something which limits and determines the cliaracter of his life of cognition, and which is peculiarly his own. Biology and anthropology strive to regard both these sources of contribution to what is the independent and unconditioned, in comparison with the dependent and relative character of the successive states, as themselves dependent upon and relative to the antecedent members of the race of men, or of other races of animals lower down in the scale which sets the standard of values. This is their legitimate task as laborers in the fields of the growing science of man. But all that they have to disclose only carries the same inquiry further back; or rather by their digging about the roots of humanity, they only carry the need of a limit to all explanations, further out and deeper down. For this picture of the development of human beings as a race that has Selflood, which perchance sprung, after the flesh, from races that had it not, is no more successful in freeing our minds from the recognition of what is absolute and unconditioned in human consciousness than is the picture which descriptive psychology presents of the development of a single soul. The real question at issue is not as to when, or by what stages, man comes to the consciousness of something absolute as given in his own cognitive being, but as to the significance of the fact that epistemological insight finds the absolute as already, somehow, consciously there.

If, however, a more detailed statement is required as to what there is in the cognitive experience of men which warrants us in affirming the implied presence of what must be called "the Absolute," our answer might be drawn from almost the entire body of the discussions which are now about to close. It will suffice to remind one who is inclined to be thoughtful at this point that the constitutional laws of the cognitive faculty, and the character of the object cognized in every act of developed self-consciousness, both warrant us in speaking of the matter in this way. Here, of course, demon- 
stration is impossible; but attention can be called to facts, and to their apparent significance. Certain principles, unchanging and of unconditioned value, are found immanent in all the life of cognitive faculty. To regard them as relative and changeable, either in the life of the individual or of the race, is to try to set into terms acceptable to reason the irrational and the absurd. For example, suppose that it is proposed to deny, at first, and then to test, in accordance with any given psychological or anthropological theory, the validity of the principles of identity and of sufficient reason. This theory itself is absolutely dependent, for its existence and for such poor claims to acceptance as it may possess, upon the unconditioned worth of these principles, and upon the mind's absolute and unchanging trust in them. Is what we call human reason itself a development? Are the fundamental principles of cognitive faculty in man a product from the evolution of things or of animals that are wholly without such principles? This is totally unthinkable. The very attempt to think it brings out the truth that human cognition, become selfconscious and critical, is compelled to recognize the presence of something absolute in human consciousness, - in the form of those fundamental cognitive principles to which all particular cognitions are relative, but which cannot themselves be regarded as dependent upon those cognitions or upon the particular objects cognized.

Nor is this presence of the absolute in the life of human cognition a purely formal affair. There is a being given to us in the activities of this life which, in some sort, worthily represents its own presence as an actuality; it is the being whose cognitive constitution embraces in its formal aspect the idea of that which is not dependent, but which is itself the ground upon which the particular experiences repose. This being is the self-known Self. So long as I take the purely subjective point of view, the one being which I know, as setting the limits to, and making rules for, all other beings, but which itself 
appears as the self-determining source of all limitations and rules, is the subject of cognition. It knows itself to be both active and passive; but both in action and in suffering alike, it is the one to whom all the varied changes belong. They may come and they may go, but it is. "It is :" the meaning of such an affirmation, so far as an answer can be giren, it belongs to the metaphysies of mind to disclose. 1 But that the Self does posit its own being as the unconditioned source, subjectirely considered, of all the shifting and relative psychoses in the stream of consciousness, there can be no doubt. In some sort, then, when the question, "How can man know the Absolute?" is raised, it may be answered by an appeal to all his cognitive experience. The answer may be made in terms of no unmeaning figure of speech: Look within thyself ; for this "word is nigh thee, in thy mouth, and in thy heart."

If now knowledge is regarded as a relation established between the knower and the realities which he regards as not himself, other glimpses of the presence and the meaning of the absolute within and without human cognitive consciousness may be gained. Here analysis deals directly with what is relative, as the very phrase to be analyzed proclaims. Cognition, considered as a relation, has been seen to be one of reciprocal influence and determination. I determine the object of my own cognition; and thus it is for its rery being that it is, and what it is as my object - dependent upon me. By a process which involres all my powers, my entire being, and which terminates in a cognitive judgment, I influence and mould it so as to make it my own. So that from this point of view, if one should renture to speak of attaining to a knowledge of the Absolute, such knowledge could only be on the condition that this absolute shonld submit itself to the human mind, to be felt, reasoned about, mentally seized and appropriated, after being intellectually moulded " to our mind." We may call this "accommodation," or "condescension," or

1 See the chapter on "The Reality of the Mind," in " Philosophy of Mind." 
what we will; but the very nature of cognition, as a relation of my being to other being, implies that it is so. Turning the transaction about, however, it appears, with even more clearness of insight and confidence of convietion, that in this very cognitive relation, I am dependent upon some other being notmyself. This being, which is to be or has already become my object, influences and determines me. Its will makes itself felt as an invincible and limiting barrier, that is no dead wall of resistance, but an expression of a force in which the teleology of immanent ideas is manifest, upon my will. Its qualifications of sensuous and other kinds incite and guide me to a knowledge of it - that it is and what it is - which I am persuaded is true to the facts of its being and its living reality. When the cognitive relation between us is once established, as well as during all the while that it is inehoate and developing, both $I$ and $I t$ are taking part in a transaction which requires for its very existence the help of us both.

Moreover, the various modifieations of the relation of knowledge between the knower and things known appear almost infinite. No individual knower is precisely like any other. No single cognition on the part of any individual knower is certain to be precisely like any other. And the reality of the things appears more than abundantly able to satisfy, in its own changing moods, the demands made upon it that it shall furnish its full share in contribution to these manifold modifications. The relations of the mind and things, in man's knowledge of them, thus seem themselves to be relative and lacking in all fixedness and independence of character.

To all this, however, there is another side. This other side is dimly apprehended and borne witness to by the consciousness of the multitude. We may not choose to give the name "cognition" to this consciousness; it may seem more appropriate to eall it a faith, a hope, an impression, or by some other term of emotion. But the analysis of knowledge shows that it is an attitude of the mind, or a factor in the attitude of 
mind, whieh all men take toward the objects of knowledge. Things change the relations in whieh, the terms on which, they will allow themselves to be eognized by us. What they mean by these changes, it is often, perhaps universally, difficult to say with any degree of eonfidenee. We have to take them as they are, and make the best guesses possible as to what they will be. But we must also trust them; and on the whole we find them worthy of being trusted. For they, too, obey laws and, in some sort at least, follow ends. They hare " mind in them;" otherwise they could not be " minded by us." Yet, further, we venture to believe that they wish us well - at least to some extent, and in some of their manifold changing relations to us. This faith in the good-will and rationality of things, as setting some sort of a limit to the relations into which we enter with them, in the act of knowledge, is a part of the act of knowledge itself. Even when we "look out" for things, lest they may hurt us, we continue to trust them to furnish the signs of their intention toward us. Some of them are treacherous indeed; but even gunpowder and dynamite have been studied, and the relations they are willing to sustain to us in action have been made objects of knowledge. Even the most capricious of the bacteria we live in the hope of knowing well enough to eseape, and perhaps to use for the furtherance of human good. The path which electricity chooses to travel, under all coneeivable cireumstances, will some day be diseorered.

Thus do the rery relations into which man's knowledge of the world of real beings and actual transaetions brings him themselres appear to faith and to hope as the manifestations of absolute will and of its unchanging, immanent ideas. Something absolute in them seems to set the limit to what would otherwise be unintelligible change in their ways of behavior relative to us, and sueh unmanageable caprice as to make life impossible for the race of men. But this faith and hope are both born of experience and are also the mother and 
nurse of experience. They suggest and guide the individual cognitions ; they are nourished and expanded or corrected, by the individual cognitions. They are significant of the great trnth which is postulated as a faith, and confirmed as a theory, by all knowledge considered as a system of changing relations between the mind and things. Things are not mere things, if by this it be meant that they are all to be regarded as completely explained by the relations they sustain to one another and to us, and by enumerating the series of the changes which these relations undergo. It is not, then, an unwarrantable conjecture, or the substitution of an unmeaning figure of speech for a reasonable proposition when it is affirmed: Things are the manifestation, the word to man, of an all-pervading Will and Mind. There is that in Things which irresistibly and forever determines the relations under which they shall become known to man. This unconditioned and unchanging being of which they partake, which gives to them the conditions of all their relations to us, and which is the permanent ground of all the changes they undergo, is the Absolute. Faith in it is the guaranty of human cognitive experience; this experience itself constitutes its perpetual recognition.

Something that may be called "absolute" is, therefore, found to be present in all the cognitive life of man as seen from the subjective point of view. Something that may be called absolute is the postulate, held by his primitive faith and confirmed by the growth of his cognition, which inheres in that relation of the Self and Things in which cognition consists. May we, however, form a conception which shall include all selves and all things, considered under all actual and possible terms of relation, as dependent upon this conception; and may we then assert reality for that conception as a possible object of knowledge? We belicve that an affirmative answer to this question is suggested by the truths which have been established as belonging to the plilosophy of knowledge. 
Such a conception cannot, indeed, be the correlate of the Unrelated, of the One and Unchanging, or of the merely abstract and undefined Ground of all relations and of all change. But it would seem that this conception must take the form of an Absolute Self. "It would seem" so; if, indeed, the suggestions which epistemology has furnished with regard to the innermost nature of Reality can be elaborated by metaphysics in a satisfactory way. For it has been shown that the fundamental and unchanging characteristics of cognition reach their supreme manifestation in self-knowledge. Here the object is most immediately and fully given to the subject, as it really is, and so as to embrace the disccrnment of intellect, the warm conviction of truth, and the vital seizure of will - all in the highest degree obtainable by human cognitive faculty. It is the being of my Self which I most fully, indubitably, and tenaciously make the object of knowledge. And as I consider all which is involved in such cognition I find that something absolute is known as present in my consciousness, no matter how subjectively directed my consideration may be.

Yet again, that which is not-myself - whether other selves or sa-called things - I know to be, only as it is somehow qualified in terms that can be vivified and verified by an appeal to my self-known Self. That things are, I cannot doubt; that they are not-me I know as incontestably as that I myself am. But what are they? - this raises a question which admits of answer only as I am permitted to use analogies derived from my experience with myself. Upon this use of analogies, however, erery man insists. Without assuming and, in his growth of knowledge, constantly evincing the truth of this proposition, all science and all philosophy cease to be knowledge and become something less than consistent dreaming. Indeed, when it is considered how experience itself cannot be built up, or subjected to sceptical criticism, without admitting its own transcendency, the 
"proof" of this assumption is seen to lie in the fact that the mind has any standard of thinking and judging whatever. And when the teleology of knowledge, and the ethical and æsthetical "momenta" which enter into it, are taken into the account, warrant appears for saying that the very structure and growth of knowledge shows Reality to be a larger and all-inclusive Self. But now since it is on this Reality that we are dependent, and since it is its Nature which gives to things their relative natures and positions with relation to one another and to us, why should we hesitate to speak of Reality as the Absolute Self?

Can man know the Absolute? Are Knowledge and Absoluteness terms which can dwell together in unity, or are they mutually exclusive and contradictory? Let us change the character of the question: May we with data of knowledge frame the conception of that Reality on which all dependent and relative beings, both minds and things, depend for their existence, and which serves as the Ground of all relations and of all changes, but is itself destroyed or diminished by none; and will human cognitive faculty bear witness to the satisfactoriness and to the validity of such a conception? The theory of knowledge, at least, does not render necessary a negative answer to these questions. On the contrary, it favors and even demands a positive answer. It also suggests what that answer shall be.

The problem of knowledge was attempted at the beginning in a wholly presuppositionless and critical way. The discussion of the problem closes with the recognition of a presupposition, which has been found lying underneath all the earlier analysis, and which comes to the surface and to the front, as the work of epistemology is concluded. Man knows Reality because Reality is of his own kinship. In knowledge, will answers to will and mind to mind. Yes; there are eren indications in the very nature of cognition that what ethics and religion crave to discover is true; and that heart 
speaks to heart a voice whose promises are often obscure, but never wholly false. Knowledge is indeed relative; but it is itself the establishment of a relation between the Revealer, the Absolute Self, and the Self to whom the revelation comes. 



\section{N D E X}

Ansolute, the, knowledge of, $364 \mathrm{f}$, $591 \mathrm{f} ., 608 \mathrm{f}$.

Adickes, his criticism of Kant, 294 (note).

Esthetics, judgments of, I 75 f., 512 f., 524.

Agnosticism, Mr. Spencer's, 370 f., 592 f.; nature of, 371 f., 382 f.; limits of, $382 \mathrm{f}$., $387 \mathrm{f}$.

Albertus, on nature of knowledge, $54 \mathrm{f}$.

Antinomies, the Kantian, 82 f., 9l, 399 f., $410 \mathrm{f}$.; of Hegel, 9l; nature of, in general, 396 f., 402 f.; Mr. Bradley's doctrine of, $399 \mathrm{f}, 417 \mathrm{f}$.

Aquinas, on nature of knowledge, $52 \mathrm{f}$.

Aristotle, his schemata, 24; theory of coguition, $36 \mathrm{f}$; ; doctrine of the syllogism, 36; influence on Leibnitz, 71 ; aud on Kant, $74 \mathrm{f}$.

Augustine, doctrine of faith and knowledge, 31 f., 46 f., 50, 126; and of free-will, 50 ; merits of, $31,47 \mathrm{f}$; compared with Descartes, 47 ; influence of, $5 \notin \mathrm{f}$.

Anthority, doctrine of, among Church Fathers, 45 f. ; Descartes upon, 57 f.

Berkeley, on nature of knowledge, $64 \mathrm{f}$.

Bonaventura, on faith and knowledge, 126.

Bradley, Mr., his doctrine of "Appearance and Reality," 89 (note), 422 (note); the antinomies of, $399,417 \mathrm{f}$; his doctrine of judgment, $435 \mathrm{f}$.

Caspari, on distinction of subject and object, 204 (note); on pseudo-concepts, 464 (note).

Categories, validity of, $9 \mathrm{f}$., 147, $268 \mathrm{f}$, 318 f., 359 f., 420 f., 532 f., $55+$ f., 570 f.
Causation, Kant's conception of, $288 \mathrm{f}$., $293 \mathrm{f}$., $414 \mathrm{f}$. ; reality of, $290 \mathrm{f}$., $320 \mathrm{f}$., 360 f., 402 f., 547 f.; relation of, between body and mind, $55 \mathrm{l} \mathrm{f}$.

Change, category of, $360 \mathrm{f}$., $401 \mathrm{f}$.

Cognition (see Knowledge).

Concept, relation of, to judgment, $143 \mathrm{f}$., $297 \mathrm{f}$. ; of experience, $326 \mathrm{f}$., $333 \mathrm{f}$., $335,342 \mathrm{f}$; ; psendo-concepts, $464 \mathrm{f}$. (note).

Consciousness, relation of, to knowledge, $6 \mathrm{f}, 107$ f., 113 f., 146 f., 197 f., 458 f.; "stream" of, in thinking, $144 \mathrm{f}$.; of Self, 197 f., 202 f., 208 f., 302 f. ; the ethical and æsthetical, $510 \mathrm{f}$.

"Critique of Practical Reason," relations of, to Kantian theory of knowledge, $73 \mathrm{f}$., $86 \mathrm{f}$., $409 \mathrm{f}$.

"Critique of Pure Reason," positions of, 24 f., 73 f., 77 f., 84 f., 255 f., 288 f., 340 f., 409 f., 516 f.

I)Ecartes, his theory of knowledge, $58 \mathrm{f}$. ; doctrine of method, $60 \mathrm{f}$.

Dreams, knowledge in, $235 \mathrm{f}$.

Dïhring, on principle of contradiction. 363 (note).

Duns Scotus, on nature of knowlerge, $54 \mathrm{f}$.

ETures, the cognitions of, $50 . \mathrm{f}$.

Epicureans, on nature of cognition, $41 \mathrm{f}$. Epistemology, problem of, $1 \mathrm{f}$., $11 \mathrm{f}$., 21 f., 106 f., 126 f., 373 f., 393 f., 489 ; relation to psychology, $5 \mathrm{f}$., $94 \mathrm{f}$.; as branch of philosophy, $8 \mathrm{f}$., $372 \mathrm{f}$., $587 \mathrm{f}$. ; sources of, $8 \mathrm{f}$. ; relation of, to metaphysics $11 \mathrm{f}$., 22, 25, $268 \mathrm{f}$., $365 \mathrm{f}$., $372 \mathrm{f}$., $495,536,587 \mathrm{f}$; ; history of, $30 \mathrm{f}$., $57 \mathrm{f}$. 
Error, nature of, 424 f., 432 f., 439 f. ; limits of, $427 \mathrm{f}$.; sources of, $456 \mathrm{f}$.

Experience, as transcendent, $12 t$ f., 256 f., 322 f., 325,329 f., 494 ; meaning of, 324 f., 331 ; conditions of, $326 \mathrm{f}$.; laws of, $333 \mathrm{f}$.; as criterion of 'Truth, $468 \mathrm{f}$., $493 \mathrm{f}$.

Faculty, the cognitive, nature of, $122 \mathrm{f}$., $502 \mathrm{f}$. (see Knowledge).

Faith, Kantiun doctrine of, 89 f., $323 \mathrm{f}$.; as "belief" in Reality, $3+4$ f., $468 \mathrm{f}$.

Feeling, Hume's doctrine of, $67 \mathrm{f}$.; implied in cognition, $124 \mathrm{f}$., $160 \mathrm{f}$., $173 \mathrm{f}$., $344 \mathrm{f}$. ; nature of, $165 \mathrm{f}$. ; classes of the cognitive, $167 \mathrm{f}$., $173 \mathrm{f}$. ; the logical, $180 \mathrm{f}$.; as regulative of cognition, $182 \mathrm{f}$.

Fénelon, on Augustine, 47.

Fichte, conception of Wissenschaftslehre, 13; on nature of cognition, $89 \mathrm{f} ., 134 \mathrm{f}$. ; principle of identity, 274.

Fischer, Kuno, on nature of philosophy, $8 \mathrm{f}$.

Grimm, on Hume, 68 (note).

Grote, on Aristotle's doctrine of cognition, 36 .

Hartmans, on problem of epistemology, 10 (note).

Hegel, criticism of Kant, 16, $90 \mathrm{f}$, epistemological position of, $90 \mathrm{f}$., $135 \mathrm{f}$., 344 ; on thought and cognition, $135 \mathrm{f}$.

Herbart, view of, as to origin of cognition, $98 \mathrm{f}$.

Hume, on nature of cognition, $65 \mathrm{f}$.; doctrine of imagination, $66 \mathrm{f}$.; influence of, $68 \mathrm{f}$.; conception of causation, 301 .

IDEATION, in judgments of cognition, $145 \mathrm{f}$., $504 \mathrm{f}$.

Identity, principle of, $205 \mathrm{f}$., $268 \mathrm{f}$., $319 \mathrm{f}$., $533 \mathrm{f}$.; as applied to the Self, $205 \mathrm{f}$., $280 \mathrm{f}$. ; logical form of, $272 \mathrm{f}$. ; applied to reality, $275 \mathrm{f}$., $533 \mathrm{f}$.

Implicates, the, of knowledge, $124 \mathrm{f}$., 155 f., 208 f., 256 f., 337 f., 343 f.; form of, $344 \mathrm{f}$.

JAMEs, Wm., on "belief" in Reality, $344 \mathrm{f}$.
Jowett, on Plato's view of cognition, $33,35$.

Judgment, nature of the cognitive, 143 f., 149,150 f., 297 f., 436 f., 453 f., $465 \mathrm{f}$.; the æsthetical, $175 \mathrm{f}$., $500 \mathrm{f}$.; the ethical, $178 \mathrm{f}$., $500 \mathrm{f}$.; as convering 'Truth, $434 \mathrm{f}$.

KaNT, his criticism, 4 f., 73 f., 516 f.; influence of, $7 \mathrm{f}$., $28 \mathrm{f}$., 58 ; conception of epistemology, $11 \mathrm{f}$., $73 \mathrm{f}$., $77 \mathrm{f}$.; his formalism, $24 \mathrm{f}$., $80 \mathrm{f}$., $301 \mathrm{f}$., $516 \mathrm{f}$.; inconsistencies of, $73 \mathrm{f}$., $288 \mathrm{f}$., $333 \mathrm{f}$., 340 ; assumptions of, $7+\mathrm{f}$., $82 \mathrm{f}$., $86 \mathrm{f}$., $255 \mathrm{f} ., 517 \mathrm{f}$. ; fallacies of, $84 \mathrm{f}$., $134 \mathrm{f}$., $255 \mathrm{f}$., $293 \mathrm{f}$.; view of intuition, $106,251 \mathrm{f} ., 257$; on nature of knowlelge, 133 f., 25 I f., 255 f., 265 f., 332 f., 339 f., 343 f., 399 ; and, especially, of mathematics, $259 \mathrm{f}$. ; view of Reality, 265 f., 293 f., 340 f., 391 f. ; on "Analogies of Experience," $293 \mathrm{f}$. ; his concept of experience, $332 \mathrm{f}$.; and theory of nescience, $391 \mathrm{f}$.; doctrine of antinomies, $399 \mathrm{f}$., $410 \mathrm{f}$.; his " Logic of Illusion," $409 \mathrm{f}$.

Kaulich, on knowledge and reality, 222 (note).

Klein, on the categories, 198 (note).

Knowledge, problem of, l f., $105 \mathrm{f}$; nature of, 5 f., 22,107 f., 113 f., 126 f., 136 f., 146 f., 202 f., 474 f.; objective, 6 f., 83 f., 113 f., 120 f., $155 \mathrm{f}$., $332 \mathrm{f}$., $340 \mathrm{f}$.; assumptions of, 14 f., 224 f., 246 f., 306 f, 337 f., 513 f.; datum of, 15 f., 95 f., 338 ; psychological view of, $94 \mathrm{f}$., $193 \mathrm{f}$., $228 \mathrm{f}$. ; origin of, $95 \mathrm{f}$., $101 \mathrm{f}$., $211 \mathrm{f}$., 258 f.; growth of, 102 f., 126 f., 211 f., 224 f. ; limits of, 104 f., 228 f., $245 \mathrm{f}$. ; certification of, $105 \mathrm{f}$., $155 \mathrm{f}$., 239 f., 393 f., 493 f. ; as consciousness, $107 \mathrm{f}$., $124 \mathrm{f}$. ; as activity, $123 \mathrm{f}$, 137 f., 146 f., 190 f.; as feeling, $124 \mathrm{f}$., 160 f., 167 f., 499 f., 506 f.; relation of, to thinking, $130 \mathrm{f}$., $258 \mathrm{f}$.; nature of the conceptual, $15 \mathrm{I} \mathrm{f}$., 252 f., $453 \mathrm{f}$.; of Things, $193 \mathrm{f}$., 208 f., 221 f., 304 f., 450 f. ; and of Self, 193 f., 243 f., 304,315 f., $348 \mathrm{f}$., 461 f., 528 ; degrees of, 228 f., 238 f., 242 f. ; kinds of, 229 f., 538 f., 546 f.; relation of, to life, $232 \mathrm{f}$, 
462 f.; contrasted with opinion, $234 \mathrm{f}$.; in dreaus, $235 \mathrm{f}$.; the absolute, $243 \mathrm{f}$., $538 \mathrm{f}$., 602 ; teleology of, 472 f., 486 f., 506 f., 519 f.; etlical and rsthetical " momenta " of, $500 \mathrm{f}$., $511 \mathrm{f}$., $52 \mathrm{I}$ f. ; relation of, to Reality, 530 f., 542 f., 547 f., 553 f., 556 f.

Leıвxıтz, views on epistemology, $69 \mathrm{f}$. ; influence on Kant, $72 \mathrm{f}$.

Locke, his method, $62 \mathrm{f}$. ; and doctrine of cognition, $62 \mathrm{f}$.; compared with Hume, 65 ; influence on Leibnitz, 70.

Logic, its attitude to epistemology, $130 \mathrm{f}$, ; view of fundamental principles, $268 \mathrm{f}$.; of "Illusion," $409 \mathrm{f}$.

Lotze. on theory of knowledge, 16, 156 ; and nature of proof, 358 .

Maxsel, his "Limits of Religious Thonght," 89 (note).

Mathematics, nature of its cognitions, $259 \mathrm{f}$. ; relation of, to truth of things, $439 \mathrm{f}$.

Memory, relation of, to cognition, $122 \mathrm{f}$., $262 \mathrm{f} ., 386 \mathrm{f}$.

Metaphysics, relation of, to epistemol$\operatorname{ogv}, 11$ f., 22, 350 f., 365 f., 530 f., 559 f., $5 \div 4$ f.

Mysticism, the Hindu, $34 \mathrm{f}$. ; its view of cognition, $61 \mathrm{f}$.

Nature, the concept of, $518 \mathrm{f} ., 536$, $575 \mathrm{f}$.

Nourisson, on Augustiue, 47, 50.

Onject, the, Kant's ambiguities concerning, I 20 f., $133 \mathrm{f}$. ; reality of, $133 \mathrm{f}$. ; distinction of, $199 \mathrm{f}$.

Opinion, as related to cognition, $234 \mathrm{f}$.

Origer, doctrine of faith and knowlelge, 31, 43 f., 46 ; merits of, 31,42 .

Paclsex, on theory of knowledge, 26 f., 263 (note); and self-knowledge, 225 (note).

Perception, Schopenhauer on, 136 ; cognition by, 148 f., 224 f., 250 f., $264 \mathrm{f} ., 376 \mathrm{f}$; ; as trans-subjective, $224 \mathrm{f}, 376 \mathrm{f}, 447 \mathrm{f}$, $474 \mathrm{f}$.; sceptical view of, $376 \mathrm{f}$., $444 \mathrm{f}$. ; final purpose in, $475 \mathrm{f}$.

Phenomenalism, fallacies of, $114 \mathrm{f}$.
Plato, on nature of knowledge, $31 \mathrm{f}$.; compared with Aristotle, $37 \mathrm{f}$.

Psychology, nature of, $4 \mathrm{f}$.; relation of, to epistemology, $5 \mathrm{f}$., $94 \mathrm{f}$., $132 \mathrm{f}$., $142 \mathrm{f}$; ; of cognition, $94 \mathrm{f}$., $130 \mathrm{f}$., $142 \mathrm{f}$., $160 \mathrm{f}$.

Qualitr, category of, $420 \mathrm{f}$.

Reality, nature of, 9 f., 153 f., 159, 279 f., 361 f., 364 f., 499,528 ; as given in cognition, 153 f., 208 f., 279 f., 341 f., 347 f., 407 f., 480 f., $530 \mathrm{f}$., $542 \mathrm{f}$.; theories of, $559 \mathrm{f}$., 571 , $574 \mathrm{f}$.; ideality of, $571 \mathrm{f}$.

Reason, problems of, $8 \mathrm{f}$.; Aristotle's view of, $37 \mathrm{f}$.; teleology of, $479 \mathrm{f}$.

Relation, the category of, $359 \mathrm{f}$., $401 \mathrm{f}$., 418 f., 554 f., 577 f., 594 f. ; Mr. Bradley's view of, $418 \mathrm{f}$.

Riehl, on Hume's epistemology, 65 ; on concept of being, 183; and distinction of subject and object, 204 (note); on Knowledge and Reality, 345; on causation, 364.

Romanes, view of faith and knowledge, $231 \mathrm{f}$.

Scepticism, limits of, 357 f., 367 f., $379 \mathrm{f}$.; nature of, $367 \mathrm{f} ., 37 \mathrm{f}$.

Schelling, on nature of cognition, $135 \mathrm{f}$. Schopenhaner, on nature of cognition, 92 f, 108, 136, 266 f., 343, 543 f.; exalts perception, 136,480 ; criticism of Jacobi, 339 ; on Kant's "Critique," 425.

Schuppe, on form and content, 147.

Science, conception of, 252 f., 298 f., $329 \mathrm{f}$., $444 \mathrm{f}$., $482 \mathrm{f}$., 543 ; its use of causal principle, 298 (note), $315 \mathrm{f}$; teleology of, $489 \mathrm{f}$.

Seashore, C. E., on illusions of sense, $45 \mathrm{l}$.

Self, the coguition of, $116 \mathrm{f} ., 127 \mathrm{f}$. 169 f , 188 f., 193 f., 206 f., 220 f., 227,348 f., 361 f., 385 f., 461 f., 528 , $549 \mathrm{f}$.; the feeling of, $169 \mathrm{f}$., $188 \mathrm{f}$., $211 \mathrm{f}$; ; reality of, $203 \mathrm{f}$., $216 \mathrm{f}$., $220 \mathrm{f}$., 349 f., $518 \mathrm{f}$. ; identity of, 205 f., $273 \mathrm{f}$., $281 \mathrm{f}$., $352 \mathrm{f}$.; illusions of, $446 \mathrm{f}$.

Solipsism, its assumptions, $116 \mathrm{f}$., $560 \mathrm{f}$. ; and fallacies, $116 \mathrm{f}$., $354 \mathrm{f}$., $563 \mathrm{f}$. 
Spencer, Herhert, on nature of thinking, 137; his agnosticism, $370 \mathrm{f}$., $426 \mathrm{f}$., 592.

Spinoza, his epistemology, 5l, $61 \mathrm{f}$.

Stoics, the, on nature of cognition, $38 \mathrm{f}$.; and criteria of truth, $40 \mathrm{f}$.

Stumpf, on objectivity of cognition, 116.

Sufficient Reason, principle of, 157, 239 f., 270 f., 283 f.; 315 f., 320 ; statement of, by logic, $286 \mathrm{f}$., $300 \mathrm{f}$.; as used by science, $286 \mathrm{f}$., $289 \mathrm{f}$., $295 \mathrm{f}$., $315 \mathrm{f}$. ; origin of, $296 \mathrm{f}$., $317 \mathrm{f}$. ; implicates of, $317 \mathrm{f}$.

Sully, on "belief," $344 \mathrm{f}$.

Syllogism, Aristotle on, 36 f.; nature of, 157 f. (See also "Sufficient Reason.")

Theory of KNowledge (see Epistemology).

Thing, nature of cognition of, $168 \mathrm{f}$., 193 f., 214,217 f., 221 f., 227,448 f., $561 \mathrm{f}$. ; real content of, $450 \mathrm{f}$.

Thought, relation of, to cognition, $130 \mathrm{f}$., $258 \mathrm{f}$., $479 \mathrm{f}$.; as active, $137 \mathrm{f}$.; complexity of, $138 \mathrm{f}$; ; as an active relating, $141 \mathrm{f}$.; principles of, $268 \mathrm{f}$; $283 \mathrm{f}$.
Truth, nature of, 2 f., 354 f., $424 \mathrm{f}$, $430 \mathrm{f}$., $434 \mathrm{f}$., $439 \mathrm{f}$.; contained in judgment, $434 \mathrm{f}$., $437 \mathrm{f}$., $502 \mathrm{f}$. ; criteria of, 40 f., 452 f., 457 f., 461 f., $466 \mathrm{f}$.; postulates of, $157 \mathrm{f}$.; as reached by argument, $283 \mathrm{f}$. ; related to conduct, $430 \mathrm{f}$., $465 \mathrm{f}$.; of perception, $447 \mathrm{f}$.; of science, $452 \mathrm{f}$., $489 \mathrm{f}$.

Volkelt, on nature of experience, 331 f. (note); and belief in Reality, 468 (note).

Volkmann, view of, as to origin of cognition, $98 \mathrm{f}$.

Werner, on distinction of subject and object, $204 \mathrm{f}$. (note).

Windelband, on listory of epistemology, $30 \mathrm{f} ., 42$ (note), 53 (note); on Des. cartes, 61 ; and Leibnitz, 70.

Wundt, on nature of thinking, 137 ; and distinction of subject and object, 223 ; classification of judgments, 278 ; criteria of truth, $461 \mathrm{f}$.; nature of cognition, 474; identity of subject and object, 534 .

ZELLER, on objectivity of cognition, $223 \mathrm{f}$.

Zeno, on nature of cognition, 39 . 





THE LIBRARY

UNIVERSITY OF CALIFORNIA

Santa Barbara

THIS BOOK IS DUE ON THE LAST DATE STAMPED BELOW. 
